


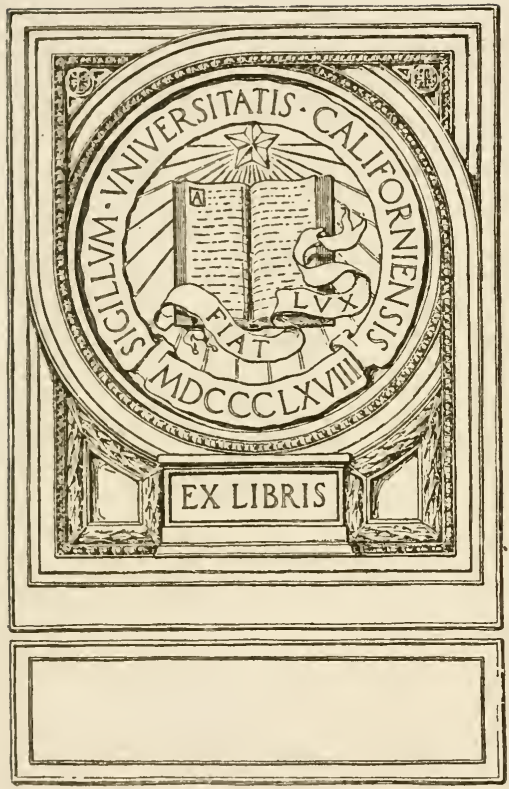

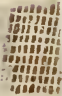


Digitized by the Internet Archive in 2008 with funding from Microsoft Corporation 
THE ANTIQUITY OF MAN 


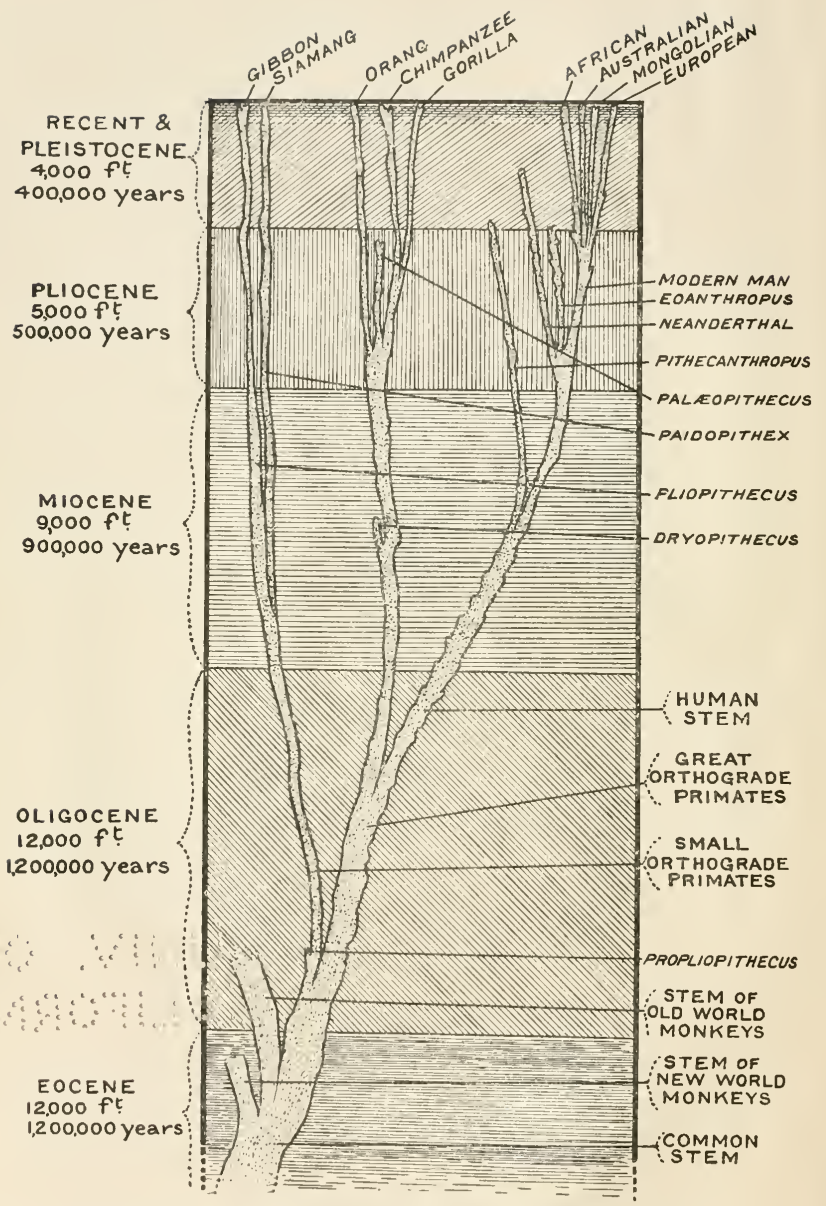

Genealogical tree, showing the ancestral stems and probable lines of descent of the higher primates. 


\section{THE}

\section{A NTIQUITY}

$\mathrm{OF}$

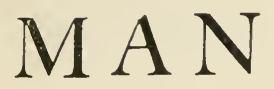

BY

\section{ARTHUR KEITH}

M. D. (AberdeEN), LL.D., F. R.C.S. (E\G.), F.R.S.

Conservator of the Museum and Hunterian Professor, Royal College of Surgeons of England; formerly President of the Royal Anthropological Institute of Great Britain and Ireland;

Author of "Embryology and Morphology," "Ancient Types of Man,"

"The Human Body" ; Editor of Treves' "Surgical Anatomy," Editor of Hughes' "Anatomy"

WITH IS9 ILLUSTRATIOAS

\section{LUNDON}

WILLIAMS ANI) NORGATE

14 HENRIETTA STREET, COVENT GARDEN, W.C. 
First Published, October 1915.

Second Impression, December I9I5

HISTORY 


\section{PREFACE}

Fully fifty years ago-in 1863 , to be quite exact-Sir Charles Lyell told the story of the antiquity of man from a geologist's point of view. His book ${ }^{1}$ became a classic; the geologist came to be regarded as the official historian of ancient man. The modern successors of Sir Charles Lyell have maintained the position he established for them. In the books of Professor Boyd Dawkins, ${ }^{2}$ of Professor W. J. Sollas, ${ }^{3}$ of Dr G. Frederick Wright, ${ }^{4}$ and of Professor James Geikie, ${ }^{5}$ the world of our remote ancestors is made to live again. The antiquity of man, from a geologist's point of view, has thus been placed clearly and fully before the English reading public. In I 865, Lord Avebury-Sir John Lubbock he was thenapproached the problem of man's antiquity from another point of view. $\mathrm{He}$ was primarily interested in the culture, the industry, the civilisation of ancient man ; the geological details of the prehistoric landscape took a secondary place in his pictures of prehistoric times. ${ }^{6} \mathrm{He}$ sought to follow the human army to its beginning in the remote past by tracing the possessions it had discarded

1 The Geological Evidences of the Antiquity of Man. London, 1863 (Ist edition).

2 Cave Hunting, 1874. Early Man in Britain, 1880.

3 Ancient Hunters, I9II.

4 The Origin and Antiquity of Man, 1913.

5 The Antiquity of Man in Europe, 1914.

6 Prehistoric Times, Williams \& Norgate, 7th edition, 1913. b 
while on the march. Lord Avebury wrote the story of the antiquity of man from the archæologist's point of view.

The problem of man's antiquity may be approached from another point of view-that of the human anatomist. The anatomist gives ancient man the centre of the stage; he depends on the geologist and archæologist to provide him with the scenery and stage accessories. It is from the anatomist's point of view that the problem of man's antiquity is dealt with in this book. This method of approach has its difficulties. The anatomist has to trace man into the past by means of fossil skulls, teeth, and limb bones-intelligible documents to him, but complex and repulsive hieroglyphs in the eyes of most people. The publishers have assisted the author to surmount the more technical difficulties by allowing a very liberal use of explanatory diagrams, which make the arguments used in the text more intelligible to the general reader. In many respects this book is supplementary to Lord Avebury's classical work-Prehistoric Times.

The main reason for the appearance of this work at the present time is that the "mystery" of man's antiquity is now culminating in a critical phase-presenting situations which may be described as of almost absorbing interest. Indeed the manner in which the story of man's antiquity is now developing recalls the point reached by Dickens in his last and unfinished novelThe Mystery of Edwin Drood. Many learned men have sifted the evidence and tried to solve the problem of Drood's fate-some solving it in this way and some in that. At the present time, geologists, archæologists, and anatomists are sifting the evidence relating to the combined problem of how and when mankind came into existence. On the evidence at present available, the author is convinced that the true solution cannot differ 
materially from the one presented in a diagrammatic form in the frontispiece of this book. The author's solution is only one of many; time will show which is right.

The mystery of Edwin Drood we can never solve; only the novelist knew what fate had in store, and he carried the secret to his grave. The mystery of man's antiquity stands in a different position. Every year brings new evidence to light-places facts at our disposal which take us a step nearer to a true solution. In recent years discoveries of fossil man have crowded in upon us, yielding such an abundance of new evidence that we have had to reconsider and recast our estimates of the antiquity of man. No discovery of recent date has had such a wide-reaching effect as that made by MrCharles Dawson at Piltdown, Sussex. Hence the reader will find that a very considerable part of this book is devoted to the significance of that specimen of humanity which $\mathrm{Dr}$ Smith Woodward named Eoanthropus dawsoni.

In accumulating the material and facts on which this book is based the author has become deeply indebted to many men. The help of some he has acknowledged in the text, but there are many whose names do not appear there. The omission does not mean that he is not grateful to them for their help. He must, however, acknowledge here the assistance he has received from time to time from the officers of the British Museum, from Mr J. Reid Moir, Mr A. S. Kennard, Mr W. H. Cook, the Rev. Edwin H. Mullins, and Mr Courtney Lyne. For assistance in preparing illustrations for this work he is indebted to his friend, Dr Stanley Beale, and particularly to $\mathrm{Mr}$ William Finerty.

ARTHUR KEITH.

July 1914 . 


\section{ADDITIONAL NOTE TO PREFACE}

A YEAR has passed since the proofs of this book were corrected and its preface written. The events of the year have revolutionised the outlook of all of us; we have burst suddenly into a critical phase in the evolutionary progress of mankind; we have had to lay aside the problems of our distant past and concentrate our thoughts and energies on the immediate present. Liège and Namur, which figure in this book as the sites of peaceful antiquarian discovery, have become the scenes of bloody war. And yet, amidst all the distractions of the present time, the author hopes there may be some who will wish to survey the issues of the present fateful period from the distant standpoint of a student of man's early evolution. It is in such a hope that this book is now put forth.

A. K.

July 1915 . 


\section{CONTENTS}

CHAP.

PAGE

I. A NEOLITHIC COMMUNITY OF KENT . . I

2. THE PEOPLE OF THE SUBMERGED FOREST • 23

3. THE DisCOVERY OF PRE-NEOLITHIC MAN . . 46

4. ENGLISHMEN OF THE LATER PALAEOLITHIC

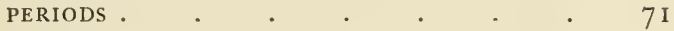

5. FURTHER EXAMPLES QF LATER PALAOLITHIC

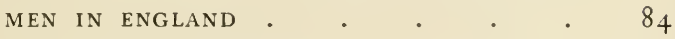

6. THE MOUSTERIAN PERIOD IN ENGLAND AND THE MEN OF THAT PERIOD IN FRANCE - IO2

7. THE DISTRIBUTION OF NEANDERTHAL MAN IN EUROPE . . . . . . .

8. THE ANATOMICAL PECULIARITIES OF NEANDERTHAL MAN

9. MEN OF THE IOO-FOOT TERRACE . . . I6O

IO. A MAN OF THE CHELLEAN PERIOD . . I 78

I I. PRE-MOUSTERIAN MAN IN FRANCE AND ITALY I 94

I2. THE IPSWICH MAN . . . . 2 I I

I 3. HEIDELBERG MAN . . . . . 228

I4. CASTENEDOLO-MODERN MAN . . 245

I 5. DISCOVERIES OF ANCIENT MAN IN AFRICA AND JAVA . . . . . . 252 
CHAP.

PAGE

I6. DISCOVERIES OF REMAINS OF ANCIENT MAN IN NORTH AMERICA . . . . . 272

17. EARLY SOUTH AMERICANS . • • • . 286

I 8. THE DISCOVERY OF THE PILTDOWN SKULL • 293

19. THE ANTIQUity OF THE PILTdown RACE • 306

20. EOANTHROPUS DAWSONI . . . . 3I6

2 I. THE DifFicUlties OF RECONSTRUCTION • • 337

22. AN EXPERIMENT IN RECONSTRUCTION • • 356

23. HEADS-ANCIENT AND MODERN-IN PROFILE . 376

24. THE BRAIN OF FOSSIL MAN . . . . 397

25. THE PILTdOWN MANDiBlE . . . . 430

26. EVIDENCE OF THE TEETH OF FOSSIL MAN • 453

27. THE FACE OF FOSSIL MAN . . . . 479

28. A CHAPTER OF CONCLUSiONS . . . . 497

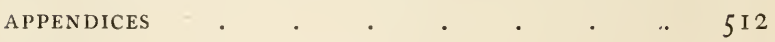

INDEX . . . . . . . . 514 


\section{LIST OF ILLUSTRATIONS}

Genealogical tree, showing the ancestral stems and probable lines of descent of the higher primates . . . frontispiece

FIG.

1. A map of the part of Kent in which Coldrum is situated . . 4

2. Megalithic monument at Coldrum viewed from the east . . 5

3. Surface-plan of the Coldrum monument . . . . . 7

4. One of the Coldrum skulls set within a framework of lines which bound the chief diameters of a modern skull of mean size

5. Side and front views of the Trent cranium

6 Side and front views of a skull from a Neolithic burial-place in Malta

7. Form of skull of ancient Egyptians of the Sixth Dynasty, from the side and from the front . . . . . . 16

8. Ground-plan of an ancient Egyptian tomb . . . . 18

9. Ground-plan of a "giant's tomb," Sardinia ; and sketch-plan of the Coldrum monument, showing points of resemblance.

Io. Skull from a Neolithic sepulchre in France, which had been trepanned in three places . . . . . . 2 I

IOA. Kits Coty house, a Megalithic monument near Coldrum . $\quad 22$

II. The land-connection between England and the Continent in early Neolithic times . . . . . . . 24

12. Diagram to show the various strata which buried the old land surface and the human skeleton at Tilbury . . . . 26

13. The Tilbury skull fitted within the standard frame for modern British skulls of average size . . . . . . 27

14. Section of the deposits exposed in a site at St Helier's, Jersey - 3 I

15. Skull of a woman, from a Neolithic cist, La Motte, Jersey . 34

16. Views of the Carnon calvaria, from the side and from above . 36

17. Side view of a skull at a depth of 30 feet in an alluvial tin mine at Sennen, Cornwall . . . . . .

18. Fragment of skull found at Aberavon, superimposed on an outline of the Newport skull 
FIG.

19. Side and full-face views of the skull found during excavations at Newport

20. The Mickleton skull, side and front .

21. Views of the Engis skull from the side and from above

22. A section of the cave explored by Lartet, near Aurignac, in 1860

23. Skull of Cromagnon man viewed from the side and from the front

24. M. Piette's section across the strata at Mas d'Azil . . . 58

25. Diagram of the ancient hearth-strata exposed in the deposits at Solutré

26. Section of the strata of the Grotte des Enfants, near Mentone.

27. Profile and full face of the Grimaldi woman . . . . 68

28. The Brïn skull (No. I) from the side and from above .

29. A section of the strata at Halling, showing the position of the skeleton.

30. Diagrammatic section across the valley of the Medway .

30A. A later and more accurate section across the valley of the Medway at Halling .

31. The Halling skull viewed from the side and from above.

32. A diagrammatic section to show the horizons Mr Mullins recognised in the cave earth at Langwith .

33. The Langwith skull viewed from the side and from the front .

34. The upper aspect of the Langwith skull contrasted with the Trent skull of Neolithic date . . . . . . . . 99

35. Section across the Brixham cave showing the strata of the floor 90

36. (A) Right half of palate from Kent's Cavern; (B) Left half of palate from Combe Capelle ; (C) Right half of palate from Tasmanian; (D) Left half of palate from modern Englishman

37. Diagram showing the submerged bed, the low or 20 -foot terrace, the middle or 50 -foot terrace in the valleys of the Thames and Medway

38. A sketch map of the chief sites of prehistoric discovery in the region of the Dordogne, France

39. The strata at the rock-shelter at Combe Capelle, showing the position of the human skeleton discovered by Herr Hauser

40. Section of the strata at La Ferrassie . . . . . . . . II3

41. Section of the cave at La Chapelle-aux-Saints . . . . 116

42. Section of the strata at La Quina . . . . . 120 
44. Section of the deposits in the rock-shelter at Krapina

45. Skulls of the modern type (Combe Capelle) and of the Neanderthal type (La Chapelle) contrasted on their lateral aspects

46. A skull of the modern type (Combe Capelle) contrasted with the Neanderthal type (Gibraltar) as seen in full face . .

47. (I.) The supra-orbital ridge or torus and other features of the face of a male chimpanzee; (II.) The form of articular cavity for the lower jaw in the Gibraltar skull, contrasted with the forms in the gorilla and modern man . . . . .

48. The skull of an orang superimposed on that of a chimpanzee to show the presence of a torus supra-orbitalis in the latter . 142

49.. Sections of the lower jaw at the middle line or symphysis of a young gorilla, a man of the Neanderthal type (Spy), of a native of New Caledonia, and of a modern Englishman . 145

50. Four lower molars, as seen when examined by X-rays . . I47

51. Drawing of the palate of the Gibraltar skull . I49

52. Outlines of the palate of the Gibraltar skull, and of a skull of a native Tasmanian . . . . . . . I 50

53. Diagram showing the poise of the head in the modern and Neanderthal types of man . . . . . . . 154

54. Superimposed tracings of the basi-cranial axis of the skull of a gorilla, of the Gibraltar cranium, and of a modern English skull

55. The Neanderthal (Spy) thigh bone contrasted with the corresponding bones of modern man and the gorilla . . . I 58

56. Swanscombe and the neighbouring Palæolithic sites on the south side of the valley of the Thames, below London .

57. Diagram showing the various deposits of the Ioo-foot terrace of the Thames valley at Swanscombe

58. Profile drawing of the Dartford cranium and its outline from above, at right angles to the view given in profile. .

59. Section of the pit in which the Bury St Edmunds fragment was found . . . . . . . . . 173

6o. Section of the deposits at Hoxne . . . . . . 173

6I. Bury St Edmunds cranial fragment viewed from the side and from the front . . . . . . . . . 175

62. The Bury St Edmunds fragment viewed from above . . 176

63. The Galley Hill skull viewed from the side and from the front, the face being restored . . . . . . I 88

64. Drawings of the Galley Hill skull from above and below . . I 89 
65. Radiograph of the Galley Hill mandible and teeth . . . I91

66. Section of the 30-metre terrace at Abbeville . . . . 195

67. (A) A profile drawing of the Moulin Quignon mandible ; (B) A profile drawing of the Galley Hill mandible . . . . 199

68. Stippled outline of the Foxhall mandible superimposed on a drawing of the Moulin Quignon specimen

69. Stippled outline of the Moulin Quignon mandible superimposed on the Spy (Neanderthal) specimen

70. Strata of the gravel pit at Clichy, Paris . . . . 203

71. The Denise frontal bone . . . . . . . 206

72. The Olmo cranium viewed from the side and from the front .

73. The Olmo cranium viewed from above, compared with a similar view of the vault of the Neanderthal calvaria . . . 208

74. Section of the Pleistocene deposits near Cromer, Norfolk.

75A. Sketch of the valley of the Gipping to show the locality in which the Ipswich skeleton was found . . . .

75B. Sketch of a section across the Gipping valley to show the horizon of the discovery . . . . . . . 217

76. The parts of the Ipswich skeleton replaced in position . . 220

77. Drawings of the Ipswich skull from the side and from the front

78. Sections across a series of tibiæ of various races

79. M. Rutot's schematic section showing the number and sequence of the strata in the valley deposits of Belgium

8o. Section of the middle (Ioo-foot) terrace at St Prest, near Chartres.

81. Diagrammatic section of the strata of the sand-pit at Mauer, showing the depth at which the mandible was found

82. The right half of the body and teeth of the Heidelberg mandible viewed from above, and contrasted with halves of the mandibles of Spy man, of a Tasmanian, and of a modern European

83. Reconstruction of the palate of the Heidelberg man, compared with Professor Boule's reconstruction of the La Chapelle palate

84. Profile of the Heidelberg mandible compared with a corresponding view of the mandible of an Australian native. .

85. Outline of the Heidelberg mandible compared with a drawing of the lower jaw and face of a female orang . . . . . 242

86. Outline of the Heidelberg mandible compared with the Spy mandible.

87. Section of the hill (Colle de Vento) at Castenedolo, near Brescia 
FIG.

88. Woman's skull found at Castenedolo, viewed from the side and from above

89. Section of the east bank of the Bengawan, near Trinil, showing the position of the fossiliferous stratum . . . . . 258

90. Profile and vertex of the cranium of Pithecanthropus . . 263

91. Cranial vault of Pithecanthropus, of the Siamang (gibbon), and of a modern European orientated on the zero base line . : 265

92. Section across the upper third of Trenton femur compared with corresponding sections of a modern European femur and that of a Neolithic European.

93. Drawing of a skull of an American Indian on which the cranial fragment found at Trenton is represented . . . .

94. Sketch map of the sites of Ameghino's chief discoveries of ancient man

95. Sketch of the south-east corner of England, to show the Weald, the position of Piltdown, and the course of the Sussex Ouse

96. Sketch of the district drained by the Sussex Ouse, showing the area over which Mr Dawson found peculiar tabular flints and races of ancient gravel deposits

97. Diagrammatic sketch of the gravel deposit in which the Piltdown skull was found

98. Outline of a modern skull to show the number and position of the cranial fragments recovered at Piltdown .

99. Map of South England and North France, to show the course and tributaries of the ancient channel river

100. Fragments of the Piltdown skull placed in position and represented in profile . . . . . . .

101. The fragment of the right parietal bone of the Piltdown skull superimposed on the corresponding points of the bone of the left side, to show the extent missing

102. The fragments of the Piltdown skull viewed from behind.

103. The Piltdown mandible, as seen in true profile, compared with a corresponding view of the mandible of an Australian native

104. Section of the human tongue, chin, lower jaw, and lip made along the middle line, to show the origin of muscles from the region of the chin or symphysis

105. A corresponding section of the same region of a young chimpanzee

106. The muzzle and front teeth of the Piltdown skull as originally reconstructed by Dr Smith Woodward .

107. Similar view of the same part of a nıle chimpanzee 
108. Drawing of the jaws, in profile, from Dr Smith Woodward's original model of the Piltdown skull . . . . .

I09. A drawing of the same parts of a male chimpanzee .

I10. A comparison of the palatal areas in a female chimpanzee, in the Piltdown specimen as reconstructed in the original model, and in a modern Englishman

I I I. Profile drawing of Dr Smith Woodward's reconstruction of the skull of Eoanthropus

II2. Profile drawing of the skull of a modern Englishman with a cranial capacity of 1425 c.c.

113. Face view of the skull of Eoanthropus as reconstructed by Dr Smith Woodward

I I4. Face view of a modern human skull for comparison with fig. I 13 .

I 5 . View of a modern skull from above, showing the bones and sutures of the vault .

I I6. View of the skull of Eoanthropus from above

I 17. Showing the bones which form the hinder or occipital part of a modern skull

I I8. (A) Drawing of the occipital aspect of the Piltdown skull as reconstructed by Dr Smith Woodward; (B) From a reconstruction by the Author .

I I9. The right and left parietal bones superimposed to show how much of each is missing .

I20. (A) Transverse vertical section of the skull of an Australian aboriginal, to show the bones forming the base, side, and roof of the brain cavity; (B) Of an orang, to show the bones forming the base, sides, and roof of the brain cavity . .

121. Reconstruction of the left half of the Piltdown skull compared with a similar section of the Gibraltar and of the Dartford skull

122. Occipital aspect of the Gibraltar skull, to show the manner in which Neanderthal skulls appear to be compressed from above downwards

I23. (A) Hinder aspect of the skull of a young gorilla about three years old; (B) The same aspect of the skull of a female chimpanzee about twelve years old

124. Fragments of test skull

125. The right parietal fragment (stippled) of the test skull, superimposed on the left parietal, to bring out the corresponding points of the two sides 
126. Showing the framework of lines on which the right and left halves of a skull are reconstructed from fragments .

127. Showing the manner in which the left temporal bone is placed in position, and the left half of the skull built up (I) in the test skull, (2) in the Piltdown skull.

128. Reconstructions of the Piltdown and test skulls viewed from behind, to show the application and fit of the occipital fragments

129. View of the reconstruction and of the original test skull .

130. Occipital view of Dr Smith Woodward's original reconstruction of the Piltdown skull contrasted with a reconstruction carried out according to the identifications of the middle line by Professor Elliot Smith

131. Drawing of the vault of the test skull, with a corresponding drawing of the reconstruction .

132. Reconstructions of the Piltdown and test skulls viewed from above

133. Drawing of the upper aspect of the Piltdown skull as reconstructed by Dr Smith Woodward, and a reconstruction based on the identification of the middle line by Professor Elliot Smith

134. Skull of a young female chimpanzee viewed from above .

135. (A) The vault of a Neanderthal skull, showing the simian form of eyebrow ridges ; (B) The vault of a modern skull, showing well-developed eyebrow ridges of the type usual in presentday races, and also an asymmetrical condition in the region of the bregma, as in the Piltdown skull .

136. Profile of the skull of a chimpanzee to show the plane of orientation

137. (A) The relationship of the external angular or malar process to the level of the base of the frontal lobes of the brain in the Gibraltar (Neanderthal) skull; (B) The same relationship in a modern English skull

138. The fronto-malar region in the skull of an orang and in the Piltdown specimen .

139. Section across the anterior end of the left side of a chimpanzee's skull and the right side of the Gibraltar skull, to show the relationship of the external angular process to the third frontal convolution .

140. Horizontal section of the left frontal bone of the Piltdown skull, and of the right frontal region of a modern skull, to show the relationship. of the external angular process to the third frontal convolution. 
FIG. Profile of the test skull and of the reconstructed skull, orientated on the lines described in the text . . . . 386

142. Profile of the reconstruction of the test skull compared with the reconstruction of the Piltdown skull . . . . . 386

143. Two reconstructions of the Piltdown skull . . . . . $3^{88}$

144. Four types of human skulls compared-Galley Hill, Piltdown, La Chapelle-aux-Saints, and Pithecanthropus . . .

145. Diagram made from a brain cast of an Australian native, with a capacity of 1450 c.c. . . . . . . . .

146. Profile drawing of the brain cast from the skull of a young gorilla superimposed on a corresponding drawing of the cast from the Gibraltar skull . . . . . . .

147. Profile drawing of the brain cast taken from the reconstruction of the Piltdown skull by the Author . . . . . 408

148. Profile drawing of the original cast of the Piltdown brain . . 409

I49. Profile drawing of the brain cast from the skull of an Australian native, with a capacity of I450 c.c. . . . 410

I 50. Profile drawing of the brain cast of the Gibraltar skull . 412

I51. The occipital aspect of the brain cast from the skull of a young gorilla, to show the slight degree of asymmetry of the left and right sides . . . . . . .

152. Brain cast from the skull of an Australian native (capacity I 450 c.c.), to show the parts of the brain presented in a view from behind . . . . . . .

153. An occipital view of the original brain cast of the Piltdown skull . . . . . . . . . .

I54. Occipital view of the Piltdown brain cast as restored by the Author . . . . . . . . .

I55. View of the upper aspect of a brain cast taken from the skull of a native Australian . . . . . . . . . 422

156. Brain cast of the Neanderthal skull viewed from above . . 423

157. Brain cast from the skull of a young gorilla viewed from above, to show the markings for the longitudinal bloodsinus . . . . . . . . . .

158. Drawings of the Piltdown brain cast as originally restored by Dr Smith Woodward . . . . . . . .

159. Drawing of the upper aspect of the Piltdown brain cast as restored by the Author . . . . . . . .

160. Right half of the mandible of an Australian native, viewed from the inner or mouth aspect to show certain human characters 


\section{LIST OF ILLUSTRATIONS}

xix

FIG.

PAGE

16r. Inner aspect of the right half of the Piltdown mandible contrasted with the corresponding view of the right half of the mandible of a young adult female chimpanzee

162. The ascending branch of a series of lower jaws, viewed from behind

163. Side view of the lower jaw and mandibular joint in a modern skull

164. Drawing of the left half of a female chimpanzee's mandiblerepresented in both the opened and closed positions-to show the mechanism of the temporo-mandibular joint of a man of the Neanderthal type (La Chapelle) . . . .

165. (A) Lower jaw of a female chimpanzee, which has been set so that the upper surfaces of the three molar teeth are in a horizontal plane; (B) Reconstruction of the mandible of Eoanthropus on chimpanzee lines, and supplied with condyles of the chimpanzee type . . . . . . .

166. (A) The original reconstruction of the mandible of Eoanthropus, viewed at right angles to the plane of the molar teeth;

(B) Similar view of a reconstruction by the Author . .

167. (A) View from above of the Heidelberg mandible; (B) Similar view of a mandible of a modern Englishman .

168. (A) True profile drawing of the model of the Piltdown mandible and teeth reconstructed under the direction of $\mathrm{Dr}$ Smith Voodward; (B) A reconstruction by the writer . .

169. The right lower canine tooth found at Piltdown compared with the corresponding tooth of man and of anthropoids .

170. Skull of a child, dissected to show the roots of the milk teeth and the crowns of the permanent canines in process of development . . . . . . . . .

171. (A) The form of contact between the lower and upper teeth of a native Tasmanian; (B) The form of contact in a female chimpanzee . . . . . . . . .

172. The development of the canine teeth in an Australian native, a female chimpanzee, a male chimpanzee, and in a male gorilla . . . . . . . . .

173. (A) Profile of the mandible and lower teeth of Eoanthropus, as reconstructed by the writer; (B) Similar view of the mandible and lower teeth of a female chimpanzee

174. Tracings from skiagrams of the lower molars of a female gorilla and of a female chimpanzee

175. Skiagrams of the three lower molars of a modern European, of Eoanthropus, of a Krapina (Neanderthal) individual, and of the Heidelberg man . . . . . . . 475

176. Reconstruction of the face of Eoanthropus as seen in profile . 480 
177. Frontal view of a reconstructed skull, compared with a cast of the original - that of an Egyptian woman . . . . 48 I

178. Frontal view of a reconstruction of the Piltdown skull by the Author, compared with the reconstruction of the test skull

I79. Frontal view of the right half of the Gibraltar skull and left half of a modern English skull set side by side to show the difference between the Neanderthal and modern types of forehead

180. Frontal view of the left half of the original model of Eoanthropus contrasted with the opposite half of a Bronze-age English skull

181. Frontal view of the right half of the forehead and face of a modern Englishman contrasted with the left half of the Piltdown skull, as reconstructed by the Author . . . . 486

I82. Profile of the skull of a native Tasmanian . . . . . 488

I83. Profile of the skull of an orang . . . . . . . 490

184. Profile of the La Chapelle-aux-Saints skull . . . . 49I

185. Reconstruction of the facial profile of the Piltdown skull carried out by the method described in the text . . . 492

186. A series of skulls laid open longitudinally to show the parts forming the base or floor of the cranial cavity

187. Genealogical tree of man's ancestry . . . . . . 50

188. Genealogical tree, showing the lines of descent of the anthropoid apes

189. Genealogical tree, showing the ancestral stems and probable lines of descent of the higher primates 


\section{THE ANTIQUITY OF MAN}

\section{CHAPTER I}

\section{A NEOLITHIC COMMUNITY OF KENT}

THE road from London to Maidstone, once it has made a steep descent from the North Downs, winds through a district abounding in traces of long-past generations of Kentish men. The traveller along this road, with his face turned eastwards, be he ever so interested in the study of ancient man, cannot fail to note the picturesqueness of the Kentish weald. From time to time he passes villages which have preserved, in spite of a whirling stream of motor traffic, much of an old-world atmosphere. Ever on the left hand, a few miles distant from the road, the traveller sees across the hedges and orchards the steep flank of the North Downs, which trend eastwards to end in the white cliffs of Dover. Here and there he may trace the Pilgrims' Way as it winds along the foot of the steep grey face of the Downs, the mediæval path to the shrine at Canterbury. The great stone monument at Coldrum, which is to give us our first glimpse into man's past, could be reached by following the grass-grown pilgrims' path; but then if that route were taken we should miss the picturesque village of Igtham and the man who has made this part of Kent a Mecca for all students of early man-Mr Benjamin Harrison. We are in the centre of some of $\mathrm{Mr}$ Harrison's most important discoveries. On the plateau of the North 
Downs, stretching northward from the steep slope which now faces us until it sinks into the valley of the Thames, $\mathrm{Mr}$ Harrison has gathered those rudely worked flintseoliths - the earliest form of tool ascribed to man. Close by Igtham, hid in a wood, are the Oldbury rock-shelters where $\mathrm{Mr}$ Harrison has found over three hundred flints worked in exactly the same fashion as those chipped by the cavemen in the south of France when the rigorous climate of the Ice age was giving place to our more genial times. On the plateau a few miles away lie the oldest and rudest of human tools-for I am assuming that the reader admits the humanity of Mr Harrison's eoliths, while here, amongst the earth that has gathered at the foot of the projecting rock, almost burying it, are the stone implements-palæoliths - which mark the last phase of the Palæolithic period.

We are not concerned at this point with the immeasurable stretch of time that lies between the earliest of the eoliths and the latest of the palæoliths; in following man into the past we are to start from that period or age of culture which succeeded the Palæolithic-the Neolithic. All over this district, on the ploughed fields and in the woods, the keen and delicately worked flints which are characteristic of the Neolithic stage of man's history can be picked up. How long the Neolithic period lasted in England we cannot yet say with any degree of certainty, but we are all agreed that it came to an end about 2000 в.c., when bronze became known to the men of Western Europe. We have only to visit Rose Wood, within a short distance of Mr Harrison's house in Igtham, to see that the passage from the Palæolithic to the Neolithic period was marked by a much greater change than a mere alteration in the manner in which flint implements were fashioned. In Rose Wood is the evidence that men were no longer vagabonds and wanderers, but had settled down in communities. Hid in the undergrowth of this coppice ${ }^{1}$ is a series of circular

1 For an account of the antiquities of the Igtham district, see Igtham -the History of a Kentish Village, by F. J. Bennett, F.G.S., 1907. 
depressions, some forty in number, marking the sites of the pit-dwellings of a Neolithic village. ${ }^{1}$ These ancient dwellings were explored over forty years ago by the Kent Archæological Society. They were found to be circular "basin-like pits, 5 to Io. feet deep and I 5 feet in diameter." Round the pits were found fragments of rude pottery and numerous flint flakes and implements. Near by is Oldbury camp-also the work of the Neolithic period.

As we turn our backs on the pit-dwellings and Oldbury camp to gain the main road and again face eastwards, it is possible that the significance of what we have just seen may escape us. So far as we know at present, the men of the more ancient or Palæolithic period had no conception of house-building or of settled communities, of defence works or of pottery. These were, with perhaps the exception of the last, discoveries of the Neolithic period. Further, it is manifest that settled communities are only possible when the land is tilled and cattle are domesticated. Agriculture was the slow and laborious invention of the Neolithic age. It does not cut the Neolithic age any shorter if we suppose-as we must suppose-that agriculture was not evolved in Western Europe. In different parts of the world and at various times, man did slowly and laboriously discover the art of bringing plant and beast into his service. That stage-a Neolithic stage - was passed through somewhere, and it must have been an undertaking which involved many generations.

Igtham, where we left the main road, is thirty miles from London; six miles further along the road lies the village of West Malling (fig. I). At the time this account begins-1910-for I propose in this survey to confine myself to the discoveries and movements of the last four years--Mr F. J. Bennett had retired from a long and active career in the service of the Geological Survey under the British Government and settled in

${ }^{1}$ For pit-dwellings in Kent, see Geo. Clinch, Journ. Anthrop. Instit., 1899 , ser. 2 , vol. ii. p. 124. 
West Malling. He was then spending his leisure hours in busily interpreting the traces of ancient man in the county of Kent. The Coldrum Megalithic monument, to which we are now making our way, was the particular object of his attention in the year I have mentioned, I9IO. It is true that my friend, $\mathrm{Mr} \mathrm{A}$. L. Lewis, ${ }^{1}$ had recognised the importance of the monument in 1877 , and published an accurate plan of the arrangement of the stones; but it was left for $\mathrm{Mr}$ Bennett to reveal its secrets and the light it could throw on the Neolithic

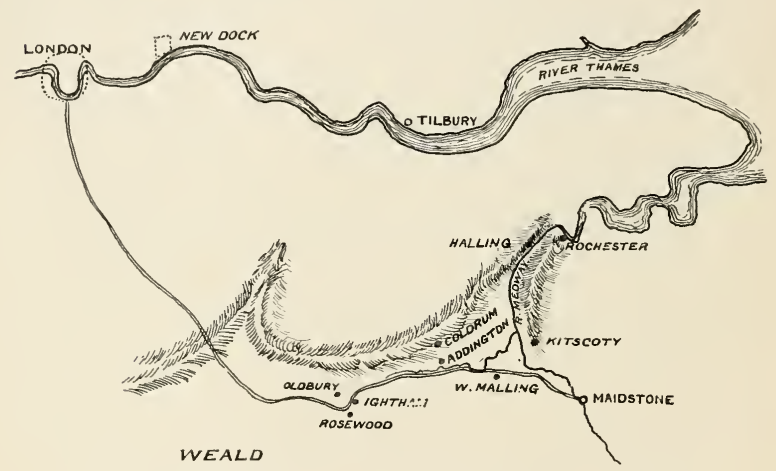

FIG. I. - A map of the part of Kent in which Coldrum is situated.

inhabitants of Kent. To reach Coldrum we follow a farm track which opens from the main road before the village of West Malling is reached. Before us, to the north, and some three miles distant, is the grey, dry pastureland that clothes the sharp face of the North Downs. Sweep away the snug farms which lie sheltered in the weald below the Downs and on the uplands of the plateau above them, replace the hedged fields with little terraced cultivated plots, and we have before us exactly the country that Neolithic man inhabited four or five thousand years ago. On our right, as we proceed north-

1 See Journ. Anthrop. Institute, Nov. 1877. 


\section{A NEOLITHIC COMMUNITY OF KENT 5}

wards, we see the same valley of the Medway opening out before us as it did before him, except that the smoke which sweeps towards us from the cement works of the gorge, by which the Medway makes its way northwards through the Downs to reach the Thames, was unknown in his time. When we reach the monument, a little distance short of the Downs, we see that it is not as Neolithic man left it. Time and circumstance have

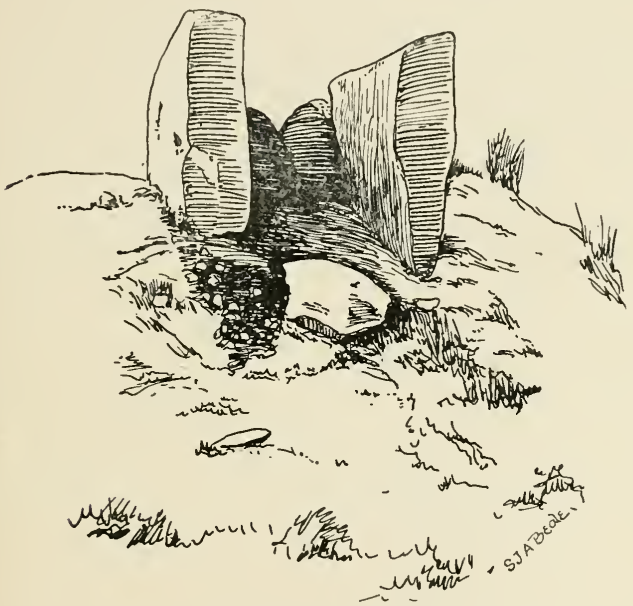

FIG. 2. - Megalithic monument at Coldrum viewed from the east (Dr Stanley Beale).

defaced it. We pass the farm and reach the raised corner of a field on which the monument stands. Half a mile further to the north is the Pilgrims' Way along the foot of the steep escarpment. We climb the slope that takes us to the main or central chamber situated on the eastern side of the monument (fig. 2).

The great stone which closed the eastern end has fallen forwards and exposed the interior of the chamber, or as we may now name it-for the nature of such 
chambers is well known-the tomb. It is a commodious chamber, ${ }^{1}$ I 2 feet 3 inches in length, east to west, and 5 feet 8 inches in width, from north to south. When Mr Lewis first saw the central chamber, a great vertical slab divided it into an eastern and western half, each half long enough to provide a wide bed for a six-foot man. The flat massive stone which forms the southern wall of the chamber shows that the Neolithic men of Kent were engineers of no mean ability. It stands 7 feet 3 inches high, is I I feet 3 inches long and I foot 9 inches thick - thus weighing many tons. That mass the men who lived in pit-dwellings transported and set up on this elevated spot. Three other vertical stones make up the northern and western walls. No covering or roofing stone is now present; the chamber lies open to the sky. On the opposite or eastern side of the Medway valley, another Megalithic monument-Kits Coty house-retains the great roofing stone (fig. IOA).

The central chamber is only part of the Coldrum monument; as $\mathrm{Mr}$ Filkins' plan shows, an irregular series of blocks surround the central chamber, enclosing a space, now overgrown with weeds and bushes, about 50 feet square. The monument was evidently set within and formed part of the eastern side of this square. In its original state the central chamber was probably roofed, the encircling stones formed the retaining wall of a great mound which covered the tomb, the entrance being from the eastern side (fig. 9). Whatever its exact original form may have been, this at least is certain : the minds of those ancient inhabitants of Kent must have been deeply moved by a faith in things unseen and of a human existence untrammelled by the flesh.

On April I6th, I9Io, $\mathrm{Mr}$ Bennett visited the central chamber. In the Megalithic monument at Addington, about a mile due south of Coldrum, he had picked up Neolithic flakes; he was now searching for similar traces

1 For a detailed description, see Mr Bennett's paper, Journ. Roy. Anthrop. Institute, 1913, vol. xliii. p. 76. 
of Neolithic man at Coldrum. "No sooner," he writes, ${ }^{1}$ " had I put my fork in near the west wall than I at once turned up, and under only a few inches of chalky soil, some human bones. This find I kept to myself, and determined to do no more without someone present to keep and record further finds in an area apparently so full

west,

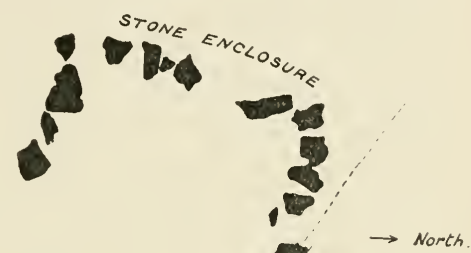

South

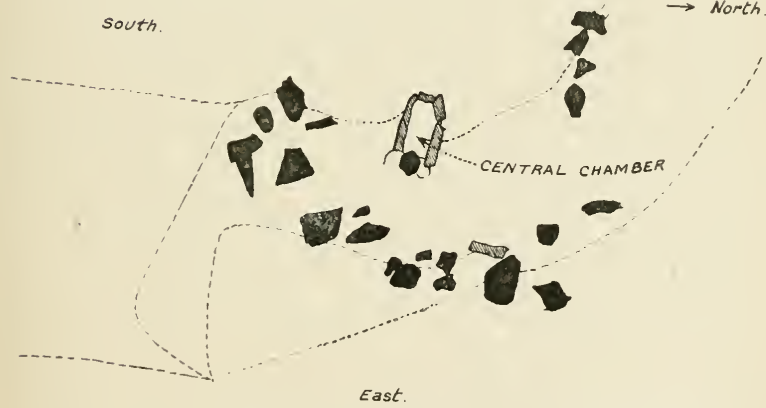

North

FIG. 3.-Surface-plan of the Coldrum monument, from a survey made by Mr E. W. Filkins.

of human remains." With the consent of the Lord of the Manor, Mr Nevill, and with the assistance of $\mathrm{Mr}$ E. W. Filkins, Mr G. Payne of Rochester, Mr F. W. Reader, $\mathrm{Mr}$ and $\mathrm{Mrs}$ Lindsay, and Miss Harker, $\mathrm{Mr}$ Bennett made a systematic examination of the central chamber. Besides human bones, only a few fragments of a rude pottery and a flint saw were found. Not a

${ }_{1}$ Journ. Roy. Anthrop. Instit., 1913, vol. xliii. p. 81. 
trace of any object belonging to a culture later than that of the Neolithic age came to light.

There is not any doubt in my mind that the bones thus discovered by $\mathrm{Mr}$ Bennett were those of the people primarily interred in this Megalithic tomb. Once chalk has permeated the porous texture of bones, preservation is secured. The Coldrum bones ring like porcelain when they are struck; the tongue adheres to the freshly fractured surface, showing that the bones no longer contain animal matter. In this manner we came by the material which provides us, for the first time, with the means of forming a true picture of what the Neolithic people of Kent must have looked like in the flesh-the people whose beliefs were centred round the Megalithic monuments. I do not propose to weary the reader with the details of my examination of the bones; they are already on record $;^{1}$ all $I$ propose here is to give in outline the mental picture which my investigation led me to form of the people.

When $I$ had arranged all the fragments, I found that at least twenty-two individuals were represented; they were of all ages, from newly born children to old men and women. Unfortunately the skulls, which give us the surest evidence of the racial nature of a past people, were few and fragmentary. There were only five, out of a group of nine, complete enough for our present purpose. But a certain feature of these skulls throws a curious sidelight on the nature of the monument. In a great number of them there were present peculiarities in their formation which could only be accounted for by supposing that the people buried in the tomb were of one family or of nearly related families. Three of the nine skulls had anomalous bones set within the joinings or sutures of the vault (see fig. 4); some of the others showed irregularities in the manner in which the sutures between the skull bones became closed.

They were people of short stature; from the length of the thigh bones the stature of the men was estimated

1 Journ. Roy. Anthrop. Instit., 1913, vol. xliii. p. 80. 


\section{A NEOLITHIC COMMUNITY OF KENT 9}

to have been about 5 feet $4 \frac{1}{2}$ inches $(1.600 \mathrm{~m}$.), and that of the women about 5 feet I inch $\left(15^{5} 67 \mathrm{~m}\right.$.). They were thus 2 or 3 inches below our modern British average. In size of brain they were apparently not below our standard. Indeed, the three male skulls had a capacity of $\mathrm{i} 600$ cubic centimetres-an amount considerably above the mean for modern men-I 480 c.c.; the two female skulls had a capacity of $1+50$ c.c., which is also above the modern mean for women-I 300 c.c. No importance can be attached to figures founded on a group of five skulls; in every race, ancient and modern, the brain is found to vary widely as regards size. Such observations as those just cited simply show us that Neolithic man, as regards brain size, had at least reached our modern standard.

It is also quite apparent that the Neolithic men in this part of England did not depart very widely from their modern successors as regards form of face and head. How near those Coldrum skulls come to modern specimens will be seen from fig. 4. I have taken one of the Coldrum specimens and set it, as seen in true profile, within a standard frame which bounds the chief limits of a modern Englishman's skull of mean size. The aimensions actually used are founded on the measurements made by Dr Macdonell ${ }^{1}$ on a large number of plague-pit skulls (seventeenth century) exhumed in the East End of London some years ago. Dr Macdonell determined the mean length of the male skulls to be I $89^{\circ} \mathrm{I} \mathrm{mm}$.; I have made the length of the standard frame in round numbers, $190 \mathrm{~mm}$. - just under $7 \frac{1}{2}$ inches. The width he found to be $140^{\circ} 7 \mathrm{~mm}$.; again I have taken round numbers and made it $I_{4} 0 \mathrm{~mm}$. The width is approximately 74 per cent. of the length. Any race of men in which the width of the head measures 75 per cent. of the length, or less, we count long-headed or dolichocephalic; if the width is 80 per cent. or more of the length, then the race falls into the short-headed or brachycephalic group : the races falling above 75 per cent.,

1 Biometrika, 1904, vol. iii. p. 191. 
and under 80 per cent., form an intermediate or mesocephalic-group. Amongst individuals of even the purest races a wide degree of variation in head width is found; we determine the place of the race by striking the mean of a series of measurements on many individuals.

The height of the vault above the ear-holes is also important. In the Whitechapel skulls-those regarded as males - the vault rises to II $4 \mathrm{~mm}$. above the earholes; the vaults of the English skull are low pitched. In the standard frame I have pitched the vault level at I $5 \mathrm{~mm}$. Now, when one of the Coldrum skulls is placed
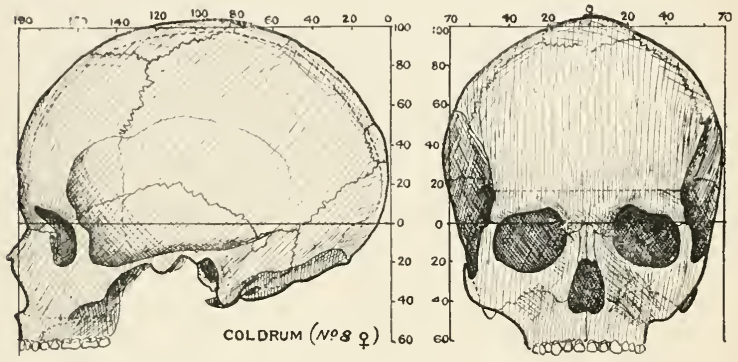

FIG. 4.--One of the Coldrum skulls set within a framework of lines which bound the chief diameters of a modern skull of mean size. The skull is represented in two aspects-profile and full-face.

within the standard frame (fig. 4) it is seen to fit fairly well. If a composite outline were made from the three male skulls, the length of the composite sk ll would be I $90.5 \mathrm{~mm}$., its width I $40 \mathrm{~mm}$., the height of the vault I $8 \mathrm{~mm}$. The width is 73.3 per cent. of the length. The two skulls regarded as females are relatively wider, the width index (cephalic index) being $77^{\circ} 9$. We are clearly dealing with a race with a head form lying towards the upper limits of the long-headed range. In actual dimensions of the head and in the proportion of width to length, this small sample of Neolithic people is not materially different from a modern group of English 


\section{A NEOLITHIC COMMUNITY OF KENT I I}

people of the industrial class; but they do differ from a sample of the Kentish people who lived at Hythe, on the southern coast of Kent, in mediæval times. During the last few years my friend, Prof. F. G. Parsons, ${ }^{1}$ has done much to unravel the evolution of the modern Englishman. In the crypt of the church at Hythe, he examined nearly five hundred skulls of people who lived in mediæval times. The heads of those Hythe people were differently shaped from the Neolithic people of Coldrum. They were shorter and broader and higher; the maximum length of the males was only I $79 \mathrm{~mm}$., the width I $42 \mathrm{~mm}$., the height I $20 \mathrm{~mm}$., the cephalic index $79^{\circ} 9$ per cent. The mediæval people of Hythe are on the border-line of the short-headed class. In accounting for the difference in head form between Neolithic and mediæval people, one has to remember that in the Bronze age typical round-headed people invaded Kent, and at later dates, during the Roman occupation, and also during the Anglo-Saxon invasion, many fresh racial elements were imported into the population of this county.

I am lingering round this small group of Coldrum people because they have to serve as a standard for our subsequent inquiries regarding the bodily features of ancient races of men. When a skull is viewed in full face (fig. 4) we have an opportunity of standardising its dimensions as seen from that point of view. The greatest width of the face is measured between the cheek or zygomatic arches. The width of the face of the male Whitechapel skulls is $130 \mathrm{~mm}$.; that we shall use as a standard width. The width of the forehead is also important. The lower width is taken between the outer ends of the ridge which crosses the forehead above the orbits-from the outer end of one external angular process to the outer end of the opposite process. The upper width (indicated by a stippled line in fig. 4) is taken between the temporal lines which bound the areas

1 See Journ. Anthrop. Instit., 1908, vol. xxxviii. p. 419; also 1910, vol. lx. p. 483 . 
on the sides of the skull occupied by the temporal muscles - muscles of mastication. The difference between these two frontal measurements is of some value. In skulls of a primitive race the lower or supra-orbital width is much greater than the upper or true frontal width. As regards the frontal widths, the Coldrum individuals show the same relative proportions as modern English people. In measuring the length of the face the forehead is not included. The forehead is really the anterior wall of the brain case; it is not, in an anatomical sense, part of the face. The length one desires to measure is from the nasion-the point where the bridge of the nose abuts on the forehead-to the lower margin of the chin. The lower jaw is so often missing in ancient skulls that it is usually impossible to obtain the "total" face length; hence we have to rest content with what is known as the "upper" face length-the distance as measured by calipers between the nasion and the point between the roots of the two central upper incisor teeth, the gnathion. Even as regards this measurement there is only one Coldrum skull available. All we can say, taking certain fragmentary parts into account, is that the face of this group of Neolithic people was rather shorter than in modern people and of about the same width.

When we come to analyse the characters which distinguish the people of the Neolithic period from the present population of Britain, we see that the changes affect, in the first place, the teeth, jaws, and face. Amongst modern Kentish folk, as is the case all over modern Britain, there is a tendency to crowding and irregularities of the teeth; the palate and jaws do not grow and expand sufficiently in youth to give room for a symmetrical eruption of the teeth. There is a decided tendency to narrowing and elongation of the face-a tendency to produce a face of a hatchet-shaped pattern. The nose is narrow and the palate contracted, and its vault is high. The teeth are not worn down as in Neolithic men; they are very liable to be attacked by caries. The front teeth, when the jaws are closed, do 
not meet edge to edge as in primitive races; like the blades of scissors, they overlap, the lower passing behind the upper. In the Neolithic people all these modern characters are absent. Abscesses or gumboils at the roots of the deeply ground teeth, however, were common; but there is not a single carious tooth to be seen in the Coldrum collection. The teeth are regular in their arrangement, the palates were well formed, but in actual size the teeth possess the same dimensions as those of modern English people. All these changes, which are appearing in the teeth and jaws of modern British people, arise, we suppose, from the soft nature of our modern diet. We believe that were modern men to resume a Neolithic diet their teeth and palates would again be moulded in the ancient manner.

It is not only in face and mouth that well-marked changes can be recognised. The bones of the lower extremities of Neolithic people were shaped in a different mould. The upper parts of the shafts of the Coldrum thigh bones are flattened in their upper parts, as if they had been compressed from front to back; the bones of the leg or shin are much more flattened from side to side, and the bones which form the ankle and foot are shorter, stouter, and show more extensive joint surfaces-evidence of freer movement. We cannot explain the disappearance of these characters. Perhaps the modern conditions under which we live-our clothing, our boots, our roads and streets-have brought about a remoulding of the lower limbs. The solution of those problems awaits further investigation. In the meantime we merely note the fact that the men of Kent do differ in certain bodily features from their predecessors of four thousand years ago. Time and environment appear to have worked certain changes in the structure of the human body.

The Neolithic men of Kent were thus of short stature,

1 The standard article on the stature of prehistoric man is that by Prof. Karl Pearson in the Philosophical 7 ransactions, 1898 , vol. cxcii. p. 169. The stature of the modern Englishman he estimates at $1700 \mathrm{~mm}$. The mean of the three Coldrum men I have calculated to have been 1645 mm. -2 inches less. 
with rather large heads in which the width was about 75 per cent. of the length. What were people in other parts of England like at this period-the later part of the Neolithic age? So far as we know they were all long-headed, not very different in size and form from those found at Coldrum. The people found in the long barrows of the Neolithic period appear to belong to the same race as the Coldrum individuals. The skull I wish to cite as typical of the Englishmen of the Neolithic period is that known as the Trent or Muskham skull. It was found in an ancient bed of the Trent, at Muskham, near Newark, Nottingham, buried naturally in deposits
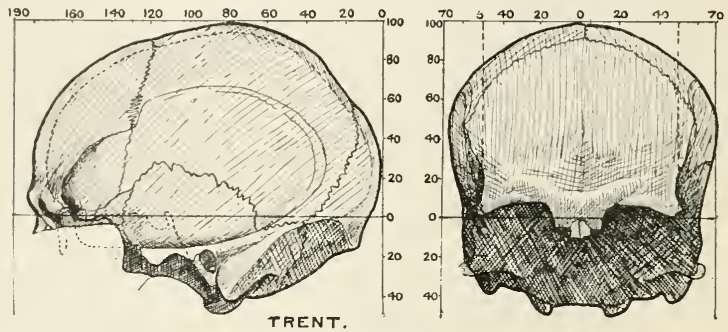

FIG. 5. - Side and front views of the Trent cranium.

laid down by the river. The objects found with it show that it is of Neolithic age. Huxley ${ }^{1}$ described it in 1862 , and made it the representative of what he named the "river-bed type" (fig. 5). The earliest Neolithic skulls we know of in England are of this type; the Coldrum and long-barrow skulls are merely variants of the type. The "river-bed" form of head is not confined to Neolithic England. In an adjoining figure I have placed corresponding drawings of a skull from Malta-from that subterranean sepulchre of the Neolithic age, the Hypogeum at Hal-Saflieni-which Dr

I Prehistoric Kemains of Caithness, by Samuel Laing. Williams \& Norgate, I866. The Muskham or Trent skull is in the museum of the Royal College of Surgeons, England. 
Zammit, ${ }^{1}$ the curator of the museum at Valetta, has given me an opportunity of investigating, as well as several other specimens from Malta of the Neolithic period. When we compare the Neolithic skulls from Coldrum and from Malta we see so many points of resemblance that we must regard them, not perhaps as of the same race, but as belonging to members of a closely related group of races. The name which must be given to this group of Neolithic races-the races characterised by a "river-bed" type of skull-there also can be no doubt about. The veteran Italian anthropologist, Professor Sergi, ${ }^{2}$ has clearly proved that the type of
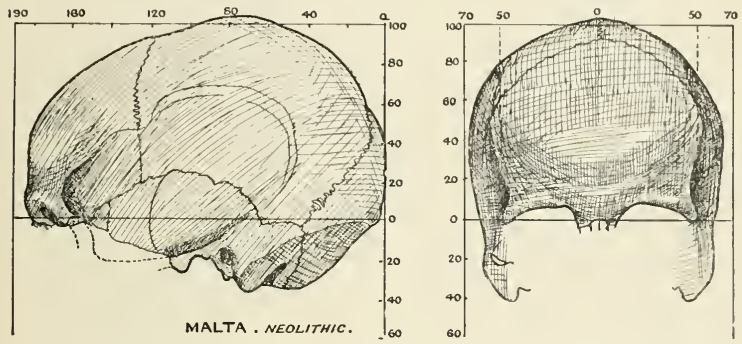

FIG. 6. - Side and front views of a skull from a Neolithic burial-place in Malta.

skull represented by the Maltese specimen (fig. 6) is characteristic of the people who lived in the lands which bound the Mediterranean-from the Levant to the Straits of Gibraltar-during the Neolithic period. Sergi's Mediterranean race had heads which in size and form were of the "river-bed" type. The back of the head, in place of being flattened, projected backwards as a boss or cap-the occipital boss seen in the Coldrum skulls. The ancient Egyptians were also members of the Mediterranean group-perhaps rather aberrant members. In fig. 7 I reproduce a composite diagram, made from

1 See Reports of Explorations of Hal-Saflieni Prehistoric Hypogeum. Malta, 1911, I9I2.

2 The Mediterranean Race, London, 1901. 
the measurements of five specimens, representing the skull-form of male Egyptians of the Sixth Dynasty-of men who were living in Egypt between four thousand and five thousand years ago. When the Egyptian, Maltese, and Kentish skulls of the Neolithic period-at least Neolithic as far as England is concerned, for in Egypt and along the shores of the Mediterranean the use of copper and bronze was already known-are compared, it will be seen that they differ in detail, but in general form are of the "river-bed" type. We find the same type in the Neolithic people of Spain, France, Switzerland, North Germany, and Scandinavia.
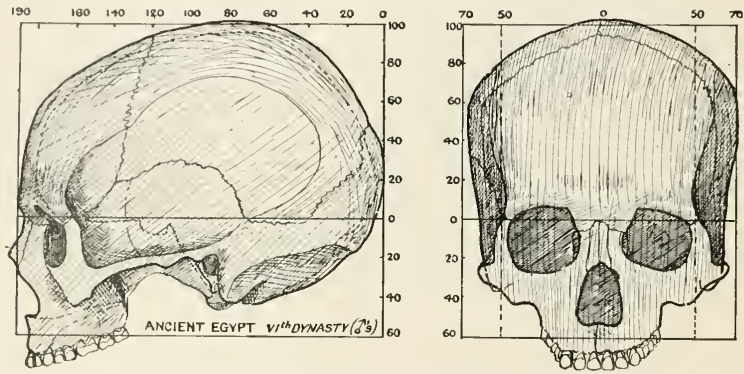

FIG. 7.-Form of skull of ancient Egyptians of the Sixth Dynasty, from the side and from the front.

We see, then, that the little group of people whose remains were buried in the central chamber at Coldrum are not an isolated patch of people; they are a sample of the kind of men who lived in Western Europe in the Neolithic period. The same, or a closely allied race, spread eastwards along the shores of the Mediterranean, both on the European and on the African side. Already in the Neolithic period the Mediterranean type of man, with a well-defined form of head or skull, was differentiated into local groups or varieties. It must not be thought that the people who built the Coldrum monument are counterparts of the people who built the 
pyramids. They were men of the same type, and we must suppose, in order to account for their resemblances, that they arose, at some remote period, from a common race or stock. We can detect, however, in the ancient Maltese and in the ancient Egyptian skulls certain negroid features - features which are absent in the skulls of the Neolithic people of Western Europe. Further, we know that at the very dawn of the Neolithic period a great wedge of round-headed humanity had been thrust into central Europe-with its base in the East and its advancing Western edge almost on the shores of the North Sea. An anthropologist in the Neolithic period, if he had tried to account for the origin and distribution of the races of Europe, had to face just the same complicated problems as we have to grapple with now. Mankind was already old; the human web already universal.

The Coldrum people not only shared their physical characters with the people of Western Europe, but they also participated in the mental life of their time. The monument itself is proof of that. We must infer that the people who set up such monuments along the shores of the Mediterranean and in Western Europe during Neolithic times must have been stirred by a common code of beliefs concerning life and death. In seeking for an explanation of the Coldrum monument, I follow the lead of Professor Elliot Smith. ${ }^{1}$ In his opinion, the birthplace of such monuments is ancient Egypt, the time of their evolution there-the five or six centuries which mark the establishment of the early dynasties-from 3400 в.c. onwards. During that period, the original simple Egyptian grave became an elaborate home for the dead-such as is shown in the accompanying diagram (fig. 8). Such a grave consisted of a mound or tumulus bounded by four stone retaining walls. The approach to the tomb was usually placed on the eastern

1 See Ancient Egyptians, Harper Brothers, I $\dot{9} 11$. Essay's and Studies presented to William Ridgway on his Sixticth Birthday, Cambridge, 1913. Man, 1913, vol. xiii. p. I93. 
side, where the retaining walls formed a vestibule or chapel, in which offerings were made to the dead. Within the mound or tumulus was a small chamber-the serdab" the home of the dead man or of his disembodied spirit," an opening in the stela allowing the spirit access to the offerings in the chapel. Under the tumulus lay the burial chamber, connected with the mound or tumulus by a vertical shaft. That is the type of structure which had been elaborated in the course of centuries by a highly

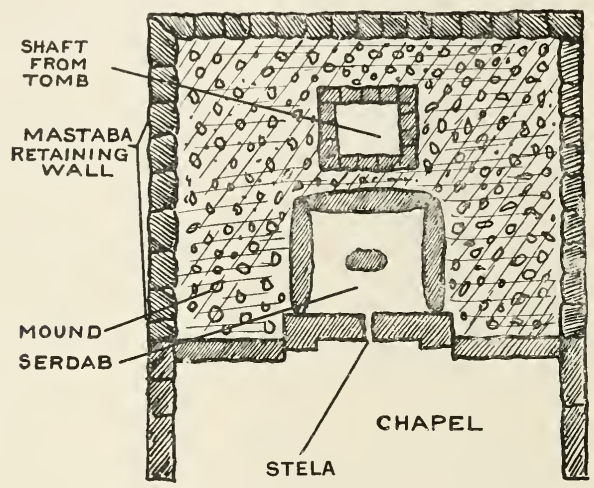

FIG. S. - Ground-plan of an ancient Egyptian tomb (Elliot Smith).

organised and ancient Egyptian community. In the Neolithic tombs of Sardinia-the giants' tombs ${ }^{1}$ - the structure is somewhat simpler (fig. 9). The spirit chamber or serdab and the burial chamber are not separated; the common central chamber of the tumulus or mound now represents, in the opinion of Professor Elliot Smith, the united serdab and burial chamber. The supporting walls or mastaba are prolonged on one side to form an approaching chamber or chapel. The plan of the Sardinian tomb proves of assistance when we come to interpret the various parts of the Coldrum

' See Dr Duncan Mackenzie's article in Memnon, 1909, vol. ii. 
monument. It possesses the great central chamber, originally approached by the declivity on the eastern side (fig. 9). The stones, now disposed irregularly round the central chamber, evidently formed a supporting wall or mastaba for the mound-long since removed. At the eastern end, it is evident from the disposition of the outlying stones (fig. 9) that the retaining wall on each side of the approach or entrance was carried forwards to enclose a chamber-similar to the chapel of the Egyptian tombs. In the monument, then, we have evidence that the Coldrum people participated in the beliefs which swayed

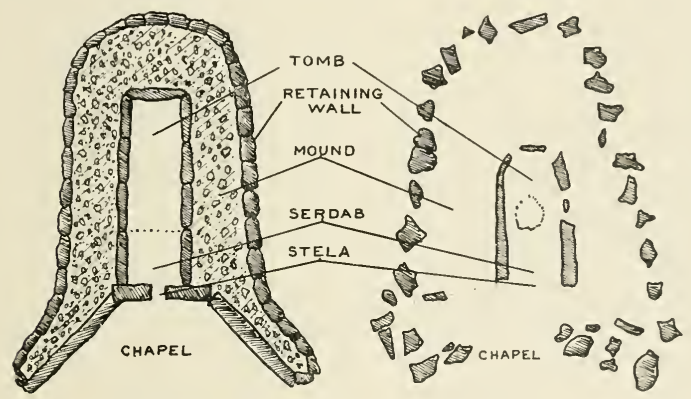

FIG. 9. -On the left, a ground-plan of a "giant's tomb," Sardinia. On the right, a sketch-plan of the Coldrum monument, showing points of resemblance to the "giant's tomb."

the people of Western and Southern Europe in the Neolithic period. The Megalithic monuments represent the mosques, the churches the chapels of the Neolithic age-concrete expressions of inward beliefs.

I have selected Coldrum as a starting-point for a survey of ancient man because it provides us with a series of facts which show us that in the essentials of life and of bodily form the Englishman of the Neolithic period-of four thousand years ago-was not materially different from his modern successors. We have changed the form of our beliefs, we have transformed our clothes and our homes and revolutionised 
our means of livelihood, but in brain and body we have changed only in minor details. We may presume that evolution works slowly so far as the human body is concerned.

One other point may serve to show that the status of Neolithic man was higher than is usually supposed. The people of France of that period buried their dead in caves or large artificially prepared subterranean chambers. None of these Neolithic sepulchral chambers have been more systematically and scientifically investigated than the one accidentally discovered in I 908 on the side of a hill, at Vendrest, some sixty miles to the east of Paris. ${ }^{1}$ Remains of over a hundred and twenty individuals, representing both sexes and all ages, were found within this ancient tomb. A fall of earth and rocks had buried the doorway of the sepulchre about the close of the Neolithic period, for all the worked flints and ornaments found within the sepulchre were of that age of culture; no traces of the Bronze or Iron periods were found. No less than eight of the skulls had been opened during life by the operation known as trepanning or trephining. It is clear, too, that in the majority of cases those Neolithic men undertook and successfully carried out operations which even modern surgeons hesitate to perform (fig. IO).

When we try to fathom the reasons which led men so long ago to practise these daring surgical procedures, we have to study the art of surgery as practised amongst modern primitive races. Lately, Dr W. E. Redman presented to the museum of the Royal College of Surgeons, England, five skulls showing how the operation of trepanning is carried out by the natives of New Ireland, one of the islands in the Bismarck Archipelago, to the east of New Guinea. Accompanying the skulls are the sharp obsidian flakes with which the operation was performed and the vegetable bandage which was applied to secure the dressings over the

${ }^{1}$ La sépulchre neolithique de Belleville à Vendrest: Rapport général par Dr Marcel Badouin. Société Préhistorique Française, 1911. 
wound. Recent discoveries have explained why an opening in the skull may relieve certain forms of headache, and it is probable that the operation is sometimes performed amongst primitive people for such a condition. At other times, perhaps, trepanning is performed to allow the evil spirit of insanity, or of delusion, to escape. Trepanning was frequently performed by the ancient Peruvians. During the Neolithic period, this operation was apparently unusual in England, for I have found records of only three or four examples. ${ }^{1}$

The reader may draw the conclusion that an operation performed by the natives of New Ireland cannot be regarded as a mark of a high state of mental evolution. Such an inference is scarcely just: a people who practise the operation of trepanning must entertain certain beliefs concerning the constitution of the human body -beliefs which provide them with the principles on which their actions are based.

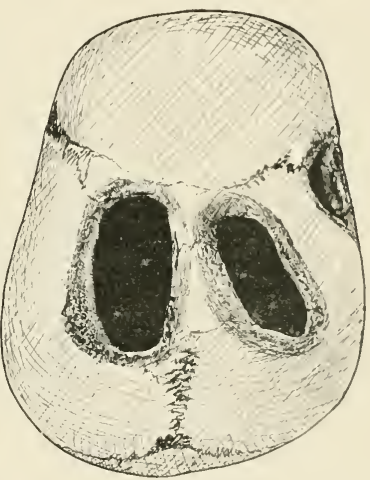

FIG. IO. -Skull from a Neolithic sepulchre in France, which had been trepanned in three places. The patient had recovered, for the margins of the openings are healed over.

The instances I have just cited have other bearings on the problem of man's antiquity. How does it come about that in ancient Peru, in Neolithic France, in the New Ireland of to-day, we find the same daring and difficult operation carried out? Has each people discovered the practice for itself, or-as seems to me more probable-was it not evolved so long ago that it has permeated the whole stock of modern man? Further, the operation of trepanning shows us that a civilisation which

${ }^{1}$ See article by Dr Wilson Parry, Lancet, 1914, i. p. 1699. 
prevailed four thousand years ago in one part of the world is still represented in the modern world. There are many modern races still in the stage of culture which was reached by the people of Europe four or five thousand years ago. -The Neolithic culture, although ancient, is still modern. It requires many thousands of years to move the whole world up a stage in civilisation.

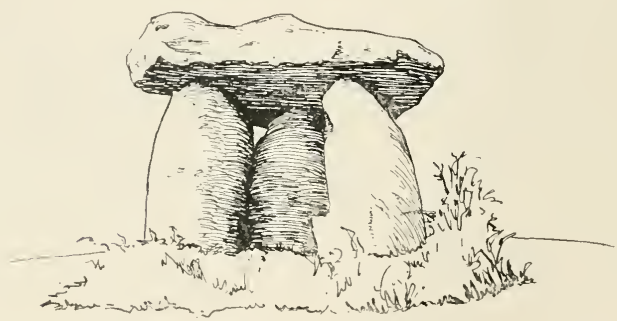

FIG, IOA, - Kits Coty house, a Megalithic monument near Coldrum. 


\section{CHAPTER II}

THE PEOPLE OF THE SUBMERGED FOREST

The Megalithic monuments and the people who built them belong to the closing phases of the Neolithic period. We are now to seek traces of the people who lived in England towards the commencement of that period. The records of the-time are not beyond recall, for we now know that large tracts of country over which the early Neolithic people roamed and hunted, perhaps established their village communities and, in all likelihood, cultivated their little plots of ground, are preserved beneath the waters of surrounding seas. At various parts of the English coast a low tide exposes the fringes of these Neolithic territories along the foreshore. The old land surfaces are easily recognised when they are marked, as is the case in some localities, by the blackened stumps of trees, still rooted to the soil on which they flourished long ago. Remnants of these submerged forests are to be seen along the West, South, and East coasts of England, round the Channel Islands, and along the North-IVest coast of France. They extend far out into the bed of the North Sea. The Dogger Bank (see Mr Clement Reid's map, fig. I I), now covered by 60 feet of water at low tide, still yields, when dredged, peat and the remains of the marshplants which once grew where now great steamers come and go. Even at greater depths-at levels which lie 120I 30 feet below the surface of the sea-the same evidences of an old land surface are to be found. ${ }^{1}$ Mr Clement Reid

1 See Mr Clement Reid's excellent manual on Submerged Forests, Cambridge University. Press, 1913. 


\section{4

has studied the plants which grew on the Dogger Bank when it formed part of Continental England, and in his opinion they are modern in character. They represent living species, of the kind which favour a moderate climate

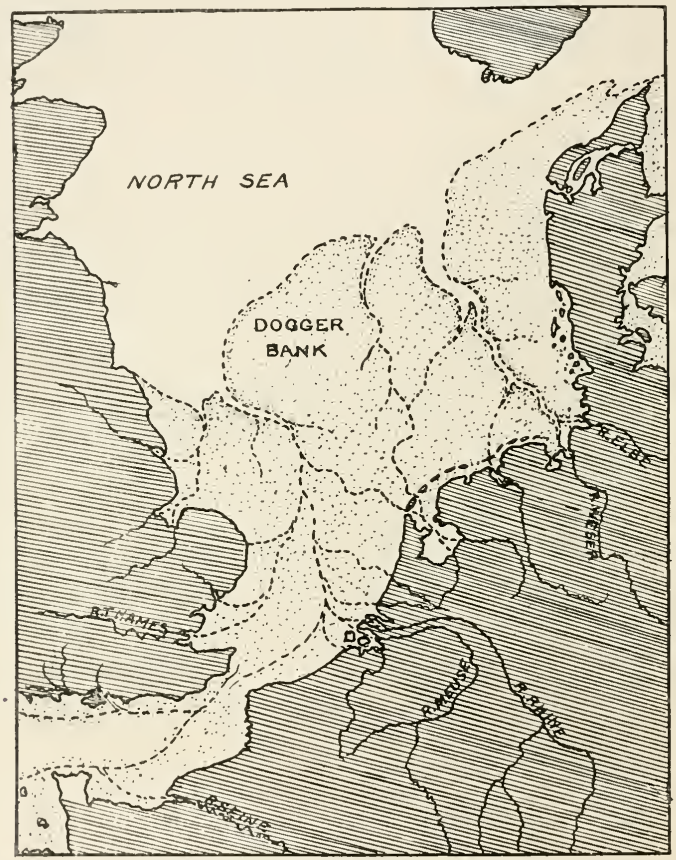

FIG. II. - The land-connection between England and the Continent in early Neolithic times (Mr Clement Reid).

and marshy surroundings. My friend, Mr J. Sinel, ${ }^{1 *}$ has studied the submerged forests off the coasts of Jersey. He has traced the old land surface, on which the forest grew, right out into the English Channel, until a depth

1 Prehistoric Times and Men of the Chamel Islands, Jersey, I9I 4 
of $\mathrm{I}+\mathrm{O}$ feet is reached. When that land surface was in existence, it is highly probable, as already stated, Lingland was joined to the Continent of Europe. Now, at various, places and at various times, worked flints have been discovered on and under this old land surface. They have always been worked in the style adopted by the men of the Neolithic period. The remains of the animals which have been unearthed at the "submerged-forest" level are those of beasts which are known to belong to the Neolithic period.

The Neolithic territories which lie deep beneath the sea are beyond our reach ; at some future and far distant period, perhaps, they may again become dry land and afford the anthropologists of the time ample means of studying some of their Neolithic ancestors whose bones, no doubt, lie preserved there for all time. Fortunately for us, there are certain marginal corners of the submerged forest land within our reach. As the sea crept upon the land, at so slow a rate, we must suppose, that its gain was not apparent in the life-time of a generation, the estuaries of the sea invaded our river valleys. The estuary of the Thames, for instance, before the subsidence of the Neolithic period began, was far out in the North Sea; London we must presume lay far above the tidal limit (fig. I I). In the course of time, as subsidence proceeded, the meadows and woodlands lying along the bottom of the valley became submerged in times of flood. Every flood or high tide left a veneer of slime behind, coating the floor of the valley and turning forest and meadow land into marsh. In the course of centuries, the marsh became a slimy expanse of mud, and the old land surface became buried under many feet of alluvial deposit or river sediment. That such has been the recent history of the Thames valley we have the most ample evidence. At the present time a trench, over 100 yards wide, a mile in length and 40 feet in depth, has been cut across the marshland of the Thames valley to form a new dock for London (see fig. I). Along the whole length of the exposed sides of the trench-about 
30 feet below the marsh level_can be traced a thick layer of peat, strewn with the trunks of great trees, all of them uprooted; not one is to be seen standing as it grew on the ancient land surface. They represent, we suppose, the crop of trees which flourished when the backwaters of the Thames first invaded the forests which grew on its banks. Below the marsh deposit and the peat is a thick stratum of ballast gravel-water-rolled stones, many of which are of considerable size, deposited in the river bed when the

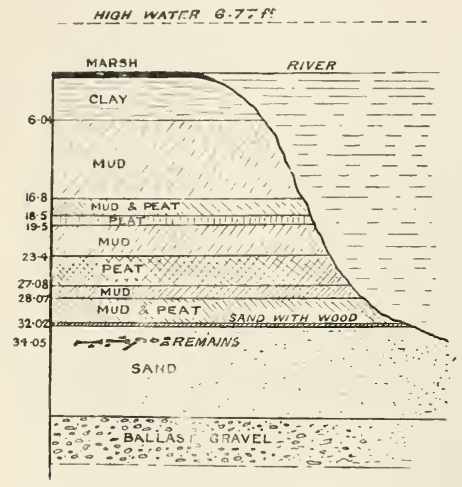

Fig, 12.-Diagram to show the various strata which buried the old land surface and the human skeleton at Tilbury. Thames was a powerful, rapid stream. In places, the ballast gravel is so thick that its deepest layer lies 60 or 80 feet below the present bed of the river. The bottom layer of the ballast gravel marks the time when the land had reached its highest point of elevation, and the estuary of the river reached its furthest limit in the North Sea.

The trench just described gives us a section across the floor of the valley of the Thames, five miles below the central part of London. To ascertain the kind of people who lived in England when the old land surface was clad with a flourishing forest, we have to go down the river still further, to Tilbury docks, situated on the marshland on the north bank of the river, twenty miles below London. When these docks were being made in 1883 , the old land surface-the Neolithic valley bottom-was met with at a depth of 32 feet below the level of the marsh, $36 \frac{1}{2}$ feet below the limit reached by the water at high tide. Three feet beneath that old land surface was 
found the skeleton of the Tilbury man. When a complete skeleton, or rather, representative parts of a complete skeleton, are found together, it is almost certain the person to whom that skeleton belonged was buried by human hands.

It could happen that the entire body of an individual might come to rest in a deep, quiet, muddy pool, and thus become naturally entombed, but in the bed of a quick-flowing river, such as the Thames then was, such a fate is improbable. As decay set in, the various
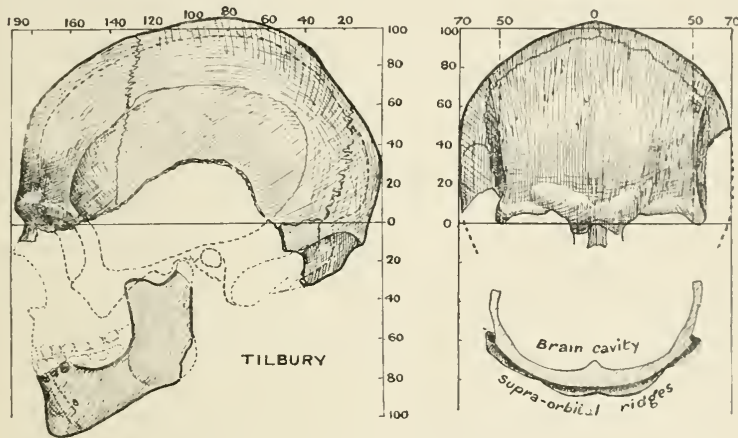

FIG. 13. - The Tilbury skull fitted within the standard frame for modern British skulls of average size.

parts of the body would become dismembered and scattered. We may reasonably presume, when a complete human skeleton is found, that we have to do with a burial. In I883, when the Tilbury remains were found, men were not on the alert for the evidence which might have confirmed such a supposition; no one expected to find "buried" human remains at such a depth. By the fortunate find at Tilbury, an Englishman of the submerged-forest age was revealed to us. When the skull is placed within the frame which fits the head of the average modern Englishman, it is seen that the ancient man of Tilbury reaches our modern standard. 
There is no feature of his head which marks him off from his successors of to-day. Like the people of Coldrum, he has a skull of the river-bed type. In brain capacity he is the equal of the average man of to-day, his capacity being just under I 500 c.c. In height he was about the same as the Coldrum men-about 5 feet 4 inches $(1.630 \mathrm{~m}$.). He has the same flattening of the thigh and leg bones as is to be seen in them. The skeleton lay 3 feet below the old land surface, laid to rest there, we presume, by the hands of his comrades. Neither he nor they could ever have dreamed of the day when great steamers would sail over the land which was their home. Such worked flints and animal remains as have been found, indicate that the old land surface-the submerged-forest surface-was inhabited at an early part of the Neolithic period.

Can we form any reasonable estimate of the centuries which have passed since the Tilbury man lived? Only three years ago, when I last discussed the discovery at Tilbury, ${ }^{1}$ I was impressed by the generally accepted opinion that there was no definite evidence of submergence in the lower valley of the Thames since the Roman occupation. Apparently, the land had been stationary during the last two thousand years. It therefore seemed to me, then, that submergence must be a slow process. If we supposed it to take placeat the rate of 2 feet in a thousand years, it would take quite fifteen thousand years for the land surface which carried the submerged forest to $\operatorname{sink}$, as at Tilbury, over 30 feet beneath the present level of the marsh. Subsidence evidently occurs at a more rapid pace than I had estimated. Mr Spurrell noted, when the Tilbury docks were being cut, that an old land surface, "strewn with Roman refuse," lay about 7 feet below the present surface level. At first sight that observation seems to show that the land surface at Tilbury had sunk 7 feet since the Roman occupation. Mr Clement Reid, whose opinion must carry weight in such a matter, thinks that much of this subsidence is only apparent, and is really due

1 Ancient Types of Man, Harper Brothers, I9II. 
to a compression or condensation of the various layers of peat-at least two in number (see fig. I2) - which lie between the "Roman" and "submerged-forest" strata. When, however, we find in the neighbouring valley of the Medway, evidence of a similar degree of subsidence, one is led to the conclusion that we have to deal with a simultaneous process affecting the whole country. The ford by which the Romans crossed the Medway at Rochester, and the road which led to the ford, are now about 8 feet below the level of mean tides. The borough surveyor of Rochester is of opinion that there has been a subsidence of about 8 feet since the Romans used the ford. The evidence, then, points to a subsidence in the lower parts of the adjoining valleys of the Thames and Medway of about 4 feet in a thousand years. If the rate of subsidence has been nearly uniform, then it would take between seven thousand and eight thousand years to give a submergence of 30 feet at Tilbury. In that case the Tilbury man would have been a contemporary of the predynastic Egyptians.

In producing such evidence, we are trying to obtain some conception of the duration of the Neolithic period. It is clear that if the process of subsidence is not continuous, but takes place at irregular intervals, with upward as well as downward movements, our calculations may be seriously upset. Besides the deepest old land surface represented by the submerged forest zone, there may occur, in the submerged land deposits, three other zones of peat or vegetable matter, which seem to indicate three later stationary periods-intervals at which subsidence did not occur, or took place very slowly. The antiquity of the Tilbury man and the duration of the Neolithic period may be longer than the estimate just given. Indeed, there are two lines of evidence which lead us to suspect that such may be the case. The submerged forest sprang up on a soil deposited over the wide and deep stratum of ballast gravel. At some places the ballast gravel is 50 or 70 feet deep, and stretches across wide tracts of the bottom of the Thames valley. The gravel represents 
deposits made in the bed of the river prior to the era of the submerged forest-when the period of land elevation was at its climax, and when the estuary of the Thames was far away in the North Sea. Yet, apparently, that deposit occurred at a very early point in the Neolithic period. A series of worked flints which Dr Frank Corner has collected from the ballast gravels of the Thames bed are of an early Neolithic type. Apparently, then, the submerged forest and the Tilbury man belong not to the beginning, but only to an early phase of the Neolithic period. One other consideration leads us to believe that the Neolithic culture extended over a long period of time. The earlier flint implements of this period are often weathered, so altered on their chipped surfaces that, in the opinion of Dr Allen Sturge, a very long period of time, much longer than I have postulated, must be assigned to the Neolithic period, in order to account for the degree of weathering or patination of the flints belonging to that period of culture. We are justified, on the evidence available at present, in regarding the Neolithic period as covering a period of six thousand or eight thousand years. We are on much surer ground, however, when we state that the period closed about 2000 B.c., than when we date its commencement at 10,000 B.c. The discovery at Tilbury shows us at least that the modern type of man was already established in England towards the commencement of that period.

The records of the Neolithic period which we have just deciphered at Tilbury are not confined to the lower valley of the Thames. When we cross the English Channel we find that contemporary deposits were accumulating in the Island of Jersey. We meet with traces of the same men, the same Neolithic culture, the same evidence of subsidence. As the steamer carries us along the south coast of the island in the early morning, past the rocky cliffs on the left, where remains of Neanderthal man were discovered only three years ago, we come presently in sight of the capital town, St Helier's, descending from the uplands of the plateau to extend 
itself on the low-lying lands surrounding the harbour. Near the harbour are the offices and the museum of the Société Jersiaise, a centre of prehistoric research. The Jersey Society has devoted particular attention to the Megalithic monuments and other records of the Neolithic period in which the island is particularly rich. Among its members none have given their time and ability to the study of this period with greater success than the curator of the museum, Mr J. Sinel. ${ }^{1}$ We propose to follow him to a deep excavation which has just been made for the foundation of a new building in the lower part of the town. Mr Sinel's diagram (fig. I4) shows the various strata which have been cut through; they have a certain degree of correspondence with the section at Tilbury. Beneath the surface layer of sand and clay, about 4 feet deep, is a layer of peat, containing fragments of pottery of the Roman period. That layer of peat was a "land surface" in Roman times. Beneath the peat comes a stratum laid down by the sea-made up of clay, containing stones and shells. That stratum bespeaks a passing period of subsidence, which might have occurred at Tilbury and left no trace behind. Then, beneath the marine stratum 
comes the submerged-forest zone, here represented by a layer of vegetable débris-of oak, alder, hazel, etc.ranging in thickness from 5 to $\mathrm{I} 4$ feet. So great an accumulation shows how long the forest age must have flourished here. Beneath the forest zone comes another sea deposit, a stratum of marine clay, sand, and shells, 3 to 5 feet in thickness, indicating a period of subsidence prior to the forest age. This zone may represent a deposit contemporary with the ballast gravel. Beneath the marine deposit comes one of clay with stones-rubble drift-a mark of the colder or glacial period. It was known, when this excavation was made in St Helier's, that flints, pottery, and remains of animals of the Neolithic period occurred in the great bed of peat representing the forest period. Mr Sinel observed these traces of Neolithic man, not only at various depths of the peat zone, but also in the upper part of the marine deposit. The marine deposit formed the land surface on which the submerged forest first grew. Men of the Neolithic culture were thus in Jersey at the very commencement of the forest era. The ancient forest land surface can be traced to the coast of France and far into the English Channel_to a depth, according to the observations of $\mathrm{Mr}$ Sinel, of I 40 feet. In the earlier part of the Neolithic period, Jersey and Guernsey-all the Channel Islands-were, like England, joined to the Continent. When we come to measure the antiquity of that time we must keep in mind the width and depth of the English Channel and of the Straits of Dover. They were carved out of Neolithic lands. When we suppose such changes have happened in eight thousand or ten thousand years, we seem to set time, with all the forces she usually commands, a task beyond her power.

The fortune which attended the sinking of the docks at Tilbury did not follow the excavation in St Helier's. $\mathrm{Mr}$ Sinel discovered no remains of a Neolithic man either in or below the forest zone; but in a small island-La Motte, or the green island-on the south coast of Jersey and three miles to the east of St Helier's, remains of 
Neolithic man were found. Dr R. R. Marett has given a full account of this discovery. ${ }^{1}$ At no very distant period La Motte had formed a small peninsula, but now its connection with the shore is broken, and it is accessible on foot only when the tide is out. At high-water the waves beat round the base of the island-it is so small that its final demolition is almost in sight-wearing away its substance and exposing to full view an exact section of its strata. The islet rises 30 feet above high-water mark. No sign is to be seen of the forest zone, but the yellow clay - a glacial deposit-on which the forest bed should rest forms the basis of the islet. Over the basal ${ }_{5} 5$ feet of yellow clay lies a stratum of sand and clay-a loess4 feet in thickness. Above that, and forming the surface stratum, is a layer of blown sand covered with vegetation. Below the blown sand lies the surface on which Neolithic man lived, for here are abundant remains of a "kitchenmidden "-charcoal, bones of ox, pig, red deer, shells of limpets, fragments of Neolithic pottery, and abundance of flint chips. In I9 I a landslide from the side of the island exposed a fresh section, in which $\mathrm{Mr}$ Sinel's son detected the projecting ends of a stone cist. It did not lie at the level of the kitchen-midden, but + feet deeper, at the junction of the loess with the glacial clay. A careful exploration, undertaken by the Sociéte Jersiaise, showed that there was a series of stone cists placed side by side, underlying the stratum of loess. The cists were filled with clay, from which $\mathrm{Mr}$ Sinel, by exercising great care, was able to remove some of the remains of the people who had been buried in these Neolithic tombs. He was able to restore, from fragments, three of the skulls. To me it seems reasonable to suppose that the people buried in these cists were members of the community who occupied the site of the kitchen-midden. At a much earlier period-186I-a skull was found at La Motte. It lay within the glacial deposit, at a depth of 18 or 20 feet below the surface of

1 "Further Observations on Prehistoric Man in Jersey," Archaologia, 1912 , vol. Ixiii. p. 203. 
the island. This skull is exactly similar in type to those recovered from the cists, and it is safest to presume that it reached the depth at which it was found in a fall of earth from the level of the tombs.

On the occasion of my visit to Jersey, three years ago, I had an opportunity of making a close examination of the skulls from the cists at La Motte. ${ }^{1}$ All are of the river-bed type. In fig. I 5, I have placed one of themthat of a woman, aged about thirty-within the standard frame of lines employed in the case of other Neolithic skulls. In size and shape the Jersey specimen differs
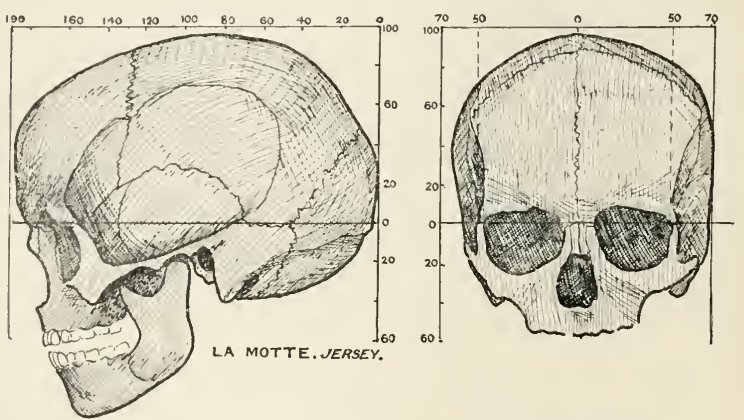

FIG. 15. - Skull of a woman, from a Neolithic cist, La Motte, Jersey.

very little from the skull from the monument at Coldrum, represented in fig. 4 (p. Io). In the Neolithic period, that human stock, to which the name "Mediterranean" has been given, had reached Jersey as well as England. In the early part of the Neolithic period the people with the river-bed type of head could reach both Jersey and England by land.

We are now to recross the English Channel to take up the study of Neolithic man in Cornwall-the extreme south-west corner of England. Jersey and Cornwall have much in common. On the uplands of both,

${ }_{1}^{1}$ See Bulletin de la Société Jersiaise, 1913, vol. xxxviii. p. 306. 
Megalithic monuments of the Neolithic period abound. Beneath the blown sand of the "links" occur, as at Harlyn Bay, the same serried cist tombs, the same Neolithic kitchen-middens. On the foreshore of Cornwall as of Jersey we can see at low tide remnants of the same ancient land surface, marked by the peat-stained stumps of the trees of the submerged forest. In Cornwall, remains of the men who lived on that ancient land surface have been found. In their day the cliffs of Cornwall overlooked wooded plains where now coasting steamers come and go. The submerged forest is not confined to the foreshore of Cornwall. It creeps up the estuaries of the streams which drain the tin-producing hills of the inlands. In those estuaries of the Cornish coast, the submerged forest lies buried, as in the valley of the lower Thames, beneath 30 to 50 feet of deposits laid down by the streams as the land sank and the invading sea crept inland. The submerged forest in the Thames valley grew on the "ballast-gravel" bed of the Thames. In the Cornish estuaries the submerged forest rests on a corresponding deposit laid down in the original or deepest bed of the streams. The Cornish streams, in ancient times, brought, not only the débris from the weathered granite of the hills, but also tin ore, which came to rest in the bottom stratum of the valleys and estuaries.

To the student of ancient man, that proved a fortunate circumstance, for the tin miners had frequently to expose and explore the old forest bed overlying the tin-producing stratum. In the museum of the Royal College of Surgeons of England, there is the roof and sides of a skull from the horizon of the Cornish submerged forest. It was found in 1809 , at a depth of 36 feet, in the Carnon Stream Tin Works, which were, for these river-bed workings came to an end nearly a century ago, situated on a western branch of that inlet of the sea which pierces Cornwall at Falmouth. Fortunately, we have a record of the strata exposed at the Carnon Works in 1807-two years before the skull was 
discovered, the record being made by $\mathrm{Mr}$ Edward Smith. ${ }^{1} \quad$ The strata lying over the skull-containing layer were the following: (I) mud and sand, 7 feet; (2) granitic gravel, shells with traces of charcoal, 4 feet; (3) fine gravel, mud, and shells, I 2 feet; (4) another thick stratum of gravel, sand, and shells, i 9 feet ; making 42 feet in all. Just below the last-mentioned stratum were found human skulls, and a piece of wood evidently shaped by man. The skulls lay immediately on the tin-producing stratum, and are therefore as old or older than the submerged forest. What became of the skulls mentioned by Mr Smith is not known. The specimen
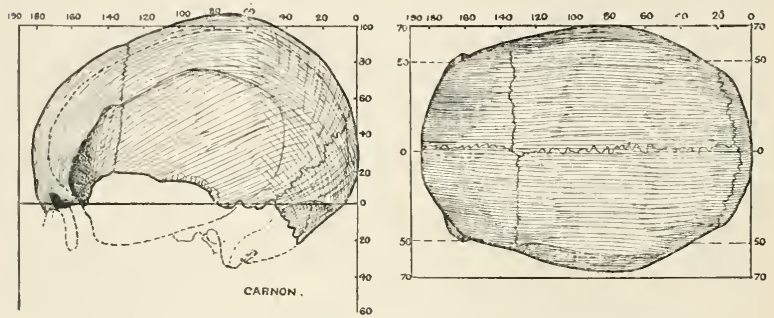

Fig. I6. - Views of the Carnon calvaria, from the side and from above.

in the College of Surgeons may be one of them, but the record which has come down with it is that it was found in I809, two years after the date at which $\mathrm{Mr}$ Smith's account was written, and the depth at which it was found is said to be, not 42 feet, but 36 feet. The condition of preservation or fossilisation of the Carnon skull is remarkable. Although that of a comparatively young person, as we see from the open conditions of the sutures between the bones, and the characters show it is a woman's skull, yet it is very heavy and rather thicker than we expect in modern skulls of young people, even of the male sex. It is $8 \mathrm{~mm}$. thick along the roof. The colour is a dull stone-grey, as if impregnated with

${ }^{1}$ See Memoirs of the Geological Survey: Geology of Falmouth and Truro, 1906. 


\section{PEOPLE OF THE SUBMERGED FOREST 37}

some unusual substance, not black as are skulls which have been buried in peat. In size and shape the Carnon skull or calvaria shows all the river-bed characters. The maximum length is ${ } 8_{4} \mathrm{~mm}$; ; its maximum width I $37 \mathrm{~mm}$.; the height above the ear-holes is estimated to have been II 7 or I I $8 \mathrm{~mm}$. The width is $74^{\circ} 5$ per cent. of the length; the brain capacity must have been about I 380 c.c. - slightly above the average for modern women.

An accurate record of another of these Cornish Neolithic skulls has been preserved by one of the best English anthropologists of the Mid - Victorian era-MrGeorge Busk. In I 862 , Mr Busk gave an account of the famous Neanderthal skull, discovered in I $857 .^{1}$ He also gave accurate drawings of cer-

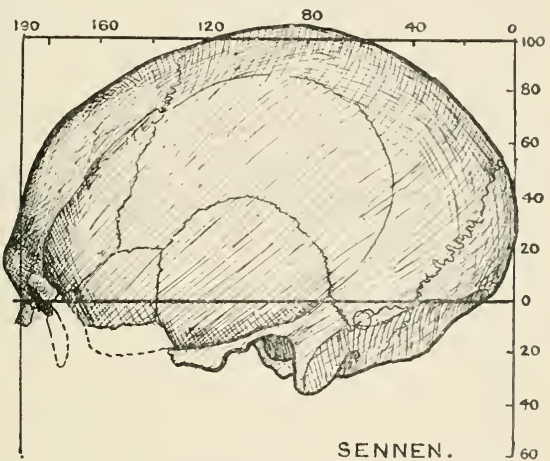

FIG. 17.-Side view of a skull at a depth of 30 feet in an alluvial tin mine at Sennen, Cornwall.

tain other ancient skulls. Amongst these he included one from an alluvial tin mine at Sennen, close to Land's End. The skull was found at a depth of 30 feet. That is all we know of the Sennen skull, except that it was found beneath the level of the sea. Where that skull is now we do not know-probably destroyed, so careless are we of our records of ancient history. There can be no reasonable doubt, however, that the Sennen skull also comes from the submerged-forest zone. Mr Busk's drawing of the skull $\mathbf{I}$ have copied and reproduced here. He does not, unfortunately, represent it either from above or from the

${ }^{1}$ Natural History Review, 186r, vol. i. p. 155. 
front. The skull is that of a man. Its maximum length is $196 \mathrm{~mm}$., somewhat longer than is usually the case in the river-bed type. The height of the vault is I $6 \mathrm{~mm}$. above the ear-holes. In all its markings it is modern in shape and size. There are thousands of men in England to-day with skulls of the same size and form.

We owe many of the discoveries of ancient man to industrial enterprises. The mining operations of the Cornish engineers brought them face to face with the records of the Neolithic period; house-builders revealed the submerged forest and Neolithic flints in the foundations of St Helier's; the Tilbury man came to light because deep docks were needed for great steamships. Along the south coast of Wales, which forms the northern shore of the Bristol Channel, the dock engineer has brought traces of the submerged forest and of Neolithic man to the light of day. It is to this region we are now directing our steps. At various points along the coast of South Wales, as on the opposite or southern side of the Bristol Channel, remnants of the submerged forest are exposed when the tide is low, especially after a storm. At various points along the coast, docks have been cut and the land surfaces of Neolithic times exposed. There seems to be no doubt that subsidence has been in progress along this coast since the Roman period. Major Thomas Gray has supplied me with evidence that the land has sunk at least 8 feet, perhaps more, since the Roman occupation-quite as much as at Tilbury and Rochester on the east side of England. Four years ago, Dr Arnalt Jones presented to the museum of the Royal College of Surgeons the frontal part of a skull which was found when docks were being made at Aberavon on the South Welsh coast, a few miles east of Swansea. This fragment came from a submerged layer of peat. Side by side with it was the pelvis of an Irish elk, which became extinct in England before the end of the Neolithic period. The layer of peat, $2 \frac{1}{2}$ feet thick, lay at a depth of I 5 feet, beneath strata of sand and clay. The peat may represent the submerged-forest zone, or one of the later land 
surfaces. At least it belongs to the Neolithic period. This case is of some interest because it raises the question : Is a fragment of a skull, such as that found at Aberavon (fig. I 8), sufficient to indicate the kind of man of which it formed a part? The fragment, consisting of the frontal bone, forming the forehead, and a small part of the parietal bone, forming the vault, is shown in fig. I 8 . It has been superimposed on the outline of another skull -one found at Newport-also of Neolithic date. It fits that skull not quite accurately, but sufficiently well to show that it was part of a skull of similar shape, but of rather larger dimensions. We are therefore at liberty to
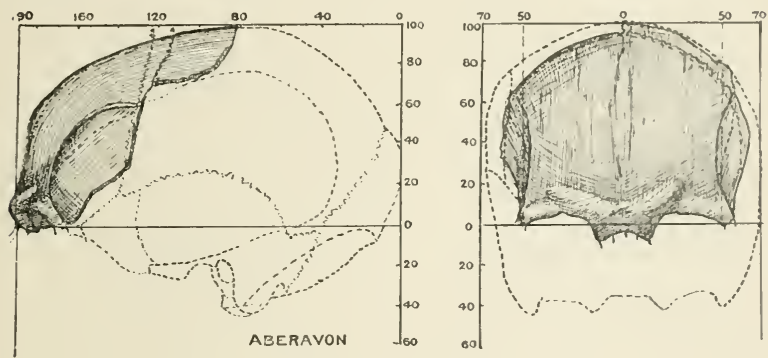

FIG. 18.-Fragment of skull found at Aberavon, superimposed on an outline of the Newport skull.

infer that it formed part of a skull very similar to the usual type of Neolithic crania. The Aberavon fragment, however, has certain characters which deserve attention. The eyebrow ridges are particularly well developed; it shows a robustness in the lines of attachment of the temporal muscles which is not usual in modern skulls. Major Gray has also given me the opportunity of examining a skull dredged in $18+0$ from the same peat deposit as the Aberavon fragment came from. This is a complete specimen, and, in the frontal region, is a counterpart of the fragment just described.

In all these finds of Neolithic man in England, the reader will note an unfortunate deficiency; there is a 
complete absence of any record of the culture of the people; in not a single case is the discovery mentioned of a typical example of a Neolithic implement or of even a flint chip. That is because we are only now awakening to the kind of evidence which is required to give our discoveries a true value as historical documents. The need of such evidence is exemplified in the next discovery I am to mention-one made when new docks were constructed at Newport, which lies also on the south coast of Wales, almost on the estuary of the Severn. Mr J. D. C. Couper, the resident engineer, made most careful records of the sections which were cut in the alluvial deposits at the mouth of the Ebbw, covering the old submerged-forest zone. The excavations exposed a deep layer of silt or mud overlying an equally deep layer of gravel. Lying within the gravel, at a depth of 60 feet below the surface level of the land and 20 feet below the Ordnance datum level, was found a human skull. ${ }^{1}$ Also remains of the wolf, of the red deer, the pelvis of a large ox (curiously ground and polished on one aspect, as if it had been used as a sledge on ice), of the horse, of all the mammals which flourished in Neolithic times. These were found at the same level, or near the same level, as the human skull. Worked flints were also found, but, unfortunately, no record was kept of them. We are thus not certain that the skull found is that of Neolithic man; the evidence, however, does justify us in presuming that it is of that date. The outlines of the skull are given in fig. I9, and again it will be seen we have to deal with a man's skull of the type we have already seen from other Neolithic horizons.

It is not necessary to multiply such examples. I may refer, however, to a skull ${ }^{2}$ which was discovered when the Manchester ship canal was being made in I 890 . It lay in a deposit of fine, sharp sand, covered by silt and other strata, amounting to 27 feet. No record was made of any objects of culture found in the same stratum as the

1 See Reports of Newport Museum, I9II.

2 Now in the museum of the Royal College of Surgeons, England. 
skull. Dr Aubrey Strahan, who has investigated the geology of the district in which the skull was found, is of opinion that the deposits which lay over this skull may have been formed in the last two thousand years, and that a skull found at such a depth may not be Neolithic. In characters the skull agrees absolutely with the riverbed type. Another skull of this type was shown to me by $\mathrm{Mr}$ Robert Newstead, curator of the museum at Chester. The skeleton of which it formed part lay at a depth of 5 feet 3 inches, in a clay deposit in the valley of the Dee, near Chester. The skeleton is certainly older than the Roman period, for at a depth of I foot
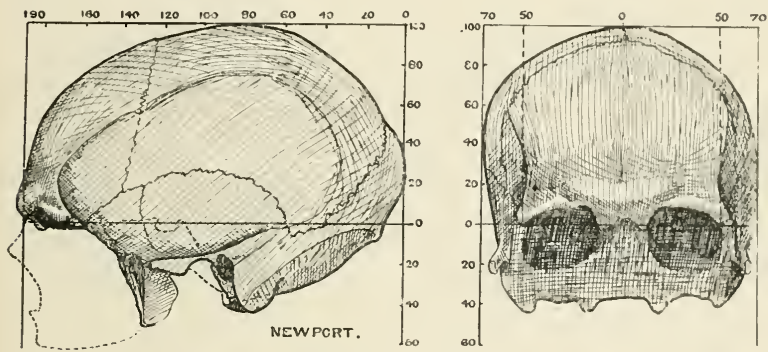

FIG. 19. - Side and full-face views of the skull found during excavations at Newport.

in the clay, pottery of that period was found. The exact age of the remains cannot now be fixed; evidence for regarding them as Neolithic is merely presumptive.

In this group of doubtful early Neolithic English skulls recovered from river-bed deposits, we must place the "Mickleton" skull, one which gave rise to much discussion in pre-Darwinian days. In 1852 , the railway from Oxford to Worcester was being made. It crossed the Cotswold Hills in the northern part of Gloucestershire, where a tunnel had to be cut, near the village of Mickleton. During the excavations at one end of the tunnel a human skull was found, now preserved in the museum of the Royal College of Surgeons. The skull lay i 7 feet 
beneath the surface of the land, within a stratum of blue clay, 5 feet in thickness. Over the clay was a layer of peat, $9 \frac{1}{2}$ feet in thickness, containing remains of pig, fox, etc. Over the peat was a surface stratum, 3 feet in depth, made up of loam, sand, and gravel. The date of the discovery is I 852 . Darwin had not yet published the Origin of Species (I 859), but the Vestiges of Creation was passing into a tenth edition. Orthodox minds were being disturbed by the discovery of facts which seemed to be at variance with Biblical tradition. The antiquity of the Mickleton skull ${ }^{1}$ became a matter of public controversy. A learned Scottish clergyman publicly censured Professor
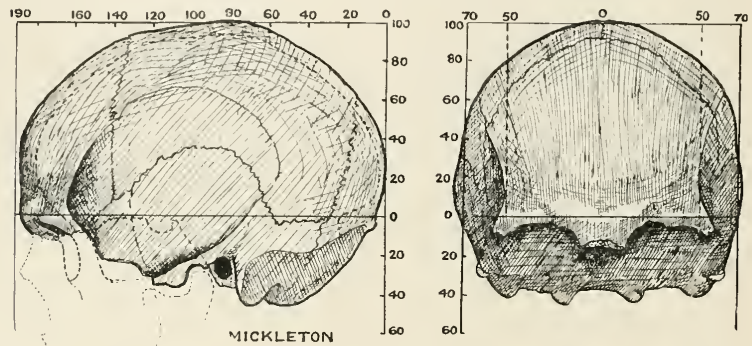

FIG. 20.-The Mickleton skull, side and front.

Baden Powell of Oxford University for countenancing a "pre-Adamite" date for the Mickleton skull." Mr Gavey, who discovered the Mickleton specimen, was of opinion that the age of the deposit was clearly indicated by the presence of a human skull : the deposit could not be earlier than the historical date assigned to the act of man's creation. In Mr Gavey's opinion, the skull of this reputed "preAdamite" was probably that of a "drunken sheep-stealer, drowned in the bottom of a hill pond, in all likelihood not more than eighteen hundred years ago." There is something to be said for Mr Gavey's contention. The

1 Edinburgh New Philosophical Journal, 1856, vol. iii. p. 247.

2 Quart. Journ. of Geol., 1853, vol. ix. p. 29. 
layer of clay in which the skull rested is the silt formed in the bottom of a hill pool; the deep layer of peat, $9 \frac{1}{2}$ feet thick, may have formed over the silt in a thousand years, and the superficial stratum, 3 feet in thickness, at a rapid pace. The animal remains found in the peat may be Neolithic or mediæval in date. The value of worked flints as a means of dating a deposit was then unknown; no evidence of this kind was looked for. The Mickleton skull is a typical example of the river-bed type, and the manner in which it has been preserved provides an excellent illustration of how the earth records its own history and stores within itself traces of the living things which inhabit it.

Our survey of the Neolithic period in England reveals a remarkably uniform and unchanging race of people-of less than medium stature, with well-shaped heads of rather more than average size. If we centre our attention merely on the physique of the people and note how little it changes, we may be led to the belief, if we think our bodily characters must change during the lapse of long periods, that the Neolithic period could not have covered a great space of time-one of eight thousand or ten thousand years. The animals which accompanied man in that period also changed very little; the natural plants of the country remained the same. Such changes as are noted in the fauna and flora are, we have every reason to think, due to the direct influence of man. In the four thousand years which have come and gone since the Neolithic period closed, we have revolutionised the conditions of life. From time to time, fresh blood, drawn from many racial stocks, has been introduced into Britain; the tongue spoken in England has changed several times, yet the backbone of the British population at the present time is a direct continuation and perpetuation of the riverbed stock of the Neolithic period.

If we reckon time by the degree of change wrought on the human body, we must count the Neolithic a short period. When, however, we note the changes which have occurred in the configuration of the land, our minds 
are drawn in an opposite direction. There is the most clear evidence that, at the commencement of that period, England and the Channel Islands were joined to the Continent. A common estuary received the Rhine and Thames. The English forest lands were continuous with those of France. And now, where those forests grew, are the wide Straits of Dover, the North Sea, the English Channel, and the silted-up estuaries. When we come to estimate the period of time in which those changes could have been effected, we are met at once with our ignorance of the causes which underlie earth-movements. $\mathrm{Mr}$ Clement Reid has given years of study to the matter, and, in his opinion, such changes might have been effected in a short period of time-fifteen hundred years. Those, however, who base their speculations regarding what has happened in the past on what is happening in the present, will allow a much longer period; but all must admit that our estimates are, at present, little more than guesses. To account reasonably for all the facts we have at present at our disposal, we must, I think, allow a period of at least ten thousand years for the Neolithic period.

There is a considerable body of evidence in favour of explaining the elevation and depression of the land in relation with the periods of glaciation. The elevation of the southern part of England is believed to have occurred when the ice-sheet of the last glaciation was retreating northwards. When subsidence was taking place in England, elevation was evidently at work in Scotland, for, as we have just seen, the Neolithic beaches of England are submerged, while those in Scotland are situated above the present shore-line. In one of these raised beaches, on the south shore of the Firth of Forth, Dr Edward Ewart discovered Neolithic flints in abundance, and certain burials apparently of the same period. The skulls of these ancient Scots are also of the river-bed type-very similar in size and form to the Coldrum skulls. Further north, in the Scandinavian Peninsula, elevation is now taking place at a rapid rate. Beyond the northern limits of Scandinavia lies the edge of the great perpetual ice-sheet. 


\section{PEOPLE OF THE SUBMERGED FOREST 45}

It is believed ${ }^{1}$ that the accumulation of a sheet of ice, several thousand feet in thickness, will depress that part of the earth's crust on which it rests. On the other hand, the part of the crust which lies immediately to the south of the ice-sheet will well upwards, it is believed, in the form of a wave, giving rise to such an elevation as is occurring in Scandinavia now. Still further south, beyond the wave of elevation, there is a secondary trough or depression. At the commencement of the Neolithic period, if we entertain the explanation just given, the icesheet was disappearing from North Britain, and England was elevated on the wave which follows the retreating edge of the ice. During the Neolithic period, as the icemargin retreated further to the north, England was overtaken in the succeeding wave of depression-which apparently still continues. Such a hypothesis, purely speculative in nature, helps us to explain some of the phenomena with which we have to deal in future chapters. At least, it fixes in our minds the fact that the Neolithic age lies wholly within the milder period which followed the last long spell of glaciation.

1 See article by Dr John W. Evans, Nature, I9I I, vol. Ixxxvii. p. $43^{8}$. 


\section{CHAPTER III}

\section{THE DISCOVERY OF PRE-NEOLITHIC MAN}

In tracing the various kinds of men who lived in the Neolithic period, the open country, the river valleys, and the submerged land surfaces served us very well. When, however, we try to follow man beyond the bounds of the Neolithic period-when the Thames was depositing the deepest layers of ballast gravel in her ancient bed-we must seek sequestered nooks where the earth keeps a more orderly register of events than in the turmoil of flooded valleys. The ideal place we seek is a cave, particularly a limestone cave, for the drip from the roof, laden with lime salts, seals up with a covering of stalagmite any bones which chance to lie on the floor. The floor of such a cave is always having additions made to it. If men make their hearths on it, human débris accumulates. Chips and dust are always falling from the roof; the mud washed in by rain or flood is added to other accumulations. In course of time the floor may grow until it actually reaches the roof, thus obliterating the cave. If no living thing has visited the cave as it became filled up, then the strata of the floor are "sterile"; but if men have used the cave as a habitation or as a passing shelter, or if they chance to die there, then the earth-buried stratum of the . floor becomes a page of history. It has taken us nearly a century to understand that caves may contain historical documents of the most precious kind. By a study of cave records, we have come by a knowledge of the races who preceded the men of the Neolithic period-the races of the Palæolithic period. 
We cannot begin a brief survey of how the very ancient world of Palæolithic man has been revealed to us more profitably than by taking our stand on the south coast of Wales, where we studied Neolithic man of the submergedforest period. To the west of Aberavon and Swansea, the peninsula of Gower juts southwards, exposing its limestone cliffs, I00 feet high, on the shore of the Bristol Channel. The Paviland cave opens on the seaward face of the cliffs, 30 feet above the tide, but not beyond the reach of the waves in time of storm. In the latter part of the eighteenth century news of the discovery of extinct forms of animals-elephant, rhinoceros, bear, lion, and hyena-in the strata of caves in South Germany had spread abroad, and the antiquarians of South Wales were led to seek for and to find similar remains in the floor of the Paviland cave. This discovery brought Dean Buckland, then reader of Geology in the University of Oxford, hot-foot to South Wales in 1822. The Dean found abundance of the bones of these extinct animals in the strata of the floor; he also discovered the skeleton ${ }^{1}$ of a tall man, coloured red with ochre, buried side by side with the bones of extinct animals. Curiously shaped flint implements, with ornaments and implements worked in bone and in ivory, lay in the same stratum. The Dean was able to explain the occurrence of a human skeleton side by side with the bones of extinct animals in a manner satisfactory both to himself and the men of his time. The animals were pre-diluvian; they had been swept within the Paviland cave by the great flood through which the ark rode in safety. The human remains were postdiluvian; they had been buried there by people who had settled in Britain after the universal deluge. It was then an article of faith that man did not exist in Western Europe before the flood.

About the same time a Roman Catholic priest, the Rev. J. MacEnery, stationed near Torquay, became interested in caves. In I 825 , in one of the wooded dales

1 See Professor Sollas's Huxley Lecture, Journ. Roy. Anthrop. Instil., 1913 , vol. xliii. p. 1. 
lying behind the picturesque town of Torquay, on the south coast of Devonshire, Mr MacEnery began to explore that great rambling subterranean series of chambers known as Kent's Cavern. In the dense layer of stalagmite, covering the floor of the cave, he found implements in stone and in bone, shaped by the hand of man, mingled with the bones of the same extinct animals as Dean Buckland had found at Paviland. The priest had the courage to draw a just conclusion from these observations in Kent's Cavern, and to face the opposition of the Dean and of the opinion of his time. $-\mathrm{Mr}$ MacEnery was convinced that man had lived in England as a contemporary of the mammoth, the rhinoceros, the cave-bear, and all those animals which we now know were native to Europe before our present climatic conditions dawned with the advent of Neolithic man. Mr MacEnery did not dare to even publish his records; they were discovered and published by the Torquay Natural History Society many years after his death. ${ }^{1}$ It was thus a priest who first broke into the world of Palæolithic man-at least in England.

How slowly a belief in man's antiquity made headway will be realised if we follow Sir Charles Lyell in his journey abroad in 1833 . He, the great geologist, was preparing a third edition of his Principles, and, as was his habit, visited every site in Europe where any discovery of note had been made. In I 833 his way lay through Belgium, and he stopped at Liége to see one of the Professors at the University - Dr Schmerling. The banks of the Meuse, before that river reaches Liége, are flanked by steep limestone cliffs, often 200 feet in height. On their vertical face open many rambling caves. Dr Schmerling had been caught in the vortex of cave exploration, and was able to place before the English geologist in I 833 the results gained by four years of severe toil in over forty caves. The collection represented those extinct forms of animals which Dean Buckland discovered

1 See a Memoir of William Pengelly; by Hester Pengelly (Mrs Forbes Julian), London, 1897. 
in the Welsh cave, but Dr Schmerling had found them in greater abundance and in greater variety. The same evidences of man's presence were found mingled with the fossil remains of animals-worked flint implements, weapons and ornaments in ivory and in bone. In one of the caves-that of Engis-Dr Schmerling found a human skull, besides other fragments in the same cemented stratum of stalagmite as contained the fossil bones. "The cranium," says Dr Schmerling," "was met with at a depth of a metre and a half (nearly 5 feet), hidden under an osseous breccia, composed of the remains of small animals, and containing one rhinoceros tusk. . . The earth which contained this human skull exhibited no trace of disturbance; teeth of rhinoceros, horse, hyena, bear, surrounded it on all sides." Dr Schmerling had thus advanced our knowledge of man's antiquity a point beyond that reached by the Rev. Mr MacEnery at Kent's Cavern. Not only had he found proof of man's existence with animals now extinctanimals which had disappeared from the face of Europe before the Neolithic age dawned $\angle$ but he had actually discovered Palæolithic man himself. Sir Charles Lyell was a true scientist, with an open and just mind, but he turned away from Dr Schmerling's discovery-still sceptical. Thirty years after the date just mentioned (1833), Sir Charles published a work which convinced thinking minds that man's antiquity was infinitely greater than usually believed. It took the scientific world thirty years to assimilate Schmerling's discovery. The discovery of the remains of a human being as the contemporary of extinct animals was more than even the open, wellbalanced mind of Sir Charles Lyell could admit in 1833 . Schmerling's work, like that of other pioneers, had to wait for a new generation.

We shall examine presently the facts which afterwards convinced Sir Charles Lyell that Dr Schmerling had made a great discovery. Meantime, let us see what kind of man

1 Recherches sur les ossemens fossiles découverts dans les cavernes de la province ce Liége, 1833. 
he discovered-the man who lived when the mammoth and woolly rhinoceros had a home in Belgium. When an exact drawing of the Engis skull is placed within the standard frame, the one we have employed in the case of Neolithic skulls, we see that in shape and size it is merely a variant of the river-bed type. It is longer, higher, and rather narrower; it is very similar to the skull of the Neolithic man found at Sennen, in Cornwall. The skull is that of a man of middle age. The maximum length is $198 \mathrm{~mm}$.; the width, I $40 \mathrm{~mm}$. , is 70.7 per cent. of the length. The height of the vault above the ear-holes is $12 \mathrm{I} \mathrm{mm}$. ; the calculated brain capacity
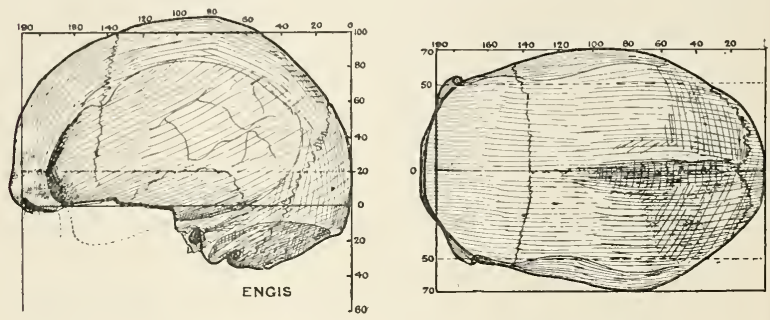

FIG. 21.-Views of the Engis skull from the side and from above.

I 500 c.c. - a little above the modern average. There is not a single feature that marks this skull off from men of the Neolithic or modern times. No doubt, if the face and the jaws had been found we should recognise certain points of difference in them, but, unfortunately, these parts were not recovered. If we believe that the human frame must change during the lapse of a long period, then we shall be inclined to regard the evidence of the Engis cave with scepticism. If, however, we regard Dr Schmerling as a competent and truthful observer-and I think the time has come when belated justice must be done to him-then we must conclude that a human type can be reproduced for many generations and over a very long period of time, and still remain almost unchanged. The man who lived in Bel- 
gium with the extinct animals of the Pleistocene period was reproduced in the Neolithic period, and still abounds in modern times. When Professor Boyd Dawkins wrote his classical work on Cave Hunting, ${ }^{1}$ he was not convinced on the evidence produced by Schmerling that the skull was contemporaneous with the fossil animals. Lately, my friend, Dr Rutot, has again, in company with Professor Fraipont, examined the Engis skull, and he, too, is inclined to place it in the list of doubtful specimens. ${ }^{2}$ It is true, as we shall see presently, that people of the Neolithic period did use caves as sepulchres, but there is no instance of Neolithic man having dug a hole in the hard breccia of a cave floor and buried his dead at a depth of 5 feet : Schmerling has placed it on record that the breccia was intact, and therefore we must admit that the river-bed type of skull was already evolved in the Palæolithic period.

The discovery which cleared away all doubts as to the great antiquity of man-which carried home the conviction that he was contemporary with extinct animalstakes us to the year i 860. The discoverer was Edouard Lartet, then aged fifty-nine. He had, in his early years, forsaken law for geology, and latterly had been caught in the passion for cave exploration. The year i 860 found him visiting the caves of Southern France, particularly those situated in the departments lying among the northern spurs of the Pyrenees. We have to deal with two of these particular departments of France-Haute Garonne and Ariège, drained by rapid-running tributaries of the Garonne. Lartet's excursion took him to the village of Aurignac, in Haute Garonne (see fig. 38). Near by the town is a little hill; on the side of the hill a cave had been discovered, buried beneath a mass of débris, which had fallen from the face of a cliff. Apparently in ancient times the cave had opened on the face of the cliff. In fig. 22, I reproduce the drawing

1 Cave Hunting, Macmillan \& Co.. I 874.

2 "Coup d'œeil synthétique sur l'époque des cavernes," Bull. de la Soc. Belge de Géologie, 1909, vol, xxiii. p. 227. 
with which Lartet illustrated his discovery. When the débris which hid the cave was removed, the opening was found to be closed by a great vertical slab of stone. Before Lartet's arrival, the human skeletons seen piled up within the cave (fig. 22) had been given a Christian burial by order of the Mayor. We now know, although Lartet was not then aware of the fact, that the pile of skeletons-representing at least seventeen individuals of various ages-were in reality the remains of Neolithic people. It was the Neolithic men who set up the slab at the entrance and used the cave as a sepulchre,

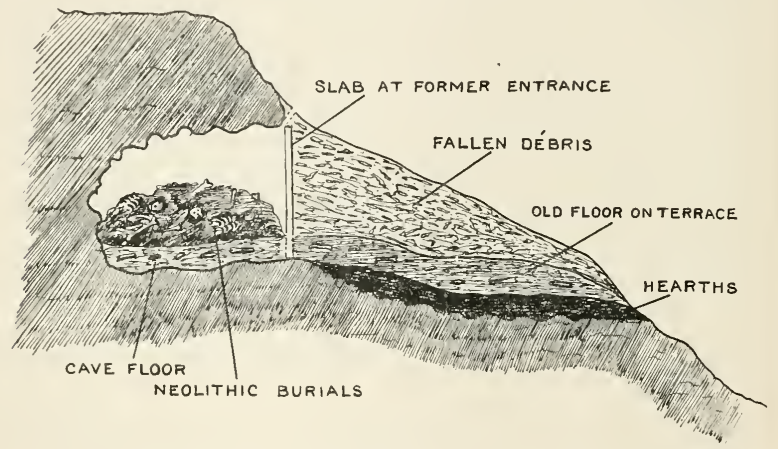

FIG. 22. -A section of the cave explored by Lartet, near Aurignac, in 1860.

a custom of the period. But when Lartet came to explore the floor of the cave- 2 to 3 feet in thickness-he found it to abound in evidences of human habitation, and to contain the remains of extinct animals, which were charred, cut, and artificially broken, showing that man not only lived at the same time as extinct animals, but actually used them as sources of his food supply. He found remains of the cave-bear, the cave-lion, the cave-hyena, the mammoth, the woolly rhinoceros, the wild pig, the Irish elk, the bison; and also remains of animals which live in our time. He found, further, as will be seen from his drawing, that the strata of the floor extended out to 
cover the little terrace in front of the cave. Under the floor of the terrace he found abundance of charcoal and remains of hearths. Embedded in the débris of the floor he found implements and ornaments of that form of human culture which is now known as Aurignacianthe same culture as was exposed at Paviland and at Engis. The flint implements of all three caves were worked in the same style-in all there were the same carvings in ivory, the same ornaments, necklaces of shells and perforated teeth, the same kind of barbed implements in bone, antlers of reindeer, and in ivory. When we consider that the culture of the people on the South Welsh coast was the same as that at the northern foot of the Pyrenees, we begin to realise that already in the Pleistocene period-when animals now extinct abounded in Europe-interchange and intercommunication had already made Europeans sharers in a common culture. Lartet also found amongst the undisturbed débris in the floor of the cave, fragments of human bones - not enough to tell us what kind of men these ancient Aurignacians were, but sufficient to indicate their bodily presence. It was the discovery at Aurignac that convinced Sir Charles Lyell that man went beyond the Neolithic horizon, and with his conversion, the new conception of man's antiquity made rapid progress.

Eight years later, in I 868, M. Louis Lartet discovered the actual men of the Aurignacian culture. The scene of the discovery is not in the region of the Garonne, but in the watershed of a companion river, the Dordogne, which, rising in southern central France, joins the Garonne at Bordeaux (see fig. 38, p. I09). The Vézère is a northern tributary of the Dordogne. The caves and rock-shelters in the cliffs which border the Vézère have yielded some of the most important and most complete records of ancient man. In I868, when a railway was being made along the lower part of the valley of the Vézère to unite the town of Perigueux with the main line along the Dordogne valley, an old rock-shelter was opened at 
Cromagnon, a little above the picturesque cliff-set village of Les Eyzies. The strata on the floor of the shelter or cave were marked by hearths and the culture of the Aurignacian period. In the upper strata were found the remains of four skeletons. They were tall people; the men were about 5 feet I I inches in height (I.8 m.) -tall, lanky fellows, more like, so far as bodily physique is concerned, the tall Sikhs of the Punjaub than any race now living. The proportion of their limbs was somewhat peculiar; their tibiæ or leg bones were relatively long, their humeri or upper arm bones, short. Individuals with similar limb proportions still occur amongst negroid races, but no modern European race can show the negroid limb proportions of the Cromagnon race-men of the Aurignacian period. The skeleton which Dean Buckland had found in the Paviland cave, regarded by him as that of a woman buried in Neolithic times, but which we now know, as proved by Professor Sollas, ${ }^{1}$ to be of Aurignacian age, was also a tall, slender manabout 5 feet 10 inches in stature. The skull of the Paviland man is not known, but we do know the form of head which characterised the Cromagnon men. Their skulls cannot be classed in the river-bed groups; they are too large and too much flattened on the vault to be assigned to that type. They differ from the Aurignacian man of Engis, who, we have seen, had a skull of the river-bed type. At Cromagnon, then, we meet with another race of men. They had massive skulls, large in all dimensions, as will be seen from fig. 23 , where the skull of the "old man of Cromagnon" is fitted within the standard frame used for Neolithic and for modern skulls. It is much too large for the conventional modern frame. The maximum length is $203 \mathrm{~mm}$., half an inch beyond the modern or Neolithic mean; the width, I 50 $\mathrm{mm}$., IO $\mathrm{mm}$. beyond ; the height of the vault, I $25 \mathrm{~mm}$., also io mm. above the modern mean for British men. It will be observed, however, that although the actual dimensions are greater, in the relative proportions of the

\footnotetext{
1 See reference, p. 47.
} 
diameters the Cromagnon skulls are not unlike those of the river-bed type. The width is very nearly 74 per cent. of the length, just as in skulls of the river-bed type. The brain capacity is much greater-roughly I 660 c.c., being 180 c.c. above the modern average. We have to remember that a certain amount-a small amount-of that is due simply to a big body; a big body needs a bigger brain for its animal administration. We have come across, in those large heads, a puzzling and unexpected fact; we are naturally astonished to find that men who have preceded us so long ago-men of a former geological epoch-should so far outstrip their
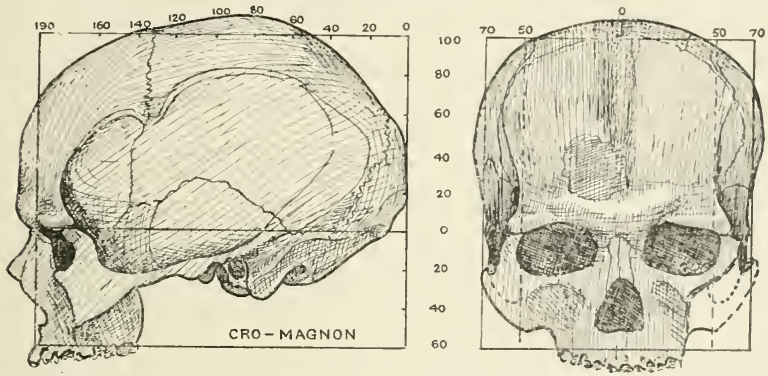

FIG. 23. - Skull of Cromagnon man viewed from the side and from the front.

successors of to-day who regard themselves as "the survival of the fittest," and believe the fittest to be the race with the biggest brains. We cannot quarrel with the facts, but how are we to explain them? The conclusion to be drawn is, not that brain mass, on the average, is to be rejected as an index of brain power, but that there are other virtues or characters which go to ensure success of a human race in the struggle of life -other than brain power. A philosopher may be miserable or die childless, when a brainless savage or an industrious labouring man may be happy and leave a large family.

Since I 868 , as we shall see later, many further dis- 
coveries of the Cromagnon race have been made. Meantime, we simply note that, although in dimensions-in stature and in size of body-these Cromagnon people far outstrip the river-bed type of Neolithic period, and probably also of the Palæolithic period, the two types are not radically different. To me, they seem to represent the "longs" and the "shorts" derived from a common stock.

At all those sites, at Paviland, Kent's Cavern, Engis, Aurignac, and Cromagnon, the discoverers of man's early history stumbled across a stage in human evolution which was manifestly older than the Neolithic phase; but how much more ancient they could not then tell. That secret they soon set out to discover. When the skeletons were found at Cromagnon (I 868), it was becoming apparent to the explorers of the French caves that the Palæolithic period, into which they had forced a way, had seen the dawn and the close of many phases of human culture, and that, in the floors of the caves, there was clear evidence that these phases passed in an orderly succession. It became clear to them that, as in historical times, a new form of culture gradually arose, and as gradually replaced the older modes of life. Hence we find, from this time forwards, that the investigators of France bent all their efforts to distinguish the various cultures represented in the caves, and to establish the order of their succession. As early as I 869 , M. Gabriel de Mortillet $^{1}$ elaborated an orderly classification of the cave cultures; but the exact position represented by the culture of the caves at Aurignac and at Cromagnon was not finally settled until I905, when the Abbé Breuil finally proved that at least two periods of culture, the Solutrean and the Magdalenian, intervene between it and the dawn of the Neolithic period. ${ }^{2}$ During those intervening periods, the climate of Europe changed; the

${ }^{1}$ See Musée préhistorique, by G. and A. de Mortillet, 1903.

2 See Bibliography of the Abbé Breuil's researches from 1899-1910, published at Fribourg, Switzerland, 1910. His more recent publications will be found in full or in abstract in that excellent periodical L'Anthropologie. 
mammoth, the woolly rhinoceros, the cave-bear, the cavelion, the cave-hyena disappeared; the reindeer became the characteristic animal in Europe in the closing phases of the Palæolithic period.

Aurignac, we have seen, is situated on a tributary of the Garonne-the Ariège. A neighbouring tributary, the Arize, issuing from the Pyrenees to the east of the Ariège, pierces a spur of limestone rocks, near the village of Mas d'Azil, forming a great tunnel or subterranean gallery, 500 yards in length (fig. $3^{8}$ ). When the public road, which follows the tunnel made by the stream, was being repaired, the strata on the banks of this subterranean stream revealed the hearths and implements of ancient man. In I 887 , M. Edouard Piette, a magistrate, who spent his leisure hours and his income most liberally in advancing our knowledge of ancient man, began a systematic exploration of the strata in the recesses of the cavern of Mas d'Azil, and discovered cultures which mark the transition from Palæolithic to Neolithic times. In I 895 he published ${ }^{1}$ a section (fig. 24 ) showing the various strata which are piled one above the other on the western bank of the Arize, as it issues from the tunnel. The uppermost, and therefore latest stratum, is situated I $3.60 \mathrm{~m}$. (4+ feet) above the level of the stream. The two upper deposits, composed of black clay with intermingled débris, amounting to a depth of 5 feet, were formed between the closing phase of the Neolithic period and the time of the Roman occupation, for they contained abundant traces of the civilisation which came and went during that interval of time-some two thousand years. The third stratum, counting from the surface downwards, is little more than a foot and a half in thickness, and, composed of a laminated assortment of differently coloured clays, brings us well within the Neolithic period, for the objects of culture are such as are found in the kitchenmiddens. The fourth stratum reveals the transition culture, the one now distinguished as Azilian. The

1 "Études d'ethnographie préhistorique," L'Anthropologie, 1895, vol. vi. p. 276 . 
fourth or Azilian stratum is only half a metre thick (19.6 inches), intensely red in colour, due to the abundance of oxide of iron which it contains. Beneath the Azilian stratum lie five others, forming collectively a deposit over 17 feet in thickness, all of them marked by the culture of the last great Palæolithic period-the Magdalenian. The deepest Magdalenian stratum, made of gravel, lies on the bed-rock, 23 feet above the present bed of the Arize. The men of the Magdalenian period settled on the ancient gravel bed of the Arize. In the bottom stratum occur the remains of their hearths. The period during which these Palæolithic deposits were

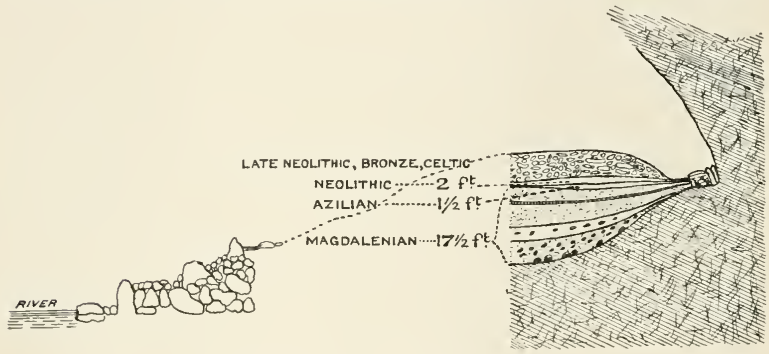

FIG. 24.-M. Piette's section across the strata at Mas d'Azil.

being formed was marked by two great intervals of flood or submergence, for the various strata, showing periods of human occupation, are separated by two thick deposits of yellow loam-the products of great and continuous floods. In all the Magdalenian strata, remains of the reindeer occur abundantly. In the Azilian stratum, which follows the Magdalenian strata in orderly sequence, the reindeer disappears; its place is taken by the stag, the remains of extinct mammals no longer occurring in the Azilian layer. The human culture, however, did not change much. The Azilians worked their flints in the Magdalenian manner; they fashioned the same carved and barbed harpoons and arrow-heads from bone and from antlers. They were partial to the use of red ochre 
as a pigment. Rounded pebbles, marked with coloured hieroglyphics, formed a peculiar and enigmatical part of their civilisation. Perhaps they had taken the first steps in agriculture; at least M. Piette found in the Azilian stratum traces of wheat husks and stones of cherry and plunı.

In this way M. Piette revealed at Mas d'Azil the long records of the closing phases of the Palæolithic period and the opening stages of the next or Neolithic period. In the Azilian stratum he found two sepulchres, but the human remains discovered by him are insufficient to give an accurate picture of the people. So far as our evidence goes, it supports the opinion that the Europeans of the Azilian civilisation were members of the Mediterranean race, and had heads of the river-bed type. Although numerous Azilian stations have been discovered in recent years, particularly in France, none have revealed the peoples of the period, with perhaps one exception. In I $895, \mathrm{Mr}$ Anderson ${ }^{1}$ described the exploration of caves situated on the west coast of Scotland near Oban, Argyllshire, and the discovery of objects of culture which characterise the Azilian period. During the exploration certain human remains were found, which have been described by Sir William Turner." The skulls of the people thus discovered are clearly those of the river-bed type-in no way differing from those of a Neolithic date. Unfortunately, the evidence which associates these skulls with the objects of Azilian culture is not complete. ${ }^{3}$

We have no reason for supposing that the transition from the Palæolithic to the Neolithic period was marked by the appearance of a new or higher type of man. Indeed, in artistic ability, there must have been a decline, for the later Palæolithic periods have furnished us with the most abundant and surprising evidence of a high artistic ability.

Hitherto, so far as we have followed the history of

1 Proceedings Soc. Antiquaries, Scolland, IS95, p. 211.

2 Ibid., p. 4 Io.

3 See Appendix A. 
man into the Palæolithic period, we have sought his traces in caves. In 1866 , two French antiquaries began a series of explorations which revealed the habitation of Palæolithic man in the open country. The site of their discovery lies near the village of Solutré, situated on the western slopes of the country drained by the Saone, which flows southwards to join the Rhone at Lyons. Although MM. Ferry and Arcelin commenced their investigation in 1866 , inspired by the writings of Sir Charles Lyell, such was the extent of the Palæolithic deposit at Solutré, covering as it does more than 2 acres of ground, that

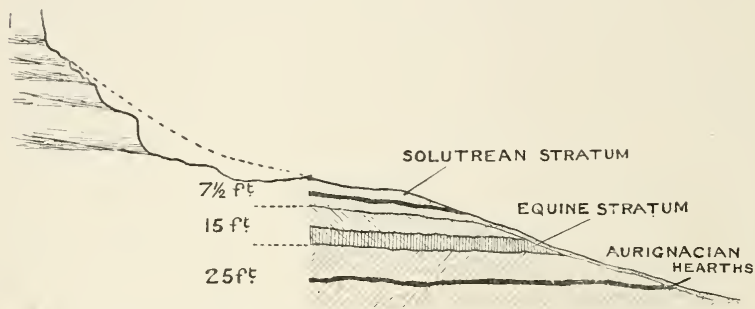

FIG. 25. - Diagram of the ancient hearth-strata exposed in the deposits at Solutré.

its exploration occupied one of them-M. Arcelin-until his death in $1904 .{ }^{1}$ In a paper which he published in I $890,{ }^{2}$ he reproduced a section of the deposits at Solutré, which serves to convey the results of his toil at a glance (fig. 25). At the western end of the section, the rock of Solutré rises to a height of 400 or 500 feet. The land slopes eastwards from the base of the rock towards the Saone, and covers the deposit which reveals the hearths of ancient man. At certain points the exploring trench had to be sunk to a depth of 34 feet to reach the original surface of the land. Wherever the trench was sunk in this ancient and extensive station, one remarkable stratum was encountered, usually at a depth of about io feet below

1 See Dechelette's Manuel darcheologie préhistorique, I9I2, vol. i. p. 133 .

${ }_{2} L^{\prime}$ Anthropologic, I890, vol. i. p. 295. 
the present surface. This, the "equine" layer, varying in thickness from I 5 to 20 inches, was made up of bones of horses, broken, cut, and charred, mixed up with the débris which accumulate on and around the hearths of ancient man. The implements of flint and of bone, the ornaments, the works of art, the remains of extinct animals, found in the equine layer, are those which occurred at Aurignac. The equine layer represents a vast kitchen-midden of man during the Aurignacian period. It has been calculated that the colony at Solutre had consumed at least one hundred thousand horses in their time. Beneath the equine stratum one-occasionally two - older Aurignacian floors, marked by extensive hearths, were found (fig. 25). In the deepest of these, implements which characterise a still older Palæolithic culture were found-implements of the Mousterian type. Above the equine layer, there is a stratum or ancient floor yielding abundant evidence of a more recent culture, the culture which succeeded the Aurignacian, and which has been named, because of its discovery here, "Solutrean." A form of finely worked flint implement -shaped like a laurel leaf-appears for the first time in this culture. Certain animals of the Aurignacian period were dying out; reindeer were becoming more abundant. Art, we know from discoveries elsewhere, was reaching a higher standard. In the Solutrean period, Solutré itself ceased to be a site of habitation, for it shows no trace of the men of the succeeding Magdalenian period which we saw at Mas d'Azil. The land surface had reached its present level when people of the Neolithic and subsequent ages buried their dead over strata containing the remains of two long Palæolithic periods.

It will be noticed that the cave strata at Mas d'Azil take up the story of ancient man where the deposits at Solutre leave off. In the 60 feet of strata, represented at the combined sites, are found the cultures of four consecutive periods-Aurignacian, Solutrean, Magdalenian, and Azilian, with superficial traces of the Neolithic period. It is plain that we have made a long journey into the past 
to reach the Aurignacian period; how long, we can but dimly perceive at present. The formation of a deposit, 30 feet deep at Solutré, must have occupied a long space of time. The process of its formation is revealed by M. Arcelin's section. The great block of stone and the rocky débris which lie in the strata between the layers containing the ancient hearths have been detached from the face of the adjacent hill, as its exposed face weathered under the frost, the wind, and the rain. The debris thus detached from the hill tended to drift down the slope in times of rain, snow, and flood, gradually covering and burying the human habitations, and sealing them up as historical records. The climate has changed since Aurignacian times, for the Palæolithic cultures lie within what is regarded as the Ice age, but which it is better to speak of as the Pleistocene epoch. We know from the kind of animals which live in the Aurignacian period that the climate was milder than in the Magdalenian age. Indeed, we shall see later that the last of the glacial phases occurred when the Magdalenian culture was at its height.

Before returning to England to apply the knowledge we have gained from our tour in France, there are two other classical sites which demand our attention. Neither at Mas d'Azil nor at Solutré, abundant as the traces of Palæolithic man were, did we find the men themselves.

To supply this blank in our knowledge we must glance at the remarkable discoveries made in the caves situated in cliffs along the French coast of the Mediterranean. A little over a mile to the east of Mentone, just beyond the French frontier, the red rocks of Grimaldi rise from the sea. The caves, where ancient man made a home, open on their southward face about 60 or 70 feet above the level of the sea. A terrace made along the foot of the cliffs serves as a highway between France and Italy. Indeed, many of the caves open just above the road. In $1872, \mathrm{M}$. Emile Riviere discovered remains of ancient man in some of the Grimaldi caves. Further discoveries were made subsequently, and disputes arose as to their 


\section{DISCOVERY OF PRE-NEOLITHIC MAN 63}

authenticity and antiquity. In 1895, the Prince of Monaco undertook their investigation. He summoned the best talent of France: Canon de Villenneuve to write the historical account; M. Cartailhac to describe

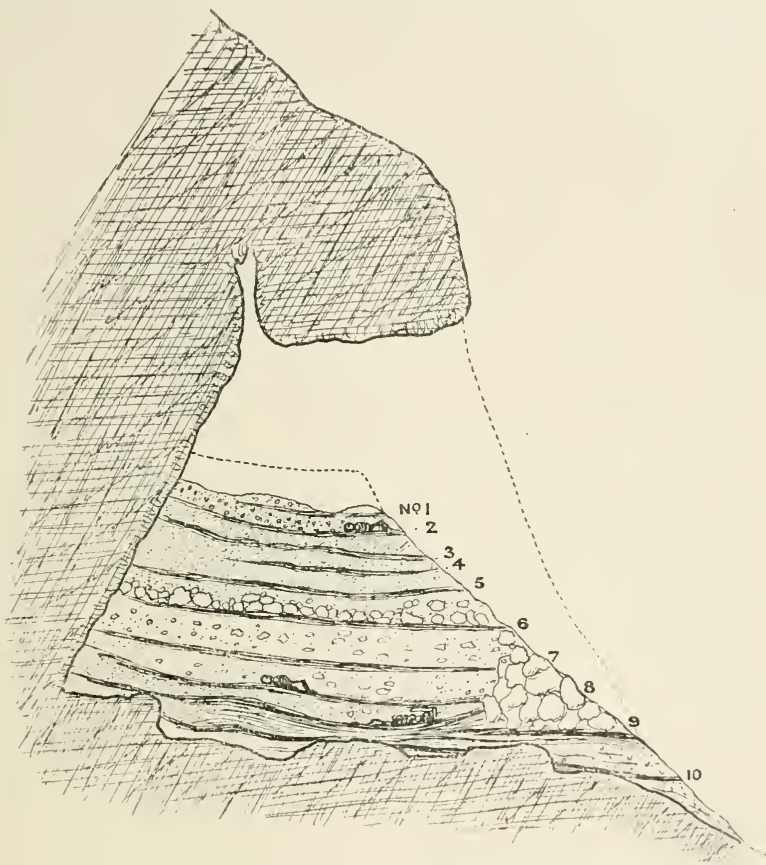

FIG. 26. - Section of the strata of the Grotte des Enfants, near Mentone. (After the section given in Professor Boule's Monograph.)

the articles of culture; Professor Boule to investigate the geology and the fauna; and Dr Verneau to report on the human remains. Systematic work was commenced in 1895 , and by 1902 five great caves and several rockshelters had been scientifically explored. Between I 906 and I9I I two magnificent volumes, issued in separate 
parts, were published at the expense of the Prince of Monaco, placing at the disposal of the scientific world a rich and instructive harvest of new facts. Altogether the remains of sixteen individuals were found in the Grimaldi caves. Here we shall deal with those discovered in only one of them-the Grotte des Enfants, so named because the skeletons of two children were discovered in its upper strata.

A summary of what was discovered during the exploration of the Grotte des Enfants is shown in fig. 26. Over 3 feet had been removed from the surface of the cave deposits before the systematic exploration commenced. Twenty-eight feet of accumulations on the original floor still remained. Nine ancient floors were found, marked by hearths and the débris of human occupation; they occurred from the top to the bottom of the cave strata. From the lowest and oldest to the highest and most recent hearth, the type of culture was the same-Aurignacian. The ornaments, the implements in stone and bone were of the same kind as were found in the cave at Aurignac. The remains of the same extinct animals came to light with a few exceptions; the woolly rhinoceros, and apparently the mammoth, never reached the sunny coasts of the Riviera. The remains of the reindeer and of the ibex occurred; so did those of the cave-bear, the cave-lion, and the cave-hyena. In the very lowest stratum of all, however, were found the remains of a species of rhinoceros, more ancient than the woolly form-the kind known as Rhinoceros Mercki. The presence of this southern form in the deepest stratum of the cave, accompanied by remains of the hippopotamus, an older form of elephant-Elephas antiquussuggests that the Grimaldi caves became inhabited at the close, or soon after the close, of a mild or warm period, during which Neanderthal man appeared in Europe.

At the level of the second hearth in the Grotte des Enfants, I'70 $\mathrm{mm}$. below the surface, was found the skeleton of an old woman of small stature, but so broken that a restoration was impossible. It was clear she had 
been buried, and that ornaments of her time (Aurignacian) had been interred with the remains. At the level of the third hearth, $2.70 \mathrm{~m}$. (9 feet) in depth, the skeletons of two young children were found, laid on their backs, with the heads to the west. At the level of the eighth hearth, $7.05 \mathrm{~m}$. (23 feet) below the surface, occurred the remains of a very tall man ( 6 feet $2 \frac{1}{2}$ inches) - a representative member of the Cromagnon race. He was extended on his back, in a grave which had been prepared for him-a slab of red clay under his head, a flat stone over it, large stones grouped round his feet. A worked piece of a deer's antler lay close by; the shells and perforated teeth which formed his necklace were placed near him. The objects of culture were the same as accompanied the men at Cromagnon. 'At the level of the underlying ninth and oldest hearth, over 25 feet from the surface stratum of the cave, was found another grave. It contained two skeletons, one of a woman of middle age, the other of a youth of about sixteen. The tall Cromagnon man lay extended on his back, but those short people lay huddled up in the contracted posture. The same kind of provision had been made for them at their death as for the tall man. Stones had been placed to protect the head; the remains of the usual kind of necklaces and bracelets were found; near by were the worked flints of the period. As is so often the case in Aurignacian burials, the skeleton of the lad was stained by red ochre.

It is a feature of the Cromagnon race-the Frenchmen of the Aurignacian period-for the men to be very tall, but for the women to be of moderate or even small stature. The little woman found at the level of the second hearth was probably of the same race as the tall man found at the level of the eighth. But what of the lad and the small woman found at the level of the ninth and oldest hearth? Dr Verneau had no doubt about them; they represented a negroid race-one not previously discovered in Europe. By a negroid race, we understand one in which the skin is pigmented; as 
regards the Grimaldi people we have to judge from the skeleton alone. One important negroid feature is absent from both of these Grimaldi skeletons, namely, the negroid contour of the forehead. In pure negroes and in negroid races, the right and left eminences of the forehead-of the frontal bones-tend to fuse together in the middle line so as to form a single eminence of peculiar shape, such as we have seen in a Neolithic skull from Malta (fig. 6, p. I 5). In the Grimaldi lad and woman, probably his mother-for they are very much alike-the forehead is of the European form, the frontal bosses are not fused. The skull is long and narrow, as is the case in most negroes, but the same head measurements also occur in white races. When we come to deal with the features of the face, we recognise that there are some negroid traits. The teeth are large, causing the jaw to protrude in front of the nasal opening and the chin to recede. The lower margin of the nasal openings as seen on the skull are not sharp as in white races, but grooved or guttered as in pigmented races. The face, too, is short, as in most black races. The orbits, although of more than average width, are narrow from above downwardsthe upper and lower orbital margins are unduly approximated, giving the face a sinister look. That, we have seen, is also a character of the Cromagnon race. The nose was apparently shaped much as it is in native Australians. These two Grimaldi skeletons then do show certain negroid features, and still, to my mind, a full analysis will prove that they are of the Cromagnon race, or of a people nearly allied to that race.

In the proportion of his limbs, the negro shows certain peculiar features which distinguish him from modern European races. In the first place, his leg is long as compared with his thigh. In the European, the leg bone (tibia) is less than 80 per cent. of the thigh bone or femur ; in negroes, the tibia is over 80 per cent., usually between $8 \mathrm{I}$ and $8+$ per cent. In Cromagnon skeletonsfrom the Paviland cave in Wales, from Cromagnon itself, and from the Grimaldi caves-the tibia varies from $8 \mathrm{I}$ 
to 85 per cent. of the femoral length. In the two negroid Grimaldi skeletons the tibial proportions are 83.8 per cent. for the woman, 83.7 per cent. for the lad. They agree with the Cromagnon race. The same result is obtained when we inquire into the proportion which the forearm bears to the upper arm. In modern Europeans, the radius of the forearm is about 74 per cent. of the humeral or upper arm length; in modern negroes, the proportion of the radius is 79 per cent. The same proportion holds true of the Cromagnon race and of the so-called Grimaldi negroids; the radius of the lad is 79 per cent., that of the woman 85 per cent. of the length of the humerus. The stature of the negroid woman is not low- $1.595 \mathrm{~m}$. ( 5 feet $2 \frac{3}{4}$ inches); the lad of sixteen measures $1.560 \mathrm{~m}$. ( 5 feet $1 \frac{1}{2}$ inches). If he had lived, he might have added 6 or 8 inches to his stature. On the palate of the Cromagnon people there is usually a bony elevation-the torus palatinus - often seen on the palate of primitive negroid races. The torus is present in the Grimaldi negroids. The woman and the lad share the ample brain capacity of the Cromagnon race. The capacity of the woman is estimated by Dr Verneau to have been I 375 c.c., that of the boy I 580 c.c. -both above the modern average. Those Aurignacians had large brains. I am of the opinion that it is a mistake to separate those two Grimaldi individuals, the mother and son, as types of a new race-a negroid race indigenous to Europe. To me these characters suggest that they are only an aberrant Cromagnon form, perhaps primitive, but nevertheless true members of the Cromagnon race. That race, in the proportion of its limbs and in certain features of the face, does show negroid traits. If I had to seek for the people which most nearly represent the Cromagnon blood in the modern world, 1 would seek them amongst the tall races of the Punjaub of India.

When one of the skulls of the Grimaldi negroids is fitted within the standard frame, which we have applied to Neolithic skulls, the fit is seen to be a good one (see 
fig. 27). The maximum length of the woman's skull is $19 \mathrm{I} \mathrm{mm}$., its width, I $3 \mathrm{I} \mathrm{mm}$.; the height of the vault above the ear-holes, I I $5 \mathrm{~mm}$.; the proportion of width to length 68.5 per cent. Her head was long and narrow. The corresponding measurements of the lad's skull are : length, I $92 \mathrm{~mm}$.; width, I $33 \mathrm{~mm}$.; height, I2 $5 \mathrm{~mm}$. The width of the skull represents $69^{\circ} 2$ per cent. of the length. The chief point of difference between the typical Cromagnon skulls and those of the two negroids lies in the characters of the cranial vault. The flattening
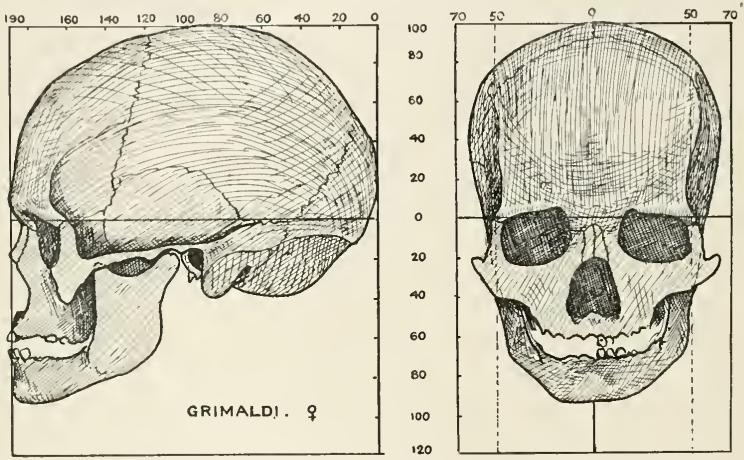

FIG. 27.--Profile and full face of the Grimaldi woman.

of the vault seen in Cromagnon specimens is absent in the negroid skulls. The vaults are raised as in negro skulls.

A discovery of a type of man differing somewhat from the Cromagnon form, but still a European of the Aurignacian period, needs only a brief description. In I89 I, a canal was being made in Brünn, the capital of Moravia, some sixty miles north of Vienna, when a human skull was found at a depth of I I $\frac{1}{2}$ feet. In the same stratum, and near the skull, were found the objects of cultureperforated shells and an ivory image-and the remains of the extinct animals which characterise the Aurignacian age. The same ancient culture which we saw on the shores 
of the Mediterranean extended to W'ales and to Moravia. When the Brünn skull-the larger of the two described by Professor Makowsky ${ }^{1}$-is placed in a standard frame (fig. 28) we are impressed by its dimensions. The maximum length is $206 \mathrm{~mm}$., its width, I $44 \mathrm{~mm}$.; the height of the vault above the ear-holes, I $25 \mathrm{~mm}$.; the width is 69 per cent. of the length; the capacity, estimated by the Lee-Pearson formula, a little over I 600 c.c. It is a man's skull, showing strong and rugged characters in the forehead and in the area for attachment to the neck. 'The Brünn type is a variant of the Cromagnon-the man was apparently a
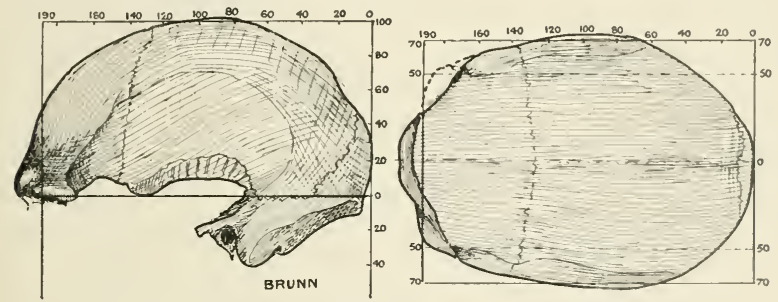

FIC, 2S, - The Brïn skull (No. I) from the side and from above.

member of an allied race. On my visit to Jersey, ${ }^{2}$ I was surprised to find in the museum of the Société Jersiaise a skull which was a replica of the Brünn example. All that is known of the Jersey specimen is that it was brought from South America. As is so often the case with the Aurignacian skulls, the Jersey skull is of a brownishred colour, as if it had been embedded for a long time in soil rich in iron.

Another Aurignacian skull, that found by Dr Hauser at Combe Capelle in 1907, in the region of the Dordogne, France, will be described at a later period, when we pass to the consideration of the Neanderthal race. In the meantime, we simply note that when

1 "Der deluviale Mensch in Löss von Brünn," Millh. Anthrop. Gesellsch. in Wien, 1892, vol. xxii. p. 73 .

${ }^{2}$ See Bullet. Société Jersiaise, 1913 , vol. xxxviii. p. 310. 
we survey the people and the state of Europe in the latter third of the glacial period, we find it populated with tall men, evidently separated into distinct races, having long, narrow heads containing large brains brains which were capable of conceiving and appreciating high works of art. It is clear that we have to go much further backwards in time to find human beginnings. 


\section{CHAPTER IV}

ENGLISHMEN OF THE LATER PAL\&OLITHIC PERIODS

In this chapter we return to England to again take up the story of ancient man. Our object is to see what traces have been discovered of the various cultures revealed by the caves of France, and specially to ascertain what kinds of men lived in England before the days of Neolithic man. The scene of our first inquiry is again in the south-east corner of England, in the county of Kent, and within a few miles of the Megalithic monument at Coldrum described in the first chapter. From Coldrum, we must follow the Medway northwards as it leaves the Weald to enter the valley in the North Downs by which it reaches Rochester and Chatham and finally ends in the estuary of the Thames (fig. I). Within this valley, and on the western side of the Medway, is the busy little town of Halling, robbed somewhat of its ancient picturesqueness by the invasion of cement works, which throw a pall of smoke, obscuring our view of the rising domes of the Downs. Opposite Halling the Medway is banked; at high tide the barges with their large brown sails seem to float some feet above the level of the wide stretch of marshland-half a mile wide-which separates Halling from the river. Between Halling and the marsh, however, is a natural terrace8 feet above the level of the marsh and 15 feet $(+5 \mathrm{~m}$.) above the zero level of the Ordnance Survey (Ordnance datum). The terrace follows the margin of the marshy floor of the valley as if it represented an ancient bank of the Medway, which it probably does. It was in this 
natural terrace, at a depth of 6 feet $(1.8 \mathrm{~m}$.$) , that a$ human skeleton was found-the skeleton of the Halling man. The evidence, we shall see, leads us to the conclusion that this man belongs to one of the later periods of Palæolithic culture. His horizon in time lies in that phase of the earth's history which geologists term the Pleistocene epoch.

The discovery of the skeleton came about in this way. In I9 I 2, Halling required a new drainage system, and in August of that year, the terrace of brick earth on the edge of the marsh was excavated to form a large sewage tank. The working face of the trench was I I feet in depth $(3.4$ m.), exposing nine strata, all laid down in running water, the various superimposed layers being clearly differentiated. As the men worked, a slip of earth occurred from the side of the trench, exposing parts of a human skeleton embedded in the fifth stratum from the top, and lying 6 feet ( $(\cdot 8 \mathrm{~m}$.) from beneath the surface of the terrace. As the fall of earth occurred a labourer caught the skull in his hands. The brain space was filled with a firm cast of fine loam or brick earth, similar to the deposit in which the skeleton lay. By a happy chance, part of the skeleton remained embedded in its place on the bank. It was also a fortunate circumstance that the scientific study of early man finds a home in the valley of the Medway. The engineers in charge of the works were alive to the importance of the discovery, and called in Dr Spencer Edwards and $\mathrm{Mr}$ W. H. Cook, active members of the Medway Valley Scientific Research Society, of which Mr F. J. Bennett, F.G.S., was then president. They proceeded at once to investigate and to record all the circumstances connected with the discovery. They examined the strata (fig. 29) overlying the skeleton, and found they were unbroken and undisturbed. No one could assert that the skeleton had been buried from the present surface of the terrace, for the demarcating lines between the strata were sharp and unbroken. Dr Edwards observed, from the position of the bones which still remained in the 
bank, that the body had been laid on its back, but turned slightly so as to lie on the left arm. Amongst the ribs, which had fallen out in a mass of brick earth, lay the lower jaw, showing that the head had been bent on the breast. The leg bone lay near the shoulder blade, showing that the lower limbs must have been flexed on the trunk. The body must have been in the flexed or contracted posture, for the extreme parts of the skeleton were less than 3 feet apart.

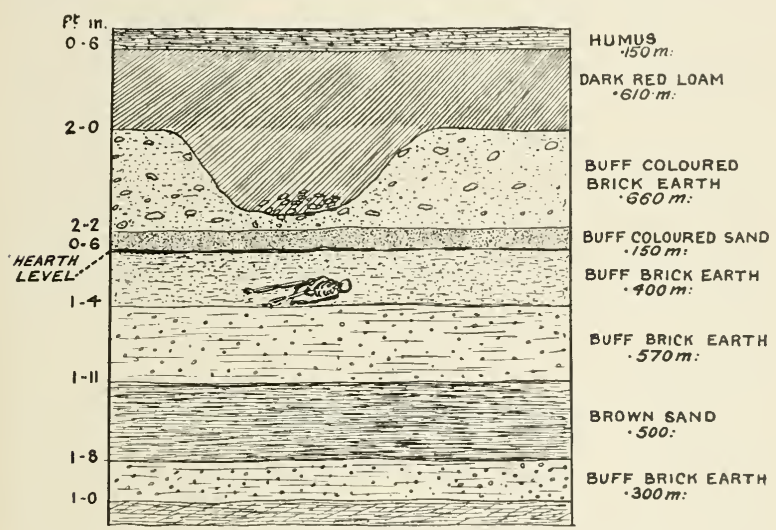

FIG. 29.-A section of the strata at Halling, showing the position of the skeleton. The dip in the second stratum, over the skeleton, marks the bed of a buried stream.

As they proceeded in their investigation an extremely important discovery was made-one which reminds us of the buried Palæolithic hearths discovered in the open country at Solutré. In another part of the trench, a long black stratum was exposed between the deposit in which the skeleton lay, the fifth layer, and the overlying or fourth deposit (fig. 29). In the black intermediate zone, remains of ancient hearths abounded-charcoal, flints splintered by heat-" pot-boilers," chipped flints, worked implements, bones of animals. It was clear, from this discovery, that an old land surface was represented by the black zone 
between the fourth and fifth strata. The strata over the black zone were unbroken; the skeleton which lay in the fifth stratum was evidently the remains of a man who had lived on the old land surface, had sat round the ancient hearths, and ultimately had been laid in a superficial grave before the upper four strata had been deposited. That was the only reasonable explanation of the facts.

The question which then presented itself to $\mathrm{Mr} \mathrm{Cook}^{1}$ was: How old is that land surface? He collected all the flints and animal remains which were to be found on it and below it. The assemblage of implements represent, in the opinion of experts-of M. l'Abbé Breuil, $\mathrm{Mr}$ Reginald Smith, Mr Reid Moir-a "late cave period," which may mean one anywhere between the Aurignacian and Azilian cultures mentioned in the last chapter. Further discoveries point definitely to the age of the Halling hearths as Aurignacian-the same age as Paviland and Cromagnon-and therefore lying well within the Pleistocene period. The Halling man thus falls in a closing phase of the Ice age.

It is important, before inquiring into the physical appearance of the Halling man, to fix as nearly as possible his horizon in time. The flint implements which were found in and round the hearths, covering the land surface under which he was buried, suggest the Aurignacian period. The carvings in bone and in ivory, the necklaces of perforated shell and tooth, which characterise this period were not found. If the date is such as has been suggested, then in those brick earths of the terrace we should find remains of extinct animals, such as the mammoth, the woolly rhinoceros, and reindeer. The remains actually found are those of a horse, of a sheep or goat, and of a rhinoceros. The radius of the rhinoceros is mineralised to a much greater degree than the other bones; it evidently has been derived from an older deposit. In the opinion of $\operatorname{Dr} \mathrm{A}$. Irving, the remains

1 In his geological investigations $\mathrm{Mr}$ Cook had the help of an expert geologist, Mr J. A. Bullbrook. 
of the horse may represent a Pleistocene variety, but the parts discovered are not sufficient to make the identification certain.

The corresponding terrace on the opposite or eastern side of the Medway valley, a counterpart of the Halling terrace, yields abundant remains of Pleistocene animals (fig. 30A). In the opinion of $\mathrm{Mr} \mathrm{A}$. S. Kennard, who must be regarded as one of our highest authorities on the age and nature of English valley deposits, the brick earths of the Halling terrace do belong to the Pleistocene period. All the evidence, then, if not definitely proving, at least gives us a very high degree of assurance in regarding the Halling man as of the Aurignacian age.

In our survey of Neolithic man in England, the Tilbury skeleton represented the most remote in point of time. That skeleton lay 34 feet beneath the submerged marsh surface in the adjoining Thames valley. The Halling man lay in a deposit of brick earth which rises 7 feet above the level of the marshy floor of the Medway. What were the changes which occurred in the neighbouring valleys of the Medway and Thames between the time of the Tilbury and Halling men? In the first place, we must examine, as $\mathrm{Mr}$ W. H. Cook and $\mathrm{Mr}$ J. A. Bullbrook have done, ${ }^{1}$ the nature and formation of the Halling terrace. We have already seen that there are at least nine distinct strata in the terrace. Each of these denotes a phase in the action of the Medway-its condition of flood, the nature of the débris it was scouring off the face of the Weald and depositing on its bank at Halling. It is also apparent that in order to have the strata deposited one above the other, either the waters of the Medway came down in greater and greater volume, or, as is more likely to have been the case, the land was sinking at the time the terrace was being formed. There was then in operation a process of submergence, with filling up of the valley. The subsidence could not have been continuous, for under the fourth deposit from the top is the old land

${ }^{1}$ See Journ. Roy. Anthrop. Instit., vol. xliv., July I9I4. 
surface on which Palæolithic man made his hearths. Eventually that land surface became covered with 5 feet of deposit, and then the formation of the terrace ceased. We know why the formation ceased. Under the valley of the Medway, recalling the condition seen in the adjoining valley of the Thames, is the old buried channel of the river. Its bottom lies about 60 feet below the level of the Halling terrace. We have seen that it was about the commencement of the Neolithic period that the land reached its highest point of elevation; it was then that the Medway occupied its buried channel. It is apparent, then, that the formation of the Halling terrace must have ceased when the process of elevation set in-the process which culminated in the Medway carving out the

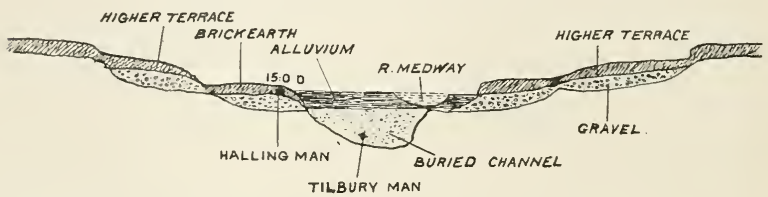

FIG. 30. - Diagrammatic section across the valley of the Medway (W. H. Cook).

valley to the depth of the buried channel. If Neolithic man appeared when the land had reached its highest point of elevation, and when the Medway had reached its lowest bed, he would have found the Halling terrace, not as we see it to-day, only a few feet above the level of the tide, but on the sides of the valley, 40 feet or more beyond the reach of the greatest floods. Tilbury man did not appear at the point of greatest elevation; submergence was well under way - the river valley was being submerged and filled up when he was living. Since his day, submergence had proceeded, bringing the Halling terrace almost back to its original level as regards the river bed. Now, it is plain that if we allow eight thousand or ten thousand years for the antiquity of the Tilbury man, we must, if we count by the rate of elevation or submergence of the land, allow much more than that period of time to cover the centuries which must have elapsed between 
the Halling and the Tilbury men. After the Halling man was buried, the terrace went on forming; then ensued a period of elevation, during which the Medway deepened its valley by 50 feet or more. Then the submergence began ; at an early phase of the submergence, Tilbury man appeared. It seems to me that a period of at least twelve thousand or fifteen thousand years must be allowed for the Halling-Tilbury interval. Our inquiries into the cave formations showed us that the depth of the deposits formed during the later Palæolithic periods may amount to as much as 60 feet ; we saw, too, the succession of various forms of cultures, the extinction of many animal species, and a great change in climate. But we had no opportunity of forming an estimate of time by such

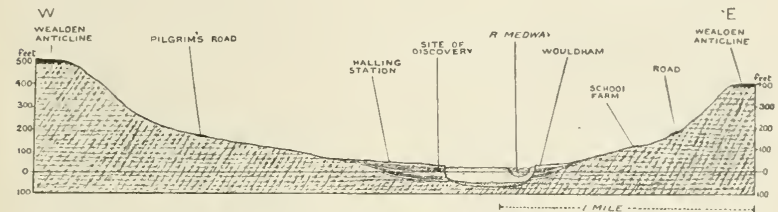

FIG. 3OA. - A later and more accurate section across the valley of the Medway at Halling by Mr W. H. Cook.

means as we find at Halling-the work done by rivers, the deepening and the filling up of valleys. I do not see, when we take all these considerations into account, that we can allow less than twenty-five thousand years as the age of the Halling skeleton.

We now turn to ascertain what kind of man lived so long ago in the Medway valley. We have seen what the Aurignacian men of the Continent were like-the tall, lank, rather negroid Cromagnon people, the robust, largeheaded Brünn type, and the river-bed type of Engis. At Halling, we again meet with the river-bed type of skull. In fig. 31 , this skull is placed within a standard frame, designed to fit the average-sized head of to-day. It is seen to fit the Halling skull very closely. The length of the skull is $187 \mathrm{~mm} .-3 \mathrm{~mm}$. short of the conventional standard; the width is $\mathrm{I}+2 \mathrm{~mm}$., being 75 per cent. of 
the length ; the height of the vault above the ear-holes is $124 \mathrm{~mm}$. - nearly $9 \mathrm{~mm}$. above the mean amount for males. ${ }^{1}$ The size of brain was, as is so often the case in Palæolithic races, above the modern average-the cranial capacity in this case being I 500 c.c. The measurements cannot be regarded as exact, for, although the cavity of the skull was filled with a solid cast of brick earth, yet all the bones were much broken, and, in the replacement of fragments, some degree of error may have crept into the reconstruction. There is not a single feature of the skull

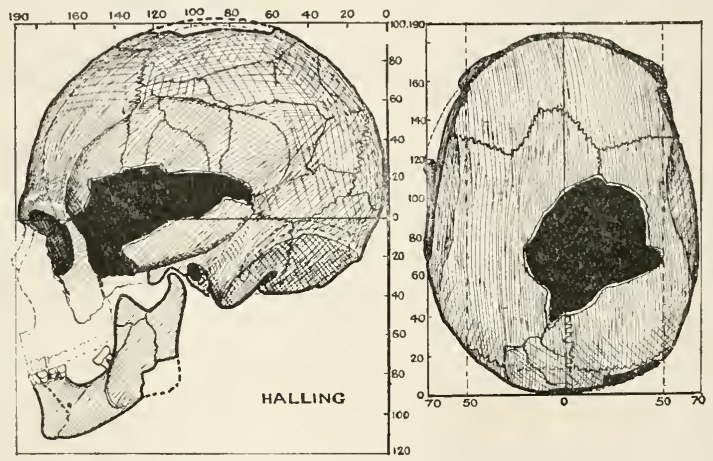

FIG. 3I. - The Halling skull viewed from the side and from above.

which one can say is primitive or ape-like. The forehead is well formed, of average size, with supra-orbital ridges moderately developed. The areas for the muscles of mastication are not larger than in modern skulls. The bones which enclose the brain cavity, often 8 or $10 \mathrm{~mm}$. thick in ancient skulls, are in the vault of this specimen, only 4 to $5 \mathrm{~mm}$. thick-in reality thin bones. The mastoid processes and other areas of the skull to which the muscles of the neck are attached do not differ in any point from those seen in modern races. Indeed, were it not for the evidence of the strata in which the skeleton lay

1 For full account of skeleton, see Journ. Roy. Anthrop. Instit., vol. xliv., July 1914 . 
and the hearths which were superimposed, and particularly the conditions of the bones themselves, one would not have suspected that this was the skull of a man who lived many thousands of years ago. The bones when originally found were soft ; when dried they became hard, porcellanous, and brown in colour. Now-a year laterthey have become of a light, stone-grey colour, with absolutely no animal matter left in them. When placed in a solution of hydrochloric acid, they crumble into a fine, grey sediment.

Of the face, no clear picture can be drawn. All the bones between the lower jaw below, and the forehead above, had been dissolved away in the brick earth. The dimensions of the lower jaw suggest a face of moderate length, contracted at its lower part, especially at the jowls or angles of the mandible, in front of and below the ears. The chin is moderately developed, narrow and peaked in shape; the height of the mandible at the symphysis is $30 \mathrm{~mm}$., its thickness, I $+\mathrm{mm}$. - both moderate dimensions. The width between the angles of the jaw was $96 \mathrm{~mm}$. ; the bicondylar width, $120 \mathrm{~mm}$.measurements which the expert anatomist will recognise as moderate for even modern men. The zygomatic or cheek arches were broken, but the total width of the face could not have appreciably exceeded the modern average.

The characters of the skull and skeleton leave no doubt as to the sex : the skeleton was that of a man, and from the condition of the sutures between the bones of the skull-all of which were open-a man not over forty years of age, probably considerably under. For a man of this age the teeth were in a surprisingly bad condition. They were deeply worn; the enamel had disappeared by wear from the chewing surfaces of the crowns, exposing the dentine, and, in some cases, the pulp cavities. Of the six molar teeth of the lower jaw, five had been lost from disease-not from caries, but from abscesses or gumboils forming at their roots. One of the premolar teeth had also perished before death; the incisors, canine, 
and premolars, some of which had fallen out after death, were much worn. The food of the Halling man was rough in nature, and he had suffered severely from dental disease. It was possible to estimate the size of his palate. It was rather shorter and wider than is common in modern Englishmen. An unexpected feature of a primitive jaw is the position of the third molar or wisdom tooth. It springs, as may be seen from fig. 3 I, not from the body of the jaw, but from the root of the ascending branch of the mandible, indicating that there was insufficient growth in the jaw to provide accommodation for the last tooth to come into its proper position. As regards the dimensions of the teeth, such of them as have been preserved, there is no point in size or form which differentiates them from the teeth of modern British people. The criticism may be made that such a skull is of no intrinsic interest because it shows no new or primitive feature. On the contrary, the discovery is of the greatest interest; it shows how steadfastly human characters are transmitted from generation to generation. If we accept the degree of antiquity I have presumed-twenty-five thousand years-and allow forty generations to each thousand years, then we see that racial characters can be transmitted for a thousand generations, and still retain their essential features almost unchanged.

Mention has been made already of the broken condition of the bones of the skull. The bones of the skeleton, in spite of the greatest care, could not be reconstructed with absolute accuracy. The shafts of the long bones, which are always dense and compact in structure, were preserved, but the spongy texture at their extremities had become reduced to dust. The thigh bones were fairly complete. Their total length was approximately $435 \mathrm{~mm}$. Applying the formula used by Professor Pearson for calculating the stature of the individual from the length of the thigh bone, we estimate the height of the Halling man at I $630 \mathrm{~mm}$. ( 5 feet 4 inches)-somewhat under medium height. His collar bones were also short, I $30 \mathrm{~mm}$., but 
stout, indicating a man with a narrow, round chest. The ribs were broad and strong. Clearly the Halling man is not of the tall, Cromagnon breed. His low stature agrees with that of the Neolithic river-bed people. Yet he differs markedly from them in certain features. In Neolithic skeletons, the upper extremity of the thigh bone usually shows a marked degree of flattening from front to back. In the Halling thigh bone, as is the case in many Continental skeletons of a Palæolithic date, this feature is absent. ${ }^{1}$ The thigh bone in this respect is also like that of modern man. The head of the thigh bone of the Halling man is very massive- $-52 \mathrm{~mm}$. in diameter, an excessive amount when one considers the shortness of the bone. His tibia does not show the compression or flattening from side to side which appears in races of Neolithic and later times. In this respect also, the tibia approaches more nearly to that of modern man. We have seen, too, that in the proportion of the limbs the Cromagnon type resembled negro races, the tibia being very long when contrasted with the femur, and the radius long when compared with the humerus. Unfortunately, the extremities of nearly all the long bones are deficient in the Halling skeleton, precluding an exact estimate of their lengths, but one can be certain that these negroid features were not present-at least not in the marked negroid degree found in the Cromagnon race of the Aurignacian period.

One very anomalous and puzzling feature was found in the vault of the skull (see fig. $3 \mathrm{I}$ ). The coronal suture which crosses the vault between the frontal and parietal bones bends towards the forehead as it approaches the middle line of the vault. So anomalous is the condition that it seemed most likely to be due to an error in reconstruction. A full investigation excluded such an explanation. In one of the Neolithic skulls found at Coldrum, a large Wormian bone was interpolated in the same part of the vault (see fig. 4, p. 10). In

1 Details of measurements will be found in the Journ. Roy. Anthrop. Instit., vol. xliv., July I9I4. 
the Halling skull, the irregularity may arise from the presence of such a bone, which has become joined to the left parietal bone. It is a remarkable circumstance that one should find two ancient skulls from neighbouring localities showing such a very uncommon form of abnormality.

When we sum up the lesson to be learned from the discovery at Halling, it falls under two heads. First, that at this early date the river-bed type of man was already in England. We have seen that Dr Schmerling had discovered this type in the Engis cave with the remains of extinct animals and the culture which characterise the Aurignacian age. The inference we draw from the discovery at Halling is that a human type may be transmitted over a long period of time and remain almost unchanged as regards size of brain and cranial characters.

But there is a much more important lesson to be learned, namely, that there probably still remain many untouched and undiscovered records of Palæolithic man in England, similar in nature to the hearths and skeleton discovered at Halling. Hitherto, we have sought for traces of Palæolithic man in caves; we hardly expected to read his history in the open country, in exposed valleys and in submerged land surfaces. Near Hastings, on the south coast of Sussex, not more than fifty miles from Halling, Mr Lewis Abbott discovered work-floors of Magdalenian date. Before the Halling discovery had been made, Mr J. Reid Moir had discovered and described a true Aurignacian floor, marked by hearths and characteristic flints, in a valley to the north of Ipswich, in Suffolk. Almost at the same time, Dr Allen Sturge discovered a similar floor in another part of Suffolk, near Mildenhall. More recently, Mr Reginald Smith, of the British Museum, has described a series of Aurignacian floors found in England-all of them buried under sandy (loess) deposits. ${ }^{1}$ We see, then, that it is possible that we may still find under or near those

1 See Journ. Roy. Anthrop. Instit., vol. xliv., July 1914. 
ancient hearths remains of men who were living in England during the later phases of the glacial age. Within a year of his first discovery, Mr Reid Moir found another Palæolithic floor-in the excavations for the foundations of a house in one of the streets of Ipswich. The flints were of a later period than the Aurignacian, namely, the Magdalenian. 


\section{CHAPTER V}

FURTHER EXAMPLES OF LATER PALAOLITHIC MEN IN ENGLAND

IN our pursuit of Englishmen of the later Palæolithic phases of culture, we now pass to the very centre of England-to the eastern strip of the county of Derby which is crossed by the direct railway route from Mansfield, in the neighbouring county of Notts, to Sheffield, in the adjoining county of York to the north. Limestone crags crop up in the eastern part of Derbyshire and streams pass eastwards to join the Trent. The eye of the passenger, as he journeys to Sheffield through this part of Derbyshire, is certain to catch the picturesque outlines of the Cresswell Crags, famous for their caves. Between I 873 and 1875, the Rev. J. Magens Mello ${ }^{1}$ and Professor Boyd Dawkins explored the strata of those caves, and found, not only the remains of the various extinct animals which characterise the later Palæolithic periods, but also- the first ever discovered in Englandone of those remarkable engravings on bone which give the cultures of the Continental caves a high place in the estimation of artists. The carving found represents the head of a horse worked in the style of the cave men-probably of Magdalenian date.) They also found flints worked in the same manner as the implements at Solutré. The discoveries at Cresswell Crags showed that the cultures of the late cave periods existed in England as well as France. The cave which is to give us the

1 Quart. Journ. Geol. Soc., vols. xxxi. p. 679, xxxii. p. 240, xxxiii. p. 579, and $\times x x v$. p. 724 . 
evidence of which we are in search-the kind of man who lived in England during the Aurignacian periodis near a station short of the Cresswell Crags, three miles to the south of them, the station of Langwith. A little way to the east of the station lies the church and rectory of Langwith Bassett. Behind the clump of trees which surrounds the church and rectory runs a brook, the Poulter, flowing eastwards along a narrow valley. The rector, the Rev. E. H. Mullins, is an accomplished geologist. He had lived many years in the parish before he discovered that in the little valley, just behind the rectory, lay a buried cave rich in records of Palæolithic date. The discovery came about in this way. In the autumn of 1903 his son, Mr A. F. Mullins, then a Cambridge undergraduate, along with two college friends, was seeking a subterranean passage which tradition said existed between the valley and the church. They began to explore an old fox's earth which was hid amongst nettles and weeds on the side of the valley, just under a projecting outcrop of limestone rock and a little distance above the northern side of the stream-the Poulter. Forcing their way in on hands and knees, they discovered that the space widened and led, by spaces they could just squeeze their bodies through, to other passages and expansions. It was then that it dawned on Mr Mullins that they had discovered a buried or filled-up cave which might yield similar treasures to those revealed by the neighbouring caves in the Cresswell Crags years before.

The household of the rectory began a systematic and laborious exploration of the cave-extending over a number of years from 1903 onwards. The net result of their labours, ${ }^{1}$ I have represented diagrammatically in fig. 32. It will be seen that the cave had become filled almost to the roof, the deposit on the floor amounting in depth to about 12 feet $\left(3^{\circ} 6 \mathrm{~m}\right.$.). When the entrance and the first or central chamber (about 13 feet in dia-

1 See account by Mr Mullins, Derbyshire Archeolosical and Vatural History Society's Journal, 1913, p. I. 
meter) were cleared, the original floor of the cave was found to be about 8 feet above the stream which flows past the entrance - the level of the stream at this point being 300 feet above Ordnance datum. In the deposit which filled the cave, $\mathrm{Mr}$ Mullins recognised three horizons, the upper horizon fading into the middle, and the middle into the lower zone. The upper horizon, about 3 feet in depth, made up of loam similar to that forming the surface soil of neighbouring fields, yielded remains of modern small animals. The middle horizon, varying from 5 to 6 feet in depth, made up of the same

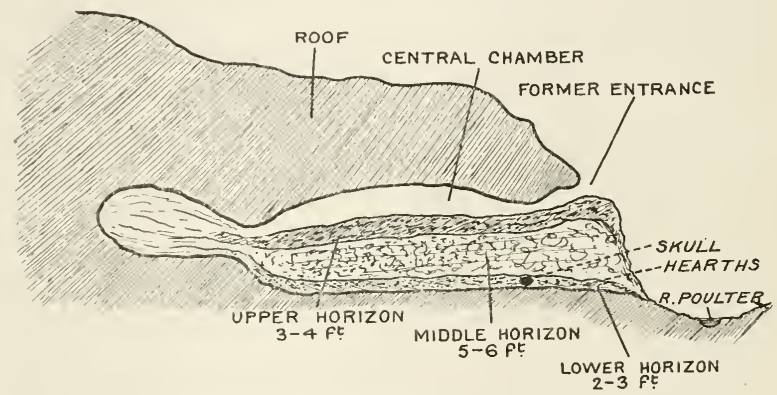

FIG. 32. - A diagrammatic section to show the horizons Mr Mullins recognised in the cave earth at Langwith.

material as the upper horizon, was studded with blocks and chips of limestone, often partially cemented together. No layer of stalagmite was seen either above or below the middle horizon. The middle stratum yielded abundant remains of extinct animals, such as characterise the later phases of Palæolithic culture. In this stratum, near the entrance, at a depth of 2 feet, was found the radius of a woolly rhinoceros; in the same stratum of the central chamber, the humerus of a cave-bear which had been gnawed by a cave-hyena. The lower or bottom stratum, made up of a sandy loam and varying in thickness from 2 to 3 feet, yielded abundant evidence of man's occupation. As will be seen from fig. 32 , the bottom 
layer of the central chamber extended through the entrance towards the present bank of the stream. The remains of ancient hearths and floors occurred at all levels of the bottom stratum, in the central chamber, at the entrance, and on the old terrace in front of the entrance. Calcined stones, "pot-boilers," and numerous worked flints and a bone pin occurred at this horizon. So did the remains of extinct animals - the woolly rhinoceros, the cave-bear, brown bear, the reindeer, the urus (Bos primigenius), the lemming, the Arctic hare, and many other members of a fauna indicating a colder climate than the present. Mr Mullins had the advantage of expert advice from $\mathrm{Mr}$ E. T. Newton, $\mathrm{Mr}$ A. C. Hinton, and $\mathrm{Mr}$ A. S. Kennard in identifying the fauna yielded by the Langwith cave- a fauna represented by sixty different species. As to the flint implements there can be no doubt; they represent the culture of the Aurignacian, and probably also of the Magdalenian period. The remains of the extinct animals found with the flints and hearths in the bottom stratum are those which usually occur in cave deposits of the Aurignacian culture. There can, therefore, be no hesitation in regarding all that lay in the deepest stratum of the Langwith cave as belonging, not to our modern period, but to the Pleistocene epoch.

The following account of the discovery of the remains of the man himself, in the deepest stratum, is given in Mr Mullins' own words :- ${ }^{1}$

"On the left-hand side of the entrance and 9 or Io feet down, quite close to the floor, and also on the side wall of the cave, under what seemed to be a natural arch, formed by a fall of the roof in an early age (but there is no sign of any such fall in the present roof), we found the Langwith skull. There were no signs of other bones along with it, but it was clear that the skull could not have been interred in any historic time by man's agency. . . .

${ }^{1}$ Letter to the Author, October 12th, 1909. 
How did the rock arch fall after the skull was there? How did 9 to ro feet of stone blocks, chips, Pleistocene bones, sand, clay, etc., completely fill up the space near this skull ?"

From what we have seen at Solutré, in the caves of Mentone and Engis, at Halling and at Paviland, we are not surprised to find a skull buried beneath or near the hearths of Aurignacian man. We also see the most likely explanation of the arch of stones over the skull; it appears to represent part of the grave. At Paviland and in the Grimaldi caves, Aurignacian man protected the head of the dead by an arrangement of stones. But where is the rest of the skeleton? Only the brain case of the skull remains - the face, the teeth, and the jaws are gone. Parts of the backbone were found-two vertebræ from the dorsal region; some joints of the fingers were recovered in the neighbourhood, but not a trace of the long bones of the limbs. We have seen, however, that at certain periods hyenas frequented the cave, and their presence may explain the disturbed and dismembered skeleton. A fragment of the skull of a young child was also obtained in the bottom stratum.

For three reasons, I failed at first to recognise the importance of the discovery $\mathrm{Mr}$ Mullins had made. The skull he put into my hands gave us, for the first time, positive evidence as to the kind of man living in England during the period of Aurignacian culture. My reasons or prejudices fell under three heads. The skull was a duplicate of the specimen found in the old deposits of the Trent at Muskam-only thirty miles to the east of Langwith. The Trent skull is the standard example of the river-bed type. I then shared the prevalent belief that the river-bed type of skull was characteristic of the Neolithic period, and that when we passed into that indefinite hinterland of time, known as the Pleistocene and characterised by Palæolithic forms of culture, we should certainly find a very different type of man. Many animals of that time had become extinct; it was probable 
that Palæolithic races of men shared their fate. Hence I kept searching for evidence which would justify me in assigning the Langwith skull to the Neolithic period. In the second place, I failed to perceive how completely $\mathrm{Mr}$ Mullins had proved that the skull was contemporaneous with the deepest horizon and that the culture of that horizon was truly Palæolithic. My third prejudice related to the condition of the skull; it was brown in colour, dense and heavy, but so fresh in its composition that I could not think it to be really ancient. The following note (February 27 th, I9I I) from Mr Mullins will explain how my doubts on this head were removed. I made a careful examination, and also records of the skull, and returned it to the discoverer, expressing my doubts as to its antiquity. $\mathrm{Mr}$ Mullins sent the skull back to me accompanied by bones of the bison, cave-bear, woolly rhinoceros, reindeer, and a bone awl, with the accompanying information: "These are sent for Dr Keith to note their state of preservation. They all come from the same side of the cave and the same horizon, except the bone awl, which I believe came from the northwest passage of the cave-upper horizon."

I had, therefore, to abandon the belief that people with heads of the river-bed type did not transcend the Neolithic period. Langwith cave revealed the fact that this type goes far back into Palæolithic times. The type is infinitely older than we had originally supposed. The discovery made by Dr Schmerling revealed this river-bed type in a cave of Aurignacian date in Belgium. The discovery at Halling was not made until I9I2. At Paviland, the skull of the Aurignacian skeleton was not found. Here, then, we have the most positive evidence of the persistence of certain human types. The river-bed form of skull still abounds in Europe-particularly in England; we find it also in the Pleistocene epoch, twenty-five thousand years ago or more.

The characters of the skull do not require minute description. In fig. 33 , the skull is set in the conventional frame of lines and viewed from the side and the front. 
In fig. 34 , it is represented from above and compared with the Trent (Neolithic) skull. The brain capacity is
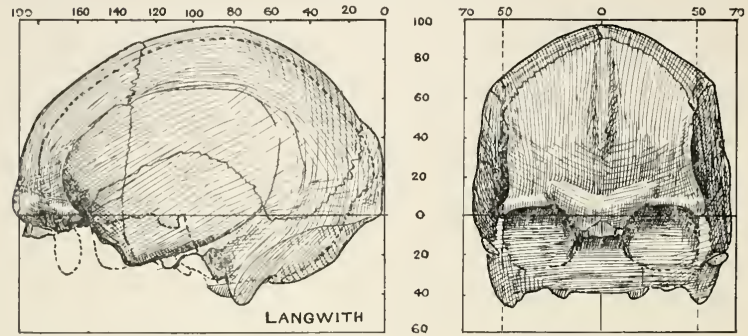

Fig. 33. - The Langwith skull viewed from the side and from the front.

low; when measured by filling the cavity of the skull with millet seed, the size of the brain is found to be only
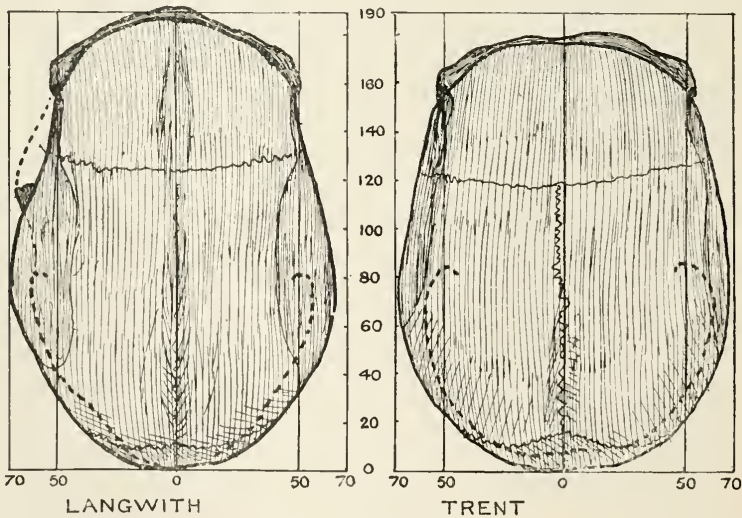

Fig. 34. - The upper aspect of the Langwith skull contrasted with the Trent skull of Neolithic date.

I 250 c.c. - about 230 c.c. under the modern average. In this respect it differs from most skulls of the Palæolithic period, which are commonly above the modern standard. 
But, if small, the skull shows no feature which we can call low or primitive, except that, as is so often the case in the skulls of Australian natives, the brain chamber gives one the impression of being imperfectly filled-the sides are flat and the vault rises almost to a keel. Nevertheless, it is a strongly modelled skull, of a man aged between forty and fifty years-so we infer from the partly closed condition of the sutures between the several bones of the vault. Very probably the man was of small stature and of slight make, as is usually the case in races with the river-bed type of skull. The maximum length of the skull is $192 \mathrm{~mm}$., $180 \mathrm{~mm}$. of that measurement being due to length of brain, the rest to thickness of bone in the frontal and occipital walls. The maximum width, just above and behind the earholes, is $135 \mathrm{~mm}$., the width being 70 per cent. of the length-a narrow skull. The height of the vault above the ear-holes, I I $3 \mathrm{~mm}$. - a small amount, especially when one remembers the bone along the vault is much thicker (9 $\mathrm{mm}$.) than in most modern skulls $(5-6 \mathrm{~mm}$.). Another measurement indicating the total height of the skull (basi-bregmatic) is $127 \mathrm{~mm}$.- -also a low amount. The distance between the orbits-at the root of the nose -is, as in modern British skulls, $24 \mathrm{~mm}$. The eyebrow ridges are pronounced, the frontal air sinuses large. The difference between the minimum width of the forehead $(95 \mathrm{~mm}$.) and the maximum width (I IO mim.), which is measured between the extremities of the supra-orbital ridges, is considerable ( $15 \mathrm{~mm}$.), certainly a primitive character. The temporal muscles of mastication are rather larger than usual. At least the lines which mark the upper limit of the attachment of those muscles are placed, as is often the case in small modern skulls, unusually far above the zygomatic or cheek arches. In the Langwith skull these lines are situated $100 \mathrm{~mm}$. above the zygomatic arches, and only $48 \mathrm{~mm}$. from the middle line along the roof of the skull. As is usual in this type of skull, the occiput projects backwards as a boss or cap. The area differentiated for the attachment 
of the neck is of moderate dimensions, and the width of the neck behind the ears, the bimastoid width, is 120 $\mathrm{mm}$. The width of the face (bizygomatic diameter) was about $130 \mathrm{~mm}$. It is a small-headed man we have to picture in the Langwith cave, but one not showing any markedly low or primitive character.

To continue our survey of the remains of late Palæolithic man in England, we now move from the centre to the south-west of England - to that part of the county of Somerset which bounds the eastern shore of the Bristol Channel. Here a range of limestone hills-the Mendips-run from east to west. Along their southern base flows the Axe, making a westward course through a marshy, flat strip of country. Near the cathedral town of Wells, only sixteen miles distant from the Bristol Channel, the Axe issues from a cave in a southern cliff of the Mendips. Close by is the famous hyena cave-Wookey Hole-first explored by Professor Boyd Dawkins in I 859, the year before Lartet examined the cave at Aurignac. In that year, and in the following, he discovered in the buried floor of the cave the hearths, the flints, the bone implements, and the extinct animals which Lartet found in the cave at Aurignac-only more abundantly; he found no human remains. Professor Boyd Dawkins arrived at the same conclusion as Lartet did, namely, that man must have existed as a contemporary of the extinct Pleistocene animals. The veteran pioneer of "Cave Hunting" 1 has lived to see a revolution in our attitude towards the question of man's antiquity. A passage he wrote in 1860 will show that the truth he contended for then is now admitted by all. "It is certain that man was contemporary in the district with the hyena and the animals on which it preyed, and the fact that the ancient implements were found only on one spot implies that they were deposited by the hand of man. To suppose that a savage would take the trouble to excavate a trench 24 feet long with miserable implements and consequently with great labour, and, ${ }^{1}$ Cave Hunting, Macmillan \& Co., 1874 . 
having excavated it, again to fill it up to the very roof, is little less than absurd." With every word of which, I am sure, the reader will agree. Nor will he more easily believe that Neolithic man would take the labour to cut through the thick stalagmitic floors of such caves to bury his dead in a stratum with extinct animals and Palæolithic flints, and take pains to cover up the date of his deed in order to deceive his cave-hunting descendants.

No human remains were found at Wookey Hole. To reach the cave which disclosed the remains of Palæolithic man himself, we have to follow the Axe along the southern foot of the Mendips until it guides us to the village of Cheddar, halfway between Wells and the coast. The caves at Cheddar have been famous for a long time, and, with the museum attached to them, form a popular resort for summer visitors. The proprietor, Mr R. C. Gough, began the excavation of a "new" cave in 1892 . In the débris at the entrance were found, as at Wookey Hole, traces of all the cultures which succeeded the Neolithic period. The floor of the cave had the usual structure-a superficial stratum of recent deposit 2 to 4 feet thick. Then followed a layer of stalagmite, 5 to I 2 inches (Io to $25 \mathrm{~cm}$.) thick. Beneath the stalagmite lay a stratum of red cave earth, 6 to 8 feet in depth, containing abundant remains of extinct Pleistocene animals. There were also found the hearths, the flint and bone work of, not the Aurignacian, but-as $\mathrm{Mr}$ H. N. Davies was the first to recognise-a later Palæolithic period, the Magdalenian, the culture found in its representative form in the station of $\mathrm{La}$ Madeleine in the ravine of the lower Vézère, France.

In December 1903, Mr Gough, to secure better drainage for the central chamber of the cave, began to open up a side recess or fissure. It was filled with the usual red cave earth and capped by a layer of stalagmite. Under the stalagmite, and embedded in the cave earth to a depth of $1 \frac{1}{2}$ feet $(450 \mathrm{~m}$.$) , he exposed a human$ skeleton, lying back down, and the thighs partly drawn upwards, as if it had been placed in the partially con- 
tracted posture. The skeleton was seen and examined by $\mathrm{Mr} \mathrm{H}$. N. Davies, and all the facts relating to the discovery were collected and placed on record by him. ${ }^{1}$ Lately, these remains have been more fully examined by Professor Parsons. ${ }^{2}$ In all its characters, the skull falls into the river-bed group. Its length is $196 \mathrm{~mm}$.; its width, I $38 \mathrm{~mm}$., is $70^{\circ} 4$ per cent. of the length; the height of the vault above the ear-holes, I I $5 \mathrm{~mm}$. The brain capacity is estimated to be approximately I $45^{\circ}$ c.c. It is thus 200 c.c. larger than the Langwith skull, and resembles that specimen in many of its features. The vault in both is $9 \mathrm{~mm}$. thick. The face, however, is preserved in the Cheddar specimen, but it shows no exceptional feature. The thigh bone is $435 \mathrm{~mm}$. long, from which we infer that the Cheddar man was of low stature-about I $620 \mathrm{~mm}$. (5 feet 4 inches). The leg bone (tibia) shows the side-to-side flattening seen in Neolithic races-less commonly in races of Palæolithic date. Thus we see, so far as the evidence will take us at present, that a people with the river-bed type of head inhabited England from the Aurignacian period onwards.

In our search for the remains of cave man in England we pass from Somerset to the shores of Torbay, situated on the south coast of the neighbouring county of Devon. The bay, one of the most beautiful in England, is bounded by two headlands or horns, about five miles apart. Amongst the green, terraced, limestone hills of the northern headland is situated Torquay, with Kent's Cavern hid in a valley in the suburbs of the town; on the southern headland is the busy fishing town of Brixham. In $1858, \mathrm{Mr}$ Philp of that town was preparing to build on the limestone hill above the harbour, when his workmen opened an unknown natural subterranean passage or cavern-some 600 feet in length-from then onwards

1 H. N. Davies, Quart. Journ. Geolog. Soc., 1904, vol. 1x. p. 335.

${ }^{2}$ Reports of Seventeenth Internat. Med. Congress, 1914, Section I., Part II., p. 9I. Professors C. G. Seligman and F. G. Parsons contributed a paper on the Cheddar man and his civilisation which appeared in the Journal of the Royal Anthropological Institute, I9I4, vol. xliv. p. 24 I. The measurements given in the text are those by Professor Parsons. 
known as the Brixham cave. In 1858 , the question as to whether man did, or did not, exist with extinct animals was being hotly debated. One of the leading geologists of the time, Dr Hugh Falconer, induced two of the premier London Societies-the Royal and the Geological - to explore the cave and settle the question. A pioneer in cave exploration, Mr William Pengelly, ${ }^{1}$ undertook to direct the work and record the results. In fig. 35, I reproduce a copy of his section across the cave to show the strata of the floor. They correspond to those just seen in the caves of the Mendips. There was a bottom stratum of gravel; a middle stratum of 5 to 6 feet in thickness of red cave earth, which contained bones of the woolly rhinoceros, mammoth, hyena, lion, bear, etc. Then over the cave earth came a stratum of stalagmite about a foot in thickness, in which an antler of the reindeer was embedded; over the stalagmite a surface stratum of

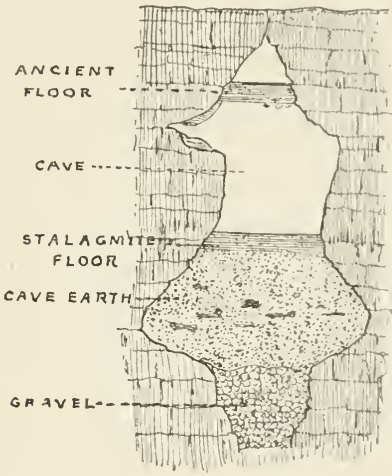

FIG, 35.-Section across the Brixham cave showing the strata of the floor. recently formed earth. In the cave earth, mingled with the bones of the extinct animals, were found flint tools shaped by man. The exploration thus settled the question as to man's contemporaneity with extinct animals, but threw no light on the kind of man nor the place of his culture in the scheme of human evolution.

To obtain light on those problems, we must pay the great neighbouring cave-Kent's Cavern-a cursory visit. In I 846 , the Torquay Natural History Society, of which William Pengelly was the moving spirit, began to explore this vast series of damp, dark passages, vaults,

\footnotetext{
${ }^{1}$ See reference, p. 96.
} 
chambers, and subterranean corridors. The task was one beyond its means. In I 864, Pengelly induced the British Association to take up the work. From I 864 to I 880 nearly, 2000 was spent on the work, and although 50,000 fossil specimens were excavated, cleaned, identified and labelled, the Herculean task of exploring Kent's Cavern is little more than begun. ${ }^{1}$ The upper strata of the floor are the same as at Brixham - a surface earth containing traces of all cultures from Neolithic down to the present. ${ }^{2}$ Below the superficial débris came: (I) the upper stalagmite, in some places 3 feet thick; then (2) the red cave earth, 3 to 5 feet thick, with bones of extinct animals and Palæolithic implements. Beneath the cave earth began a second and older series of deposits, commencing with (3) the lower stratum of stalagmite, covering (4) a great depth of breccia, composed of chips of sandstone and slate firmly cemented together. The lower or older deposits contain evidences of early human cultures which do not concern us at present. The upper strata, however, have a direct interest for us because they belong to the time of the later phases of Palæolithic culture. In the upper stalagmite, and in the upper layer of cave earth, just under the stalagmite, were found implements in bone and stone worked in the last Palæolithic phase-the Magdalenian -the same culture as characterised the cave at Cheddar. In I867, Mr Pengelly found the right half of a human palate, with four teeth still in place, at a depth of 20 inches $(500 \mathrm{~m}$.) in the upper stalagmite. The palate lay unnoticed in its museum case at Torquay until I9I2, when my friend, Dr W. L. H. Duckworth,

${ }^{1}$ See a Memoir on William Pengelly, F.R.S., by his daughter, Mrs Forbes Julian, London, 1897 .

2 I am much indebted to the late Mr Arthur R. Hunt and other members of the Torquay Natural History Society for information regarding the exploration of Kent's Cavern, and for opportunities of seeing the collections in their museum. See Mr Hunt's papers on Kent's Cavern in Geological Magazine, I902, vol. ix. p. II 4 ; Proc. of Geologists' Assoc., I9oo, vol. xvi. p. 425 ; Journ. Torquay Nat. Hist. Soc., 1914, vol. i. p. 267 . Also a short account of Kent's Cavern, Torquay, 1898. 
rescued it from oblivion. ${ }^{1}$ In fig. 36 , I give a drawing of this specimen-the right half of a palate. Side by side I have set the left half of a palate from a famous French skull of Aurignacian date, that found at Combe Capelle. ${ }^{2}$ In shape and size, these two halves are very similar. The teeth, too, agree in dimension, shape, and character. In the adjoining drawing in fig. 36, I have represented the left half of the palate of a modern English skull, and the right half of the palate of a member of an extinct primitive race-the Tasmanian. The area of a well-

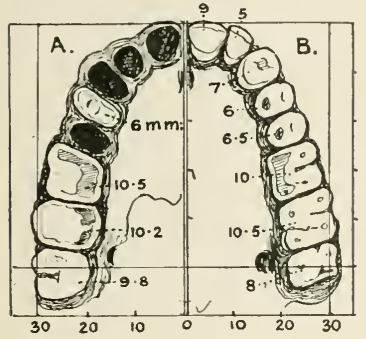

KENT'S CAVERN. AREA $2960 \mathrm{~mm}$ :
COMBE CAPELLE $2900 \mathrm{~mm}$ :

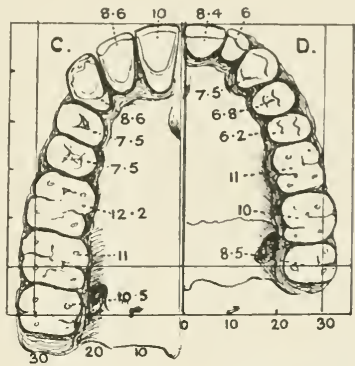

TASMANIAN $3680 \mathrm{~mm}$ :
$2830 \mathrm{~mm}$

FIG. 36. -A. Right half of palate from Kent's Cavern.
B. Left
C. Right
Combe Capelle.
D. Left
Tasmanian.
modern Englishman.

developed palate of a modern Englishman is about $2800 \mathrm{~mm}$., the area being the space bounded by the outer margins of the crowns of the teeth. The hinder border of the area is demarcated by a line joining the posterior margin of the last or third molar teeth (see p. I 50). The particular Tasmanian palate represented in fig. 36 has an area of $3680 \mathrm{~mm}$., I $200 \mathrm{~mm}$. more than in the English palate. In the case of the two palates of Palæolithic man represented in fig. 36, the palatal area

1 See Journal of the Torquay Natural History Society, 1913. See also Brit. Assoc. Reports, Dundee, 1912.

2 See p. 108 . 
is only about $100 \mathrm{~mm}$. above the average modern Englishman. The palate and teeth from Kent's Cavern do show a degree of robust development which is uncommon in modern mouths, but there is no character present which suggests that a strange or unknown race is represented.

The back-front diameters of the teeth are also given on the drawings. Measured along the line of the arch of the teeth, the three molars of the Kent's Cavern palate have a combined length of $30.5 \mathrm{~mm}$., which, although above the average of our modern molars, is yet rather below that of primitive native races such as Australians or Africans (see dimensions on fig. 36). The cusps are worn off the chewing surfaces of the first and second teeth; they had each four cusps-the full number-but the fourth cusp is absent from the last molar. The roots of the teeth are long and well separated, and, in my opinion -but here I differ somewhat from Dr Duckworth-show no trace of those features which characterise that peculiar and ancient Palæolithic race-Neanderthal man. ${ }^{1} \mathrm{Mr}$ George Jackson has shown me similar teeth and palates from caves opened near Plymouth. Thus, at Kent's Cavern, we have evidence of a closing phase of the Palæolithic culture, and just enough of one of the men of the time to show that he was not different from those found in other English caves.

To complete our survey of late Palæolithic man in Britain, we must continue our tour by passing eastwards along the south coast of England to the summit of the South Downs in the county of Sussex. The remarkable earthworks or camps on the top of the Downs at Cissbury, near Worthing, belong to the Neolithic period; but the circular pits and depressions, about fifty in number, which occupy the same site, have yielded a peculiar culture, at first supposed to belong to an early part of the Neolithic period. In I 868, General Pitt Rivers began an investigation of those pits; the result of his explorations, and of others of a later date, was to show that the pits were in reality the filled-in mouths of vertical shafts which went 
down 30 to 40 feet in the chalk. The significance of these shafts or mines was also clear; they were sunk to obtain the kind of flint most suitable for working into implements. They were flint mines. The veins of suitable flints were followed by driving horizontal galleries from the vertical shaft. The miners left tools behind them-now preserved in the filled-up mines. It has been customary to regard the culture of the Cissbury miners as representative of the dawn of the Neolithic civilisation. Recently, Mr Reginald Smith, of the British Museum, has again examined the Cissbury culture, and the objects of the same period obtained from Grimes Graves, near Brandon, in Norfolk, and, in the light of what is now known of the cave men of the Aurignacian period, has come to the conclusion that the Cissbury miners were not a Neolithic, but a Palæolithic people. The evidence ${ }^{1}$ he has produced is such that most students will now agree with $\mathrm{Mr}$ Smith that the flint implements probably belong to the period of the Aurignacian culture - the period of Cromagnon, of Grimaldi, and of Halling. Remains of the reindeer, of the mammoth, and of the rhinoceros occur in the caves of that period of culture; not a trace of them has been found at Cissbury. The ancient ox or urus (Bos primigenius), however, occurs. We scarcely expect the fauna of the period to be fully represented in mines. In Belgium, similar ancient flint mines occur. The Belgian miner - as may be seen in the Royal Natural History Museum of Brusselswas a short-headed or brachycephalic man, quite different from all Aurignacian races; his civilisation was not Aurignacian, but that of the Neolithic period. The miners at Cissbury, on the other hand, had heads of the river-bed type. In the buried shafts at Cissbury, the skeletons of two individuals were found and described by Professor Rolleston. One is the skeleton of a man under 5 feet $(\mathrm{I} \cdot 500 \mathrm{~m}$.$) in height, and showing a$ left-sided palsy, contracted in boyhood. ${ }^{2}$ The length of

1 See Archceologia, 1912, ser. 2, vol. xiii. p. 109.

2 See Rolleston, Journ. Anthrop. Instit., 1878, vol. vill. p. 377. 
the skull is $184 \mathrm{~mm}$., width $\mathrm{I} 32$, the width index being 7I. He had a brain capacity of I 350 c.c.-about the same as the Cheddar man-and was buried in the contracted posture with his grave protected by blocks of chalk. The other skeleton ${ }^{1}$ was that of a woman with a very large head (length i $95 \mathrm{~mm}$., width I $44 \mathrm{~mm}$., the width index being 74). The brain capacity was estimated by Professor Rolleston to be 1732 c.c.-a great amount, particularly in a short woman with a stature of only 5 feet. If $\mathrm{Mr}$ Reginald Smith is right in regarding the Cissbury people as Aurignacians-the exploration of Grimes Graves now undertaken by the Prehistoric Society of East Anglia will settle the matter-then we have to enlarge our conception of the activities and amenities of that time. ${ }^{2}$ We know that on the Continent art reached a higher standard in the later phases of the Palæolithic period. Cissbury was evidently the home of a community of miners. Even at this early date there was a tendency towards the specialisation of human industries-a tendency which has become so pronounced in modern civilisation.

To bring this chapter to a close, we shall return to the very centre of London, to the north bank of the Thames between Trafalgar Square and Westminster. The land here holds the same relationship to the Thames as the Halling terrace - at which we started - bears to the Medway. In 1892, foundations were excavated in this area for a new Admiralty building, exposing a section of the north bank, or low terrace of the Thames, which was carefully studied and recorded by Mr Lewis Abbot. ${ }^{3}$ Eleven feet below high-tide level was found an old land surface, bearing in an "Arctic bed" remains of plants which are natives of a cold climate. That bed marks a closing phase of the glacial period, evidently corresponding to the date of the formation of the lowest terraces of the

1 See Rolleston, Jcurn. Anthrop. Instit., I876, vol. vi. p. 20.

2 A human skull has been found. It is of the same type as the Cissbury specimens.

3 See Proc. Geol. Assoc., I892, vol. xii. p. 346. 
Thames and Medway valley. Mr Hazzeldine Warren ${ }^{1}$ has described a similar and apparently contemporaneous Arctic bed in the valley of the Lea, to the east of London. Over the Arctic bed in the foundation of the Admiralty building, $\mathrm{Mr}$ Abbot found a deep bed of gravel, containing remains of Pleistocene mammals and also a flint implement typical of the Solutrean culture-the culture following the Aurignacian, but preceding the Magdalenian. We have seen that in the cave at Langwith, with the evidence of an Aurignacian and of a Magdalenian culture, animals of a sub-Arctic climate were present. We are therefore justified in concluding that towards the close of the Palæolithic period the climatic conditions were much colder than now. We are uncertain as to the causes of climatic change, but we cannot believe, from our knowledge of historic times, that such changes can be brought about except by imperceptible degrees extending over a long period of time. Yet, long as is the period which has elapsed since Arctic conditions last ceased, the river-bed type of man has persisted, with his body altered only in minor details.

Note.-The skeleton of the Cissbury man is preserved in the University Museum, Oxford. Professor Arthur Thomson and the author have re-examined this skeleton, and regard the somewhat peculiar features of the limb bones as due to natural rather than to pathological causes. The recent exploration of Grimes Graves has revealed a mixture of cultures-of both Neolithic and Palæolithic dates.

1 See Quart. Journ. Geol., 1912, vol. lxviii. p. 213. 


\section{CHAPTER VI}

THE MOUSTERIAN PERIOD IN ENGLAND AND THE MEN OF THAT PERIOD IN FRANCE

IN this chapter we are to take another great step backwards into the past. The period of Neolithic man lies far behind us; in the two preceding chapters we have made a cursory survey of the men of the late Palæolithic cultures, and formed, on the limited evidence at our disposal, some estimate of their antiquity. As nearly as we can guess at present, the point in time which we have reached is some twenty-five thousand or thirty thousand years back. We are now to enter a middle Palæolithic period during which the men of Europe worked their stone implements in a very characteristic style - the fashion and culture which is universally known by the name of Mousterian, because the workmanship, in its typical form, was found at an early stage of prehistoric exploration (1863) in one of the Vézère caves of France, Le Moustier. The Mousterian period was probably as long in its duration as the late Palæolithic, the Neolithic, and the Metal ages put together-twenty-five thousand years. The evidence on which this statement is based will become apparent as we proceed with this survey. Thus, we are writing under the belief that the Mousterian age commenced some fifty thousand years ago. Very probably these estimates may need readjustment in the light of further discoveries.

The story of late Palæolithic man, as told in the last chapter, came to an end on the low or 20 -foot terrace af the north bank of the Thames, at the British Admiralty 
buildings. The scene of our search for the records of his predecessor-Mousterian man-lies also in the Thames valley, on the south bank of the river, ten or twelve miles below London. In this region the North Downs invade the valley of the Thames, exposing their flanks to the enterprise of the makers of cement who have attacked them from the strips of flat land bordering the river. We may complain of the pestilence of smoke with which these manufacturers - both of brick and cement-fill the valley below London, but as students of ancient man we are deeply indebted to them. Without them, we should never have known that in the stretch of bank which faces the full tide of traffic on the Thames, early man has left his records more abundantly than in almost any other part of the world. The manufacturer has exposed the ancient work-floors and the scattered stone implements, but the recognition of their nature and significance has been the work of an army of voluntary students and collectors who, in a brief history like this, scarcely receive the mention their labours have well earned.

The records of the Mousterian period-the one which is to engage us in this chapter-lie in this stretch on the south side of the Thames valley, especially in a side recess where the Darenth, breaking through the North Downs from the Weald of Kent, receives a tributary - the Crayand joins the Thames (see fig. 56, p. 16r). On the western or London side of the Darenth estuary have been deposited the Crayford brick earths, rising 60 feet $(18 \mathrm{~m}$.) above the level of the river. Those brick earths, deposits of the ancient Thames in times of flood, have been studied by many men, but the authorities who are to be our chief guides are two in number: firstly, Messrs Hinton and Kennard, ${ }^{1}$ and secondly, Mr R. H. Chandler. ${ }^{2}$ In fig. 37, I have combined the diagrams those authorities have drawn embodying observations which they have made at Crayford. We see, in the first place, the submerged Neolithic surface, with the horizon of Tilbury man

1 See reference, p. 107.

2 See reference, p. 105. 
indicated, although Tilbury is a few miles lower down the river, and on the opposite or northern bank. Then comes, in point of antiquity, the low or 20 -foot terracethe terrace in which the Halling man of the Aurignacian period was found, but 1 must also state that the representation of this terrace at Crayford has been washed away by the Thames long ago. Then, above the level of the low or 20-foot terrace come the Crayford brick earths, representing a still older deposit of the Thames-the

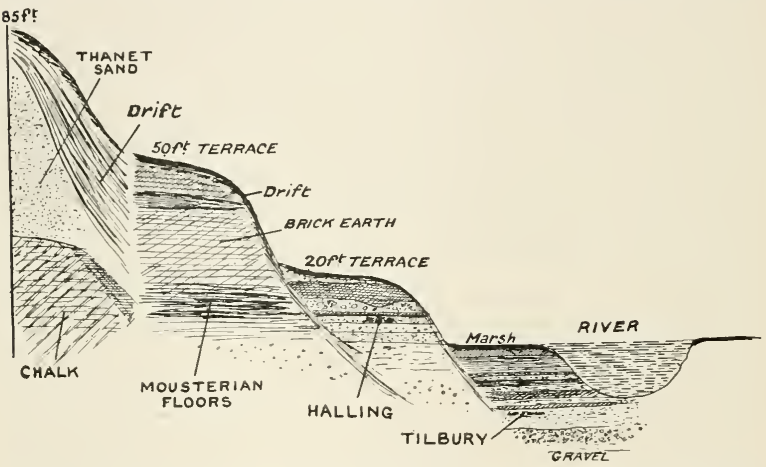

FIG. 37.-Diagram showing the submerged bed, the low or 20 -foot terrace, the middle or 50 -foot terrace in the valleys of the Thames and Medway (after Hinton, Kennard and Chandler).

middle or 50-foot terrace. We must examine the structure of this terrace. In the first place, its lowest layer or stratum is made up of gravel - the ballast gravel which marks the ancient bed of the river. That gravel rises now 30 feet above the present level, not of the bed of the river, but of the river itself. When the beginnings of the middle terrace were being laid down, the Thames was flowing on a bed at a level more than 30 feet above its present bed. Were the Thames to resume the level of its ancient bed it would bury a considerable part of London by its sediment. Then, above the gravel bed, follow strata of sand, about I4 feet in depth, indicating 
that the river was flowing more slowly-the land was subsiding, and the valley was being filled up. Above the sands come another series of beds, known as the Cyrena beds, containing in abundance the shells of certain molluscs and bones of small mammals. Then follow the typical brick earths-loamy deposits from the backwaters of a muddy and flooded river. From the gravel of the old river bed to the surface of the brick earth the deposits laid down by the river during a period of land subsidence amount to over 30 feet in depth. From the very beginning to the very end of this deposit, men who worked their flint implements in the Mousterian style lived on the southern bank of the Thames, for, at all levels of the brick earths, these implements have been recovered. Messrs Hinton and Kennard, and $\mathrm{Mr}$ Chandler, recognised that the implements were Mousterian in type in $1905,{ }^{1}$ and their inferences were fully supported by the collection of implements which $\mathrm{Mr}$ Brice Higgins obtained from all horizons of the Crayford brick earths, and which have been described and recorded by $\mathrm{Mr}$ Reginald Smith. ${ }^{2}$

The section of these brick earths as recorded by $\mathrm{Mr}$ Chandler and $\mathrm{Mr}$ Leach $^{3}$ (see fig. 37) throws a very definite light on the climate both before and after the formation of the 50-foot terrace. Over the brick earths lies a deposit technically known to geologists as a drift or "trail " - a mixture of chalky blocks, gravel, sand, and sludge. Such a deposit results from the freezing of a surface soil, which in the thaw slips bodily down from higher to lower ground. After the Crayford brick earths were deposited, there evidently followed a cold period-marked by the formation of trail. We have seen, from the Arctic beds in the low terrace at the Admiralty buildings, and from $\mathrm{Mr}$ Warren's discovery in the low terrace of the adjoining Lea valley, that during the late Palæolithic periods there was a return to a sub-Arctic climate. The drift or covering

1 See reference, p. I07.

See Man, I9I4, vol. xiv. p. 4 and p. 31

3 See Proc. Geol. Assoc., 1912, vol. xxiii. p. 186. 
over the Crayford brick earths may have been produced then; at least it was formed before the lower terrace was finished, for that terrace shows no disturbance of ice action in its upper strata.

Not only is there a trail over the Crayford brick earths, but, as Mr Chandler shows in his section (fig. 37), and as has been recognised for a number of years, there are the most definite signs of another drift or trail-a frozen landslide-on the side of the valley, occupying a period in time prior to the deposition of the Crayford brick earths in which the tools and culture of Mousterian man are embedded. This earlier trail or ice-deposit is known in England as "Coombe rock" - a mixed, contorted mass of chalk, sand, and loam, the results of a partially thawed landslide. Even before the period of the earlier trail, Mousterian man was in the valley of the Thames, for under the Coombe rock occur his old work-floors.

Five miles lower down the valley-almost opposite Tilbury-there is another deposit of brick earths, which, like those at Crayford, form part of the 50-foot or middle terrace. They occur on the western bank of a side valley by which the Ebbfleet enters the Thames, being exposed at an excavation or pit known as Baker's Hole (fig. 56, p. I 6r). Here, ${ }^{1}$ under the Coombe rock, were found several thousands of Mousterian implements - evidently representing a tool manufactory or workshop of this remote period.

From the study of the deposits in the valley of the Thames, we are able to form some conception of the position which the Mousterian period occupies in the scale of prehistoric time. It is manifest that this period is older than the formation of the low or 20-foot terrace, for when the middle or 50 -foot terrace is traced towards the river, it is found to dip under, and therefore to have been deposited before the lower or more recent terrace. Further, we see that it lies between two cycles of severe climate. The duration of the Mousterian period was

1 See Archarologia, 1911, vol. lxii. p. 522 ; also G. C. Robson, Trans. Oxford University Junior Scientific Club, I910, June, p. 337. 
sufficiently long to cover a period which saw a wide variety of climatic changes in England. We have no reason to suppose such changes occurred more rapidly then than they do now. We see, too, that at the beginning of the period the Thames had excavated its valley to almost its present level, and then subsidence of the land set in, and the valley was filled up at least to the height of the Crayford brick earths-60 feet above the present level. The 50-foot terraces on both sides of the river are all that remains of the great bed of deposits laid down in the valley during the time the men of England were in that stage of culture called Mousterian.

The south side of the Thames valley is not the only place where old Mousterian work-floors have been found. In drawing up a list of the deposits of the Thames valley, arranged in their order of formation, Messrs Hinton and Kennard ${ }^{1}$ mention the discovery of Mousterian floors on the north bank of the Thamesat Grays, almost opposite Crayford, at Stoke Newington, over which northern London has éxtended, and at Acton, to the west of London. No true cave-habitation of this date has been found in England, but near Mildenhall, in the county of Suffolk, East Anglia, Dr Allen Sturge found a Mousterian work-station or floor. ${ }^{2}$ The brick earth, fully 30 feet in depth, in which the flints were found by Dr Sturge, is situated on the side of a low hill which rises on the eastern side of the valley of the Larka tributary stream of the Great Ouse. The Mildenhall brick earths are of the same geological age as those at Crayford. Further, as Dr Allen Sturge discovered, they have been overwhelmed by a glacial movement, just as the brick earths at Crayford were covered over by "drift."

Thus we have the most ample evidence that England was inhabited by men of the Mousterian culture; but so far not a trace of his actual body has been found. That

1 "The Relative Ages of the Stone Implements of the Lower Thames Valley," Proc. Geol. Assoc., 1905, vol. xix. p. 76.

2 See Proc. Prehistoric Society, East Anglia, I91 I, vol. i. p. 69. 
is the more strange, seeing that remains of the animals of the period are well preserved in the brick earths which contain Mousterian flints. Two forms of elephants occurred with him in the Thames valley-the mammoth and a form nearly allied to the African elephant ( $E$. antiquus); three forms of the rhinoceros; the musk ox, and other mammalian species associated with a cold

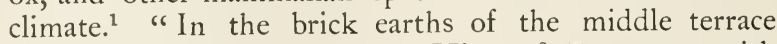
of the Thames," writes Mr Hinton, " "we meet with evidence of the invasion of England by swarms of mammals which can only have come from Siberia and Eastern Europe - the lemming, numerous voles, the reindeer, and the saiga antelope." At some part of the Mousterian period - perhaps during its whole extentEngland was part of the Continent; otherwise such an invasion of mammals which were then new to this country could not have taken place. We see, therefore, that Mousterian man and his culture could have entered England by land.

To study the men of the Mousterian times, we must transfer the scene of our inquiry to the Continentpreferably to that part of France we have already visited in search of the men of the later Palæolithic periods, the region drained by the Dordogne and its tributaries. A little over sixty miles from Bordeaux, the Dordogne receives a small southern tributary, the Couze. In the face of the terraced limestone cliff or hill on one side of this valley, at a site known as Combe Capelle (fig. 38), a Swiss archæologist, Herr O. Hauser, made an important discovery-one which serves exceedingly well to introduce us to the Mousterian period of France.

In the opening months of I909, he commenced a systematic exploration of a terrace, almost on the summit of one side of the valley, which was known to yield numerous Palæolithic flints, and suspected to have served as a rock-shelter for ancient man. His excavation at the foot of the sheltering rock exposed the following strata

1 Messrs Hinton and Kennard, Proc. Geol. Assoc., 1905, vol. xix. p. 83 .

2 Proc. Geol. Assoc., 1907, vol. xx. p. 53. 
(fig. 39) : (I) a layer of soil, about a foot in depth, containing blocks of limestone detached from the face of the rock by exposure to wind, wet, and changes of temperature; (2) a stratum, over a foot in depth, containing flints and other evidences of the Solutrean culture-the one preceding the Magdalenian, the latter being unrepresented at Combe Capelle. Then followed three strata belonging to various phases of the Aurignacian

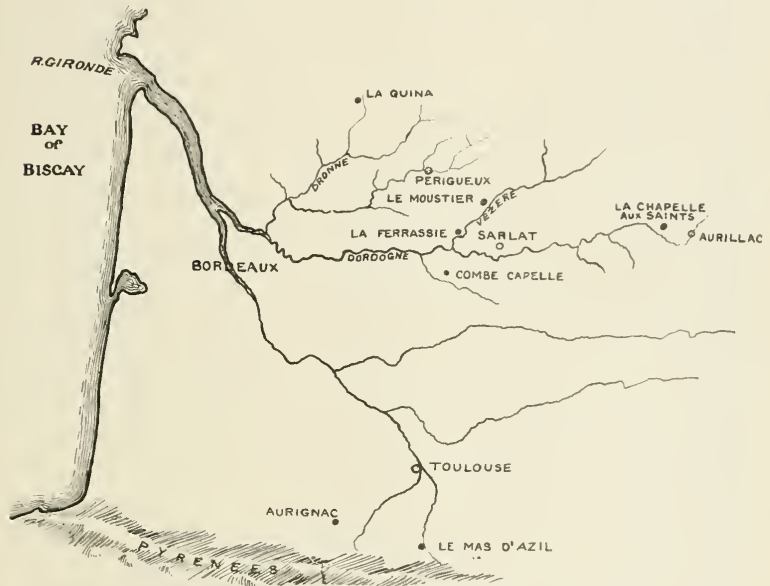

FIG. 38. - A sketch map of the chief sites of prehistoric discovery in the region of the Dordogne, France.

culture-the lower, the middle, and the upper-separated by two sterile deposits, showing that during two intervals the rock-shelter had been forsaken as a human habitation. At the bottom of the lowest Aurignacian stratum a human skeleton was found, with the clearest evidence that it had been buried. As was the custom in those times, the site selected for the grave was near the place of habitation. The position of the skeleton was much the same as at Halling, the knees being bent and the thighs drawn up. He, the dead man, had been provided 
with abundance of flints, and the perforated shells, which probably ornamented his body in life, were close by.

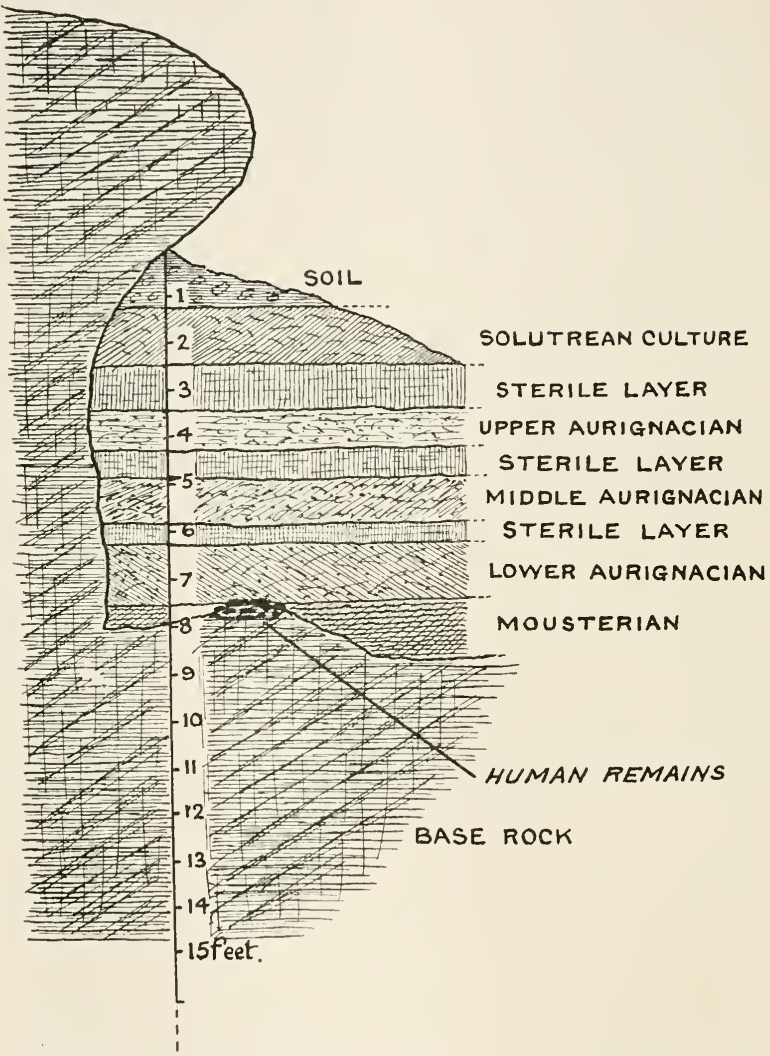

. 9 \& FiG. 39. - The strata at the rock-shelter at Combe Capelle, showing the position of the human skeleton discovered by Herr Hauser.

What is most important for our present inquiry is that the bottom stratum of all contained, not objects of the 
Aurignacian culture, but of the preceding or Mousterian civilisation. Indeed, one of the implements which lay near the skeleton, and was probably interred with the body, was a Mousterian " point "- a small, wedge-shaped, flint implement or scraper.

On the evidence observed and recorded by Herr Hauser, ${ }^{1}$ we must regard the man found at Combe Capelle as representative of a native of the Dordogne about the beginning of the Aurignacian period. The type is familiar to us-it is a variant of the modern-looking, narrow-headed men of the Aurignacian period, a type which would excite no comment, if dressed in modern garb, in any assemblage of modern Europeans. The head is merely a variety of the river-bed type. ${ }^{2}$ The length of the skull, I $98 \mathrm{~mm}$., is $6 \mathrm{~mm}$. longer than the Langwith specimen; its width is only $130 \mathrm{~mm} .-5$ $\mathrm{mm}$. narrower. The narrowness of the head is very apparent when a comparison is made of the width and length - the width is only 65.7 per cent. of the length, a narrower head than even that found at Langwith. The vault of the skull is well sprung, its height above the ear-holes being $120 \mathrm{~mm}$. The brain capacity is about I +40 c.c.-slightly under the modern average. The facial features are those we are familiar with to-day. The size of the teeth and development of the palate are average, the length of the palate being $5 \mathrm{I} \mathrm{mm}$.; its width at the second molars, $64 \mathrm{~mm}$. (see fig. $36, \mathrm{p} .97$ ). The three molar teeth, measured along the line of the crowns, are $28.5 \mathrm{~mm}$. for the upper, $34 \mathrm{~mm}$. for the lower-rather more than is usual in modern dentitions. He was a man of small stature, unlike the Cromagnon type, also of the Aurignacian period, but in this respect like the river-bed people. The length of his thigh bone is only $425 \mathrm{~mm}$.; his stature, a little over $1550 \mathrm{~mm}$. ( 5 feet 2 inches). Thus, we see, at the close of the Mousterian period and at the beginning of the Aurignacian

1 Prachistorische Zeitschrift, 1910, vol. i. p. 273.

2 For full description of skeleton, see Professor Kilaatsch's account, Praehistorische Zeitschrift, 1910, vol. i. p. 285. 
the men in the Dordogne valley were people of modern types-the Cromagnon people, tall; the Combe Capelle, short.

In the autumn of I909, while Herr Hauser was exposing the Aurignacian man at Combe Capelle, M. Peyrony, the schoolmaster at Les Eyzies, the picturesque cliff village on the Vézère, was uncovering a human skeleton in a stratum of Mousterian age. M. Peyrony had devoted many years to the exploration of the prehistoric sites along the valley of the Vézère, and, at the time of which I write, the autumn of I909, was exploring the deposits at the foot of a rock-shelter at La Ferrassie (fig. $3^{8}$ ), on the western side of the valley, four miles above the point at which the Vézère joins the Dordogne, and nearly twenty miles to the north of the site at which Herr Hauser was excavating. M. Peyrony worked in conjunction with Professor Capitan of the Collège de France, Paris. The deposits at the rock-shelter showed the following strata $^{1}$ (see fig. 40 ). The upper stratum, 4 feet in depth, was made up of soil, with blocks of limestone which had fallen from time to time from the face of the sheltering rock. Then followed three strata of Aurignacian age-representing three phases of the culture of that time-forming a thickness of 6 feet. At a depth of Io feet came the deposit which particularly interests us here-a deposit of the Mousterian period. It was about 20 inches in thickness, and contained the typical flint implements and chips of the period, with broken fragments of the bones of reindeer, bison, and horseremnants of ancient feasts. In the lower part of this stratum a skeleton came to light, lying on its back with the lower limbs strongly bent. There were no evident signs of grave furniture or of deliberate burial, but we may be certain, seeing that a complete skeleton was represented and that the strata had been the site of human habitation, that the body had not been entombed by

1 For an account of this station, see Revue Scientifique, I9I0, vol. xlviii. p. 193 ; Bull. et Mím. Soc. d'Anthrop. Paris, 1910, ser. 6, vol. i. p. 48 . The skeletons are also described by Professor Boule (see reference, p. I 17 ). 
natural means. Unfortunately, the skull was broken beyond repair, but other parts of the skeleton were fairly complete, every bone being marked by those peculiar characters which denote, as Professor Capitan recognised, the Neanderthal race. In the same stratum, another skeleton showing Neanderthal characters was discovered in the following year, I9Io. Thus, almost in the same

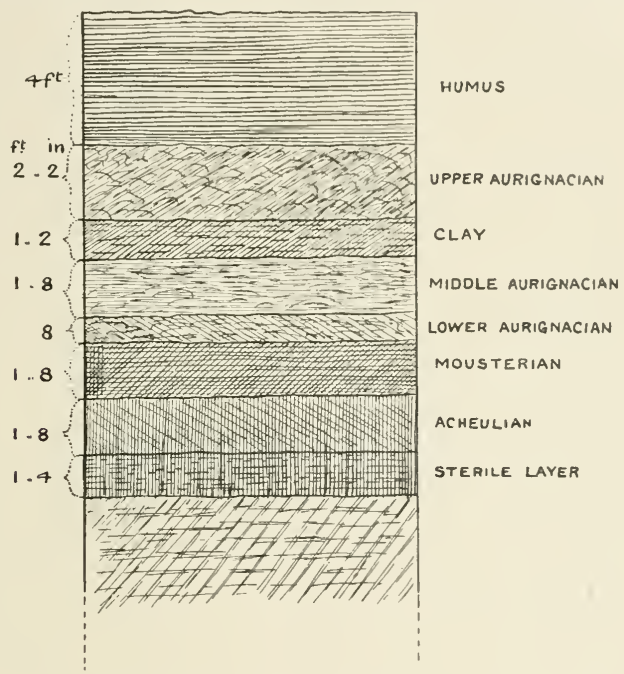

FIG, 40.- Section of the strata at La Ferrassie.

month, and less than twenty miles apart, two ancient human skeletons were discovered, one at La Ferrassie and one at Combe Capelle. The last named was found in the oldest Aurignacian stratum, and belonged to a man akin to modern races, while the skeleton found at Ia Ferrassie, in the Mousterian stratum, was of a race or type totally different from any human race now living. They were found folded down between untorn and undamaged pages of the records which Nature makes of the earth's history. As will be seen by a comparison 
of figs. 39 and 40, the La Ferrassie record is the older. Men began to live at the rock-shelter of Combe Capelle in the Mousterian period; their records cease at the Solutrean. At La Ferrassie, the records begin in preMousterian times-it was inhabited when the characteristic hand-axes of the Acheulean culture were fashioned; the records at Ferrassie close with the Aurignacian period.

It was not the discovery at La Ferrassie, however, which drew the attention of Europe to the unexpected fact that the Neanderthal type of man was immediately succeeded by men of the modern type. The credit of having first demonstrated that Neanderthal man was not converted into modern man, during the middle part of the Pleistocene period, must be assigned to Herr O. Hauser and his colleague, Professor Klaatsch of Breslau. In I908, the year before the exploration at Combe Capelle, Herr Hauser was excavating on the west bank of the Vézère, fifteen miles above La Ferrassie, in a cave on the lower terraces behind the little town of Le Moustier (fig. 38).

The site he had chosen was situated at a lower level than the famous cave investigated by Lartet and Christy in 1863 , where they found the types of flint workmanship which are now regarded as characteristic of the Mousterian period. Early in I 908, Herr Hauser's workmen began to expose, at a depth of 5 feet below the floor of the cave, and accompanied by objects of the Mousterian period, a human skeleton. Further excavation was stopped until the autumn, when, surrounded by a company of German anthropologists, in the heart of France, the skeleton was finally extracted from its ancient bed, with expert eyes looking on to bear witness to its authenticity and antiquity. The skeleton was that of a lad of perhaps sixteen years of age; his canine teeth and third molars were not fully erupted; the growth lines of the long bones were unclosed. There could be no question : he had been deliberately buried. Near his right hand was a hand-axe of the Acheulean culture, but typical implements of the Mousterian period were near by. 
Charred remains of the ancient ox-the urus-were noted. The body had been laid on its right side, with the face turned down, and a pillow of stones placed under the head. The skull was badly crushed, and Professor Klaatsch was not altogether fortunate in the reconstruction of its fragments. The head was remarkably large and capacious, and showed all the curious features of the Neanderthal race. Every bone of the body, as Professor Klaatsch has described in great detail, ${ }^{1}$ showed certain features which differentiate them from the corresponding bones of modern man. The skeleton, or what remained of it, was subsequently acquired by the Museum of Ethnology, Berlin, where it is now preserved, the skull having undergone recently another reconstruction. Herr Hauser's discovery of a Neanderthal skeleton in a stratum of Mousterian age in 1908, and in the following year, of a skeleton of the modern type in a stratum of Aurignacian age, effected a revolution in our attitude towards the nature of Neanderthal man, and our conception of the antiquity of men of the modern type.

While these explorations were being carried out at La Ferrassie and at Combe Capelle, in the autumn of 1909 , equally important in their final result, perhaps more important discoveries were being made higher up in the valley of the Dordogne. Seventy miles to the east of the Vézère, the Dordogne is joined from the north by a small tributary stream, the Sourdoire, which has carved a valley out of an agricultural country-a plateau of limestone in the department of Corrèze. For some years three excellent archrologists, the Abbés A. and J. Bouyssonie and Bardon, then stationed in that part of France, had investigated local sites of prehistoric man with great skill and success. In the autumn of 1908 , they were exploring a small cave, situated in a terraced field rising on the side of the valley of the Sourdoire, near the agricultural village of $I_{a}$ Chapelle-aux-Saints. The cave was of small dimension-even when cleared

1 Archives für Anthropologie, 1909, ser. 7, vol. iv. p. 287. Ergebnisse der Anatomie und Entwickl., 1907, vol. xvii. p. 431. 
out it was not high enough for a man to stand erect in. At its widest part it only measured about I 3 feet (4 m.), whilst the furthest recess was less than 20 feet from the low entrance on the face of the limestone terrace. The deposits on the original floor were about 3 feet in depth, and exhibited two strata or zones (fig. $4 \mathrm{i}$ ), an upper one, rather less than 2 feet in depth, and a deeper, a little over a foot in thickness. The upper stratum was sterile so far as our present inquiry is concerned, but the deeper one, a yellowish clay laden with

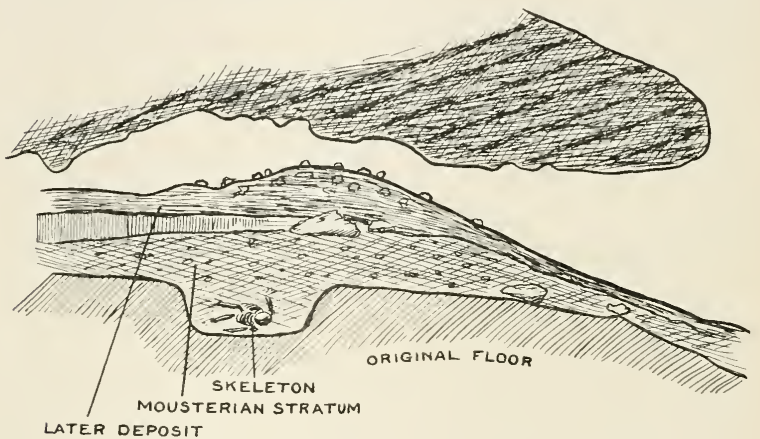

FIG. 4I. - Section of the cave at La Chapelle-aux-Saints (Boule).

remains of extinct animals and implements of the Mousterian culture, has an immediate bearing on our search. The animals represented in the deeper stratum were the woolly rhinoceros, the reindeer, a Pleistocene form of horse, the boar, the ibex, the bison, the cavehyena, and the Alpine marmot. The implements, over a thousand in number, were the typical products of the Mousterian period-the Mousterian " points," scrapers, and flakes. The remains of two distinct hearths were noted near the level of the original floor.

The Mousterian stratum was observed to dip down into a depression in the floor, near the centre of the cave (fig. 4I). In this depression, the abbes exposed the skeleton of a man-again of the Neanderthal type. The 
body had been laid on its back, head to the west, and with knees, thighs, and elbows flexed-the contracted posture. The head was protected by an arrangement of flat stones, near which was part of the skeleton of the leg and foot of an ancient type of ox. Other stones were placed round the body, between it and the sides of the depression in the floor-regarded by the abbés as a grave purposely dug for the body. Numerous beautifully worked flints of the Mousterian period lay near the skeleton. The Mousterian stratum over the gravel was intact; the cave had been occupied in the Mousterian period long after the body had been laid to rest. Even at this early period, a species or kind of man, not directly related to modern races, was burying the dead and furnishing them with an outfit as provision for a long journey. The human mind, even then, held hopes and beliefs as to what happened after death. Clearly the Mousterian period and Neanderthal man do not represent the human dawn. Still, they belong to that remote date at which the middle terrace of the Thames valley-on which so much of central London is now built-was being formed by the action of the river.

The discovery at La Chapelle-aux-Saints marks a stage in the progress of our knowledge of ancient man. We see, in 1908, that the methods employed in the exploration of caves have become exact and systematic, replacing the somewhat haphazard efforts of an earlier period. The splendid memoir ${ }^{1}$ written by M. Marcelin Boule, Professor of Palæontology in the National Museum of Natural History, Paris, where the La Chapelle man now finds a home, represents the most thorough and exact investigation ever made of an ancient human skeleton. The man of La Chapelle-aux-Saints was worth all the pains which Professor Boule has bestowed on him. The skull was broken, parts of the face were defective, some parts of the skeleton were missing, but such blanks were supplied by the two skeletons found by MM. Capitan and Peyrony at La Ferrassie. Professor Boule estimates the age of

1 Annales de Paléontologic, I9I1, vol. xi. pp. I-270, I6 plates. 
the La Chapelle man at fifty or fifty-five years, but the open condition of the sutures between the bones of his massive skull suggests a younger age-perhaps under forty. For such an age, the teeth, which were planted in jaws of exceeding strength and size, are in a surprisingly bad state. All the molar or chewing teeth had been lost from disease during life. The dimensions of the skull (see fig. 45) greatly exceed those of an average modern man. The maximum length is $208 \mathrm{~mm}$.; the width, I $56 \mathrm{~mm}$., represents 75 per cent. of the length; the skull being thus, in spite of its great length, on the border line which separates the long-headed and medium-headed groups. The height of the vault above the ear-holes is about I $8 \mathrm{~mm}$. - a low amount for such a long and wide skull. The great capacity-over I 600 c.c., at least I 20 c.c. above the modern average-seems inconsistent with the great beetling, ape-like eyebrow ridges and massive jaws. Nor was it a simple brain. The cast taken from the interior of the skull-the subject of a special memoir by Professor Anthony ${ }^{1}$ - shows that all the parts of the human brain were already fully represented. Like all men of the Neanderthal race, ${ }^{2}$ the La Chapelle man was not tall-under 5 feet 4 inches ( $\mathrm{I} \cdot 600 \mathrm{~m}$.). He had many characters which may justly be called simian or primitive, but he had others which cannot be so classed - such as the size of the brain and the relative proportion of the limbs. In apes, in certain modern and ancient races-such as the Cromagnon people of the Aurignacian period-the forearm and leg are relatively long as compared with the upper arm and thigh, but in Neanderthal man, the forearm and leg are relatively short, even when a modern European is taken as the standard.

In the evidence provided by the discoveries at Le Moustier, La Ferrassie, and La Chapelle-aux-Saints, one is forced to the conclusion that the Dordogne, during the Mousterian period, was inhabited by men of the Neanderthal type; in the succeeding period-the Aurig-

1 L'Anthropologie, I9I I, vol. xxii. p. I.

2 See p. 137. 
nacian-men of the modern type took their place. At least, men of the modern type have never been found in a stratum of Mousterian age in this region; only remains of Neanderthal man have been so found. Such an inference has the further support of discoveries made by Dr Henri Martin in the department of Charente, adjoining the department of the Dordogne on the north-west. For several years, Dr Martin has explored a deposit of the Mousterian age, situated at the foot of an old rockshelter at La Quina and buried under débris which had fallen from the cliff. In the valley near the cliff flows a small stream-the Voultron-on its way to join the Dronne (fig. 38), another of the northern tributaries of the Dordogne. The deposit at La Quina showed three strata, belonging to different phases of the Mousterian period. Dr Martin found not only the typical implements of the middle and later stages of the period, with remains of the reindeer, the horse, and primitive ox (Bos primigenius), but also rude implements worked in bone. In I9Io he found a human astragalus or ankle-bone which was recognised by its peculiar form to be that of a man of the Neanderthal type-so distinctive is the structure of this race. In September I9I I, two years after the famous discoveries in the region of the Dordogne, Dr Martin found in the lowest part of the deeper of the two Mousterian strata, a human skeleton, again of the Neanderthal type. The bones were embedded in a greenish sandy clay, a silt deposited in the bed of the Voultron when that stream flowed nearer to the foot of the rock-shelter than it does now. The discoverer formed the opinion that the body had fallen in the stream and had thus become naturally entombed. When we remember the instances already cited, where men of both the Mousterian and Aurignacian periods have buried their dead near or under the sites of habitation, we are inclined to regard La Quina as a similar case-one of burial.

The skeleton found at La Quina is probably that of a woman-the first of her race to be discovered in France. Neanderthal women, we shall see, have also been found 
elsewhere-in Croatia. Probably, too, the Gibraltar skull is that of a woman. We are familiar with the sexual differences which distinguish the average modern man from the average woman. Our knowledge is founded on the study of hundreds of individuals. When a totally new form of mankind is discovered, we cannot foretell the manner or the degree of sexual differentiation. Hence

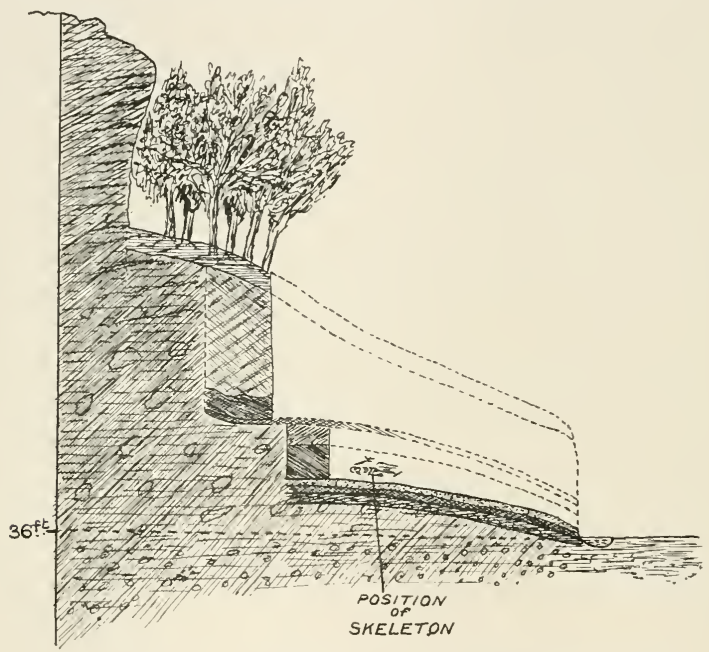

F1G. 42.-Section of the strata at La Quina, the strata removed during excavations being represented by stippled lines (Dr Henri Martin).

the uncertainty as regards the sex of the individual represented by the La Quina skeleton. The skull is long, $202 \mathrm{~mm}$; rather narrow in comparison with the length, I37 mm., giving a head index of $67 .{ }^{1}$ The eyebrow ridges are as greatly and prominently developed as in male skulls, and such is not the case in skulls of modern women. The jaws of the La Quina woman are strong and the teeth big. The bones of the vault of the

${ }^{1}$ For a full account of the La Quina skeleton and its discovery, see account by Dr Henri Martin, Revue Scientifique, 1912, p. 49. 
skull are about $5 \mathrm{~mm}$. in thickness, the same as in modern skulls of average thickness, whereas in the skulls of Neanderthal men in particular and Palæolithic men in general, the vault has a thickness of 8 or $10 \mathrm{~mm}$. The brain capacity of the skull is estimated by Professor Anthony ${ }^{1}$ at 1350 c.c., about the same as for modern women, but 250 c.c. less than the capacity of the $\mathrm{La}$ Chapelle man's skull. The stature is calculated to have been I. 500 m., about 5 feet.

The four years between I907 and I9I I witnessed a remarkable series of discoveries of Neanderthal man in France. All of them belonged to the Mousterian period. Before 1907, several important finds had also been made in France. In I 889, a lower jaw was discovered in the cave of Malarnaud, in the famous department of Ariège, at the foot of the Pyrenees. In I895, in a cave some distance to the west, at Isturitz (Basses-Pyrénées), M. l'Abbé Breuil discovered the lower jaw of an individual of the Neanderthal race. In the same year as the Malarnaud specimen was discovered, M. Piette, who explored the Mas d'Azil deposits, found certain fragmentary bones of the face in a cave near Gourdan, in the valley of the Cean, a southern tributary of the Dordogne.

The list for France is complete when the discovery of three fragments of jaws by M. Favraud, in a Mousterian stratum in the department of Charente, is mentioned.

1 The brain is fully described by Professor Anthony. See reference, p. 407. 


\section{CHAPTER VII}

THE DISTRIBUTION OF NEANDERTHAL MAN IN EUROPE

IN the light of those recent discoveries of Neanderthal man in Mousterian strata of South-Western France, we may now proceed to give a brief review of similar finds made in other parts of Europe. Taking Spain first, there is only one discovery to note, but it is an important one. Recent correspondence proved that the skull found at Gibraltar in I 848 was the very first recorded discovery of the remains of Neanderthal man. ${ }^{1}$ Colonel Kenyon, Commandant of the Royal Engineers at Gibraltar in I910, found the following entry in the Minutes of the Gibraltar Scientific Society, dated March 3rd, 1848 :"Presented a Human Skull from Forbes Quarry, North Front, by the Secretary." The secretary then was Lieutenant Flint of the Royal Artillery. The skull was brought to England by Mr George Busk in I862, and presented by him, in I 868, to the museum of the Royal College of Surgeons, England, where it is now preserved. The subsequent history of this specimen is instructive. Exhibited at scientific meetings in England and France, examined by Huxley, Broca, Busk, Falconer, who proposed the name of Homo calficus (from Calphe, the ancient name for Gibraltar), ${ }^{2}$ the place of this skull among the records of ancient man did not become apparent until the twentieth century was well begun. ${ }^{3}$ Dr Gustav Schwalbe, the veteran Professor of Anatomy in the University of

1 See Nature, I9I I, vol. Ixxxvii. p. 3 I 3.

2 Ibid., p. 3 I 4.

3 For a full description of the Gibraltar skull, see Professor Sollas's account, Phil. Trans., 1908, ser. B, vol. cxcix. pp. 281-339. 
Strassburg, had by then established the separate identity of the Neanderthal race. ${ }^{1}$ Anthropologists gradually came to see that the Gibraltar skull-hitherto so obscure in its nature-was only a variant of the Neanderthal type. Further inquiries were made into its history. In I 9 IO, Dr W. H. L. Duckworth ${ }^{2}$ of Cambridge University explored the site of Forbes Quarry from which the skull came. He found the quarry was situated under the northern face of the famous rock-on the side looking across the flat tongue of land which joins the rock to Spain. Even in 1910-sixty-two years after the discovery of the skull-there could still be seen the remains of a cave in the limestone cliffs of the quarry. The operations carried out by the quarrymen also exposed a section across the débris of chips and blocks which had been detached from the face of the cliff and gathered at its foot as a cemented mass or breccia. In the floor of the cave Dr Duckworth found alternate layers of stalagmite and sea-sand, which had to be explored by blasting, so strong a cement did the compound form on the floor. He found neither fossils nor implements there. In other caves, however, he did make an important discovery-namely, flints worked in the Mousterian manner. It was clear the rock had been inhabited in Mousterian times. The Gibraltar skull itself carries evidence of having come from the floor of such a cave as Dr Duckworth saw at Forbes Quarry: the nose and orbits are still choked with a mixture of sand, limestone, and cement, similar to the material in the floor of the cave. In the cemented matter on the skull there still remain shell fragments. After sixty-two years of investigation we are now in a position to assign this remarkable document - the Gibraltar skull-to its approximate place in time. All the skulls of the Neanderthal type have come from deposits of Mousterian age ; we may allocate the Gibraltar

1 See Verhand. der anat. Gesellsch., 1901, p. 44; also see reference, p. 157.

"Journ. Roy. Anthrop. Institute, I9I I, vol. xli. p. 350 ; "An Account of a Second Visit," ibid., I912, vol. xlii. p. 515. 
individual to that period now with some degree of certainty.

In spite of the numerous discoveries which have added to our knowledge of Neanderthal man, the Gibraltar skull still holds a unique place. In no other specimen is the base of the skull preserved. The base of the Gibraltar skull is remarkably straight and simian in its conformation (fig. 54). ${ }^{1} \quad$ The face, too, is less broken than in any other specimen (fig. $4^{6}$ ). The nose is most capacious, and reminiscent, in the region of the face surrounding the nose, of the condition seen in the skulls of gorillas. Yet the upper jaw is not projecting or simian; the face is not prognathous. The lower jaw, unfortunately, was never found, and a part is missing from the vault of the skull, leaving some doubt as to the exact size of the brain. On a former occasion I estimated the capacity by measuring the more intact half of the skull with millet seed, and found the brain space to be just under I Ioo c.c. ${ }^{2}$ At a subsequent date a brain cast was made of plaster ; the cast displaces I I 50 c.c. of water. The cast is too flat on the vault, and hence a little must be added-perhaps 50 c.c.-making the brain size about I 200 c.c. Professor Sollas and Professor Boule give slightly higher estimates - the former giving 1260 c.c., the latter 1296 c.c. The brain is smaller than that of any other Neanderthal individual so far discovered. The La Quina specimen makes the nearest approach, with a capacity of I 367 c.c. Very probably, as Professor Sollas has supposed, the small brain may indicate that the skull is that of a woman. We shall return to some of the most peculiar features of the Gibraltar skull in another chapter. ${ }^{3}$ The fact which we note at present is this, that, whether of the Mousterian date or of an earlier one, we have in this specimen the most definite evidence that the Neanderthal type of man, like men of the modern type, was divided into races, the

1 See the investigations of Professor G. L. Sera, Archivio per l'Antropologia, 1909, vol. xxxix. pp. 5-66.

2 See Ancient Types of Man, I91 1, Harper Brothers; also Nature, 1910, vol. Ixxxiii. p. 88 .

3 See p. 156. 
Gibraltar race differing very materially from its alliesperhaps contemporaries-in Central and Southern France. As we look into the world of ancient man, the problems of human origin become more complex, and their solution more intricate and difficult. The world of ancient man was apparently more complex than the highly variegated one of modern times.

In this cursory survey of Europe in search of the discoveries of Neanderthal man, we pass from Spain to Jersey. An elevation of 60 feet would unite Jersey to the west coast of Normandy by dry land-a union which has been made and broken many a time even in recent geological history. At St Brelade's Bay, on the south coast of Jersey, granite cliffs rise to a height of 200 or 300 feet. In a cleft on their face opens La Cotte de St Brelade-a cavern excavated by the sea when the waves beat against the coast, 60 feet above their present level. Until igio the cave was buried beneath a mass of rubble, 30 feet deep. The chance discovery of a flint implement on the beach below the site of the cave led to its exploration by the Société Jersiaise. Dr R. R. Marett of Oxford University has published a full and "clear account of the discoveries at St Brelade. ${ }^{1}$ In the deeper strata of the cave, representing ancient floors, remains of hearths were discovered. The prehistoric strata of the floor yielded an abundance of flint implements worked in the typical Mousterian manner. Remains of the woolly rhinoceros, the reindeer, a species of horse and of ancient ox, revealed the sources from which the ancient cave men drew their food supply. Near one of the hearths twelve human teeth were found, all of them parts of a single set, and all of them showing those peculiar features which stamp and distinguish the teeth of Neanderthal man. ${ }^{2}$

1 See Archcologia, I9I I, vol. lxii. p. 449 ; vol. lxiii. p. 203. Also E. T. Nicolle and J. Sinel, Man, Dec. 1910, p. 185. Bullet. Socicté Jersiaise, 1912 , vol. xxxvii. p. 213.

2 See account of the teeth by Keith and Knowles, Journ. of finut. and Physiol., 191 i, vol. xlvi. p. 2. Also Bullet. Soc. Jersiaise, 1912, vol. xxxvii. p. 223. The characters of Neanderthal tecth are again mentioned at p. 147 of this book. 
The evidence from Jersey is thus in harmony with that obtained from the caves in France-the Europeans of the Mousterian period were people of the Neanderthal type. Further, we see that this peculiar human species reached the western seaboard of the Continent ${ }^{1}$ in Mousterian times.

From Jersey we proceed to Belgium, where some most important discoveries of Neanderthal man have been made. In the Royal Natural History Museum at Brussels is preserved the famous specimen known as the Naulette mandible. Only the region of the chin and the left part of the body of the jaw remain-enough to tell us that it is from the face of a woman of the Neanderthal race. All the teeth had dropped from their sockets after death. The region of the chin and the tooth sockets show those peculiar features which mark the Neanderthal species of man. The Trou de Naulette, in which this specimen was discovered in I 866, is one of a series of great limestone caves visited by the modern tourist as he passes up the valley of the Lesse, on his way to the Ardennes, in the eastern part of Belgium. Its exploration belongs to the early period, I 865-I 866, and was carried out by M. Edouard Dupont, aided by a grant from the Belgian Government. The strata on the floor reached a great depth; the actual stratum in which the mandible was found lay i 4 feet $(4.50 \mathrm{~m}$.) below the present surface. Remains of the mammoth, rhinoceros, bear, and reindeer occurred in the same horizon, and with them were found worked implements of the Mousterian culture. The Naulette jaw, like the Gibraltar skull, had to wait until the beginning of the twentieth century for its real nature to be recognised.

Twenty years later than the exploration of the Naulette cave a party of explorers from the University of LiégeMarcel de Puydt, Julien Fraipont, and Max Lohestmade a discovery of the highest importance. The Lesse,

1 For a general account, see Prehistoric Man in the Channel Islands, by J. Sinel, I914. Another Jersey cave of Mousterian date is mentioned by Mr Sinel. 
on which the Naulette cave is situated, joins the Meuse at Dinant; fifteen miles further down (northwards) is the busy town of Namur ; thirty miles beyond Namur, Liége. The little valley in which the party from Liége made their famous discovery ${ }^{1}$ lies about eight miles to the east of Namur. On the eastern side of the valley is a limestone cliff sheltering a cave-the "grotte de Spy." A terrace in front of the cave slopes down to the little stream which flows southwards along the valley. The skeletons of two men of the Neanderthal species were exposed in the terrace at a depth of I4 feet. Strata representing three different periods of ancient human occupation were passed through. The bodies lay on the hearths of the third stratum, a layer only 6 inches thick. Lately, Dr Rutot ${ }^{2}$ has again examined the evidence relating to the antiquity of that stratum, and from the remains of the extinct animals, the workmanship of the flints, and also a piece of bone used as a human tool, concludes that the skeletons are of the same date as the men found at Le Moustier, La Chapelle, and at La Quina, with this difference, that, in his opinion, the culture accompanying all of them, including the men of Spy, should be assigned not to the end of the Mousterian, but to the beginning of the Aurignacian age. These Spy men were typical representatives of the Neanderthal species, with large, robust skulls, holding brains which, in point of size, were above the average of the modern European.

From Belgium we pass northwards to Germany. To reach the lower valley of the Rhine, where we propose to begin a survey of the discoveries of men of the Mousterian period in Germany, we may follow the Meuse northwards, or, as will suit our purpose better, pass directly to Düsseldorf, situated some sixty miles to the north-east of Liége. In the valley of the Düssel, which joins the Rhine at Düsseldorf, is situated the

1 "Le race humaine de Néanderthal," par Julien Fraipont et Max Lohest, Archives de Biologie, 1887, vol. vii. p. 587.

2 "La position réelle des squellettes de Spy," Bullet. Sociilí b’elge de" Géologie, 1909, vol. xxiii. p. 235. 
celebrated Neanderthal cave. This northern tributary of the Rhine, after passing Elberfeld, and some distance above its termination, enters a deep ravine, with a limestone cliff on one side-the left or south side-rising to a height of 160 feet. At the time of the discovery, the early spring of 1857 , the Neanderthal cave opened on the face of this limestone cliff, 60 feet above the level of the Düssel and roo feet below the neighbouring plateau (fig. 43). By good fortune a physician in the adjacent town of Elberfeld, Dr Fuhlrott, was interested in fossil remains and in cave exploration, and kept a

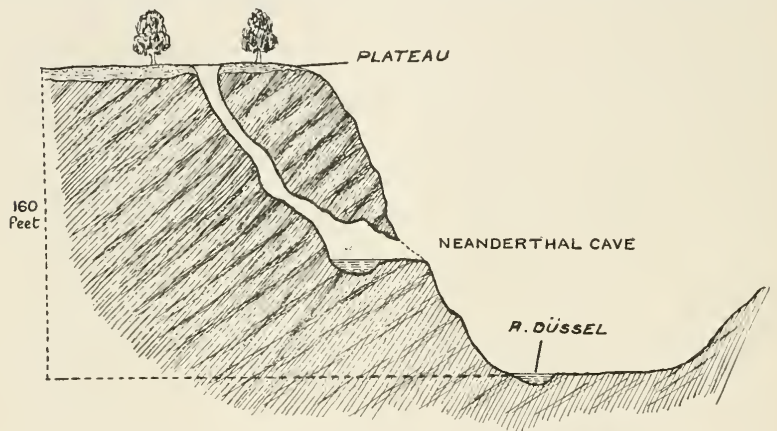

FIG. 43. - Lyell's diagram of the Neanderthal cave.

watch on a party of workmen who were quarrying near the cave. When the cave was cleared out, Dr Fuhlrott secured from the workmen certain remarkable bones, which at first he did not believe to be those of a human being. They lay at a depth of 4 or 5 feet in the loam filling the floor of the cave. Dr Fuhlrott afterwards dispatched the various parts of the skeleton-the vault of a skull, right and left thigh bones, and right and left humerus (the left was imperfect), fragments of the pelvis, shoulder blade, and of ribs-to Professor Schaaffhausen of Bonn, an expert anatomist. Nothing was found in the cave or observed afterwards which gave a clue to the antiquity of the Neanderthal skeleton; no remains 
of extinct animals were discovered. No implements were seen or found, for at that time (1857) the various cultural phases of the Palæolithic period had not been recognised. Professor Schaaffhausen had no doubt as to the antiquity or humanity of the cave-bones from Neanderthal. In $185^{8,}{ }^{1}$ he published an excellent description of them, in which the following passage occurs : "Whether the cavern in which they were found, unaccompanied with any trace of human art, was the place of their interment, or whether, like the bones of extinct animals elsewhere, they had been washed into it, they may still be regarded as the most ancient memorial of the early inhabitants of Europe."

Now that we are fairly certain as to Neanderthal man's place in time and his relationship to other human races, it is interesting to survey the original and classical discovery as it appeared to a contemporary spectator-keenly interested in the problem of man's antiquity-Sir Charles Lyell." "I visited the spot in 1860," he writes, "in company with Dr Fuhlrott, who had the kindness to come expressly from Elberfeld to be my guide, and who brought with him the original fossil skull, and a cast of the same, which he presented to me. ${ }^{3}$ From a printed letter of Dr Fuhlrott we learn that, on removing the loam, which was 5 feet thick, from the cave, the human skull was first noticed near the entrance, and further on the other bones lying in the same horizontal plane. It is supposed that the skeleton was complete, but the workmen, ignorant of its value, scattered and lost most of the bones, preserving only the larger ones. ... On the whole, I think it probable that this fossil skull may be of about the same age as that found by Dr Schmerling in the Liége cavern; but, as no other animal remains were found with it, there is no proof that it may not be newer. Its position lends no countenance whatever to the

1 See translation of paper by Geo. Busk, Natural History Review, 186i, vol. i. p. 283 . The original is in Müller's Archives, 1858, p. 453.

Antiquity of Man, 1863 , p. 76.

3 Now in the museum of the Royal College of Surgeons, England. 
supposition of its being more ancient. . . When, on my return to England, I showed the cast of the cranium to Professor Huxley, he remarked at once that it was the most ape-like skull he had ever beheld."

To Sir Charles Lyell the discovery of the skeleton was an isolated and puzzling event. He never guessed it was the first representative of a distinct race inhabiting Europe during a definite part of the Pleistocene period. We see, too, how narrowly the Neanderthal remains escaped destruction at the hands of the workmen, and how Huxley became interested in fossil man through Sir Charles Lyell. Huxley's contribution to our knowledge of Neanderthal man ${ }^{1}$ is certainly one of the most complete and incisive analyses ever made of this peculiar fossil man. His final judgment was to the effect that, ape-like as many of the characters of the skull were, Neanderthal man was merely an extreme variant of the modern type of man, not a separate species or type. A contemporary of Huxley's, Dr William King, Professor of Anatomy in a remote college-Queen's College, Galway, Irelandreached an opposite conclusion $;^{2}$ but his quietly worded verdict was rendered ineffective partly by the vigour and emphasis of Huxley's statement, and partly because at that period men were not prepared for a prehistoric world peopled by different species and different genera of mankind. "So closely," Professor King wrote, "does the fossil cranium resemble that of the chimpanzee as to lead one to doubt the propriety of generically placing it with man. . . ." He was inclined to regard the Neanderthal remains as representing not a new species, but a new genus of mankind. He was content, seeing that only the vault of the skull was known, to create a new species-Homo neanderthalensis - for the reception of the new species of man discovered by Dr Fuhlrott at Neanderthal. Professor King did not know, however,

1 Man's Place in Nature, 1863. See also Natural History Review, I 864 , vol. iv. p. 429 .

2 "The Reputed Fossil Man of the Neanderthal," Quart. Journ. of Science, I 864 , vol. i. p. 88 . 
what we are now well aware of, that Neanderthal man had a large and complex human brain, that he was a skilful artisan, that he buried his dead and had certain beliefs regarding death. If he had known those things he would not have written : "The Neanderthal skull is so eminently simian . . I am constrained to believe that the thoughts and desires which once dwelt within it never soared beyond those of the brute." Professor King was not prepared to believe that a human brain might be wrapped in an ape-like skull, nor that human civilisation was so old that since its dawn mankind had lived long enough to actually become separated, not into distinct races, as we see in the world to-day, but into distinct species, of which apparently Neanderthal man represents merely one, while all the modern races of mankind represent a second.

The discovery of the Spy men in I 886, so similar in all their characters to the prototype found at Neanderthal, dissipated the idea which was held by many anatomists that the peculiar characters of the Neanderthal cave bones were due to the chance incidence of disease or to a disordered form of growth. It took sixty years to show that King was right and Huxley wrong. The researches of Professor Schwalbe, of Professor Klaatsch, and, more recently, of Professor Boule, have firmly established King's verdict-that Neanderthal man represents a separate species. Nor can we doubt, from what has been discovered in recent years, that the remains discovered in the Neanderthal cave belong to the Mousterian period. A cave in the same locality yielded the remains of the extinct kinds of animals which are usually associated with implements of the Mousterian culture.

When it is remembered that the classical discovery of Neanderthal man was made in Germany, it is surprising that so few traces of him have been found in that country during the intervening half-century. At Taubach, near Weimar, a hundred and seventy miles to the east of Düsseldorf, there is a deep deposit of the Pleistocene period, varying in thickness from 20 to 30 feet. The 
deposits were apparently laid down on the bottom or on the beach of an ancient inland lake. A primitive race of men seem to have lived on the shores of the lake. At least the flints they shaped are found abundantly in a stratum-probably an old land surface-i 8 feet below the present soil. In the same stratum occur the remains of a fauna which seems older than that of the Mousterian period, for the rhinoceros $(R$. Mercki) and the elephant (E. antiquus) are not the forms we expect to find with Neanderthal man. The implements, however, have been adjudged by many experts to belong to the period of the Mousterian culture; by others they are assigned to other dates-more ancient and also more recent. ${ }^{2}$ Two human teeth were discovered at this cultural level (see fig. 50, p. I47); a description of them was published in I 895 by Dr Nehring. ${ }^{2}$ These teeth, although they do not show the typical Neanderthal characters, may very well have belonged to an individual of this race. ${ }^{3}$

The further discoveries of Neanderthal man in Europe need only a brief mention. In Moravia, within the northern outskirts of the watershed of the Danube, two discoveries have been made of Neanderthal man. In both cases only fragments of the lower jaw were found. They were found in the floor strata of a cave-one at Schipka and another at Ochos in 1906. The remaining discovery requiring our attention-one of the very first magnitude - takes us to the Hungarian province of Croatia, stretching westwards to the Adriatic. We owe the discovery to Professor Gorjanovic-Kramberger, a Professor in the University of Agram. In I 899, he commenced the exploration of a deposit, situated on a terrace on the side of a valley near the little town of Krapina, and through which the Krapinica flows-an early feeder of the Save. The section of the deposits exposed in his investigations is shown in fig. 44 . He

${ }^{1}$ See Aus dem Werdegang der Menschheit, Dr H. von ButtelReepen, Jena, I9I3.

'Zeitschrift fuir Ethnologie, 1895 , vol. xxvii. p. 338.

${ }^{3}$ See Prehistoric Man, by W. L. H. Ducisworth, Cambridge, 1913. P. Adloff, Deutsch. Monatsschrift für Zahnhcilk., I9I I, Heft ii. p. 804. 
began his work at the end of 1899 , and in 1906 was in a position to publish a splendid monograph embodying his observations and conclusions. As will be seen from fig. 44, the deposits he explored on the side of the valley, $2+$ feet in depth, represent the accumulations on the floor of a rock-shelter which had been occupied by ancient man. On the original floor of the shelter lay a

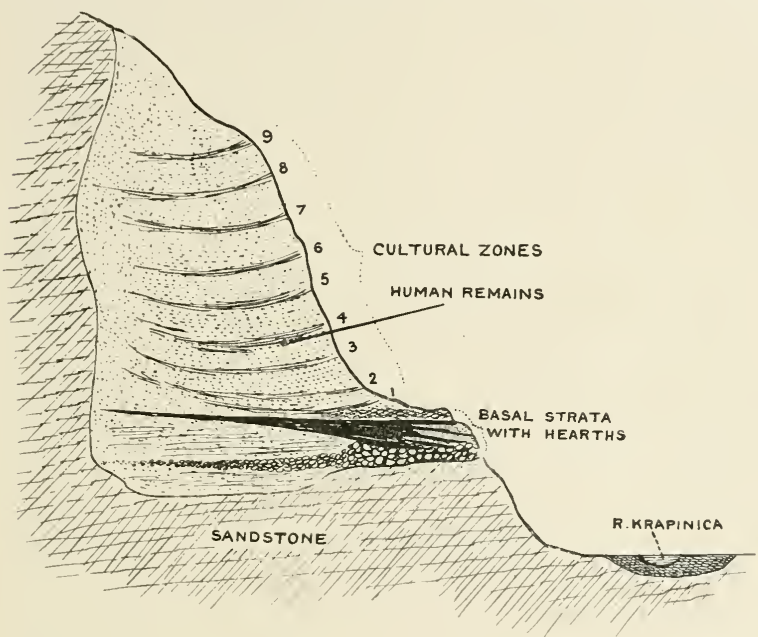

FIG. 44.-Section of the deposits in the rock-shelter at:Krapina:(Kramberger). The numbers $\mathrm{I}$ to 9 indicate the deposits formed during periuds of human habitation.

bed of gravel deposited when the Krapinica flowed flush with the floor of the cave- 80 feet above its present level. The superimposed strata, showing nine different horizons marked by human occupation-hearths, tools, and débris of meals-proved to be the richest treasury of the Neanderthal race ever opened by the explorer's spade. Over two hundred fragments of human skeletons were found, representing at least ten individuals of all ages and both sexes. One hundred upper and one hundred and 
twenty lower human teeth were collected, all of them showing, in a varying degree, the characteristic form we now associate with the Neanderthal race. Over two thousand fragments of bones of the animals of the period were found, including those of the same ancient form of rhinoceros as occurred at Taubach (R. Mercki). The cave-bear occurred abundantly; it was evidently a favourite article of diet. The rhinoceros bones had been broken open to extract the marrow. The mammoth and many other ancient and modern animals were also represented. Some of the human bones were charred, and some had been apparently split open: on that slender basis the Krapina men have been suspected of cannibalism. The implements, like those at Taubach, are not of the typical Mousterian forms, but experts ascribe them to the culture of that period. Some evidence, as at La Quina, was noted of bone having been shaped for use as a tool; perhaps wood was also worked. Krapina provided, for the first time, an opportunity of studying the children and the youth of this strange species of man. As is well known, there is a close superficial resemblance between the skulls of man and anthropoid ape during infancy and childhood. The brutal and distinguishing features appear on the ape's skull during the years of growth; the human skull during that period changes to a less degree. Hence it is not surprising to observe that the children at Krapina were in form of head and face more like men of the modern type than is the case with their parents. The great simian eyebrow ridges assume their massive size and characteristic Neanderthal form at maturity. The skulls of the women retain the cranial features of the young to a greater degree than is the case with the male sex. Hence the Neanderthal women were less distinctly marked off from the modern type of mankind than was the case with the men. Indeed, to account for the variety of forms found at Krapina, Professor Klaatsch has suggested that some of the individuals may represent captives which Neanderthal people had made from their enemies 
- the contemporary representatives of Homo sapiens. Professor Kramberger is of opinion that, amongst the individuals he discovered, there are some which bridge the gap between these two types of man-the Neanderthal and the modern. The writer has observed no fact which supports such an opinion; the closer the records from Krapina are studied, the more one becomes convinced that there are no intermediate or hybrid individuals represented. The skulls are fragmentary; not one is complete. Yet they are sufficiently perfect to show that they carry all the marks of the Neanderthal race. Further, as we saw from the Gibraltar skull, those Krapina people give us the most certain assurance that the Neanderthal species of man, like the modern species (Homo sapiens), was separated into distinct races. The Krapina and Gibraltar races differed from their contemporaries in France and Belgium. As in modern races, there were, in the Neanderthal species, both long-headed and the round-headed races. The skull from the Neanderthal cave is a sample of the long-headed race; those of the Krapina people represent a short-headed variety; the Gibraltar skull belongs to an intermediate group.

Thus we see that, in the Mousterian period, in the middle Pleistocene age, when the middle or 50 -foot terrace was being laid down in the Thames valley, Europe was inhabited by a peculiar race of mankindof quite a different type from the races which now populate it. This race spread from Gibraltar in the South to Weimar in the North, from Croatia in the East to Jersey in the West. The culture of this period has been found both in Italy and in England. In neither of these countries, however, has any fossil trace of Neanderthal man been found so far. The future may make good that blank, for we see no reason why he should not have occupied both of these countries as well as Central Europe. The most marvellous aspect of the problem raised by the recognition of Neanderthal man as a distinct type is his apparently sudden disappearance. He is 
replaced, with the dawn of the Aurignacian period, by men of the same type as now occupy Europe. What happened at the end of the Mousterian period we can only guess, but those who observe the fate of the aboriginal races of America and of Australia will have no difficulty in accounting for the disappearance of Homo neanderthalensis. A more virile form extinguished him. He suddenly appears in Europe-from whence, future investigations may disclose; the one thing we are now certain of is that he was not suddenly converted into the modern type of man. 


\section{CHAPTER VIII}

THE ANATOMICAL PECULIARITIES OF NEANDERTHAL MAN

IN the two preceding chapters attention has been concentrated on the various sites and dates at which the remains of Neanderthal man have been found, and on the varying place which has been assigned to him by anthropologists. We have seen him regarded as the product of disease, of Nature in a freakish mood, as an ancestral form of man, representing the stage mankind passed through during the Pleistocene period, as an extreme variant of modern man which had retained an undue proportion of simian or ape-like characteristics. Then we reached our present concept of him as a separate and peculiar species of man, which died out during, or soon after, the Mousterian period. All the time we have been talking round him, as it were, never attempting to lay bare or analyse those features which mark him off from all the modern races and varieties of mankind, and give him, in the eye of the anthropologist, an altogether novel and peculiar position.

To make the structural differences between the Neanderthal and modern species of mankind clear we cannot do better than select those two Pleistocene skulls found in the region of the Dordogne-the one at Combe Capelle representing the modern type, and the other from La Chapelle-aux-Saints, the Neanderthal type. In the instances chosen, the Neanderthal is the larger in all dimensions, save one. It is the more capacious, having the larger brain capacity; it is longer and wider, but it is not so high; its vault is peculiarly low. The 
depression of the vault is even more marked when the Combe Capelle skull is set side by side with the one
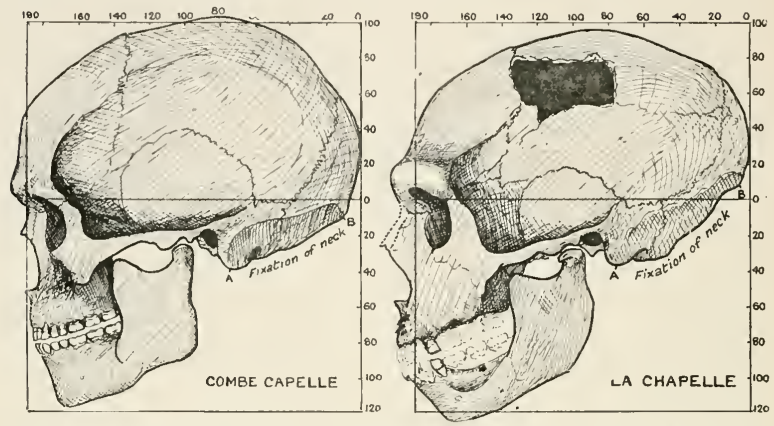

Fig. 45. - Skulls of the modern type (Combe Capelle) and of the Neanderthal type ( $\mathrm{La}$ Chapelle) contrasted on their lateral aspects.

from Gibraltar. The first rises above the upper limit in the conventional linear frame; the second falls far short
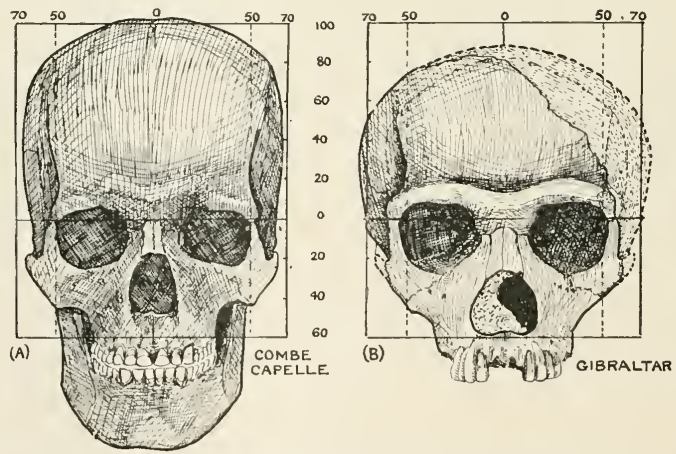

FIG. 46. - A skull of the modern type (Combe Capelle) contrasted with the Neanderthal type (Gibraltar) as seen in full face.

(fig. 46). The Neanderthal skull gives us the impression of being compressed from above downwards into 
a bun-like form; the modern skull is flattened in an opposite direction, from side to side. All Neanderthal skulls show this peculiarly depressed platycephalic form-especially apparent in the hinder or occipital region-a feature which must have given Neanderthal man in life the peculiar appearance of having the hinder part of his head buried, apparently, in a thick, bull-like neck (see fig. 53). It is true that in certain modern varieties of mankind-as in a strain which still occurs in Holland, in England, and has been also found in ancient graves in America ${ }^{1}$ - the skull is low-domed or platycephalic, but the resemblance to the Neanderthal type is only superficial. To find a counterpart of the platycephalism of Neanderthal skulls we have to go outside the limits of human species to the skulls of such anthropoids as the gorilla and chimpanzee. The functional meaning of this peculiar form of skull, found in anthropoid and in the Neanderthal species of man, will be discussed at a later stage in this chapter (see p. I 57). Meantime we simply note the fact that the general form of the brain is modified to suit the skull in which that brain is contained. Hence, although the brain of Neanderthal man equals or exceeds that of the modern type of man in point of size, yet in its general conformation it resembles the brain casts taken from anthropoid skulls.

The kind of skull, just described, reveals a radical difference in head-formation, and can be readily recognised in a museum or laboratory. But let us suppose we are back in the world of Pleistocene man and are brought face to face with Neanderthal man in life-which of his features would force themselves on our attention as distinctive marks? The colour of the skin, the texture of the hair, the cast of countenance, the play of eye and lips which distinguish at a glance the better-marked varieties of modern mankind-the African, the Mongolian, the European-are not available, for we have only, as regards fossil forms of man, the limited range of characters

1 See reference, p. 273. 
revealed by the dry bones of the face and limbs. We feel assured, however, that certain features of the face would have at once struck us as totally different from the corresponding features in all varieties of modern man. To find eyebrow ridges like those of Neanderthal man,

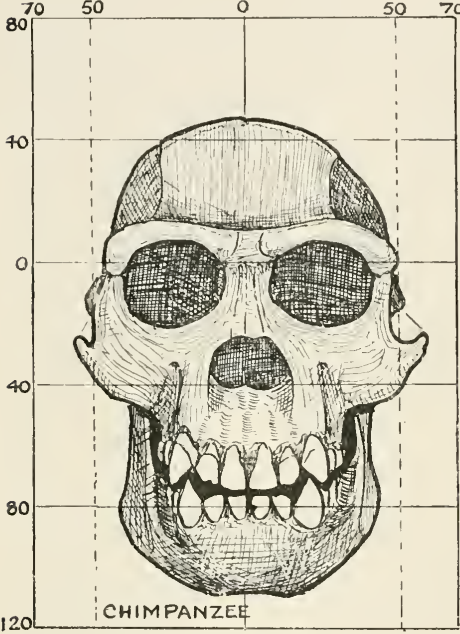

(])
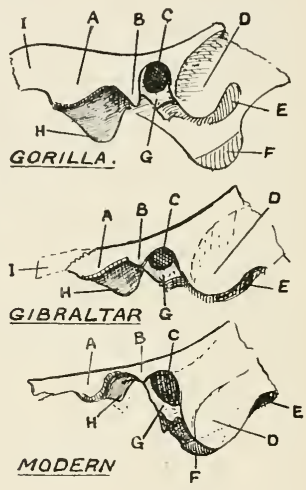

(II)

FIG. 47.-I. The supra-orbital ridge or torus and other teatures of the face of a male chimpanzee. II. The form of articular cavity for the lower jaw in the Gibraltar skull, contrasted with the forms in the gorilla and modern man.
A. Articular eminence.
B. Post-glenoid spine.
C. Meatus of ear.
D. Mastoid process.

E. Digastric fossa.

F. Occipital condyle.

G. Tympanic plate.

H. Mesial part of articular eninence.

great continuous horizontal bars of bone, overshadowing the orbits - a supra-orbital torus - we have again to refer to the anthropoid skull. In the skull of the chimpanzee (fig. 47) and of the gorilla we see the same development of the forehead and supra-orbital region. In modern races the supra-orbital ridges vary enormously 
in form and in degree, but they never assume the anthropoid or Neanderthal form. Their usual development is that shown in fig. +6 (Combe Capelle). The supra-nasal or middle parts of the ridge are quite distinguishable from the lateral or temporal parts. No doubt they tend to become less developed in civilised races. There is also no doubt that the supra-orbital ridge or torus is part of that bony scaffolding erected on the face and skull to serve the purposes of mastication. The outer or temporal projections of the supra-orbital ridge give attachment to two of the chief muscles of masticationthe right and left temporal muscles. The upper jaw sends upwards, between the eyes, supporting processes to transmit strains from the palate to the supra-orbital bar (see fig. 46). On the outer side of each orbit, the cheek or malar bone also reaches up to the supra-orbital bar, transferring to it the strains and stresses caused by other muscles of mastication - the masseters-which rise from the cheek bones and from the zygomatic arches. A fuller knowledge of the mechanism of mastication is likely to throw light on the nature of the various shapes and types assumed by the supra-orbital ridges. Meantime we simply note the fact that Neanderthal man had eyebrow ridges of the anthropoid type.

We have just seen that in general form of cranial cavity and of supra-orbital ridges, Neanderthal man resembles anthropoid apes, while, in these features, the modern type of man differs from them. Are we, then, to conclude that Neanderthal man is directly related to, is a direct descendant of, an anthropoid form, while modern man is not? I do not think so. We must take into account the condition of the supra-orbital ridges in all anthropoid apes. In the Malayan orang, which is a distant cousin to the African anthropoids-the gorilla and chimpanzeethe supra-orbital ridges do not form a prominent torus. When the outlines of the skull of a chimpanzee and orang are superimposed, as in fig. 48 , some light is thrown on the cause of their great development in the former and slight size in the latter. In the orang the face is 
turned more upwards, and holds such a relationship to the whole skull that the strains and stresses arising during mastication are transmitted, not to the forehead, as in the chimpanzee, but to the skull as a whole. There is no need in the orang for a frontal scaffolding of bone. The retrogression of the supra-orbital ridges in the orang is apparently secondary. The gorilla and chimpanzee appear to retain the original form - the form found in the oldest and most primitive of anthropoid apes, the gibbon. On the other hand, the divided or bipartite condition of

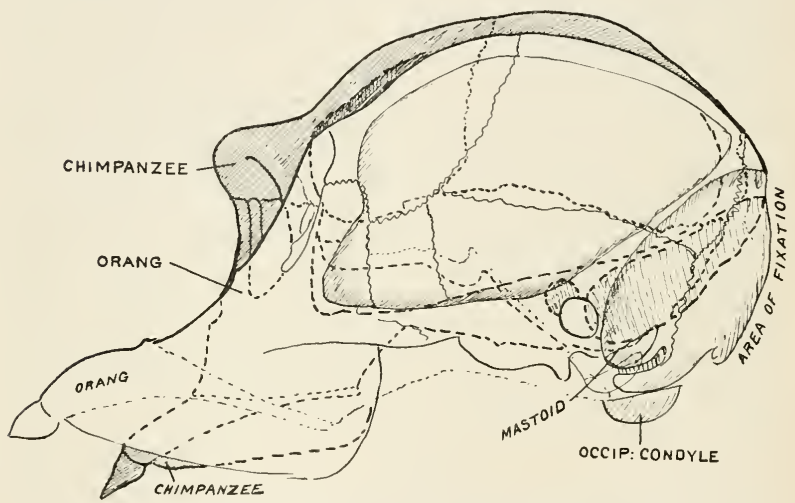

FIG. 48. - The skull of an orang superimposed on that of a chimpanzee to show the presence of a torus supra-orbitalis in the latter.

the supra-orbital ridge seen in modern human races (fig. 46) is also met with amongst old-world monkeys. ${ }^{1}$ If we suppose that the old-world monkeys are still more ancient and primitive than the anthropoids, then it might be argued that it is modern man that has retained the primitive or original form of supra-orbital ridge, and that the torus shape, seen in the gorilla, chimpanzee, and Neanderthal man, has been evolved at a more recent date.

I am discussing at some length the development of the

${ }^{1}$ D. J. Cunningham, "The Evolution of the Eyebrow Region of the Forehead," Trans. Roy. Soc. Edin., I 908, vol. xlvi. p. 283 
supra-orbital ridges, because we could not cite a better instance of the kind of evidence we have to use in tracing the genealogy of man. We might explain the presence of a torus form of supra-orbital ridge in Neanderthal man by supposing he has arisen from a gorilla-like stock, and modern man from a monkey-like ancestry. That would explain why modern man has a forehead of one form and Neanderthal man one of quite another type. We should thus fall back, as Professor Klaatsch ${ }^{1}$ has done, on the theory that mankind is multiple in originthat one human race has been evolved from one ancient stock of primates, while another race has arisen from another and quite different simian stock. But in successfully explaining this one and minor feature we should find, if we accept a "polyphyletic theory" of man's origin, that the great majority of structural relationships were not capable of being thus explained. We must take all the characters of the human body into consideration, not one or more isolated features, and when we do so it is plain that the Neanderthal type and the modern type of man share the great common inheritance of human characters. We must suppose that this community of structure is due to a community of origin-to the fact that they arise from a common ancestor. Further, when we begin to analyse the structural nature of man and his nearest allies-the gorilla, chimpanzee, and orang-we find he shares so much with them, much more than with old-world or new-world monkeys, that, to explain the widespread community of structure, we are compelled to suppose the great anthropoids and all human forms, living and fossil, to have arisen from a common stock. Now in that common stock from which anthropoids and men have been evolved we have reason to believe that the torus form of supra-orbital ridge was a character. In the ancestry of modern races it has been modified. Indeed, in many living peoples there is a tendency to assume the condition seen in fœtal or infantile stages, where those ridges are still undeveloped. In Neanderthal man,

${ }^{1}$ See Nature, ig1 I, vol. Ixxxv. p. 508. 
on the other hand, the torus form of supra-orbital ridge and the platycephalic shape of cranium of the simian ancestor have been retained.

The great majority of those structural features which mark Neanderthal species off from modern races are essentially of a simian or anthropoid nature. For instance, when the circumnasal region of the Neanderthal face is examined (fig. 46) it will be seen to have the inflated or blown-out appearance to be observed in the gorilla or chimpanzee (fig. 47), differing materially from the collapsed or deflated condition seen in the face of the existing or modern types of mankind.

We are surprised to note, however, that one simian feature is absent from the nasal region of the Neanderthal skull. In the chimpanzee's skull (fig. 47) the lateral margins of the nose descend towards the teeth, bounding a groove or gutter on the floor of the entrance to the nasal cavity. These nasal grooves or gutters are also present in the skulls of many primitive modern racesan anthropoid or simian condition. The simian nasal gutter is present in the Combe Capelle skull to a slight degree, but not a trace of it is present in the Gibraltar skull. There, as in the most highly evolved of modern skulls, the lateral margins of the nose turn inwards to the nasal spine, forming a sharp lower margin at the entrance to the nose (fig. 46). The simian nasal gutter is a character to be ascribed to the modern type of man rather than to the Neanderthal type, although in the latter it may, as in the specimen from La Chapelle-aux-Saints, have some degree of representation.

From the time of the discovery of the Naulette jaw in I 866 it has been recognised that the Neanderthal species have certain peculiar markings or characters of the chin. In a later chapter (see p. 323) it will be necessary to describe in some detail the exact manner in which certain muscles of the tongue-muscles which play an important rôle in articulate speech-make an attachment to the hinder or lingual aspect of the mandible in the region of the chin and symphysis of the lower jaw. At the present 
point it will be enough to refer the reader to the diagrams given in fig. 49, which represent sections made at the middle line or symphysis of the lower jaw. The first figure represents a vertical section of the chin region of a very young gorilla-under two years of age. The upper or alveolar border, on which the incisor teeth are implanted, projects well in front of the lower border. Strictly speaking, there is no chin-at least no eminence at the lower border. On the hinder aspect of the symphysis (indicated by an arrow in fig. 49) there is a pit-the "genial" pit. From the lower part of this pit arise the two chief muscles of the tongue-the right and

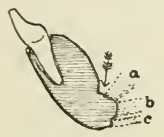

YOUNG GORILLA

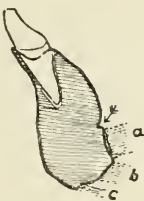

SPY -

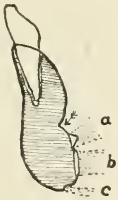

NEW CALEDONIAN.

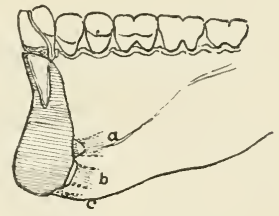

MODERN ENGLISH.

FIG. 49.-Sections of the lower jaw at the middle line or symphysis of a young gorilla, a man of the Neanderthal type (Spy), of a native of New Caledonia, and of a modern Englishman.

$a$, attachment of the genio-glossus muscle; $b$, of the genio-hyoid muscle; $c$, of the digastric muscle. The arrow points to the genial pit.

left genio-glossal muscles ( $a$, fig. 49). Beneath these muscles is a linear impression for another pair of muscles, also concerned in the movements of the tongue, the genio-hyoid muscles $(b)$. Below the linear impression and on the lower border or aspect of the chin region another pair of shallow impressions in the bone mark the attachment of the digastric muscles which can depress the jaw and help to open the mouth (c, fig. +9$)$. The second section in fig. 49 represents the condition of parts in a Neanderthal mandible-one found at Spy. The upper or alveolar border is still the more anterior or projecting; the lower border and the region of the chin recede. There is no chin eminence. On the hinder 
aspect the genial pit is almost filled up, but there is still a remnant to be seen (fig. 49). The muscles of the tongue arise from areas corresponding to those in the gorilla $(a, b, c)$. The next section in fig. 49 shows the region of the chin in a representative of a modern primitive race-a native of New Caledonia, in the Pacific Archipelago. The upper and lower borders of the lower jaw are nearly equally prominent in the anterior or symphyseal region; indeed, the chin eminence is slightly developed. On the posterior aspect of this particular mandible there is a trace of the genial pit-a simian trait ; but there are also present below the pit special minute projections of bone-tubercles or spines from which the special muscles of the tongue arise (see fig. $49, a, b$ ). Those tubercles or spines are absent in mandibles of the Neanderthal type. Lastly, the region of the chin of a man of modern European origin is shown. The lower border is the more prominent; there is here a welldeveloped chin eminence. On the posterior aspect there is no trace of the genial pit ; the genio-glossus muscles (a) arise from two projecting points or spines of bone.

We cannot account satisfactorily for the various structural features exhibited by the series of specimens just described unless we suppose the simian condition to be the older, the ancestral form, and the others-the Neanderthal and the modern-to represent modifications of the simian form. There can be no doubt that, in the region of the chin, Neanderthal man retains a simian condition to a greater extent than does the mandible of the modern type of man. When we seek to explain these changes on a functional or physiological basis we proceed on the belief that these changes have been brought about by the interaction of at least two factors. In the first place, the teeth have become smaller; retrogression in the size of the teeth leads to the front or incisor teeth receding backwards in the mouth, leaving the nose above and the chin below more prominent. Undoubtedly another process has been at work. The lower border of the mandible, in the region of the chin 
as well as in the region of the cheek, bounds the floor of the mouth. In order to secure free movements of the tongue and easy, articulate speech, it is highly advantageous to have the floor of the mouth opened out. In anthropoids the lower border of the mandible encroaches on, and diminishes the area of, the floor of the mouth. In the most highly evolved forms of men the lower border of the mandible is widened or opened out (see fig. I67, p. 449). In Neanderthal man the expansion of the lower border of the mandible is less complete than in men of the modern type.

It is when we come to study the teeth of Neanderthal man that we first obtain a real clue to his position among

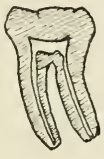

A.

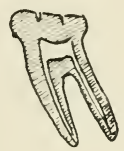

B.

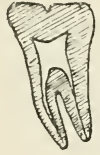

c.

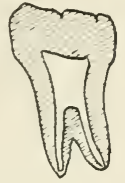

D.

Fig. 50. - Four lower molars, as seen when examined by X-rays.
A. Of a chimpanzee.
C. Of a tooth found at Taubach (Adloff).
B. Of a modern European.
D. Of a Krapina individual.

the ancestral forms of modern man. In 1907, Professor Adloff, then in Königsberg, published a very important series of conclusions he had reached from a study of the teeth found by Professor Kramberger at Krapina. ${ }^{1}$ What he found is shown in a brief and diagrammatic manner in fig. 50. In that figure, A represents the lower molar of a chimpanzee, as seen when examined by X-ray transillumination. The pulp cavity, in the body or crown of the tooth, is small; the fangs, containing extensions of the pulp cavity, as far as their tips, are long. The lower molar of a modern European-a man of the modern type (fig. 50, B)-shows a similar form of pulp

1 "Die Zähne des Homo primigenius von Krapina," Anat. Anz., 1907, vol. xxxi. p. 273. See also Das Gebiss des Menschen und der Anthropomorphen, Berlin, 1908. Also see reference, p. 473. 
cavity and of roots. In Neanderthal man the pulp cavity attained remarkable dimensions (fig. 50, D); the cavity has extended downwards at the expense of the roots, which accordingly become very short. The molar teeth are large in crown and body and exceedingly short in root. In $\mathrm{C}$ (fig. 50) the lower molar found at Taubach (see p. I 3 I) is represented. It has the Neanderthal characters. To this peculiar form of molar tooth which became evolved in Neanderthal man I have proposed the name of "taurodont," because in general form there is a resemblance to the molar teeth of the ox. ${ }^{1}$ To the more primitive form, seen in apes and also in modern types of men, the name "cynodont" is given, because there is a superficial resemblance to the condition found in the molars of the dog. When I first studied Dr Adloff's observations and conclusions I admit that I was not convinced that Neanderthal teeth represented a high degree of specialisation. I was still, as was then the case of many anatomists, under the belief that Neanderthal man represented our Pleistocene ancestral form. Even when I came to study the Neanderthal teeth found at St Brelade in Jersey ${ }^{2}$ I still clung to the hope that the taurodont form of tooth-seen in Neanderthal man-might have reverted to the more primitive or cynodont form during the evolution of modern man from a Neanderthal type. That belief I now see to be untenable, and I admit that in the character of the teeth Neanderthal man has departed widely from the primitive or simian type, while races of the modern type have retained the older or more simian type of molar tooth. In short, with all his primitive or simian features, there are certain structural modifications in which Neanderthal man shows a greater degree of specialisation than men of the modern type do. We saw such a feature in the gutter or groove at the entrance to the nose. The nasal gutter is a

1 See "Problems relating to the Teeth of the Earlier Forms of Prehistoric Man," Proc. Roy. Soc. of Med., 1913 , vol. vi. (Odont. Sect.), p. 1.

See reference, p. 125 . 
simian feature which has persisted in modern races to a greater degree than in this peculiar Pleistocene species of man.

Indeed, were one to summarise the influences which have led anatomists to give up the Neanderthal type as an ancestral form of man, and to regard it as an extinct

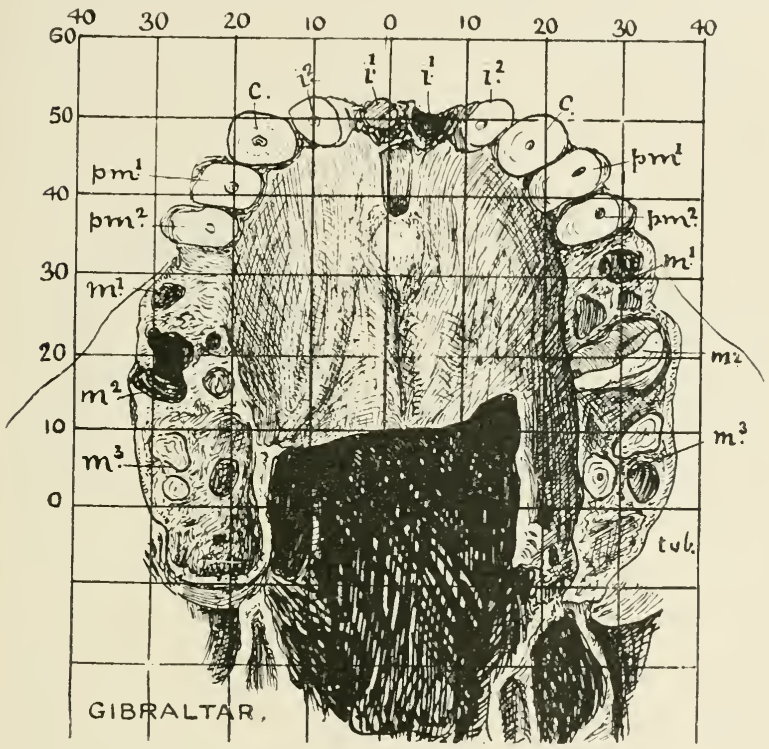

FIG. 51.-Drawing of the palate of the Gibraltar skull.

and separate species of humanity, Dr Adloff's writings must be given an important place, second only to the influence exercised by Professor Schwalbe's early publications. ${ }^{1}$ No doubt the change in our attitude towards Neanderthal man was also affected by Hauser's discoveries at Le Moustier and at Combe Capelle, and by the inference which Professor Klaatsch drew from these

\footnotetext{
1 See reference, p. 123.
} 
discoveries. ${ }^{1} \quad$ Professor Boule's ${ }^{2}$ investigations finally establish Neanderthal man as a distinct and extinct species of man.

In the palate, as well as in the teeth, there is evidence of a specialisation. The only skull in which the palate has been preserved nearly intact is that found at Gibraltar ; a careful drawing showing the exact dimensions and state of that palate is reproduced in fig. $5 \mathrm{I}$. It is at once seen, not only to be larger than the palate of modern man, but also different in shape. Its distinguishing feature is its great width, as compared with its length. The primitive

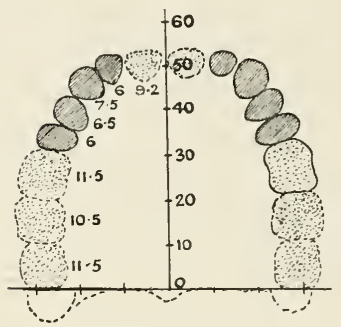

GIBRALTAR.

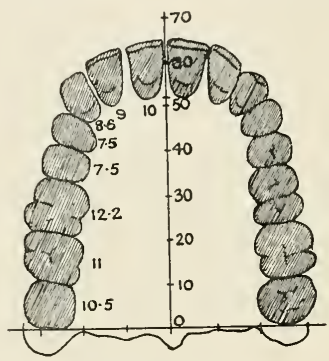

TASMANIAN.

Fig. 52. -Outlines of the palate of the Gibraltar skull, and of a skull of a native Tasmanian, showing a contrast in shape.

form of the palate-that seen in anthropoid apes-is one with approximately parallel sides, on which the molar and premolar teeth are set (see fig. I IO, p. 328). In the figure cited the palate of a female chimpanzee is represented. The width, measured between the outer margins of the second molar teeth, is $58 \mathrm{~mm}$.; its length, represented by a line drawn from between the crowns of the middle incisor teeth to a point situated at the middle of a line joining the hinder borders of the last molar teeth (see fig. I IO), is $70 \mathrm{~mm}$. The palate is long and narrow, the width being 80 per cent. of the length. In fig. 52 the outline of the palate of the Gibraltar skull is reproduced

1 See reference, p. II 5 .

2 See reference, p. I 7 . 
side by side with the palate of a native Tasmanian-the latter serving as a representative of the modern type of man. It is at once seen that the Tasmanian is the more simian in form of palate. Its length is $65 \mathrm{~mm}$., its width, $70 \mathrm{~mm}$., the width representing 107 per cent. of the length. In the Gibraltar skull the length is much less, $54 \mathrm{~mm}$., the width rather greater, $7 \mathrm{I} \mathrm{mm}$., representing I $3 \mathrm{I}$ per cent. of the length. From the drawing which Professor Boule has reproduced of the reconstructed palate of the La Chapelle man, ${ }^{1}$ one estimates that its palatal length was $59 \mathrm{~mm}$., its width, $7+\mathrm{mm}$. ; the width proportion, I 25 per cent. We thus see that not only the teeth, but also the palate of Neanderthal man had departed more widely from the simian type-had undergone a greater degree of specialisation-than the palate and teeth of races of the modern type. What was the meaning-the functional significance- of such a specialisation? The Neanderthal teeth, in the writer's opinion, are of the type seen in herbivorous mammals. The wide palate, the wide dental crowns and big bodies of the teeth seem to indicate powerful side-to-side grinding movements of the mandible during mastication. On the evidence of the teeth and palate one is inclined to regard Neanderthal man as specially adapted to live on a rough vegetable diet.

In the evolution of the early ancestral form of man from an anthropoid type, the palate, jaws, teeth, and other parts concerned in mastication appear to have undergone retrogression, as the brain became a larger and more efficient organ. The brain, by its invention, saved the labour of the jaws. The area of the palate (see p. 97) may be taken as an index of the extent to which the masticatory system is developed. The capacity of the cranial cavity of the skull serves as a rough index of the brain power. It will be of interest to inquire how Neanderthal man stands in respect of palate and brain development. The area of the Gibraltar palate is $31.60 \mathrm{~cm} .{ }^{2}$; the brain capacity, $\mathrm{I} 200$ c.c. The ratio of brain to palate is 38 c.c. of brain to $\mathrm{I} \mathrm{cm}^{2}$ of palate. The corresponding area of 
the palate of the La Chapelle man is calculated from Professor Boule's drawing to have been $35^{\circ} 00 \mathrm{~cm} .^{2}$ The brain capacity of the La Chapelle individual being about 1600 c.c., the brain-palate ratio is $46: \mathrm{I}$, a higher brain ratio than in the Gibraltar skull. Among anthropoid apes, selecting a female chimpanzee as the most favourable example for the purpose of comparison, the brain capacity is found to be about 350 c.c.; the area of the palate, $36.50 \mathrm{~cm} . "$; the brain-palate ratio, $8.7: \mathrm{I}$ - a small brain and a large palate. The female chimpanzee and the La Chapelle man have palates, although very different in shape, almost of the same size. The brain of the chimpanzee, on the other hand, is only a quarter or one-fifth of the La Chapelle brain. Taking now a very primitive example of modern man, the skull of a native Tasmanian, in the museum of the Royal College of Surgeons, England, we find the brain capacity to be I 350 c.c. ; the palate, $36.70 \mathrm{~cm}^{2}$; the brain-palate ratio, $36.7: 1$. The palate, in comparison with the brain, is larger than in the two Neanderthal specimens just cited. In the Aurignacian man from Combe Capelle the area of the palate is approximately $27^{\circ} \mathrm{I} \mathrm{cm} .^{2}$; the brain capacity, I 440 c.c. ; the brain-palate ratio, $53^{\circ} 3:$ I - a ratio which holds true in a large proportion of modern races. The brain-palate ratio of modern Englishmen is $56 \cdot 3: \mathrm{I}$. The palates of Neanderthal men were absolutely and relatively large, yet the ratio between brain and palate falls within the limits of variation seen amongst existing primitive races.

In fig. 47 (p. I 40) another peculiar feature of Neanderthal man is represented. The socket or cavity, in which the condyles of the lower jaw are jointed to the base of the skull, just in front of the ear-passages, is depicted in the form seen in the gorilla, in the Gibraltar skull, and in a man of the modern type. In the gorilla the socket is very shallow, and is placed on a platform or thickening of bone at the root of the zygomatic arch-the articular surface lying almost flush with the lower border or floor of the ear-passage (fig. 47). In men of the modern 
type the hinder part of the socket-the glenoid fossais deep, being excavated to the depth of the roof of the ear-passage. The front part of the articular platform has become developed as in the gorilla, forming an articular eminence in front of the socket. It is only the hinder or præ-auricular part of the anthropoid articular platform which remains undeveloped, giving rise to the well-known socket for the jaw - the glenoid cavity. When the condition of parts in the Gibraltar skullrepresenting the Neanderthal type-is examined, it is seen that the resemblance is much closer to the anthropoid than to the form found in the modern types of man. In this region of the skull Neanderthal man shows distinctly simian traits. So, too, in the passage of the ear. The plate of bone which forms the floor of the passage- the tympanic plate-is shaped in Neanderthal man as in the gorilla. In the modern type of man it has come to form the posterior slanting boundary for the glenoid cavity or mandibular socket (fig. 47 , II.).

In the auricular region of the skulls of Neanderthal men there is another simian feature to which attention may be directed, although it is not concerned in the function of mastication. In skulls of the modern type a pyramidal-shaped process of bone-the mastoid processdescends immediately behind the ear. To this process certain muscles of the neck, concerned in moving the head, are attached (see fig. 53). It is only slightly developed at birth, attaining its full size when the individual has reached adult years. In the gorilla a mastoid process is present, but in place of growing downwards to form a pyramidal process, it expands into a flange-like plate, forming part of the bony occipital platform on which the muscles of the neck are implanted (see fig. 47 , II.). The pit or fossa from which the digastric muscle arises is left exposed on the anthropoid skull below the mastoid process. In skulls of the modern type the pyramidal process covers and hides the digastric fossa (fig. 47). In Neanderthal skulls the mastoid process does not assume a distinct pyramidal form; in its shape and relationship 
it is intermediate to the form seen in young anthropoids and that which occurs in men of the modern type. It will thus be seen that in the mastoid region Neanderthal skulls show a series of characters which may justly be regarded as simian in nature and origin.

Mention has already been made of the flattened platycephalic skull of anthropoids and of Neanderthal man. It is now necessary to look somewhat more closely into the nature of this character. In fig. 53 the poise of the
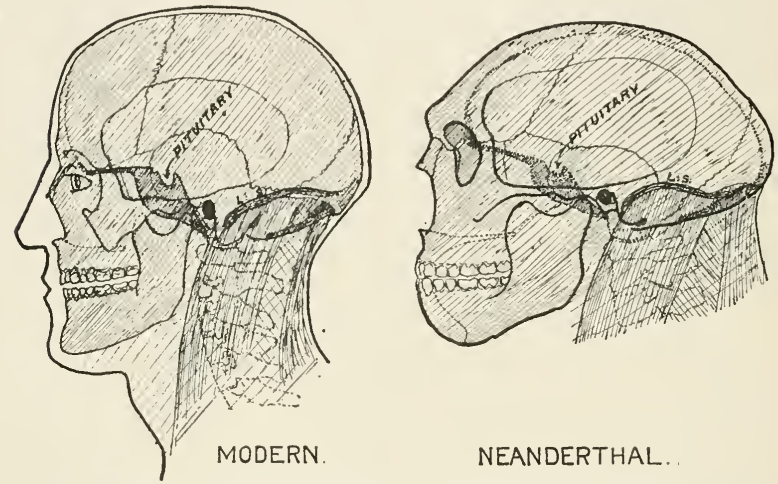

FIG. 53.-Diagram showing the poise of the head in the modern and Neanderthal types of man. The Gibraltar skull was used as the basis of the drawing of the Neanderthal type, a lower jaw being modelled from one of the mandibles found at Spy.

head in the modern type of man and in the Neanderthal type are contrasted. In the Neanderthal poise one has the impression that the occipital region of the head was partly buried in the neck, owing to the head being tilted or extended backwards. To some degree this is true; the head was carried in a more extended or retroflexed position, for it will be observed that the muscles of the neck have attained a more extensive attachment to the occipital region than in the contrasted type. In Neanderthal man the muscles of the neck ascend above the posterior end of the lateral blood sinus (see fig. 53, L.S.) ; 
in modern men the muscles of the neck are usually attached short of this point. Indeed, the head is fixed to the neck in the Neanderthal race in much the same manner as in young anthropoid apes. We have just seen that the mastoid process, also part of the area of fixation of the skull to the neck, is also partially simian in character.

It seems to me very probable that this peculiar poise of the Neanderthal head is related to the great development of the face and jaws. If the illustrations in fig. 53 be examined it will be seen that the hinder border of the lower jaw lies just in front of the spinal column. If the reader will let the head fall forwards on the front of the neck, it will be found difficult to move the jaw, as in chewing, because it is wedged behind against the backbone. But if the face be thrown upwards-the occiput, of course, sinking backwards and downwards at the same time-it will then be found that the mandible has room for the most ample movements. It is for a similar reason, apparently, that Neanderthal man's head was fixed in an extended pose-one which gives his great lower jaw room to move.

There is another modification in the basal part of the skull which tends to throw the face forwards and thus give freedom to the lower jaw. In I $^{86} 3$, Huxley ${ }^{1}$ called attention to the manner in which the base or cranial axis of the skull becomes bent with the evolution of the higher forms of primates. The greatest amount of bending is seen in modern human skulls. Now, in the illustrations given in fig. 53 the basal axis of the skull is represented by the stippled area. The pit or fossa for the small pituitary body or gland is situated on the upper (intracranial) aspect of the basal axis. The part of the base behind the pituitary - the postpituitary partslants downwards and backwards, lying over the pharynx; the part in front-the prepituitary part-stretches horizontally forwards, towards the root of the nose. In ordinary monkeys the prepituitary and postpituitary parts

$$
1 \text { Man's Place in Nature, and other Essays, p. } 192 .
$$


form an almost straight line-there is little or no bending. In anthropoids the bending becomes apparent. In fig. 54 the degree of bending at the pituitary angle in a gorilla is represented; it amounts to $\mathrm{I} 42^{\circ}$. Some years ago Professor G. L. Sera ${ }^{\text {I }}$ drew attention to the fact that this angle is very open in the Gibraltar skull-the only Neanderthal specimen in which the base is preserved. The angle is almost as great as in the gorilla, $140^{\circ}$ (fig. 54). In skulls of the modern type it varies from $120^{\circ}$ to $130^{\circ}$. There can be no doubt that the wide,

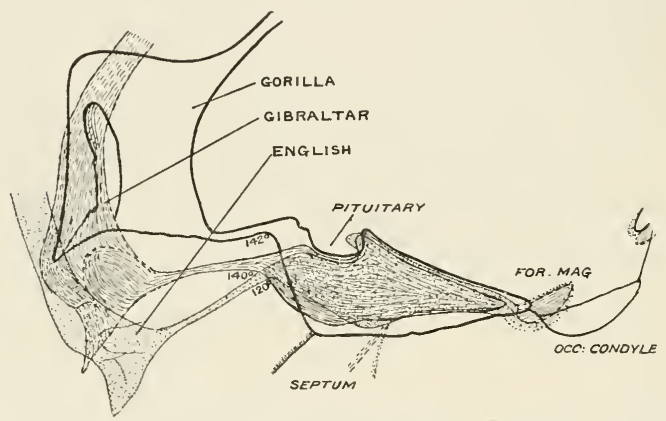

FIG. 54- - Superimposed tracings of the basi-cranial axis of the skull of a gorilla, of the Gibraltar cranium, and of a modern English skull, to show the extent of the pituitary angle.

open angle is the primitive or simian one; in this respect the Gibraltar skull is very primitive. We can see, further, by a reference to figs. 53 and 54, that the wide, open angle is related to the downward flattening-to the degree of platycephalism-of the skull. A widely open pituitary angle, as in the Gibraltar skull, tends to pitch the face forwards, thus giving room for movements of the mandible. It has the same effect as a backward tilt of the head. The prepituitary part of the cranial base represents the axis of the maxillary part of

1 "Nuove Osservazione ed Induzioni sul Cranio Gibraltar," Archiv Antropologia, 1909, vol. xxxix. p. 5. 
the face as well as of the cranial cavity. If this anterior part of the cranial base is bent downwards-towards the nose and mouth-as in skulls of the modern type, the facial parts are also necessarily bent downwards and backwards. The long base, the wide, open pituitary angle of the cranial axis, the long compressed form of the vault, the straight upper margin of the squama of the temporal bone, as seen on the side of the skull (see fig. 53), are all characters apparently correlated with a great maxillary development. They are also primitive or simian features. The essential difference between the Neanderthal and the modern types of skull is that the first, the Neanderthal, is an extended skull - the cranial base is opened out or extended at the pituitary angle. In the second or modern type the skull is "flexed"the bending of the cranial axis is increased.

I have dealt with the Neanderthal skull at some length. Every bone of the skeleton has its distinctive or specific characters. We have seen that Dr Henri Martin was able to identify an astragalus found at La Quina as that of a Neanderthal individual. It would be impossible to distinguish one modern race from another by the discovery of a single astragalus or ankle bone. The ribs, too, are peculiarly rounded. Professor Schwalbe $^{1}$ and Professor Klaatsch ${ }^{2}$ have made detailed analyses of the peculiar characters of the limb bones. Lately, Professor Boule ${ }^{3}$ has attempted to restore a complete skeleton and give to it a life-like pose. He represents Neanderthal man as a loose-limbed fellow with an easy, shuffling gait-knee and hip joints slightly bent. All the parts of his body are as perfectly adapted to the upright posture as those of modern man. I will content myself here by merely giving an outline drawing of the thigh bone of one of the Spy men-set between

1 "Kritische Besprechung von Boule's Werk L'homme fossile de la Chapelle-aux-Saints," Zeitschrift für Morph. und Anthrop., 1914, vol. xvi. p. 527 .

Prachistorische Zeitschrift, I910, vol. i. p. 272. Ergebnisse der Anatomie, 1907, vol. xvii. p. 43 I.

3 See reference, p. 117. 
the thigh bone of a man of the modern type and of a gorilla-as a sample to stand for the rest of the skeleton. It will be seen at a glance that the Neanderthal thigh bone does manifest in its shape and general conformation a more simian character than the thigh bone of modern man. In the case of the tibia or leg bone anthropoid affinities are even more marked.

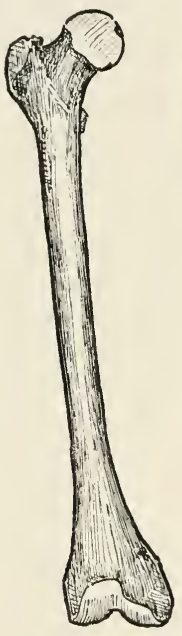

MODERN.
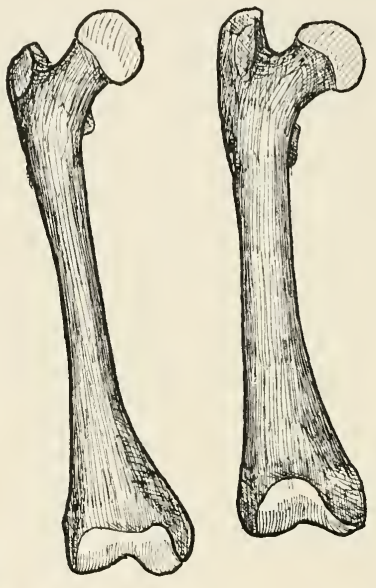

NEANDERTHAL. GORILLA.

FIG. 55.--The Neanderthal (Spy) thigh bone contrasted with the corresponding bones of modern man and the gorilla.

A survey of the characters of Neanderthal man-as manifested by his skeleton, brain cast, and teeth-have convinced anthropologists of two things : first, that we are dealing with a form of man totally different from any form now living; and secondly, that the kind of difference far exceeds that which separates the most divergent of modern human races. If we were dealing with a fossil animal which lay outside the pale of humanity 
we should probably give Neanderthal man, not only separate specific, but even a separate generic, rank, and distinguish varieties or even species of Neanderthal men. Further, in most of the points in which the Neanderthal man departs from modern man he approaches the anthropoids. His peculiarities are pronouncedly simian. But not all of them; he has also his own peculiar adaptations and specialisations.

It is when we survey the great assemblage of his simian characters that we understand how he came at first to be regarded as our Pleistocene ancestor. Evolution was in the air-evolution from a simian ancestor. Here was a human form with simian characters swarming in the details of his structure. The belief in man's recent origin was also, in those early days, dominant. Neanderthal man presented himself to the pioneers of evolution as a later or Pleistocene stage in man's evolution. When, however, it was realised that men of the modern type, just as highly evolved in structure of bone and brain as men are now, must have been in existence when Neanderthal man was still living, it was apparent that if the Neanderthal type did at any stage become converted into a man of the modern type, that stage of evolution must have occurred before the Mousterian period, the one we are now dealing with.

Further, in size of brain Neanderthal man was not a low form. His skill as a flint-artisan shows that his abilities were not of a low order. He had fire at his command, he buried his dead, he had a distinctive and highly evolved form of culture-Neanderthal man was certainly not a dawn form of humanity. To find that form we must go to a period which lies far beyond the mid-Pleistocene age. 


\section{CHAPTER IX}

MEN OF THE IOO-FOOT TERRACE

Our journey round Europe, described in the previous chapters, has led to the conclusion that it was inhabited, during the long Mousterian period, by a people altogether different from ourselves. When, therefore, we set out to seek for pre-Mousterian man, we are naturally on the tiptoe of expectation to see what kind of being we shall find. Was modern man evolved in some distant part of the world, reaching Europe for the first time in the Aurignacian period? Or was he the original inhabitant of Europe, being ousted during the time of the Mousterian culture by an intrusion or invasion of a foreign and strange species of man (Homo neanderthalensis)? It is clear that we must know the past history of the whole world before we can answer those questions with certainty. Meantime, we must rely on such facts as we now possess. We are feeling our way into a very distant period-one which lies fifty thousand years or more behind the present. Naturally, the further back we go the greater become our difficulties and our doubts. Geological records, like historical documents, suffer by the lapse of time-they become mutilated, destroyed, or completely swept away. Seen in a distant perspective, a long period of time appears to us a short one.

The culture of the period we now enter-the Acheulean - is sparsely represented in the floor strata of caves and rock-shelters. At La Ferrassie, it will be remembered (fig. 40, p. I I 3 ), the stratum lying under the Mousterian contained objects of the older culture-the Acheulean. 
The chief records of this culture lie in deposits along the river valleys, in old stream-beds or deposits laid down at various intervals during the Pleistocene epoch. The site which yields the classic implements of this culture (beautifully worked flint hand-axes) is situated at St Acheul, near Amiens, in the valley of the Somme. A replica of the terrace at St Acheul can be found in England, in that stretch of the Thames valley where we commenced to study the deposits and culture of the

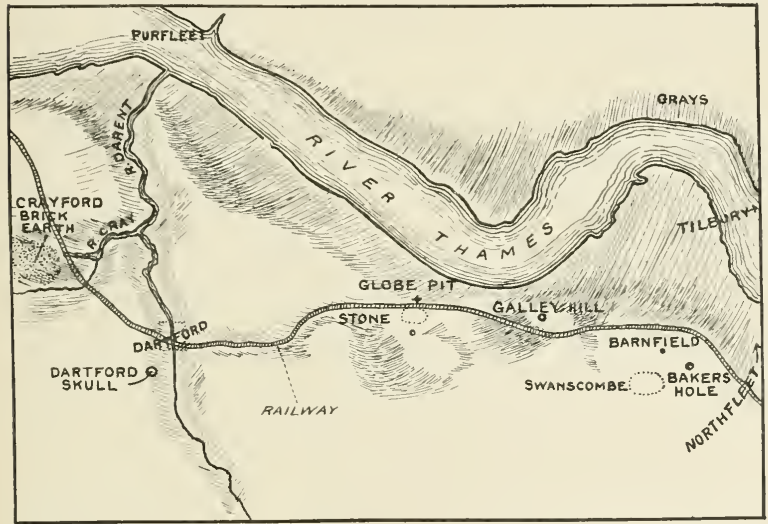

FIG. 56.-Swanscombe and neighbouring Palæolithic sites on the south side of the valley of the Thames, below London.

Mousterian period, and where I propose to take up the search for man of the older or Acheulean period. Fig. $5^{6}$ shows the position of the various deposits-remnants of ancient beds of the Thames-to be investigated. The Mousterian culture was found in the 50-foot terracethe low terrace of Continental writers; it is the much older terrace-the Ioo-foot-which is to yield us traces of Acheulean man. At Swanscombe, situated on the south side of the valley, half-way between Dartford and Northfleet, the gravels and loams of the roo-foot terrace form an extensive deposit, in some places over 30 feet in 
thickness, resting on the chalk bluffs overlooking the river. To obtain the chalk for the production of cement, the overlying gravel deposits have to be cleared away. In the process of removal thousands of flint implements have been discovered at various levels in the gravel deposits. They exhibit a variety of styles in workmanship, many of them bearing evidence of great technical skill. In former days the implements were gathered by the workmen, and, from them, passed into the possession of collectors. Swanscombe became renowned for its palæoliths.

In the corresponding deposits of the Somme valley, Professor Commont, ${ }^{1}$ by a careful series of investigations extending over the opening decade of the present century, observed that the implements were always arranged in the same sequence or order when the deposits in which they occur are rightly dated. It was formerly believed that there was no cultural sequence of implements in the Thames deposits. Collectors believed that the same stratum might yield implements of the most varied types of workmanship. To settle the question of sequence, a representative of the British Museum, Mr Reginald Smith, and one from H.M. Geological Survey, $\mathrm{Mr}$ Henry Dewey, were delegated, in the summer of 1912, to investigate the implements and deposits of the 100foot terrace at Swanscombe. ${ }^{2}$ The Associated Portland Cement Manufacturers, the owners of the chief pit at Swanscombe-at one time known as the Milton Street pit, but now as the Barnfield-gave them every facility and encouragement in their investigation. In fig. $57, \mathrm{I}$ give, in a diagrammatic form, the chief results of their inquiry. They found that three series of deposits were represented in the 100 -foot terrace-each series representing formations of a distinct period, each period marked by its own form of culture, a distinctive style of flint workmanship. The deepest and oldest of the three

1 See reference, p. 194 .

2 See their report : "Stratification at Swanscombe," Archaologia, 1912, vol. lxiv. p. $1>7$. 
series of deposits is named here the "Strepyan," because the implements found in it are of the type which M. Rutot discovered and named in the corresponding valley deposits of Belgium - especially at Strépy, a village to the west of Charleroi, lying within the watershed of the Meuse. The Strepyan series of deposits consist of a deep bed of gravel (the "lower" gravel), made up of several layers ; over the gravel a deposit of loam ("lower" loam) (see fig. 57). The gravel was laid down in the bed of the Thames when the river was flowing at a level of about $\mathrm{I} 00$ feet above its present bed. The Strepyan series

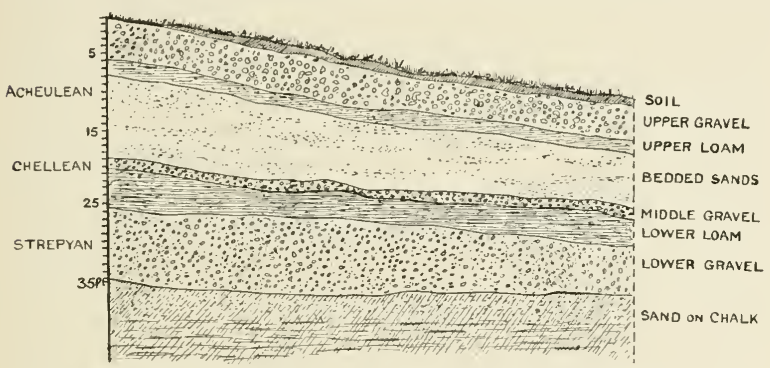

FIG. 57.-Diagram showing the various deposits of the roo-foot terrace of the Thames valley at Swanscombe, modified from Mr Dewey's sections.

ends with a stratum of loam-a deposit formed in still water in times of flood. The second series of deposits, lying over the Strepyan, and therefore more recent, yielded, in its basal bed of gravel, the same kind of flint implement as occurs in the ancient deposits at Chelles, in the valley of the Marne, about eight miles to the east of Paris. At the time, then, when the second series of deposits in the 100-foot terrace began to be deposited, culture or civilisation of the natives of the Thames valley had entered the "Chellean" phase or stage. In the sands and loam, the later deposits of the second series, another culture appears - the older Acheulean, usually known as St Acheul I. The third and most recent series of the IO०-foot terrace again commences with a stratum of 
gravel, in which implements of the later Acheulean type occur-St Acheul II. The stratum of gravel (" upper" gravel), marking the commencement of the third series, lies under the surface soil (fig. 57). The sands and brick earths which were probably present when the terrace was finished have been washed away long ago. To find the continuation of the third and last series of the roo-foot terrace, we must descend from the level of that terrace at Swanscombe to the level of the 50-foot terrace. That terrace has been already mentioned-at Crayford and at Baker's Hole (p. IO3). Lying at the base of the brick earths, in which the culture of the Mousterian period is preserved, occur Palæolithic floors of the late Acheulean period. Acheulean man lived on the floor of the valley before the brick earths of the 50-foot terrace were deposited. In I $880, \mathrm{Mr}$ F. C. J. Spurrell ${ }^{1}$ found such a floor under the brick earths of the 50 -foot terrace at Crayford. From the floor he gathered not only a finished implement, but also the chips which the workman had struck off in fashioning it, and part of the lower jaw of a rhinoceros-all of which he presented to the Natural History Museum at South Kensington. It is clear, then, the period we have now entered-the Acheulean-must be one of great duration. At its close the valley of the Thames was excavated almost to its present depth, for at such a level, buried beneath the deposits of the middle terrace, we find the work-floors of Acheulean man.

The commencement of the Acheulean period is recorded, as we have just seen, in the upper series of the roo-foot terrace. It is plain, then, that the Thames carried out an enormous task during the Acheulean period. At the beginning of the period the floor of the Thames valley lay flush with the Ioo-foot terrace. A process of land submergence was then in operation, attended by a filling up of the valley, and by the formation of the upper series of Acheulean deposits on the roo-foot terrace. Afterwards an opposite movement set in, one of elevation of the land, leading to an excava-

${ }^{1}$ Quart. Journ. Geol. Soc., I88o, vol. xxxvi. p. 544. 
tion, or, more probably, a re-excavation of the valley almost to its present depth. At Swanscombe the magnitude of such an operation is apparent, for the corresponding (roo-foot) terrace on the opposite or north side of the valley lies eight to ten miles distant. The whole width of the valley was apparently cut down to an extent of 100 feet during the later part of the Acheulean period. It does not matter for our present argument whether the Thames cut her valley for the first time, or whether, as seems more probable, she only cleared out a former channel which had become silted up during a former period of submergence. It is clear, when we consider the magnitude of the operations involved, that the Acheulean culture covers a long period of time, one more than equal to all the later Palæolithic periods put together-Mousterian, late Palæolithic, Neolithic, and Metal phases of human culture. If we pitch the commencement of the Mousterian period, as a provisional hypothesis, at a distance of fifty thousand years, we must give fifty thousand years more to reach the opening phases of the Acheulean period.

Considering the great duration of the Acheulean period, and the abundant evidence of the activity and culture of the men of that time, it is surprising that so little has been discovered of the men themselves. In nearly every case where remains of man have been ascribed to the Acheulean period, the authenticity of the discovery has been questioned or denied. The very first instance I am to cite is one which is placed-and rightly placed so-to what the geologist calls a "suspense" account. Those suspense cases often prove the most instructive. Such cases should not be allowed to pass into oblivion; the facts ought to be placed on record, to await the fate which will be assigned to them in the light of discoveries made at a future date. The suspense cases may prove false or prove true. They stimulate further research. The first discovery I am to mention brought to light the "Dartford" skull—supposed to be of Acheulean date. Dartford, as may be seen from 
fig. 56 , lies some five miles to the west of Swanscombe, situated in the valley of the Darent where that stream breaks through the line of the roo-foot terrace and enters the marshy land on the south bank of the Thames. On the western side of the valley of the Darent, on the outskirts of the town of Dartford, a pit had been opened in a deposit of gravel, some 18 feet in depth. The stratified gravels, containing interpolated patches of loam, represented a deposit of the ancient Darent. The substratum of chalk on which the gravel rests is about 45 feet above the Ordnance Datum line, and 30 feet above the Darent, which is about a third of a mile distant, to the east. In 1902, the pit, having proved unprofitable from a commercial point of view, was taken over by an ardent student of ancient man-Mr W. M. Newton, who then resided in Dartford. Between I 902 and 1908 " every bit of gravel excavated-some 5000 tonspassed under the deliberate scrutiny of my workman, and every evening his daily finds had my careful examination." 1 The majority of the implements discovered were of the later Acheulean type. They occurred especially plentifully near a black band in the gravel, which $\mathrm{Mr}$ Newton regarded as an indication of an old land surface. He also found numerous examples of "figure-stones"-curiously shaped natural flints, which, in some cases, had been deliberately chipped to give a semblance to the form of certain animals. Such figure-stones received the serious consideration of $\mathrm{M}$. Boucher de Perthes (see p. I 96).

The account of the discovery of a human skull, in the gravel of the Dartford pit, I shall give in Mr Newton's own words : ${ }^{2}$ -

"I was, as you know, much interested in the gravel as producing implements and other curious forms of man-worked flints in the shape of animals and heads of animals. I was in the pit almost every

' See Mr Newton's paper on "Palæolithic Figures of Flint," Journ. British Archaolog. Assoc., March 1913, p. 3 .

2 A letter to the Author, dated February 27 th, 1911. 
morning and evening. Two men were working the face at the south end of the pit; two-Randall, Heron-the face at the north end. It was in the north face that the skull was found by the two men just named. They had broken into what is commonly termed a 'pot-hole,' into which it was impossible to see, as it lay 8 feet above the level of the floor of the pit, and about the same depth below the upper ground level. There was not the slightest appearance of any disturbance of the gravel such as might be produced by a deep grave above the pot-hole, and below the hole there were patches of sand, some loosely bedded large flints, and a black band that crops out at several points in the working.

"On the morning of May 26th, I902, I entered the pit soon after 6 o'clock, when the skull was handed to me out of a heap of sand in which it had been preserved during the night. I had been in the pit the previous evening, after the men had left, and noticed that there had been a 'fall' of gravel from the north face. The men informed me that with the fall the pot-hole disappeared and the skull was found in the débris. The men and I agreed at the time the skull must have come from the pot-hole.

"In the afternoon of the same day on which I obtained the skull, the north face of the pit was photographed for me by $\mathrm{Mr} \mathrm{E}$. H. Youens. Needless to say, I was impressed with the importance of the discovery. I offered rewards for the jaw, teeth, or any other bones; but, after much careful searching and sifting, no other human remains were found except the small pieces from the black deposit at a subsequent date. I did not publish an account of the finding of the skull, as I did not wish to draw attention to what I was doing with respect to the animal formsfigure-stones." 
Before discussing the value of the Dartford skull ${ }^{1}$ as a historical document, let us see what kind of man it represents-for there can be no doubt as to the sex, so strongly are the male characters developed. The skull, from which all the face is missing, is of unusual dimensions. The brain capacity is I 740 c.c.-fully 250 c.c. above the modern average. The great size of the brain need not make us sceptical of the antiquity of the skull. Even in the Neanderthal race, with all its ape-like characters, we have seen that some individuals, as at La Chapelle, went far beyond the modern average in mass of brain. Indeed, when we have become familiar with the implements of Acheulean man, we are prepared to find that the brain that conceived and executed such works of art must have been one of a high order.

The great dimensions of the Dartford skull are equally apparent when it is measured within the conventional frame (fig. $5^{8}$ ). The maximum length is $207 \mathrm{~mm}$.- I 7 $\mathrm{mm}$. above the average for modern English skulls; the width, I $50 \mathrm{~mm}$., is ro $\mathrm{mm}$. above the average. The width is almost 73 per cent. of the length : it is a dolichocephalic skull. The height of the vault is equally remarkable; it rises $129 \mathrm{~mm}$. above the ear-passagesI $3 \mathrm{~mm}$. beyond the modern average. The supra-orbital ridges are prominent, but moulded as in modern man. The width of the forehead at the level of the supraorbital ridges is remarkable- $\mathrm{I} 20 \mathrm{~mm}$. The face must have been large and strongly developed. The forehead is wide, measuring I I $2 \mathrm{~mm}$. between the temporal lines. The neck was thick, and the skull strongly implanted on it. The mastoid processes are massive, their apices reaching $35 \mathrm{~mm}$. below the level of the upper border of the ear-holes. The width of the skull taken over the mastoid processes is $140 \mathrm{~mm}$. The bones of the vault vary from 7 to $8 \mathrm{~mm}$. in thickness.

If the question is put to a modern anthropologist: Does

1 Mr Newton presented the skull to the museum of the Royal College of Surgeons in $191 \mathrm{I}$, where it is now preserved. I am indebted to Mr A. S. Kennard for the first knowledge of Mr Newton's discovery. 
the Dartford skull show any feature which at once distinguishes it from skulls of the modern type? he must return the answer: No, not one! But it must also be remembered that the same may be said of every skull found in deposits which are later than the Mousterian period-the Combe Capelle, Cromagnon, Brünn, Grimaldi crania, not one of these shows any features which we are not familiar with in modern skulls. Indeed, in many of its characters the Dartford cranium agrees with the Cromagnon type (see figs. 23, 62). In some minor characters it resembles the Piltdown skull. We thus obtain little or no aid from the skull itself in fixing its

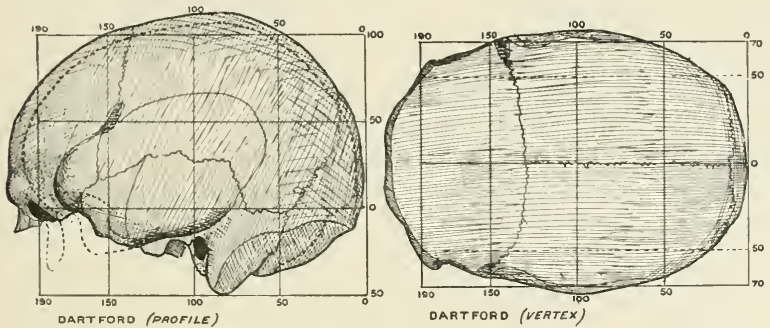

Fig. 58.-Profile drawing of the Dartford cranium and its outline from above, at right angles to the view given in profile.

degree of antiquity. That must be determined on the evidence attending its discovery in the pit at Dartford.

We have to admit at once that the evidence of the Dartford skull being Acheulean in date is purely presumptive; the cranium was found apparently at a depth of 8 feet below the surface, in a gravel pit yielding abundance of Acheulean implements. It is believed to have been embedded at the level of the "black band," which may represent an old land surface. The pot-hole signifies a local subsidence of the gravel. To carry conviction, the cranium should have been seen and examined while still embedded in a stratum known to be Acheulean in date. We must also be certain that the stratum containing the skull, and all the more superficial strata, 
were intact and undisturbed. We have no guarantee of this kind in the case of the Dartford skull. In commercial ventures it is seldom that such a degree of verification is possible, and yet, if we insist rigidly on such conditions, we may reject the most valuable of documents and records. We should further expect that other bones besides those of man should occur at the same level, but at the Dartford pit no animal remains were observed. Further, we should expect the skull to show a high degree of mineralisation-or fossilisation-but the Dartford skull is not heavy. Its surface is weathered, pitted, and of a light brown colour; when a fragment is broken, the freshly fractured surface is grey and chalky. The condition does not suggest, but it does not exclude, a high antiquity. There is one remarkable feature to be seen on the inner surface of the cranium. The skull apparently lay, while embedded in the gravel, with its right side down and its left up. There was a perforation on the upper or left side, at which a drip of water must have entered, and then have passed round the inner aspect of the vault, making its exit at a small hole on the right or deep side of the skull. The drip has worn a groove or channel in the bone, about $10 \mathrm{~mm}$. wide and $3 \mathrm{~mm}$. deep. The earholes contained a brown, sandy loam similar to that found in the pit. Further, the skull shows no signs of battering or erosion; it could not have rolled far in the moving gravel in the bed of a stream. As a document, then, the Dartford skull is inconclusive. We cannot cite it as evidence that men of the modern type lived in England during the Acheulean period; yet we cannot reject it, for it is probably authentic.

To visit the site of the discovery of part of a human skull which can be assigned to the Acheulean period with some degree of surety we must leave the valley of the Thames for an interval and visit East Anglia, where the older deposits of the Pleistocene period are represented more completely and consecutively than in any other part of England-perhaps more fully than in any part of Europe. Our quest takes us to the town of Bury St 
Edmunds in West Suffolk, situated on the Lark, a tributary of the Ouse. From the deposits in the valley of the Lark, a few miles below-to the north of-Bury St Edmunds, Dr Allen Sturge has gathered a collection of implements which represent man's handiwork during all the periods of Palæolithic culture. About two miles to the west of Bury St Edmunds lies the rural parish of Westley, where the land rises about 100 feet above the level of the Lark. On the highest ground, in this area, numerous depressions or pockets in the chalk occur, some IO to I4 feet in depth, filled with deposits of brick earth. In I 882, Mr Henry Prigg, a well-known archæologist, lived in the neighbourhood, and kept a close watch on such pits as were worked for the brick earth, because they were known to yield implements of that type which we now recognise as characteristic of the Acheulean culture. Remains of the mammoth also occurred; it was also said that a human skeleton had been found at a considerable depth in one of them. Late in the autumn of 1882 a workman found part of the vault of a human skull at a depth of $7 \frac{1}{2}$ feet $(2.27 \mathrm{~m}$.) in the brick earth. Mr Prigg verified the find, and published an account of the fragment and of the palæoliths found in neighbouring pits at about the same horizon as the skull. $\mathrm{Mr}$ Reginald Smith assures me that these palæoliths are of the type usually assigned to a late phase of the Acheulean period.

In order to throw a clearer light on the age and nature of the brick earths in which the Bury St Edmunds find was made, it is advisable, before describing the kind of man indicated by the fragment, to extend our journey twenty miles to the eastward, to Hoxne, where the implements of the. Acheulean type were first discovered. It is a cross-country journey, which takes us into the shallow valley of the Waveney, a stream flowing eastwards on the confines of Suffolk and Norfolk. As long ago as I797, John Frere collected flint "spear heads" by the score from the brick earths of Hoxne, described them, ${ }^{1}$

1 Archaologia, 1800 , vol. xiii. p. 206. 
and recognised both their antiquity and their human origin. John Frere's discovery was forgotten until the year I 859 , when Boucher de Perthes, after a struggle of twenty-five years, convinced the world in general and the leading English geologists in particular, that the curiously shaped flints in the terraces of the Sommeparticularly those at St Acheul-were of human workmanship and fashioned when species of animals now extinct were alive. It was then that the importance of Frere's investigations at Hoxne was realised. Sir John Evans and Sir Joseph Prestwich visited Hoxne, and found the brick earths and Frere's implements. In I 895-96, nearly a century after Frere's discovery, the British Association sent a Committee - its most active member being $\mathrm{Mr}$ Clement Reid-to investigate the relationship of the deposit of brick earth to that of boulder clay, a deposit resulting from the greatest of the Pleistocene glacial episodes. The annexed diagram (fig. 60) is compiled from the records of the Committee. ${ }^{1}$ The Committee found that the Hoxne brick earths, about 7 feet in thickness, represented the topmost of a series of deposits filling an ancient valley which had been about 50 feet in depth. The valley had been cut by a stream in the chalky boulder clay and the mid-glacial sands; it was clear the Hoxne valley had been formed and filled after the time of the deposition of the boulder clay and the close of the major glaciation. The bottom of this ancient valley is rather below the present level of the valley of the Waveney. The lower 20 feet of the deposits filling the valley are composed of clay laid down in still, fresh water. Then follows a deposit containing remains of plants which prefer a temperate climate. Then another deposit, about 20 feet in depth, of black loam with remains of Arctic plants. Then, finally, a layer of gravel on which rest the brick earths, containing Acheulean flints.

An inspection of the strata at Hoxne convinces us that

${ }^{1}$ See Report of British Association for 1896 (Liverpool), Section C, p. I. 
the Acheulean period occurred long after the time of the major glaciation; a valley had been cut to a depth of at least 50 feet and filled up again. In the interval between the formation of the boulder clay and the brick earth the climate had changed at least twice. We have seen, from the formation of the roo-foot terrace, that the Acheulean period is very remote from our day; at Hoxne we see that the major glaciation was equally distant from the Acheulean period.

Returning now to the pit at Bury St Edmunds, we

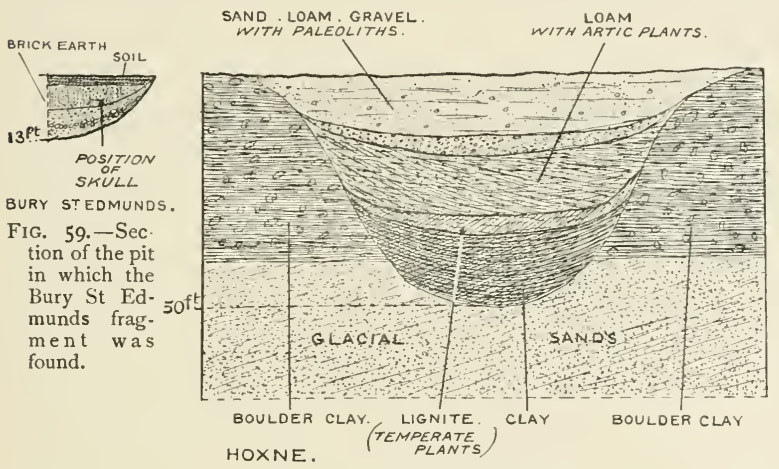

FIG. 60.-Section of the deposits at Hoxne.

cannot have any doubt that the brick earth, in which the fragment of skull was found, is of the same age and formed in the same way as the brick earth at Hoxne (fig. 60). They are dated by the later type of Acheulean implements. The fragment itself, which is preserved in the Moyses Hall Museum at Bury St Edmunds, still shows, in its interstices, particles of red brick earth. It is stained a light reddish-brown. When struck, it has the resonance of porcelain. The freshly fractured surface has the colour of chalk, except that the spaces in the bone are tinged from the brick earth. The edges of the fragment are brown and rounded. It is evident, 
from the weathered, rounded edges of the specimen, that only a fragment had been present in the pit; the workmen had not detached it from a complete skull. It may have been the stray part of a skull, lying on the surface of the land in Acheulean times, and washed, with other surface deposits, into the pit. At the present time the Lark is roo feet below the level of the pits.

Unfortunately, the fragment is not sufficient to permit one to reconstruct the original skull with any degree of certainty. A short time ago ${ }^{1}$ an opportunity was given me of making a minute examination of this fragment of a human skull. From the appended illustrations the extent of the fragment will be seen. The upper twothirds of the frontal bone, and about the anterior third of the right and left parietal bones are preserved. In attempting to reconstruct the original, I first searched for an English skull showing, in the fronto-parietal region, the same form and proportion of parts, the same kind of sutural lines between the bones. Its prototype I found in a skull obtained from a gravel deposit in the east end of London-of uncertain antiquity. I next tried to find a counterpart for it amongst all known examples of Neanderthal skulls. The male crania, such as the Neanderthal calvaria itself, the specimens from Spy or from sites in France, were altogether different. The only crania, presumably Neanderthal in nature, which at all resembled the Bury St Edmunds specimen were those fragmentary skulls of women and children found at Krapina. In none of those, however, was the sharp, frontal bend present which is to be seen in the upper region of the forehead of the Bury St Edmunds fragment. The frontal bone, at this bend, is remarkably thin-only $3.6 \mathrm{~mm}$. ; I cannot believe that on such a forehead great simian eyebrow ridges were implanted. In the upper part of the frontal bone, and in the parietals, the bones thicken to the moderate dimensions of 6 to $8 \mathrm{~mm}$. The characters, so far as we have examined them, clearly indicate a person with a head of the modern type.

1 See Journ. Anat. and Physiol., 1913, vol. xlvi. p. 73. 
Mr Prigg formed the opinion that it was part of a woman's skull, and with that conclusion I agree. Further, from the fact that the sutures between the separate bones are closed on the inner aspect and open on the outer, the woman may be regarded as over forty years of age.

The next point I tried to determine was: How much of the frontal bone is missing? In an average English skull the length of the frontal bone, measured from the bregma (see fig. I I 2, p. 33I) to the nasion at the root of the nose, measures about I $30 \mathrm{~mm}$. The actual amount present in the Bury St Edmunds fragment is $89 \mathrm{~mm}$. I have presumed that about $35 \mathrm{~mm}$. was missing from
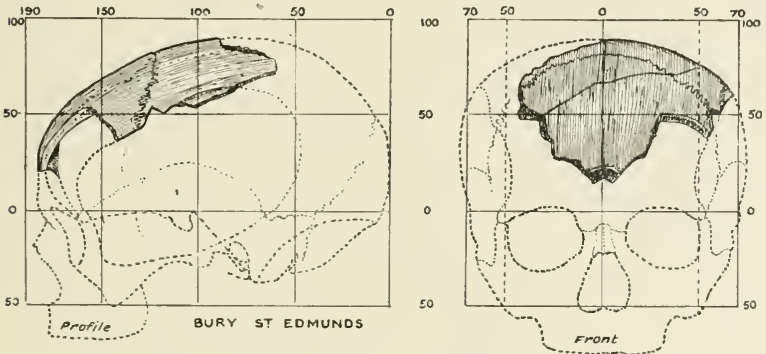

FIG. 6r. - Bury St Edmunds cranial fragment viewed from the side and from the front.

the lower part. If such an amount is restored, the forehead assumes a natural proportion. It is not likely that I have underestimated the amount missing, for, in the lower part of the frontal bone (see fig. 6I), there is present an extension of the frontal air sinus. It is unusual in skulls of the modern type to find the air sinuses ascending more than $30 \mathrm{~mm}$. above the nasion. In Neanderthal skulls the frontal air sinuses have a less extensive development than in skulls of the modern type.

From the drawings which are given in figs. 61 and 62 it will be seen that the Bury St Edmunds fragment can be conveniently oriented within the outline of a modern skull. The original skull was certainly, as regards length, 
below the modern average, even for women. I have allowed $125 \mathrm{~mm}$. for the length of the parietal bones measured along the vault of the skull-a very ample allowance. The lambda, at the hinder end of the sagittal suture between the parietal bones (see fig. 6I), has been placed $10 \mathrm{~mm}$. in front of the occipital projection or pole of the skull. The length of the skull is thus represented as $183 \mathrm{~mm}$.; it could be made shorter, not longer. The vault is remarkably flat on the top-a character in which
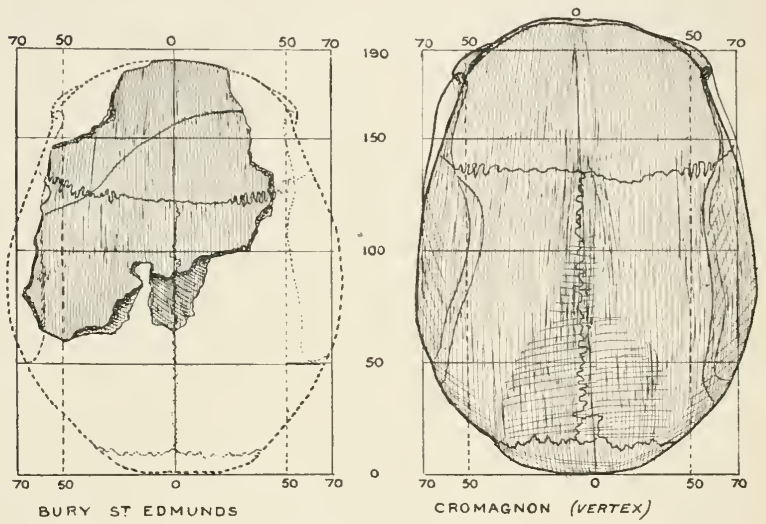

FIG. 62. - The Bury St Edmunds fragment viewed from above. The upper aspect of a Cromagnon skull is placed beside it for comparison.

the Bury St Edmunds fragment resembles Neanderthal skulls. It may be suspected that the pressure of the earth, in which the fragment lay, has produced a posthumous flattening, but such an explanation is improbable when the symmetrical character of the coronal suture, between the frontal bone and the parietals, is observed. From the width and flattening of the vault, one infers that the original transverse diameter of the skull could not have been less than $\mathrm{I}_{4} 8 \mathrm{~mm}$., the width being thus 80 per cent. or 8 I per cent. of the length. Such a skull would be classed as brachycephalic, but it is 
of a totally different type from modern brachycephalic skulls, the vault is so low. At the utmost, on the allowances given for the frontal and parietal bones, the height of the vault above the ear-holes could not be more than $105 \mathrm{~mm}^{1}$ The brain capacity of such a skull, using the Lee-Pearson formula, I $83 \times 148 \times 105 \times 4 \times$ $206=\mathrm{I} 3+0$ c.c. $-\mathrm{a}$ brain capacity about equal to that of the modern Englishwoman.

Thus of all the people who lived in England during the long Acheulean period, fashioning the multitude of implements which mark the deposits of their time-many of them implements which show high skill and artistic tastes-only two documents remain to tell us what kind of men and women they were. One of these documents, the Dartford skull, is of doubtful authenticity ; the other, the Bury St Edmunds fragment, is such a mutilated document that one may well hesitate in forming any certain conclusion as to the type of person it represents. We know only their flint implements. Such habitations or shelters as they may have built, such implements as they fashioned in less durable material than stone, have been destroyed by the lapse of time. We have seen that valleys, which had been filled up, were again excavated during the Acheulean period, except in such cases as at Hoxne, where the river system had been changed. The filled-up valley at Hoxne, with brick earths on the top, containing the implements discovered by Frere, remains now as at the close of the Acheulean period. In the Thames valley the Acheulean deposits have apparently been swept away, all except a fringe or terrace here and there.

In the next chapter but one a search will be made on the Continent for remains of Acheulean man. The Continent, it will be seen, repeats the story of Englandsuch remains as have been found of the Acheuleans are of the modern type of man, not of the Neanderthal type.

1 In my paper in the Journ. of Anat. the illustrations show the correct height, $105 \mathrm{~mm}$., but an error is made in the text. The height is given as $115 \mathrm{~mm}$. instead of $105 \mathrm{~mm}$. 


\section{CHAPTER X}

\section{A MAN OF THE CHELLEAN PERIOD}

In this chapter we again return to the valley of the Thames to take up the story of early man in England. The period now entered-the Chellean-is one of greater duration than even the Acheulean, which has just been surveyed. The site of our first inquiry is at Galley Hill, a few hundred yards to the west, and rather nearer the river than the Barnfield pit at Swanscombe (fig. 56). The school and schoolhouse at Galley Hill stand on the brow of the roo-foot terrace, overlooking the river. The London road passes behind the school as it threads its way eastwards, along the brink of the Ioo-foot level. In 1888 the cement workers had quarried into the chalk bluffs both to the north and to the west of the school, until they had almost reached the London road. Workmen were then-in I888-busy removing the gravel of the roo-foot terrace in order to expose the underlying chalk. The stratum of gravel-as they approached the road-was between 10 and I I feet in thickness. It was while this area was being worked near the London road, a little to the west of the school, that the skeleton of the Galley Hill man came to light-the only representative so far discovered of the generations who lived during the period of Chellean culture. Our conception of the antiquity of man, especially of man of the modern type-for undoubtedly the Galley Hill man is formed in the same mould as we are-turns on the authenticity of this discovery. It is therefore of the greatest importance to examine with care every fact relating to the find at Galley Hill. 
The discovery was made late in September 1888. The first evidence I am to cite is a letter from $\mathrm{Mr}$ Robert Elliott ${ }_{1}-\mathfrak{a}$ printer by trade, but an enthusiastic collector of everything relating to prehistoric times-to $\mathrm{MrE}$. T. Newton, the letter being written when $\mathrm{Mr}$ Newton was preparing for publication a descriptive account ${ }^{2}$ of the Galley Hill man in 1894-six years after the actual discovery:-

"According to my promise, I write to let you know the particulars of my find of human remains in undisturbed gravel, capping the chalk, at the top of Galley Hill, in Kent, at the end of September 1888.

"It was my custom to visit the pits at Milton Street, Swanscombe, Galley Hill, and neighbouring excavations every fortnight regularly (in search of flint implements) for more than two years before the discovery of the human remains-so that I was well acquainted with the fact beforehand.

"It was on one of my fortnightly visits that I was informed by a man, named Jack Allsop (who had for a long time looked out and saved for me any implements or stones of similar shape, obtained while screening the ballast), that he had found a skull under the gravel. This I could hardly credit at first; but on my asking him to show it to me, he produced it in several pieces from the base of a pillar of laminated clay and sand, where he had hidden it. I asked where the rest of the bones were. He pointed to the section opposite this pillar, and a few feet from it, and told me that he had left the other bones undisturbed for me to see; and there, sure enough, about 2 feet from the top of the chalk and 8 feet from the top of the gravel, portions of bone

1 Mr Elliott died, at the agre of seventy, in 1909. He was a Scot-one of the "black" Elliotts from the border country. In his old age he fell into financial straits, and had not Dr Frank Corner, at great personal sacrifice, rescued the Galley Hill and other specimens, they would have passed into a Continental museum.

2 See Quart. Journ. Geol. Soc., I895, vol. li. p. 505. 
were projecting from a matrix of clayey loam and sand. He also told me that several of the men employed at the works, the master of the neighbouring school, and others had seen the skull.

" The section of gravel was Io or I I feet thick, and extended for a considerable distance along the south and east end of the pit; several pot-holes or pipes running from it, deep into the chalk. I carefully examined the section on either side of the remains, for some distance, drawing the attention of my son, Richard, who was with me, and of Jack Allsop to it. It presented an unbroken face of gravel, stratified horizontally in bands of sand, small shingle, gravel, and, lower down, beds of clay and clayey loam, with occasional stones in it-and it was in and below this that the remains were found. We carefully looked for any signs of the section being disturbed, but failed: the stratification being unbroken, and much the same as the section in the angle of the pit remaining to this day; but it was then clear and not covered by rubbish, as it now is in places, all the 'callow' loam at the top being at that time removed to allow of the gravel being got at.

"I went on my knees, and with the point of my geological hammer and a knife tried to work round each piece of bone; but soon gave up the attempt, as the bones were so friable and fragile that many went to pieces as soon as touched, so that I decided to work about a foot each way from the bones. Jack Allsop and I went to work, and we were fortunate enough to obtain the fragments which are now in your keeping [ $\mathrm{Mr}$ Newton's]. So friable were they that we had to place them on soft, newly screened sand to harden in the atmosphere, where I allowed them to remain between four and five hours, by which time they became a little hardened, and 1 carefully wrapped them in soft paper and brought them home. These bones had been left in situ by Jack Allsop, because of their 
being too soft for him to get out, and also in order that I should see them exactly as he found them. Within a few days of my obtaining them, you will, I think, remember that I brought the skull to you in pieces, and you kindly offered to piece the remains together for me; but I preferred taking them away, as I then intended to work the subject up and describe and publish my find. This I have been unable to do, not having the necessary leisure from business, and I regret not having placed them in your hands before. The remains have been in my museum ever since, and no one has interfered with them, except myself and a few friends in my presence. So you have them exactly as they were found, except that I have dipped them in a solution to preserve them. In May last, my friend, $\mathrm{Mr}$ Frank Corner of Poplar, saw these remains and urged me to place them in someone's hands, so that a description of them might be published.'

It will be observed from $\mathrm{Mr}$ Elliott's letter that the master in the school, which overlooks the site of discovery, also saw the remains when they were still embedded in the gravel bank. By good fortune, the schoolmaster, $\mathrm{Mr}$ Matthew $\mathrm{H}$. Heys, was also interested in prehistoric research, and was, as the following letter shows, alive to the importance of the find made by the workmen. In the summer of 1910, when Dr Frank Corner, into whose possession the Galley Hill remains had passed, gave me an opportunity of verifying $\mathrm{Mr}$ Newton's description of the skull and skeleton, I obtained the following letter from $\mathrm{Mr}$ Heys :-

"Some time ago, in I 888, my attention was called to some bones found in the gravel in close proximity to the Galley Hill School, where I was then the head teacher. As soon as the intimation of this find was received, I visited the gravel pit, and there saw a few bones and about a third part of a skull (part of the top and side) just exposed by a workman 
excavating the gravel. To all appearances these bones were human. These were so intensely interesting to me, as I found almost daily Palæolithic implements in this gravel, and here might be the remains of a man belonging to the clan or tribe who had made these very implements. No doubt could possibly arise to the observation of an ordinary intelligent person of their deposition contemporaneously with that of the gravel, for there was a bed of loam, in the base of which these human relics were embedded. The underneath part of the skull, as far as I could see, was resting on a sandy gravel. The stratum of loam was undisturbed. This undisturbed state of the stratum was so palpable to the workman that he said, 'The man or animal was not buried by anybody.' The gravel underneath the skull, of which I took particular notice, was stratified and undisturbed.

"My next step was to induce the workman to desist from exposing these relics further until a photograph of them in situ had been taken; and meanwhile he was to cover them carefully with gravel. To my utter astonishment and indignation, a day or two after, and before I could get a photographer, I found they had been removed by $\mathrm{Mr}$ R. Elliott, then a stranger to me, and without their having been photographed. My anticipated possession of them was thus thwarted. I soon learned there was a working arrangement between Mr Elliott and the workman whereby the latter was subsidised to find fossils, implements, etc., for the former.

"For a long time I took but little interest in the discovery, and this may account for my meagre description given to $\mathrm{Mr}$ E. T. Newton at the time when he read a paper before the Geological Society, of their Galley Hill skeleton. However, since then, I have been reconciled to the loss, for they fell into better hands than mine in many respects.

"I cannot give details of the loamy stratum 


\section{A MAN OF THE CHELLEAN PERIOD ${ }_{1} 83$}

which formed the matrix for these osseous remains, nor exact measurements of the position of the ancient relics. The gravel bed was about io feet thick, resting directly upon the chalk and the loamy stratum, about 2 feet 6 inches from the bottom.

" MatThew H. HeYs.

"July 12th, 1910."

There can be no doubt that in September I 888 the Galley Hill skeleton was found at a depth of about 8 feet in the roo-foot terrace, resting in a stratum of loam. The workman, Jack Allsop, $\mathrm{Mr}$ Elliott, and $\mathrm{Mr}$ Heys were all qualified to form an opinion as to whether or not the terrace over the skeleton was intact. In their opinion it was. That was also the opinion which $\mathrm{Mr}$ Newton formed in 1894 - on an examination of all the evidence then available. Mr Newton's verdict must carry weight with all geologists, for he has spent a lifetime in laying, soundly and solidly, a foundation for our knowledge of the animals which lived during recent geological periods. His eminence as a geologist, and especially his caution as a thinker, are the best guarantees we could have that these human remains belong to a man who lived while the I00-foot terrace was still in process of formation. As for my part, when I commenced a systematic examination of these remains in $1910 \mathrm{my}$ attitude towards them was one of scepticism. The discovery of a man-differing only in details from men now living in England-in-so ancient a formation seemed at variance with a belief in the orderly succession of evolutionary stages in man's early history. It was only when I saw that there was no possibility of denying the authenticity of the discovery without doing an injury to truth, that it became apparent to me, as it had done to many other inquirers, ${ }^{1}$ that the find at Galley Hill had

1 M. A. Rutot, "L'âge probable du squelette de Galley Hill," Bullet. Société Belge de Géol., I 909 , vol. xxiii. p. 239. Professor V. CuiffridaRuggeri, Archiv. per "Antropol., 1910, vol. xl. p. 3. Professor H Klaatsch, Zeitsch. für Ethnologie, 1909, vol. xli. p. 537 ; Prachist. Zeitschrift, 1910, vol. i. p. 296. 
to be accepted as a fact, and that our beliefs regarding man's antiquity must be modified accordingly.

The gravel terrace in which the Galley Hill skeleton was found represents a direct extension of the deposits at Swanscombe. As was mentioned in a former chapter, $\mathrm{Mr}$ Reginald Smith and Mr Dewey found that the gravels in the Barnfield pit at Swanscombe represented at least three series of deposits of three different ages. In which of these three series of deposits were the human remains embedded at Galley Hill ? In the Barnfield pit (see fig. 57) there are two strata of loam-an upper, containing implements of the Acheulean period; a lower, resting on the deepest or basal layer of gravel, and lying under a bed of gravel containing implements of the Chellean age. In the gravels at Galley Hill the same types of implements were found as at the Barnfield pit. There can be little doubt that the skeleton lay in the lower bed of loam-the one under the Chellean gravel. The stratum belongs to the oldest or basal series of deposits of the roo-foot terrace. In the basal gravel occur the Strepyan or oldest form of Palæolithic implements.

M. Rutot, who has done so much to systematise and date the deposits found in river valleys, not only recognised that the Galley Hill man lay in a deposit of Strepyan age, but regarded him as a representative of that time. It is in the deposits of the same period, as M. Rutot was the first to demonstrate, that the early Europeans really applied themselves to stonecraft in earnest-shaping in a rough and crude manner the kind of implements which foreshadow the magnificent tools of the Chellean age. That the pioneers of the great periods of stone culture-the inventors of the palæolith - should be highly evolved men with big brains did not surprise M. Rutot. When, however, we look more closely at the facts revealed at the time of the discovery there is good reason for assigning the Galley Hill man to the subsequent or Chellean period. When, as at Galley Hill and at Halling, representations of a complete 
skeleton are found, with all the parts in close proximity, it is almost certain that the remains have not been entombed by Nature, but by the hand of man. When $\mathrm{Mr}$ Newton read his paper before the Geological Society, Sir John Evans, who took part in the discussion which followed, said that "the occurrence of a nearly perfect skeleton was suggestive of an interment," and "ventured to maintain an attitude of doubt regarding the antiquity of the remains." At that time, twenty-six years ago, the custom of burial was supposed to have been introduced at a comparatively late stage of human evolution. Since then, the discoveries in France have revealed deliberate burials as long ago as the Mousterian and Aurignacian periods. If we accept the discovery at Galley Hill as authentic, we must also accept the great antiquity of the human custom of burying the dead. We hardly do justice to the men who shaped the Chellean weapons if we hold them incapable of showing respect for their dead. Certain it is that the remains found at Galley Hill are not those of a low type of man. In size, and in the richness of its convolutions, the brain of the Galley Hill man does not fall short of the average man of to-day.

We must admit, then, that a burial had been made at Galley Hill-but when? It was before the Thames had laid down the final series of deposits in the roo-foot terrace. Mr Elliott, Mr Heys, and Jack Allsop saw that the overlying, stratified deposits were unbroken. They showed no trace of having been broken by a burial made from the present land surface. As at Halling, we must search for an old land surface, such as may be represented in the Barnfield pit by the stratum of gravel, containing implements of the Chellean type, and lying over the lower stratum of loam-the one in which the human remains were apparently embedded. Weighing all the evidence, we are forced to the conclusion that the Galley Hill skeleton represents a man of the Chellean period, buried when the lower gravel formed a land surface. The land surface of Chellean times 
became submerged by the later or Acheulean deposits of the terrace.

Having thus brought forward the evidence relating to the high antiquity of the human remains found at Galley Hill, we proceed to ascertain what kind of individual they represent. As to the sex there can be no doubtthe bones of the skull and limbs show all the characters which mark the male. Nor can there be much doubt as to his age. The sutures between the bones on the vault of the skull are almost closed-represented only by traces; he was past middle age, probably about fifty. His thigh bones, both of which were found, measure $422 \mathrm{~mm}$., indicating a stature of $1600 \mathrm{~mm}$. ( 5 feet 3 inches)-a short man. Unfortunately, neither of the leg bones-tibiæ-are complete, but by comparing the fragments with complete specimens of both Neanderthal and modern types of man, an approximate estimate may be made of their original length-between $320-325 \mathrm{~mm}$. The leg was thus about 77 per cent. of the length of the thigh - the usual proportion for modern man. The relatively long leg of negroid, Aurignacian, and of some Neolithic races, was not a character of the Galley Hill race. As to the relative proportions of the upper limb, little can be said, for the bones of the forearm were never found. The lower end of the right humerus has been broken away. The original length of this bone was probably between 305 and $315 \mathrm{~mm}$.a dimension to be expected in a modern man of 5 feet 3 inches. One peculiar feature of his organisation is worth noting here. The pectoral muscle, which rises from the inner third of the collar bone or clavicle, and from the front of the thorax, and which passes in front of the arm-pit to act on the upper end of the humerus, was particularly well developed. The impressions for this muscle on the collar bone and humerus are extensive and pronounced. The bones are those of a well-made man of medium strength. The skeleton does not show a single feature which can be called Neanderthaloid, nor any simian feature which is not 
also to be seen in the skeletons of men of the modern type. The Galley Hill man represents no strange species of mankind; he belongs to the same type as modern man.

Such are the general features of the Galley Hill man. For students of human races the form of head and face has a special significance. In this part of our inquiry a special difficulty confronts us. We have seen that the bones when first exposed were quite soft; the skull warped as it dried. To anthropologists, who refuse to recognise any but perfect specimens, the Galley Hill skull will probably be regarded as an unreliable document. Were we to wait for the discovery of perfect prehistoric crania, the early story of man could never be written. We have to make the best of what is found, and, in the case of the Galley Hill skull, it is not difficult to make a due allowance for defects which arise from warping or earth-pressure. The skull, in all its characters, is of the type familiar to students of the human body-it is an extremely long, narrow skull, with a low vault. When viewed in profile and placed within the conventional frame (fig. 63), it is seen to exceed the average modern English skull by I4 $\mathrm{mm}$.- fully half an inch-its maximum length being $204 \mathrm{~mm}$. From the front the skull appears to be flattened from side to side (fig. 63), the width having been originally just under I $40 \mathrm{~mm}$. The man was pronouncedly long-headed, the width being approximately 69 per cent. of the length. We have already seen that most of the Palæolithic Europeans, especially of the Aurignacian period, had exceptionally long heads. In any large modern population in the western side of Europe, individuals with heads of a very similar size and shape could still be found. The height of the vault above the ear-holes in this ancient skull is I $20 \mathrm{~mm}$. - a low amount when compared with the length, and yet in absolute amount rather above the modern average. In size of brain the Galley Hill man is not unlike the modern average man, but an exact estimate is not possible. From direct measurement it was found 
that the brain mass measured between I 350-I 400 c.c., but when we employ the indirect method and calculate the capacity from the diameters of the skull-using the Lee-Pearson formula-a capacity of I 500 c.c. is obtained. In actual size of brain, the Galley Hill man did not differ materially from modern men. The cast of the brain, which $\mathrm{Mr}$ F. O. Barlow made from the skull, shows that, so far as concerns the convolutionary pattern, the Galley Hill man was not inferior to the average modern European. The areas or lobes which are specially
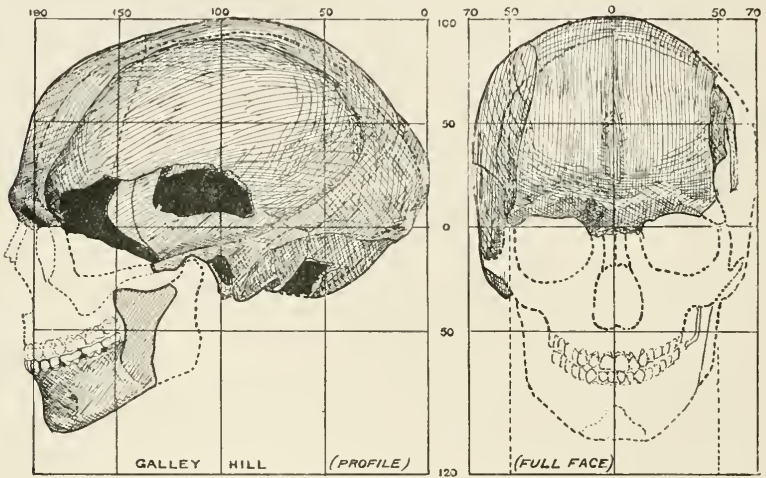

FIG. 63.-The Galley Hill skull viewed from the side and from the front, the face being restored.

associated with the senses of sight, hearing, and touch, are all there; so, too, are the convolutions which are concerned in speech and in movements of the limbs and body.

The question of speech naturally leads our inquiry to the lower jaw-particularly to the region of the chin. Fortunately, the greater part of the left half of the lower jaw, and the whole of the region of the chin, were recovered. There are no Neanderthal marks at the symphysis of the jaw : the markings which indicate the origin of the chief muscles of the tongue are shaped and 


\section{A MAN OF THE CHELLEAN PERIOD I 89}

placed as in modern man. From the conformation of the brain and of the chin-being exactly as in modern man-we draw the conclusion that the faculty of speech was fully evolved. It is difficult to suppose that the race who invented and mastered the high art shown by Chellean implements had not, long before, attained the gift of speech. When it is remembered we are dealing with a period-the Chellean-which, so it is estimated from the physical changes that have occurred since, lies at
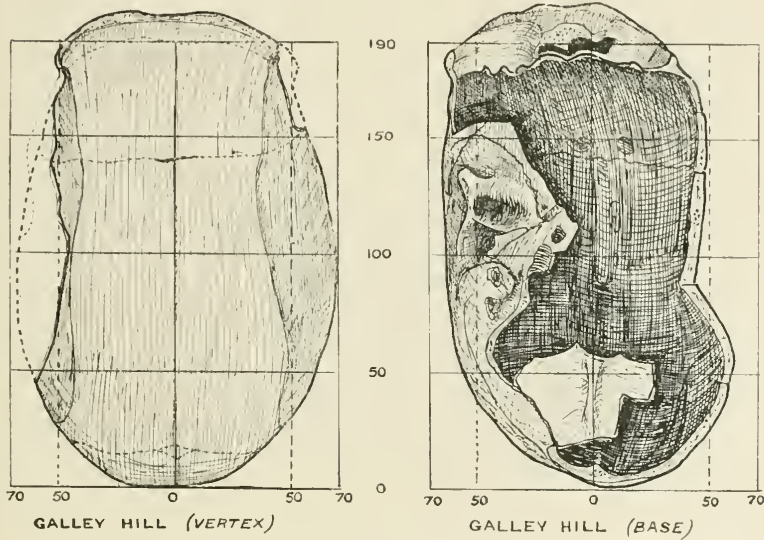

Fig. 64.-Drawings of the Galley Hill skull from above and below. The latter shows the degree of twisting or torsion.

least between a hundred thousand and a hundred and fifty thousand years beyond our time, it will be seen that a great claim is made, not only for the antiquity of man, but for the antiquity of human culture.

The reader will have a difficulty in believing that human remains, to which so great an antiquity is assigned, do not show in their structure, as well as in their degree of fossilisation, some evidence of their ancient origin. They do. In the first place, the condition of preservation is peculiar-quite unlike any bones of Neolithic or of 
Palæolithic date I have ever seen. Mr E. T. Newton is perfectly familiar with the degree of fossilisation seen in bones from the roo-foot terrace. He and other authorities regard their condition as evidence of their high antiquity. There are several structural parts which indicate a primitive form of man. The skull is thick, the vault varying from Io to $\mathrm{I} 2 \mathrm{~mm}$.- -altogether an exceptional measurement. The eyebrow ridges, although of the modern, bipartite form, are yet exceptionally pronounced. The middle or supraciliary parts are continuous with the lateral or malar parts, as in the most uncivilised of modern races. In the lower jaw itself, very primitive features are present.

A drawing of the mandible from the side is seen in figs. 63 and 67 . The ascending branch or ramus, which articulates with the base of the cranium, by means of the articular condyle, does not show the sigmoid notch or bay usually seen on its upper border. This notch is situated in front of the articular condyle, and behind the coronoid process to which the chief muscles of mastication are attached. In all modern races, in most of the late Palæolithic, and in all Neolithic races, the sigmoid notch is deep and well marked. In the Galley Hill ascending ramus such a notch is almost absent. Its absence is a primitive feature. The joint on the base of the skull, for the condyle of the jaw, shows in its shape and size the characters seen on the skulls of primitive races of the modern type. The ear-hole is remarkably large; the mastoid process behind it, on the other hand, is small. The area for the temporal muscle, the chief muscle of mastication on the side of the skull, is abnormally extensive, indicating large muscles of mastication.

Five teeth remained implanted in the mandible-the two premolars and three molars of the left side. The other lower teeth-incisors and canine-had dropped from their sockets after death. The crowns of the molar teeth are worn - not deeply - in the manner seen in the dentitions of races living on a crude, vegetarian diet. 


\section{A MAN OF THE CHELLEAN PERIOD I9I}

The teeth themselves are not large, the total length of the crowns of the three molar teeth being $34^{\circ} 5 \mathrm{~mm}$. The last molar is slightly longer than the second. The width of the molars-the diameter between the cheek and tongue margins-is less than the length. All of those features are such as we expect in an individual of a very primitive type : a combination of such characters would be very difficult to find in any European of modern or of Neolithic date.

When the Galley Hill jaw and teeth are examined by

FIG. 65.-Radiograph of the Galley Hill mandible and teeth.

$\mathrm{X}$-rays, we see that there is no trace of the peculiar specialisation-the enlargement of the pulp cavitytaurodontism-which characterises, in a greater or lesser degree, the teeth of Neanderthal man (see p. I47). In fig. 65 is reproduced an X-ray photograph of the teeth and mandible. The teeth show primitive characters ; in all their parts they are of an older and a more simian type than the molars of Neanderthal man. ${ }^{1}$ The pulp cavities, in place of being large, as in adult apes with

1 For an account of the Galley Hill teeth, see reference, p. 179 (Newton), p. 148 (Keith). 
worn teeth, are particularly small. The smallness of the cavity is due to the fact that it is being rapidly filled up by the formation of secondary dentine-Nature's way of protecting the sensitive pulp from being exposed, as the crown is worn by chewing. In shape of root, as well as in size and relative proportion of crown, Galley Hill teeth show a primitive human type. We need not, then, reject the Galley Hill remains on account of the modernity of their structure and characters; they do show such primitive marks as we should expect in an ancient form of European.

Mention has been made of the large muscles of mastication. The facial parts of the skull are gone, and we cannot measure the size of the palate directly. But we can estimate its size by an indirect method. More than half of the lower jaw is present; the size of the arcade, formed by the lower teeth, is known. From the lower set we can calculate the form and size of the upper set. In this way we reach the conclusion that the area of the palate (see p. 97) was between 29 and $30 \mathrm{~cm} .^{2}$-its length being $53 \mathrm{~mm}$., its width, 66 or $67 \mathrm{~mm}$. These dimensions are not exceptional ; on many modern skulls, especially of primitive races, palates of equal or even greater dimensions are to be found.

Why is it, then, that anatomists and geologists have been so reluctant to acknowledge the antiquity of the Galley Hill remains? The anatomist turns away from this discovery because it reveals no new type of man, overlooking the much greater revelation-the high antiquity of the modern type of man, the extraordinary and unexpected conservancy of the type. The geologist regards the remains with suspicion for two reasons-first, he has grown up with a belief in the recent origin, not only of modern civilisation, but of modern man himself. He expects a real anatomical change to mark the passage of a long period of time. Further, at a much later date than the formation of the roo-foot terrace, a very primitive type of man survived in Europe-such a type as answers exactly to the evolutionist's expectation 
A MAN OF THE CHELLEAN PERIOD 193

of a human ancestral form. The discovery of human remains of the Neanderthal type confirmed geologists in their opinion that Pleistocene man must be of a more primitive - at least, of a different type to modern man. Hence the rejection of all remains - such as those found at Galley Hill-which do not conform to this standard. 


\section{CHAPTER XI}

PRE-MOUSTERIAN MAN IN FRANCE AND ITALY

A JOURNEY of a little over one hundred miles from Galley Hill lands the traveller at the town of Abbeville, situated on the estuary of the Somme in the north-east of France. On the higher grounds of the northern suburbs of Abbeville, we find an exact counterpart of the terrace we have left at Galley Hill. Thanks to the pioneer labours of M. Commont, ${ }^{1}$ Professor at l'École Normale of Amiens, a city on the Somme fully twenty miles above Abbeville, not only the exact structure of the 100-foot or 30-metre terrace-also named the middle terrace-is known, but also the sequence of flint implements contained in the various strata of this terrace. Indeed, it was M. Commont's discoveries in the terrace of the valley of the Somme which led to the inquiries at Swanscombe by Mr Reginald Smith and Mr Dewey. These gentlemen found in the roo-foot terrace of the Thames valley, as we have just seen, the same triple series of deposits, and the same cultures as M. Commont had previously discovered in the 30-metre terrace at Abbeville and at Amiens. Even in the most ancient Palæolithic times, intercommunication between France and England must have been sufficiently advanced to allow a free interchange of culture. In fig. 66 is given M. Commont's section of the roo-foot terrace at Abbeville, as shown in the Carpentier gravel pit. The lowest

1 Les gisements paléolithiques d'Abbeville (Lille, I910). See also L'Anthropologie, 1908, vol. xix. p. 527 ; ibid., 1911, vol. xxii. p. 575 . Compt. rend., I9I I, vol. cliii. p. 1256. 
series of deposits, resting on the chalk, is made up of a gravel, a greenish clay, and a chalky loam or marle. The worked flints found in this series belong to an older culture than the Chellean - they are preChellean. The second series of deposits is represented by a gravel and an overlying bed of light-coloured sands yielding flints of the Chellean period. The third series of deposits begins with a seam of flints, or gravel, containing implements of the first Acheulean ${ }^{1}$ culture;

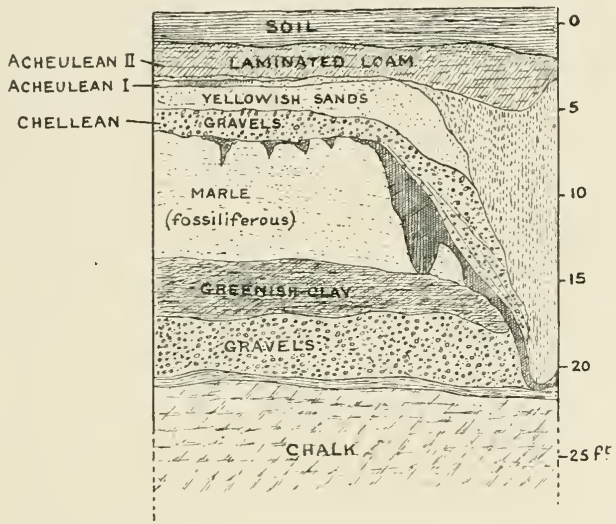

FIG. 66. -Section of the 30-metre terrace at Abbeville (V. Commont).

in the overlying bed of red, sandy, laminated loam"limon fendille"-occur the later Acheulean implements of the type found in the brick earths at Bury St Edmunds. Often in the deeper layers of the last-mentioned stratum occur black bands of manganese. At the Carpentier pit, as at the Barnfield, the series of deposits end with the late Acheulean culture; but in other sites in the same terrace, and particularly in the lower or 50-foot terrace, deposits of a later date occur, containing implements of the Mousterian, Aurignacian, and even late Palæolithic cultures. Our visit to Abbeville assures us that in the 
river valleys of the adjoining parts of France and England occur the same sequence of terraces, deposits, and cultures.

The investigations of $\mathrm{M}$. Commont belong to the commencement of the twentieth century. Seventy years before his time even more remarkable discoveries were made at Abbeville. In I $825, \mathrm{M}$. Boucher de Perthes, then a man of forty-one, was placed in charge of the customs of the town. In the years following the date of his appointment, cave exploration was attracting the attention of antiquaries. It was in 1833 that Schmerling published the results of his investigations at Engis. No one had ever looked, or even thought of looking, in the gravel deposits of valley terraces for human implements until Boucher de Perthes took up his abode in the Somme valley. The terraces were known to contain the remains of extinct animals, and their formation was supposed to predate man's appearance. About the year 1832 this antiquarian exciseman first noticed very curiously shaped stones in the gravel pits. These stones, we now know, represented human implements of the Acheulean type. We are not surprised that he recognised in those stones the work of man's hand and of man's brain, but we have a difficulty in understanding why those to whom he showed them did not agree with him. Even in I 847 , when he had published the first part of his great work, Antiquités Celtiques et Antédiluviennes, he had not gained a single convert. Indeed, his discovery was regarded in the light of a joke. In $185^{8}$ the public attitude towards Boucher de Perthes' work began to change, and in that change Dr Hugh Falconer, whom we have come across before as explorer of the Brixham cave, gave a helping hand. He had in his younger days made known the extinct animals found in the Siwalik formations in India, and in 1858 was searching the caves on the shores and islands of the Mediterranean for fossil animals. On his way to the caves he had the good fortune to call at Abbeville and to meet Boucher de Perthes. He realised at once that this local antiquarian, 
in charge of the customs-house at Abbeville, had made a great discovery-one which revealed an ancient and unsuspected chapter of human history. Falconer was one of a remarkable group of British scientists, embracing Sir Charles Lyell, George Busk, who brought the Gibraltar skull to England, Joseph Prestwich, a wine merchant and geologist, John Evans, a paper manufacturer and antiquarian, and John Lubbock, banker, naturalist, and anthropologist. Falconer prevailed on his friends to visit Abbeville. The result was that this brilliant school of geologists became convinced that Boucher de Perthes' discovery was right-the implements were of human workmanship, and that man had lived when the I 00 -foot terrace was being formed.

In 1863 another famous discovery by Boucher de Perthes brought the English geologists back to Abbeville. The discovery was made in the Moulin Quignon pit in the roo-foot terrace at Abbeville, a few hundred yards to the east of the Carpentier pit (fig. 66), so thoroughly investigated by Commont.

The Moulin Quignon pit, like others along the valley of the Somme, had yielded a rich harvest of Palæolithic implements-both Acheulean and Chellean types-to Boucher de Perthes, but not a trace of the man who fashioned them, although liberal rewards were held out to the workmen in the pits. On March $23 \mathrm{rd}$, I $86_{3}$, the long-expected discovery was made ; on that day Boucher de Perthes removed with his own hand a human jaw from the lower gravels of the Moulin Quignon pit. The mandible lay ${ }^{1}$ in a well-known, particularly black stratum of sand and gravel which contained many fints of the Acheulean type- "coup-de-poing," or "hand-axes," as they were then called. The black stratum was $5 \mathrm{~m}$. (I $6 \frac{1}{2}$ feet) below the surface of the pit, almost on the chalk. The section of the Carpentier pit (fig. 66) shows how the upper or third series of deposits may dip down almost to the chalk, as they evidently did at Moulin

1 For a full account of the discovery of, and conference on, the Moulin Quignon jaw, see Natural History Review, 1863, vol. iii. p. 423. 
Quignon. The news of this discovery brought the English group of geologists hot-foot to Abbeville. It was the first discovery of "river-drift" - terrace-gravel man. At first the visitors were impressed favourably. Then it was found that some of the implements in Boucher de Perthes' collection were forgeries, foisted on him by the workmen. The Englishmen returned home in doubt, bringing with them the jaw, and also an isolated human tooth found in the same stratum. Falconer and Busk took the jaw to the museum of the Royal College of Surgeons, and cut it across to see the state of fossilisation. They also made a section of the isolated tooth. The cut surface of the tooth and of the jaw appeared surprisingly well preserved and fresh; they were really shocked to find it contained as much as 8 per cent. animal matter. That was the circumstance which turned their suspicion into a serious doubt, although on the shelves of the museum in which they had met there was a series of specimens, prepared by John Hunter in I792, to show that the bones of Pleistocene animals may contain as much as 30 per cent. of animal matter. Gimbernat had even made a jelly from the bones of the mammoth. Then a curious thing happened. In May of the same year, I 863, the English geologists went to Paris to meet in solemn conclave their confrères of France and pass sentence on the jaw. The conference broke up leaving the French section convinced that the Moulin Quignon jaw was an authentic document, and the English that it was a forgery. French anthropologists continued to believe in the authenticity of the jaw until between I 880 and 1890 , when they ceased to include it in the list of discoveries of ancient man. At the present time opinion is almost unanimous in regarding the Moulin Quignon jaw as a worthless relic. We see that its relegation to oblivion begins when the belief became fixed that Neanderthal man represented a Pleistocene phase in the evolution of modern races. That opinion, we have seen, is no longer tenable.

Was Boucher de Perthes tricked? Let us look at the 
specimen, or rather at an exact cast of the specimen, for it is on that I have had to base my examination. The mandible was originally covered by the black specks of the stratum in which it lay. Mr Busk found he could brush these specks off; that does not invalidate its authenticity. The shape of the mandible is remarkable. In fig. 67, I reproduce the appearance of the jaw as seen from the side, in true profile. Beside the Moulin Quignon specimen, I have placed a similar outline of

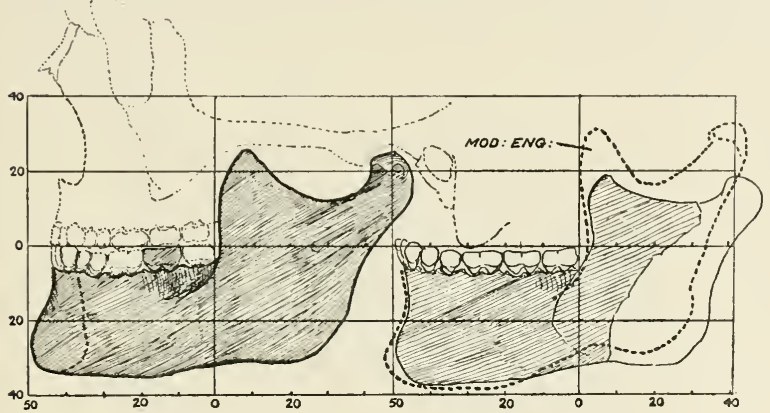

(A) MOULIN QUIGNON

(B) GALLEY HILL.

FIG. 67.-(A) A profile drawing of the Moulin Quignon mandible. (B) A profile drawing of the Galley Hill mandible. On the latter a stippled outline of a modern English mandible is superimposed.

the mandible of the Galley Hill man. It is then seen that the ascending branch of the Moulin Quignon jaw, bearing the articular condyle and coronoid process, is altogether of remarkable width $-50 \mathrm{~mm}$. at its widest part. The body of the jaw is not deep as measured from its upper or tooth-bearing border to its lower. Indeed, it is shallow, but its thickness, measured from the inner to the outer surface in the region of the molar teeth, is of more than average amount. In the region of the chin and symphysis, all the markings and features found in the chin region of modern man are present. When a comparison is made with the Galley Hill mandible (fig. 67), the Moulin Quignon specimen is, on the whole, 
the less primitive. Its ascending branch is the wider, but the Galley Hill ramus shows the more shallow, and therefore more primitive, notch between the condylar and coronoid processes. The mandible which shows the nearest approach to Boucher de Perthes' specimen is one known as the Foxhall mandible. ${ }^{1}$ It was found in the same year, 1863 , in the sand pit of Foxhall, near Ipswich. The exact stratum from which it came is not known. Huxley, Busk, and Falconer had the Foxhall specimen by them when they were investigating the Moulin Quignon mandible at the College of Surgeons.

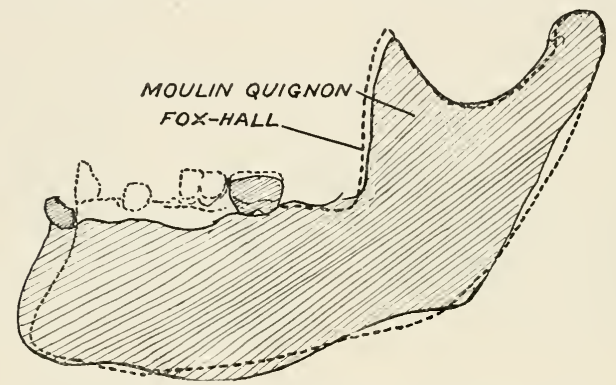

FIG. 68. - Stippled outline of the Foxhall mandible superimposed on a drawing of the Moulin Quignon specimen.

The condition of preservation was similar in both cases. In fig. 68, I superimpose the drawing given by $\mathrm{Dr}$ Collyer of the Foxhall jaw on a contemporary drawing published of the Moulin Quignon specimen $;^{2}$ they are almost identical. In the following figure, 69 , I contrast the Abbeville jaw with that of a Neanderthal man-one of the specimens found at Spy. It is at once apparent how different they are. The Neanderthal (Spy) specimen is by far the more simian, and if we did not know that men of the modern type must have been contemporaries of the Neanderthal species, we should never hesitate in

1 "The Fossil Human Jaw from Suffolk," Robert H. Collyer, M.D., Anthrop. Review, I867, vol. v. p. 221.

2 J. L. Rome, F.G.S., The Abbeville Jaw, Hull, 1864. 
accepting the Spy mandible as the true representative of Pleistocene man.

Were our predecessors right in rejecting the Abbeville mandible? I think not. Boucher de Perthes gives the most circumstantial account of its discovery. There is not a single point mentioned by Busk or by Falconer which makes its antiquity impossible. It was almost an isolated case in I863, but since then the discoveries at Galley Hill, at Bury St Edmunds, at Clichy, and at Grenelle have been made. Our predecessors were largely

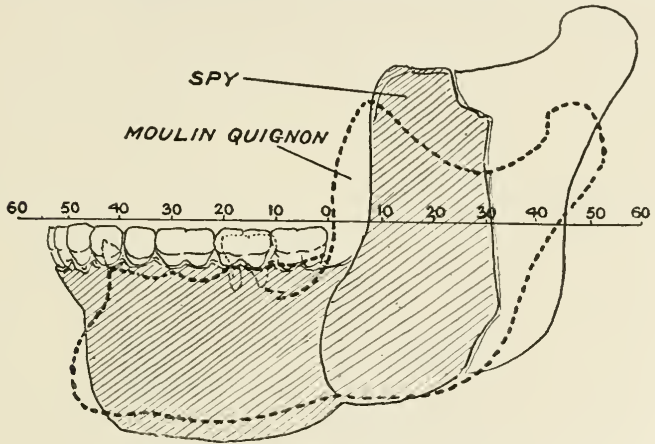

FIG. 69.--Stippled outline of the Moulin Quignon mandible superimposed on the Spy (Neanderthal) specimen.

influenced by prejudice. Time will probably show that the pioneer of Abbeville was not only right about the human implements of the terraces, but also about the human remains. He died in $\mathrm{I} 868$ : it was not until I 908 that a statue was erected to him in Abbeville.

In our search for men of the most ancient Palæolithic periods, we now move from Abbeville on the estuary of the Somme to Paris on the banks of the Seine. The greater part of Paris is built on deposits-on terraceslaid down by the Seine. The river deposits of Paris offer certain advantages for our present purposes. Galley Hill and Abbeville lie in the tidal reach of their valleys. When submergence of the land sets in, the 
tidal reaches of the valleys become filled up. Afterwards, as the land rises again, the deposits are scoured out. All that remains of these deposits are the fragments preserved as terraces on the sides of the valley. At Paris we are far enough above sea-level to safeguard the valley deposits; they may be disturbed in part, but at many places we may expect to find the very oldest deposits lying in their original condition on the lowest part of the valley. At Chelles, for instance, eight miles to the east of Paris, the ancient deposits, with typical specimens of the Chellean culture, rest on the floor of the valley of the Marne. If ancient river deposits do contain human or other remains, there is no place where they were so likely to be discovered as in the foundations of Paris-for no area has been so extensively excavated.

In the year I 868 a gravel pit was still worked off the Avenue de Clichy, right in the heart of that part of Paris which lies on the north bank of the Seine. The problem of man's antiquity was still being debated. On the $\mathrm{I} 8 \mathrm{th}$ of April of that year-I868-M. Eugène Bertrand, then a student in Paris, visited, as was his wont, the gravel pit off the Avenue de Clichy to see what fossil bones had come to light. The remains of extinct Pleistocene mammals had been found from time to time. On that morning he was informed that the labourers had exposed a human skeleton on the working face of the pit. M. Bertrand was an expert observer and familiar with the strata of the pit. The depth at which the skeleton lay was $5.25 \mathrm{~m}$. ( $17 \cdot 3$ feet) from the surface. It was embedded in the fourth layer from the top. Fig. 70, which shows the sequence of the overlying strata, is taken from a paper recently published by $\mathbf{M}$. Rutot. M. Bertrand gave an account of his discovery to the Anthropological Society of Paris in the same year. ${ }^{1}$ The antiquity and authenticity of the Clichy skeleton was accepted by all the authorities in France except oneM. G. de Mortillet, who believed that the workmen at the pit had deceived M. Bertrand. The clear-sighted

1 Bull. Sor. d'Anthrop., I 868, ser. 2, vol. iii. p. 329. 
Professor Hamy had no doubt as to any of the facts relating to the discovery. In his excellent treatise on Ancient Man ${ }^{1}$ he records all the essential facts bearing on the authenticity of M. Bertrand's observations.

The same fate overtook the Clichy skeleton as the Abbeville jaw. With the acceptance of Neanderthal man as our Pleistocene ancestor, it was relegated to oblivion,

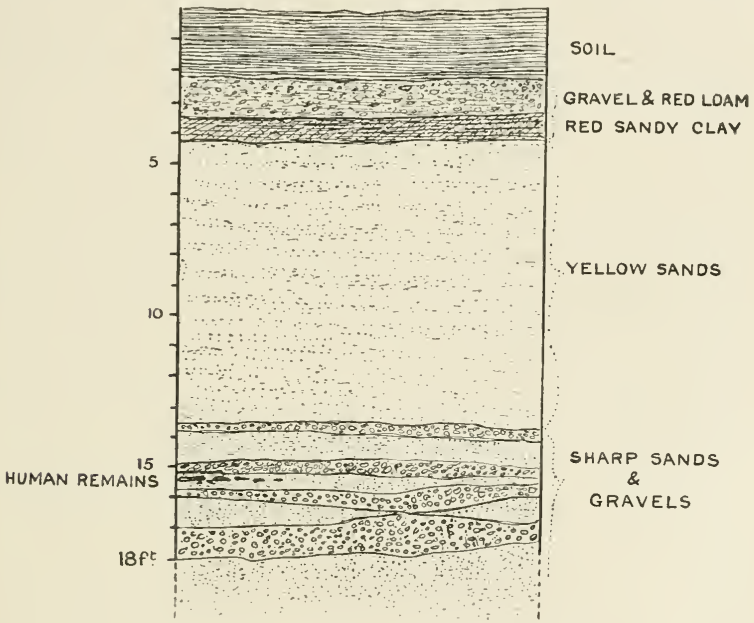

FIG. 70.-Strata of the gravel pit at Clichy, Paris (after M. Rutot).

and would probably have remained there had it not been for M. Rutot. M. Rutot has spent a lifetime in studying the river deposits of the valleys of Belgium. He is convinced that his observations of the valley deposits of Belgium may be applied to the valleys of the adjoining countries. He is certain that the terraces of the Seine at Paris must have been formed at the same time and in the same way as those in the valleys of the Meuse, of the Thames, and of the Somme. In I 9 Io he visited Paris

${ }^{1}$ Précis de paléontologie humaine, E. T. Hamy, Paris, 1870. 
and verified his conclusions. ${ }^{1}$ At Clichy he found the same deposits, in the same order as at Abbeville, as at $\mathrm{St}$ Acheul, and as at Galley Hill. Each stratum carried in it the corresponding Palæolithic culture. The skeleton at Clichy, he has proved, lay in a deposit which corresponds to the one in which the Galley Hill skeleton was embedded. At Galley Hill the human remains lay in the loam under the middle gravel, the stratum which contains palæoliths of the Chelles period. At Clichy the human skeleton lay in a grey loam with bands of gravel and of sand which at St Acheul contains the typical Chellean industry.

The discoveries at Clichy and at Galley Hill revealed very similar kinds of men. At Clichy a whole skeleton was represented; we have clearly to do with a burialone made probably from a Chellean land surface. As at Galley Hill, the individual found had a remarkably long head, $2 \mathrm{O}_{4} \mathrm{~mm}$., with a width of $\mathrm{I}_{3} 8 \mathrm{~mm}$. - almost to a millimetre the length and width of the Galley Hill skull. Unfortunately, at Clichy the lower part of the forehead was broken away, but the bones of the vault have the same extreme thickness as at Galley Hill- Io to I $3 \mathrm{~mm}$. The height of the vault above the ear-holes is almost the same-I $8 \mathrm{~mm}$., a low roof for such a long skull. The ear-holes are wide and the mastoid process smallexactly as in the Galley Hill skull. On the other hand, there is a difference as regards the lower limbs. The Galley Hill tibia was not flattened from side to side; in the Clichy skeleton flattening was present. Both were persons of low stature. Can we suppose that the workmen at Galley Hill and at Clichy had a supernatural knowledge and implanted those two similar but peculiar varieties of men in the same geological stratum, and in the midst of the same ancient, Palæolithic culture? As regards size of brain, the Clichy man, judging from the measurements of the skull, should be about of the same brain capacity as the Galley Hill man-under I 500 c.c.

1 "Revision stratigraphiques des ossements humains quarternaires de l'Europe," Bull. Soc. Belge de Géol., 1910, vol. xxiv. p. 123. 
I have cited only this one instance from the ancient valley deposits of Paris, because it is not necessary to prove more than one case-one instance of a modern type of man who lived before the Mousterian period, the heyday of Neanderthal man in Europe. At Grenelle, on the south bank of the Seine, in Paris, human remains of the same type have been found at an even greater depth, and others of a different type at more superficial horizons. There is no doubt that even in the earliest Palæolithic periods-one hundred thousand or even one hundred and fifty thousand years ago-the culture and the people in the valley of the Seine and in the valley of the Thames were very much alike.

From Paris our present inquiry takes us along the valley of the Rhone towards the north of Italy. At Lyons it is well to break our journey and visit Le Puy, situated on the upper waters of the Loire in a mountainous country to the north of the Cevennes. In the museum of the town is preserved the frontal bone of a human skull, which was found embedded in a volcanic matrix. The history of the specimen is well known. An account of it was published in 1844 , but the fullest description is that given by Dr Sauvage in I $872 .^{1}$ In 1859 , Sir Charles Lyell visited Le Puy, and examined the volcanic deposits on Mount Denise, where the specimen was found. The actual site of discovery is situated in a vineyard terrace near the summit of a hill. The matrix in which the specimen is embedded guarantees its antiquity. The frontal bone is that of a person who lived before the last volcanic eruption which occurred in Central France. In the same deposit as the skull are found the remains of the cave-hyena and hippopotamus. The date of the eruption and of the skull is therefore mid-Pleistocene-about the same age as the Bury St Edmunds fragment. Perhaps it may be older. Its interest for us is that although so ancient it differs in no essential particular from the frontal bone of a modern. skull (fig. 7I). From its dimensions one infers that it 1 "L'homme fossile de Denise," Rev. d'Anthrop., I872, vol i. p. 289. 
formed part of a relatively small skull - somewhat larger than the skull represented by the Bury St Edmunds fragment. The frontal bone is not thick, only $6.5 \mathrm{~mm}$., and the supra-orbital ridges are not pronounced. From other features we infer the Denise skull was that of a young woman. Other bones of the human skeleton have also been found in the same volcanic deposit, but, unfortunately, to meet a demand on the part of visitors to Le Puy, many spurious specimens were offered for

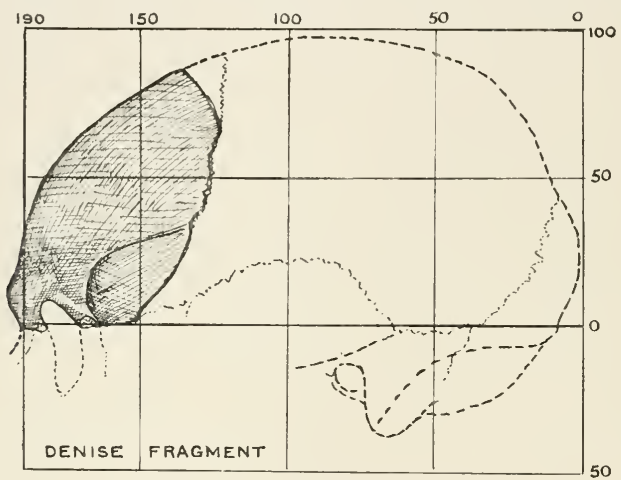

FIG. 7I.-The Denise frontal bone.

sale, thus throwing doubt on those which are undoubtedly genuine.

The final discovery I am to cite as evidence that the inhabitants of Europe in pre-Mousterian times were people, not of the Neanderthal, but of the modern type, is that made in 1863 by Signor Cocchi, Curator of the Museum of Geology in Florence. ${ }^{1}$ In making the railway southwards from Arezzo, in the upper waters of the Arno, a cutting or trench over 50 feet deep had to be dug. During the excavation the Olmo skull was discovered. It lay at a depth of almost 50 feet ( $5 \mathrm{~m}$.)

1 "L'Uomo fossile nell' Italio Centrale," Mem. dell. Soc. Ital. de Sc. Nat. Milan, 1867, vol. ii. No. 7. Abstract in Bullet. Soc. d'Anthrop., I868, ser. 2 , vol. ii. p. 40 . 
beneath the surface, in a deep stratum of blue clay-a deposit formed in the floor of an ancient lake. That the skull lay in this stratum there can be no doubt. It is still preserved in the Geological Museum of Florence, its cavity being filled-as when found-by a mass of the blue clay. Over the blue clay of the railway cutting were deposits-about I 2 feet in thickness-which Cocchi regarded as of late Pleistocene and also of recent formation. The blue clay in which the skull was embedded he assigned to the older Pleistocene deposits. The remains of the mammoth, and of an early form

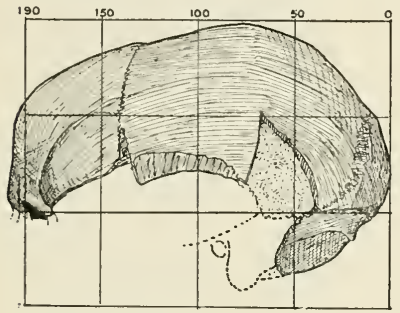

OLMO. (PROFILE)

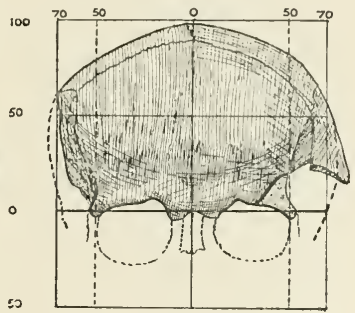

OLMO (FULL FACE)

FIG. 72. - The Olmo cranium viewed from the side and from the front.

of Pleistocene horse (Equus larteti), occurred at the same horizon as the skull. Near the skull, charred wood marked the site of an ancient hearth. The culture of the period is represented by a Palæolithic implement which may well belong to the Chellean period. The exact cultural horizon to which the skull should be assigned cannot be fixed with any degree of certainty, but for our present purpose it is sufficient to be convinced that the skull is older than the period of Mousterian culture. Of that, I think, there can be no doubt.

The skull is clearly a variant of the modern type. A few years ago, my friend, Professor Sera, was good enough to obtain for me an exact cast of the Olmo skull, and it is from that cast that the accompanying drawings have been made. When viewed in profile, the skull is 
seen to be of about the same length as the Galley Hill and Clichy specimens (fig. 72). Its length is $202 \mathrm{~mm}$.; its width is more difficult to estimate exactly, owing to some degree of distortion by earth-pressure, but it cannot have been less than $150 \mathrm{~mm}$.-giving a head index of 74 . The vault is low, about i $6 \mathrm{~mm}$. above the earpassages, and remarkably flat-a feature recalling the Bury St. Edmunds fragment. As in that fragment, the frontal bone is sharply bent, producing a wide and vertical fore-
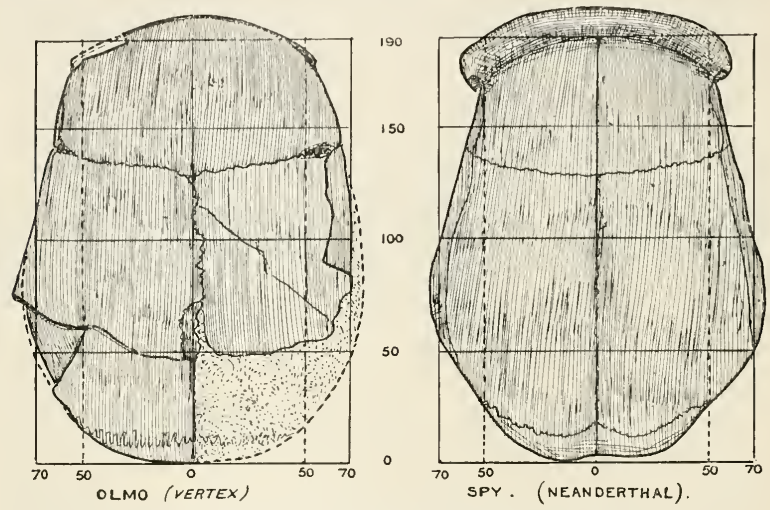

FIG. 73.-The Olmo cranium viewed from above, compared with a similar view of the vault of the Neanderthal calvaria.

head. The brain capacity is estimated at I 560-I 600 c.c. - a large and capacious skull. The forehead shows a smaller development of supra-orbital ridges than in the skulls of the more primitive of modern races. The width of the forehead, at the level of the upper margin of the orbits, is only Io6 $\mathrm{mm}$.; higher up, the minimum width is $100 \mathrm{~mm}$. On the other hand, the bones of the vault are remarkably thick-I I $\mathrm{mm}$. There is not a single feature in this skull we can call simian. In this it agrees with other human skulls of great antiquity.

We have now completed a tour of Europe in search of pre-Mousterian man. The European of the Mousterian 
period-Neanderthal man-from an anatomist's point of view, was of a most primitive type. He possessed many features which are rightly regarded as ape-like. In the deposits of the two long periods which preceded the Mousterian-the Acheulean and Chellean-probably covering between them a stretch of a hundred thousand years -at least, the Thames filled up and scoured out its valley twice during that space of time-we have found no trace of Neanderthal man, nor of his ancestor. The deposits of the Thames, of the Somme, of the Seine, of the Arno, from one side of Europe to the other, have revealed the same story - the existence of a man, a mere variant of modern man, one with a thick skull, a big brain, and a long head. How are we to account for this unexpected revelation? There are two ways : we may hold with the majority of anatomists and geologists, and simply refuse to believe in the authenticity of these discoveries because they run so contrary to our preconception of how and when modern man was evolved. Or, with Sergi and with Rutot, we may put our preconceptions aside, and, as we are bound to do, accept the revelations of those discoveries as facts, and alter our conception of man's evolution to harmonise with our facts. We have, in the first place, to conclude that man of the modern type is much older than we supposed. We expected to find him in a process of evolution during the Pleistocene period, but we have traversed more than the half of that period and find our own species much as we find him at the present day. It is clear we must seek for his evolution at an earlier time than the Pleistocene. Neanderthal man is a different and very primitive species of man. Where and when he was evolved we do not know, but clearly he was an intruder when he entered Europe at a late stage of the midPleistocene period. Further, we have to take a more complex view of the world of ancient man. In our first youthful burst of Darwinianism we pictured our evolution as a simple procession of forms leading from ape to man. Each age, as it passed, transformed the men of the time one stage nearer to us-one more distant from the ape. 
The true picture is very different. We have to conceive an ancient world in which the family of mankind was broken up into narrow groups or genera, each genus being again divided into a number of species-much as we see in the monkey or ape world of to-day. Then out of that great welter of forms one species became the dominant form, and ultimately the sole surviving onethe species represented by the modern races of mankind. 


\section{CHAPTER XII}

THE IPSWICH MAN

On several occasions, in the course of our search for traces of ancient man, a cursory glance has been bestowed on the three eastern counties of England-Norfolk, Suffolk, and Essex-which represent East Anglia. At Ipswich, in Suffolk, Mr Reid Moir discovered, in quite superficial strata, work-floors and hearths of two of the later Palæolithic periods-the Aurignacian and the Magdalenian. A little further to the north, near Mildenhall, Dr Allen Sturge's excavations revealed workfloors of the Magdalenian and of the Mousterian periodsthe work-floor of the latter being overwhelmed by an icemovement of the last glacial phase of the Pleistocene period. Between Mildenhall and Ipswich lies Bury St Edmunds, with its deposits of brick earths and its remains of Acheulean man and his culture. Twenty miles to the east of Bury St Edmunds, in the watershed of the Waveney and on the borders of Suffolk and Norfolk, are the Hoxne brick earths, with worked implements of the Acheulean period. Those brick earths, we have seen (fig. 60, p. I 73), are the upper of a series of deposits which fill an ancient valley which was some 50 feet in depth. In the deeper deposits of this buried valley no flints of the Chellean or of any previous period were encountered. We shall probably be near the truth if we regard the lignite deposit of the Hoxne valley-laid down in a temperate interval-as being as old, or older, than the Chellean period. The Arctic bed between the lignite deposit and the Acheulean brick earths on the surface 
may well represent one of the sub-Arctic oscillations which are attributed to the Chellean period. However that maybe, it is quite evident that the great layer of chalky boulder clay, and the thick bed of glacial sands which lie under the boulder clay, are very much older than the deposits of the Hoxne valley, for the valley had been carved out of these deposits by a stream which no longer exists. Any remains of man or of his works found in or under undisturbed chalky boulder clay belong to a much older period than any we have dealt with in former chapters.

The boulder clay, which forms a thick sheet over a great part of East Anglia, is regarded by geologists as a

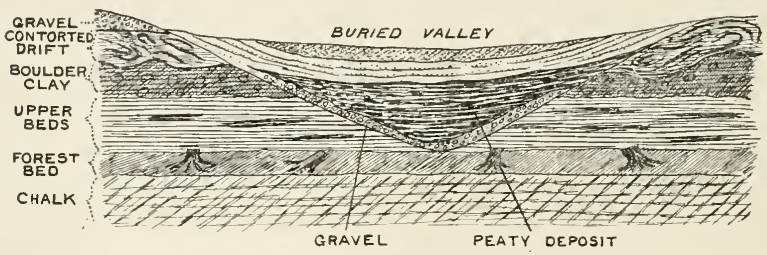

FIG. 74--Section of the Pleistocene deposits near Cromer, Norfolk

(Sir Charles Lyell).

product of the most severe of all the glacial cycles. It is important for our present inquiry to ascertain the position of the chalky boulder clay in the series of deposits laid down at an early part of the Pleistocene period. The accompanying illustration (fig. 74) is copied from the first edition of Sir Charles Lyell's Antiquity of Man (1863). In that illustration the Rev. S. W. King represents a section of a cliff, on the coast of Norfolk, a few miles to the east of Cromer. The cliff is there 35 feet high. The section is similar to that at Hoxne. An ancient valley is seen in the section, filled with various deposits. The valley has been cut in the boulder clay, which is here capped by a stratum of "contorted drift" and a layer of gravel. The midglacial sands, seen at Hoxne, are absent. In their place 
is an early Pleistocene deposit-upper or Runton beds, composed of laminated mud, loam, sand, and vegetable débris, laid down in valley, estuary, and sea during many an alteration in the level of the land. Deeper still are the remains of an ancient submerged forest-the Cromer forest bed. Tree trunks, some of the stumps still rooted as they grew, make up the Cromer forest beds. These beds take us to the boundary line between the Pleistocene and the Pliocene. Sir Charles Lyell looked on them as representing a transition period. The plants and trees are those which are still familiar to us, but the mammals are of a kind which mark the fauna of the late Pliocene period. Three forms of elephants then lived in East Anglia - the predominant species being Elephas meridionalis. The modern roebuck and beaver were also there; so were an ancient form of rhinoceros ( $R$. etruscus), a large, extinct form of beaver (trogontherium). Lately, $\mathrm{Mr} \mathrm{A}$. C. Hinton has detected in these beds part of the arm bone of a monkeybelonging to a species very like the kind still living at Gibraltar. These deposits represent a long period of time. Sir Charles Lyell was of opinion that the interval between our time and the deposition of the roo-foot terrace was much shorter than that which lay between the terrace formation and the deposition of the Cromer beds.

Having thus ascertained the position of the boulder clay among the deposits belonging to the early part of the Pleistocene period, it is necessary to fill in some details bearing on its relationship to the $100-$ foot terrace of the Thames valley. Most geologists hold the opinion that the boulder clay is older than the Ioo-foot terrace because, at Hornchurch, in Essex, the valley terrace rests on the boulder clay. My friend, Mr A. S. Kennard, has called this opinion in question. ${ }^{1}$ He regards the $100-$ foot terrace as the older. Both views are probably right, for in the 100-foot terrace there are deposits of very different ages. In the deepest stratum of gravel of the

\footnotetext{
1 See Proc. Soc. Antiquaries, April I7th, 1913.
} 
Ioo-foot terrace, M. Rutot recognises deposits which belong to the very beginning of the Pleistocene period. The deepest stratum of the terrace $^{1}$ may thus be older than the chalky boulder clay. But the upper strata of the terrace are certainly more recent than the chalky boulder clay, for in and under that deposit $\mathrm{Mr}$ Reid Moir has discovered worked flints which belong to a much more primitive culture than the Chellean-more primitive than even the Strepyan, which preceded the Chellean. There can be no doubt, therefore, that human remains lying in or under a bed of undisturbed, chalky boulder clay belong to a much earlier phase of the Pleistocene period than any yet discovered in the Ioofoot terrace.

The circumstances attending the finding of a human skeleton under a stratum of chalky boulder clay I will give in the words of the discoverer, Mr J. Reid Moir : ${ }^{2}-$

"About a mile to the north of Ipswich, on the estate of Mrs W. N. Fonnereau, is situated the brickfield of Messrs Bolton and Laughlin, which is famous to geologists for the various deposits which have been exposed by the excavation of the London clay for brickmaking. These deposits, which are given in descending order, are :-

Chalky boulder clay.

Middle glacial sand and gravel.

Decalcified red crag.

London clay.

Woolwich and Reading beds.

"This brickfield is about ten minutes' walk from my house, and for the past six years I have been in the habit of visiting it on an average three times a week, and searching for flint implements in the beds above the London clay. It will thus be seen that I

1 See p. 162.

2 For a full account of the discovery and of the anatomical characters of the Ipswich skeleton, see Journ. Roy. Anthrop. Instit., I912, vol. xlii. p. 345 . 
have had every opportunity of making myself fully acquainted with this particular district. Realising the importance of finding human bones in any of the deposits from which I have obtained implements, I have always impressed upon the workmen the necessity of keeping a sharp look-out for such remains, and of immediately communicating with me should any come to light.

"On Friday, October 6th, I9r I, Mr Bolton and Mr Laughlin, for the purpose of measuring up the amount of work done by the workmen, were in one of their pits when one of the men called out that he had found a portion of a human skull. Mr Laughlin went over to the spot, and, giving instructions for the remains to be carefully preserved and further digging to cease, went up to his office and telephoned to me. This was about ten minutes to two, and by 2 o'clock I was down at the pit, and found that a portion of a human skull, attached to an almost perfect cranial cast, and some teeth, had been recovered. It was pointed out to me that two bones were projecting from the vertical face of the section, and at a depth of about 4 feet from the surface, but as I had to be back at my office before a quarter to three I did not stop to examine the site, but, wrapping the skull fragment and cast in a piece of sacking, carried them home. Before leaving the pit, however, I arranged for two of the workmen to meet me at 2 o'clock on the following day and dig out the remainder of the skeleton. At this time it had never even crossed my mind that we were dealing with anything of great importance, and, in fact, I was quite under the impression that the bones belonged to a late interment.

"Thinking, however, that my two friends, Messrs Canton and Snell, who had been associated with me in my work for some little time, would care to come with me, I telephoned to them, and they agreed to do so. I also asked Mr Frank Woolnough, the 
curator of our museum, if he would care to go down and take some photographs of the spot where the bones were, as I knew he was anxious to get a series of interesting local views. Before any digging commenced we had a good look at the material-a hard clay-which covered the bones, and were surprised to find that no signs of any previous digging were visible. We therefore got the workmen to remove the overlying material with the greatest care, and kept the work under continual observation.

"When the bones were reached it was found they were in a most friable condition, so I gave orders to have the surrounding material dug up in large blocks, and this was accordingly done. When we came to examine these blocks and their contained relics, my friend, $\mathrm{Mr}$ Canton, who is a member of the Royal College of Surgeons, strongly advised me to send them off at once to the museum of the College, where they would be properly treated by experts. Seeing the condition of the bones, and recognising the importance of having them attended to without delay, I at once agreed to his advice, and the same evening carefully packed the remains in a suitable box, which was forwarded to Professor Keith, the Conservator of the College Museum."

The accompanying sketches, figs. $75^{\mathrm{A}}$ and $75^{\mathrm{B}}$, will make clear the position of Mr Moir's discovery. Ipswich is situated in the valley of the Gipping-ten miles from the open sea. On the sides of the valley the same terraces and the same deposits are to be recognised as in the valley of the Thames. Passing northwards through Ipswich the traveller soon leaves the town and the valley and finds himself on a plateau, about I 50 feet above the level of the sea, and covered everywhere by a thick stratum of chalky boulder clay, varying in depth from I 5 to 25 feet. The plateau slopes gently to the west until it reaches the brim of the valley of the Gipping-or 
rather a side recess of the main valley. Messrs Bolton and Laughlin's brickfield is situated on the edge of the valley - the surface level of the plateau at this spot being I 29 feet O.D.

At the brickfield the chalky boulder clay has become

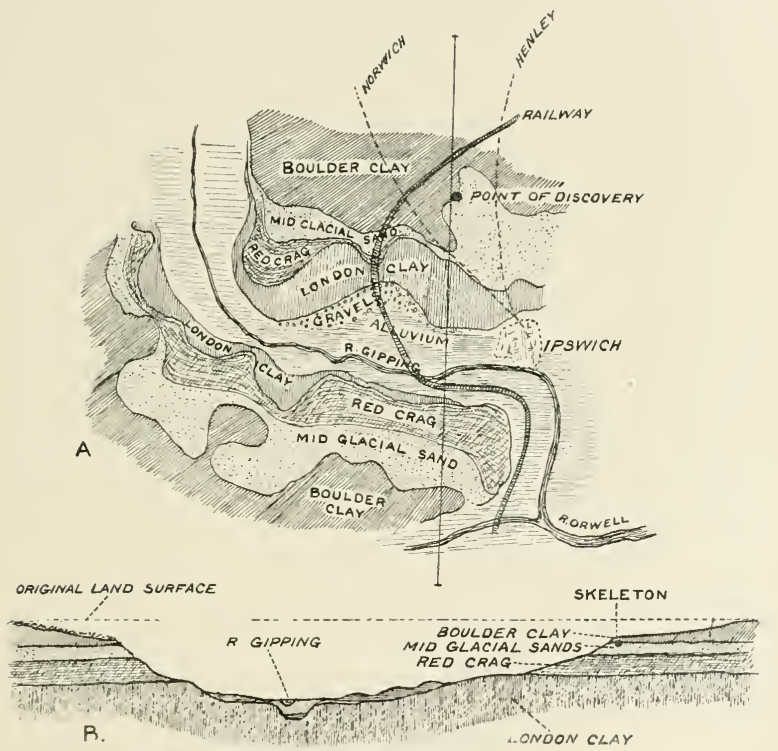

FIG. 75 A. - Sketch of the valley of the Gipping to show the locality in which the Ipswich skeleton was found.

FIG. 75B. - Sketch of a section across the Gipping valley to show the horizon of the discovery (the line of section is shown in $75 \mathrm{~A}$ ).

reduced to a stratum of about 4 feet in depth. In parts it is "weathered" - the chalk and clay being altered in composition and appearance by exposure. That the stratum at the brickfield represents a direct extension of the great sheet of boulder clay, Mr Moir proved by sinking a series of pits from the brickfield to the crown of 
the plateau. In the map prepared by the officers of the Geological Survey the chalky boulder clay is shown to extend to the pit.

Immediately after the discovery, Mr Moir called in the help of expert geologists. $\mathrm{Mr}$ Wm. Whitaker, F.R.S., wrote : ${ }^{1}$ " There is no doubt in my mind that the pit gives a junction section of the boulder clay with the underlying sand and gravel. ... I fail, however, to understand how man could have lived at the time of the commencement of the boulder clay, and I am in hopes that further excavation may throw more light on this strange occurrence. As yet we have the skeleton and nothing else." Professor Marr, F.R.S., of Cambridge University, examined the site of the discovery, but, while admitting that the stratum over the skeleton represented boulder clay, thought it possible that " the clay may have moved from another place" after its primary deposition. The Rev. Dr A. Irving of Bishop-Stortford, who has paid close attention to the more recent deposits of Essex, also examined the stratum which lay over the skeleton, and formed the opinion that it does not represent an extension of the chalky boulder clay, but is a much more recent deposit, to which he applies the term of "rubble drift."

The antiquity of the Ipswich skeleton thus depends on the proof of two things: (I) that the stratum which lay over the skeleton was truly a part of the great sheet of chalky boulder clay, laid down during or after the period of maximum glaciation ; (2) that it was absolutely intact and undisturbed since the time of its deposition. $\mathrm{Mr}$ Moir was keenly alive to the fact that a skeleton found at a depth of $4 \frac{1}{2}$ feet $(\mathrm{I} \cdot 38 \mathrm{~m}$.) was, unless convincing evidence to the contrary could be produced, most probably placed there by a gravedigger's spade. He therefore took every means of verifying the unbroken and undisturbed nature of the stratum in and under which the skeleton lay, for it was embedded between the weathered boulder clay above and the

1 See Journ. Roy. Anthrop. Instit., 1912, vol. xii. p. 35 I. 
mid-glacial sands below. $\mathrm{He}$ and those who worked with him satisfied themselves that the overlying stratum was continuous and unbroken. We have already seen the measures he took to prove the continuity of the stratum with the main sheet of chalky boulder clay.

We now turn to the skeleton itself to see what evidence may be obtained of its antiquity by a close examination of its state of preservation and of its structure. When the blocks of matrix containing the fragmentary remains of the skeleton came to the museum of the Royal College of Surgeons, we set to work and slowly dissected away the boulder clay, leaving the fragments implanted on a matrix of glacial sands. By placing the blocks together it was easy to reconstruct the original posture of the skeleton. From fig. 76 it will be seen that a whole skeleton was represented, and that it was placed on the right side in the ultra-contracted posture. We have already discussed the significance which is usually attached to the discovery of a complete human skeleton, with all the parts in their natural position. The most reasonable explanation is to suppose that it has been placed where found by burial. In this case, unfortunately, we have no clear idea of the conditions under which the chalky boulder clay was deposited - whether in deep water or on an old land surface. If, as $\mathrm{Mr}$ Moir supposes, it was laid down on an old land surface, then it is possible that the burial was made from that surface. At least it was not made from the present land surface, for the overlying stratum was intact. The contracted posture scarcely helps us in fixing a date. Contracted burials occur at all periods-Neolithic and Palæolithic. It will thus be seen that it is necessary to believe, if a pre-boulder clay date is accepted, that the custom of burial may even go back to the earliest part of the Pleistocene period.

Nothing was found with or near the skeleton to give a clue to date. If the conditions were such as to secure the preservation of a human skeleton, it is also probable that remains of animals of the same period should be 
preserved in the same stratum. At the horizon at which the human skeleton lay no animal remains have been found at Bolton and Laughlin's pit. In the glacial sands, however, bones of Pleistocene animals occur, and in

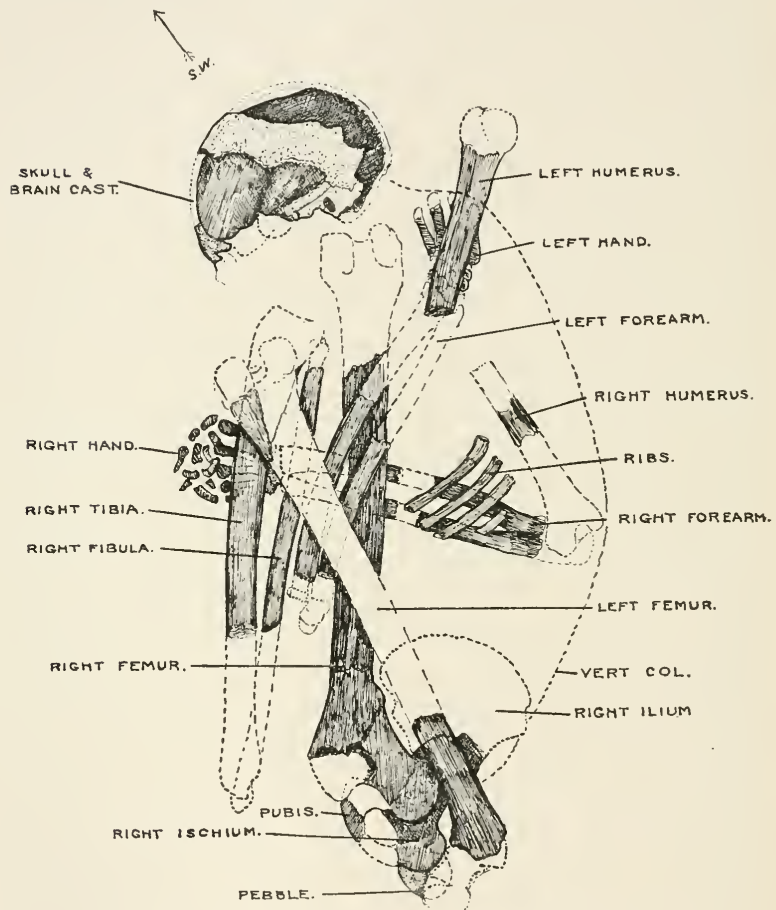

FIG. 76. The parts of the Ipswich skeleton replaced in position.

many cases the condition of these bones is very similar in their state of preservation to the bones of the Ipswich skeleton. The substance of the bones is grey and chalky in appearance, crumbling to a white dry dust on pressure. The bones, when dissolved in hydrochloric acid, leave 
no animal matrix behind. No stone implements of any kind were found with the skeleton, but in the boulder clay at the place of discovery, and in other localities, $\mathrm{Mr}$ Moir has collected many specimens representing a rude and early stone culture, very similar to the series of implements which $M$. Rutot has obtained from the older Pleistocene deposits in Belgium. To this early Pleistocene culture-the one which precedes the Strepyan -M. Rutot has given the name of Mesvinien. Whether or not the Ipswich man represents an inhabitant of East Anglia prior to the deposition of the chalky boulder clay, there is no doubt men were then in that part of England; and in the opinion of those who have studied the works of their hands and brains, they were workmen who showed a considerable knowledge of flint fracture.

The Ipswich skeleton represents a tall man, 5 feet $10_{4}^{3}$ inches $(1.800 \mathrm{~m}$.) in height. The cavity of the skull was filled with a sandy, chalky loam, giving a fairly accurate cast of the brain which had at one time occupied the space. The skull itself was much broken, but it was possible to reconstruct the main features of the head. The brain capacity for so tall a man is low, only I 430 c.c. All the characters of the skull are those we are familiar with in modern man. The characters we associate with Neanderthal man were absent. The forehead was retreating, and the supra-orbital ridges were pronounced, but of the divided modern type. When viewed from the side and from the front (fig. 77), the skull fits comfortably within the frame designed for modern English skulls. The maximum length is $192 \mathrm{~mm}$., about the same as in an average modern Englishman. Its width is $144 \mathrm{~mm}$., slightly beyond the modern average, giving a cephalic index of 75 . The vault is flat on the top and also remarkably low, only i I $\mathrm{mm}$. - characters reminding us of the Bury St Edmunds fragment belonging to a time long after the deposition of the chalky boulder clay.

The characteristic mark of the Ipswich man lies in his tibia or shin bone. No human tibia of a similar shape has 
ever been described before, and after a prolonged search I have been unable to find any specimen which resembles it either in ancient or modern man, in health or in
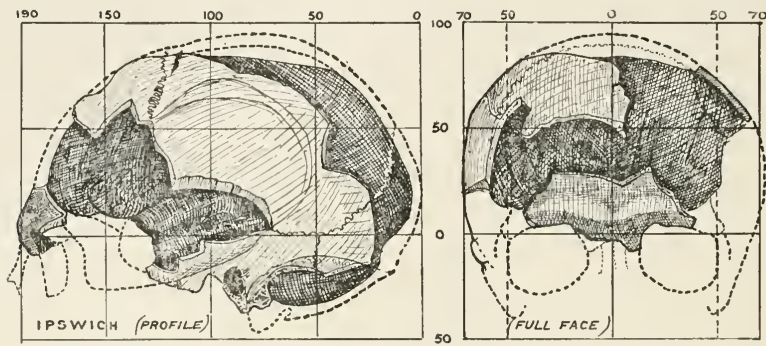

FIG. 77. - Drawings of the Ipswich skull from the side and from the front.

disease. As regards the Ipswich tibia, there is no sign of inflammation, nor is there any reason to attribute its peculiar features to either a freak of growth or to an

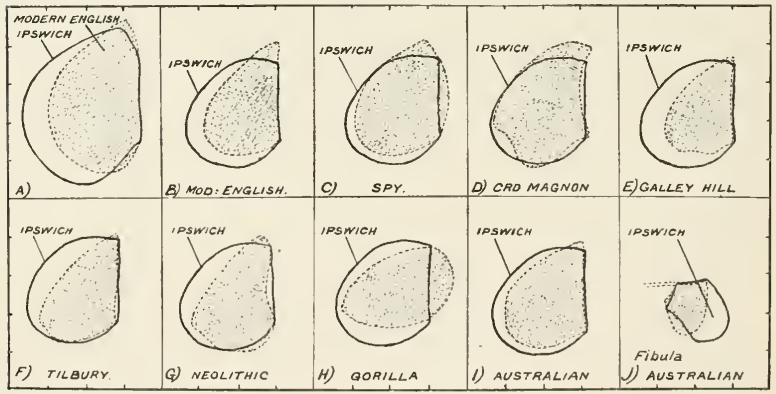

FIG. 78.--Sections across a series of tibiæ of various races. A. A section across a modern English tibia at the junction of upper third with lower twothirds, compared with similar section of the Ipswich tibia. The others represent sections at the mid point of the tibia, except the last, which represents a section of the fibula.

individual peculiarity. I expect it to prove a character of the race.

To give a clear idea of the peculiar characters of the Ipswich tibia, I reproduce in fig. 78 a series of sections 
across the tibiæ of various races of men, giving with each an outline section of the Ipswich tibia. ${ }^{1}$

The peculiar feature of the lpswich tibia is the absence of the sharp, bony crest, which can be felt in all modern bones, descending on the front of the leg, just under the skin. In place of a sharp crest there is a flat, anterior surface. Although the absence of this sharp crest is a simian character, yet the Ipswich tibia cannot be said to resemble the same bone of anthropoid apes (fig. $78, \mathrm{H}$ ), whereas the tibia of Neanderthal man does show a distinct approach to the anthropoid form (fig. 78, C). In the Ipswich man the tibia is the opposite of the platycnemic leg bone of Neolithic races, in which there is a side-toside flattening (see fig. $78, \mathrm{G}$ ). In the Ipswich specimen the flattening is from front to back. The functional meaning of this peculiar character I cannot explain; I look upon it, as on the teeth of Neanderthal man, as a form of specialisation, the functional significance of both characters being unknown. The Ipswich fibula, too, is of a peculiar form (fig. $78, \mathrm{~J}$ ). The femur shows none of the flattening in its upper third which is so frequently present in Neolithic races.

With that brief description we shall leave the Ipswich skeleton. As $\mathrm{Mr}$ Moir and the writer are well aware, the discovery of human remains so near the surface, so destitute of all characters of a primitive or ape-like nature, cannot carry the conviction of a skeleton found at a depth which places its antiquity beyond dispute. If, however, the Ipswich skeleton had shown characters as distinctive as those of Neanderthal man, or as those of the Piltdown man-found at a depth of a little over 3 feet below the surface-would anyone have doubted that its age was older than the deposition of the boulder clay? I do not think the age would then have been called in question. But under the presumption that the modern type of man is also modern in origin, a degree of high antiquity is denied to such specimens. It is, therefore, all the more important that every discovery of human remains,

1 For full description of skeleton, see reference, p. 218. 
made under circumstances which makes their high antiquity a reasonable presumption, should be placed fully on record, with no fact kept back and none put forward that is not proven.

In a former chapter, while describing the Moulin Quignon mandible, reference was made to a lower jaw found at Foxhall (see p. 200), which lies a few miles to the east of Ipswich. The deposit from which the mandible is believed to have come is formed of midglacial sands, a stratum of which is to be seen under the boulder clay at Bolton and Laughlin's pit (fig. 75). As already said, the evidence in favour of the antiquity of this specimen is only presumptive.

If we are unable to trace man by his actual remains to a point beyond the boulder clay, in the deposits of East Anglia, it is otherwise as regards his implements. Sir Charles Lyell expected these deposits to yield traces of early man. In $\mathrm{I} 863$, when he wrote the first edition of his Antiquity of Man, he expressed this conviction very clearly as follows :-

"Neither need we despair of one day meeting with the signs of man's existence in the Cromer forest bed [see fig. 74, p. 2 1 2], or in the overlying deposits, on the ground of any uncongeniality of the climate or incongruity in the state of the animate creation with the well-being of our species."

It is clear Sir Charles Lyell realised that the world was suitable for man's habitation at the end of the Pliocene period, and that he was prepared to find human remains in deposits as old as the Cromer beds. Before the nineteenth century was out his prophecy came true. In I 897, Mr Lewis Abbott discovered flint implements definitely shaped by man's hand in the "elephant" stratum of the Cromer beds. ${ }^{1}$ In I9I I, Dr W. L. H. Duckworth of Cambridge found another specimen. ${ }^{2}$ So

1 W. J. Lewis Abbott, F.G.S., "Worked Flints from the Cromer Beds," Natural Sicience, 1897 , vol. x. p. 89.

2 W. L. H. Duckworth, Cambridge Antiquar. Soc. Communic., IوII, vol. xv. p. 156. 
far, however, no skeletal remains of the Cromer men have come to light.

Early in the present century, the members of the Prehistoric Society of East Anglia carried the history of man far beyond the limit predicted by Lyell. Three well-known formations or deposits of the Pliocene period occur in East Anglia-the Norwich Crag, the Red Crag, and the Coralline Crag. The Coralline Crag is the oldest, dating back to at least the middle of the Pliocene period. Then follows the Red Crag; then the Norwich, which, in turn, is succeeded, in point of time, by the Cromer beds. The deepest stratum of both the Norwich and Red Crags is formed by a "stone-bed," representing, apparently, the sweepings of the old land surface which preceded the deposition of the stratified, shelly, sandy formations of the Crags. In 1910, Mr Reid Moir ${ }^{1}$ discovered that the stone-bed under the Red Crag contained a series of flints showing definite evidence of man's work. The worked flints, collected by Mr Moir, prove that pre-Crag man-man of the Pliocene epochhad already evolved a series of implements, representing several types as regards shape and workmanship. It is true that the "humanity" of the sub-Crag flints has been questioned, and even denied, by men who have given the subject of flint fracture their serious consideration. We have seen, however, that it took Boucher de Perthes a great part of a lifetime to convince his fellows of the humanity of those high works of art-palæoliths. A more rapid success has attended the labours of Mr Reid Moir. The ready acceptance of his results is largely due, as he would be the first to acknowledge, to the support and advocacy of Sir E. Ray Lankester. ${ }^{2}$

As early as $1905, \mathrm{Mr}$ W. G. Clarke ${ }^{3}$ had observed "eoliths" in the stone-bed under the Norwich Crag. Since then Mr Clarke has collected a series of worked

1 See Proc. Prehist. Soc. East Anglia, 191 1, vol. i. p. 17.

2 See Proc. Roy. Soc., Nov. 16, 1911 ; also special publication of the Roy. Anthrop. Instit., 1914.

3 Proc. Prehist. Soc. East Anglia, 1912, vol. v. p. 160. 
flints representing an "industry" of a later date than Mr Moir's series which come from under the Red Crag. Thus it will be seen that recent discoveries in East Anglia carry the history of man in England to beyond the bounds of the Pleistocene epoch-well into the Pliocene period. We shall see that M. Rutot had, before these discoveries were made in East Anglia, classified the Pliocene "industries" represented in the Pliocene deposits of the Continent.

The antiquity represented by the sub-Crag flints cannot be calculated with any degree of accuracy. Geologists assign to the Pliocene period a duration of over a million of years. Estimates of the Pleistocene period, as we shall see in another chapter, vary from one hundred thousand years to one million five hundred thousand years. The more I become familiar with the evidence relating to this period, the more my judgment is drawn towards the lower estimates. The scale employed in the preceding chapters allows for about three hundred thousand years for the Pleistocene period. If that allowance is accepted, then an equal period must be added to take us back to the time of the pre-Crag man.

So far only passing allusions have been made to the glacial cycles which occurred during the Pleistocene epoch. Mention was made of a disturbance-due to sub-Arctic conditions which followed the Mousterian period. This, the last of the glacial phases of the Pleistocene period, was recognised by Professor James Geikie, ${ }^{1}$ who named it the "Mecklenburgian" glacial epoch in 1894. Subsequently, it has come to be known as the "Würmien" glacial epoch-the term introduced by Professor Penck of Berlin in $1903 .^{2}$ We have also seen that under the Mousterian brick earths at Crayford there are signs of a pre-Mousterian glaciation-probably occurring in the

1 The Antiquity of Man in Europe, Edinburgh, I9I4. In the 3rd edition of The Great Ice Age (I894) Professor Geikie distinguished four periods of glaciation, separated by three interglacial phases. Independent researches led Professor Penck to a similar conclusion.

See his later paper, "Das Alter des Menschengeschlechtes," Zeitsch. für Ethnologic, 1908, vol. xl. p. 390. 
Acheulean age. The disturbed appearance seen under the brick earths may represent effects of Professor Penck's third glaciation, the "Rissien," the "Würmien " being the fourth. The chalky boulder clay belongs to Professor Penck's second and major epoch-the "Mindelien." His first glaciation-the "Günzien"-fell in the Pliocene period, and corresponds in time to the deposition of the Norwich Crag.

The glacial phases afford the student of ancient man a series of milestones to mark his journey into the past. Unfortunately, we are not certain of the exact number of glacial phases, and, what is still more unfortunate, we are not yet in a position to offer a complete explanation of their occurrence and recurrence. The day will certainly come when their cause, their duration, and their sequence will become common knowledge. At the present time, the only explanation which answers the needs of those who are tracing man's history in recent deposits is that put forward by the late Major-General Drayson in I $888 .^{\circ} \mathrm{He}$ postulated a secondary rotation of the earth-a rotation completed in a cycle of 31,602 years. It is unnecessary here, even if the writer were qualified, to undertake the task of analysing General Drayson's explanation. His work and conclusions are being vigorously advocated by Major R. A. Marriott, ${ }^{2}$ D.S.O. The important point for us is this, that if Drayson's hypothesis is well founded, the last ice age reached its maximum about thirteen thousand years ago, a date which fits very well with the evidence brought forward by geologists.

1 The Earth's Past History, Chapman \& Hall, 1888.

2 Major R. A. Marriott, D.S.O., The Change in the Climate, Marlborough, London, 1914. 


\section{CHAPTER XIII}

HEIDELBERG MAN

IN this chapter we set out from England to make our last tour of Europe in search of the remains of ancient man. On our last journey attention was directed to such remains as could be ascribed to men of the Acheulean and Chellean periods. On the present occasion we are in search of human remains belonging to a still earlier part of the Pleistocene period-to the very earliest part of that epoch, which, as we have just seen, is represented in East Anglia by the deposits of glacial sands and boulder clay. On such a quest our steps are naturally directed to Belgium, because of the labours and discoveries of M. Rutot, Conservator of the Royal Museum of Natural History in Brussels. He has spent a lifetime in the study of the various deposits which have accumulated in the valleys of Belgium-particularly in the industrial southern part of that country, where the valleys have been carved out and filled up by streams flowing eastwards to join the Meuse. In fig. 79 , I reproduce an illustration of $\mathrm{M}$. Rutot's which gives in brief the conclusions he has reached concerning the number and the order of the deposits laid down in the valleys of Belgium during the Pleistocene period. ${ }^{1}$ From the diagram (fig. 79) it will be seen that M. Rutot recognises five series of strata in these deposits; but for our present

1 See the following papers by M. Rutot: "Glaciations et humanité," Bull. Soc. Bclge de Gíol., 1910, vol. xxiv. p. 59. "Revision stratigraphique des ossements humains quaternaires," ibid., I910, vol. xxiv. p. I23. "L'âge de la máchoire humaine de Mauer," ibid.. I908, vol. xxiii. p. II7. 
purpose we need only direct attention to three of these. In the deepest and oldest series of all-lower Pleistocene series-occurs a thick bed of clay to which M. Rutot attaches particular importance, and names "glaise moseen," indicated simply as "clay" in fig. 79. That stratum he regards as marking the great floods which followed the break-up of the second and most severe of the Pleistocene ice ages-the "Mindelien." The chalky

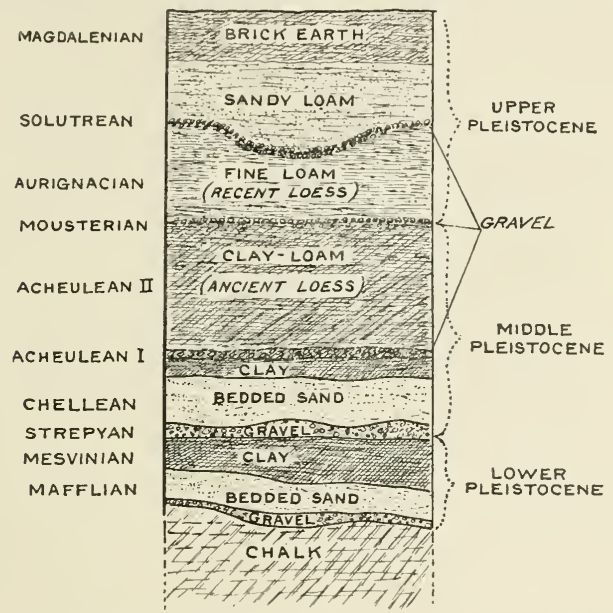

FIG. 79.-M. Rutot's schematic section showing the number and sequence of the strata in the valley deposits of Belgiun.

boulder clay of East Anglia is also looked upon as a product of the same glaciation. If the age ascribed to the Ipswich man is well founded, then his place, in M. Rutot's system, lies below the "glaise moseen"in the oldest deposits of the Pleistocene floor of river valleys.

The second of the strata in M. Rutot's section which demands our attention is a mixture of fine sand and clay"ancient loess" or "limon gris"-a deposit which, in M. Rutot's opinion, was laid down during the floods 
following the "Rissien" or third glacial phase. The ancient loess was certainly in process of formation during the period of Acheulean culture, for it contains implements of that culture (fig. 79). The upper loam of the roo-foot terrace in the valley of the Thames (see fig. 57, p. 163) appears to correspond in time and circumstance to the ancient loess. The Bury St Edmunds cranial fragment finds its place in this horizon of M. Rutot's scheme. Lastly, in the upper and final strata of his scheme, M. Rutot recognises in the brick earths and loams the deposits which followed the fourth and last of the Pleistocene ice ages-the "W'ürmien." In such deposits are found the implements of the two final Palæolithic cultures - the Solutrean and Magdalenian. The strata of brick earths which covered the skeleton in the low terrace at Halling may be correlated with the final deposits of M. Rutot's scheme. M. Rutot's observations and conclusions have a very direct bearing on the inquiry we now have on hand, for he has shown that his scheme holds true, not only for Belgium, but is also applicable to the valley deposits of the Rhine, the Somme, the Seine, and apparently also to those of the Thames valley.

The elaboration of the valley deposits of Belgium into a complete system forms only a part of M. Rutot's discoveries. In the lower or older series of the Pleistocene valley deposits he has recognised certain forms of worked flints which represent the earliest phases of Pleistocene culture. The implements are of the type known as eoliths. He recognises three stages in the evolution of such early forms towards the true Palæolithic types. The first and oldest Pleistocene cultures he has named "Reutelien," the second "Mafflien," the third and final of the Eolithic stages "Mesvinien." Then follows, in the lowest of the middle Pleistocene beds, the most primitive of the Palæolithic cultures, the one to which M. Rutot gave the name "Strepyien"-the prelude of the high art of Chellean culture.

It is also of importance for our present inquiry to note 
that M. Rutot distinguishes the deposits corresponding to those of the 50-foot terrace of the Thames valley as the deposits of the low terrace; those corresponding to the roo-foot terrace as the middle terrace. In the deepest or oldest deposits of the low terrace, he finds the shaped stones which represent his second Pleistocene culture-the " Mafflien." Then follows the "Mesvinien." Both of these cultures lie in and under the "glaise moseen"-which we suppose to correspond to the chalky boulder clay. At least it is a remarkable fact that in the chalky boulder clay and mid-glacial sands of East

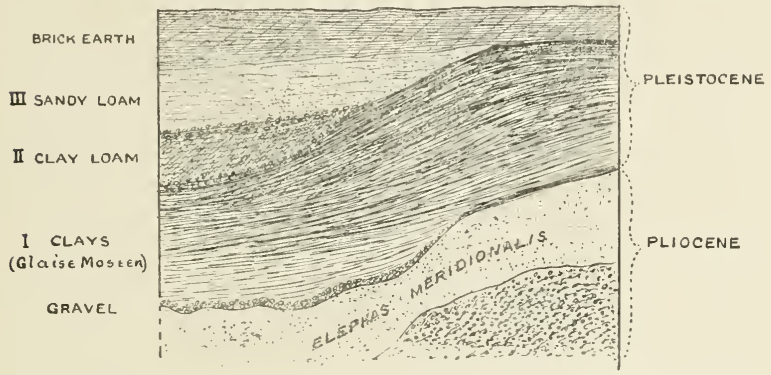

FIG. So.-Section of the middle (Ioo-foot) terrace at St Prest, near Chartres.

Anglia Mr Reid Moir has found Eolithic cultures very, similar to those distinguished by M. Rutot as " Mafflien" and "Mesvinien."

One other observation of M. Rutot, with an important bearing on our present inquiry, is reproduced in fig. 80 . The figure reproduces M. Rutot's section of the famous gravel deposits at St Prest, situated in the valley of the Eure, a tributary of the Seine, about fifty miles to the south-west of Paris. The deposits at St Prest represent those of the 100 -foot terrace - M. Rutot's middle terrace of river valleys. The section at St Prest is of particular interest because here the Pleistocene deposits of the terrace rest directly on other formations of a late Pliocene date. It was in the deep 
Pliocene gravels of St Prest, containing remains of a Pliocene elephant (Elephas meridionalis), that M. Desnoyers ${ }^{1}$ found, in I 863 , the bones of extinct animals showirg clear signs of having been cut or hacked by man (see p. 3 I 3). Four years later, M. Bourgeois found in the same Pliocene gravels, flint implements representing the last of the Pliocene cultures-to which M. Rutot has given the name "St Prestien." Over the Pliocene strata at St Prest, M. Rutot recognises the usual Pleistocene deposits of the roo-foot terrace-particularly the "glaise moseen" (fig. 80). It is at the horizon represented by the junction of the Pliocene and the Pleistocene deposit of the roo-foot terrace that M. Rutot finds the earliest of the Pleistocene cultures - the "Reutelien."

Having thus surveyed the early Pleistocene deposits of Belgium and of Northern France through the eyes of M. Rutot, and the phases of human workmanship which he has detected in them, our next step is to seek for the remains of the men who lived when such valley deposits were being formed. At the present time only one specimen is available - the famous Heidelberg mandible. The mandible was found in the deepest strata of a valley deposit, lying ten miles to the south-east of Heidelberg. That old University town is situated on the Neckar, ten miles above its junction with the Rhine at Mannheim. Below Heidelberg, the Neckar is joined by the Elenz, a stream flowing northwards along a shallow valley, and through a rich, agricultural country. On the eastern side of the valley, fully four miles above the junction of the Elenz with the Neckar, is the rural village of Mauer. Close by the village is the sand-pit of Mauer-also on the eastern side of the Elenz valley. Opposite the pit, the bottom of the valley stands I $34 \mathrm{~m}$. ( 440 feet) above the level of the North Sea, and two

1 M. J. Desnoyers, Compt. Rend., I863, vol. lvi. pp. 1073, I I99. E. T. Hamy, Précis palcontologie humaine, Paris, 1870. M. G. Gourty, "Les Dépôts de St Prest," Bull. Soc. d'Anthrop., 1913, ser. 6, vol. iv. p. 6. 
hundred and sixty miles distant from the mouth of the Rhine. On the side of the valley, where the great sand-pit has been dug, the land rises 85 feet above the bottom of the valley, but so extensively and so deeply has the pit been worked that its floor has almost reached the level of the bed of the present stream. The working face of the sand-pit has a total depth of $25 \mathrm{~m}$. (79 $\frac{1}{2}$ feet).

For a long time the Mauer pit has been closely studied by geologists on account of its clear representation of Pleistocene deposits, and because of the extinct fauna preserved in its deeper strata. No site in Europe, it was realised, was more likely to yield the bones of early Pleistocene man than the sand-pit at Mauer. No one was more fully alive to this possibility than Dr Otto Schoetensack, Lecturer on Geology in the University of Heidelberg. Half an hour's journey by rail took him to the pit almost daily. After waiting and searching for twenty years, the owner of the pit, Herr J. Rösch, was able to inform him on October 2 Ist, 1907, that his twenty years' search had at last been realised. "Yesterday," he wrote, "the desired evidence was obtained, for $20 \mathrm{~m}$. below the surface soil, and above the floor of my sand-pit, there was found the lower jaw of primitive man, in good preservation, and with all its teeth." In the following year, I908, Dr Schoetensack prepared and published a monograph on the lower jaw of Homo heidelbergensis which in exactness, directness, and fullness will always serve as an example for future discoverers of prehistoric remains. ${ }^{1}$

Before discussing the anatomical characters of the Heidelberg mandible, it is necessary to see what light may be obtained as to its antiquity. Concerning the authenticity of the find there cannot be any doubt; the bed in which the mandible lay was covered by a series of deposits, amounting in all to 78 feet. In the deposits

1 Der Unterkiefer des Homo heidelbergensis: Ein beitrag zur Palaenntologie des Menschen, von Otto Schoetensack, Leipzig, Igos. I regret to add that Dr Schoetensack died in 1913. 
over the mandible Dr Schoetensack recognised twentyfour different strata. They fall into three series: (I) the uppermost, formed by recent loess (fig. 8I, D), a fine earth, a product of floods and drought; (2) the ancient loess (fig. $8 \mathrm{I}, \mathrm{C}$ ), a sandy loam, also a deposit from muddy waters; ( 3 ) the Mauer sands (fig. 8 I, A, A, $B, B)$. In one of the lower strata of this series the mandible was found. In the lower strata, remains of the following extinct animals were found:- the lion (Felis leo fossilis), an extinct form of cat, a $\operatorname{dog}$ (Canis neschersensis), two forms of bear, a species of bison, an early Pleistocene form of horse, and an early form of rhinoceros (R. etruscus), and an elephant (E. antiquus). From this fauna, Dr Schoetensack concluded that the Mauer sands correspond in date of formation "to the preglacial forest beds of Norfolk." If Dr Schoetensack's opinion is right, then we ought to find the English contemporary of the Heidelberg man in those beds which lie under the chalky boulder clay of East Anglia or above the Cromer forest beds (see fig. 74, p. 2 I 2).

By a different process of reasoning, M. Rutot reached the same conclusion as Dr Schoetensack. The sands at Mauer represent a valley deposit corresponding exactly to those he has studied in Belgium, both in age and in manner of formation. In fig. 8I, I reproduce a diagrammatic section of the strata in the sand-pit at Mauer, as interpreted by M. Rutot. We have seen that in the valley deposits of Belgium he has recognised three particular strata, representing products of the floods which followed each of the three cold phases which fall within the Pleistocene period. The stratum of recent loess, over I 8 feet in depth - the uppermost of the Mauer pit-represents, in M. Rutot's scheme, the débris of the last or "Würmien" ice age. The underlying strata of ancient loess, over I 7 feet in depth, is the product of the third or "Rissien" glaciation. Although no traces of human culture were found in the stratum of recent loess at Mauer, there can be no doubt, for the following reasons, that its deposition belongs to the later Palæolithic 


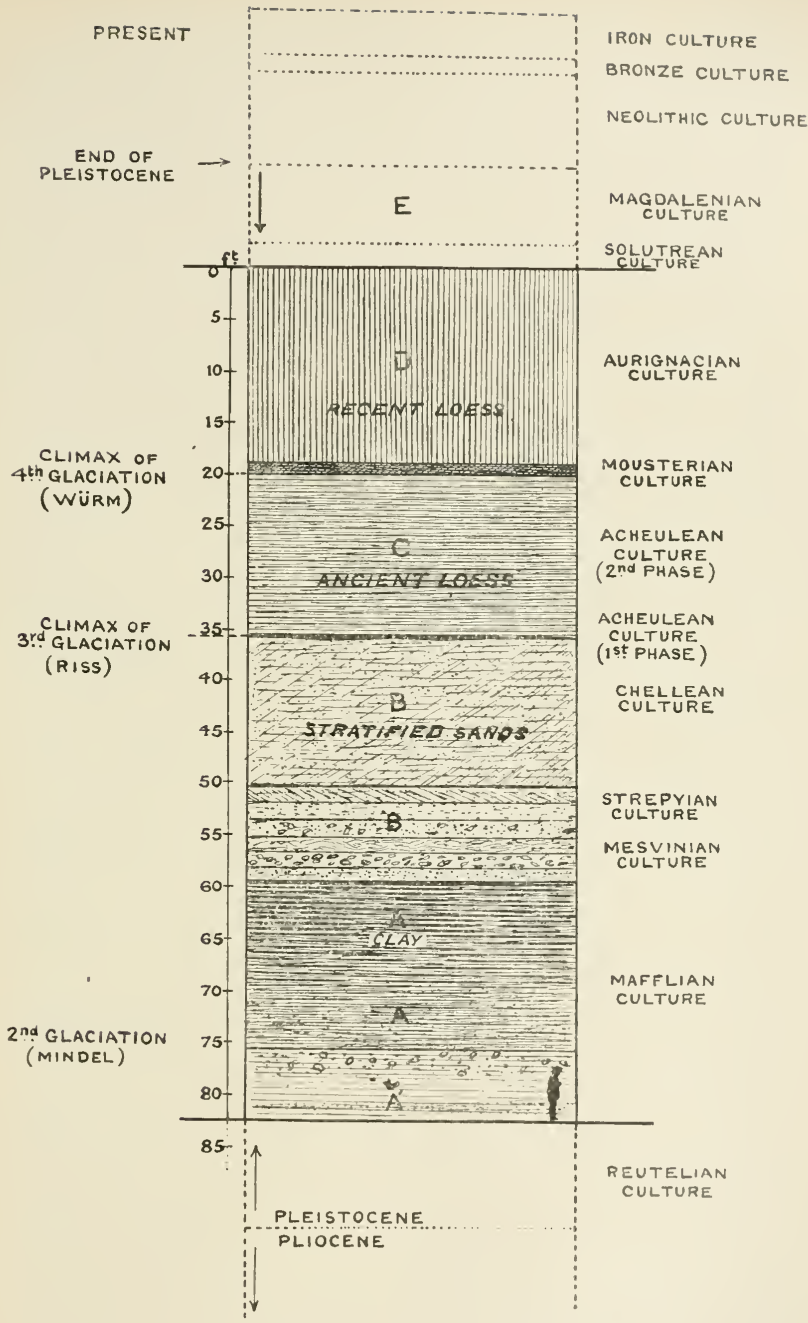

FIG. 81.-Diagrammatic section of the strata of the sand-pit at Mauer, showing the depth at which the mandible $\left(A^{\prime}\right)$ was found (after Schoetensack and Rutut). 
periods. Along the valleys of the Rhine and of the Danube the deposits of recent loess are known to yield implements belonging to the Aurignacian culture. In the same regions, representations of the Mousterian period are found under the recent loess, but above the ancient loess. The latter deposit corresponds to the "limon gris" of Belgium and France, and in that deposit occur implements of the Acheulean period.

Near the middle horizon in the stratified series of Mauer sands are thick beds of clay and sandy clay, nearly 13 feet in total depth, which M. Rutot identifies with the "glaise moseen" ( $\mathrm{A}, \mathrm{A}$ in fig. 8I), and regards as deposits of the great floods which marked the close of the second and greatest of the glaciations ("Mindelien"). The mandible lay 10 feet below the clay bed at Mauer. In the strata of Belgium, which lie immediately over the clay bed, occurs the last of the Eolithic culture, the one to which M. Rutot gives the name of "Mesvinien"; in the strata below the clay bed are found M. Rutot's "Mafflien" implements. He infers, therefore, that the Heidelberg mandible represents a race belonging to the "Mafflien" phase of Eolithic culture. The valley deposits containing the still older Pleistocene phasethe "Reutelien"-are not represented in the Mauer deposits. Thus from two different lines of reasoning we are led to the conclusion that in the Heidelberg mandible we have a fragment of a European belonging to a very early stage of the Pleistocene period.

An important inquiry has now to be made: How much can be inferred concerning Homo heidelbergensis, seeing that we know only his lower jaw and his lower teeth? In the first place, the characters of the teeth leave us in no doubt as to his race; he represents, beyond all question, a variety - a primitive variety-of Neanderthal man. It is strange that we have not found a single trace of this race since we parted from the deposits of the Mousterian period until now. The pre-Mousterian strata have yielded us only remains of men of the modern type. Here, however, we come 
across Neanderthal man of a more primitive type than any yet found in Mousterian deposits. The teeth show those peculiar features which differentiate them from those of men of the modern type-the enlarged pulp cavities, the swollen crowns and bodies, the curtailed roots (see figs. 50 and 175). These are not primitive or simian characters, but the reverse ; they are modifications confined, so far as we have yet discovered, to this peculiar variety or species of man-Homo neanderthalensis. In these same features, man of the modern type-Homo sapiens, as he is named-resembles the apes. Here, then, is an important fact-that at the commencement of the Pleistocene period that peculiar feature of the teeth which characterises the Neanderthal species of men was already evolved. It is true that on the last occasion I wrote a systematic account of the remains of fossil man, I still clung to the belief that the Neanderthal molars might in the course of further evolution revert to the more primitive form, and that Neanderthal man might stand to us as a direct ancestor. On the evidence now available I see that such a belief is untenable.

One other feature of the Heidelberg dentition impresses the anatomist. At such an early date as the beginning of the Pleistocene period he was prepared to find in the canine or eye teeth some resemblance to the pointed canine teeth of apes. This expectation was founded on the form of the canine teeth of modern man, and the peculiar manner of their eruption. In the Heidelberg dentition the canines are even less ape-like than in modern man-they have subsided into the ranks of the ordinary teeth. In this we find a second point which bears on the antiquity of man. In an early species of man the canine teeth had assumed the "human" form by the commencement of the Pleistocene period.

The Neanderthal nature of the Heidelberg mandible is rendered apparent by such a comparison as that made in fig. 82. The body of the Heidelberg jaw, that part

1 Ancient Types of Man, Harper Brothers, I9II. 
of it which carries the teeth, is set beside the opposite half of a mandible from Spy. In the adjacent figure halves of an English and of a Tasmanian mandible are contrasted. The Spy mandible represents the Neanderthal type; the Tasmanian illustrates a primitive modern type. It is unfortunate for our comparison that the molars of the Spy mandible are the smallest known in a Neanderthal specimen. Their total length, measured along the arch of the teeth, is $32.2 \mathrm{~mm}$.; the three Heidelberg molars measure $36 \mathrm{~mm}$. Amongst the Krapina molar teeth there are many of a larger size than

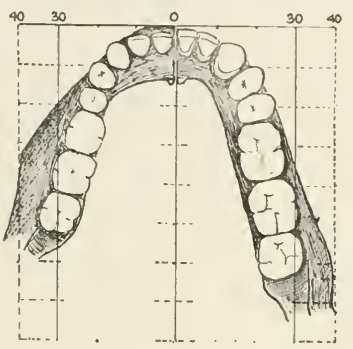

MODERN ENGLISH

TASMANIAN.

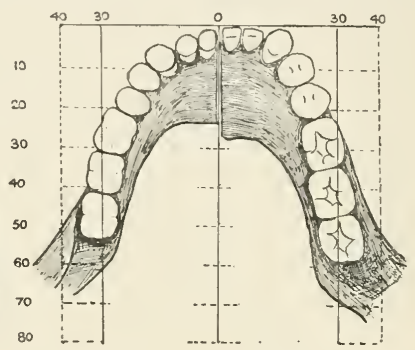

sPY.
HEIDELBERG

FIr. 82.-The right half of the body and teeth of the Heidelberg mandible viewed from above, and contrasted with halves of the mandibles of Spy man, of a Tasmanian, and of a modern European.

those of the Heidelberg mandible. In the Tasmanian mandible the molars are particularly large for a modern dentition, totalling $36.4 \mathrm{~mm}$, rather more than the Heidelberg molars. The front teeth-incisors, canines, premolars - of the Heidelberg mandible are of the same shape as those in the Spy mandible, only slightly larger. The Tasmanian teeth are quite different-more primitive.

The teeth of Neanderthal man are arranged in an arch of characteristic form, the arch being flattened in front and the two sides of the arch widely separated (fig. I67). Those characters are easily recognised in the Heidelberg mandible. In the primitive modern jaw the dental 
arch is elongated and more simian in form. As may be seen from fig. 82 , the long diameter of the dental arch measured $62 \mathrm{~mm}$. in the primitive Tasmanian, $60 \mathrm{~mm}$. in the Heidelberg mandible, and $54 \mathrm{~mm}$. in the Spy mandible. In width, however, the Neanderthal dental arch is much the greater. It measures $68 \mathrm{~mm}$. in the Heidelberg specimen, $69 \mathrm{~mm}$. in the Spy, and 6r $\mathrm{mm}$. in the Tasmanian mandible. The peculiar adaptation of the Neanderthal teeth-their wide crowns, large bodies, short roots, and the wide and relatively short dental arch, all point to a rough vegetable diet necessitating

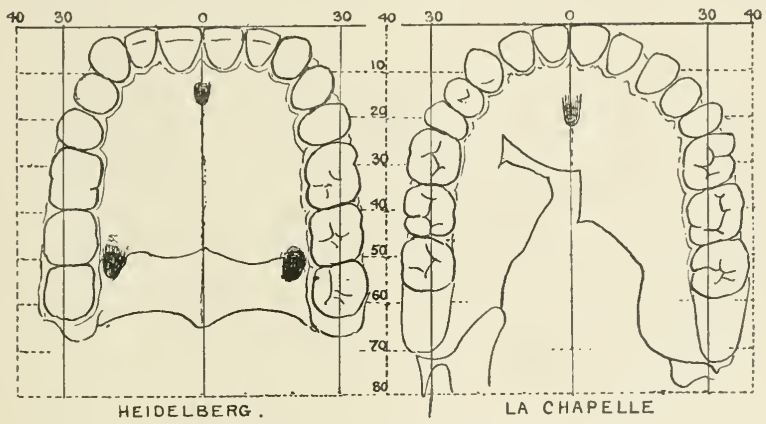

FIG. 83-Reconstruction of the palate of the Heidelberg man, compared with i'rofessor Boule's reconstruction of the La Chapelle palate.

a grinding rather than a cutting manner of mastication. From the arch of the lower teeth it is possible to reconstruct the size and arrangement of the upper teeth and palate of the Heidelberg individual. In fig. 83 this reconstruction has been carried out in order that a direct comparison may be made between the palate of the Heidelberg man and the Neanderthal variety discovered at La Chapelle-aux-Saints (see p. I 5 I). The palate in the latter case was broken and the teeth lost. Professor Boule was therefore obliged to reconstruct the palate in that case also. The palatal area in each is almost the same- $-35 \mathrm{~cm} .{ }^{2}$ in the La Chapelle specimen, $36.7 \mathrm{~cm} .^{2}$ in the Heidelberg specimen, and $36.7 \mathrm{~cm} .^{2}$ in 
the Tasmanian. The width in the two palates shown in fig. 83 is almost the same, $72 \mathrm{~mm}$.; and the length is nearly the same, $60 \mathrm{~mm}$. in the La Chapelle and $63 \mathrm{~mm}$. in the Heidelberg palate. From the palate we infer that the Heidelberg man cannot have stood much lower in the human scale than Neanderthal man of the Mousterian period.

If we confine our attention to the teeth, we have no hesitation in assigning the Heidelberg jaw to a primitive variety or race of Neanderthal man. From the very first, anatomists have been struck by the apparent

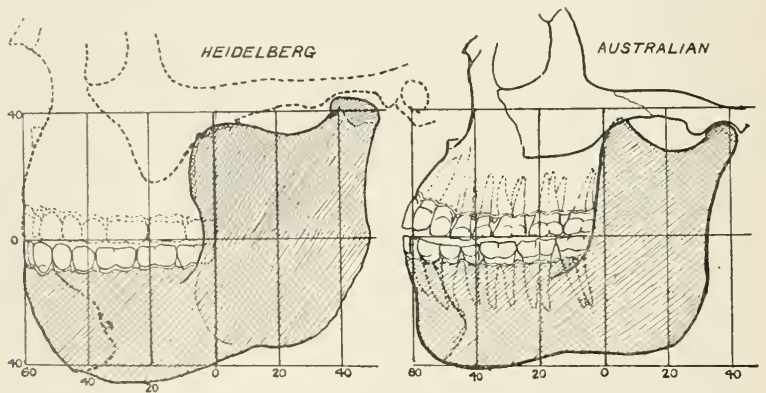

FIG. 84.-Profile of the Heidelberg mandible compared with a corresponding view of the mandible of an Australian native.

discrepancy between the "humanity" of the teeth and the massive power - almost bestiality - of the jaw itself. The impression we obtain from a close inspection is one of its great strength. This is even noticeable when a comparison is made such as is shown in fig. 84 . In that figure the Heidelberg mandible is shown in profile, and placed beside a corresponding view of the mandible of an Australian native. The comparison brings out an extreme degree of divergence. This is particularly evident in the ascending branch or ramus to which the muscles of mastication are attached. The size or area of this branch may be taken as an index of the size and strength of the muscles of mastication. In 
height the ascending branch of the Australian mandible is practically the same as that of the Heidelberg specimen, but in width the latter measures $60 \mathrm{~mm} .-22 \mathrm{~mm}$. more than the primitive Australian native. The area represented by the outer surface of the ramus of the ancient mandible is $34 \mathrm{~cm}^{2}$; the corresponding area in the Australian measures $22 \mathrm{~cm}^{2}$; an average modern European mandible, I $8 \mathrm{~cm} .{ }^{2}$. These measurements give some idea of the surpassing strength which must have characterised the masticatory system of the Heidelberg man. The chief difference, however, is seen in the region of the chin and symphysis. In the Australian, although there is no prominent chin, yet the anterior or labial surface of the mandible ascends almost at right angles to the lower border of the jaw. The alveolar border, on which the teeth are implanted, is not prolonged forwards markedly in advance of the lower border of the mandible. The reverse is the case in the Heidelberg jaw-the alveolar border is prolonged far forwards and the chin recedes almost as in an ape. On its posterior or lingual aspect the symphysis of the Heidelberg mandible shows the genial pit already described in connection with the chin region of Neanderthal man (see p. I 45); but there is this difference, the pit is deeper, wider, and more ape-like than in any specimen belonging to the Mousterian period. As regards the markings of the chin-the markings connected with the attachment and mode of action of the muscles of the tongue-the Australian mandible shows all those features which characterise modern man. In the Heidelberg mandible, on the other hand, we see the same peculiarities as in Neanderthal man, but to an exaggerated and to a more primitive degree.

To show how the Heidelberg mandible compares with that of an anthropoid ape, I have superimposed its outline, in fig. 85 , on a drawing made from the mandible and face of a female orang-both on the same scale. In height and area of the ascending branch of the jaw there is not much difference between the ape and Heidelberg 
man, but in actual shape, particularly in the form of the coronoid process, the anthropoid and Heidelberg types depart widely. Although the Heidelberg muscles of mastication must have been of great strength, yet the markings for their implantation on the mandible are those seen in human jaws-but never on the mandibles of anthropoid apes. In the region of the symphysis there is also a striking difference. On the posterior aspect of the anthropoid symphysis is seen the wide pit or genial

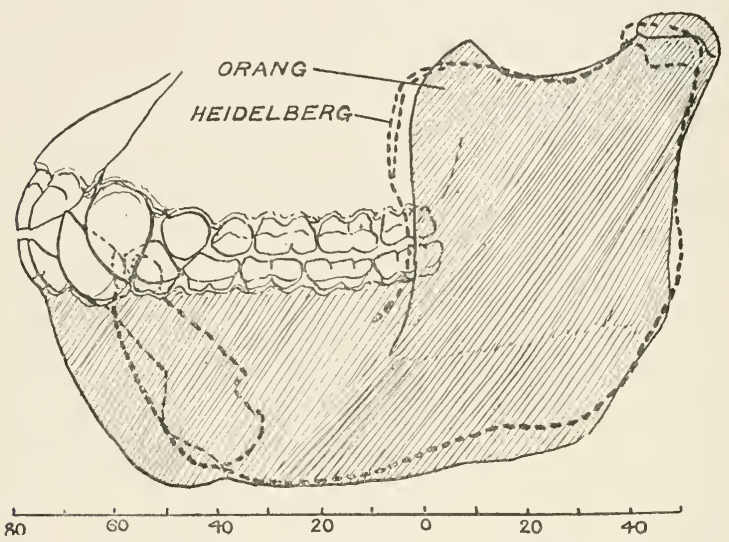

FIG. 85.-Outline of the Heidelberg mandible compared with a drawing of the lower jaw and face of a female orang. Both are drawn to the same scale.

fossa, bounded at the lower border of the symphysis by the simian plate. There is no simian plate, nor any trace of it, in the Heidelberg mandible.

In fig. 86 a final comparison is made to show the degree of resemblance between the mandibles from Spy and Heidelberg. The differences are those of degree, not of kind. It is true that the ascending branch of the Heidelberg specimen is much the larger. As regards size and shape, the body of the mandible - the part on which the teeth are implanted-is very much alike in both cases. In the region of the symphysis the Heidel- 
berg mandible shows more primitive characters; its upper or alveolar border is more projecting; there is no indication of a chin. In the Spy specimen the rudiment of a chin is apparent. Again, on the posterior aspect of the symphysis the genial pit-a simian structure-is almost filled up in the Spy specimen. This pit is open almost to the extent seen in young gorillas in the Heidelberg mandible (see also page +33 ).

There is another feature worthy of note, illustrated by the various drawings represented in fig. 82. In these drawings

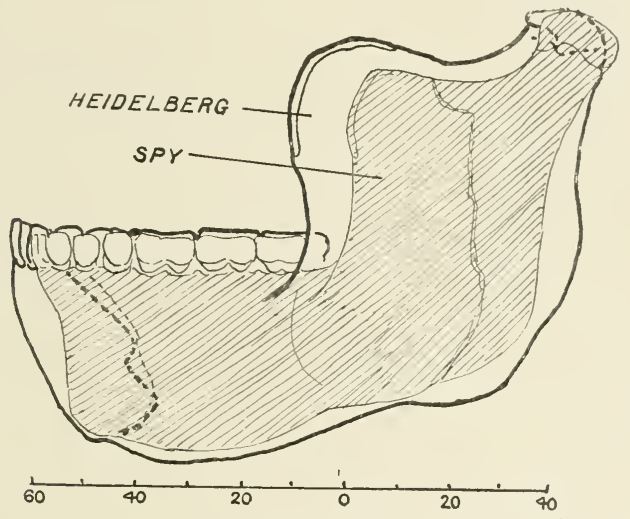

FIG. S6. - Outline of the Heidelberg mandible compared with the Spy mandible.

the Heidelberg, the Spy, a Tasmanian mandible, and a European mandible are represented from exactly the same point of view - at right angles to the chewing plane of the teeth. Such a view gives a clear idea of what is meant by the opening out of the floor of the mouth. The lower border of the mandible bounds that floor. Even in the primitive Tasmanian very little of the symphysis or of the lower border of the mandible is seen within the arcade of the teeth (fig. 82). In the Heidelberg mandible, and to some degree in that from Spy, the lower part of the symphysis encroaches, as in the ape (see fig. $165, p .+46$ ), on the floor of the mouth. 
Yet, in spite of this ape-like feature, we must grant, I think, the possibility of speech to the Heidelberg man. We cannot withhold such a faculty from Neanderthal man, such as the one found at La Chapelle-aux-Saints, who had a brain above that possessed by the average modern man. In the Heidelberg mandible we find the usual Neanderthal features of the chin, only they are more primitive-more simian in their development. If we allow full speech to the Mousterian man, we must, at least, assume the beginnings of such a faculty for Heidelberg man.

A suggestion made by Professor Elliot Smith ${ }^{1}$ has a direct bearing on the problem we are now considering. $\mathrm{He}$ is of opinion that the human brain must have reached almost its full development, and that speech was probably in full process of evolution, before the mandible, tongue, and other parts which subserve the purposes of speech had become finally and fully adapted to their new functions. That is very likely to have been the case. At least, we find in men of the Mousterian period a dentition very similar to that seen in the Heidelberg individual, and with mandibles, perhaps not so robust or so primitive, but yet in essential characters like the Heidelberg. In Neanderthal man these characters of teeth and jaw are associated with a large brain-one which was capable of subserving the faculty of speech. We have every reason to suppose, then, that the Heidelberg man, with similar characters of jaw and teeth, had also reached a high development of brain. If Professor Elliot Smith's suggestion holds true, namely, that in the process of human evolution the brain leads the way, it is possible that the brain of the Heidelberg man may prove as large as that of Neanderthal man.

1 See his address as President of the Anthropological Section of the British Association at Dundee, 1912. 


\section{CHAPTER XIV}

\section{CASTENEDOLO-MODERN MAN}

No revelation of prehistoric man could be more convincing than the discovery of the Heidelberg mandible. We have no shadow of doubt as to its authenticity or significance. We accept as a definite and indisputable fact that there lived a primitive form of Neanderthal man in South Germany in early Pleistocene times, bestial in structure beyond all kinds of men now living. The discovery we are now to relate is the old and well-known story of Castenedolo-the antithesis of the one narrated in the last chapter. At Castenedolo, in North ltaly, we obtain all the details relating to the finding of remains of a people of the modern type embedded in strata much older than the sands at Mauer. As the student of prehistoric man reads and studies the records of the "Castenedolo" find, a feeling of incredulity rises within him. He cannot reject the discovery as false without doing an injury to his sense of truth, and he cannot accept it as a fact without shattering his accepted beliefs. It is clear we cannot pass Castenedolo by in silence: all the problems relating to the origin and antiquity of modern man focus themselves round it.

If the map of North Italy be examined, it will be seen that the railway between Milan and Verona keeps close to the southern flanks of the Alps, and passes the town of Brescia on the way. In 1860 , Professor Ragazzoni-an expert geologist-was a teacher in the Technical Institute of Brescia. He was particularly interested in the fossil shells of the Pliocene formations which abound in North 
Italy. One of the favourite sites for collecting such specimens was a low hill, only about roo feet high, which rises from the plain at Castenedolo, about six miles to the south-east of Brescia. Fig. 87 reproduces a section which he drew to explain the geological formation of the hill. The exact number and sequence of the strata do not concern us now. We note that the second stratum is a deposit of boulder clay indicating one-probably the greatest-of the Pleistocene glaciations. The strata which have a direct interest for us are those numbered 8 and 9: No. 8 a deposit of greenish-blue clay containing shells-about 5 feet in thickness; No. 9 a deposit rich

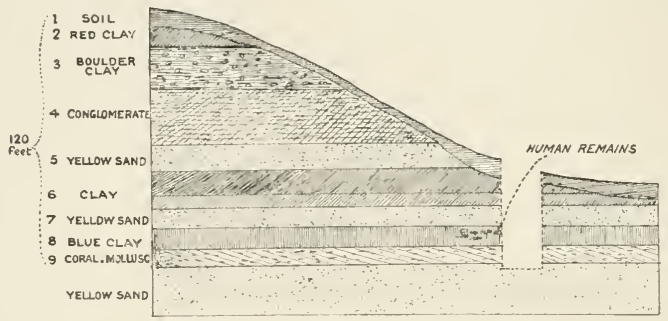

FIG. 87.-Section of the hill (Colle de Vento) at Castenedolo, near Brescia (Ragazzoni).

in coral débris and in fossil shells. About the age of the coral stratum there is no dispute; it was deposited when a Pliocene sea lapped against the southern flanks of the Alps. Were it to occur in England it would lie under the Red Crag of Suffolk, for it belongs to the older Pliocene formation. The overlying blue clay, deposited from still, muddy waters, is not much later in date than the coralline stratum.

Late in the summer of I860, Professor Ragazzoni visited Castenedolo, and had descended the pit, cut at the foot of the hill (see fig. 87), and was searching the coralline stratum for Pliocene shells. As he searched he uncovered, on the face of the pit between the blue clay above and the coral stratum below, the fragmentary vault 
of a human skull. It was coated and impregnated by the clay and shells of the strata between which it lay. Ragazzoni examined the overlying strata-one of yellow sand, another of grey sand-above the clay, and could see no trace of a disturbance at their lines of junction. He searched further and found a few other cranial fragments near the same site. He took his "finds" home, and showed them to some of his colleagues at the Technical Institute. His discovery was received with incredulity.

Until r 880-twenty years after the first discoverynothing further was found in the pit. In that year, however, a friend of Ragazzoni's-who believed in the first discovery-commenced to excavate in the pit about twenty paces from the site at which the human remains were found. In two months he exposed, at the same horizon, between strata 8 and 9, numerous and scattered fragments of the skeletons of two children. The fragments were left in situ until seen and examined by Professor Ragazzoni. Again the overlying strata were found intact. Then a further discovery was made-the skeleton of a woman in the contracted posture, compressed and disturbed by earth-pressure. The woman's skeleton lay within the clay stratum-a little over $3 \frac{1}{2}$ feet from the surface of the bank. The other human remains lay at a depth of $6 \frac{1}{2}$ feet from the top of the bank-the surface level of the soil.

In 1883 , Professor Sergi, ${ }^{1}$ then a rising anthropologist, visited Ragazzoni at Brescia and saw the human remains found in the Pliocene strata at Castenedolo-still covered by fragments of the original matrix in which they had been embedded. He found that the remains were those of people of the modern type. Two children, a man, and a woman were represented by the fragments, but only the skull of the woman was complete enough for a re-

1 Professor Sergi has kindly supplied me with copies of the papers he has written on the Castenedolo remains. See Archivio per l'Antrop. e l'Etnol., 1884, vol. xiv., No. 3. Ibid., I886, vol. xvi., No. 3. Rizista de Antropologia, ig12, vol. xvii., fas. iii. See especially his latest work, Le Origine Umane: Ricerche paleontologiche, Torino, 1913. 
construction. Professor Sergi was impressed by both the discovery and the discoverer. He went with Ragazzoni to the pit, made a fresh section of the strata, and was convinced that all was as Ragazzoni claimed, namely, that he had discovered human remains in undisturbed beds of a Pliocene age. The race was of the modern human type. Some time before he died, Professor Ragazzoni placed the human remains discovered at Castenedolo in Professor Sergi's custody, and they are now preserved in his department in the University of Rome.

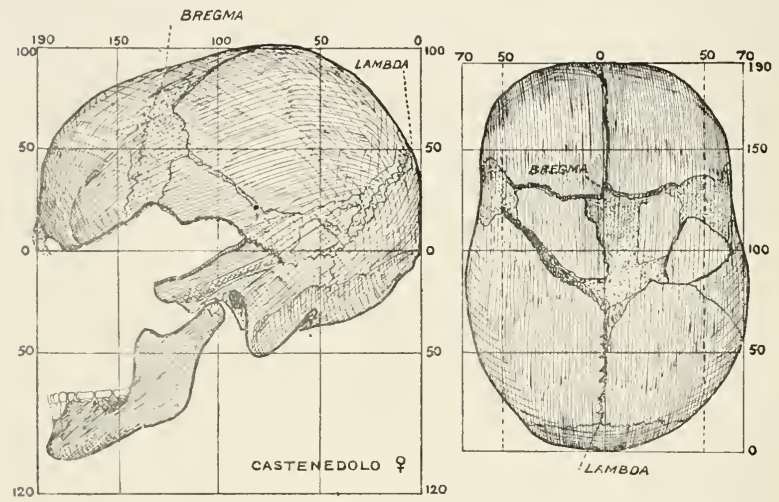

FIG. 88.-Woman's skull found at Castenedolo, viewed from the side and from above (after Sergi).

In fig. 88, I reproduce two drawings of the woman's skull copied from Professor Sergi's excellent illustrations, but fitted within the conventional standard lines used in former illustrations. The length is $189 \mathrm{~mm}$.; the width, I $35 \mathrm{~mm}$., being $7 \mathrm{I}^{\circ}+$ per cent. of the length. The dimensions are above those of the average modern European woman. The vault of the skull rises I I $5 \mathrm{~mm}$. above the ear-holes, the pitch of the roof being thus an ordinary one. The brain capacity must have been about I 340 c.c. - the average for modern European women. The bones of the vault are not thick. The forehead is 
wide ( $103 \mathrm{~mm}$.) and almost vertical. There is a complete absence of supra-orbital ridges. The lower jaw is small, the chin pointed, the angle between the ascending ramus and body very obtuse $\left(130^{\circ}\right)$, as in women with long, narrow, oval faces. It is a long, narrow skull, with not a single character we can identify as primitive. Indeed, if tested side by side with the skulls of modern women belonging to primitive races, we should select the Castenedolo skull as representing the more highly evolved example of the modern type. Yet there is also this striking fact to be kept in mind : it is an exact counterpart of the skull found at a depth of 50 feet in a Pleistocene deposit at Olmo, which lies a hundred and fifty miles to the south of Brescia. The Olmo skull is that of a male, the Castenedolo that of a female, but both are of the same race. The discovery at Castenedolo convinced Professor Sergi that men of the modern type were already evolved in the Pliocene period. His sincere and intrepid advocacy compelled the attention of his contemporaries. The leading anthropologists of Paris gave it a mixed reception. Quatrefages believed in the Castenedolo discovery, and he and Hamy gave it a place in that Valhalla of ancient skulls-the "Crania Ethnica." Gabriel de Mortillet and Topinard refused to believe in it. Sergi, however, has never faltered in his belief. Even, as he himself relates, when Ragazzoni summoned him and Professor Issel to examine another Castenedolo skeleton exposed in situ in I 888 , and when both were convinced that the skeleton represented a comparatively late interment, his faith in Ragazzoni's former discoveries did not waver. To him those early discoveries were guarantees that men of the modern type were evolved as long ago as the beginning of the Pliocene period.

Castenedolo is a test case: it raises all the issues relating to the antiquity of modern man. Are we quite sure Sergi is mistaken? Let us review briefly the principal facts on which our knowledge of the antiquity of man rests -man as we know him to-day-separating "certainties" from the "probabilities" and the "possibilities." Beyond 
any doubt we have traced men of the modern type-men belonging to races as highly evolved in body and brain as any race now living-to the beginning of the Aurignacian period. The men of Combe Capelle and of the Grimaldi caves were as highly evolved as any modern people, and yet they may have seen-probably did see-the Neanderthal men, with their simian brow-ridges. In the Mousterian period modern man appears to have existed no longer in Europe. At least not a trace of him occurs in any deposits of that period; only the remains of that man of an altogether different build of body-Neanderthal man. Then beyond the Mousterian period what do we find? In deposits of Acheulean and Chellean date not a trace of Neanderthal man; only remains of men of our own type-long-headed and big-brained. To me the discoveries at Galley Hill, at Clichy, at Olmo are certainties - giving a sure foothold from which one may safely step further back into the past. To othersequally competent to judge-they are either impossible or "not proven." They are "impossible" if we suppose that the world has always been populated by a single type or species of man, and that at every geological period this single type of mankind was slowly progressing towards his present state. Is such a belief well founded? Before we reach the middle of the Pleistocene period we find humanity has been evolved for so long a period that already there has been time for the differentiation of at least two distinct species of men of a totally different type-modern and Neanderthal. Are we quite certain the modern type may not be as old-in point of evolution - as the Neanderthal? That I think we must admit, and with that admission we must also grant the possibility of the discoveries at Galley Hill, at Clichy, and at Olmo as true.

Our difficulties increase as we go back. The discovery at Heidelberg is an unquestionable fact. It revealed a primitive form of Neanderthal man living in Europe early in the Pleistocene period. Have we any evidence of modern man at that date? There is the discovery at 
Ipswich. If the skeleton discovered there had been of a type totally different to that of modern man its antiquity as a "preboulder-clay" man would not have been questioned. But being of the modern type, and lying beneath only a shallow stratum, it can never be cited as certain evidence that modern man was in East Anglia in the opening third of the Pleistocene period. To me its value is merely potential. All the facts pertaining to it should be placed on record, but it can never be used as the basis from which to make another step into the past.

Beyond Heidelberg our record ceases in Europe with two exceptions-the discovery at Piltdown and the one discussed in this chapter, Castenedolo. One cannot say that the existence of man of the modern type in the Pliocene period is outside the range of possibilities. Sergi can cite the evolution of the wolf, the bear, the gibbon, and another anthropoid ape-Dryopithecus-as having been already evolved early in Pliocene times, not the same species which now lives, but from an anatomist's point of view quite as highly evolved as the living species. What is possible in the evolution of apes may also be granted as a possibility in the case of man. But when I grant the possibility of men of the modern type having been in existence during the Pliocene period, I do not think the discoveries at Castenedolo prove it. The deepest of the bones lay only $6 \frac{1}{2}$ feet below the surface of the land. Quatrefages mentions the fact that the bones were not fossilised to the degree noted in animal bones from the same deposit. A skeleton in a contracted posture must be regarded-unless proof to the opposite can be produced-as a burial, not necessarily from the present land surface, but from a land surface. To me the discovery at Castenedolo is simply a possibility ; it does not provide us with any sure foothold in our search into the antiquity of man. So far as modern man in Europe is concerned, we lose all trace of him at Galley Hill. We see the last of Neanderthal man in the sand-pit at Mauer. 


\section{CHAPTER XV}

DISCOVERIES OF ANCIENT MAN IN AFRICA AND JAVA

$U_{P}$ to this point our attempts to follow man's history into the remote past have been confined to Europe. We propose now to see what was happening to ancient man in the rest of the world during the advance and retreat of the ice sheet in Europe. We must confess at once that as yet we know very little of ancient man outside Europe, but nothing is more certain than that the coming generation will make good the blanks in our knowledge and explain many of the puzzling events of ancient Europe-such as the sudden appearance of men of the modern type in the Aurignacian period.

Only a generation ago, when early or ancient man was spoken of, our thoughts and minds turned involuntarily to Babylonia or Egypt. As knowledge increased, these ancient places moved gradually from the background to the foreground of time. Behind ancient Egypt lie other and more ancient Egypts, and it is in the valley of the Nile we shall commence our survey. A rapid journey from Cairo to Capetown will provide an opportunity of judging what is known of the antiquity of man in Africa. Students of Egyptian history are now generally agreed that settled rule, under a dynasty of kings, commenced in the lower valley of the Nile about 3500 в.c. In the opening decade of the present century, archæologists began to recognise that certain graves and cemeteries were older than the First Dynasty-were " predynastic." They presently were able to distinguish "late," " middle," and "early" predynastic interments. The people buried 
in such graves were contemporaries of the Neolithic people of Europe. These predynastic graves, and the ancient Egyptians buried in them, have been examined and described by Professor Elliot Smith : ${ }^{1}-$

"The early predynastic graves consist of shallow pits of a broad oval or rectangular form, scraped in the gravel or fine, yellow-grey alluvium, immediately beyond the area of cultivation. . . . The body was buried lying usually on the left side, with the arms and legs loosely flexed, the hands being between the knees and the face. The head was usually directed towards the south, or what those primitive people considered south. . . W With the dead were buried many objects which the deceased had treasured in this life, or his friends believed he might need in a future existence: pottery, vessels of stone, slate palettes, ivory figures, beads, occasional objects made of gold and copper, knives, and weapons made of flint and other stone.

"The predynastic or proto-Egyptian was a man of small stature, his mean height estimated at a little under 5 feet 5 inches in the flesh for men, and almost 5 feet in the case of women, being just about the average for mankind in general, whereas the modern Egyptian fellah averages about 5 feet 6 inches. He was of a very slender build, for his bones are singularly slight and free from pronounced roughnesses and projecting bosses that indicate great muscular development. In fact, there is a suggestion of effeminate grace and frailty about his bones which is lacking in the more rugged outlines of the skeletons of his more virile successors. ...

"So far as their physical characteristics are concerned, the predynastic Egyptians are probably the nearest approximation to that anthropological abstraction-a pure race-that we know of. About 2 per cent. of them are definitely negroid, and perhaps

I The Ancient Egyptians, Harper Brothers, I9II. 
another 3 or 4 per cent. display features which suggest the influence of negro admixture, but in so undecided a manner that it would be rash to dogmatise concerning them.

"The problem of the relationship of the early Egyptians and the Arabs is one that presents singular elusive difficulties. . . . But the modern Arab, such as those now dwelling in the provinces of Yemen and Hejaz, and the wandering Bedouin who make their way into Egypt, present so close a likeness to the proto-Egyptian racial type that it would be a matter of some difficulty to discriminate between their osseous remains."

Dr Seligmann has also recognised the close resemblance between the Hadendoa-a tribe living on the western shores of the Red Sea near Suakin-and the predynastic Egyptians.

Thus, although the inhabitants of modern Egypt differ in many minor features from the men who lived along the Nile six thousand years ago-a difference which, as Professor Elliot Smith has shown, is largely the result of admixture with alien races-yet the early predynastic type still persists. We have seen the same persistence of ancient type in England. The Neolithic Briton of the river-bed type still survives.

The cemetery at Naga-ed-Der, which first provided Elliot Smith with the skulls and remains of predynastic Egyptians, lies on the Nile over four hundred miles south of Cairo. Our next point of investigation takes us south of Khartoum to Gebel Moya, a station situated on an arid range of granite hills between the Blue and White Niles. In I 9 Io, Mr Henry S. Wellcome commenced a series of explorations at Gebel Moya, and discovered a cemetery of prehistoric date. Some of the graves may have been dug in the time of the earlier Egyptian dynasties. In the deeper graves "fossilised" skeletons of a tall negro race were found, belonging to a race not unlike the tall, longlimbed negro tribes who now live along the valley of the 
White Nile. The remains of those people have been recently described by Dr Douglas Derry. ${ }^{1}$ As in modern negroes of the same region, lip ornaments were worn, and in the women the lower incisor teeth were extracted. The discovery is important in this respect : it shows us that three thousand or four thousand years ago a tall negro type was in existence, and inhabited this part of the Soudan, practising the same bodily mutilations as their modern successors.

The next point in our journey from Egypt to the Cape takes us to German East Africa. In I9I4, Dr Hans Reck discovered in a stratified deposit at Oldoway, in the northern part of German East Africa, a human skeleton, in the contracted posture, and exhibiting all the features of a typical negro. The stratum in which the skeleton lay-one composed of calcareous sand-contained remains of extinct animals of the Pleistocene period. The antiquity of the skeleton is probably not so great as the stratum in which it lay, for a complete human skeleton laid in a contracted posture signifies a burial, unless the opposite can be proved-or, at least, unless a natural entombment can be rendered probable. The teeth were artificially pointed by having been filed-a custom still prevalent among negro tribes of East Africa. It is very probable that the negro was fully evolved in early Pleistocene times, but the evidence from Oldoway cannot be accepted as having finally proved this degree of antiquity. ${ }^{2}$

So far as concerns ancient man, South Africa is distinctly a land of the greatest promise. In recent years several announcements of the discovery of ancient human remains have been made, but, so far, no full and authentic details have been made public. In his presidential address to the Royal Society of South Africa, Dr L. Peringuey discussed the evidence relating to the antiquity of man in South Africa. He could not show the fossil

1 See Proc. of Seventeenti Internat. Congress of Medicine, London, 1913. Sec. 1 : Anat. and Embryology, pt. 2, p. 99.

2 See Illustrated London Nerus, April 4th, 1914. 
bones of any African of Palæolithic times, but he was able to exhibit many examples of the workmanship of the people of that period. In the ancient river deposits of South Africa many implements very similar to those of the Chellean, Acheulean, Mousterian, and Aurignacian cultures have been discovered. The sequence of cultures in Africa appears to be less definite than in Europe. Dr Peringuey insists that stone implements of the Chellean type are found lying side by side in the same stratum with the implements of the Mousterian type, as if both cultures had been prevalent at the same time. The remarkable fact remains that, in South Africa, the European Pleistocene cultures are represented in deposits containing the remains of extinct forms of animals-animals which were alive when Palæolithic man lived in South Africa.

No better evidence of the antiquity of man could be provided than that afforded by the Bushmen of South Africa-a negroid race, rapidly hastening towards extinction. As artists, the Bushmen represent Europeans of the Aurignacian period; they decorate their rockshelter with realistic representations of hunting scenes in the same manner as Europeans did before the Ice age came to a close. But it is not as modern representatives of ancient artists that they are cited here : it is because in the structure of their bodies they reveal a very highly specialised form-probably a very ancient form of mankind - not primitive and ape-like, but a highly differentiated form of the negro type. The Bushman is the product of a long series of evolutionary stages. In estimating the antiquity of man, we must allow sufficient time for the evolution of such highly specialised representative types of modern man-such as the Bushman, the West African negro, the fair-haired North European, and the yellow-skinned Chinaman.

From Africa we now pass to Asia-a part of the world from which the student of early man has expected so much and, so far, has obtained so little. It is true that we are provided in India and China with two very 
distinctive types of mankind, so divergent that we must suppose them to be the product of a very long period of time. In Egypt and in England we have seen how little the native types have changed with the lapse of six thousand years. India and China will yet reveal the story of their prehistoric ancestral races, but in the meantime we must be content with citing one observationthat made by Dr Fritz Noetling of Tasmania when he was in the service of the Geological Survey of India. When investigating a conglomerate deposit in Burmahwhich contained the remains of animals belonging to the earliest part of the Pliocene period-he found flints showing distinct traces of having been worked by man. ${ }^{1}$ As in all cases where chipped flints of an Eolithic type have been discovered, the "humanity" of Dr Noetling's Burmah implements has been called in question.

So far, our search in Africa and Asia for traces of ancient man has yielded only unimportant results. A visit to Java, however, will make amends. This island has given us the remains of a being which, after twenty years of debate, still occupies an undecided place between the realms of ape and man.

Dr Eugene Dubois, who discovered the remains of this strange being, named it Pithecanthropus erectus, because, although it possesses the human erect posture, it yet possesses many ape-like traits. ${ }^{2}$ Dr Dubois saw in this ancient being the representative of an extinct family of animals which occupied a position between the human family on the one hand and the anthropoid family on the other. Pithecanthropus, in the opinion of the discoverer, was but the harbinger of a family of "Missinglinks." The story of the discovery of Pithecanthropus is well known. The site lies on the east bank of the

1 See Records of Geol. Survey of India, 1894, vol. xxvii. p. IOI. Also Natural Science, i 897 , vol. x. p. 89.

2 The more important papers on Pithecanthropus are: Dr Eugene Dubois, Pithecanthropus erectus, Eine Ubergangsform, Batavia, 1894. Professor G. Schwalbe, "Studien ueber Pithecanthropus crectus," Zeitschrift fïr Morphologie und Anthrop., 1899, Bd. i. pp. 16-240. Dr Eugene Dubois, Trans. Roy. Dublin Soc., I896, vol. vi. p. I. 
Solo or Bengawan, a stream which, rising among the volcanic hills of the province of Madiun, in the central part of Java, pursues a north-easterly course to the sea. A native hamlet named Trinil is near the scene of $\mathrm{Dr}$ Dubois' explorations. A section of the deposits which form the east bank of the Bengawan, with the stratum in which the remains of Pithecanthropus were found, is shown in fig. 89.

The deposits are of the kind we have already studied

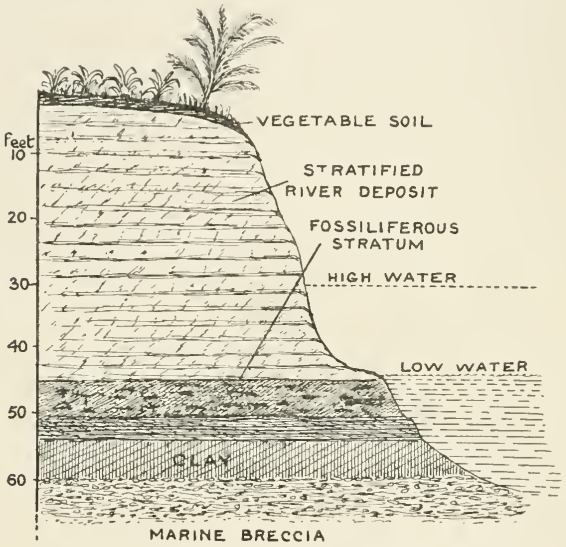

FIG. 89. - Section of the east bank of the Bengawan, near Trinil, showing the position of the fossiliferous stratum (Dubois).

in the river valleys of Europe. The stratum which directly concerns us is the fossiliferous bed, about 4 feet in thickness, lying at the level of the present streamthe Solo or Bengawan. The fossiliferous stratum is well named. Between I89I and I894, Dr Dubois removed from this layer fossil bones representing twentyseven different kinds of mammals - most of them belonging to species which are now extinct. After comparing the animal remains thus discovered with these which are found in Pliocene and Pleistocene deposits of India, Dr Dubois came to the conclusion that 
the fossiliferous stratum must be assigned to a late part of the Pliocene period. The section of the Trinil strata reproduced in fig. 89 is therefore comparable to that of the Cromer forest beds given in fig. $7+$, p. 2 I 2. Below the fossiliferous bed is a stratum of conglomerate, representing the gravel bed of the ancient Bengawan. Under the conglomerate is a layer of clay - a deposit laid down in quiet, muddy water. Under the clay rests a marine deposit containing fossil shells of early Pliocene forms-corresponding to the "Crag" formations of East Anglia. Over the fossiliferous bed in which the remains of Pithecanthropus were found are stratified deposits amounting to 45 feet in thickness. These stratified beds of sand and fine, volcanic débris recall the Mauer sands overlying the Heidelberg mandible. Both at Trinil and Mauer the strata represent valley deposits. The fossiliferous bed, made up of a fine, triturated deposit of volcanic ashes and sand, represents the basal layer. After the valley deposits had been laid down during a period of subsidence, elevation of the land commenced, the stream then cutting a new valley out of its old deposits and exposing the deeper strata on its banks. Dr Dubois, who was a surgeon in the colonial military service of Java at the date of this discovery, and who is now Professor of Geology in the University of Amsterdam, came to the conclusion that the animal remains in the fossiliferous layer belong to a late phase of the Pliocene period-one corresponding to the forest beds of East Anglia. The remains of Pithecanthropus, which were discovered in that stratum, would thus belong to a somewhat earlier date than the Heidelberg mandible.

To settle the date more definitely, and in the hope of finding further remains of this fossil humanoid form, Frau Lenore Selenka, with assistance from certain scientific societies in Germany, fitted out an expedition in I 906 to continue Dr Dubois' exploration at Trinil. ${ }^{1}$

${ }^{1}$ Die Pithecanthropus Schichten auf Javu, M. Lenore Selenka and Professor Max. Blanckenhorn, Berlin, I911. 
From one point of view the expedition was eminently successful. A great harvest of fossil forms was collected, but no further trace of Pithecanthropus was discovered. Seventeen specialists examined and described the great collections brought home by the Selenka expedition. The conclusions drawn by Dr Stremme and Dr Janensch from a study of the mammalian remains was that the fossiliferous bed was late Pliocene in date of formation, but those who examined the other collections fixed its date in the older Pleistocene. In this also we see a resemblance to the Cromer forest beds, which oscillate in the geological scale on either side of the border-line between Pliocene and Pleistocene.

We now proceed to examine the kind of being who lived in Java when the Cromer forest beds were being formed in Norfolk. The picture has to be built from (I) the vault of a skull; (2) a left thigh bone; (3) three teeth, two of them belonging to the upper molar series-a second of the left side, a third or wisdom tooth of the right side, the third or remaining tooth being a second lower premolar of the left side. There can be no doubt that all the parts, if not belonging to the same individual, at least all belong to the same species. They were found at the same horizon of the fossiliferous stratum. There is no question of a burial here, for the various parts were scattered over a distance of twenty paces-spread, apparently, by the running waters of the stream. If we do not admit that the femur, the teeth, and the calvaria, which lay near each other in the bed of an ancient stream, are parts of the same individual or same kind of individual, then we must make a very improbable supposition. We must suppose that the femur is that of a man showing a few, minor, ape-like traits; that the teeth are from another human being in which certain simian features were manifest; and that the calvaria belonged to a largeheaded anthropoid showing marked human affinities. We cannot conceive that chance could bring three such strange individuals side by side in one narrow area of the bed of a stream. With Dr Dubois, we think there is 


\section{ANCIENT MAN IN AFRICA AND JAVA 26I}

only one explanation-they represent parts of the same individual.

How difficult it is to fix the exact position of Pithecanthropus in the common family tree of man and ape becomes manifest when we consider the structural characters of the thigh bone, the teeth, and the skull. The thigh bone is less ape-like in its general form, and in its individual features, than the thigh bone of Neanderthal man. The human thigh is moulded to suit the needs of a body balanced perfectly on the lower extremities. If a thigh bone has a human form, we infer that the animal to which the thigh bone belonged had a human gait and a human posture of body. We infer that the feet, the legs, the pelvis, the backbone, trunk, and neck of such an animal were all shaped and adapted as in modern races of mankind. The Trinil femur signifies a being adapted to the upright posture. The erect posture was already evolved in Pithecanthropus. Those who have studied the complex structural changes needed to adapt the human body to its peculiar posture cannot conceive that such changes have been evolved twice-once in the human ancestry, and at another time in the forerunners of Pithecanthropus. The natural inference is that the human family of ancient Java and all human races are the common descendants of a stock in which the human posture and method of progression were already evolved. In stature, shape, and weight of body, Pithecanthropus was human. Dr Dubois estimates from the length of the femur $(455 \mathrm{~mm}$.) that the stature should have been about 5 feet 8 inches ( $1 \cdot 700 \mathrm{~m}$.), and the weight about I I stones (70 kilos).

From the three teeth discovered by Dr Dubois, one infers that the dentition was, in the main, human in type. No trace is to be seen in the molars of an expansion of the pulp cavity or of a shortening of the roots-characters of the Heidelberg dentition. The roots of the molar teeth of the Java individual are widely separated as in apes, and as in the more primitive races of modern man. The crowns of the teeth are large, and their humanity 
is made manifest by the fact that their transverse (cheektongue) diameter is absolutely and relatively great as regards the long diameter. In simian teeth the length exceeds the width of the crown. In some minor features there is a resemblance to the molar teeth of the orang. The upper wisdom tooth (third molar), although of great size, being $15 \mathrm{~mm}$. in width by $\mathrm{II}^{\circ} 3$ in length (the corresponding diameters in a native Tasmanian are I $2 \times 10.5$ ), yet shows a manifest reduction in development. The two posterior cusps have become reduced to form a crenulated, hinder margin on the crown instead of distinct cusps. As to the development of the canine teeth, a guarded statement must be made. The temporal ridges on the skull, being only slightly developed-as compared with their condition in the skulls of anthropoid apes-suggest small temporal muscles and canine teeth reduced to human dimensions. It will be seen in a subsequent chapter that I applied a similar process of reasoning to the skull found by $\mathrm{Mr}$ Charles Dawson at Piltdown. The subsequent discovery of a pointed canine tooth, which apparently belongs to the same individual as the skull, showed that this line of reasoning cannot be relied upon.

If in build of body and form of teeth Pithecanthropus possessed just those features one would postulate for a primitive form of man, it is otherwise as regards the skull. When closely examined, its simian rather than its human characters are forced on our attention. In fig. 90 the Trinil calvaria is placed within the standard frame in which skulls of the modern human type have been set. As regards length, it falls well within the range of human dimensions, being only $5 \mathrm{~mm}$. short of the mean for modern man. When we analyse the various elements which go to make up the length of the skull-the length of the brain and the thickness of the supra-orbital wall in front, the occipital wall behind-we see that the proportion of bone to brain is much greater in Pithecanthropus than in modern man. His brain cavity measured I $55 \mathrm{~mm}$. in length, the supra-orbital 
wall, $23 \mathrm{~mm}$., the occipital, $7 \mathrm{~mm}$. The bony walls make up over I 6 per cent. of the total length, whereas in modern men they usually form about 7 to 9 per cent. of the total length. In the gorilla the bony walls may form 20 per cent. of the total length of the skull. The width of the Trinil skull may be estimated at I $35 \mathrm{~mm}$., but only $7 \mathrm{~mm}$. of that amount represents the side walls of the skull, which are thin. The width is 72.5 per cent. of the length. Pithecanthropus thus falls into the long-headed group of humanity.

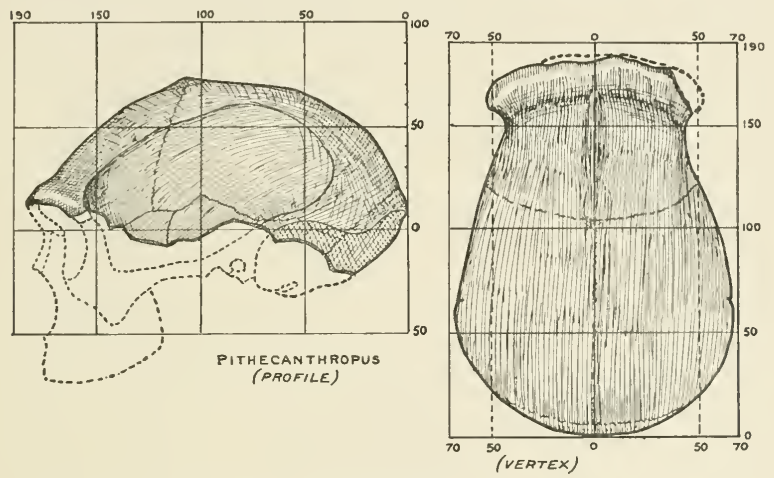

FIG. 90.-Profile and vertex of the cranium of Pithecanthropus, from a cast of the original.

How low Pithecanthropus must be placed in the human scale-how very simian he was-becomes manifest in the low pitch of his cranial vault. We have hitherto measured the height of the vault from the ear-holes, but there are two reasons why that base line must be abandoned in this case: (I) because the temporal bone and ear-passage are missing; (2) because in anthropoid skulls- to which that of Pithecanthropus has certain unmistakable resemblances-the ear-holes bear a different relationship to the cranial cavity to that obtaining in human skulls. We must therefore fall back upon another zero or base line-one which can be applied 
to the Java fragment. The base line is that shown in many of the illustrations in this book (see fig. 72). Even when such a base line is used we meet with a difficulty. Our base line crosses the hinder lower angle of the parietal bone. That angle is present in the calvaria of Pithecanthropus, and can be utilised (fig. 90). In front the zero line should cross the fronto-malar junction, but, as will be seen in fig. 90, this line is made to pass nearly io $\mathrm{mm}$. below this junction. The line is placed at such a low position because the fronto-malar junction in anthropoid skulls is situated much higher, as regards the floor of the brain cavity, than in human skulls. This point will be again discussed when we come to deal with the Piltdown skull (see p. 380). It is sufficient at present to draw attention to the fact that the bones forming the side of the skull behind the fronto-malar junction, the frontal and sphenoid (fig. 90), are disposed, not as in human skulls, but as in those of anthropoids (see fig. I 38, p. 382). That is an important fact in fixing the position of Pithecanthropus in the scale of human evolution. In the ironto-malar region of the Java skull all the anthropoid traits are retained.

The importance of the height of the vault of the skull above this zero line (fig. 90) is readily understood. As the brain grows in size and complexity, the extra room required is obtained-as Professor Arthur Thomson clearly demonstrated fifteen years ago ${ }^{1}$ - by the expansion of the roof and sides. The vault rises above the base line as the brain grows. In average skulls of the modern type the vault rises about $100 \mathrm{~mm}$. above this standard line; in the Gibraltar skull-the lowest pitched of all Neanderthal skulls - the vault rises to $86 \mathrm{~mm}$. above the zero line, but in Pithecanthropus the height is only $7+\mathrm{mm}$. (fig. 9I). In the great anthropoids-the orang, chimpanzee, and gorilla-the height of the cranial vault varies from 50 to $60 \mathrm{~mm}$. above the base line. Thus in height of cranial vault Pithecanthropus is rather nearer to

1 "On Man's Cranial Form," Proc. of Internat. Medical Congress, Madrid, 1903. 
the anthropoid than to the human form. In total length and width of brain, however, Pithecanthropus is altogether human.

There is another important anthropoid feature in the vault of the Java skull. When human skulls, whether of the Neanderthal or modern types, are orientated on the base line employed here, the highest part of the vault lies between $I \frac{1}{2}$ and $2 \frac{1}{2}$ inches ( 35 to $50 \mathrm{~mm}$.) behind

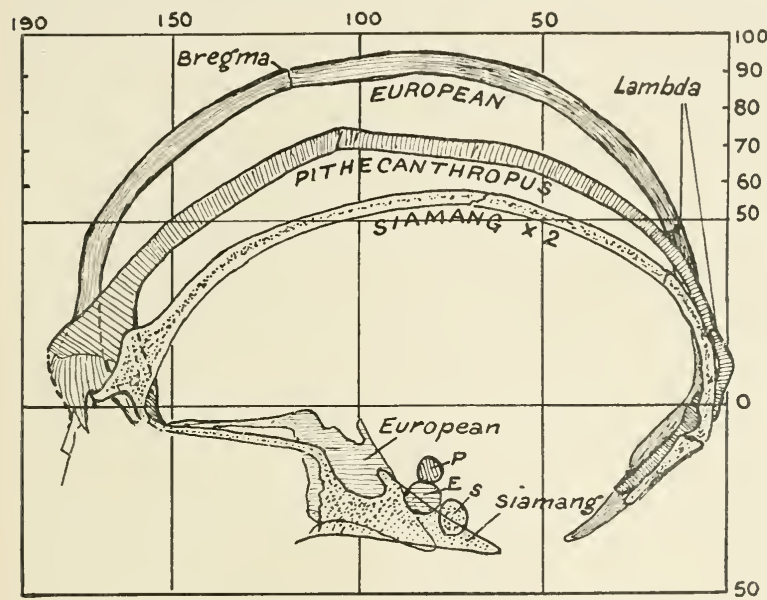

FIG. 91.--Cranial vault of Pithecanthropus, of the Sianang (gibbon), and of a modern European orientated on the zero base line. The Siamang's skull is represented twice its natural size.

the bregma (see fig. 9I). But in anthropoid skulls the bregma itself forms the highest point. In this respect the skull of Pithecanthropus is anthropoid (fig. 9I). This feature of the cranial vault depends on two factors. We have already seen that in anthropoid skulls, and also in the Gibraltar skull, the base is markedly extended or unbent at the pituitary angle (see fig. 54, p. I 56). The extension of the cranial base leads to a flattening of the roof of the skull. Another factor, probably a more important one, in raising the vault of the skull so that its highest point 
is post-bregmatic in position, results from the great growth of that part of the brain which lies under the parietal region of the vault. The parietal lobes of the human brain are known to be the seats of the higher functions of the brain. In the course of the evolution of the human brain these parietal association areas have undergone a great growth and expansion. Such a growth tends to raise the part of the vault under which the parietal areas are situated. We should expect these parietal association areas to be of relatively small development from a mere inspection of the Pithecanthropus skull. As a matter of fact, such is the case. Dr Dubois succeeded in taking a cast of the cavity of the skull. The cast showed very clearly the convolutionary pattern of the brain. He noted that in the region of the parietal association areas the brain was poorly developed.

The forehead of Pithecanthropus shows many anthropoid features. It is low and receding; the orbits are crossed by a true simian bar of bone-the torus supraorbitalis. This gorilla-like feature is one which also persists in Neanderthal man. The forehead is very narrow-only $8_{4} \mathrm{~mm}$. when measured between the temporal lines. In human skulls these lines diverge as they ascend on the frontal bones; in anthropoid skulls they approach towards each other as they pass backwards on the vault. In Pithecanthropus the temporal lines - run almost parallel with each other. This condition represents a developmental stage in young anthropoids. The minimum width of the forehead in Pithecanthropus, as we have seen, is $84 \mathrm{~mm}$. - Io to $20 \mathrm{~mm}$. less than is common in modern skulls; but as regards the width just above the orbits, the measurement is about the same as in modern skulls-rO2 or $\mathrm{rO}_{4} \mathrm{~mm}$., nearly $20 \mathrm{~mm}$. less than in the more robust Neanderthal skulls.

In Pithecanthropus the head was attached to the neck exactly as in a young anthropoid ape (see figs. 90, I 36). The occipital lines, which limit the area to which the muscles of the neck are attached, and which spread out on the skull as the muscles of the neck grow, almost reach 


\section{ANCIENT MAN IN AFRICA AND JAVA 267}

the upper border of the occipital bone in Pithecanthropus. The point named, the "lambda," is situated at the upper border of the occipital bone (fig. 9I). In the skulls of adult anthropoids these lines ascend above the lambda. The mastoid processes are broken away, but we may safely presume that they were shaped as in young gorillas-mere bosses, not projecting, pyramidal processes as in modern man. Thus in the region of the orbits, and in the manner in which the skull was fixed to the neck, Pithecanthropus had much more in common with Neanderthal man and with anthropoid apes than with men of the modern type.

If we knew only the calvaria, if Dr Dubois had not discovered the human-like thigh bone, then we should have regarded Pithecanthropus as a big form of anthropoid. The brain cast, however, would probably have made us hesitate in coming to such a conclusion, for in the cast Dr Dubois was able to recognise many human characters. The brief preliminary ${ }^{1}$ description which he published in I898-the final description and figures have yet to appear-depicts a very primitive form of human brain. He estimated the brain capacity to be about 850 c.c. In size of brain Pithecanthropus takes a place between the great apes and the various races of man. In orangs, chimpanzees, and gorillas the brain capacity varies from 290 c.c. to 6 IO c.c., the mean for male gorillas being 5 I 8 c.c. In human races the brain . capacity varies from I 300 c.c. to I 500 c.c., but the capacity may be as low as 930 c.c. or as high as 2000 c.c. Clearly, in size of brain, Pithecanthropus is a transitional form between man and ape. If the specimen found represents an average individual, then we may suppose, as Dr Dubois has postulated, that in this humanoid race the brain capacity ranged between 710 c.c. and 1060 c.c.

"The most peculiar feature of the brain cast," writes Dr Dubois, "is the narrowness of the frontal part of the

1 "Remarks upon the Brain Cast of Pithecanthropus erectus," Fourth Intcrnational Congress of Zoology, Cambridge, 1898, p. 78. Journ. Anat. and Physiol., 1899, vol. xxxiii. p. 273. 
cerebrum, whereby it differs from every normal human brain, as from all ape brains. In the frontal region the convolutions are perfectly distinct. The most conspicuous feature is the second frontal fissure, as clearly developed as in any human hemisphere. . . The important inferior frontal convolution has attained a fair development. I found the average area of the exposed superficies equal to half the average area in twelve European hemispheres, but at least double that in the brain of a large chimpanzee or an orang-utan. This seems to indicate that our fossil being possessed already a certain amount of power of speech. The pars triangularis is present in this convolution, as results from the presence of two anterior branches of the Sylvian fissure. But the pars orbitalis has only a very rudimental development."

It is clear, then, that the region of the brain which subserves the essentially human gift of speech was not ape-like in Pithecanthropus. The parts for speech are there; they are small, but clearly foreshadow the arrangement of convolution seen in modern man. In another equally important region of the brain-in that part of the parietal lobe which lies between the primary centres for sight, hearing, and common sensation-there is a simple, rather pithecoid condition. In this intermediate region the higher association areas are developed in the brain of modern man-areas in which memories are formed in connection with things heard, seen, or touched. In this area the brain of Pithecanthropus had not reached a "human" level.

Taking it all in all, Dr Dubois' discovery in Java throws more light on our early, human ancestry than any other yet made. We were not prepared to find an ancestral type in which the human posture was fully developed, and yet in which the brain remained in so primitive a condition as in Pithecanthropus. We had pictured man rising to his present estate by a gradual and simultaneous change in all his parts. In Pithecanthropus we find a being human in stature, human in gait, human in all his parts, save his brain. The full 
development of the brain came last. Even in Pithecanthropus the parts of the brain connected with the faculty of speech are present; whether speech was actually evolved is a moot point ; at least we may think the potentiality was there.

All the structural characters of Pithecanthropus, so far as we know them, are exactly of the kind we expect to find in an early ancestral type of man. Does Pithecanthropus, then, represent the stage of evolution mankind had reached at the end of the Pliocene period? Can we conceive, keeping in mind the extraordinary complexity of the modern human brain, that the simple brain, human in form as it is, could have expanded into the brain of modern man, with its crowded, highly evolved "association" areas, in the course of the Pleistocene period? We know for certain that men of different species - Neanderthal and modern - were evolved by the middle of the Pleistocene period with brains just as complex in form and large in size as the modern brain. We have seen that a period of ten, twenty, or thirty thousand years can pass and leave the human brain almost unaltered. Can we conceive that in the stretch of time between the end of the Pliocene and the middle of the Pleistocene, even allowing two or three hundred thousand years for that space, the brain of Pithecanthropus could have evolved into the modern human form? I cannot conceive such a rapid rate of evolution.

We see, however, in all forms of animal life the persistence of certain archaic types-certain groups of animals retain the characters of an ancient stock, while their cousins or collaterals branch out into new forms. The fish is an older form than the amphibian, the amphibian is older than the mammal, but all three types still survive. The gorilla of to-day is not a human ancestor, but retains, we suppose, in a much higher degree than man does, the stock from which both arose. It is in that light I would interpret Pithecanthropus; a true survival, into late Pliocene or early Pleistocene 
times, of an early stage in the true and direct line of human evolution - a stage we may expect to find evolved, not in the Pliocene, but in the preceding or Miocene period. We may accept Pithecanthropus as representing a very early stage in human evolution (see fig. I 87 , p. 5०9).

Our search for traces of ancient man, outside the bounds of Europe, has detained us rather too long in Java. There are still the islands of the Pacific and Australia to be surveyed. So far, no fossil remains of man have been discovered in Australasia ; ${ }^{1}$ but there is no need to seek there for fossil forms. Ancient and primitive man still survives-more primitive than any fossil form of modern man yet found in Europe. Sir William Turner measured the brain capacity of twentyfour skulls of native Australian women. The mean capacity was I I 6 c.c. ; four of them were under I000 c.c., one was as low as 930 c.c. With brains of a smaller size than 930 c.c. we can scarcely expect a human intelligence. Of all the races of mankind now alive, the aboriginal race of Australia is the only one which, in my opinion, could serve as a common ancestor for all modern races. The common ancestor has to yield descendants which, on the one hand, might become the typical inhabitant of Central Africa, and, on the other, the fair-haired native of North-Western Europe. The

1 After I had written the above, information reached England that the remains of Pleistocene man had already been discovered in Australia. When the British Association met in Sydney, Aug. 21, I9I4, Professors T. W. Edgeworth David and J. T. Wilson were in a position to show a fossilised human skull, which was of Pleistocene age-" perhaps early Pleistocene." The specimen had been obtained some years ago from a well-known Pleistocene formation of the Darling Downs, Queensland. When discovered it was partly hid by a dense coating or mask of mineralised matter. This skull - known as the "Talgai "skull-is being investigated by Dr Arthur Smith of the University of Sydney, and a full account of the discovery may be expected at an early date. Enough is already known of this early native of Australia to leave us in no doubt that his brain was of modern size and that his characters are those we expected to find in an early Australian type (see Nature, Sept. 9, 19I5, p. 52). Another important discovery is announced from South Africa. In a Pleistocene deposit at Boskop, Transvaal, an elongated, large human calvaria has been found (see Nature, Aug. 5, I9I5, p. 6I5). 
Australian native has those intermediate and generalised characters needed for such an ancestral form. If we agree that the Australian native, or some other primitive race, may be accepted as a common ancestor for white and black races of mankind, let us ask the following. question: How long will it take for the evolution of two such divergent races as the negro and European from such a common stock? In answering that question we have to bear in mind how durable certain modern human types are.

It is when we approach the antiquity of man from this point of view that we see that we must postulate a very long period of time for the evolution of modern types of man. The whole length of the Pleistocene period does not seem to me sufficiently long for the purpose. Certainly, the common ancestor of modern races must have reached a higher stage by the close of the Pliocene period than that represented by Pithecanthropus. It is for that reason that we must regard the humanoid form discovered by Dr Dubois in Java as representing a Miocene rather than a Pliocene stage in man's evolution (see frontispiece). 


\section{CHAPTER XVI}

\section{DISCOVERIES OF REMAINS OF ANCIENT MAN IN NORTH AMERICA}

Our survey of the "old" world revealed two ancient, extinct, and interesting human types-Neanderthal man and Pithecanthropus-but the evolutionary stages of modern man we did not discover. When we come across him first, in mid-Pleistocene times, modern man is already fully evolved. If the modern man was already in existence soon after the close of the Pliocene period, as the evidence given in former chapters leads one to suppose, then we ought to find traces of him at an early Pleistocene date in the "new" world, All geologists are agreed that America and Asia were not separated by Bering Strait in the earlier part of the Pleistocene period, nor in the Pliocene period, and that man could then have obtained easy access to the new world from the old. Anthropologists are also agreed that the pre-Columbian population of America did enter America from the Asiatic side. ${ }^{1}$ They are also agreed that the native peoples of America, from Hudson Bay to Cape Horn, are descended from the same human stock as has populated the eastern regions of Asia and many of the islands of the Pacific. The American Indian, in all his varieties, is a descendant from a primitive Mongolian type of man. If, however, we ask : How long ago is it since the Mongolian type of modern man was evolved? When did the American

${ }^{1}$ See an excellent summary by Dr Alěs Hrdlička, "The Derivation and Probable Place of Origin of the North American Indian," Proc. Internat. Congress of Americanists, London, 1912, p. 57. 
branch of this stock enter the new world? we receive very uncertain answers from those who have studied the early population of America. At present, only a tentative answer can be returned to the questions just asked, but to those who watch the vigour and success with which the thriving anthropological schools of America are pursuing the study of ancient races and ancient civilisations, it is quite apparent that a full answer will be given us at no distant date.

There is no need here to give a general review of the evidence relating to the antiquity of man in North America. That has been excellently done in the publications issued by the Bureau of American Ethnology, and by Dr G. Frederick Wright in his latest work, The Origin and Antiquity of Man. The investigations of Dr Wright, and of other American geologists who have studied the physical condition of North America during the Pleistocene period, are of the greatest service to anyone in search of the remains of ancient man. They have shown us that the variations of climate in North America during the Pleistocene period were very similar to those of Europe. There were the same southward extensions of the ice sheet in the colder phases; the same northward retreats in the interglacial or milder intervals.

It is beyond the scope of this work to give a systematic description of the ancient remains of man discovered in America. All we propose to do here is to make a rapid journey across North America from east to west, citing the evidence of the more important discoveries of the remains of ancient man as we go. The line of our journey follows the zone occupied by the fringe of the ice sheet during the period of maximum glaciation. In America, as in Europe, the glacial deposits are the treasure-houses of the student of prehistory.

1 See Bulletins of Bureau of American Ethnology, Smithsonian Institution, Washington, particularly No. 33: "Skeletal Remains suggesting or attributed to Early Man in North America," by Dr Alěs Hrdlička, I907. 
We shall commence our journey some fifty miles to the south of New York-at Trenton City, situated at the head of Delaware Bay, in the State of New Jersey. The great expanse of gravel on which Trenton has been built was deposited by the Delaware during the Ice age. This gravel has yielded the kind of evidence of which we are in search-the stone implements and the fossil remains of ancient man. During the most severe of the glacial phases the edge of the ice sheet lay only sixty-five miles to the north of Trenton. In the valley of the Delaware river the deposits laid down along the southern edge of the ice sheet can still be seen. The marginal deposit of the ice sheet-the moraine-is connected with the gravel bed on which Trenton is built by a terrace which descends on each side of the valley of the Delaware river. There can thus be no doubt that the Trenton gravels are deposits of the Ice age. They were laid down at the mouth of the river at sea-level. Since their deposition the land has risen, so that now the ancient gravel delta is 50 feet above the present level of the sea.

The story of the discovery of traces of early man in the Trenton gravels recalls early incidents in the valley of the Somme. The place of Boucher de Perthes is taken by Dr C. C. Abbott. In I 875 the Pennsylvania Railroad had opened a pit in the gravel bed near Dr Abbott's house. Dr Abbott watched the pit from day to day, and ultimately found numerous examples of roughly chipped stone implements, recalling the palæoliths found in valley terraces of Europe. They occurred at all levels of the gravel, and in strata which had never been disturbed since the date of deposition. Dr Abbott's discovery was received with the same degree of scepticism as had been extended to the earlier efforts of Boucher de Perthes in France. Fortunately, his investigations attracted the attention of Professor F. W. Putman of the Peabody Museum of Harvard University. Under his direction Mr Ernest Volk commenced a long series of accurate investigations which proved the truth 
of Dr Abbott's statements. ${ }^{1}$ Under the surface layer of black soil lay a stratum of yellow sand and loam, regarded by American geologists as a post-glacial deposit. Above this post-glacial stratum were found traces of Indian occupation-hearths, Indian stone implements, and Indian burials. In the underlying beds of gravel, which, as already mentioned, are glacial or Pleistocene deposits, traces of man were also found in the form of rudely shaped implements of stone.

Remains of the men who actually shaped those implements were first discovered in December 1899 by Mr Volk. A "railroad cut" had laid open a section of the gravel in the suburbs of Trenton. On the exposed face, within a stratum of sand and clay $7 \frac{1}{2}$ feet below the surface, $\mathrm{Mr}$ Volk found part of the shaft of a human thigh bone. He recorded his discovery by photographing the fragment in place before removing it from the bank. Parts of the bone of a human skull were also found. In the opinion of $\mathrm{Mr}$ Volk and Dr Hrdlicka both specimens - the fragment of thigh bone and fragment of skull-show certain incised markings apparently made by ancient man.

Through the kindness of Dr Peabody, the writer obtained accurate casts of these two specimens found in the Trenton gravels for the museum of the Royal College of Surgeons, England. Only about one-third of the upper part of the shaft of the left thigh bone is represented, and about an equal proportion of the left parietal bone of the skull (fig. 93). In the extensive collection of skulls and skeletons in the museum of the Royal College of Surgeons-representing all races-the writer could find exact duplicates of those two fragments in only one skeleton, that of an Indian from an ancient cemetery in the State of Illinois. On the inner aspect of the cranial fragment the impressions of the convolutions

1 "The Archæology of the Delaware Valley," by Ernest Volk, Papers of the Pcabody Museum of American Natural History and Ethnology, Harvard University, I91 I, vol. v. See also note by Dr C. Peabody, Proc. Internat. Congress of Americanists, London, 1912, p. 3. 
of the brain are most sharply preserved. The main fissure of the brain-the fissure of Sylvius-is clearly represented, and the size and shape of the important convolutions which surround the hinder end of the fissure can be studied as clearly as on the brain itself. In size and shape the convolutions do not differ from those of the brain of modern man. The cranial fragment is clearly part of a parietal bone, which in size and shape agrees with the corresponding bone in a well-developed cranium of an American Indian. The thigh bone is flattened from back to front in its upper third-a feature seen in American Indians, and also many modern and ancient primitive races (fig. 92). No one can study the Trenton fragments and remain unconvinced that the man who

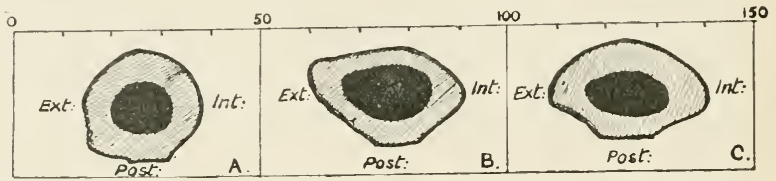

FIG. 92.-Section across the upper third of Trenton femur (B) compared with corresponding sections of a modern European femur (A) and that of a Neolithic European (C).

lived in the valley of the Delaware when the Trenton gravels were being deposited was a man of the modern type, and almost certainly of the Indian race. In size of brain and in posture of body he did not differ from the men who succeeded him in post-glacial times.

The antiquity of modern man in the Delaware valley thus turns on the age of the Trenton gravels. They are admitted by all geologists to belong to the glacial period; but to what point of the glacial period?. Dr G. Frederick Wright regards the gravels as deposits of the milder interval which preceded the last extension southwards of the ice sheet-the extension to which American geologists give the name of "Wisconsin," because the effects or deposits of that, the final glaciation, are particularly evident in the State of Wisconsin. Dr Wright is of opinion that a period of twelve thousand or even 
fourteen thousand years may have elapsed since the deposition of the Trenton gravels. Professor Chamberlin, on the other hand, regards the "Wisconsin" phase as having reached its climax twenty thousand or even sixty thousand years ago. If the deposition of the Trenton gravels preceded the "Wisconsin" glaciation, then a greater age than fourteen thousand years must

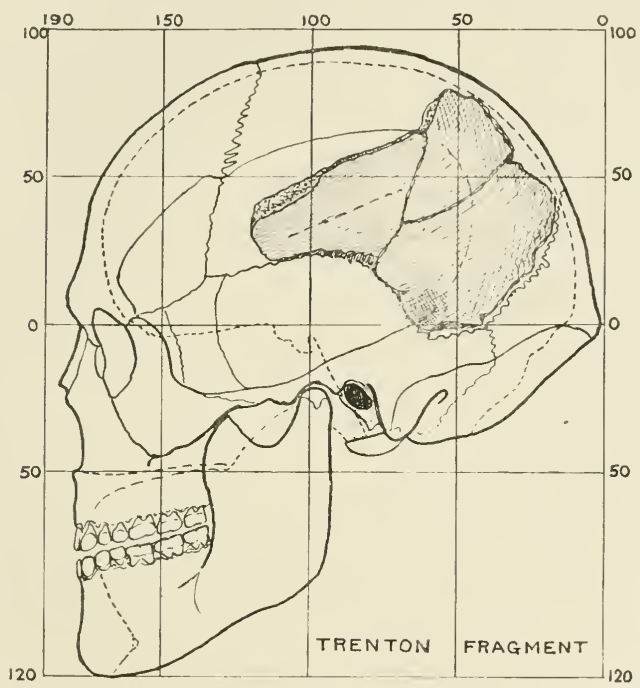

FIG. 93.-Drawing of a skull of an American Indian on which the cranial fragment found at Trenton is represented.

be assigned to these human fragments. If the glaciations of Europe and North America occurred at the same time-which is an unproved, but not improbable supposition-then the last or "Wisconsin" phase of the one and the last or "Würmien" phase of the other would correspond. We have seen that before the last glacial phase in Europe occurred, mankind in the eastern hemisphere had entered on the Aurignacian stage of culture, 
and, in structure of body, belonged to the modern type. The introduction of the Aurignacian culture in Europe appears to have taken place about thirty thousand years ago - an estimate which must be regarded as merely a tentative one. It does seem very probable, then, that the ancient men of Trenton were living in the Delaware valley when the Cromagnon race inhabited the rockshelters along the valley of the Dordogne.

The discovery at Trenton has a very direct bearing on the antiquity of men of the modern type. Let us look more closely at its significance. It is a guarantee that before the last period of glaciation modern man, in the form of that highly evolved race-the American Indianwas living on the eastern sea-board of North America. That race, as we have seen, represents a branch of the Mongolian stock. It is therefore plain that, long before the last period of glaciation, the Asiatic ancestry of the American Indian must have been in existence. We obtain, by researches carried out in Europe, a glimpse of Palæolithic man in the western part of the old world; the discovery at Trenton gives us, indirectly, the information we stood in need of, namely, that, at an equally early part of the Palæolithic period, men of the modern type were in existence in the eastern part of the old world. It is plain, to account for modern man in Europe, in Asia, in America, long before the close of the Ice age, we must assign his origin and evolution to a very remote period.

Having thus obtained reliable evidence of the great antiquity of man on the eastern sea-board, we pass to the Central States, approaching them from the south, along the valley of the Mississippi. Our first stopping-place is Natchez, on the eastern bank of the river, and about two hundred miles above the delta. Here, in I 846 , came Sir Charles Lyell in search of evidence regarding man's antiquity. On the eastern side of the valley at Natchez rises a high terrace of yellow loam or loess, a deposit formed by floods during the latter part of the glacial period. At the time of Lyell's visit part of a human 
pelvis had been discovered in this ancient deposit. The site of the discovery was a ravine cut in the loess deposit by a tributary stream. Lyell visited the ravine to examine the details of the discovery for himself.

"I satisfied myself," he writes," "that the ravine had been considerably enlarged and lengthened a short time before my visit. From a clayey deposit, immediately under the yellow loam, bones of the mastodon and the megalonyx (an extinct form of sloth) had been detached and fallen to the bottom of the cliff. Mingled with the rest, the pelvic bone (os innominatum) of a man was obtained by Dr Dickeson of Natchez, in whose collection I saw it. It appeared to be quite in the same state of preservation, and was of the same black colour as the other fossils, and was believed to have come from a depth of about 30 feet from the surface."

The pelvic bone thus brought to light differs in no respect from that of modern man: it differs materially from that of Neanderthal man. Professor Joseph Leidy, an expert palæontologist of the highest rank, examined the specimen again in $1889,{ }^{2}$ and observed that the degree of fossilisation was exactly the same as that of the bones of extinct mammals which were found with it, and that "it differs in no respect from an ordinary average specimen of the corresponding recent bone of man."

Lyell was afraid to use the bone found at Natchez as evidence; it seemed to him suggestive of too great an antiquity for man. He had calculated that the formation of the delta of the Mississippi had occupied a period of one hundred thousand years, and he recognised that the loam or loess lying over the fossil bones was older than the delta. The plateau at Natchez was, in his opinion, almost as old as the classical roo-foot terrace at Abbeville. $\mathrm{He}$, therefore, was inclined to regard the pelvic bone as having slipped from a recent Indian grave in the loess deposit, and subsequently had become mingled with the bones of extinct animals. "No doubt," he adds, "had

1 Antiquity of Man, rst edition, 1863, p. 202.

2 See Dr Hrdlička's account; reference on p. 273. 
the pelvic bone belonged to any recent mammifer other than man, such a theory would never have been resorted to; but so long as we have only one isolated case, and one without the testimony of a geologist who was present to behold the bone, while still engaged in the matrix, and to extract it with his own hands, it is allowable to suspend our judgment as to the high antiquity of the fossil." After what we have seen at Trenton, the plea of "isolation" cannot any more be urged. The legitimate inference must be drawn, be the loess of the Mississippi valley what age it may, that man was living in the Mississippi valley during its deposition.

Further evidence is found in support of this conclusion as we journey northwards along the Mississippi, and reach those states which were covered by the ice sheet at intervals of the Pleistocene period. For our present purpose it is more profitable to leave the Mississippi and follow its great tributary, the Missouri. At Kansas City we reach the "furthest south" of the ice sheet. The loess deposits are everywhere abundant, forming high terraces or bluffs on either side of the Missouri. On the west bank of the river, some distance above Kansas City, near Lansing, is the farm of $\mathrm{Mr} \mathrm{M}$. Concannon. In $1902, \mathrm{Mr}$ Concannon and his sons made a tunnel into the terrace of loess, on the side of the valley, to serve for the storage of apples and other farm produce. At a distance of 70 feet from the entrance of the tunnel, and at a depth of over 20 feet below the surface of the land, a human skeleton was found. Somewhat nearer to the entrance a child's jaw and an artificial chert chip were obtained.

There is no doubt as to the authenticity of the discovery at Lansing, nor is there any room for difference of opinion regarding the kind of man discovered. The skull is now in the National Museum, Washington. Both skull and skeleton have been examined and described by Dr Hrdlicka. They are parts of a man of medium stature (about $1 \cdot 65$ m.), and about fifty-five years of age. "All the parts of the skeleton, and particularly 
the skull, approach closely in every character of importance the average skeleton of the present-day Indian of the Central States. ... . The forehead is somewhat low and sloping when compared with that of a well-developed skull of a white man, but appears normal in comparison with the forehead of undeformed skulls of Indians." The dimensions are such that the Lansing skull would fit exactly within the conventional frame used for modern specimens of average size. The length is $189 \mathrm{~mm}$.; the width, I $39 \mathrm{~mm}$. ; the height of the vault above the earholes, about $122 \mathrm{~mm}$.; the brain capacity a little over I 500 c.c. - in all respects a well-developed skull of the modern type. Clearly the men living in Kansas when the loess at Lansing was being deposited had all the physical characters of the American Indian.

As regards the age of the Lansing terrace, in which these human remains were found, Dr G. Frederick Wright, who has given a lifetime to the study of glacial deposits, has no doubt. "A question has been raised," he writes," "as to whether the deposit of loess at Lansing was original or secondary. Professor T. C. Chamberlin maintained that the evidence was doubtful, and that it might be a secondary redeposition of the material, of great age indeed, but much younger than the main body of loess in the valley. Professor N. H. Winchell and Dr Warren Upham (both very high authorities upon such subjects), after repeated visits, adduce overwhelming evidence that the deposit is original, and that the skeleton was buried by the loess at the time of its deposition during the "lowan' stage of glacial recession." The "lowan" interglacial period preceded the final or "Wisconsin " glacial phase, and followed the "Illinoian" glacial phase. " The age attributed to the Lansing skeleton is thus about the same as the estimate for the Trenton fragments. Both appear to belong to the temperate interval which preceded the last glaciation.

Another discovery of the remains of "loess men" was

1 See reference on p. 273.

2 The writer here follows Dr Wright's terminology. 
made some distance further to the north. The city of Omaha is situated on the west bank of the Missouri, about a hundred and fifty miles above Lansing. Some ten miles north of Omaha, the State of Nebraska, on the west side of the Missouri, " presents some rather bold elevations composed of accumulations of loess, modified in contour by the action of wind and rain. The southern portion of one of the most prominent of these elevations, known as Long's Hill, consists of a ridge, about 600 yards long, running parallel with the Missouri. The ridge is covered with timber of recent growth." 1

In I 906, Mr Robert F. Gilder, of the Omaha World Heraid, commenced a series of excavations in a mound on Long's Hill. The mound had, at a previous date, been excavated by a party in search of the remains of the famous Indian chief, Black Hawk. Beneath the level of the mound, Mr Gilder's excavations revealed the remains of a number of human skeletons. With or near the bones several stone implements were found. Amongst these were two flint blades of the ordinary type. When a question subsequently arose as to the antiquity of these human remains, Professor E. H. Barbour, of the University of Nebraska, undertook the conduct of all further excavations. The result of his exploration was to show that fragments of the human skeleton were found at a depth of I I $\frac{1}{2}$ feet in loess which had apparently never been disturbed since its deposition. Professor Barbour was convinced that the deeper human remains were as old as the deposit in which they were embedded. In his original excavation, Mr Gilder encountered, at a depth of 5 feet below the surface of the mound, a layer of clay, hardened by fire. Above this layer of baked clay were found remains of at least twelve individuals, representing men, women, and children. Beneath the baked clay stratum the remains of eight or nine bodies were unearthed, some of the fragments lying as much as I 1 f feet below the overlying surface of the land. Dr

\footnotetext{
${ }^{1}$ Quotation from Dr Hrdlička's description.
} 
Hrdlička made a minute examination of these skeletal remains, and found that they possessed all the features which characterise the American Indian. The foreheads of some of the men's skulls were particularly low and receding, with strongly marked supra-orbital ridgesfeatures which still occur in certain Indian tribes of the Central States.

I agree with Dr Hrdlička that at Long's Hill we have to deal with an ancient Indian cemetery. The question is: How ancient is that cemetery? In Europe we find the custom of burial practised as early as midPleistocene times. The evidence we have obtained at Trenton, at Natchez, at Lansing justifies us in regarding North America as already inhabited by races of Indians during deposition of the loess. Is it not probable, then, that the earliest burials at Long's Hill date back to that interglacial phase which saw the deposition of the loess?

It is clear from the researches published recently by the late Professor N. H. Winchell ${ }^{1}$ that the Middle States of America were inhabited at an earlier date than is indicated by the discoveries just described. The loess men are supposed to belong to the last interglacial period-the milder interval between the last two phases of glaciation, the "Illinoisan" and "Wisconsin" phases. Beneath the deposits of the Kansan glaciation, which preceded the Illinoisan, Professor Winchell has found stone implements of a rude Palæolithic type, fashioned by the men who lived before the great Kansan glaciation. The remains of the men of that period have not yet been discovered.

From the Middle States we now pass westwards to the Pacific slopes in search of the ancient men of America. The story of the Calaveras skull, although grown stale from frequent repetition, cannot be passed over. ${ }^{2}$ It is the "bogey" which haunts the student of early manrepelling some, fascinating others, and taxing the powers

1 N. H. Winchell, "The Palæoliths of Kansas," Minnesota Historical Socicty, 1913, vol. xvi. part 1.

2 For the literature referring to the history and nature of the Calaveras skull, see reference on p. 285 . 
of belief of every expert almost to breaking point. The skull itself-or what was found of it, for the greater part of the vault was missing-is now preserved in the Peabody Museum of Harvard University. It passed into the Peabody Museum in the following manner. Soon after its discovery in I 866, Professor J. D. Whitriey, State Geologist of California, having verified its reputed history, brought the skull to Harvard University, and examined it in conjunction with Professor Jeffreys Wyman, one of the most skilled anatomists then living. The matrix of gravel which adhered to the skull was observed to be similar in character to that of the gold-bearing stratum in which the skull is said to have been found. In Professor Wyman's opinion, there were no signs of an inferior race in the characters of the skull. "It agreed," he wrote, "with other crania from California." A recent examination by Dr Hrdlicka confirms Professor Wyman's observations. On searching the great collection of human crania in the National Museum at Washington, Dr Hrdlicka found two crania and some fragments of skulls from caves in Calaveras county, California, collected in I 857 . One of these cave skulls is, in all essential features, closely related to the Calaveras specimen. The cave skulls show a greyish, calcareous, stalagmitic deposit, much like that which partially covers the Calaveras skull. In Dr Hrdlicka's opinion, the infiltration and fossilisation of the Calaveras skull furnishes no test of its antiquity. The fact that the Calaveras skull is similar in form and in state of preservation to Indian skulls found in the Calaveras county must raise a suspicion as to the authenticity of the original specimen. It does not prove, however, that the original specimen is not really ancient. We have seen from the discoveries made in the loess deposits how persistent the American-Indian type may be.

If we regard the Calaveras skull as really a cave specimen, in spite of its history, there still remain other mysteries connected with the ancient bed of the Stanislas even more difficult of solution. The skull was not the only evidence of man in the ancient gold-bearing river 
gravels in Calaveras county. These gravels lie buried under tides of lava which swept the western flanks of the Sierra Nevada in the Miocene and Pliocene periods. There are the most circumstantial accounts of the discovery, in the gravel beds of these ancient Pliocene streams, of stone mortars, stone pestles, hammer stones, spear heads, etc., not only by miners, but by expert and reliable geologists. Indeed, were such discoveries in accordance with our expectations, if they were in harmony with the theories we have formed regarding the date of man's evolution, no one would ever dream of doubting them, much less of rejecting them. The consequence of accepting the discoveries of Calaveras county as genuine have been well expressed by Professor W. H. Holmes, when he presented the results of his investigations to the Smithsonian Institution in $1899 .{ }^{1}$ "To suppose that man could have remained unchanged physically, mentally, socially, industrially, and æsthetically for a million of years, roughly speaking (and all this is implied by the evidence furnished), seems in the present state of our knowledge hardly less than admitting a miracle." It is equally difficult to believe that so many men should have been mistaken as to what they saw and found. In the meantime, and until the matter of Pliocene man in California has been finally settied by a new and systematic exploration, we must be content to return the same verdict for Calaveras as for Castenedolo-the Scottish verdict of " not proven."

The reader must not think, because our journey across the States along a tract of country which at one time lay buried beneath an extension of the Arctic ice sheet has revealed no strange, primitive, or new type of human being, that it has been made in vain. On the contrary, we have received the most ample confirmation of the conclusions forced on us by the evidence in Europe, viz., that the antiquity of the modern type of man is much greater than is usually supposed.

1 "Review of the Evidence relating to Auriferous Gravel Man in California," Smithsonian Report, I899, pp. 419-472 (issued 1901). 


\section{CHAPTER XVII}

\section{EARLY SOUTH AMERICANS}

At the time Boucher de Perthes was striving to convince his contemporaries that man had existed in Europe with extinct forms of animals, a famous Danish traveller and naturalist, Dr Lund, was exploring caves in Brazil and coming to a similar conclusion as regards the antiquity of man. He left Europe in 1835 when the tide of curiosity in man's antiquity was rising. In 1844 he was able to report that he had examined eight hundred caves, in the limestone hills of Lagoa Santa, in the Brazilian province of Minas Geraes. Six of these caves yielded remains of man-sone so abundantly that they must have served as ancient sepulchres, as was the case in early Europe. Up to 1844 , Dr Lund remained unconvinced that these early Brazilians, whose bones he found in the caves, had been contemporaries of the extinct animals, represented so plentifully in cave deposits. In one of the caves he at last found the bones of man and of extinct animals, mingled together, and in a like condition of fossilisation. If the bones had been of any animal other than man, their antiquity would never have been questioned, but being human all sorts of doubts were raised as to how and when they became mixed with remains of extinct animals.

The final result of his investigations Dr Lund gave as follows : ${ }^{1}$ -

1 See Dr Hrdlička's excellent, if somewhat critical, account of Lund's discoveries : "Early Man in South America," Bulletin No. 52, Burcau of American Ethnology, 1912, p. I 59. 
"In view of the facts to which 1 have here referred, there can then remain no doubt as to the existence of man on this continent in an epoch anterior to that in which the last races of the gigantic animals whose remains abound in the caves of this country became extinct, or, in other terms, as to his existence here anterior to the historic period.

"As to the ethnographic peculiarities of the skulls from this deposit, I had occasion to confirm my former conclusions, namely, that they offer all the characteristic features of the American race; and I have firmly convinced myself that the extraordinary depression of the forehead which is observed in some of the individuals is not artificial."

It must be kept in mind that Dr Lund's investigations were carried out long before methods of precision and of dating had been applied to cave exploration in Europe. As our knowledge of the early cultures of South America increases, the objects of human workmanship which were collected by Dr Lund during his investigations of the deeper strata of the caves may give a clue to the antiquity of the human remains. We do not know when the strange animals, which apparently lived at the same time as the Brazilian cavemen, became extinct, but if we apply to South America the rules which guide the palæontologist elsewhere, we must regard them as being at least as old as the latter part of the Pleistocene period.

As to the kind of man discovered by Dr Lund in the Lagoa Santa caves, there is no difference of opinion. Those who have examined his collections in the University Museum, Copenhagen, and in the Natural History Museum, South Kensington, London, agree that, in racial features, those ancient Brazilians do not differ from tribes still living in South America. The skulls are not unlike those of the low-browed "Nebraska loess men." We have in Dr Lund's discoveries further evidence of the persistency of the American-Indian type. 
Dr Lund's discoveries gradually passed out of notice, and South America, as a possible home of ancient man, ceased to attract attention until the commencement of the present century, when there was a sudden revival of interest. That revival was entirely due to I)r Florentino Ameghino. He became interested in prehistoric research at an early age. ${ }^{1}$ In 1873 , being then in his nineteenth year, he made his first discovery of ancient man. At that time he was living in the town of Mercedes, some distance to the west of Buenos Aires (see fig. 94), on a flat sweep of the pampas across which there meandered a stream named the Frias. On one side of the stream, the banks of which rose over 6 feet above the level of the water, young Ameghino began to disinter the partially exposed carapace of an extinct Edentate near to a spot at which he had previously found a human skull. In the soil round and under the carapace he was surprised to note traces of charred wood. He then sank a trench on the side of the stream, in order that he might examine, in a systematic manner, those strata containing traces of man (fig. 94).

He carried the trench down to a depth of about 5 feet below the bed of the stream, and about Io or I I feet below the surface of the bank. Altogether seven strata were exposed (see fig. 94); in the deepest layer, below the level of the bed of the stream, he found human remains. In the same stratum as the human bones he found parts of extinct animals, living animals, worked flints, fragments of charred bone, bones which were broken, perforated, and incised, baked earth, and a great attendance of charcoal. He believed he had discovered "the fossil man of Argentina." In 1875 the Argentine Scientific Society awarded him a diploma on account of his investigations, but in 1878 , when he wished the Society to publish an account of his discovery, it refused to help him. Thereupon he

1 For an account of Ameghino's anthropological discoveries, see Robert Lehmann-Nitsche's "Nouvelles Recherches sur la Formation Pampéenne," Rivista del Musco de la Plata, 1907, vol. xiv. pp. I43-488. Also Dr Alěs Hrdlička's work referred to on p. 286 . 
carried his results to Europe, and obtained the sympathetic attention of the leading anthropologist in FrancePaul Broca.

Certain defects which mar all of Ameghino's scientific papers are apparent in his very first effort-a lack of precision and of detail, and particularly a decided tendency to overestimate the antiquity of all the geological strata of the Argentine Republic. The stratum on the Frias (fig. 94) which contained the

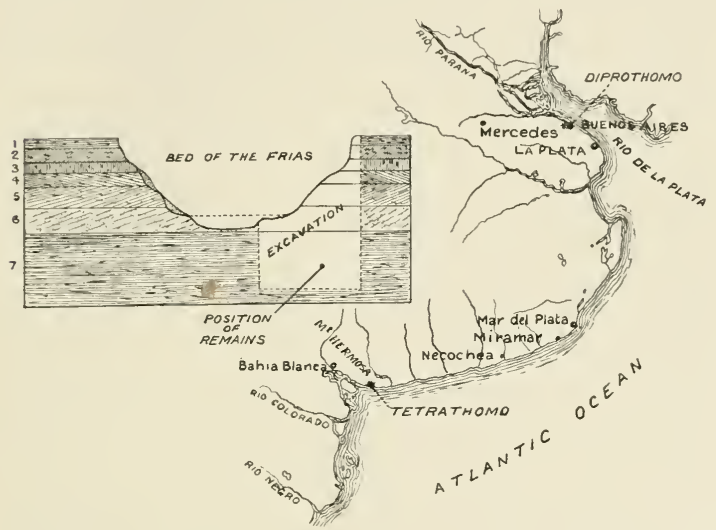

FIG. 94.-Sketch map of the sites of Ameghino's chief discoveries of ancient man. Inset is his section across the Frias, showing the strata and the position of the exploratory trench.

human remains he regarded as of Pliocene date, and supposed the bones had become naturally entombed, not deliberately buried. The accepted opinion regarding these Pampean formations is that they are alluvial deposits belonging to the Pleistocene period-formations not unlike the loess of the Mississippi valley in manner and date of formation. There can be no question that the bones were buried by human agency. The greater part of a skeleton of an old woman of short stature $(1.500 \mathrm{~m}$.$) and fragments of another individual were$ 
represented in his first discovery. There is no question, then, that Dr Ameghino's first discovery represented a burial. It is clearly not a burial made from the present land surface, but when and how it was made are problems which cannot now be solved definitely. The human remains are clearly of some degree of antiquity.

In I902, at the age of forty-eight and after an uphill life-struggle, Ameghino found himself Director of the National Museum of Buenos Aires. With a series of discoveries, following each other in rapid succession, he really startled the anthropologists of Europe. He claimed to have discovered fossil forms which demonstrated the evolution of modern man-or of a form of man of the modern type-in the southern regions of South America. The oldest and most primitive human ancestor he named Tetraprothomo, and regarded the only remains which were found of this ancient, human type-an atlas and a thigh bone-as of Miocene age. As will be seen from fig. 94, the remains of Tetraprothomo were discovered at Monte Hermosa, on the east coast of Argentina, some distance north of the mouth of the Rio Colorado.

The second and later stage in man's evolutionDiprothomo - was based on the fragment of a skull, obtained from a formation which he regarded as of early Pliocene date. The third link in Ameghino's human, ancestral chain was Homo pampcus, also a Pliocene form. The fourth and final stage, Homo sapiens, appeared in the Pleistocene deposits of the pampas. ${ }^{1}$

It will be sufficient to give a brief account of the discovery of Ameghino's early Pliocene forerunner of man-Diprothomo. In 1896 an English firm of contractors had almost finished the construction of a dry dock on the south bank of the La Plata, at Buenos Aires. The concrete floor of the dock had been sunk to a depth of $12.36 \mathrm{~m}$. (40.7 feet) below the level of the water at low tide. Subsequently, an additional hollow, 20 inches deep, had to be sunk through the floor of the dry dock, reaching a total depth of about 42 feet below the level of

$$
1 \text { For full account, see references on p. } 288 .
$$


low tide. In sinking the additional pit, the fragment of a human skull was found by a workman. The fragment was given to $\mathrm{Mr}$ Junor, who was in charge of the works, and by him it was presented to the National Museum, Buenos Aires. Thirteen years later, Dr Ameghino published an account of this fragment. The deep stratum of the Pampean formation from which it was extracted he regarded as early Pliocene in date of formation, and the fragment he conceived to be part of a small and peculiar skull of an ancient and extinct genus of humanity, which he named Diprothomo.

There is no reason why the specimen should be rejected as worthless because of its defective history. On the other hand, there are the very soundest grounds for rejecting Ameghino's conclusions as regards the age of the stratum and the nature of the cranial fragment. Geologists refuse to regard the stratum in which the fragment was found as older than Pleistocene, and anatomists are unanimous in regarding the cranial fragment as representing the frontal bone and part of the parietals of a human skull which in size and shape must have been very similar to skulls of American Indians. ${ }^{1}$ From what has been shown in this and in the previous chapter, there is no reason for being surprised at the discovery of a fossil skull, showing American-Indian features, in a deposit of Pleistocene age. Ameghino's Diprothomo thus represents a man of the American-Indian type living in the Argentine during Pleistocene times.

Ameghino's Miocene form of man-Tetraprothomohad also to go by the board. Only the atlas and the thigh bone of this strange evolutionary form were discovered. The thigh bone proved to be that of an extinct carnivorous animal of the cat genus, and as large as a puma; but the atlas was human. Unfortunately, the antiquity of the atlas may very well be called in question.

1 See Professor Schwalbe's "Studien zur Morphologie der südamerikanischen Primatenformen," Zeitsch. für Morph. und Anthrop., I9I0, vol. xiii. pp. 209-258. 
The exact stratum from which it was obtained is unknown.

There is no need to recount the remaining discoveries which have been made in the Argentine Republic. They are fully described by Dr Lehmann-Nitsche and by Dr Hrdlicka. ${ }^{1}$ The result of a survey of the discoveries of ancient man made in South and North America leads to the same conclusion, that we cannot trace man beyond a point in the Pleistocene period, and that the oldest human remains so far discovered, both of the northern and southern parts of the western hemisphere, are of the same American-Indian type. Indeed, the resemblance between the skulls recovered from deposits of a Pleistocene age in the United States and those found in the Pampean deposits of the Argentine Republic is very striking. Thery are not only of the same race; they might belong almost to members of the same tribe. We have seen no evidence to lead us to suppose that any race preceded the American Indian in the new world.

Yet, one cannot conclude such a survey as this with any feeling of satisfaction or of certainty. We seem to leave so much unexplained. Those who have studied the elaborate civilisations and the multitude of languages of America are almost unanimous in regarding them as independent evolutions. ${ }^{2}$ The animals which had been domesticated, and the numerous native plants which had been brought under cultivation by indigenous races in preColumbian times, seem to point to an antiquity beyond that revealed by the discoveries of the geologist or of the anatomist. The writer feels certain that human secrets still lie hidden in America. The discovery of implements of a Palæolithic type in the State of Kansas under deposits of the phase of maximum glaciation suggests an earlier history for man in America. ${ }^{3}$

1 See references, p. 288.

2 See South American Archaology, by T. A. Joyce, London, 1913, p. 189 .

3 See "A Consideration of the Palæoliths of Kansas," by N. H. Winchell, Minnesota Historical Society, 1913, vol, xvi. part I. 


\section{CHAPTER XVIII}

THE DISCOVERY OF THE PILTDOWN SKULL

ENGLAND owes much to the disciples of Gilbert White. Everywhere, especially within her southern parts, you will find them observing and recording those strange facts which, when rightly understood, will carry our island story leagues beyond the dawn of written history. The little jealous es and disputes which occasionally ruffe the serenity of their lives leave untouched the splendid freemasonry which binds them together, and which knows no distinction of class. The lord of the manor and the village shoemaker meet at this point on equal terms. Those local historians are drawn from all classes; the squire, the vicar, the lawyer, the doctor, the bank clerk, the watchmaker, the grocer, the baker, and the village labourer all enroll themselves amongst the followers of the immortal Gilbert.

It is to one of these men we owe the finding of the Piltdown skull, which, from a historical point of view, is the most important and instructive of all ancient human documents yet discovered in Europe. $\mathrm{Mr}$ Charles Dawson, its discoverer, a lawyer by profession, lives in the historic town of Lewes, situated picturesquely in a gap of the South Downs where the Sussex Ouse breaks through from the Weald and empties its silent waters in the English Channel at Newhaven (fig. 95). It is just in such a quiet town as Lewes that we expect followers of Gilbert White to appear. It was in Lewes that Dr Gideon Mantell practised as a physician in the earlier part of last century, and spent his leisure time in making known to all the world the remarkable reptiles which abound in 
the old-world strata now exposed in the cup or hollow of the Weald. Mr Charles Dawson followed in his footsteps; for twenty years and more he has spent his leisure hours in searching the strata of the Weald, and has brought to light many things new to science.

About the time he began to search the Weald a new influence was at work among the naturalists in the southeast corner of England. Lewes is situated on the south side of the green cup of the Weald; on the other side of

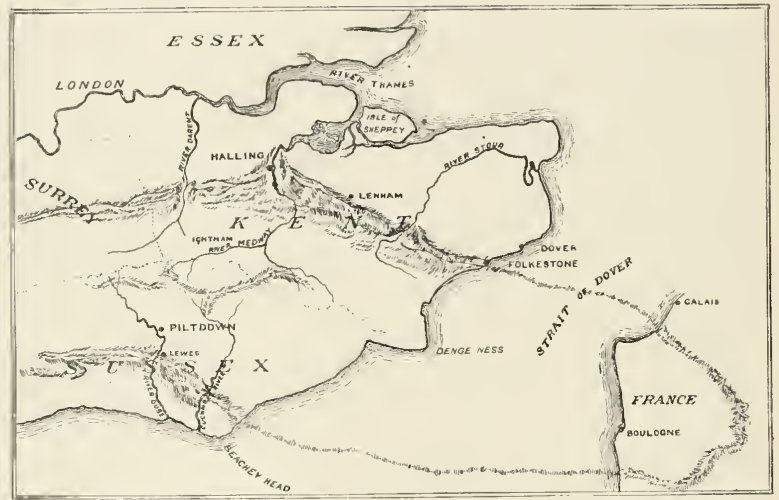

FIG. 95. - Sketch of the south-east corner of England, to show the Weald, the position of Piltdown, and the course of the Sussex Ouse, The former extension of the boundaries of the Weald to France is indicated.

the cup, thirty miles north of Lewes, lies the Kentish village of Ightham, and it was here, in a grocer's shop, that the new influence had its mainspring-Mr Benjamin Harrison. He was a young man in 1859 when $M$. Boucher de Perthes was compelling his reluctant contemporaries to acknowledge that the elaborately worked flints he had recovered from the ancient gravel terraces of the Somme, in the north-west of France, were the handiwork of long extinct races of man. Mr Harrison ${ }^{1}$

${ }^{1}$ For further details of Mr Harrison's busy life, see Ightham: the Story of a Kentish Village, edited by F. G. Bennett, F.G.S., The Homeland Association, Ltd., London. Also Brit. Med. Journ., 1912, ii. p. So5. 
searched the gravels of his own locality, and soon found implements of the same types as M. Boucher de Perthes had found in the deposits laid down in former times by the Somme. Mr Harrison, however, carried the history of flints a great stride further back. Little more than a mile north of Ightham rises up the chalky bank of the North Downs which forms the northern lip of the Wealden cup. Crossing the Pilgrims' Road, which winds along the foot of the bank or escarpment, Mr Harrison had, in his almost daily excursions, a stiff upward climb of some 500 feet to reach the plateau of the North Downs, stretching away northwards into the valley of the Thames. Here, in the gravel deposits of the plateau, immensely older than the terrace gravels of the valleys, $\mathrm{Mr}$ Harrison found rudely shaped flints, which he recognised as being of human workmanship. They were primitive in form when compared with the palæoliths from the valley gravels, and he distinguished them as " eoliths." Although he recognised them first in I 865 - forty-eight years ago-eoliths were not accepted as genuine products of man's hand until I888, when the late Sir Joseph Prestwich-a geologist noted for his sound judgment-brought them before the scientific world.

Even when Mr Dawson began his researches in the Weald twenty years ago, eoliths, although gradually gaining adherents, were still the subject of hot contention. It was about this period, too-the end of last centurythat a great truth, the inception of which we owe to our colleagues of France, began to leaven the researches of the Wealden workers. This truth is simply the recognition that the law of change or progress, which influences all the worldly affairs of men, holds true not only of present but also of past generations of mankind. Every generation has its own distinctive fashions and ideas; it builds its houses, it tills its fields, it makes its implements, it writes its books, it wears its clothes and paints its pictures in a manner slightly different to the generation which went before it. It is not difficult to distinguish a house built in the time of Queen Elizabeth from one 
built in the time of her great successor-Queen Victoria. The law of evolution and of change has always held true. The French archæologists recognised that this law is valid for the men who shaped the implements found in caves and valley gravels.

When the stages in the evolution of these implements have been distinguished, we are provided with a scale of sequence of time to guide us safely and surely towards the very beginnings of humanity in the far past. Each generation of Palæolithic men we now know copied and modified the flint tools of an older generation. One has only to survey the researches which $\mathrm{Mr}$ Lewis Abbot has made in the deposits and strata of the Weald to see how fruitful the acceptation of this conception has proved to the Sussex naturalists.

From this cursory introduction the reader will perceive that $\mathrm{Mr}$ Dawson's discovery of fossil remains of man in the Weald of Sussex was not altogether a matter of chance. Business had taken him into the Weald. His way lay along quiet, sheltered country roads, following upwards the sluggish waters of the Ouse, until he reached that upland, open, and bracing country some eight miles to the north of Lewes. Here Piltdown Common is situated, a moorland tract, on which golfers may enjoy the "ancient" game under ideal conditions. The common is part of a wide sweep of fertile, well-wooded land, with old-world farm-houses, comfortable and sheltered, spread across it. Sussex churches, Sussex villages, and Sussex gardens make it a country worth seeing even by those who are not in pursuit of fossil man and his works. The land at Piltdown lies $\mathrm{r} 20$ feet above the sea; but when we look southwards to catch a glimpse of the English Channel, the green South Downs rise up, with Lewes at their foot, and cut off the view. Westwards, the South Downs continue their course along the sea-board, sheltering Brighton from the north. In the wooded and undulating country to the north-west lies the source of the Ouse, some twelve miles distant. Standing on the common, we see that the Ouse is about a mile distant to the 


\section{DISCOVERY OF THE PILTDOWN SKULL, 297}

west. In the course of time it has cut a valley through the Piltdown plateau, until now its bed lies 80 feet below the level of the common. It has a journey of fifteen miles to make before it reaches the sea at Newhaven.

In the middle of the Weald, to the north, the land rises to form a wooded ridge-the "forest" ridge-forming the watershed between the Ouse and the Medway, a

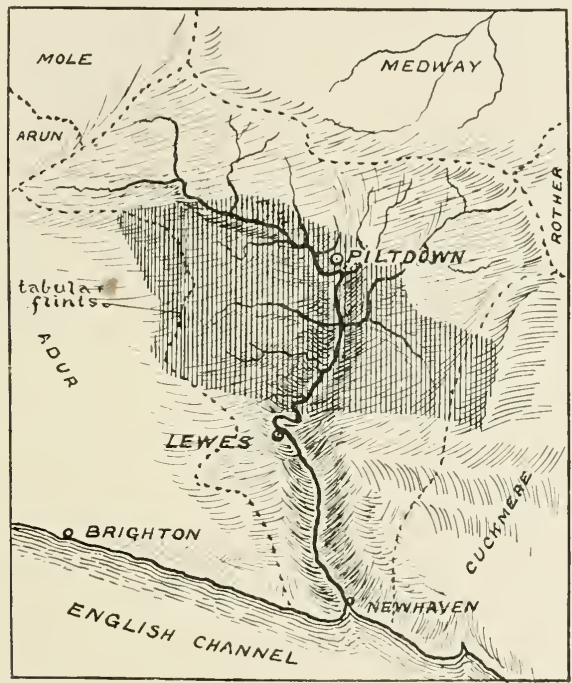

FIG. 96. - Sketch of the district drained by the Sussex Ouse, showing the area over which Mr Dawson found peculiar tabular flints and traces of ancient gravel deposits (after Mr Dawson's illustration).

tributary of the Thames. The "forest" ridge hides from view the North Downs, which rise sharply up and separate the Weald from the Thames valley.

Having thus accompanied Mr Dawson into the Weald, he himself will take up the narrative, as told in a communication to the Geological Society of London. ${ }^{1}$

1 From the Quarterly Journal of the Geological Society, March 1913, vol. lxix. p. 117 . 
"Several years ago I was walking along a farm-road close to Piltdown Common, Fletching (Sussex), when I noticed that the road had been mended with some peculiar brown flints, not usual in the district. On inquiry, I was astonished to learn that they were dug from a gravel bed on the farm, and shortly afterwards I visited the place, where two labourers were at work digging the gravel for small repairs to the roads. As this excavation was situated four miles north of the limit where the occurrence of flints overlying the Wealden strata is recorded, I was much interested and made a close examination of the bed. I asked the workmen if they had found bones or other fossils there. As they did not appear to have noticed anything of the sort, I urged them to preserve anything that they might find. Upon one of my subsequent visits to the pit, one of the men handed to me a small portion of an unusually thick human parietal ${ }^{1}$ bone. 1 immediately made a search, but could find nothing more; nor had the men noticed anything else. The bed is full of tabular pieces of iron-stone closely resembling this piece of skull in colour and thickness; and although I made many subsequent searches, I could not hear of any further find nor discover anything-in fact, the bed seemed to be quite unfossiliferous.

"It was not until some years later, in the autumn of I 9I I, on a visit to the spot, that I picked up, among the rain-washed spoil-heaps of the gravel pit, another and larger piece belonging to the frontal region of the same skull, including a portion of the left superciliary ridge. As 1 had examined a cast of the Heidelberg jaw, it occurred to me that the proportions of this skull were similar to those of that specimen. I accordingly took it to Dr A. Smith Woodward at the British Museum (Natural History) for comparison and determination. He was immediately impressed with the importance of the discovery, and we decided to employ labour and to make a systematic search among the spoil-heaps and

1 The right and left "parietal" bones form the greater part of the roof and sides of the brain cavity of the skull. 
gravel, as soon as the floods had abated. . .." Their labours were rewarded in the spring of $19 \mathrm{I} 2$ by the discovery of the greater part of a fossil human skull.

We propose to follow $\mathrm{Mr}$ Dawson to the site of the gravel pit. Leaving Piltdown Common, we throw open the white gate which guards the private approach to Barkham Manor - an English farm-house rendered homely and picturesque by the passage of centuries. The avenue leads us straight to the farm-house; the approach is flanked on either hand by a line of trees, which spring at regular distances from wide green margins, carpeted by Sussex turf. Here the farm carts come and go. Just before the house is reached the avenue of trees ends; the road is then bounded by a hedge on the right and an open meadow on the left, which sweeps up to the hospitable doorway. If the visitor is not sharp-eyed he will miss the pit. It lies on the right hand between the roadway and the hedgemerely a narrow trench some + feet deep. Even to the professional eye it is a most unlikely spot to yield the remains of fossil man, and the bones of the animals which flourished in his time.

The stratum of gravel is seen to be surprisingly shallow -rather less than 4 feet at this particular point. As the section of the side of the trench shows (fig. 97), the gravel rests on a bed-rock formed by one of the ancient Wealden rocks-the Hastings beds. The gravel is stratified-laid down by running water. The lowest or bottom layer, scarcely 6 inches in thickness, is the most important. The sand and gravel of this layer is cemented together by iron oxide; everything embedded in the bottom layer is stained a deep brown from iron impregnation, washed out from ancient Wealden deposits. ${ }^{1}$

It was from this bottom or "dark" layer that $\mathrm{Mr}$ Dawson removed the right half of a peculiar human lower jaw. In the same stratum Dr Smith Woodward

1 In a recent publication $\mathrm{Mr}$ I)awson distinguishes a fourth unfossiliferous stratum placed below the bottom or dark layer, and above the Hastings beds. Quart. Journ. Geol. Soc., I9I4, vol. lxx. p. 82. 
found a small but very important part of the skull - the part which gives us a reliable index to the width and form of the posterior or occipital part of the head. There can be no doubt that it was from this bottom layer that the piece of skull handed to $\mathrm{Mr}$ Dawson by the workmen came and the other fragments recovered from the spoilheaps. In the bottom layer eoliths were also found-

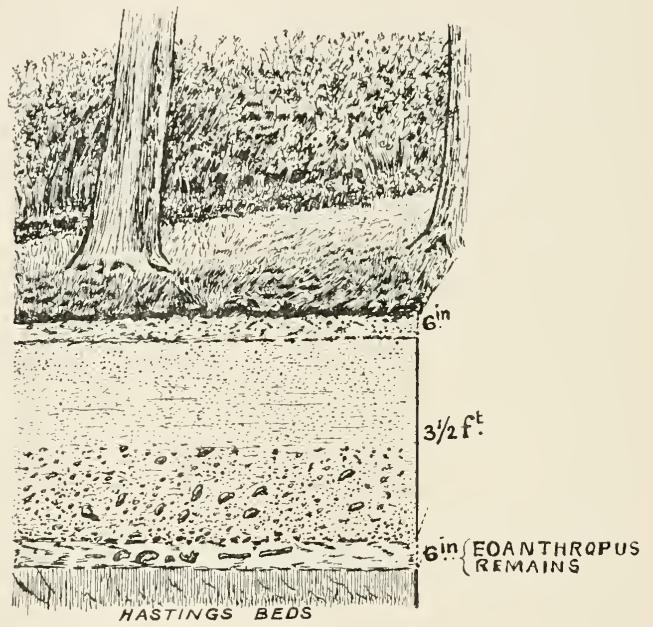

FIG. 97--Diagrammatic sketch of the gravel deposit in which the Piltdown skull was found. The section represents the face of the pit, with the hedge and trees beyond.

the rudely worked implements which $\mathrm{Mr}$ Benjamin Harrison had discovered on the Kentish plateau in 1865. In some of these the edges were sharp, showing that they had come to rest soon after falling in the bed of the ancient Ouse; others were blunted and abraded, showing that they had been rolled for a long distance before coming finally to rest in the bottom bed at Piltdown. In this same bed was found the much-rolled cusp of a Mastodon - a primitive genus of elephant which was in existence 
before even the Miocene period began; it is supposed to have been dislodged from some ancient stratum and redeposited here during the denudation of the Weald. More remarkable still, Dr Smith Woodward was able to identify two unrolled fragments of a molar tooth belonging to Stegodon - a form of elephant whose remains are known to occur in Indian deposits of the Pliocene period, but never before found in Western Europe. The shallow pocket of gravel at Piltdown, Sussex, yielded not only a new form of man, but an elephant which was new to the fauna of ancient England. The same stratum also yielded portions of two teeth of a hippopotamus, and two molar teeth of a beaver which has not yet been found in deposits older than the Pleistocene. The beaver may have been in existence during the Piocene period, but we have no evidence of that. The contents of the pocket of gravel at Piltdown was a surprise to geologists. The animal remains indicate that the bottom layer of gravel was laid down in the Pliocene period-a very remote age if we try to count by years.

In the gravel, just above the bottom or dark layer, were found worked flints of a more highly evolved type than eoliths. They are not stained brown as are the eoliths, but are "brilliantly coloured iron-red." $\mathrm{Mr}$ Dawson regards them as belonging to that stage of Palæolithic culture known as the "Chellean," or to an indefinite and older period, which saw the early evolution of the Chellean culture-the "pre-Chellean." Now, as we have already seen, the Chellean period of culture is assigned to the middle third-to an early part of the middle third-of the Pleistocene period. It has to be noted, however, that these flints did not occur in the bottom layer in which the human and animal remains were found; they are not stained dark brown as are the eoliths and bones. Mr Lewis Abbot, whose opinion in all that pertains to the geology of the Weald deserves serious consideration, has no hesitation in regarding the bottom stratum as Pliocene in the date of its formation, 
while the upper and looser strata he regards as having been disturbed and redeposited at a later date.

As regards these more highly worked implements from the Piltdown gravel, there is room for a difference of opinion. No one has a better right to give an expert judgment on such implements than Mr J. Reid Moir. The result of a minute examination of the better worked flints from Piltdown led him to the following conclusions :

"These later and more Palæolithic-looking specimens do not, however, appear to me to be of such definite forms as to be classifiable. They most certainly do not agree with the usual definition of a Chelles implement; and by the large surface of fracture and irregularity of the secondary flaking I would place them in a period preceding the Chelles phase. In fact, I have myself found implements very similar to these in deposits which, without doubt, considerably predate those containing the Chelles type. I therefore consider that, as these pre-Chellean implements are the latest constituents contained in the Piltdown gravel, the deposit must be very ancient. There is also no doubt that a very long period intervened between the time when the Eolithic implements and the later or pre-Chellean type were made. This intermediate period is apparently not represented by implements of the Piltdown gravel."

We have thus evidence from two independent sources that the Piltdown gravel pockets contain animal remains and human artifacts of two different ages. The bottom layer, with its animal remains and eoliths, is apparently of Pliocene date; the overlying beds belong to about the commencement of the middle third of the succeeding period-the Pleistocene. ${ }^{1}$

1 In the summer of $1914 \mathrm{Mr}$ Dawson made another remarkable discovery at Piltdown. He found a fossilised slab-like piece of an elephant's femur, showing the most indubitable evidence of having been worked into shape by human hands. It was found in the spoil-heaps and probably came from the upper layer of gravel, and may therefore be regarded as preChellean in date. Until Mr Dawson's discovery we had supposed that man did not begin to fashion implements in bone until the Mousterian period. 
Meantime, however, we are supposed to be standing by the pit, almost at the front door of a picturesque farm-house in Sussex. The present stream of the district-the Ouse-is nearly a mile distant, and 80 feet below the plateau on which the farm-house is placed. When the gravel of the pit was deposited, however, the Ouse flowed over the ground on which we standshifting its bed from time to time, now laying down a new stratum of gravel, and many a year later coming back to plough it up again and mix deposits together of very different ages. It is clear that the face of the country must have greatly changed since the Piltdown gravels were laid down.

As we leave the pit there arè several thoughts which must occur to everyone. How many of those ancient ancestors of ours have already been dug up and used as metal to mend our roads? Had it not been for Mr Dawson, Piltdown man, his flints, and the remains of ancient elephants, hippopotamus, and beaver would have long ere now been ground to dust under the wheels of lumbering farm waggons. Another surprise is that so shallow a deposit, lying almost on the surface of the open land, can yield evidence of so ancient a phase of the earth's history and of the men of England. Had it chanced, however, that the human remains thus recovered had been of a type similar to the men still living in the world, what would have been the result? Judging from what has happened in other cases, the universal verdict would have been that some mistake had been made, so strong is the belief that modern man is of modern origin. The condition of fossilisation of the human bones would then have had little influence on the verdict, for the rate at which bones become fossilised, when they become impregnated with iron, is extremely rapid. By good fortune, the human remains, as we shall see later, carry most certain indications of great antiquity in their peculiar features.

The ancient human remains at Galley Hill, at Ipswich, at Castenedolo, and probably also at Olmo, were appar- 
ently interred in the places where they were found. At Piltdown we are concerned, as at Heidelberg and at Trinil, with fragmentary remains which had been naturally entombed in the bed of an ancient stream. Only parts of the skull were found at Piltown, and, as at Trinil in Java, the fragments were scattered some yards apart. The individual may have been drowned and dismembered in the stream, or the skull may have been exposed on dry ground and subsequently swept, with other animal remains, into the stream in a time of flood.

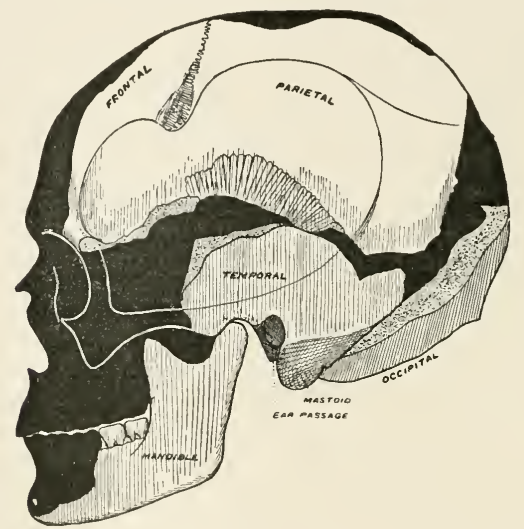

FIG. 98.-Outline of a modern skull to show the number and position of the cranial fragments recovered at Piltdown. The black areas represent missing parts.

A reference to fig. 98 will show how much of the human skull was recovered. The greater part of the left half of the brain case was found-only the middle part of the forehead and a part of the posterior or occipital bone were missing. The part of the occipital bone which was missing on the left side is present on the right, and it is thus possible, for the right and left sides of the skull are approximately symmetrical, to reconstruct the width and form of the hinder part of the head. Only one 
DISCOVERY OF THE PILTDOWN SKULL 305

fragment of the right half of the brain case was recovered -about two-thirds of the right parietal bone-but that is sufficient to give an exact basis for reconstruction of the whole skull. The right half of the mandible, we may be certain, is a replica of the missing left half. With these cranial fragments and the associated animal remains and human implements, Dr Smith Woodward returned to his work-rooms in the British Museum (Natural History) early in the summer of 1912, and set himself down to study their characters and their significance. About the end of the summer rumours of this remarkable discovery were circulating in the scientific circles of London. The discovery, however, was not made public until December I8th, I9I2, when, at a crowded meeting of the Geological Society, $\mathrm{Mr}$ Charles Dawson and $\mathrm{Dr}$ A. Smith Woodward gave a clear and full account of one of the most remarkable discoveries of the twentieth century. 


\section{CHAPTER XIX}

THE ANTIQUity OF THE PILTDOWN RACE

A GREAT company assembled in the rooms of the Geological Society of London on the evening of December i 8 th, I 9 I 2 , to receive the first authentic account of the discovery at Piltdown. An unknown phase in the early history of humanity was to be revealed; a revelation of that kind stirs the interest of many men, and draws them from their studies and laboratories to brave the heated atmosphere of overcrowded meeting-rooms. The various fragments of the skull had been pieced together; the missing parts had been filled in ; a complete skull was thus brought before the meeting. It was quite plain to all assembled that the skull thus reconstructed by Dr Smith Woodward was a strange blend of man and ape. At last, it seemed, the missing form-the link which early followers of Darwin had searched for-had really been discovered. No one had ever suspected that a secret of this kind lay hid away in the Weald of Sussex. We shall attend the meeting of geologists, however, not so much to learn what kind of beings those ancient inhabitants of England were, as to ascertain their position in the scale of time-to see their place in the scheme of man's evolution. We want to hear from the lips of those who have studied the recent history of the earth, and who have discovered the sequence and the dates of more recent land changes and deposits, how long ago it is since these ancient people lived in the Weald of Sussex. We shall take, in the first place, the opinion of Dr Smith Woodward himself. In his opinion the Piltdown remains "are almost (if not absolutely) of 
the same geological age" as the Heidelberg mandiblethe oldest human remains yet found on the continent of Europe. The geological age of the Heidelberg mandible, as we have seen in a former chapter, has been accurately fixed. It was discovered in a deposit laid down in the ancient bed of a tributary of the Neckar not long after the P'leistocene stage of the earth's history was well begun. The Cromer beds were in process of formation in East Anglia. Dr Smith Woodward's opinion, then, is that the Piltdown form of man was living in Southern England at an early part of the Pleistocene period, and that, at the same date, a very different kind of man was inhabiting Central Europe.

The reader maly naturally break in with the question : How long ago is that? The facts which will yield an estimate of geological time certainly exist, and in the opinion of men like Rutot, Sollas, and Penck are sufficient to afford an approximate estimate-the first step towards accurate figures. We shall take the estimate of Professor Sollas ${ }^{1}$ first. He regards the deposits which were laid down during the Pleistocene period as forming, when superimposed, a thickness or depth of 4000 feet (see frontispiece). He estimates that the formation has proceeded at the rate of a foot per century, and that therefore the collective deposits of the Pleistocene period probably have taken about four hundred thousand years to form. The estimate given by Professor Rutot is much less-one hundred and forty thousand years. Short as it is, that estimate deserves our serious consideration, for it is founded on a prolonged study of the Pleistocene formations found along the river valleys of Belgium. There is a third estimate which must also weigh with us in coming to a conclusion as regards the duration of the Pleistocene period-that of Professor Penck. ${ }^{2} \mathrm{He}$ has studied the changes produced by Alpine glaciers during the Pleistocene cycles of extreme cold. He is of opinion that such changes indicate for the Pleistocene

1 Nature, 1900, vol lxii. p. $48 \mathrm{r}$.

2 See A. Penck, Zeitschrift für Ethnologie, 1908, vol. xl. p. 390. 
period a duration of at least half a million of yearsperhaps they may have occupied as much as a million and a half. These figures are mere provisional estimates, subject to modification as our knowledge increases. The numerous changes in climate, of elevation and depression of the land, the transformation of our animals, the elaboration of human culture, the evolution and distribution of human races, all bespeak an enormously long period of time.

To arrive at an estimate of the antiquity of the Piltdown remains, we must also allow for the time which has elapsed since the Pleistocene period ended and our present era began. There is a general agreement that about fifteen thousand years would cover this recent period; but it must also be added that Dr Allen Sturge, ${ }^{1}$ from a study of the Neolithic age, which commenced soon after the Pleistocene period came to a close, regards such an estimate as totally inadequate. When, therefore, Dr Smith Woodward assigns the Piltdown remains to an early phase of the Pleistocene epoch, we may, in the present state of our knowledge, suppose him to refer the Piltdown race to a time which is removed about half a million years from the present. Beyond any question, the Piltdown skull represents the most ancient human remains yet found in England.

Having thus attempted to give Dr Smith Woodward's opinion of the antiquity of the Piltdown remains in terms of years, we must again return to the meeting of geologists and take up the narrative there. The discoverer of the remains, Mr Charles Dawson, ${ }^{2}$ said "he was quite prepared, from an anthropological point of view, to accept an earlier date for the origin of the human remains, and Dr Woodward and he had perhaps erred on the side of caution in placing the date as early Pleistocene." In $\mathrm{Mr}$ Dawson's opinion, then, it is possible that the Piltdown race may belong to the period preceding the Pleistocene-the Pliocene. Professor Boyd Dawkins said

1 Proc. Prehistoric Socicty of East Anglia, I9 I I, vol. i. p. 43.

2 Quart. Journ. Geol., I913, vol. 1xix. p. I 5 I. 
" he agreed with the authors of the paper that the deposit containing the human remains belonged to the Pleistocene age, and that the Pliocene mammalia in it-Mastodon arvernensis and the rest-had been derived from a Pliocene stratum formerly existing in that area." That opinion, coming from one who has the right to speak with authority, must evoke surprise. When he found the remains of the same species of Mastodon in the Doveholes cave in Derbyshire in 1903, unaccompanied by human remains, Professor Boyd Dawkins unhesitatingly assigned the contents of that cave to the Pliocene period; but when the same remains are found in Sussex, accompanied by humm remains, the deposit, in his opinion, should be referred to a much later date. In Professor Boyd Dawkins' opinion man is an evolutionary product of the Pleistocene period, and first reached Britain about the middle of that epoch. Much more guarded opinions were given by $\mathrm{Mr}$ Clement Reid and by $\mathrm{Mr} \mathrm{A}$. S. Kennard, who have made a special study of the later deposits in the south of England, "It was impossible," said Mr Reid, "to speak with confidence, but the whole evidence suggested that the Piltdown deposit and the plateau on which it rests are not preglacial or even early Pleistocene; they belong to a period long after the first cold period had passed away, but they occur at the very base of the great implement-bearing succession of Palæolithic deposits in the south-east of England." $\mathrm{Mr}$ Kennard regarded the Piltdown gravel as being of the same age as the roo-foot terrace of the Thames valley, which, as we have already seen, is made up of strata belonging to various stages of the Pleistocene epoch. Mr Kennard's opinion is of the greatest interest, because it was from the roo-foot terrace of the valley of the lower Thames, at a depth of 8 feet, in I 888, that a human skeleton was found at Galley Hill. If $\mathrm{Mr}$ Kennard is right, the Galley Hill man, who was of the same type as modern man, must have been almost contemporaneous with the very primitive human being reconstructed by Dr Smith Woodward. Mr E. T. 
Newton, who, in I 896 , brought the Galley Hill discovery before the same Society as now discussed the Piltdown find, was also present. It must have puzzled him to explain why the audience, which in 1896 refused to accept the Galley Hill discovery, because the remains were those of a being framed much as we moderns are, should extend so ready an acceptance to the very simian form of man Dr Smith Woodward had raised from the Piltdown fragments. Here we are concerned only with the opinion Mr Newton formed of the antiquity of the Piltdown remains. To him, "the highly mineralised condition of the specimens seemed to point to their being of Pliocene age rather than Pleistocene."

The writer is a student of the human body, and is therefore not in a position to offer any conclusive evidence which will help to settle whether the Piltdown man was Pleistocene or Pliocene. Yet there is one point which must weigh with those who seek to place this newly discovered human form in its proper place in the scale of time. The lower jaw, especially in the region of the chin, is marked by certain characters which separate it sharply from the corresponding part of all human mandibles and link it closely with the jaw of apes. Even in the Heidelberg mandible, which belongs to the early Pleistocene age, the human features have already begun to appear. In the Piltdown mandible the conformation is that of the ape; a simian stage is still preserved. The Heidelberg mandible shows that the human contour of the chin had already appeared at the beginning of the Pleistocene, but a change of this kind has not become manifest in the Piltdown mandible. This feature suggests that Piltdown man represents, as the animal remains accompanying him suggest, a Pliocene form. I am of opinion that future discoveries will prove that the remains found at Piltdown represent the first trace yet found of a Pliocene form of man.

The reader may feel by the time he has reached this point that enough has been said about the time at which the Piltdown man lived. Probably he is already wearied 
with the clash of expert opinion. Yet that difference is perhaps not so great as it appears. It will be remembered that $\mathrm{Mr}$ Lewis Abbot, who has given as much time as anyone to master the later geological history of the Weald, expressed the decisive opinion that in the Piltdown gravel two ages are represented. The lower or bottom stratum, which contained the Pliocene remains and human bones, is, in $\mathrm{Mr}$ Abbot's opinion, Pliocene in date; the upper levels, in which the rude Palæolithic implements lay, have been disturbed at a later time, and are to be regarded as Pleistocene in age. If $\mathrm{Mr}$ Abbot is right, and a survey of the full evidence favours his inference, then the divergence of opinion is explicable: those who maintain that the Piltdown gravel is Pleistocene are right, and so are those who regard it as Pliocene. Indeed, in a subsequent communication $\mathrm{Mr}$ Dawson wrote of the "dark" or Eoanthropus stratum as follows : ${ }^{1}$ "We cannot resist the conclusion that the third or 'dark' bed is, in the main, composed of Pliocene drift, probably reconstructed in the Pleistocene epoch. ...P Putting aside the human remains and those of the beaver, the mammalian remains all point to a characteristic fauna of Pliocene age ; and, though all are portions of hard teeth, they are rolled and broken. The human remains, on the other hand, although of much softer material, are not rolled, and the remains of the beaver are in a similar condition."

So far we seem to have gone a long way merely to reach the conclusion that the Piltdown man is probably of Pliocene age. To assign even the remains of man to the Pliocene period carries but a shadowy significance to most of us. If, however, we again visit Piltdown and survey the changes which have occurred in the Weald since fossil man was living there, we obtain some insight into his great antiquity. Mr Dawson discovered and delimited the remains of a great sheet of gravel which, in former times, covered the Piltdown plateau. The sheet apparently extended (see fig. 96) for about twelve

${ }^{1}$ Quart. Journ. Geol., 1914, vol. 1xx. p. 85. 
miles in one direction and eight in another, and must have formed a great deposit for such a small stream as the predecessor of the Sussex Ouse to lay down. Only some patches and pockets of the original deposit have come down to us. The plateau is now 120 feet above the level of the sea, but it is probable that it lay almost at sea-level when the great sheet was being deposited. The formation of so extensive a gravel bed must have occupied a long space of time, for the oldest or bottom layer is apparently Pliocene in date-the upper or disturbed layer is much later, probably middle Pleistocene in age. Over that wide Pliocene plain the ancient Ouse had meandered, shifting its bed from time to time and laying down gravel, sand, and fossil remains, gathered on the higher lands of the Weald. The present Ouse has cut a valley, 80 feet deep, in the plateau. That valley has been excavated since the time the more recent gravel beds were laid down on the plateau. How often the valley has been re-excavated, as the land rose ; how often it has been filled up, as the land sank, we cannot as yet tell because the matter has not been investigated. But it is clear that there have been many variations in the level of the land since the gravel was first laid down on the Piltdown plateau. The human remains lay in the most ancient gravel deposit. Since the Piltdown man lived, then, the great expanse of gravel, measuring nearly roo square miles, has been laid down and a valley, at least 80 feet deep, has been slowly eroded by a comparatively small stream. As the first gravel was being laid down the culture of man was represented by rudely chipped stones-eoliths. As things are to-day, man's culture is represented by the wireless messages and aeroplanes which cross the Weald, and the great steamers passing down the channel, and the rural homes and country houses which everywhere meet the eye.

No one suspected, until Mr Dawson made the discovery, that deposits of a Pliocene or early Pleistocene date occurred in the Weald of Sussex. It is not likely that Piltdown is the only site at which such deposits 


\section{ANTIQUITY OF THE PILTDOWN RACE 3 I 3}

occur in the region of the English Channel. If one looks at a map representing the bounds of England in late Pliocene times-the date at which we suppose the Piltdown man to have lived-it will be seen (fig. 99) that in place of the English Channel there is a great river which was joined by all the streams issuing from the southern area of the Weald. It will be seen, too, that the Somme and the Seine also lie within the watershed of the great channel river. Now on a tributary of the Seine is situated St Prest, near which there is, as

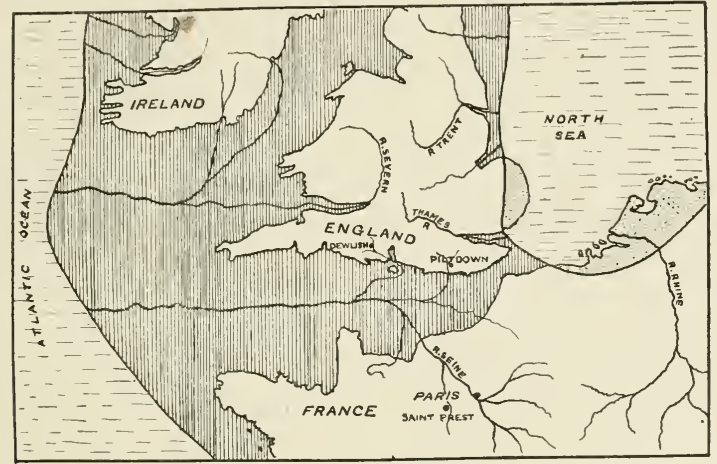

FIG. 99.- Map of South England and North France, to show the course and tributaries of the ancient channel river (after Boyd Dawkins).

M. Rutot has indicated, a deposit very similar in nature and in age to that at Piltdown. We have already seen that the deeper strata of gravel at St Prest contain remains of Pliocene animals and have always been regarded as of a Pliocene age (see fig. 80, p. 23I). Over the Pliocene beds are others of a later or Pleistocene age, just as at Piltdown. So long ago as I 863, M. Desnoyers ${ }^{1}$ recognised that many of the fossil bones of animals existing in the Pliocene period, and found in the deepest and oldest deposits of St Prest, showed definite evi-

1 .I. J. Desnoyers, Compt. rend., 1863, vol. lvi. p. 1073. See also references given on p. 232 . 
dence of having been worked by man. More striking still, the land on which these deposits occur is 80 feet abcve the adjoining tributary of the Seine, the Eureet-Loir, the same height as the Piltdown deposits lie above the Ouse. The Pliocene age of the St Prest deposits has never been called in question.

There is a further striking similarity between the deeper deposits at St Prest and the dark bed at Piltdown. Mention has been made of the eoliths which occurred with the human remains in the dark bed. Shaped flints of a corresponding type also occur in the Pliocene beds at St Prest. They were discovered and described by a geologist, M. Bourgeois, ${ }^{1}$ in 1867 , four years after $M$. Desnoyers recognised the human markings on the fossil bones. In M. Rutot's opinion the St Prest implements are of a later and more highly evolved type than the Kentish eoliths. The discoveries made at $\mathrm{St}$ Prest fifty years ago have a very direct bearing on the problem of the age of the Piltdown remains.

The evidence of another Pliocene deposit may be cited here. In the south of England, about one hundred miles to the west of Piltdown, but still within the watershed of the old channel river, there occurs another trace of the Pliocene period which is of the greatest importance to the student of man's evolution. This trace occurs at Dewlish, a small village in the chalky uplands of Dorset (fig. 99). Near the village of Dewlish the chalk plateau, about 300 feet above sea-level, ends in a sharp bank or escarpment, about roo feet in height, similar to the chalk brim of the Weald. On this plateau, near Dewlish, there was discovered by accident a deep trench cut in the chalk and filled with layers of sand and gravel. The trench was investigated by the Rev. O. Fisher, and has been described by him in two communications to the Geological Society of London. ${ }^{2}$ It

1 See Paléontologie humaine, by E. T. Hamy, Paris, 1870, p. 98.

2 Quart. Journ. Geol., r888, vol. xliv. p. 819; I905, vol. lxi. p. 35. Since the above was written, the Dorset Field Club has reopened the trench. The evidence is in favour of a natural-not human-formation. 
was found to be over roo feet in length, one end extending so as to open on the free face of the escarpment. Its depth was found to be over $\mathrm{I} 2$ feet. It was narrow and filled in with sand and gravel, which do not now occur on the surface of the plateau at Dewlish; and in the gravel were found remains of elephants of the ancient kind found at St Prest and at Cromer-Elephas meridionalis-which is accepted as a true representative of the Pliocene period. In the gravel also occurred certain flints which were regarded by $\mathrm{Mr}$ Grist ${ }^{1}$ as similar to the eoliths of the Kentish plateau. $\mathrm{Mr}$ Clement Reid inspected the trench-the only one of the kind known-and found it did not represent any cleft or fault produced by natural agencies. No stream could have produced such a trench; there is no stream now on the plateau. Mr Fisher could only account for it on the supposition that it was dug by the hands of man, and was designed, like similar trenches at the present day, as an elephant trap. If $\mathrm{Mr}$ Fisher's inference is right, and no other satisfactory explanation has been offered, we have the startling revelation that in the Pliocene period mankind had already reached an advanced stage in his evolution.

We have already mentioned the sub-Crag implements discovered by Mr Reid Moir (p. 225). They indicate the existence of human beings towards the middle of the Pliocene period. The Kentish eoliths are as ancientperhaps more ancient-than the sub-Crag implements. When, therefore, we take into consideration these facts, and the similarity between the Piltdown and St Prest deposits, we are persuaded that Mr Dawson and Dr Smith Woodward were ultra-cautious in assigning a Pleistocene date to the human remains found at Piltdown. All the evidence seems to point to a Pliocene age. Hence the importance of their discovery, for although the handiwork of Pliocene man has been recognised for a considerable number of years, the man himself was unknown until $\mathrm{Mr}$ Dawson brought him into the light of day.

1 C. J. Grist, "Some Eoliths from Dewlish, and the Question of Origin," Journ. Roy. Anthrop. Inst., I910, vol. xl. p. 192. 


\section{CHAPTER XX}

\section{EOANTHROPUS DAWSONI}

Having thus settled, so far as the evidence will permit, the approximate position of the Piltdown man in the scale of time-and beyond question he represents the earliest specimen of true humanity yet discovered-we now proceed to see what sort of being he was. The truth is that we have to discover his characters from fragments of the skull, for no other part was found. The characters of his limbs and body are matters of inference. The reader will quickly realise the number and size of the actual parts of the skull which were found, by examining fig. IOO; the missing parts are indicated by stippled lines. The bone which forms the forehead-the frontal bone-is only partly present. Fortunately, the region which forms the upper margin of the left orbit has been preserved in its outer part, so that we can form a definite opinion as regards the supra-orbital ridges. These are not formed as they are in the chimpanzee, gorilla, and Neanderthal man, but are more like the conformation seen in modern human races. A great part of the left side of the frontal bone has been recovered; the right side is wholly missing, but we know that the right and left sides of the frontal bone are nearly symmetrical, so we can reconstruct the greater part of the forehead with some degree of assurance-all except the middle part lying over the root of the nose.

Taking the bones which form the roof of the skull just behind the frontal bone, we see that practically the whole of the parietal bone is present on the left side. It forms 
the roof and side of a great part of the brain chamber, and is therefore of the utmost importance. We want especially to know about the brain, for that is the master organ of the human body. It will be noted that even on the left side certain fragments of the parietal bone are missing along its upper margin, hinder border, and at its lower angle behind. The dimensions of these missing parts can be estimated with accuracy. The parietal bone of the opposite or right side is also represented. Only

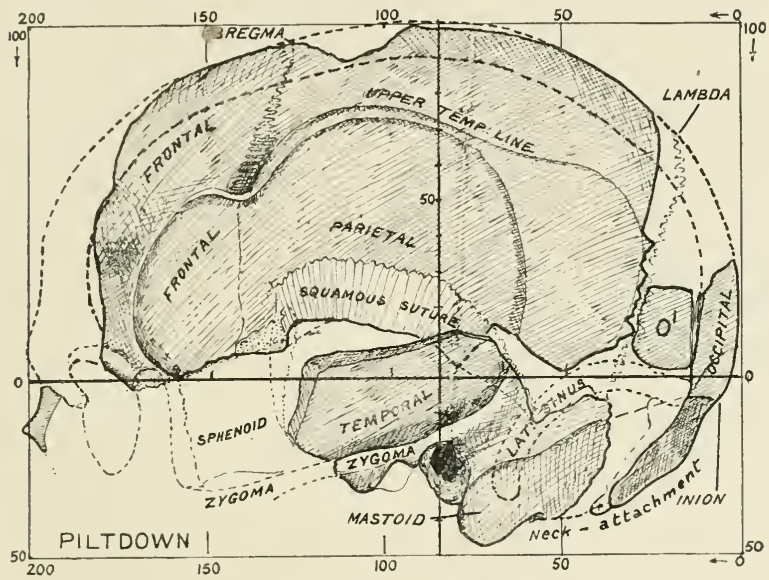

FIG. 100,-Fragments of the Piltdown skull placed in position and represented in profile.

about two-thirds of that bone is present, and, unfortunately, the part which is missing is the upper area which reaches up to the middle line on the roof of the skull, where it should come into contact with the opposite or left parietal bone. The actual part of the right parietal bone recovered is indicated in fig. IOI, where it has been superimposed over the corresponding area of the left side.

Coming now to the hinder or occipital end of the skull, we find the bone of that region represented by a considerable fragment. The actual part of the occipital 
found is best seen in a hinder view of the skull such as is shown in fig. IO2. To the lower part of the occipital bone the neck is fixed; part of the region for the fixation of the neck is represented in the fragment found (fig. I00). At the lower end of the fragment is seen the hinder margin of the foramen magnum, by which the spinal cord makes its exit from the brain cavity to enter

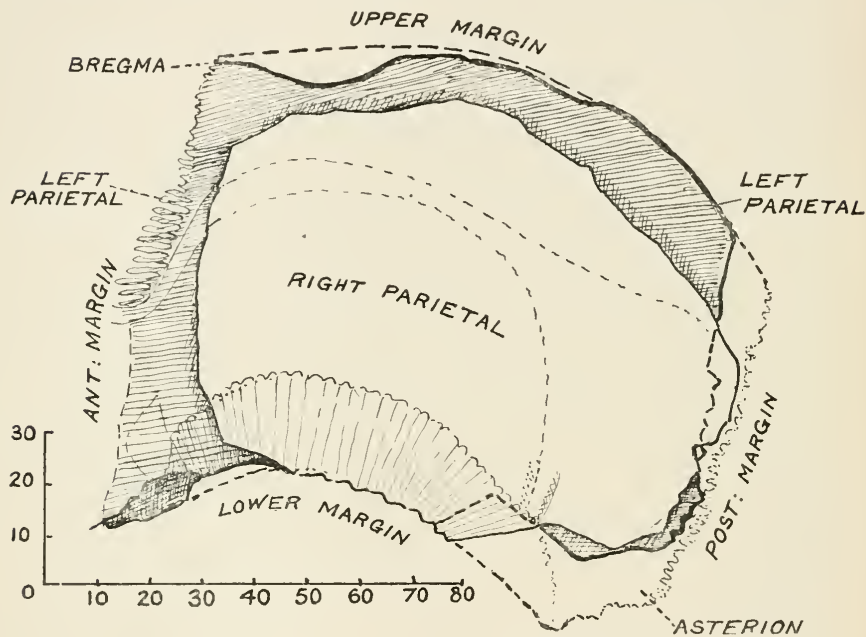

FIG. IOI.-The fragment of the right parietal bone of the Piltdown skull superimposed on the corresponding points of the bone of the left side, to show the extent missing.

the spinal column. The tabular part of the occipital, which rises up from the neck to form the projecting hinder part of the head, is also fragmentarily represented. By great good fortune, Dr Smith Woodward recovered a most essential fragment of the right half-the fragment which gives us an indication of the width of the occipital bone, up almost to its articulation or point of contact with the right parietal bone (see figs. IOO and I02, $\mathrm{O}^{\prime}$ ). On the occipital bone the ridge which marks the middle 
line of the head and of the neck is preserved (fig. 102). We therefore know the width of the right half of the occipital bone, and we may be certain the left half was almost exactly of the same size. Hence in the drawing of the recovered fragments the right half of the occipital bone is represented as if it were on the left side, in place of the right (fig. IOO).

The frontal, parietal, and occipital bones form the front, roof, and hinder part of the brain chamber. The temporal bone, which helps to complete the lateral wall of the chamber, also forms part of the floor or base of the cranial cavity. Almost the whole of this bone was found - of the left side (fig. I oo). A fragment is missing, but sufficient of its upper border is preserved to give us its true relation-

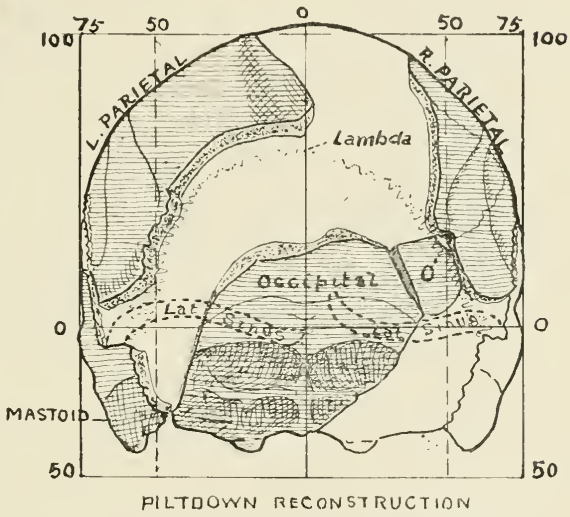

FIG. 102. - The fragments of the Piltdown skull viewed from behind. ship to the parietal bone. As may be seen in fig. I00, a mutual point of contact is present on the opposing margins of the temporal and parietal bones. It will thus be seen that all the essential components of the brain chamber are present; there are sufficient parts to form almost a complete half of the brain chamber. In the case of the skull a half is almost as good as a whole, for the left and right halves of every head are approximately similar.

All of these fragments of the Piltdown skull are, at first sight, very similar to the same parts of a modern human skull except as regards their thickness. The 
Piltdown bones are surprisingly thick. The farm labourer who first saw the skull described it as a cocoanut. In most modern heads the thickness of the bones forming the brain chamber varies from 4 to $6 \mathrm{~mm}$. ( $\left(\frac{1}{6}\right.$ to $\frac{1}{4}$ of an inch); in native races, and occasionally in Europeans, the thickness may amount to 8 or even $10 \mathrm{~mm}$., but in no normal modern skull are all the bones so uniformly thick as in this recently discovered specimen. As already pointed out, the ancient skulls found at Galley Hill, Clichy, and Olmo are thick, but not to the extent seen in the Piltdown fragments. Thickness is also a character of most Neanderthal skulls. In the Piltdown cranium the frontal, parietal, occipital, and temporal bones vary in thickness from 8 to $12 \mathrm{~mm}$., the average all over being about $\frac{2}{5}$ of an inch. The bone is naturally formed; there can be no question of disease. My colleague, Mr Shattock, has definitely settled that point. ${ }^{1}$ There can be no doubt that sufficient of the skull has been recovered to provide us with the means of reaching a just and certain conclusion as regards the size and shape of that part of the head which contains the brain. Very few ancient skulls are so well represented as that of Pildown.

The discovery of almost a complete half-the right-of the lower jaw or mandible by $\mathrm{Mr}$ Dawson is a most fortunate circumstance (fig. IO3). It lay in the ironstained cemented stratum with unworn eoliths and the fragment of the tooth of an early Pliocene form of elephant. The importance of the mandible is at once apparent; it provides us with the skeletal outline of the face of this ancient form of man. Each half of a human mandible consists of two distinct parts: (I) a horizontal part or body (fig. I03), which carries the teeth and forms the lower part of the outline of the face-from the angle of the jaw below the ear to the chin; (2) a vertical part, which ascends from the angle to terminate in an articular knob or condyle. The socket-the glenoid cavity-for the articular knob is

${ }^{1}$ See Proc. Internat. Med. Congress, London, 1913 (Pathological Section). 
situated on that part of the base of the skull which is formed by the temporal bone immediately in front of the ear. We have already seen that the temporal bone of the left side was recovered, revealing the characters of the articular cavity, which is shaped exactly as in modern races, and in this respect quite unlike the same joint in an ape's skull. In the Piltdown skull we have

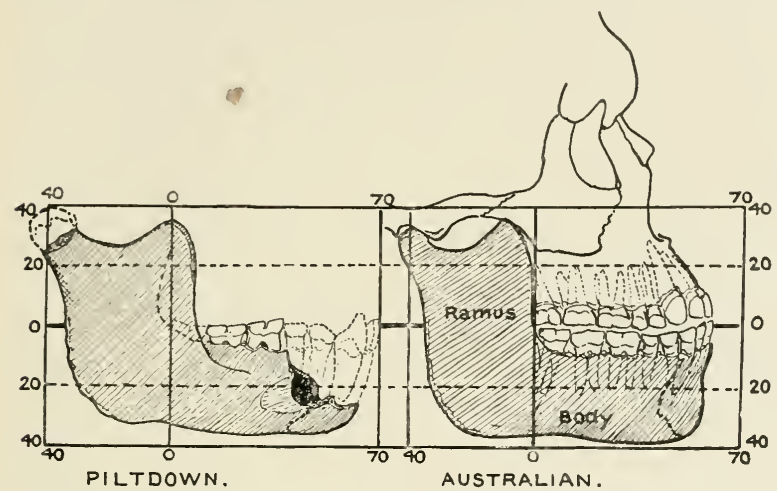

FIg, 103.-The Piltdown mandible, as seen in true profile, compared with a corresponding view of the mandible of an Australian native. The missing teeth and parts of the Piltdown mandible are indicated by stippled lines.

thus the greater part of one half of the mandible of the right side; on the left side the articular socket for the jaw is present; by transposing or reversing the right half of the mandible to take the place of the left half, it will be seen that we obtain a representation of the skeletal outline of one half of the Piltdown head (see fig. I 76, p. 480 ).

Unfortunately, a fragment is missing from each part of the right half of the mandible (fig. IO3). All of the ascending part is present; the areas for the attachment of the chewing muscles are intact, save the articular knob itself. That is no great loss, because the shape of the socket in which it plied is known to us, and as that socket, although large, is shaped as in present-day 
man, we may presume the articular knob or condyle of the jaw also had a modern human form. The part missing in the body or horizontal part of the jaw leaves some room for speculation. That region of its upper border which lies hidden behind the lower lip in life, and carries the sockets of five teeth-the two right incisors, the right canine, and two right premolar teethhas been broken away. The part which bears the three molar teeth is present; the first and second molar teeth fill their sockets, but the third or wisdom tooth has dropped out after death. The deficiency thus affects the upper or alveolar border of the jaw in front; the whole of the lower border of the body of the mandible is present. As the body approaches the region of the chin (see fig. . I64) it becomes modelled in a form which is peculiar to apes.

Early in the summer of I9I2, when Dr Smith Woodward commenced his examination of the Piltdown fragments, he realised that the peculiar and characteristic features of this ancient form of man were centred in the region of the chin. Such features had never been found or seen in any mandible or skull to which the term human could be applied. The peculiar characters of the chin, which arrested his attention, can best be realised by a reference to such illustrations as are shown in figs. IO4 and I05. In fig. IO5 is represented the arrangement of parts seen in the chin region of a young chimpanzee-about four years of age, just before the milk teeth are shed. When a section is made so as to separate the lower jaw and the tongue into right and left halves, it is seen that the jaw in the region of the symphysis - the line of fusion of the right and left halves of the jaw-is composed of two parts, an upper part to bear the incisor teeth, and a lower part which is for the attachment of muscles. It is the lower or muscular part which principally concerns us. There is no projection of the anterior surface at the lower border of the symphysis to represent a chin in the chimpanzee; the anterior or labial surface of the jaw slopes 
downwards and backwards to a chinless lower border. On the hinder surface of the symphyseal region-the surface directed towards the tongue-there is seen a deep pit, almost large enough to take the tip of the little finger. From the interior of the genial pit arise the two chief muscles of the tongue-the genio-glossus muscles. The lower margin of the pit is formed by a plate of bone-the simian plate-which unites the lower borders of the right and left halves of the jaw (fig. 105). It is a strengthening plate. From the posterior margin of the plate two pairs of muscles take their origin-the

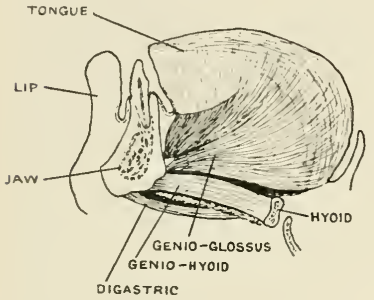

MAN.

FIG. I04, - Section of the human tongue, chin, lower jaw, and lip made along the middle line, to show the origin of muscles from the region of the chin or symphysis.

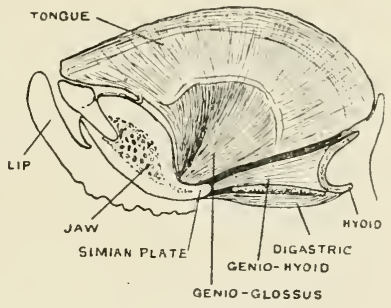

CHIMPANZEE.

FIG. 105.-A corresponding section of the same region of a young chimpanzee.

genio-hyoid muscle, which draws the larynx forward during the act of swallowing, and the digastric muscle, which depresses the front part of the jaw, and thus assists in opening the mouth. Such is the conformation of the symphyseal or chin region of the lower jaw in apes (see fig. 105).

When a corresponding section is made of the symphyseal region of a human lower jaw, a very different conformation is seen (fig. 104). There are the same two parts exposed in the section-the upper dental part, which carries the incisor teeth, and a lower part for the attachment of muscles. The dental part, compared with that of an ape, is small and 
vertical in direction. The human teeth being relatively small, the dental part of the jaw has retreated backwards in the mouth. The muscular part, on the other hand, has been advanced; there is now a prominent, or, at least, a well-marked chin. The genial pit and simian shelf seen in the ape's jaw are absent. In place of rising from a pit, the main muscles of the tongue-the right and left genio-glossus-arise from an elevation of bone bearing two tubercles. The genio-hyoid, in place of rising from the upper margin of the shelf of bone, springsfrom the lower part of the elevation which has filled up and replaced the pit, while the digastric muscles are attached to the lower border of the jaw just behind and below the chin.

It will thus be seen that the simian and human mandible differ markedly in the region of the symphysis or chin. The meaning of that difference will be discussed in a later chapter (p. 45 I). The type to which the Piltdown jaw belongs there can be no doubt; both the genial pit and the simian plate are present. These are ape-like features. Dr Smith Woodward recognised them as such, and in his work of reconstructing the original form of the skull the presence of these simian features exercised a dominating influence. Hence, when he came to replace the missing parts of the jaws, the incisor and canine teeth, he followed simian rather than human lines. The teeth of man form a uniform series ; there is no break or diastema in front of, or behind, the canine teeth; the canine tooth does not project prominently beyond its fellows. From the ape-like features of the chin it was inferred that projecting simian canine teeth must have been a characteristic of the Piltdown form of man. A massive canine tooth was therefore modelled; not very projecting (see figs. I06, I08), thick and rather stumpy, its longest or front-to-back diameter being I 4.5 mm., its side-to-side, Io $\mathrm{mm}$. The diameters of such a tooth are equal to those of the canine of a male chimpanzee, and far beyond the limits of the largest human canines known. As in the chimpanzee, a break or interval in the dental series was left both in front of and 
behind the canine. The width and conformation given to the front or incisor teeth were those of the chimpanzee ; when the Piltdown lips parted one would have seen the same ferocious dental array as in that ape (figs. 107, 109). As regards the rest of the teeth-the two premolar and three molar-man's dentition rather than the chimpanzee's was copied. The first and second molar teeth were found actually in the jaw ; they were not larger than the corresponding teeth of certain modern races, and are distinctly human in pattern-at least more human than
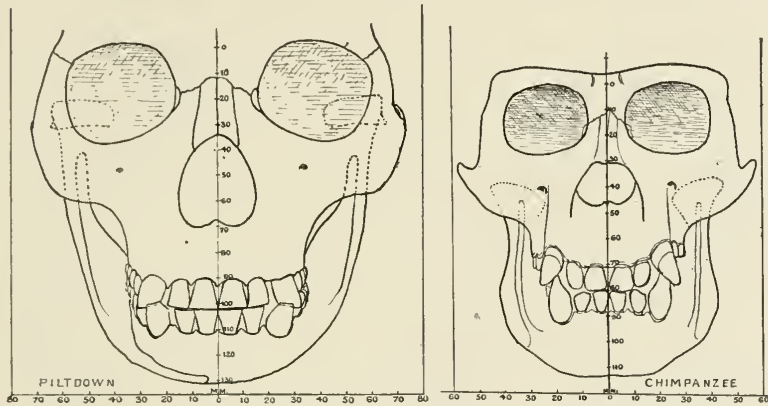

FIG. I06. - The muzzle and front teeth of the Piltdown skull as originally reconstructed by $\mathrm{Dr}$

FIG. 107.-Similar view of the same part of a male chimpanzee. Smith Woodward.

anthropoid. The premolars had to be made much larger than in human jaws, but they were given a human not a simian form. Thus in the first reconstruction of the Piltdown skull there appeared to be a mixture of dentitions. In front the teeth were simian; behind they were human.

We are dealing at present with the parts which were actually found when the discovery was first announced. In the autumn of I9I 3 a canine tooth was discovered which must be assigned to the Piltdown mandible. It was, as Dr Smith Woodward had anticipated, essentially simian in form-it was more like that of a female 
chimpanzee or gorilla than that of a human being. By the time this tooth was discovered I had come to the conclusion, for reasons which will be given in another chapter, that a massive human and not a projecting and simian canine had really been present. In that I was mistaken, but as regards the actual dimensions of the tooth my estimate was approximately right. I allowed I $\mathrm{mm}$. for the longest (front-to-back) diameter; it proved to be I I $\mathrm{mm}$. Dr Smith Woodward had represented it as $14.5 \mathrm{~mm}$. In the chief point, however, Dr Smith Woodward was right; the simian chin was correlated with a simian canine tooth.

As will be seen from figs. I06 and 107, Dr Smith Woodward made the muzzle and front teeth of Eoanthropus wider and more massive than in the chimpanzee. He made the region of the chin and symphysis-the anterior line of fusion of the two halves of the mandible-. particularly strong (fig. I08). The symphyseal areas of union or fusion between the two sides of the mandible are stippled in figs. I08 and I09. In the Piltdown mandible this area, as restored by Dr Smith Woodward, is even greater than in the chimpanzee. While the teeth implanted in the front part of the mandible and the symphyseal region are truly simian, the hinder part of the mandible, the molar teeth, and also the ascending branch or ramus, are, to my eye, entirely human. We have thus in this newly discovered form of man a remarkable mixture of simian and human characters.

One other feature may be pointed out here. It will be observed in fig. IO3 that the greater part of the last molar or wisdom tooth lies behind the anterior margin of the ascending ramus of the jaw, being thus hid from view. In the Australian jaw (shown in the same figure), as is usually the case in man and apes, this tooth lies wholly in front of the ramus and is freely exposed. The Piltdown ascending ramus is remarkably wide ( $44 \mathrm{~mm}$.), and its width is evidently due to a forward extension of its anterior border. On the anterior border is inserted the temporal muscle, the chief agent in biting or in suddenly 
shutting the lower jaw. Such a forward extension of the ramus must give the temporal muscles greater power and purchase over the front part of the jaws and canine teeth.

It is necessary to examine in more detail the original reconstruction of the apparatus of mastication in the Piltdown man. Our estimate of the position of any newly discovered form of human being turns largely on the relationship between his alimentary and cerebral systems. It scems fairly certain that the tendency in human evolution is to increase the work of the brain and

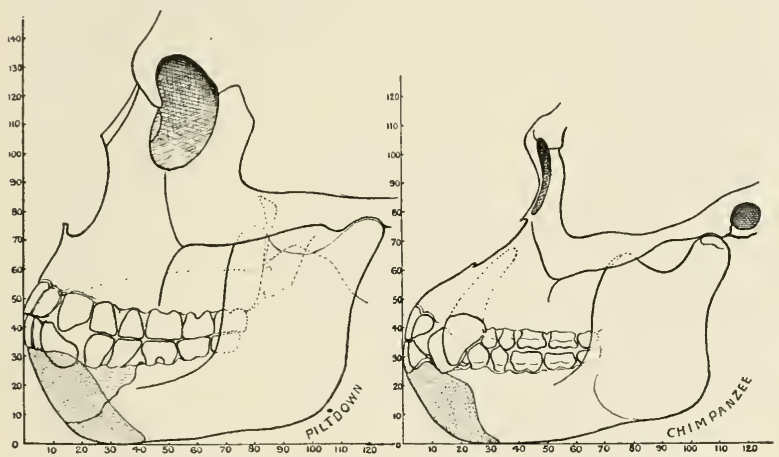

FIG. I08.-Drawing of the jaws, in profile, from Dr Smith Woodward's original model of the Pilt-

FIG. I09.-A drawing of the same parts of a male chimpanzee. down skull.

diminish the work of the stomach. An increase of brain power has made the task of our digestive system easierat least those parts of our body which are concerned in mastication. We therefore need some means of indicating -even if the method adopted be but a rough approximation to the truth-the relative development of cerebral and alimentary powers in any newly discovered form of human being. We may take a concrete example. In fig. I 10 is represented the palate of a female chimpanzee; the teeth are set round the circumference of the palate. Within the semicircle of teeth lies the tongue, but the 
whole area of the palate, all that lies inside the outer margins of the teeth, is directly concerned in mastication, and the total area of the palate may therefore be accepted as the degree to which the apparatus of mastication has been developed. We suppose that a large palate means a crude and not a richly nutritious diet. Now, in this female chimpanzee the area of the palate is $36.5 \mathrm{~cm} .{ }^{2}$; the brain measured 320 c.c.; there was $\mathrm{I} \mathrm{cm}^{2}$ of palate to 8.7 c.c. of brain; that represents a common palato-cerebral ratio amongst man's nearest allies-the anthropoid apes. In modern Englishmen-my estimate is founded on an accurate investigation of twenty-two medical students-the average palatal area is $26.6 \mathrm{~cm} .^{2}$;

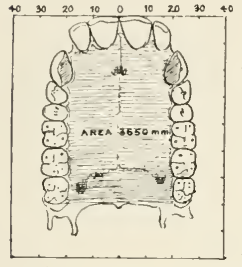

a chimpanzee, 9

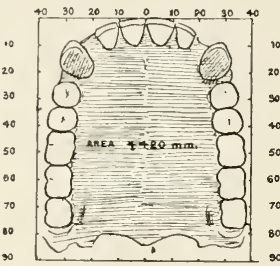

B. PILTDOWN PALATE

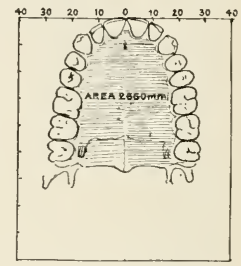

c. MODERN ENGLISM PALATE

FIG. I IO. - A comparison of the palatal areas in a female chimpanzee (A), in the Piltdown specimen as reconstructed in the original model $(\mathrm{B})$, and in a modern Englishman (C).

the cerebral development, 1500 c.c. ; the palato-cerebral ratio was therefore $\mathrm{I}: 56 \cdot 3$, in place of $\mathrm{I}: 8.7$ as in anthropoids. We therefore turn with some interest to see what ratio may hold in this newly discovered form of man. Dr Smith Woodward has reconstructed the palate. Accurate indications as to its shape were available as soon as he had obtained the form of the lower jaw and teeth, for the upper and lower jaws must fit and the teeth correspond in all higher animals, according to certain definite laws. Now the area of the palate thus reconstructed (see fig. I IO, B) is $44^{.2} \mathrm{~cm} .^{2}$-larger than in the female chimpanzee; it is the size of palate seen in the adult male chimpanzee. In the male adult orang and gorilla the palatal area may reach $70 \mathrm{~cm} .^{2}$ Dr 
Smith Woodward estimated that the brain capacity of Eoanthropus was about I070 c.c. In this new form of man the palato-cerebral ratio is therefore about $I: 24$. This ratio holds an intermediate position between that of the chimpanzee $(1: 8)$ and that of modern Englishmen $(1: 56)$. We appear, therefore, to be dealing with a very primitive form of man-one which, so far as concerns its development of palate and of brain, supplies us with a stage half-way between ape and man. In modern native races the palato-cerebral ratio may be as low as $1: 36 \cdot 7$. In the Gibraltar skull, as we have seen, ${ }^{1}$ the ratio is $1: 3^{8}$.

We have already noted that the front teeth of this new form of man and the region of the chin are essentially ape-like-quite different to any known form of human being. The humanity of this being, however, becomes more and more apparent as the mandible is followed backwards and upwards to its socket at the base of the skull. The socket is robust and massive, but its conformation is absolutely that seen in the more primitive of modern human races. When Dr Smith Woodward came to fit the fragments of the skull together, he found that the parts were human in form and must be fitted together as in modern human skulls. The shape which the reconstructed head of Eoanthropus took in his hands is shown in a series of figures (figs. I I I, I I 3 , and I I 5). Students of anatomy will at once recognise the peculiar features of this newly discovered form of man ; but in order that those who have not made a special study of man's body may also have a standard for comparison, corresponding drawings of the skull of a modern Englishman are reproduced here so as to be available for comparison. The Englishman chosen has a brain capacity of 1425 c.c. - 60 less than the average amount. The walls of his brain case have an average thickness of $6 \mathrm{~mm}$., whereas in Eoanthropus the thickness is quite ro $\mathrm{mm}$. along the vault. Both skulls have been poised on the same horizontal plane-one which approximately indicates the lower limits of the cerebrum. The higher

1 See p. 151. 
or cerebral part of the brain lies above the line on which the skulls are orientated. ${ }^{1}$ In the modern head (fig. I I 2) the roof of the skull almost reaches the roo-mm. line; in Eoanthropus it passes slightly above the 90- $\mathrm{mm}$. line. When we allow for the great thickness of the skull, it is plain that the brain of Eoanthropus will fall-as regards

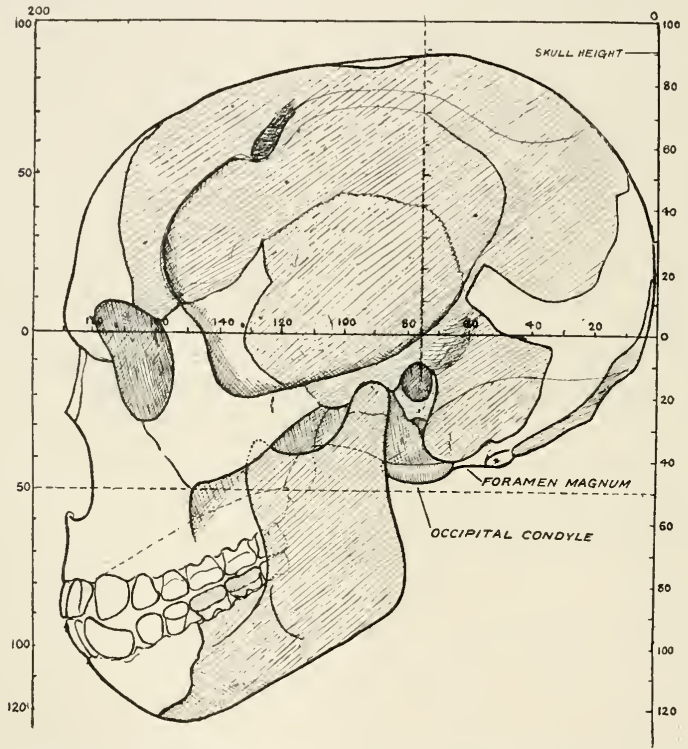

FIG. I II. - Profile drawing of Dr Smith Woodward's reconstruction of the skull of Eoanthropus (half natural size). The parts present are shaded ; the missing parts are left blank.

height-about I $5 \mathrm{~mm}$. ( $\frac{2}{5}$ inch) short of the modern English brain. As regards the total length of the skull, the ancient and modern man are much alike - the maximum length in each case being about $190 \mathrm{~mm}$.

It is clear from these diagrams that the face of

1 For details concerning this line or plane-the subcerebral plane-see Keith, Journ. of Anat. and Physiol., I910, vol. xliv. p. 251. 
Eoanthropus is much more massive than that of the modern man. As regards details of head conformation they have much in common. In both a prominent mastoid process lies behind the ear-hole; it is shaped in the Piltdown man as in modern human races. As the mastoid is one of the structures by means of which the

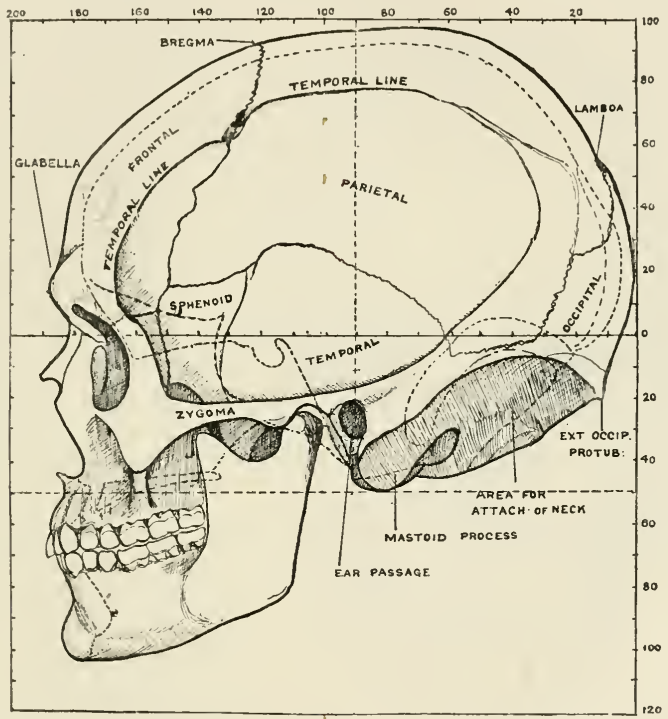

FIG. I I 2. - Profile drawing of the skull of a modern Englishman with a cranial capacity of 1425 c.c. (half natural size).

muscles of the neck move and balance the head, we must infer, from the fact that this process is present in its modern shape in Eoanthropus, that the head in that ancient type of man was carried and balanced just as it now is in us. The eye-socket of Eoanthropus will be seen to be set obliquely; when the skull is viewed in true profile, more of the orbit is then to be seen than in modern human races, and much more than in anthropoid 
apes. Above the outer angle of the orbit it will be seen that the temporal line or crest-from which a muscle of mastication arises--ascends steeply on the frontal bone, whereas in all modern human skulls the curvature is less acute and its backward trend more marked (see figs. I I I, I I2). The muscles of mastication evidently did not

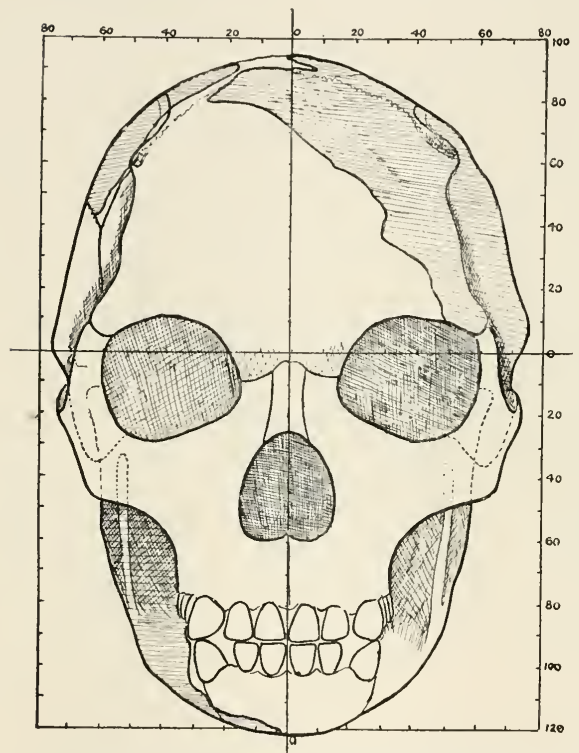

work exactly as in modern man, or why this difference in the conformation of the temporal crests?

When a fullface drawing of the skull of Eoanthropus is compared with that of a modern skull (figs. I I 3, I I 4) a number of differences become apparent. In actual width, both at the base of the skull and across the cheek bones,

10 Eoanthropus is considerably the greater. The

Fig. 113.-Face view of the skull of Eoanthropus as recon-actual width of structed by Dr Smith Woodward (half natural size). The the modern skull
parts shaded are those actually found. at its base is 132 $\mathrm{mm}$.; in Eoanthropus the width here measures $150 \mathrm{~mm}$. The chief difference, however, lies in the filling of the brain case. In the modern skull the sides are nearly vertical, with a slight outward bulge half-way to the vertex; in Eoanthropus the cranial cavity is so imperfectly filled that the sides lean inwards and gradually fade into a contracted crown or roof. In the modern skull, as seen 
from the front, the roof is usually dome-shaped. The forehead of Eoanthropus gives the impression of being contracted and ape-like; its lateral borders, formed by the lines for attachment of the temporal muscle, approximate as they ascend. In anthropoids these lines may actually meet on the vertex of the skull and form a median crest. In the modern human forehead the temporal lines become wider apart, and the brow broadens. towards the crown or dome of the head (fig. I I 4 ). In Eoanthropus, then, we see an ill-filled head with sides which slope inwards. In a general sense we may construe such charactersassimian in nature.

To complete this cursory review of the skull of Eoanthropus as it originally left the hands of its reconstructor, I add

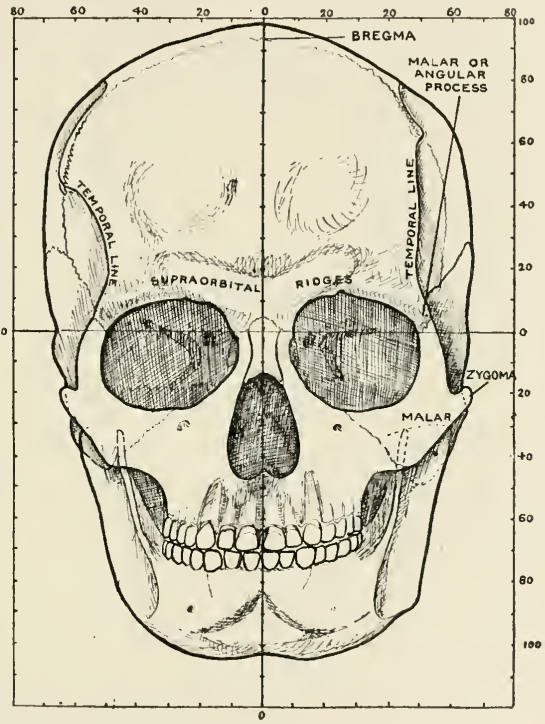

FIG. I I 4.-Face view of a modern human skull for comparison with fig. I 3 (half natural size). two further figures. In fig. II 5 the modern skull is viewed from above; in fig. I 6 the same view is reproduced of the skull of Eoanthropus. In the modern skull the arrangement of bones is simple. The frontal bone, forming the forehead, is joined behind to the right and left parietal bones at the coronal suture. At the posterior end of the vertical view only the upper part of the occipital bone is seen; it becomes joined to 
the parietal bones at the lambdoid suture (fig. II 5). Along the middle line, between the right and left parietals, passes the sagittal suture. At some distance to either side of the sagittal suture is seen the upper limit of attachment of the temporal muscles-the temporal lines (fig. I I 5). Part of the bony scaffolding for the support of the face and jaws is seen on the forehead-the supraorbital ridges.

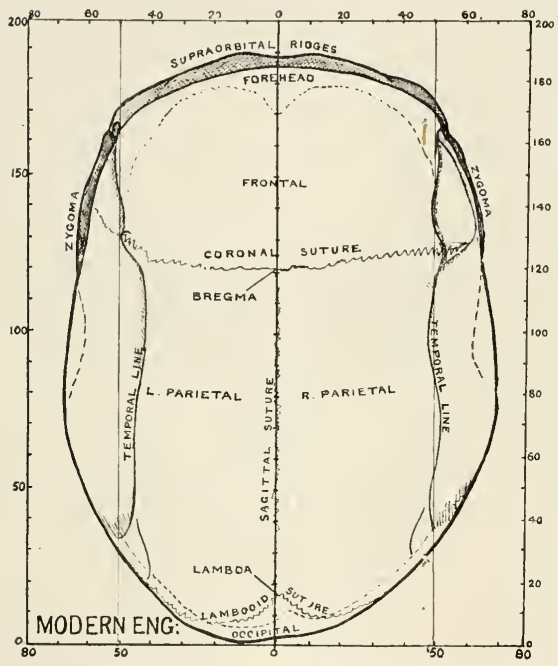

The cheek bars or zygomatic arches are just apparent ; they pass on each side of the head in front of the ear, to end in the cheeks and thus strengthen and support the face. When we turn to the same view of the skull of Eoanthropus (fig. I I 6) we see representatives of the same parts, but their clear interpretation is not an easy task because of the FIG. I1 5. - View of a modern skull from above, showing great deficiency
the bones and sutures of the vault ( $\frac{2}{5}$ natural size). in the forehead and along the whole length of the roof. The zygomatic arches, it will be observed, project far beyond the sides of the skull, as in anthropoid apes. There is no definitely moulded supra-orbital ridge shown; the forehead is given a wedge shape. The coronal suture is very apparent on the left side; but of the sagittal suture, or of the lambdoid, there is no certain trace on this aspect of the skull. The temporal lines are clearly visible, both upper and lower. Only the upper of these lines are represented 
in the drawing of the normal skull (fig. I I 5). As regards general mass it is clear that the skull of Eoanthropus is the greater. It will also be noted that there is a marked irregularity in its contour, and that there is a noticeable degree of asymmetry in its conformation, the right side

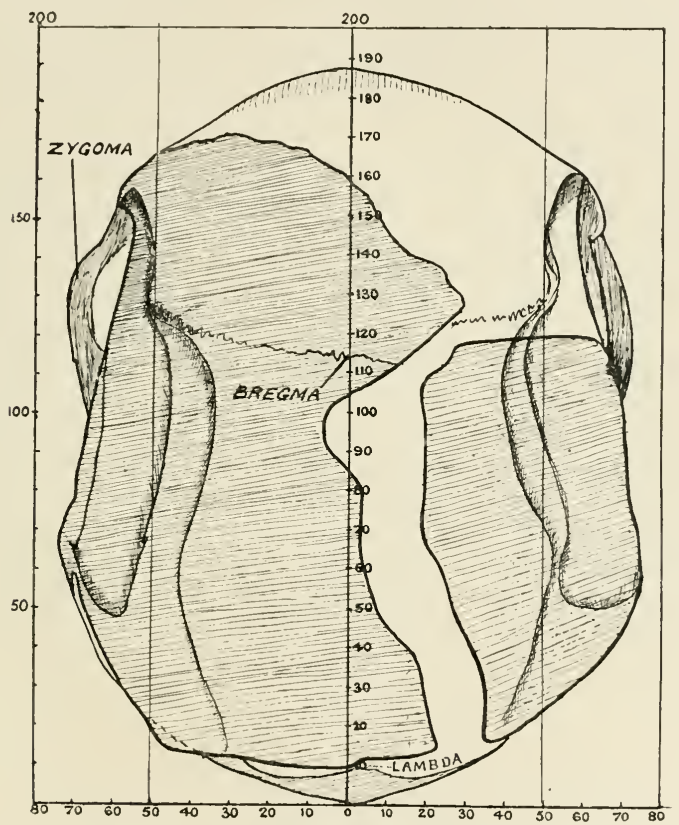

FiG. I 16.-View of the skull of Eoanthropus from above. The parts shaded are those which were actually found (half natural size).

being smaller and not quite of the same form as on the left side.

When he had fitted the fragments of the skull into their approximate position, Dr Smith Woodward was able to obtain a cast of the cavity which held the brain. So closely does that organ fill its space that such a cast 
reveals not only the size and form of the brain, but also many of the finer markings which give the anatomist a clue to the actual anatomy of the brain. The brain cast was entrusted to Professor Elliot Smith for examination. No one is so well qualified as he to interpret the significance of its features. His verdict, pronounced after his first preliminary examination, was that, "taking all its features into consideration, we must regard this as being the most primitive and most simian human brain so far recorded.'

When we sum up all the characters which Dr Smith Woodward has portrayed in this new form of being-the anthropoid characters of the mouth, teeth, and face, the massive and ill-filled skull, the simian characters of the brain and its primitive and pre-human general appearance-one feels convinced that he was absolutely justified in creating a new genus of the family Hominidæ for its reception. This new genus he named Eoanthropus. Ever since Darwin impressed the truth of his theory of man's origin on his fellow-scientists we have expected to encounter man's progenitors, but no one, so far as I know, ever anticipated the discovery of one showing the remarkable mixture of simian and human characterssuch a one as $\mathrm{Mr}$ Dawson brought to light at Piltdown. 


\section{CHAPTER XXI}

THE DIFFICULTIES OF RECONSTRUCTION

In this chapter I propose to lead the reader into the rather intricate problem of skull reconstruction. So far as concerns the Piltdown fragments, I became involved in the puzzle of fitting them rightly together in the most casual manner. Indeed, from a reference to the published proceedings of the famous meeting on December I 8 th, at which the discovery was announced, it is clear that I was then of opinion that any problem of reconstruction had been fully solved by Dr Smith Woodward. When the privilege of taking part in the discussion was extended to me, I gave it as my opinion that "the reconstruction of the skull had been executed with great skill "—only making the reservation that " in the reconstruction of the chin region of the mandible and the form of the incisor, canine, and premolar teeth, the characters of the chimpanzee had been too closely followed."

That opinion was based on a cursory examination of Dr Smith Woodward's reconstruction of the skull at the commencement of the meeting. In May of the following year (I9I3), anatomists were supplied with exact replicas in plaster of the various fragments, and also a copy of the original reconstruction-all of them the work of that excellent modeller, Mr F. O. Barlow. One day, soon after the arrival of the models at the museum of the Royal College of Surgeons, I sat down and depicted on the skull of an Australian native-one with a brain capacity of 1450 c.c. - the exact areas of the Piltdown 
fragments, in order that visitors to the museum might have a ready means of ascertaining the actual parts of the skull which had been recovered. It will be remembered (see fig. Ioo, p. 3I7) that the greater part of the left parietal bone-which forms so large and important a part of the brain chamber-was recovered; I was surprised to find that the superficial area of the Piltdown parietal bone was only slightly smaller than that of the Australian native, the exact figures being $12 \mathrm{I} \cdot 7 \mathrm{~cm} .^{2}$ for Piltdown, 132.9 for the Australian. This surprise was increased when I came to compare the areas of that part of the temporal bone-the squama or plate-which reaches up on the side of the skull and actually overlaps the lower bevelled ridge of the parietal (see fig. I I 2). It is true that part of the squamous plate was broken, but its original size can be estimated with some degree of exactitude. The Piltdown squama was larger than that of the Australian native; the area of the first named was 24.7 $\mathrm{cm}^{2}$, of the second, $2 \mathrm{I}_{4} 4 \mathrm{~cm}^{2}$ Now, students of the human body have been in the habit of regarding a large temporal squama as indicating a large brain. It is true that a mere increase in thickness of the skull leads to an increase in the area of the squama, but even allowing for the thickness of the Piltdown skull, the plate was remarkably extensive for a brain of 1070 c.c. The size of the parietal bone and temporal squama indicated a capacity nearly equal to that of the Australian native. To find an explanation of these discrepancies-or peculiar characteristics, they may prove to be-of the Piltdown race, I turned to Dr Smith Woodward's reconstruction to see if there was any apparent error in the manner in which the fragments had been fitted together. It was then I noticed a very marked degree of asymmetry in its formation; the right side was not only smaller than the left, but there was also a marked degree of flattening on its hinder part.

We have always supposed that the skulls of primitive races were remarkably symmetrical ; in the lower forms of man, as in anthropoid apes, the right and left halves 
of the brain and of the skull are fairly exact copies of each other. Symmetry is a primitive mark; it is the most highly evolved - the most specialised-forms of human brains and heads which manifest asymmetrical conditions. A deformity of one or both sides of the head may be due to disease in life, or to earth-pressure after death, but no suggestion has ever been made that the asymmetry of the Piltdown skull was due to either of these causes. It was due, then, to either a high specialisation of the brain or to an error in reconstruction. In either case it was important to discover an explanation of those peculiar features which I have just mentioned, for when we come to finally assign any being to its scale in humanity, it is not the mandible, the face, the teeth, or limbs which guide us, but the master organ of the human body-the brain. We cannot tell the shape and size of the brain until the various skull bones which form the brain case are rightly fitted in position.

In fitting the parts of the skull together, we must begin at the hinder or occipital end of the head in this particular case, because the only fragment which reveals the middle line of the skull, and at the same time gives us a true indication of the width of the Piltdown head, belongs to the hinder aspect of the skull and forms part of the occipital bone. The aspect of the Piltdown head which we are to try and build up is exactly that seen in the person who sits in front of us in church or theatre. If the hair and soft covering parts were to become transparent we should see that the central part of the hinder wall of the skull is formed by the occipital bone (fig. II7). The lower or nuchal part of the bone is implanted in the neck, and gives attachment to those muscles which move the head. The nuchal part is shaded in fig. II 7 , so that it may be the more easily recognised. On either side of the occipital bone are placed the right and left temporal bones. In fact, the mastoid parts of the temporal form lateral extensions of the area for the attachment of the neck. The mastoid processes are in reality levers by which the muscles of the 
neck may balance and turn the head. A large part of the occipital-the supra-nuchal part-extends above the neck, under the scalp, until it reaches the two great bones which form the roof and sides of the skull, the right and left parietal bones. The suture or joint-line at which the parietal and occipital bones meet is known as the lambdoidal suture (fig. I I 7). On each side of the

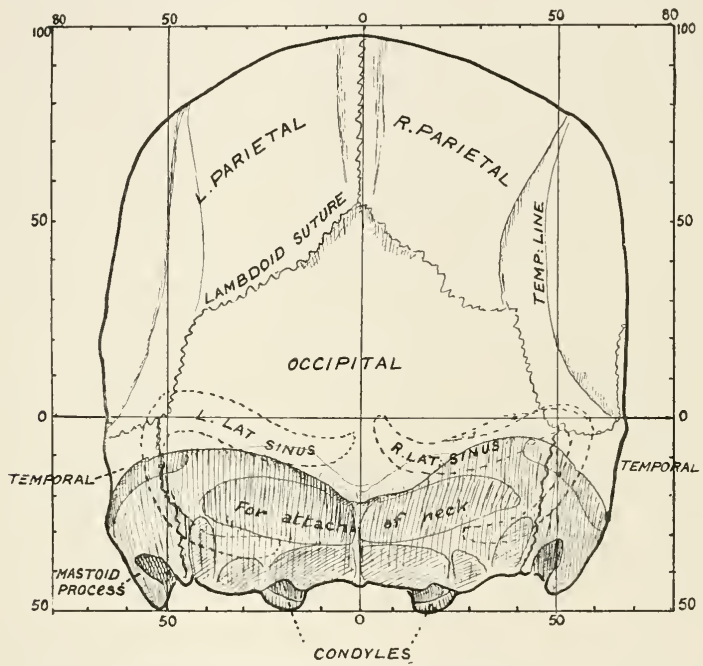

FIG. 117.- Showing the bones which form the hinder or occipital part of a modern skull (capacity I 425 c.c.).

hinder aspect of the skull this suture is clearly seen to be made up of two parts-an upper oblique and a lower, almost vertical.

Those are the parts which enter into the formation of the hinder part of the skull; before the Piltdown fragments can be rightly replaced one must bear such a picture in mind. It is also necessary to point out that the occipital bone is made up of right and left halves. In the nuchal region the ridge or elevation 
which indicates the middle line-the junction of the right and left halves-is very apparent; it lies between the attachment of the muscles of the right and left sides of the neck, the sides of the neck being always of nearly equal size. The right and left halves of the occipital, which lie above the neck, always show, in modern skulls, a certain degree of dissimilarity or asymmetry. As a rule, the larger the brain and skull the greater the degree of asymmetry.

To bring out this feature of the occipital bone, I have been in the habit of representing the hinder view of the skull within such a framework of lines as is shown in fig. I I 7. It is within such a framework that we must build up and form our knowledge of this newly discovered extinct form of man. There are three vertical lines-the mid-line, and the right and left lateral lines drawn parallel to the mid-line at a distance of 2 inches (50 mm.) from it. The two lateral lines which form the sides of the frame are $80 \mathrm{~mm}$. from the mid-line. A skull wide enough to fill the space between these extreme lines would have a width of $180 \mathrm{~mm}$. (7 inches), that being a very wide skull. Another line is important - the horizontal or zero line, which crosses the hinder and lower angles of the right and left parietal bones. Above that line lies the chamber for the cerebrum-the active organ of mind; below it the chamber for the cerebellum. Along or just below this line, on the inner aspect of the occipital bone and in the marginal space between the cerebrum above and cerebellum below, lie the great lateral blood-sinuses (fig. I I7). The right sinus is usually a continuation of another great bloodsinus which passes along the roof of the skull, under the mid-line. Of the other two horizontal lines which bound the framework for the skull, one is placed $50 \mathrm{~mm}$. (2 inches) below the chief or zero line, the other Ioo $\mathrm{mm}$. above it. A skull which reaches both the upper and the lower horizontal lines would have a height of $150 \mathrm{~mm}$. ( 6 inches) - that is, a skull of rather more than average height for Englishmen (fig. I I 7). 
When the outline of the occipital aspect of a modern skull is set in such a frame, it will be found that the left half of the occipital bone extends further outwards than the right half. In fig. I I 7 this normal asymmetry is exemplified. The vertical part of the left lambdoidal suture passes out beyond the left lateral line; on the right side it falls short of that line. The left half of the occipital bone is the larger, because the corresponding part of the brain is the larger. The left hemisphere of the brain controls the right half of the body; hence it is believed that the preponderance of the left occipital pole of the brain is connected with right-handedness. ${ }^{1}$ The occipital asymmetry is due to a specialisation of the two halves or hemispheres of the brain. There is the most indubitable evidence that the left occipital region of the Piltdown brain was larger than the right; the impress of the cerebral lobes on the inner aspect of the occipital fragment leaves no doubt on this matter.

The reader may naturally resent the introduction of so many technical details. I can only plead that the method employed is of the utmost importance; it must be exact and logical if we are to obtain abiding results. It is into such a framework as has just been sketched that the Piltdown fragments must be fitted; at every turn we shall be checked by our guiding lines. One other matter, however, must be mentioned. It is clear that the hinder aspect of the skull will alter as we raise or lower the front end of the skull. It is therefore necessary to fix a chief or zero horizontal line at the front part of the skull to correspond with that which crosses the hinder lower angles of the right and left parietal bones. ${ }^{2}$ The hinder horizontal line, it will be remembered, represents the lower limit of the cerebrum; in the frontal region a similar line must be chosen-one to indicate the lower limits of the frontal lobe of the cerebrum. If the anterior part of the base of the skull is preserved, this is an easy matter, but in

1 See Professor Elliot Smith, Anat. Anz., 1907, vol. xxx. p. 574.

2 See A. Keith, Journ. of Anat. and Physiol., I9Io, vol. xliv. p. 25 I. 
the majority of fossil skulls the anterior part of the base is rarely preserved. As a rule, however, the lowest point of the eyebrow ridge-to be more exact, the junction of this ridge with the malar or cheek bone-is sufficiently near the plane we want to serve to mark the level of the lowest part of the frontal lobe, so far as human skulls are concerned. Having thus sketched the method to be employed, we are in a position to undertake the reconstruction of the Piltdown skull.

When we place Dr Smith Woodward's reconstruction of the Piltdown skull within the framework just described, we are at once in a position to see how far this very ancient type of man agrees or differs in head form from modern man. In fig. I 8 the parts of the skull actually recovered are shaded; the missing parts are left as blanks. The whole occipital bone was not found; only the middle part of the lower or nuchal part, with the ridge which marks the middle line of the neck and skull, and a considerable part of the upper or supra-nuchal part. A fragment (marked $\mathrm{O}^{\prime}$ in fig. I i 8, A) carries the supra-nuchal part of the occipital on the right as far as the lambdoidal suture, where it comes almost in contact with the right parietal. We have, in this fragment, a sure indication, not only of the width of the upper part of the occipital bone, but also of the position and direction of the lambdoidal suture. The right lambdoidal suture, it will be observed (fig. I I 8, A), crosses the right lateral $(50-\mathrm{mm}$.) line very obliquely; it is not vertical, as we should expect from a comparison with a modern skull (fig. I I 7). A remnant of the left half of the lambdoidal suture is preserved on the hinder margin of the left parietal bone (fig. I i 8). It ought to be, as far as direction is concerned, symmetrical with the corresponding part of the right, and also, in accordance with the law already stated, should be situated further from the mid-line. Exactly the reverse is the condition shown in Dr Smith Woodward's reconstruction, the parts $a, b$ and $a^{\prime}, b^{\prime}$ (fig. I I 8) certainly correspond, but the one is lying obliquely and crossing the $50-\mathrm{mm}$. line, the other (the 
left) is nearly vertical, and inside in place of being outside that line. Further, the right half of the skull is considerably larger than the left. There is no possibility of making the right and left halves of the occipital bone even approximately symmetrical on these reconstructional lines. It may be thought that a marked degree of asymmetry was an inherent character of this ancient man, but before we accept such a conclusion it is necessary to remember that the more primitive the type of man, the greater the degree of symmetry in the right and left parts. We have also to keep in mind that the extreme degree of asymmetry may be due to malposition of parts.
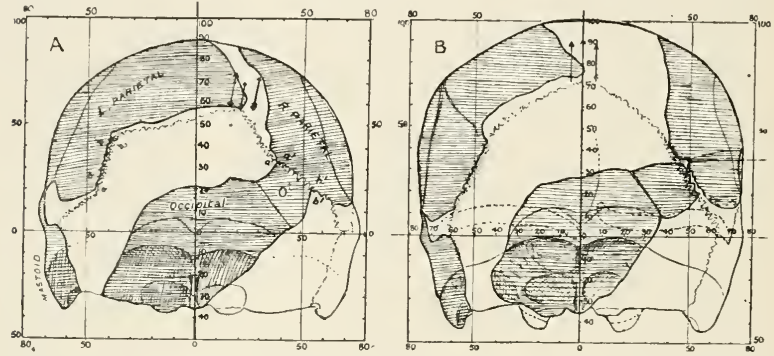

FIG. I18.-A. Drawing of the occipital aspect of the Piltdown skull as reconstructed by Dr Smith Woodward. B. From a reconstruction by the Author. The point of perforation by the pickaxe is indicated.

On looking round for an explanation of the peculiar arrangement given by Dr Smith Woodward to the Piltdown fragments, I observed that he had placed the middle line of the roof along the fragment marked "left parietal " in fig. I I 8 , A. If such were the true middle line, then there ought to be some evidence of the suture between the right and left parietal bones, which meet along the mid-line. But of this suture there is not a trace. On fig. I I $8, \mathrm{~A}$, I have placed three arrows, the middle one crossing the hinder angle of the left parietal bone. An examination of the original fragment leaves me in no doubt that the middle line lies at the point marked by the middle arrow, but, as will be seen sub- 
sequently, Professor Elliot Smith has formed a different opinion. Leaving the full proof that my identification of the middle line is correct to another chapter, let us try, as in fig. I $\mathrm{I} 8, \mathrm{~B}$, the effect of placing the fragments so that the middle arrow falls into a median position. The extreme asymmetry of the lambdoidal suture disappears. That is a presumptive proof that the parts have been placed in their right position. It is only when the point chosen in fig. I $18, \mathrm{~B}$, is placed in the middle line that an approximate symmetry is obtained.

When the upper angle of the parietal is replaced in its proper position the change in the skull is revolutionary. The height of the brain chamber is increased by nearly half an inch. The width and fullness of the top parts are enlarged. The brain capacity is augmented; the shape of the brain itself is changed. The anomalous conformation of the occipital bone, the extreme asymmetry of the lambdoidal suture, almost disappear, and all the points we are familiar with in human skulls-no one has ever denied the humanity of the fragments-leap to the eye. The right and left halves of the lambdoidal suture become not only symmetrical, but the left half, as should be the case because of the preponderance of the left hemisphere of the Piltdown brain, oversteps the $50-\mathrm{mm}$. line to a greater degree than it does on the right side. We have here the most ample confirmation that the lines on which we are proceeding must be right, for by taking them as our guides most of the anomalies of the original reconstruction disappear.

There were two points in this preliminary part of my investigation which gave me a great deal of trouble. One relates to the two parietal bones. Both bones are rather mutilated-particularly the right. We have to determine what parts are missing from each bone. It will be seen that this question must be answered before we can proceed to the final adjustment of the two parietal bones on the sides of the head; the corresponding points must occupy the same positions on the right and left sides. The answer to this problem is given in fig. I I 9, 


\section{6

where the right and left bones are superimposed. On each side the lower border is preserved-the margin of which is bevelled for articulation with the plate or squama of the temporal bone. The most remarkable fact is that almost the same amount is missing from the hinder and lower border of each side. Fortunately, we can tell exactly how much is missing on the left side, because we possess the temporal bone of that side. When the

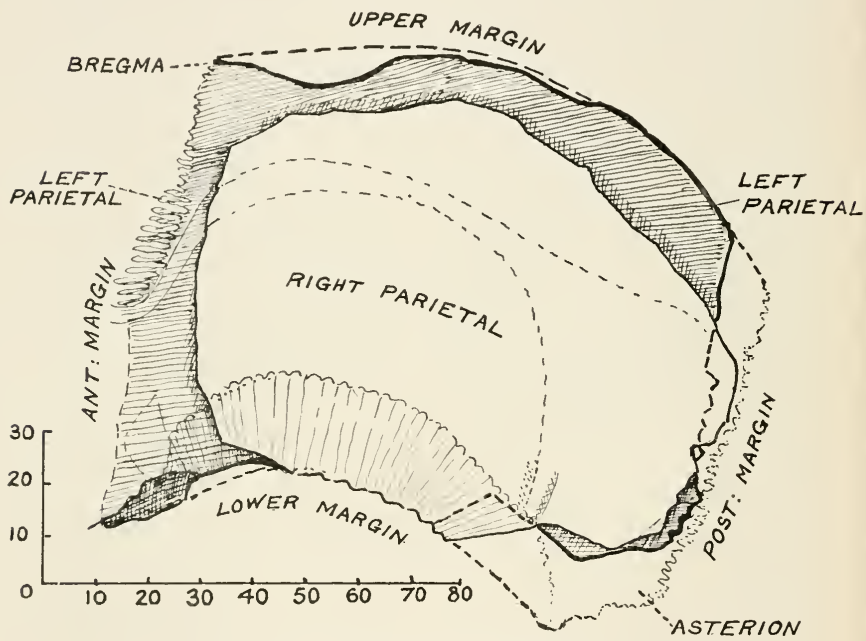

FIG. I I9. - The right and left parietal bones superimposed to show how much of each is missing.

temporal is articulated with the lower border of the left parietal we see at once how much is missing at the hinder angle. When the left parietal was intact (see fig. IOO, p. 3 I 7) its hinder angle came into contact with the adjacent parts of the temporal. Along the hinder margins of the two parietals remnants of the sutural lines are preserved. On both sides a trace of the middle part of the lambdoid suture can be detected-the preserved part on the right side rising upwards and projecting 
rather further back than on the left side. On both sides the lower part of the lambdoid margin is missing for an extent of $12 \mathrm{~mm}$. (about half an inch). On the left side, although the parietal reaches up to the middle line, a long marginal fragment, at least $10 \mathrm{~mm}$. wide, has been broken away from the hinder border. On the right side the upper or roofing part of the parietal is altogether absent, the missing part at the hinder end being about $55 \mathrm{~mm}$. in width. Having ascertained those facts, we are now in a position to adjust the hinder margins of the parietal bones on the right and left sides of the head. It is apparent that they must be adjusted so that the lower border of each bone is on the same level, and occupy the same relative position on each side. The distance of the hinder border of each parietal bone from the mid-line is indicated by the width of the occipital bone, which has been already determined.

Having thus settled the corresponding points in the right and left parietal bones, I now turn to the second point-small and seemingly unimportant, but one which gave me much trouble at first. It relates to the little fragment of the occipital which Dr Smith Woodward found (fig. I I $8, \mathrm{O}^{\prime}$ ). Our conception of the head and brain-form of this ancient human type turns on being certain that this fragment is rightly placed. A close inspection of the original occipital bone in $\mathrm{Dr}$ Smith Woodward's keeping raises the suspicion that the fragment has not been rightly adjusted. When one scrutinises the fine vascular grooves and markings on the inner aspect of the fragment, and traces them to the crack where the union has been made to the main piece, the fine vascular grooves and markings cease and are not caught up and continued beyond the join, which they should be if the fit were a true and accurate one. My suspicion that the union was not quite right arose, however, from two other observations. On the hinder margin of the right parietal is still to be seen a triangular notch (fig. IO2), marking the point where evidently the workman's pick pierced the skull. On the adjacent 
marking of the occipital fragment there is also a graze of the pick. That this graze is the opposite side of the same unfortunate blow there can be no doubt, for when the occipital fragment is brought opposite to the margin of the parietal, so as to complete the perforation made by the pick, it is clear from the agreement in thickness and in texture of the parts brought into contact that we have found a true relationship. Indeed we can surmise the disaster wrought by the workman's unfortunate blow. The skull was evidently embedded in the gravel so as to expose its right hinder aspect to the blow.

By the same blow the hinder part of the right parietal was broken into two fragments-the splintering line starting from the point at which the pick perforated (fig. I I 8, B). I found, further, that when the occipital and parietal bones were articulated as in the original model that the lower border of the right parietal always became half an inch too high. Detaching the occipital fragment, and giving it what was apparently its true articulation with the adjacent margin of the parietal, I found that all the parts, previously out of place, slid into position. As I had suspected, there is a fragment missing at Dr Smith Woodward's line of junction, the true relationship of the fragment being that given in fig. IO2. The failure to recognise the true position of the occipital fragment has given rise to some of the difficulties of those who have tried to discover the true nature of the Piltdown skull.

I have probably wearied my readers with the details concerning the reconstruction of the hinder aspect of the Piltdown head. It is not the skull itself which is the aim of our search; it is rather the brain which lay within it - the organ with which this early representative of mankind measured and registered the world in which he lived. To know the brain we must rightly reconstruct the brain case. We are already in a position to form a rough estimate of its size. When the reconstruction in fig. IO2 is compared with that of a modern man (fig. I I 7) it is seen that the head of the ancient man is the more 
massive. In the modern sample, represented in fig. I I 7, the greatest width of the skull is $13+\mathrm{mm}$.; in the Piltdown skull this measurement is a little under I $50 \mathrm{~mm}$.; in Dr Smith Woodward's reconstruction the greatest width is also I $50 \mathrm{~mm}$. If we deduct $10 \mathrm{~mm}$. from this amount on account of the great thickness of the bony walls, the width measurement of the Piltdown skull is still $\mathrm{I} 40 \mathrm{~mm}$. $-6 \mathrm{~mm}$. more than in the modern skull represented in fig. I I 7. As regards height of the cerebral chamberthe height of the roof of the skull above the horizontal or subcerebral plane - there is not much difference between the ancient and modern example, if we allow for the greater thickness of the Piltdown skull. The roof of the skull in our example of modern man falls short of the Ioo-mm. line; the roof of the Piltdown should just reach that line. If the length of the skulls were approximately equal, it is clear that the ancient brain should be the larger. The Piltdown brain was, as regards bulk, about the average for modern races.

The reader may very properly offer the criticism that the conclusion as regards the width and size of the Piltdown skull turns on that small fragment of the occipital bone. He may well ask for confirmatory evidence. Substantiation of the conclusions reached can be obtained by a totally different method-one which carries us right into the principles of skull reconstruction. If a cut is made across a skull so as to expose its walls in a vertical cross-section as in fig. 120 , the composition of the bony wall enclosing the brain is seen to be simple. The base of the skull at this point is made up of three bony elements - a bar of bone in the middle, a pyramid of bone, the petrous part of the temporal, on each side of it. The lateral walls and roof are formed by two enclosing bones-the squama of the temporal and the parietal bone on either side. Now, as may be seen from fig. I 20, the brain cavity of anthropoid apes and of men is enclosed by corresponding bones, but in the ape the parietal bones and the plate of the temporal are small in size. As regards the size of the bones in the base of 
the skull, man and ape are very much alike. In the ape the basilar process, and especially the petrous bones, are large. The petrous bones, which contain the organ of hearing, are of great size in the anthropoid ape, because they have also to afford a joint for massive jaws and attachment for the huge muscles of the neck.

Two important points should be noted in the human skull. The brain has so increased in mass that the petrous pyramids of the temporal bones have been forced into a horizontal position. The opening of the

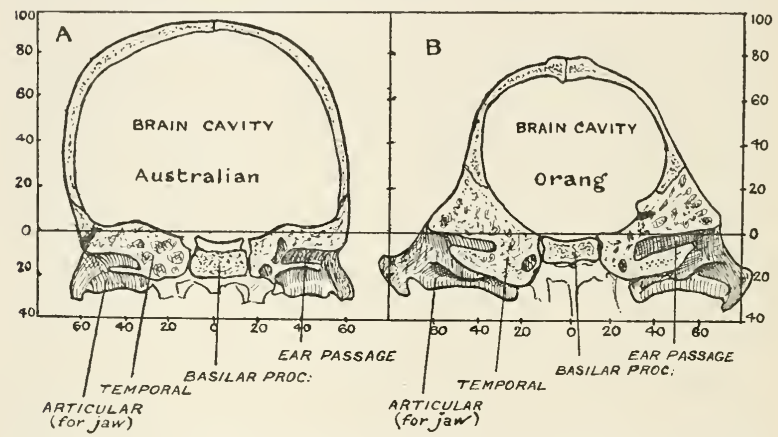

FIG. 120.-A. Transverse vertical section of the skull of an Australian aboriginal, to show the bones forming the base, side, and roof of the brain cavity. B. Of an orang, to show the bones forming the base, sides, and roof of the brain cavity.

ear-passage lies below the level of the brain in the human skull. In the anthropoid the petrous bone is set obliquely; the ear-hole is situated at a higher level as regards the brain cavity. The other point which is important for our present purpose is that the petrous bone reaches within a definite distance of the middle line of the base of the skull; it affords us a means of estimating the width of a skull. Now we have the left temporal bone of the Piltdown skull-almost the whole of the petrous portion and a great part of the side plate or squama.

In fig. I 2 I the composition of the Piltdown skull in 
transverse section is shown. I have supposed that the basilar process is of rather more than average width$26 \mathrm{~mm}$. In such a skull, with great massive bones, this bar was probably considerably above the dimensions seen in modern skulls. From the dimensions of the petrous part of the temporal bone we infer that the width of the Piltdown skull was at least equal to that of either of the two skulls shown for comparison in fig. I 2 I -about I $50 \mathrm{~mm}$. We have thus an assurance that the indications given us by the occipital bone concerning the width and size of the Piltdown skull are well founded. The
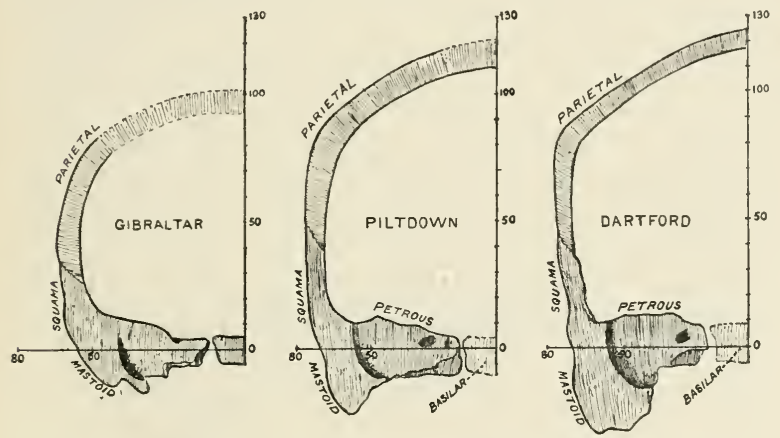

FIG. 121.-Reconstruction of the left half of the Piltdown skull compared with a similar section of the Gibraltar and of the Dartford skull.

massiveness of the petrous bone, and its degree of obliquity as regards the transverse axis of the base of the skull, are primitive or simian marks (fig. I20); yet in this respect the Piltdown skull is less simian than the Gibraltar skull (fig. I 21).

A study of the occipital aspect of the Piltdown skull brings before us another feature in which it resembles those of the modern type. When viewed from behind, the heads of men of the modern type give the impression of being compressed from side to side (fig. 1 17). In that extinct species of man-Homo neanderthalensis-the head was compressed in an exactly opposite direction, 
from above downwards. All known members of the race have their heads shaped thus. In fig. 122 is given an occipital view of the Gibraltar skull-the smallest of all the Neanderthal skulls yet discovered, the size of the brain cast being approximately i 50 c.c. Whereas the Piltdown skull almost fills the square in which it is placed (fig. I02), the Gibraltar skull falls far short as regards height. In its width the Gibraltar skull is only

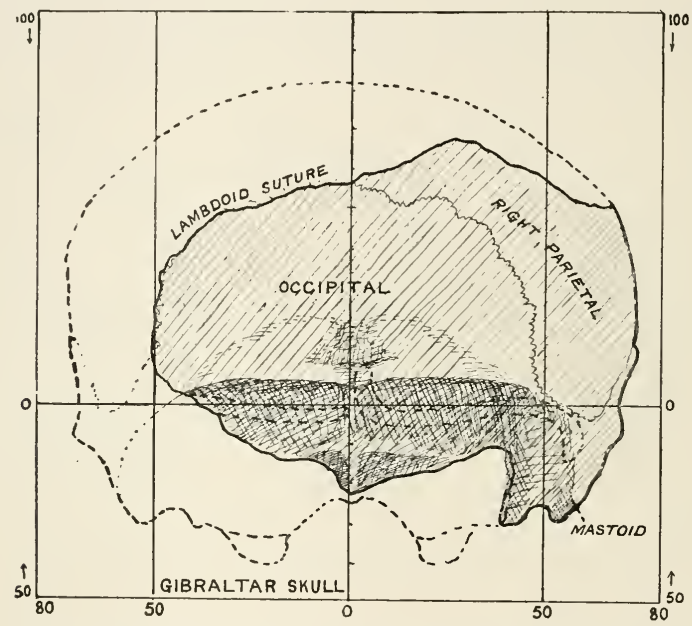

FIG. 122.-Occipital aspect of the Gibraltar skull, to show the manner in which Neanderthal skulls appear to be compressed from above downwards.

5 or $6 \mathrm{~mm}$. less than the Piltdown, but as regards height it is $18 \mathrm{~mm}$. less. In this feature of the skull-. platycephaly it is called-the Neanderthal species resembled anthropoid apes. Two drawings of the occipital aspect of a young gorilla and of a juvenile chimpanzee will serve to illustrate this point (fig. I 23). The skull of the chimpanzee is more platycephalic than that of the gorilla. In shape of head the Piltdown race resembled modern races of mankind. 
The drawings of the occipital aspect of anthropoid skulls bring out certain other instructive characters. In the gorilla and chimpanzee the lambdoid suture-the line of junction between the occipital and parietal bones - is almost symmetrical as regards the two sides. In the Gibraltar skull we see the same kind of asymmetry in this suture as in modern races, and as in the Piltdown skull-an asymmetry due to the greater extent of the left half of the occipital bone. At the present time we attribute that preponderance to the larger size of the left occipital lobe of the brain, and indirectly to righthandedness. At the beginning of the Pleistocene period - probably much earlier-specialisation already had appeared as a distinguishing feature of the human brain.

Piltdown man had not only the flat-sided head-form of modern man, but he also held and balanced his head much as we carry ours. This we believe was not the primitive method. Adult anthropoids are bull-neckedthe head is deeply implanted in their strong, thick necks. In modern man, as in Piltdown man, the head is balanced on the neck; there is a sharp demarcation at the junction of the neck with the head. In newly born anthropoids the neck is slender and the head relatively large. As the ape passes into childhood the neck grows in thickness, while the head-as regards size of brain-remains almost stationary. As the neck grows, it encloses and spreads over the occipital region. In fig. 123, A, B, the area of neck-attachment is demarcated by shading. In the young gorilla the attachment has extended upwards until it has reached a little above the level of the lateral blood-sinuses. In the chimpanzee, an older animal, the neck has extended upwards nearly an inch above the sinuses. In the Gibraltar skull, as in all Neanderthal skulls, the condition is that seen in the young gorilla (see figs. I 22 and 123), but in the Piltdown skull, and in nearly all modern skulls, the attachment of the neck never reaches even the level of the lateral sinuses (see figs. I02 and II7). In this respect the Piltdown race 
corresponds with modern races and differs from the Neanderthal species and anthropoids.

One other remarkable feature is seen in the Piltdown skull, in connection with the fixation of the head to the neck. In the young chimpanzee the mastoid area of the temporal bone on each side is growing outwards into a thick, wing-like process to give an increased area for attachment of certain of the neck muscles (fig. I 23, B). In the Gibraltar skull the same area forms merely a flattened knob-a condition which may be described as partially simian (fig. I22). In the Piltdown skull we see, as in modern races, a pyramidal mastoid process projecting

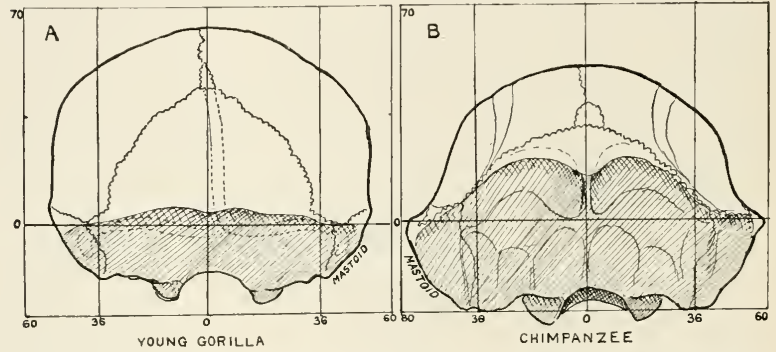

FIG. 123.-A. Hinder aspect of the skull of a young gorilla about three years old. B. The same aspect of the skull of a female chimpanzee about twelve years old.

downwards behind the ear. It is a special adaptation to the balancing of the head on the neck. I have always regarded the wide attachment of the neck to the skull as a provision for enabling an animal to exert its bodily strength through its head and jaws. A full consideration of the lightly balanced head of the Piltdown man, with great jaws and apparently projecting canines, on the one hand, and Neanderthal man, with his closely set head, strong jaws not furnished with fighting canines, renders this view no longer tenable. There seems to be no necessary correlation between projecting canines and firm fixation of the head.

In this chapter I may seem to have entered into too 


\section{DIFFICULTIES OF RECONSTRUCTION 355}

many technical and uninteresting details. My justification is that we are dealing with the only document in our possession which throws light on human conditions at a long past period of the earth's history-to a period which we have been in the habit of supposing as antecedent to the appearance of real man. We have therefore to scan that document with all the precision and critical acumen at our disposal if we are to lay our knowledge of early man on a sound basis. So far as we have gone, we see that, beyond any cavil, we are dealing with a human being with a head above average dimensions, and a brain very little, if any, below the amount allotted to the average European of to-day. Except for the thickness of his skull bones, the head was shaped and balanced as in us. Not only so, we see that asymmetry, which we believe to indicate a specialisation of the right hand, was already present. Further, we realise that, as regards shape of head, this early Pleistocene or Pliocene form of man was more like ourselves than was the Neanderthal type of man who survived to mid-Pleistocene times. 


\section{CHAPTER XXII}

\section{AN EXPERIMENT IN RECONSTRUCTION}

IF I were free to choose I would not inflict the reader with further dry and technical details concerning the Piltdown skull. The sharp controversy, however, which has sprung up amongst British anatomists makes a plain and simple narrative impossible; we must take nothing for granted; every point has to be proved. Under ordinary circumstances it ought to be a simple task for an anatomist to restore such a skull as that which has been hidden away these hundreds of thousand years in the Piltdown gravel ; why, then, is there so much difficulty? There are two reasons. In the first place, the simian characters of the mandible indicate that the skull should be a small onefor the simian skull and brain cavity are small when contrasted with the human cranium. The law of correlation of the various parts of the animal body does not always hold true; the discoveries of recent years have shown that Nature in her time has built up animal forms in which characters culled from diverse animal types have been combined.

But there is another reason why we naturally suppose the brain of the Piltdown race to be a small one. We still live in the shadow of the times when man's first appearance was regarded as one of the most recent events in the earth's history. I am not speaking of pre-Darwinian days, but of some thirty years ago, when the theory of evolution was making headway, and when thinking people had accepted as a truth the origin of man from a more humble form. The contemporaries and successors of 


\section{AN EXPERIMENT IN RECONSTRUCTION 357}

Darwin believed, and rightly believed, that they had made a great advance when they proved that men-such as you and $\mathrm{I}$ are-lived with animals now extinct, animals like the mammoth, the woolly rhinoceros, and the cave-bear. The anatomists and geologists of thirty years ago were very careful, almost penurious, when they drew a draft on the bank of Time; they believed that their credit was strictly limited when they dealt at that bank. They were convinced that men of the modern type may have appeared towards the end of the Pleistocene period-some fifteen thousand years ago or more-when those extinct forms of mammals were living. They expected to discover, as they searched further into the past and reached the beginning of the Pleistocene and end of the Pliocene, a series of intermediate forms which would carry us rapidly towards a simian stage. Until a year or two ago, many of our leading authorities believed that Pithecanthropus - a humanoid form, with a brain capacity of 850 c.c., little more than half that of modern man-represented our stage of evolution at the beginning of the Pleistocene period. The same men looked on Neanderthal species as representative of Pleistocene man, while modern races appeared just before the dawn of the recent period.

These two circumstances-a lower jaw with simian features and a belief in the recent evolution of the modern human brain-would naturally lead the discoverers of Eoanthropus to the conclusion that they had to deal with a primitive, small-brained form of man. During these last twenty years, however, another line of evidence has been slowly accumulating, which seems to point to a much earlier date as marking the period of man's evolution. Our estimate of the antiquity of the modern type of man must be sufficiently long to give time for the differentiation of that type into the most diverse forms-African, European, Mongolian. It is more than twenty years ago since Sir Joseph P'restwich became convinced that the Kentish "eoliths" were of human workmanship, and were of Pliocene-not even late Pliocene-date. Four years ago Mr Reid Moir discovered under the "Red 
Crag" of Suffolk-a Pliocene deposit-flints which are admitted by most experts to be shaped by man's hand. In England and in Italy, as we have already seen, remains of men of the modern type have been found in natural deposits and strata which are of a mid-Pleistocene age.

All those discoveries of the modern type of man are disputed. It is therefore important to determine the size and form of brain in an early Pleistocene, or late Pliocene, type of man-one whose authenticity is beyond question. It will be seen, therefore, as I labour to make clear the nature of the Piltdown skull, that it is not the correct rendering of the details of the head-form which is the real object I have in view; it is a much wider issue. We want to know what stage of brain development this particular type of man had reached so long ago. If the Piltdown man is a fair sample of his time, and if the opinions of Dr Smith Woodward and Professor Elliot Smith are well founded, then indeed we human beings have progressed rapidly to our present estate, and the great mask of civilisation which man has made a part of himself is in a geological sense merely a mushroom growth. If, on the other hand, we believe that in this early form of man we find a comparatively large, if somewhat simple, human brain, then our story is very different. Behind us must lie vast periods of human endeavour, reaching a much longer way into the geological past than most of us have hitherto suspected.

At this point I propose to give an account of a recent experiment, of which I was the willing subject, because it serves to bring out the difficulties of rightly interpreting and of reconstructing ancient skulls. The question is often asked: Are four fragments of a skull, such as those found at Piltdown, sufficient to give us a definite clue to the original form of skull? Apparently not ; at least it was clear that reconstructions by Dr Smith Woodward and by myself indicated men of a totally different type. To test the matter, Professor F. G. Parsons of St Thomas's Hospital Medical School, London, made a proposal to me, namely, that he and 


\section{AN EXPERIMENT IN RECONSTRUCTION 359}

some of his fellow-anatomists should select a skull, cut fragments from it corresponding to those found at Piltdown, and that I should attempt to reconstruct the entire skull from these fragments. I gladly accepted the proposal, and resolved, however the result should turn out, to make the experiment the subject of an address I had promised to the fellows of the Royal Anthropological Institute. ${ }^{1}$

On January i 6 th, I 914 , a fortnight before my lecture was due, the four pieces of a skull shown in fig. I 24

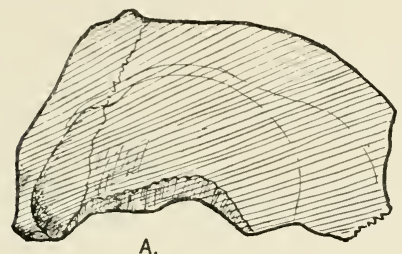

A.

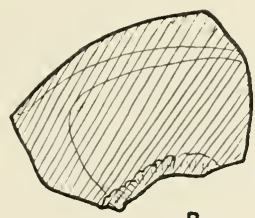

B.

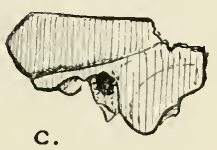

í 2030 so

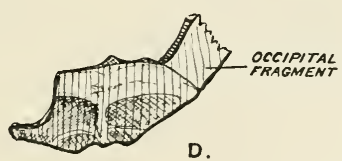

D.

FIG. 124.-Fragments of test skull. A, Left parietal fragment; B, right parietal fragment; C, left temporal; D, occipital fragment.

came to me from Dr Douglas Derry of University College, London. They were representatives of the Piltdown fragments, and the task of reconstruction offered the same difficulties. Only on one piece-the occipital fragment-could any certain sign of the middle line of the skull be detected.

In fig. I 25 is given the first step in the work of reconstruction. A drawing of the fragment of the right parietal bone is laid on a drawing of the left bone, so that corresponding points are superimposed. It is clear that

\footnotetext{
${ }^{1}$ See Journ. Roy. Anthrop. Inst., vol. xlix., July I9r 4.
} 
when we attempt to build up the right and left sides of the skull, the parietal fragments must be so placed that the corresponding points of the right and left parietal bones match each other on the two sides of the skull. Our procedure is based on the fact that the skulls of all animals are built on a symmetrical plan-the right and left halves being alike, except in minor details. By a reference to fig. I I 9 it will be seen that the designers of this experiment had succeeded in reproducing a close parallel of the Piltdown problem.

The next step in the solution of the problem is shown

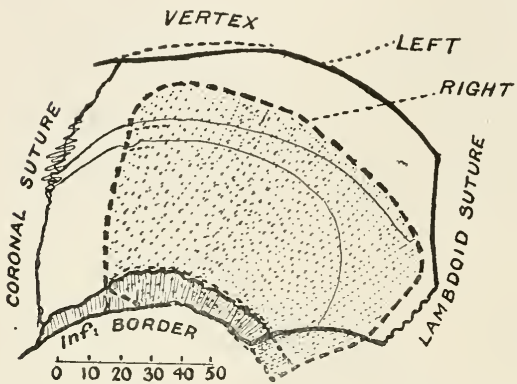
in fig. 126 . The left parietal fragment being the more complete is first built up, the missing parts being replaced by plasticine or modeller's wax. The left half of the skull is built up on a board, FIG. I25.- The right parietal fragment (stippled) of the marked with test skull, superimposed on the left parietal, to bring measured lines,
out the corresponding points of the two sides.

represented by those shown in fig. I26. The lines are really those which form the standard or conventional framework, employed in the illustrations of this book when skulls are viewed in profile. When the left half is completed, the right half is then undertaken, as shown in fig. I 26. The right half of the skull is built up on a similar framework of lines, the parietal fragment being placed so that it corresponds in all points with the parietal in the side already built up. If our reconstruction is right, then, when the right and left halves are brought together, to form the complete roof of a skull, all the corresponding points of the two sides should fall into corresponding positions. If the two sides are found to agree, we may 
presume that the points which were identified as marking the middle line of the skull along the roof, from forehead to occiput, were approximately right. If the two sides are still discrepant, it is clear that we are wrong in our identification of the middle line of the skull, and we have to make other identifications and begin again.

Having thus built up that part of the roof of the skull which is formed by the two parietal bones, the halves are again separated and the next step taken is that shown in
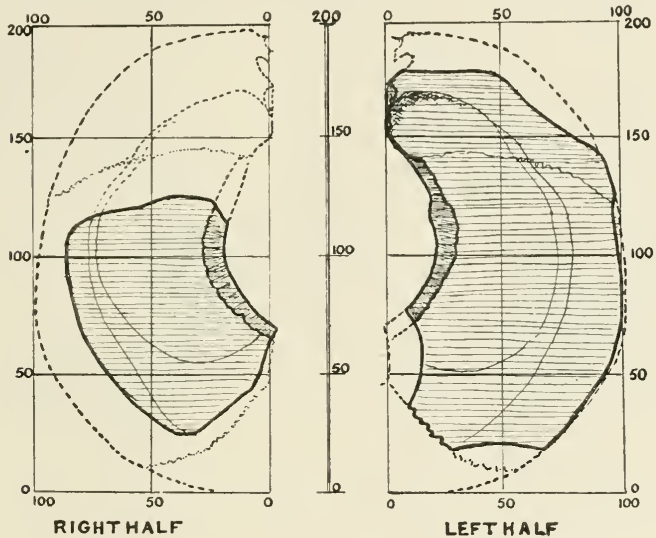

FIG. 126.-Showing the framework of lines on which the right and left halves of a skull are reconstructed from fragments.

fig. I 27. The left temporal bone is placed in position. There is not much difficulty in this part of our task. On the upper margin of the temporal there was preserved, exactly as in the fossil skull, a point at which the temporal and parietal bones made a true contact. Besides, even supposing such a point of contact were absent, we could not go far wrong, because there are so many markings on both the outer and inner aspects of the temporal and parietal bones to guide us to their correct apposition. When the temporal bone is applied we obtain the first real indication of what the original width of the skull 
must have been. The temporal bone sends its petrous portion (fig. 127) inwards on the base of the skull. The apex of this petrous process reaches within 10 or $15 \mathrm{~mm}$. of the middle line of the skull. In the majority of human and anthropoid skulls the distance of the apex from the mid-line is about $12 \mathrm{~mm}$. ; the allowance made in the reconstructions shown in fig. 127 is $13 \mathrm{~mm}$. The application of the temporal fragment at once shows if the former steps have been rightly made. If the parietal
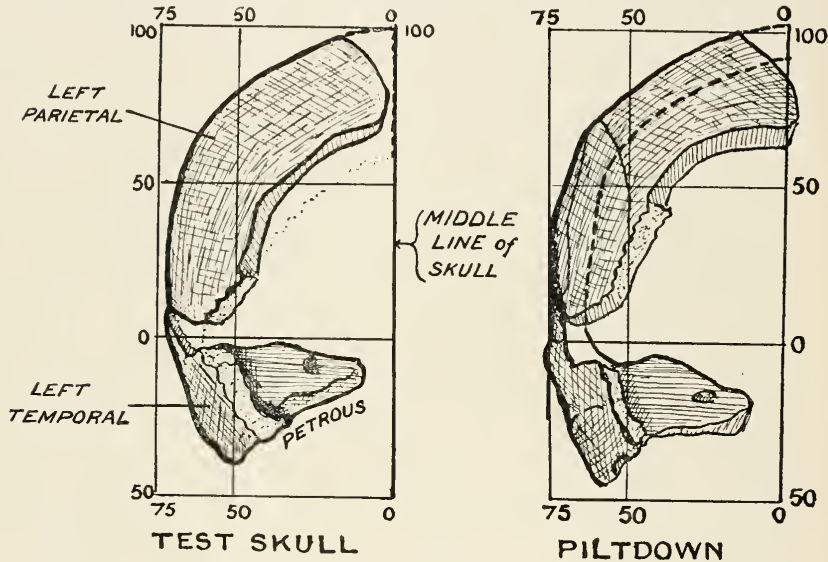

FIG. 127.- Showing the manner in which the left temporal bone is placed in position, and the left half of the skull built up (I) in the test skull, (2) in the Piltdown skull.

halves have been made too wide or too narrow, the apex of the petrous bone will be too far from, or too near to, the middle line along the base of the skull.

The identity of the problems presented by the test and Piltdown skulls is apparent in fig. I27. We note that in size and shape the fragments are not unlike. Certain minor points of difference are also to be recognised: (I) the parietal bones of the fossil skull are nearly twice as thick as those of the test skullthe first being 8 to I I $\mathrm{mm}$. thick, the latter from 4 to 6 


\section{AN EXPERIMENT IN RECONSTRUCTION 363}

mm.; (2) the Piltdown skull is actually the wider and the higher, but the extra width and height are due to the greater thickness of the bones. In the dimensions of the brain chamber they are nearly alike. A third point of difference must be noted. As in anthropoid skulls, the petrous part of the temporal bone descends as it approaches the middle line (see figs. 120 and 127), whereas in modern skulls this process is nearly horizontally placed so far as concerns its upper border. It is clear, however, that in shape of the bones and

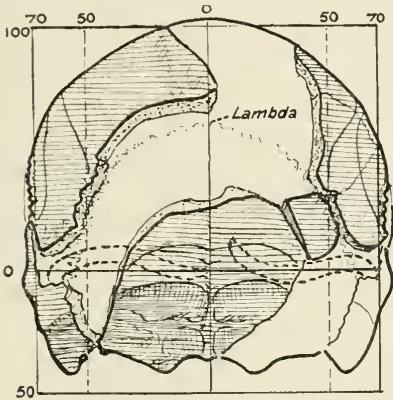

PILTDOWN RECONSTRUCTION

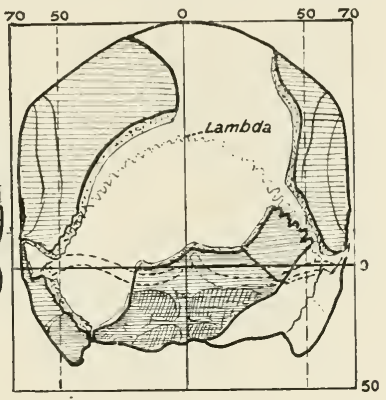

TEST RECONSTRUCTION

FIG. I28.-Reconstructions of the Piltdown and test skulls viewed from behind, to show the application and fit of the occipital fragments.

formation of the skull, Piltdown and modern man are framed on identical lines.

We now pass on to another stage of the reconstruction, illustrated by fig. I 28 . The first step consisted in shaping the right and left parietal regions; the second of completing the left half of the cranium by applying the temporal bone, and, as I ought to have added in the previous paragraph, to the right half also-the missing right temporal bone being replaced by modelling a duplicate of the left temporal bone. In the third stage, the right and left halves of the skull are brought into apposition, leaving a wide, gaping space in the hinder wall to be filled by the occipital fragment. In fig. 128 
the occipital fragment has been placed in position. If we have proceeded rightly in the two previous stages, then the occipital fragment ought to slip into place, without force or pressure, and take up a natural relationship with neighbouring parts of the skull. In the case of the test skull, an approximately correct result was obtained on the third attempt; in the case of the Piltdown skull, where the problem is more complex, an approach to symmetry and a correct adjustment of parts came only after many experimental reconstructions.

How near a true reconstruction of the original form

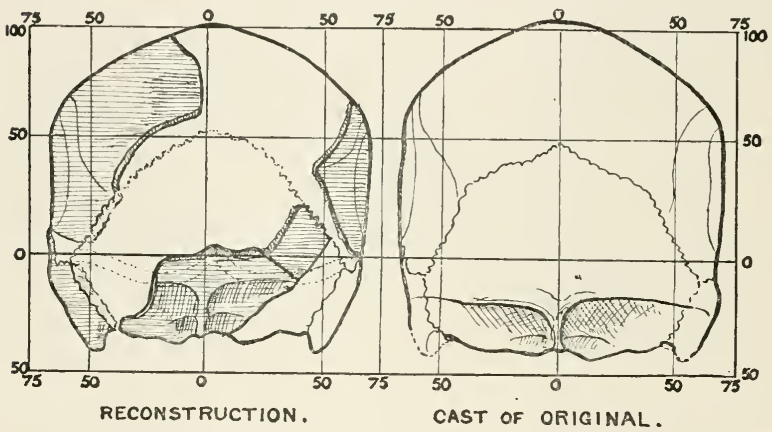

FIG. 129.-View of the reconstruction and of the original test skull.

can be obtained by the use of such a method is apparent in fig. I29. As regards the width and height, the reconstruction was in close agreement with the original skull from which the fragments given to me had been cut. The general form was rightly reproduced. There were certain minor errors which could have been eliminated had there been sufficient time at my disposal. It is obvious in fig. I 29 that the right parietal fragment is placed too low, and that the occipital bone is too high. But as regards general outline and chief diameters the result of this experiment was reassuring.

The criticism may be made here that in Dr Smith Woodward's original reconstruction the right and left 
halves of the skull have the appearance of being symmetrical (fig. I $30, \mathrm{~A}$ ). The right half, however, is really the larger, and when we examine the details it is at once seen, as already pointed out, that the right and left halves of the lambdoidal suture are altogether unlike. No animal skull has ever been seen with such a degree of asymmetry of the two sides of the occipital bone. Professor Elliot Smith is of opinion ${ }^{1}$ that a slight adjustment of the parietal fragments will remove those defects and leave the brain capacity much of the same size as represented in Dr Smith Woodward's reconstruction.

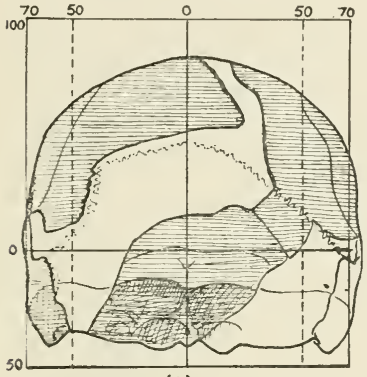

PILTDOWN (A)

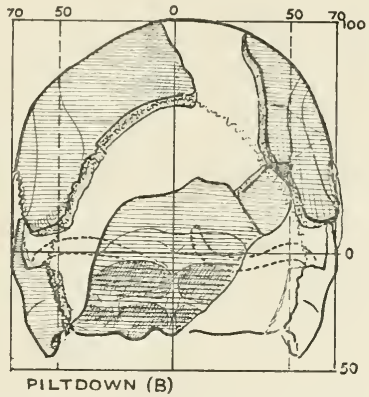

FIG. I30.-Occipital view of Dr Smith Woodward's original reconstruction of the Piltdown skull (A) contrasted with a reconstruction carried out according to the identifications of the middle line by Professor Elliot Smith.

In fig. I $30, \mathrm{~B}$, another reconstruction of the Piltdown skull is reproduced. In this reconstruction the middle vertical line of the diagram cuts the hinder angle of the left parietal fragment at the point where Professor Elliot Smith believes he can detect definite signs of the suture between the right and left parietal bones. If that is the position of the suture-for I can see no trace nor sign of it-then that point must be placed in the middle line of our reconstruction. The left parietal, in fig. $130, \mathrm{~B}$, has been orientated on the middle line as

1 See Nature, 1913, vol. xcii. p. 318. Also Quarterly Journ. Geol. Soc., 1914 , vol. Ixx. p. 95. 
determined by Professor Elliot Smith, and if the adjustment may be truthfully described as a slight one, its effect, as regards the size and shape of the skull, is revolutionary. Instead of being, as in Dr Smith Woodward's original model, a wide skull with a depressed crown-somewhat resembling the Neanderthal form of crania-it becomes a narrow, high skull, exactly similar in outline and structural details to modern skulls. The "slight" adjustment has certainly removed many of the defects of the original model, as well as transformed the chief character of the skull, but an inspection of fig. 130, B, will show that there still remains a high degree of asymmetry which can be largely removed by placing the parts in the position shown in fig. I28. Whether the reconstruction shown in fig. $130, \mathrm{~B}$, or in fig. $128, \mathrm{~A}$, is accepted as the right one, there is one conclusion which cannot be avoided - the Piltdown skull in its occipital aspect is a counterpart of that of modern man.

In the preceding paragraphs the narrative has strayed in advance of the natural sequence of events. The actual reconstruction of the experimental skull occupied me the better part of two days. Having made exact drawings of it, according to the method used in this book, I handed the skull and drawings to Dr Derry at University College. He then showed me the cast of the original-the skull of an ancient Egyptian-a woman, with a peculiar form of head and a brain capacity of I 395 c.c. The estimate I returned of the brain capacity, namely, I4I 5 c.c., was not very wide of the truth, and as regards general form and actual dimensions 1 was relieved to find the method I had followed had given-except in one respect-a fairly accurate reproduction of the original.

How closely the problem of the experimental or test skull simulates the one presented by the Piltdown fragments becomes very apparent when we view the reconstructed skulls from above (fig. I 32). In neither skull is there any certain mark of the middle line along the vault. In the test skull, the sagittal suture of the vault was prematurely obliterated, and, as may be seen from fig. I $3 \mathrm{I}$, 
only at one point-immediately in front of the bregmawas the middle line really represented. There were two guiding marks to help me: (I) on the under surface of the projecting frontal fragment-in front of the bregma (fig. I 3 I) - an indication of the great blood-sinus which passes backwards under the middle line of the vault could be detected; (2) I surmised, as proved to be the case, that the sagittal suture, between the right and left parietal bones, turned a little to the left as it reached the

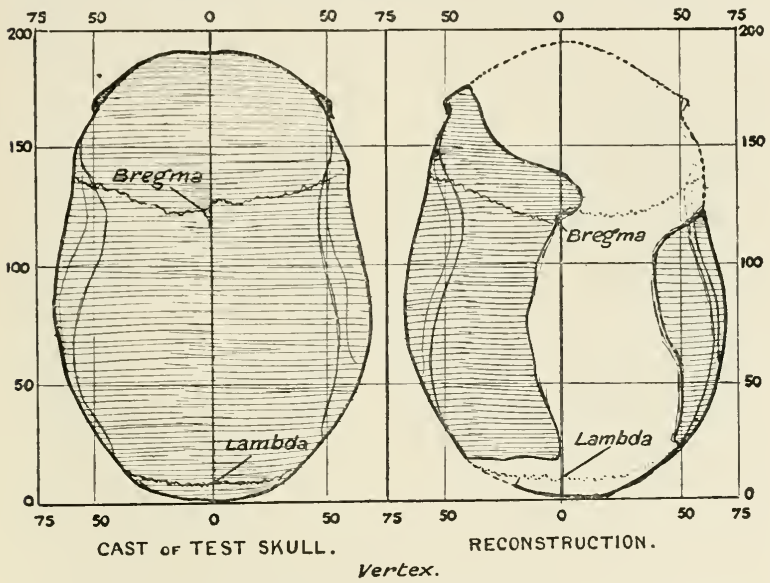

FIG. 131.-Drawing of the vault of the test skull, with a corresponding drawing of the reconstruction.

bregma. It was only on such a supposition that I could account for a trace of an oblique suture on the hinder part of the frontal projection-apparently the commencement of the coronal suture of the right side. The position of the lambda (fig. I $3 \mathrm{I}$ ) was also rightly placed. The vascular markings under the hinder angle of the parietal fragment, and the fact that the lambda is rarely placed more than $10 \mathrm{~mm}$. in front of the occipital end of the skull-when orientated on the plane described in this book-showed me that at least i $5 \mathrm{~mm}$. had been cut 
away from the hinder end of the left parietal bone (fig. I 3 I).

As may be seen in fig. 1 32 , the markings presented by the Piltdown skull, in the region of the bregma, are very similar to those of the test skull. The left coronal suture can be definitely traced to the broken edge behind the frontal projection. On the hinder margin of the frontal projection itself can be traced a short part of an oblique suture (fig. I 32 ). It is not unusual in modern skulls, especially in large specimens showing a considerable

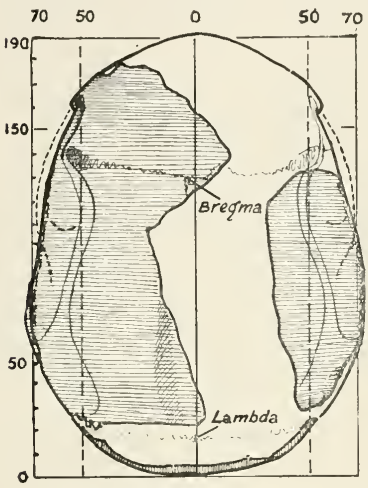

PILTDOWN

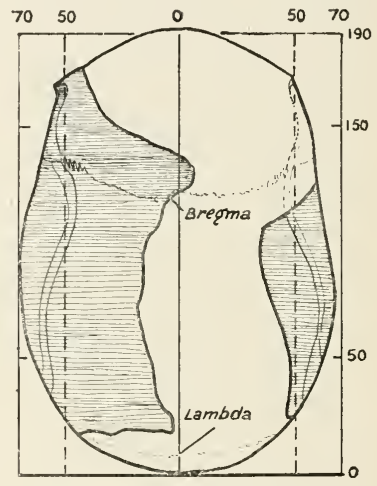

TEST RECONSTRUCTION

FIG. 132,-Reconstructions of the Piltdown and test skulls viewed from above.

degree of asymmetry in the conformation of the right and left halves, to find a forward inclination at the commencement of the right coronal suture (see fig. I35, B). In such cases, as in the test skull, but often to a greater degree, the anterior end of the sagittal suture diverges to the left of the middle line. On the under surface of the frontal projection of the Piltdown fragment we also find an indication of the middle line in the form of a ridgelike elevation. The corresponding aspect of the test skull is marked by a groove, as is usually the case in modern skulls. But a median elevation of the skull, fitting into a groove or depression between the right and 
left frontal lobes of the brain, is not a rare occurrence in even modern skulls. In the reconstruction of the Piltdown skull, shown in fig. I 32 , the frontal projection is so placed as to pass $15 \mathrm{~mm}$. to the right of the middle line of the vault. At the hinder end of the reconstruction it will be seen that I have placed the lambda I $5 \mathrm{~mm}$. in front of the occiput. A fragment, at least $15 \mathrm{~mm}$. in extent, is missing from the hinder end of the left parietal bone just in front of the lambda. In so thick a skull it is probable that the lambda was situated as far forwards as is shown in fig. I 32 .

The similarity of the Piltdown and Egyptian skulls, seen in the reconstructions represented in fig. I 32 , leaves us in no doubt that in both cases the head was built on similar lines-at least as regards the part of the cranium containing the brain. In actual width the Piltdown is the greater, because of the thickness of the bones; the brain chamber in both is approximately of the same width. As we have already seen, Professor Elliot Smith's determination of the middle line of the vault is slightly different from that shown in the preceding illustrations. In fig. I 33 are reproduced corresponding drawings made from Dr Smith Woodward's original reconstruction and a reconstruction made with the parts placed on the middle line of the vault as identified by Professor Elliot Smith. In the latter reconstruction (fig. I $33, \mathrm{~B}$ ) the middle line is only a few millimetres to the left of that represented in the Piltdown reconstruction shown in fig. I 32. In each case the size and form of the skull as viewed from above are those we are familiar with in modern skulls. On the other hand, the upper aspect of the skull of Eoanthropus, as originally modelled by $\mathrm{Dr}$ Smith Woodward, is altogether peculiar in its form. It is wide and short, the malar processes on each side of the forehead appear projecting, almost as in apes, while the temporal lines converge towards the middle line, somewhat after the manner seen in the skulls of young anthropoids (fig. I 34). With the correct apposition of parts all those peculiar features disappear, and the characters seen in modern 
skulls take their place. Both Professor Elliot Smith and Dr Smith Woodward locate the lambda at the posterior extremity of the parietal fragment (fig. I 33).

From an examination of the vault we can learn a great deal concerning the peculiar cranial characters of the Piltdown race. The condition of certain parts may be described as ultra-modern-a condition which we scarcely expected to meet with in a very ancient form of man. We can best realise the significance of such features by

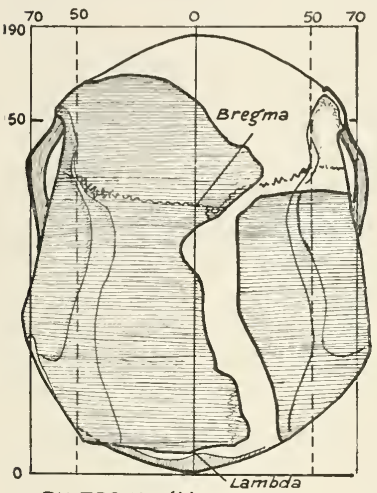

PILTDOWN (A)

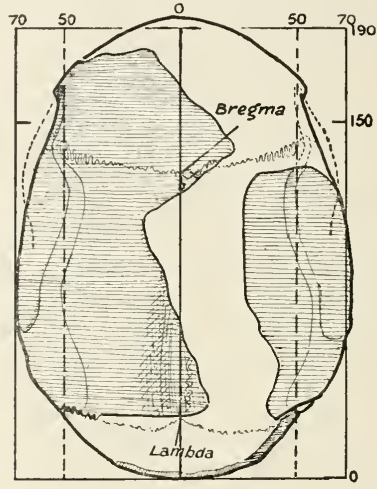

PILTDOWN (B)

FIG. I33.-Drawing of the upper aspect of the Piltdown skull as reconstructed ijy Dr Smith Woodward (A), and a reconstruction based on the identification of the middle line by Professor Elliot Smith (B).

examining their degree of development in the cranial vault of an anthropoid ape-such as a female chimpanzee, the least brutal of the anthropoids in appearance (fig. I 34). The forehead of the chimpanzee, just above the orbits, is crossed by a strong bar of bone-the supra-orbital ridge or torus. The projecting outer ends of the bar form the bony projections known in human anatomy as the external angular or malar processes, the ends of which can be felt distinctly at the outer margin of our own foreheads. Two great bars of bone - the zygomatic arches-pass from the cheeks to the base of the skull in front of the ears. 
All these outlying parts of the skull form a bony scaffolding from which the muscles acting on the jaws gain an extensive origin. The brain case of the ape is small and does not provide space enough for the origin of the great muscles of mastication. Hence the outlying bony framework.

Before leaving the chimpanzee's skull, two other points should be noted :

(I) that the face is so projecting, so thrown forwards or prognathous, that it is very apparent in front of the supra-orbital ridge ; (2) buttresses or bony flanges are thrown out around the hinder part of the skull to increase the area for attachment of the muscles of the neck. In the chimpanzee, then, we see a primitive condition, one in which the brain is small-it varies in size from 300 to

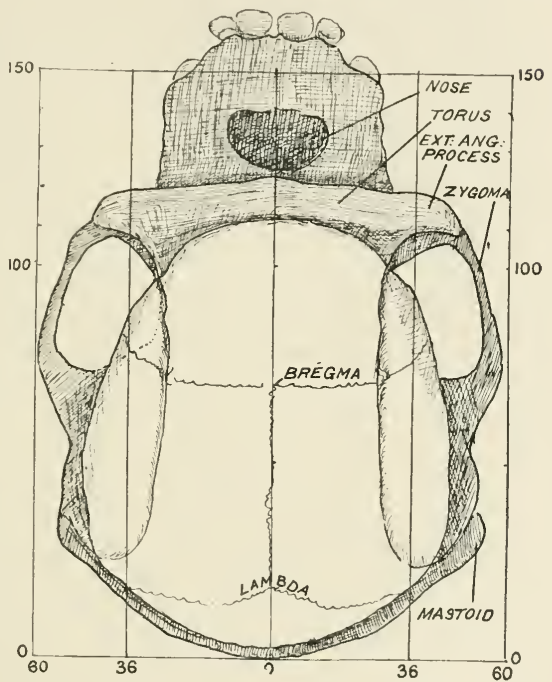

134.-Skull of a young female chimpanzee viewed from above. The skull was set on the plane described on p. 378 .

400 c.c., a fourth of the human size-and in which bony scaffolding and processes are thrown out to meet the needs of a brutal musculature. The various features just enumerated in the chimpanzee's skull are also represented in that strange, mid-Pleistocene species of humanity-Neanderthal man (fig. I 35, A). The great supra-orbital bar is apparent-no development of this kind has ever been seeii in a modern human skull-ending 
in strong and prominent external angular processes. The zygomatic arches projected outwards, coming clearly into view when the skull is looked at from above. The great increase in the length and width of the cranial cavity in Neanderthal skulls renders those brutal features much less apparent than in the chimpanzee. There is another simian feature in the shape of the Neanderthal cranial cavity. In Neanderthal man we have seen that the brain cavity was compressed from above downwards, as in anthropoid apes. It will also be noted, if one surveys
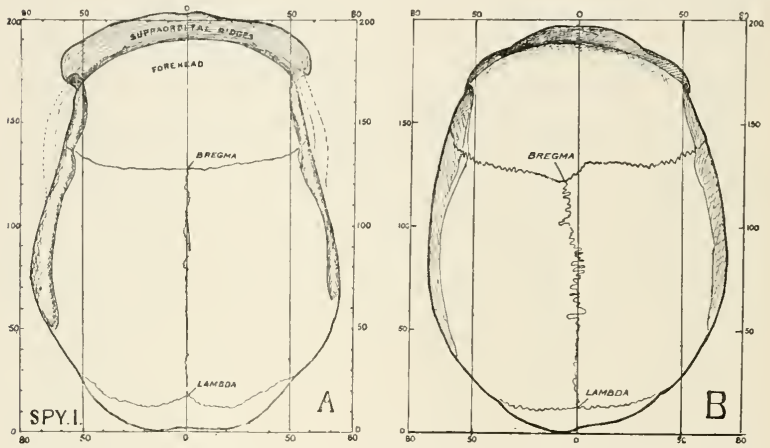

Fig. I35.-A. The vault of a Neanderthal skull, showing the simian form of eyebrow ridges. B. The vault of a modern skull, showing well-developed eyebrow ridges of the type usual in present-day races, and also an asymmetrical condition in the region of the bregma, as in the Piltdown skull.

the vault of the chimpanzee's skull from front to back, that the cranial cavity increases in width until almost the occipital region is reached; then it contracts abruptly. The same configuration may be noted in Neanderthal skulls. The significance of this feature is not known, but it is a simian character which is absent in the skulls of modern man and also in the Piltdown specimen. In these skulls the greatest width is reached above the region of the ear, some distance in front of the occiput (compare A and B in fig. I 35).

In modern skulls the dimensions of the supra-orbital 
ridges, external angular processes, and zygomatic arches have the form and dimensions shown in fig. I $35, \mathrm{~B}$. These processes are of a similar shape and size in ancient skulls of the modern type. The outer part, which ends in the external angular process, is demarcated more or less sharply from the elevations of the brow ridges situated over the root of the nose. The external angular process projects only 5 or $6 \mathrm{~mm}$. beyond the contour of the forehead and brain case.

We now turn to the Piltdown skull (fig. I 32). Only one part is preserved of the supra-orbital region, that is the external angular process of the left side. Although this process is thicker and stouter than in any modern skull I have ever seen, it is not projecting or prominent. Indeed, as will be seen when the skull is viewed from the front, it does not project more than 3 or $4 \mathrm{~mm}$. beyond the lateral contour of the forehead (fig. I 78 , p. 482). That is exactly the opposite condition to what we expected to find in a very ancient representative of humanity. As regards this feature, the Piltdown skull is ultra-modern. It is just such a condition as we should expect to find correlated with a large brain.

A view of the skull from above gives us an opportunity of forming an opinion on two of its chief dimensionsits length and width. In Dr Smith Woodward's reconstruction the maximum length is $190 \mathrm{~mm}$.- approximately the same as in an average modern Englishman. In the same reconstruction the width is represented as $150 \mathrm{~mm}$.a wide skull, 8 or $10 \mathrm{~mm}$. more than is usual amongst English people. The thickness of the skull must be taken into account in estimating these dimensions; we must reduce each of these measurements by Io $\mathrm{mm}$. to make them comparablewith the more slender modern skull. Taking Dr Smith Woodward's measurements, I 90 for length and 150 for width, we see that the width is 79 per cent. of the length. The Piltdown skull is thus on the verge of being classed amongst the round-heads-the brachycephalic group of humanity, with a width proportion of 80 per cent. or more. 
We have always expected to find long-headedness as a character of ancient man; it is so among most of the skulls of Pleistocene age, but not invariably so. In the reconstruction of the Piltdown skull shown in fig. I 32 the length is represented as $194 \mathrm{~mm}$., slightly more than in Dr Smith Woodward's reconstruction. There is this difference, however: I have reduced the allowance for the forehead and increased the length of the occipital region (figs. I 32 and 133 ). The maximum width is also the same-I $50 \mathrm{~mm}$. The width is thus 78 per cent. of the length. In relative and absolute measurements of length and width my reconstruction differs very little from that of Dr Smith Woodward. Thus, as exemplified in the specimen discovered, the Piltdown race tended towards round-headedness. In anthropoid apes the actual cranial cavity is of the round or short form. The real significance of round and long heads we do not know ; brachycephaly is found in anthropoid apes and in the most highly evolved of modern human races.

Before leaving the upper aspect of the Piltdown skull, there is one other feature which deserves mention. In figs. I 34 and I 35 the temporal lines are indicated; they are arranged approximately symmetrically on each side of the skull. Now, the temporal ridges have an important bearing on the problem we have in hand. They will be observed to commence at the external angular processes of the frontal bone, and to sweep backwards on each side of the skull, crossing the coronal suture and ultimately terminating behind, above the ear. The lines limit, on each side of the skull, that area from which the temporal muscles take their origin-the chief muscles which act on the lower jaw. With a large jaw we expect to find a large and extended temporal muscle. If the muscles are large, then we should expect these lines to reach well upwards on the side of the skull, towards the middle line. Nature is economical in her use of material; the bones of the skull have to enclose and form a brain chamber ; they have also to serve as a surface from which the muscles of mastication take their origin. If the brain 
cavity is small, as in the chimpanzee, then the muscles may occupy the whole lateral aspect of the skull, and the temporal lines may actually meet along the middle line of the roof of the skull. As the brain cavity enlarges, a larger space becomes available than the temporal muscles need, and therefore the temporal lines are placed at a distance from the middle line. If the brain cavity becomes very large, these lines are widely separated from the middle line. What, then, was the condition in the Piltdown skull? In Dr Smith Woodward's reconstruction the temporal lines reach within $40 \mathrm{~mm}$. of the middle line; in the modern English skull with a capacity of 1425 c.c., shown in fig. I 1 5, p. 334, the lines reach within 50 $\mathrm{mm}$. of the middle line. With a capacity of only ro70, as estimated by Dr Smith Woodward, and with such a long and projecting jaw as he found with the skull, we expect the temporal muscles to be large and the temporal lines to ascend further on the sides of the skull than they actually do-if the skull were a small one. We have seen that the middle line cannot be as in Dr Smith Woodward's reconstruction; when the parts are placed so that the sutures are symmetrical we find that the temporal lines are not $40 \mathrm{~mm}$. but $52 \mathrm{~mm}$. from the middle line. In the Dartford skull, with a capacity of 1750 c.c. and with a lower jaw which we may presume was not much larger than in us, the distance is only $70 \mathrm{~mm}$. All those facts are in harmony with the other evidence I have brought forward, namely, that we are dealing with a skull with a fairly large brain capacity.

In this chapter we have surveyed the Piltdown skull from two aspects-from behind and above. The result of that survey, and the comparison of the fragments of the skull with corresponding parts of modern skulls, convince students of anatomy that in general conformation, in actual dimensions, and in brain capacity the head of the Piltdown race was remarkably similar to that of modern races. 


\section{CHAPTER XXIII}

\section{HEADS-ANCIENT AND MODERN-IN PROFILE}

$\mathrm{IT}_{\mathrm{T}}$ is more than six years now since Colonel Willoughby Verner brought me, from a cave in Spain, some fragments of a human skeleton. They were still thickly encrusted by the stalagmite which covered the floor of the cave, and when struck they resounded exactly as if they had been made of porcelain. They were petrified-true fossils. Colonel Verner discovered the cave; it had never been explored before-at least in modern times. On the walls were crude hieroglyphs. Nothing was found to give a clue to the date at which the cave had been inhabited or when the human remains came to be deposited there. Among the few fragments were the upper ends of both right and left thigh bones of a small person, probably under 5 feet $(1500 \mathrm{~mm}$.) in height, truly human in shape, but with peculiar features which were new to me. It was therefore important to find out more about this individual-to discover the characters of the head-but all that was available for this purpose were the left temporal bone, the hinder half of the left parietal bone, and a fragment of the right. My attempt to reconstruct the skull from these fragments taught me a great deal. I saw that it would be possible to reconstruct the whole skull from these fragments with some approach to accuracy, but before such a task could be carried out a new method of studying skulls must be first elaborated, and then applied. The same problem confronted me when I obtained the cranial fragment found near Bury St Edmunds. It came to be a matter of great import- 
ance to know what kind of person this Bury St Edmunds fragment belonged to, for it is the only human fragment so far found in England belonging to the very remote mid-Pleistocene Acheulean age.

When I began my investigations one point became very evident; the method we employ in measuring and recording modern skulls and heads was useless. For that purpose we give the head or skull a definite pose; we place it so that the ear-hole and the lower margin of the orbit are on a level, on the same plane-the Frankfurt plane. In ancient skulls the lower part of the orbit is nearly always broken away; often the temporal bone, with the necessary ear-passage, is missing. As a rule little more than the vault of fossil skulls is found; therefore in the vault we must find the base line from which we are to reconstruct the whole skull. Now on the vault there are two very definite points which, at first sight, would seem to serve our purpose. At the front end, on the lower brink of the forehead, just over the root of the nose, is the projection or point known as the glabella (fig. I 36 ). At the hinder end, just where the vault slopes down to join the neck, is a well-marked projection - the inion or external occipital protuberance (fig. $\mathrm{I} 36, \mathrm{O}$ ). A line drawn from the glabella in front to the inion behind would seem to provide us with the kind of base line we need for the reconstruction of the missing parts of the skull. I could not accept these points because I knew them to be-at least in certain skullsmovable and variable in position as regards the brain, and the points needed for a base line must be fixed, at least as regards their relationship to the brain. In the young anthropoid ape both glabella and inion are low down near the base of the skull. The vault of the skull rises high above a base line joining those two points. As the young ape grows the muscles of mastication increase in size, the neck increases in thickness, with the result that the glabella and inion ascend towards the vault of the skull (fig. I36). Hence in the adult the vault of the skull appears to be lower than in the young. 
If we used the inio-glabellar base line we should infer that the brain of the adult was much smaller than that of the young. The same change occurs, but in a less degree, in human skulls. Hence we must look for a more fixed base than that supplied by the inion and glabella.

Ultimately the base line which I selected was one which roughly corresponds with the lower margin of the cerebrum or brain proper. It is plain that the secret we wish to wring from such fragments of skulls as may

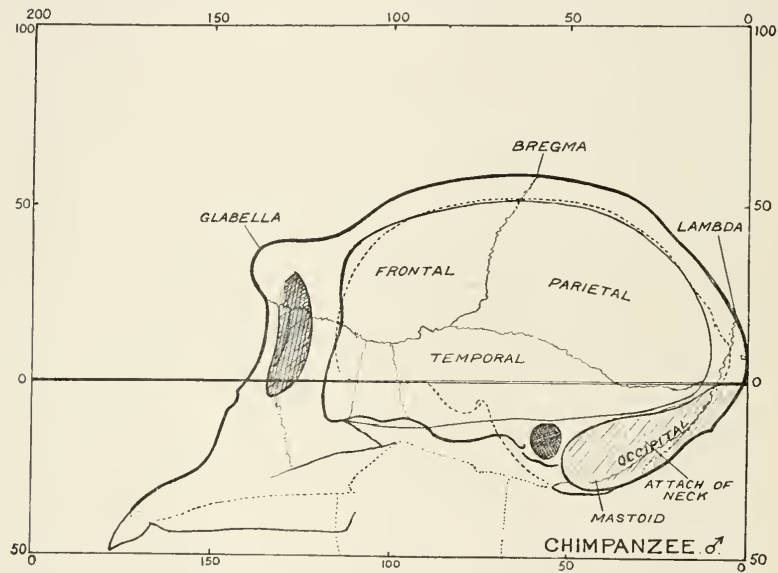

FIG. 136.-Profile of the skull of a chimpanzee to show the plane of orientation. The outline of the brain chamber is stippled.

come to light is the kind of brain they enclosed. Our methods should therefore be framed with that object in view. Now the hinder lower angle of the parietal bone is a wonderfully persistent part of the skull. To that angle is attached the horizontal partition which separates the cerebrum above from the cerebellum below, not only in man, but in all animals allied to man. The posterior inferior angle of the parietal-the "asterion" as the point is named-is one which will serve well the purposes of a standard or base line for the hinder end of 
the skull. At the front end of the skull it is more difficult to get such a point as we want. The point needed should correspond with the lower limit of the frontal lobe of the cerebrum. If the base of the front part of the skull is preserved in the region of the presphenoid, then we have the level or plane which will serve our purpose. A line drawn along the skull from the level of the presphenoid to the asterion would give us just such a base line as we need, for between that base line and the vault of the skull lies almost the whole of the cerebrum. The anterior part of the base, however, is usually broken away or decayed, and we have to fall back on some other point. The one which seems to me most suitable is the external angular process of the frontal, or, to be more precise, the junction of this process with the malar bone (fig. I37). The base line, then, on which we propose to orientate a cranium for examination is one which begins anteriorly at or near the fronto-malar junction and passes across the hinder lower angle of the parietal behind (fig. I $4 \mathrm{I}$ ).

Seeing we are to place so much reliance on the external angular process and its junction with the malar bone, we must look closely at its relationship to the brain. In fig. I $37, \mathrm{~B}$, the relationship of this process to the brain is shown in a modern English skull. The angular process, marked by two *** is $5 \mathrm{~mm}$. ( $\frac{1}{5} \mathrm{inch}$ ) above the level of that part of the base of the skull on which the frontal lobes of the brain rest. Numerous observations on modern human skulls have shown that the outer end of the process-the frontal-malar junction-fluctuates a little above or a little below the level of the brain ; but for the purpose we have in view it is a reliable enough guide and gives us approximately the anterior brain level. This rule holds good, not only for skulls of the modern type, but also for those ancient ones of the Neanderthal type. Strong and massive as the angular process is in the Gibraltar skull, its outer end is a fairly accurate index to the level of the basal parts of the frontal lobes (fig. I $37, \mathrm{~A}$ ). When, however, we examine the condition 
in anthropoid apes we find a different relationship (figs. I 36 and I38, A). The outer end of the process lies $20 \mathrm{~mm}$. ( $\frac{4}{5}$ inch) above the base of the frontal lobes. If we draw our base line at the fronto-malar level, we should greatly underestimate the brain capacity of an anthropoid skull. An anthropoid condition is one we must be prepared to meet in a primitive human skull, such as the Piltdown, especially when we keep in mind the simian characters of the lower jaw. So far as concerns

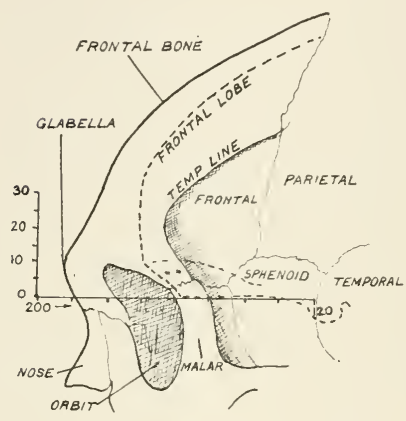

GIBRALTAR.

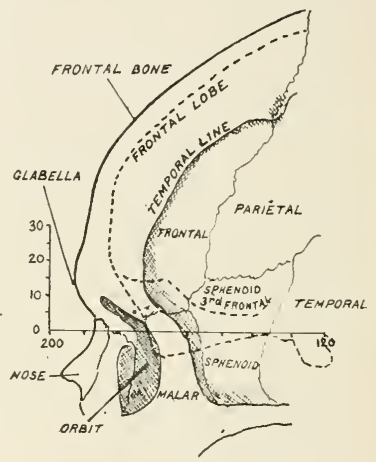

MOD : ENGLISH.

FIG. 137.-A. The relationship of the external angular or malar process to the level of the base of the frontal lobes of the brain in the Gibraltar (Neanderthal) skull. B. The same relationship in a modern English skull.

the skull itself, we have met only with the true characters of a human skull, inclining decidedly towards the modern type. We expect, then, that the angular process of the frontal will be about on a level with the base of the frontal lobe. But we must make certain of this relationship. Now, there is a reliable method of telling whether the external angular process is situated as in anthropoids or as in man. If the reader will examine the figure of the modern English skull (fig. I 37, B), he will see the various bones which form the side of the skull behind the angular process-the area which is covered by the 
temporal muscle and is known as the temporal fossa. In this area the coronal suture descends between the frontal and parietal bones until it ends in a transverse line or suture which separates the sphenoid - the part of that bone known as the " great wing "- -from the frontal and parietal bones. It will be further noted that the suture between the angular process and malar is continued backwards between frontal bone and malar. In the English skull the trend of the fronto-malar suture is backwards and upwards. In the anthropoid skull, however, the fronto-malar suture descends almost vertically (see fig. $138, A$ ). The vertical position of this suture tells us at once that the angular process is in the anthropoid position, and therefore lies some distance above brain level. A very slight degree of the anthropoid condition is present in the Gibraltar skull (fig. 137, A) and to a considerable degree in Pithecanthropus (fig. 90). What is the condition in the Piltdown skull? There can be no doubt about this point; the sutures necessary for a solution of the question are present (fig. I38). The fronto-malar suture, shorter than ever seen in a human skull hitherto, is truly horizontal in direction. As viewed in the actual specimen, its trend is backwards with a tendency to ascend. We may be certain, then, that when we select the external angular process of the frontal as marking the lowest level of the frontal lobes we are using a base line which will give us reliable results.

We have evidence from another source which tells us we are proceeding on a safe basis. The external angular process holds a definite relationship to an important part of the frontal lobe, that part known as the third or inferior frontal convolution, which is generally regarded as directly connected with the acquisition and use of speech. The chief speech-centre is supposed to be represented in that convolution. The third frontal convolution lies directly behind the angular process; in many heads a distinct elevation or "bump" marks the position of this important area of the brain. The inferior frontal con- 
volution is situated at a higher level than the more deeply placed parts of the frontal lobe. In a modern skull it lies $\frac{1}{2}$ an inch above the base line (see fig. I $37, \mathrm{~B}$, where the lower margin of the third frontal convolution is indicated by a stippled line). In the Piltdown skull that part of the roof of the eye-socket on which the third frontal convolution rests is preserved; we therefore know the level of that convolution in the Piltdown skull (fig. I $38, \mathrm{~B}$ ). If we allow for the greater thickness of the skull bones, the relationship of the inferior convolution of the frontal lobe to the external angular

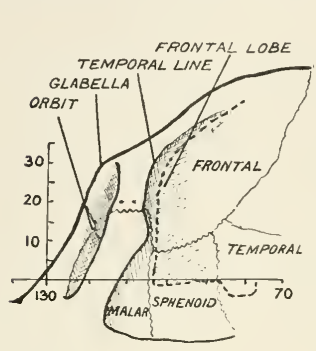

ORANG .

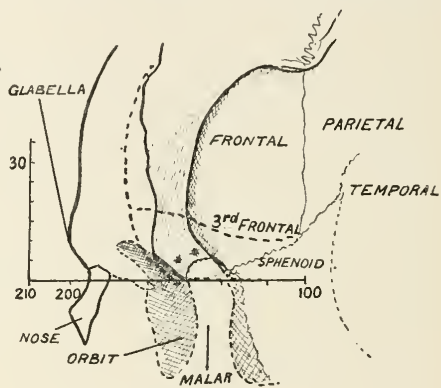

PILTDOWN.

FIG. 138. - The tronto-malar region in the skull of an orang and in the Piltown specimen.

process is almost the same in the Piltdown skull as in modern man (figs. I 37 , I38). In the fronto-malar region the characters of the Piltdown skull are not simian; indeed, as will be shown in the next paragraph, they are rather ultra-modern.

The temporal line - a line or ridge marking the anterior limit or space from which the temporal muscle takes its origin-descends on the angular process (fig. I38). As we have already shown, that process itself must be regarded as part of the bony scaffolding thrown out as a basis for the apparatus of mastication. Now the relationship of the temporal lines to the frontal lobe 
of the brain is a matter worth our attention. When the anthropoid skull is examined in true profile it will be seen (figs. I 36 and I $37, A$ ) that the temporal line is situated in front of the anterior limit or frontal pole of the brain. In the Gibraltar skull this line descends behind the frontal pole, but only $8 \mathrm{~mm}$. ( $\frac{1}{3}$ inch) behind it. In modern English skulls this is also the case, but the temporal line is still further back, from $\frac{1}{4}$ to $\frac{3}{4}$ of an inch (fig. I 37). Now in the Piltdown skull-even supposing the forehead is curtailed and made vertical-the temporal lines are at least $15 \mathrm{~mm}$. $\left(\frac{3}{5}\right.$ inch $)$ behind the frontal poles. The relationship of the temporal lines to the frontal poles of the brain is thus the opposite of simian; the line is further back than in the average modern skull. Indeed, a glance at the various figures just given (figs. ${ }^{2} 37$ and I $3^{8)}$ will show that the frontal part of the temporal lines in the Piltdown skull are more vertical-have a different contour-to any hitherto seen in a human or anthropoid skull. In all human skulls, ancient and modern, the external angular process bends backwards and downwards as it joins the malar or cheek bone. In the Piltdown skull the terminal backward bend is almost absent; it ends abruptly, pointing outwards.

I know that I am trying the patience of my readers when I labour these points. My excuse is that this fragmentary skull is the only document from which-at the present time-we can learn anything of a race of mankind which is removed from us by twenty thousand or thirty thousand generations of human lives. We have to interpret that document, to see how far our modern methods of interpretation will give us a glimpse of the mental status of man at such a remote period. We are making some headway, and it is clear that a region of the head which lies so close to the brain centres of speech is one which we must explore to its full value. I propose, therefore, we should view this region, not only as seen with the head in profile, but also from above. In fig. I 39 a horizontal section has exposed the anterior part of the floor of the skull of a chimpanzee, that part on which 
the left frontal lobe rests. The impress of the third or inferior frontal convolution is seen. Far in front of the fossa or impress for this convolution is seen the external angular process of the frontal. On the right-hand side of the figure is shown a corresponding section of the Gibraltar skull. The external angular process is in front of the third frontal convolution. If one could conceive a great increase in the bulk of the frontal lobes of the

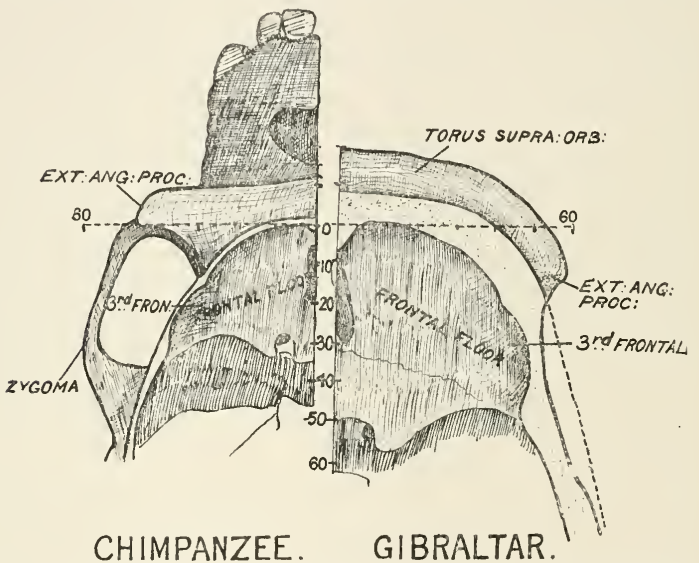

FIG. 139. - Section across the anterior end of the left side of a chimpanzee's skull and the right side of the Gibraltar skull, to show the relationship of the external angular process to the third frontal convolution.

chimpanzee's brain it is easy to see how the condition in the Gibraltar skull might be evolved from a simian arrangement. In fig. I 40 the condition of parts in the Piltdown skull is contrasted with that of a modern specimen. The external angular process is less prominent in the Piltdown skull; it is also situated rather further back, more directly over the third frontal convolution than in the modern skull. It is clear that as regards this relationship the Piltdown skull is the opposite of simian. As regards the development and relationships of the 
external angular process, modern man is rather more simian than Piltdown man.

Having thus established a base line from which we can work, we are now in a position to reconstruct and interpret the lateral aspect of the Piltdown skull. We shall see what this ancient man looked like when his head was viewed in profile-the most instructive of all views to a student of anthropology. The points needed for a base line-the external angular process and posterior interior angle of the parietal bone-are preserved and can be

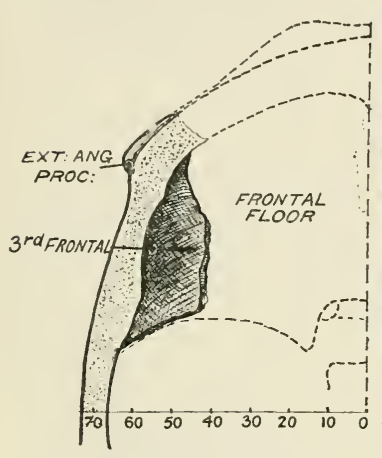

PILTDOWN.

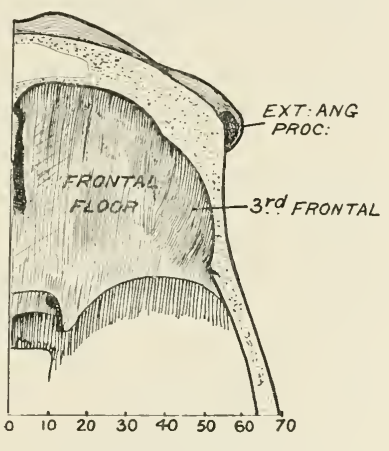

MODERN.

FIG. I 40.-Horizontal section of the left frontal bone of the Piltdown skull, and of the right frontal region of a modern skull, to show the relationship of the external angular process to the third frontal convolution.

defined with precision. It was also on this base line that the experimental reconstruction, described in the previous chapter, was carried out. That experiment throws a clear light on the nature and dimensions of the Piltdown skull, and hence it is necessary for us to return to it once more.

In fig. ${ }+\mathrm{I}$ are shown drawings of the original Egyptian skull and of the reconstruction as seen from the side. The reconstruction reproduces the height of the original with exactitude; in both, the vault rises just above the upper limit of the frame, and is thus a little more than $100 \mathrm{~mm}$. (102 mm.) above the base line. The upper margin of 
the ear-hole is I $5 \mathrm{~mm}$. below the base line, and therefore the height of the vault above the ear-hole is I $7 \mathrm{~mm}$, a very common measurement in the skulls of modern Englishmen. Turning now to fig. I 42 , where the test

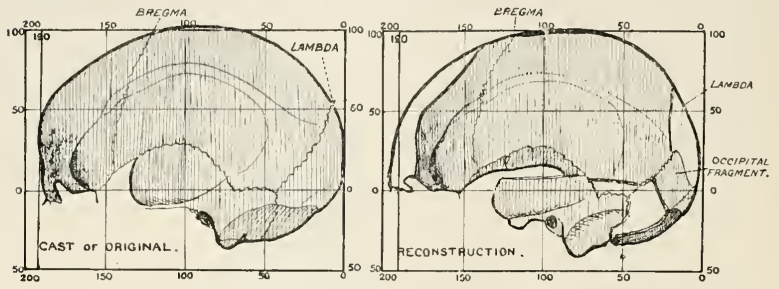

FIG. I4 I. - Profile of the test skull and of the reconstructed skull, orientated on the lines described in the text.

reconstruction is compared with the Piltdown skull, the reader will be impressed with the degree of resemblance which they show. In the ancient skull the vault rises to the same height; the ear-hole is at the same level. The auricular height of the Piltdown skull is approximately

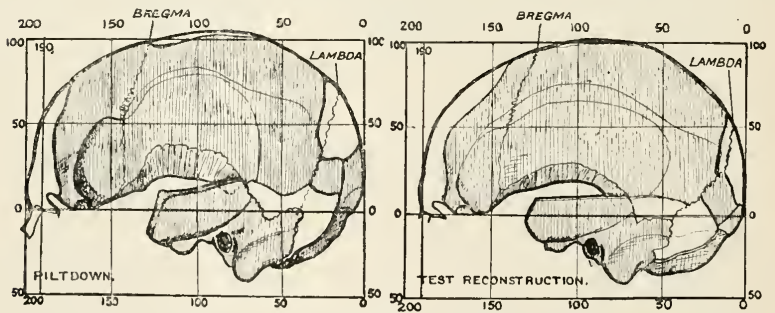

FIG. 142.-Profile of the reconstruction of the test skull compared to the reconstruction of the Piltdown skull.

the mean for modern Englishmen-II $7 \mathrm{~mm}$. But a deduction has to be made; the vault of the fossil skull is so thick that we must reduce the height by about $5 \mathrm{~mm}$. to obtain a comparable measurement. In the Gibraltar skull the auricular height of the vault is $98 \mathrm{~mm}$., with no allowance made for the thickness of the vault. 
In the latter skull the vault rises $88 \mathrm{~mm}$. above the base line; in Pithecanthropus the vault was very low, only $74 \mathrm{~mm}$. above the base line (fig. I 44). The importance of the auricular height as an index of brain development is very apparent ; the more the brain expands, the larger it becomes, the more is the vault of the skull lifted above the base line. As regards height of vault, the Piltdown skull is in agreement with skulls of the modern type.

Every well-planned experiment is instructive, and in this respect the one which my colleagues designed for me formed no exception. It will be seen from fig. I 4 i that my attempt to restore the forehead was a complete failure. In the original skull the upper part of the forehead is prominent, while the lower part, above the root of the nose, recedes, thus falling short of the conventional anterior limit-the $190-\mathrm{mm}$. line. The reconstruction shows exactly the opposite conditions, the total length of the skull being nearly $5 \mathrm{~mm}$. more than it should have been. I made an unpardonable blunder in two respects. In the first place, I had concluded from the rather large size of the mastoid process-placed just behind the ear-that the fragments I had to put together were parts of a man's skull, and therefore gave the reconstructed skull the prominent eyebrow ridges of the male. If I had looked carefully, I should have seen that the area for the attachment of the neck in the skull I had to reconstruct (fig. I + I) was small-a characteristic female mark, for the neck of a woman is more slender than that of a man. The contour of the boss on the frontal bone, too, should have wakened a suspicion of a forehead which was drawn inwards, not prominent, in the region of the eyebrows.

This error again drew my attention to the reconstruction of the Piltdown forehead. I was all along alive to the fact that we have as yet no means of drawing any accurate conclusion as to the shape of forehead from so small a fragment of it as was found by $\mathrm{Mr}$ Dawson at Piltdown, but I supposed, with a set of teeth and a mandible so well developed as those which belong to 
Eoanthropus, that the eyebrow ridges must have been prominent. It will be seen from fig. I 42 that I originally carried the forehead almost to the $200-\mathrm{mm}$. line, giving the skull a total length of $200 \mathrm{~mm}$. I am now convinced of that being too much. In every form of reconstruction of the skull of Eoanthropus one feature is always in evidence - the height and prominence of the upper part of the frontal bone. The curve given by the contour of the profile in front of the bregma (figs. I 42, I 43) suggests not a low and receding forehead as in Neanderthal man, but a high forehead, prominent in its upper part, and rather retracted than projecting as it

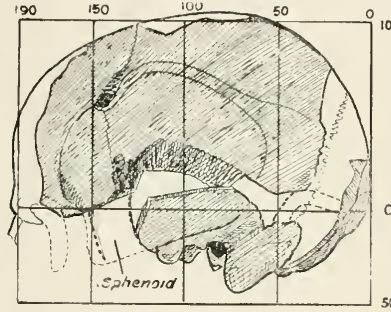

PILTDOWN (A)

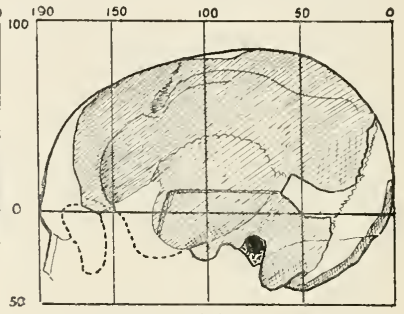

FILTDOWN (B)

Fig. I43.-Two reconstructions of the Piltdown skull. A, By the Author; B, from the model by 1)r Smith Woodward.

merges in the eyebrow region. Hence, in revising my attempts to obtain the true form of the head of Eoanthropus in the light of my experiment in skull reconstruction, I remodelled the eyebrow region, making the maximum length of the skull $\mathrm{I} 94 \mathrm{~mm}$. (fig. I 43).

One other point may be mentioned here, raised by the mistake I made regarding the sex of the test skull-that of an ancient Egyptian woman. In every race of mankind there occur men with a rather feminine conformation, and women who, in form of face and thickness of neck, are rather masculine in character. In every collection of a hundred human skulls there are eight or ten of doubtful sex. Does the Piltdown specimen belong to this undeterminate group? We cannot tell until we have 
more than one specimen at our disposal. The size of the mastoid process suggests a male, but the small area for the attachment of the neck is strongly in favour of the skull being that of a woman. The small part of the supra-orbital ridge, preserved over the outer angle of the left orbit, is stout, but neither long nor prominent. In the male we expect a greater supra-orbital development than in the female. The supra-orbital ridge of Eoanthropus suggests a woman's rather than a man's skull. The mandible is big; so are the teeth; there is a prominently pointed canine tooth. These characters rather suggest a male. But if they are female characters, then in the male we shall find even a greater simian development of the teeth, for amongst the great anthropoids males are provided with larger and more prominent teeth than females. On the whole, the evidence favours the opinion that the Piltdown skull is that of a woman.

The importance of the small occipital fragment becomes again apparent in the reconstruction of the hinder part of the head (fig. I 4 I). In the test skull part of the suture line for the occipital bone was preserved on the left parietal bone. The same suture line was also preserved on the occipital fragment of the right side. By reversing the fragment and transposing it from the right to the left side indications are obtained for the reconstruction of the hinder part of the test head (see fig. I4I). In the case of the Piltdown specimen the occipital fragment gives us a clue to the width and backward projection of the occipital region (fig. I 42 ).

The result of our examination of the Piltdown skull in profile has been to emphasise its close resemblance in size and conformation to average skulls of the modern type. But there are also differences. Some of these have been mentioned-the thickness of the bones, the form of the angular or malar process of the frontal bone, the lofty character of the frontal bone in the upper part of the forehead. Two other peculiar features require mention. One of these is shown in fig. 142. The temporal line, 
which commences on the angular process of the frontal bone (fig. I 38 ), ascends vertically for some distance on the side of the Piltdown skull before turning backwards. In all other kinds of human skulls this line bends backwards almost as soon as it begins to ascend. This peculiar feature may be due to a vertical character of the forehead, or to a peculiarity in the form and manner of action of the temporal muscle. The other strange feature of the Piltdown skull, as seen in profile, is the vertical disposition of the suture between the occipital and parietal bones (fig. I 43). ${ }^{1}$

We have now reached one of the points towards which we have been working. We have examined and verified the contours and measurements of the Piltdown skull from behind, above, and now from the side, with the view of obtaining those measurements which give us a clue to the brain capacity. We have seen that the width of the skull is I $50 \mathrm{~mm}$., its length, I $94 \mathrm{~mm}$., its auricular height, I $7 \mathrm{~mm}$. Before we can apply to these measurements the formulæ which are used for estimating the brain capacity of the modern skull we must make a reduction on account of the thickness of the bones-reducing the length to $190 \mathrm{~mm}$., the width to $140 \mathrm{~mm}$., the auricular height to II $2 \mathrm{~mm}$. The formula ${ }^{2} \mathrm{I}$ am to employ to obtain the brain capacity is that worked out by Dr Alice Lee and Professor Karl Pearson. When that formula is applied the result is $190 \times$ I $40 \times$ I $12 \times{ }^{*} 4+206=$ I 397 c.c. -a brain capacity which is almost the same as that of the Egyptian woman's skull which formed the subject of our experimental reconstruction. The female skulls found in the plague pits of Whitechapel, in the east of London, had, on an average, a brain capacity of I 300 c.c. ; the male, I 477 c.c. $^{3}$ The brain capacity of the Piltdown skull is thus above that of the average modern Englishwoman, and below that of the modern Englishman. The actual

1 See also p. 495.

3 Phil. Trans., I 899, vol. I96A, pp. 225-264.

3 See Dr W. R. Macdonell's researches, Biometrika, 1904, vol. iii. p. I9I. 
brain cast, taken from the interior of my earlier reconstruction of the Piltdown skull, measured a little over I 500 c.c., but in my earlier reconstructions I reproduced the wide forehead seen in Dr Smith Woodward's model. When a reduction is made on this account, and also because of an overestimate in length, the capacity of the skull of Eoanthropus may be safely calculated as reaching I 400 c.c., an amount equal to the average capacity of modern Europeans. If Dr Smith Woodward and I are right as regards sex, then in the male of the Piltdown race we may expect to find a brain capacity of at least I 550 c.c. That result is perhaps surprising when we take the simian characters of the lower jaw attributed to this skull into account, and still more unexpected to those who suppose man's evolution has been a consecutive and continuous series of steps upwards to his present estate. We must not infer that the facts are wrong-it is more likely our preconceptions which are at fault.

So far, we have confined our attention to a general survey of the Piltdown head in profile and satisfied ourselves that we are dealing with one which falls easily, so far as dimensions are concerned, within the modern standard. To appreciate its peculiar features we must go further afield and see how it compares with other ancient types, such as those found at Galley Hill, at La Chapelleaux-Saints, and at Trinil in Java. In fig. I 44 are set side by side, within squares of exactly the same size, the three skulls just named, with the skull of Eoanthropus for comparison. The skull from Galley Hill we may dismiss with a brief note. It represents the modern type of man, and from the analysis just given it will be seen to have many points in common with the skull of Eoanthropus. As may be observed in fig. I 44, there are also many structural points in which they differ. The La Chapelle skull is the largest of the Neanderthal type yet discovered. The big brain which once filled it was living, thinking, and dreaming dreams before the last bout of the glacial period held Central Europe in its grip. 
When orientated in the same manner as the Piltdown skull, and placed within the same framework of lines, we see (fig. I 44) that we are dealing with a man with a massive head. The vault, however, is relatively low, it barely reaches the $100-\mathrm{mm}$. line; the great supra-orbital buttress
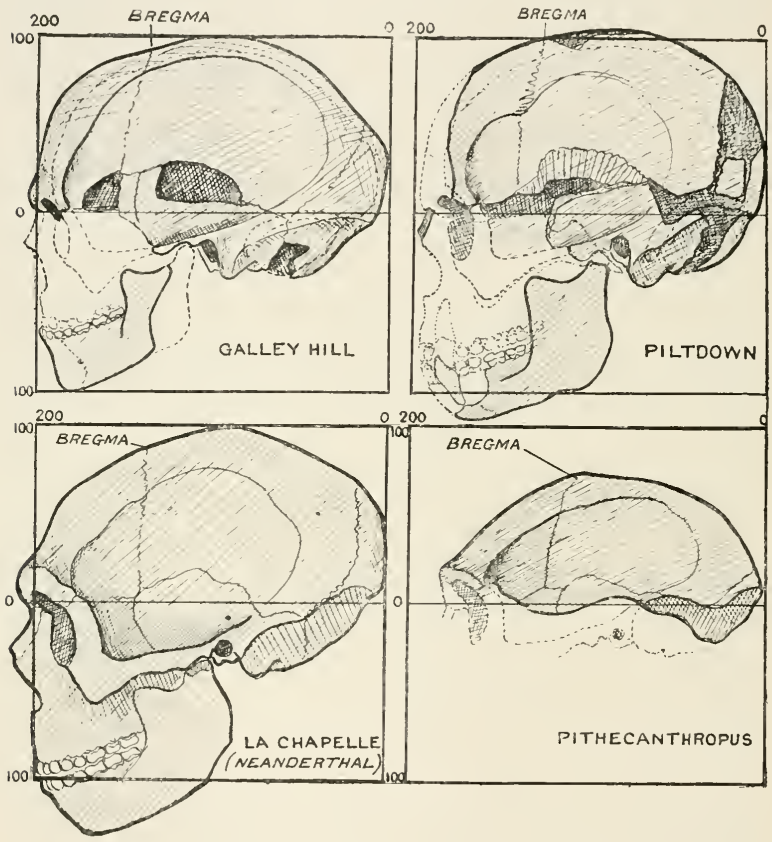

FIG. 144.-Four types of human skulls compared-Galley Hill, Piltdown, La Chapelle-aux-Saints, and Pithecanthropus.

projects $8 \mathrm{~mm}$. in front of the anterior 200-mm. line. We are not surprised when we learn from Professor Boule that the brain of this fossil man measured I 625 c.c. -fully 200 c.c. more than the Piltdown brain, and therefore well beyond the average for modern man. We are not concerned at present with the peculiar attachment 
of the Neanderthal head to the neck, the absence of the pyramidal projecting mastoid processes, nor the manner in which the inion rises high above our base line (fig. I+4). In the Piltdown skull as in the modern, the inion lies below the level of the base line (fig. I 43).

The features we shall fix our attention on are those relating to the formation of the brain case, so far as the side wall of the skull is concerned.

Five bones enter into the formation of this wall-the frontal, parietal, and occipital along the vault, and two others below, near the base, the temporal and great wing of the sphenoid. The two bones named last merit our attention first. They cover the greater part of the temporal lobe of the brain, and hence give us some clue to its size and development. In the ape's skull (see fig. I 36, p. 378) the upper margins of these bones seldom rise more than $10 \mathrm{~mm}$. above the base or standard line. The upper margin of the temporal bone where it overlaps the lower margin of the parietal at the squamous suture is nearly straight. The great wing of the sphenoid is comparatively small. All those features are indications of a small temporal lobe to the brain. In the large Neanderthal skull of La Chapelle the upper margin of the temporal bone is more curved than in the ape, and rises $20 \mathrm{~mm}$. above the base line. The great wing of the sphenoid attains a wide development. In modern skulls, and particularly in the ancient one from Piltdown, the upper margin of the temporal is highly arched; it rises about $30 \mathrm{~mm}$. above the base line. In the Piltdown skull we know that the great wing of the sphenoid must have been of wide extent, for the impress it has left on the lower margin of the parietal and of the frontal bones is $35 \mathrm{~mm}$. long, and clearly demarcated (fig. I 43). The great wing of the sphenoid is larger than in modern skulls of a moderate capacity. A survey of those features alone is sufficient to make us realise that the Piltdown race was in some respects highly evolved - at least had departed widely from simian lines of evolution.

In order that the reader may have an opportunity of 
comparing the profiles of a complete set of ancient types, I have included the most primitive form of fossil skull to which the term human can be appliedthat of Pithecanthropus. The geological evidence leads us to believe that Pithecanthropus-the erect, ape-like man of Java-was a contemporary of the English Eoanthropus. When the Java skull is posed and placed within our standard frame (fig. I44), we see at once that we are dealing with a type which carries the human form of skull a long way towards a simian stage. The vault falls 25 $\mathrm{mm}$. short of the roo-mm. line. The highest point of the vault, in place of being a couple of inches behind the bregma as in the other three types of skulls shown in fig. I 44, is at or near the bregma as in apes (fig. 1 36). The glabella is I $5 \mathrm{~mm}$. short of the anterior $200-\mathrm{mm}$. vertical line; the sphenoid is wide as in men, but the upper margin of the temporal bone is low and straight as in apes. Dr Eugene Dubois calculated that the brain capacity of Pithecanthropus was 855 c.c., but in the opinion of the writer, when due allowance is made for the missing basal parts of the skull, the capacity may prove to be somewhat greater-probably a little over 900 c.c. From a comparison with Pithecanthropus we see that Eoanthropus is a totally different kind of human beingone in which the brain development, at least so far as regards size, has reached a modern standard.

In this chapter I have kept the discrepancies between the profile of the Piltdown skull as reconstructed by Dr Smith Woodward and myself in the background. The differences become very apparent when Dr Smith Woodward's reconstruction is placed within the standard frame employed here (fig. I 43). The vault, in place of rising to the $100-\mathrm{mm}$. line, falls I I $\mathrm{mm}$. short of that level. The lowness of the vault in his reconstruction has been already explained. It is due, as we have seen, to the left parietal bone being tilted inwards beyond the middle line, thus depressing the vault of the skull. In his reconstruction the length of the skull is $190 \mathrm{~mm}$.; in mine, I $94 \mathrm{~mm}$. We shall see, when we come to deal 
with the basal parts of the skull, that Dr Smith Woodward has given the occipital bone an impossible position, thus contracting the posterior end of the skull. At the lower end of the occipital fragment of the Piltdown skull the posterior margin of the opening or passage for the exit of the spinal cord from the skull - the foramen magnumis distinctly preserved in the Piltdown fragment. Now, even in modern and highly evolved human skulls the posterior margin of this opening lies between 30 and 40 $\mathrm{mm}$. behind a line passing vertically through the ear-hole. In Dr Smith Woodward's reconstruction this margin is only 2 I $\mathrm{mm}$. behind the ear line (see fig. 1 86, p. 494). One result of the misplacement of the occipital bone is to shorten the base of the Piltdown skull so much that the space for a pharynx - the passage-way for air and food-is almost obliterated. The position of the occipital bone is in reality clearly indicated. When we transpose the occipital fragment, described in a former chapter, from the right to the left side (fig. I 42 ), and articulate it with the hinder margin of the left parietal bone, we obtain a definite indication of the amount to which the occipital bone enters into the formation of the length of the skull. The lower part of the lambdoid suture is $30 \mathrm{~mm}$. in front of the posterior vertical line in my reconstruction; only 20 $\mathrm{mm}$. in that of Dr Smith Woodward. It is in the occipital region that the discrepancy lies as regards the total length of our reconstructions.

Another remarkable feature of the Piltdown skull as reconstructed in fig. I 43 is the height to which the temporal bone rises on the side of the skull. It reaches $40 \mathrm{~mm}$. above the base line-more than can be seen in the very largest of modern skulls. We have always, until now, regarded a high temporal bone as an index of a large brain. The height of the squama of the temporal is not so apparent in Dr Smith Woodward's reconstruction, because of the tilting inwards of the temporal bone. As to the place at which the upper margin of the temporal bone comes into contact with the lower margin of the left parietal bone of the Piltdown 
skull, there is no room for doubt ; as regards that point, Dr Smith Woodward and I are in absolute agreement. The line and area of contact are shown in fig. I 43. The difference of opinion relates to the amount broken off or missing from the temporal bone. A glance at fig. I 43 will show that two fragments are broken from the squama of the temporal, one from its upper border and another from its anterior border. So little is missing, in Dr Smith Woodward's opinion, that he brings the broken margin of the temporal almost in contact with the anterior inferior angle of the parietal bone; whereas in my opinion an interval or gap must be left here, at least 8 or $10 \mathrm{~mm}$. wide. By articulating the temporal in the manner mentioned, Dr Smith Woodward, as may be seen from fig. 143, leaves no room for the great wing of the sphenoid. We have already seen that the impress of the great wing on the lower border of the frontal and parietal bones gives us the most certain information that the great wing had an exceptionally wide development. In the next chapter we shall see, from certain markings on the brain cast, that by approximating the temporal too closely to the parietal one of the main convolutions of the temporal lobe has almost been obliterated, and the temporal lobe itself given a distorted form.

The evidence which we obtain from a minute examination of the Piltdown skull in profile confirms the conclusions we reached during a survey of its other aspects. It is a skull with dimensions above the average and with certain peculiar characters, but in its general conformation it does not differ materially from human skulls of the modern type. The characters which mark Neanderthal skulls are all absent. 


\section{CHAPTER XXIV}

THE BRAIN OF FOSSIL MAN

IN the previous chapters I have thrust the tedious and technical details relating to the reconstruction of the Piltdown skull before the reader, but our real objective is to see what sort of brain was enclosed within it. The cranial wall is moulded to fit the brain. Hence when the skull is rightly reconstructed-but not until thenit provides us with a means of telling the size and shape of the brain. So exactly does the brain fill its cavity that the impress of its various parts - of its lobes and convolutions-are preserved. When a cast is taken of the interior of the cranial cavity, we see before us a rough image of the organ which guides mankind through the intricacies of life and reveals the world in which men live. In the case of the Piltdown skull, considerable parts of the cranial walls are missing, but enough are preserved to show us not only the general form and size, but also to give us definite information relating to the mental capacity of its original owner.

We all agree that a man with a big head or a large brain is not necessarily an exceptionally clever man. Those, however, who have studied the brain as experts are firmly convinced that unless a man has a certain size of brain he cannot think and act as ordinary men do. Professor Elliot Smith is of opinion that a brain must reach a weight of 950 grammes (or about 1000 c.c. in volume) before it can serve the ordinary needs of a human existence-before it can become the seat of even a low form of human intelligence. If we accept this definition, 
and most of us are content to accept the Professor of Anatomy in the University of Manchester as our leading authority on this matter, then it is certain that Pithecanthropus - that peculiar fossil form of man from Javafalls rather below the human limit. His discoverer, Dr Eugene Dubois, has estimated that the brain was about 855 c.c.; for certain reasons I regard this as rather an underestimate -900 c.c. will probably prove to be nearer the truth. The anthropoid apes fall far below the human level. A gorilla has been found to have a brain capacity of 6 Io c.c.; in an exceptional chimpanzee it was as low as 290 c.c. In the majority of great anthropoids-orangs, chimpanzees, and gorillas - the capacity fluctuates between 400 and 500 c.c. Amongst modern human races the brain is found to vary in size ; it may be as low as 950 c.c. or as high as i 900 c.c. The late Sir William Flower divided human skulls into three sizes-small or microcephalic, medium or mesocephalic, and large or macrocephalic. In this manner of classifying skulls an individual with a brain space of less than I 350 c.c. falls into the microcephalic group; if above I450, into the macrocephalic group. Thus, including all the races of mankind in our survey, we are prepared to regard those with a brain measuring between I 350 c.c. and I 450 c.c. as having reached the standard brain size of modern human races. Suppose, then, the Piltdown man, who lies thirty or fifty thousand generations behind us, were to reappear among us in the flesh, to what group would he be attached? If we take Dr Smith Woodward's estimate of I070 c.c., then he is microcephalic and falls almost to the limit which lies between the lowest human and the highest prehuman brain capacity. Dr Smith Woodward had a brain cast made from the Piltdown skull. When that cast is measured, it is found to displace I I95 c.c. of water ; in round numbers, then, the size of the brain, even when the cranial fragments overlap their normal positions, measures 1200 c.c. - thus reaching a middle place in the small-headed group. As I write, another official reconstruction of the skull has been exhibited at a meeting of 
the Geological Society, held on the I 7 th of December 1913 , exactly a year after the famous one mentioned in a former chapter. In the new official reconstruction the hinder end of the skull has been opened out to a very considerable extent. As amended, the cranial capacity cannot fall much short of I 300 c.c. Thus we see the brain capacity of this very ancient man, even in official hands, steadily climbing from the bottom to the top of the microcephalic group of humanity.

The reader will now begin to see why I have taken so much care to verify and prove every step taken in the reconstruction of the Piltdown skull. If my methods are right, if the laws which hold good for skulls in general are applicable at Piltdown, then we must promote this early Pleistocene or late Pliocene man to a still higher group. In the previous chapter we found from the measurements of the skull that the brain capacity should be about 1400 c.c. The original reconstruction assigns the Piltdown individual, as regards mere size of brain, to the small-headed group ; my one gives him or her a good place in the medium-headed group. In either case, the important fact remains that so long ago as the beginning of a former geological period a form of mankind had come well within the human standard of brain size. We could have no better assurance that the antiquity of man is very great.

Size of brain, as we have already admitted, is a very imperfect index of mental ability. We know that certain elements enter into the formation of the brain which take no direct part in our mental activity. A person who has been blessed with a great, robust body and strong, massive limbs requires a greater outfit of nerve tracts and nerve cells for the purposes of mere animal administration than the smaller person with trunk and limbs of a moderate size. Dr Eugene Dubois ${ }^{1}$ and the writer ${ }^{2}$ have made

1 Report of the Fourth International Congress of Zoologists, Cambridge, 1898, p. 78. Koninklijke Akad. van Wetonsch. te Amsterdam, I914, vol. xvi. p. 647 .

2 Journ. Anat, and Physiol., 1895, vol. ix. p. 282. 
endeavours to ascertain how much of the human brain is made up of this purely animal constituent. An appeal to the conditions found amongst anthropoid apes gives us some assistance in solving the problem. In size of body man differs very little from the great anthropoid apes; indeed the male gorilla and orang often attain a weight of 70 or $80 \mathrm{~kg}$. (I 54 to I 76 lbs.), or even more. With a brain volume of +50 c.c. an anthropoid has a sufficient nerve organisation to undertake the more animal form of its activities. When the brain reaches a volume of I 300 or I 400 c.c., as in man, we need not trouble greatly about the amount which is due to mere size of body; it cannot be more than 6 per cent. or 8 per cent. of the whole. Besides, we have reason to infer that the Piltdown individual was not a Hercules. We have the impress of the neck preserved on the skull. The muscles of the neck were not particularly strong, nor was the neck massive as in the gorilla or as in Neanderthal man. The bones of the skull are thick and massive; it is possible that the bones of the skeleton were also thick and strong, but the indications preserved on the skull point to rather a moderate development of the muscular system. We have no reason, then, to regard the brain volume of Eoanthropus as dependent on a massive development of the body.

We now turn from a consideration of the gross volume of the Piltdown brain to survey its particular featuresthe size and arrangement of the lobes and convolutions. A survey of the original brain cast prepared under the direction of Dr Smith Woodward led Professor Elliot Smith to express the following opinion: "Taking all its features into consideration, we must regard this as being the most primitive and the most simian human brain so far recorded." Such an opinion cannot be lightly brushed aside; it must command our respect and also our most careful consideration. Unfortunately, our knowledge of the brain, greatly as it has increased of late years, has not yet reached the point at which we can say, after close examination of all the features of a brain, that its owner 
had reached this or that mental status. The statement which Huxley made about the ancient human skull from the cave of Engis still holds good of the brain : "It might have belonged to a philosopher or might have contained the thoughtless mind of a savage."

That is only one side of our problem ; there is another side. Huxley's statement refers to the average brain, which is equal to the needs of both the philosopher and the savage. It does not in any way invalidate the truth that a small brain with a simple pattern of convolutions is a less capable organ than the large brain with a complex pattern. If, then, we find a fairly large brain in the Piltdown man, with an arrangement and development of convolutions not very unlike those of modern man, we shall be justified in drawing the conclusion that, so far as potential mental ability is concerned, he had reached the modern standard. We must always keep in mind that accomplishments and inventions which seem so simple to us were new and unsolved problems to the pioneers who worked their way from a simian to a human estate.

For the interpretation of the brain casts of ancient man we must carry with us a comparable image of a modern brain. The brain cast represented in fig. 145 is taken from the skull of an Australian native ; the capacity of the skull was I 450 c.c. The type specimen we are to use lies on the border-line between the medium and largeheaded groups of humanity. The fissure of Sylvius is clearly visible on the cast; it separates the temporal lobe below from the two great upper lobes-the frontal and the parietal. ${ }^{1}$ On the brain cast the central fissure which separates the frontal from the parietal lobe is indistinctly marked, but its situation can be fixed with a fair degree of certainty. A fourth lobe, the occipital, lies behind; a depression represents the parieto-occipital fissure (see fig. I 45), which marks the small occipital lobe off from the parietal. Below, the occipital lobe becomes united with the temporal lobe.

Of those four main lobes of the brain just enumerated 1 See Appendix B. 
the frontal deserves our first consideration. It constitutes a large and important part of the brain. On its lower surface is seen the hollow impression formed by the roof of the orbit; on the rounded lateral and upper surfaces which lie under the forehead can be detected at least three longitudinal elevations separated by irregular shallow depressions. The elevations indicate the upper, middle,

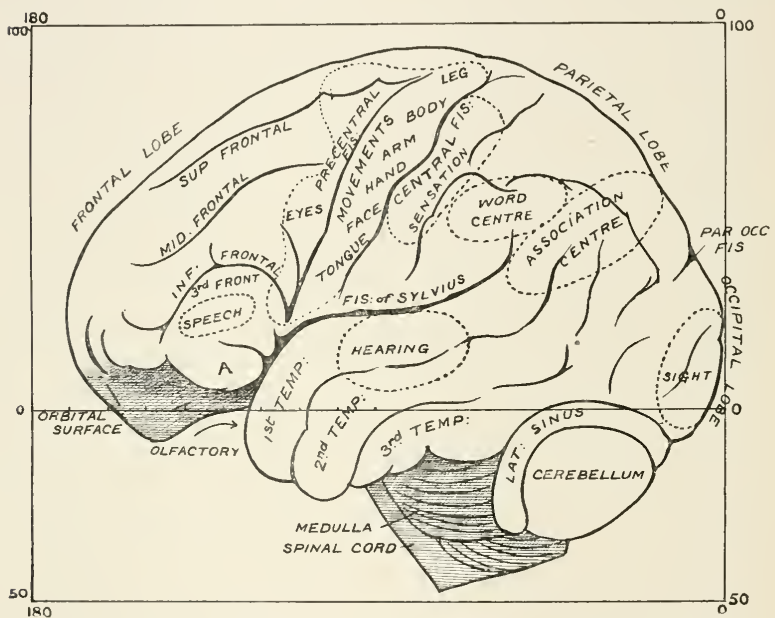

FIG. I45.-Diagram made from a brain cast of an Australian native, with a capacity of 1450 c.c. The divisions between the various lobes and convolutions of the brain have been emphasised. The functional values of various parts are indicated.

and lower frontal convolutions. The lowest or third frontal convolution is very well marked; it overlies the hollow caused by the roof of the orbit, and is separated from the temporal lobe by the stem or beginning of the fissure of Sylvius. Now the inferior frontal convolution is of particular importance for our present purpose; it attains a large and special development in the human brain. In the anthropoid brain, on the other hand, it is not large, nor does it possess the human conformation. 
At the present time we regard the main mass of this convolution as one of the parts of the brain directly concerned in speech. The exact rôle it plays in thinking and speaking we are really not quite certain about. But we may say that if this part of the brain is found developed in any race of ancient man, that such a race possessed at least the potentiality, if not the actuality, of speech. As to the functional value of the upper and middle frontal convolutions, we are at present not in a position to offer any certain opinion. These convolutions attain a much greater development in man than in the anthropoids, and we are justified in believing that they do take an active part in carrying on the functions of the brain.

Behind the three frontal convolutions just named lies an important area of the brain (fig. I 45). In the centre of this area descends the central fissure-the boundary between the frontal and parietal lobes. Just in front of the central fissure is the pre-central area, concerned in the movements of the body. In the lower part of the precentral convolution, just above the fissure of Sylvius, lie the centres for the tongue, lips, and face, close to the third frontal lobe, which is connected with speech. In the pre-central convolution we meet with centres for the hand, arm, body, and leg, arranged in a definite sequence from below upwards. In front of the areas more directly concerned in exciting and controlling the muscles lie other areas - association areas - probably concerned in treasuring up memories of how certain acts are performed. These association areas extend to the hinder ends of the upper, middle, and lower frontal convolutions.

Below the fissure of Sylvius lies the temporal lobe, on which three convolutions - the first, second, and third - can usually be recognised with great distinctness on brain casts. The functional value of the two lower, the second and third, is scarcely known to us. But in the upper convolution is situated the centre of hearing - that part of the brain which receives messages from the ear, 
and apparently treasures the memory of sounds and associates particular sounds with particular meanings. This part of the brain must also be regarded as concerned in speech.

The occipital lobe is connected with sight. On the occipital pole itself, and on the surface which lies buried in the fissure between the two hemispheres of the brain, is the area where impressions streaming in from the eyes reach the horizon of our consciousness. Spread out on the surface of the brain, in front of the visual area of the occipital pole, are others which are known as association areas-evidently connected with the elaboration and interpretation of the visual impressions which reach the brain. The parietal lobe constitutes the central part of each hemisphere of the brain; it lies behind the frontal lobe, above the temporal, in front of the occipital. The part of the parietal lobe lying just behind the central fissure--the post-central convolution-receives sensory impressions coming from the skin and body generally (fig. I 45), but the greater part of this lobe seems to serve the higher purposes of the human brain-the purposes of memory and interpretation. For instance, the part which lies above the hinder end of the fissure of Sylvius seems to be concerned in the interpretation of written or printed words. At least, in many cases of "word-blindness"- - cases where words can be read but not understood-this area of the parietal lobe is found to have been destroyed by disease. The "word-interpreting " centre is placed in this association area, which often rises above the surrounding parts of the brain into a distinct elevation or eminence. Enough has been said to show that, imperfect as our present knowledge of the brain is, we may hope to obtain some light on the mental status of fossil man by a careful study of brain casts. Indeed, I firmly believe that the day will come when we can estimate the functional value of every convolution of the brain.

Having thus formed a broad picture of the chief features to be seen on the brain cast of a modern skull, 
we are in a position to apply our knowledge to casts taken from fossil skulls. It will be well, however, to have a clear idea of a simple and primitive brain, such as is seen in the highest of anthropoids-the gorilla. In fig. I 46 , I have set a profile drawing of the brain cast taken from the skull of a young gorilla on the same aspect of the cast of the Gibraltar skull-the smallest of the ancient human skulls. Both were drawn on the same scale and poised on corresponding planes. The superimposition of the two drawings is an easy matter, for they have both the same general form-they are flattened as if the vault had been compressed towards the base. The fissure of Sylvius of the ape is laid over the same fissure of the human brain. The triangular hollow between the temporal lobe and the cerebellum, filled in life by the part of the temporal bone which contains the ear, is also superimposed. The superimposition of these two drawings (fig. I46) shows us that in the evolution of the brain from a simian to a human stage all the lobes and convolutions were involved. There has been a general and extraordinary elaboration of all parts. The parietal lobe has been affected most ; the temporal lobe least. We know something of the nature of the changes which have occurred. While enumerating the lobes of the brain, we noted that certain areas or centres were primary - the areas for -sight, hearing, common sensation-and that round the primary areas, association areas had arisen. It is the expansion and elaboration of these association areas-complex mechanisms built up of nerve cells and nerve fibres adjusted to serve definite purposes-which raises the human above the simian brain. In this expansion the simple arrangement of convolutions has been replaced by a more elaborate and complex one. In the last two months of fœtal life the human brain passes from a stage in which the convolutions of the brain have a simple, somewhat anthropoid arrangement to the more complex human form. Even amongst modern people the degree to which the simple arrangement is replaced by the more 
complex varies very widely. It is highly possible that these later changes of the fotal brain may represent the later stages in the evolution of the human brain.

While the passage from the simian to the human stage of development has affected every lobe of the cerebrum and of the cerebellum, there is one part which has undergone a peculiar change, one which is often fore-

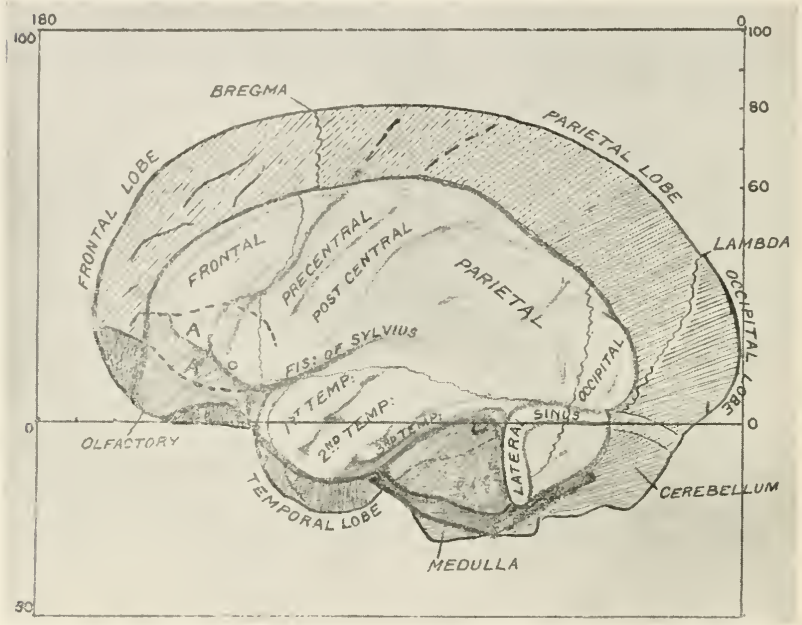

FIG. 146.- Profile drawing of the brain cast from the skull of a young gorilla superimposed on a corresponding drawing of the cast from the Gibraltar skull. The Gibraltar cast exceeds that of the gorilla in all dimensions.

shadowed to a slight degree in the anthropoid brain. The change concerns the lowest part of the frontal lobe - the inferior or third frontal convolution. The actual part concerned is marked on the gorilla brain in fig. I 46 by the letter $A$. In the human brain this part has grown and expanded to such an extent that it reaches right back to the stem of the fissure of Sylvius, forming the anterior boundary of the stem (fig. I+5, A). The old lower boundary of the third frontal convolution (marked 0 
in fig. I 46 ) becomes included above the new development of the third frontal convolution, and in the human brain forms an intrinsic part-the anterior ramus or branch of the Sylvian fissure. It is in this manner that Professor Elliot Smith explains the changes which have occurred in the evolution of the third frontal convolution of the human brain. ${ }^{1}$ The change is especially remarkable when we remember that this new orbital part of the frontal lobe is related to the faculty of speech.

When we turn to an examination of the Piltdown brain cast we naturally centre our attention on the third frontal convolution. We at once see (fig. I 47) that as regards size and general conformation it reached the human standard. In Dr Smith Woodward's reconstruction (fig. $\mathrm{I}_{4} 8$ ) this convolution appears even larger than in mine, because the upper part of the frontal lobe has been tilted beyond the middle line, thus exposing more of the lower or orbital surface of the convolutions. A comparison of either of these drawings with fig. I 49 , which represents a brain cast from the skull of an Australian native, with a capacity of $\mathrm{I} 450$ c.c., shows that the ancient man of Sussex is little, if any, the inferior of the modern Australian. In all three brains one can see a depression indicating the anterior ramus (A.R. in figs. I 47, I 48, I 49). In the ape's brain, it will be remembered, this branch of the Sylvian fissure is not included within the third frontal convolution, but forms its lower boundary. In the Gibraltar brain cast (fig. I 50) the third frontal convolution is smaller, and the anterior ramus, although it was probably present in the actual brain, is not apparent on the cast. So far as concerns the third frontal convolution of the Piltdown brain, there is nothing to suggest that it represents a

${ }^{1}$ In this matter and in others, the reader, if he wishes fuller information on the brain of fossil man, should consult the following papers by Professor Anthony: "Le système operculaire supérieur du Complex Sylvien," Bull. ct Mém. Soc. d'Anthropologie de Paris, Oct. 1912, p. 294 (with Dr de Santa Maria) ; "L'Encéphale de l'homme fossile de la Quina," ibid., March 1913, p. 117. Professor Elliot Smith's account of the brain of anthropoids will be found in the Catalogue of the Wuseum of the Royal College of Surgeons of England, Physiological Series, vol. ii., 1902. 
very primitive human state. It is true that it is more depressed, more excavated, as it approaches the fissure of Sylvius than it is in modern brains, but this compression is due, as I suppose, to the massive buttress of bone which apparently pressed within the commencement of the fissure of Sylvius. If our present conception of the function of the orbital part of the third frontal convolu-

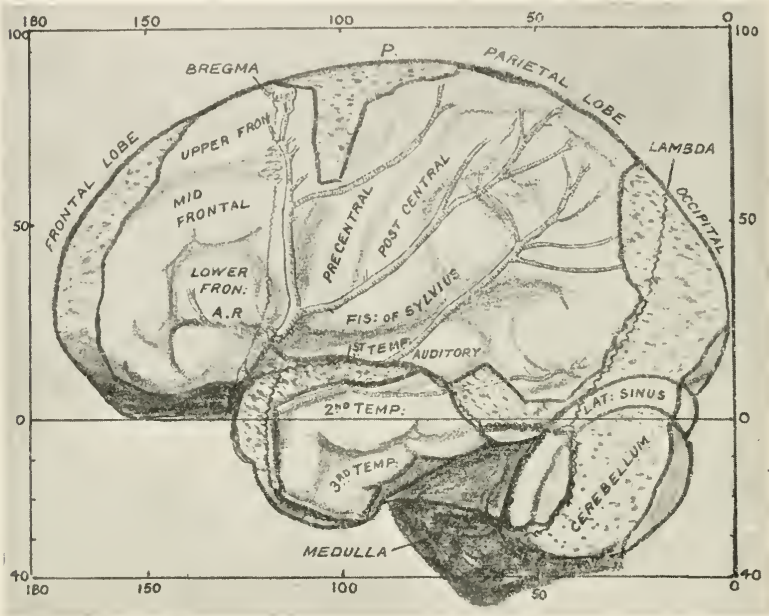

FIG. 147.-Profile drawing of the brain cast taken from the reconstruction of the Piltdown skull by the Author. It is represented half size and set within a standard frame of lines which permits direct comparison between the various drawings given here. The positions of the sutures between the containing bones are indicated. The missing parts are stippled.

tion is well founded, namely, that it takes a part in the mechanism of speech, then we have grounds for believing that the Piltdown man had reached that point of brain development where speech had become a possibility. When one looks at the jaw, however, and the projecting canine teeth, one hesitates to allow him more than a mere potential ability.

It is convenient now to direct our attention to the 
temporal lobe, which is separated by the stem of the fissure of Sylvius from the inferior frontal convolution. We have two reasons for taking our survey of the brain in this order : (I) because part of the first temporal convolution is directly concerned with the sense of hearing, and in the interpretation of sounds and words ; (2) because we here meet with one of the chief dis-

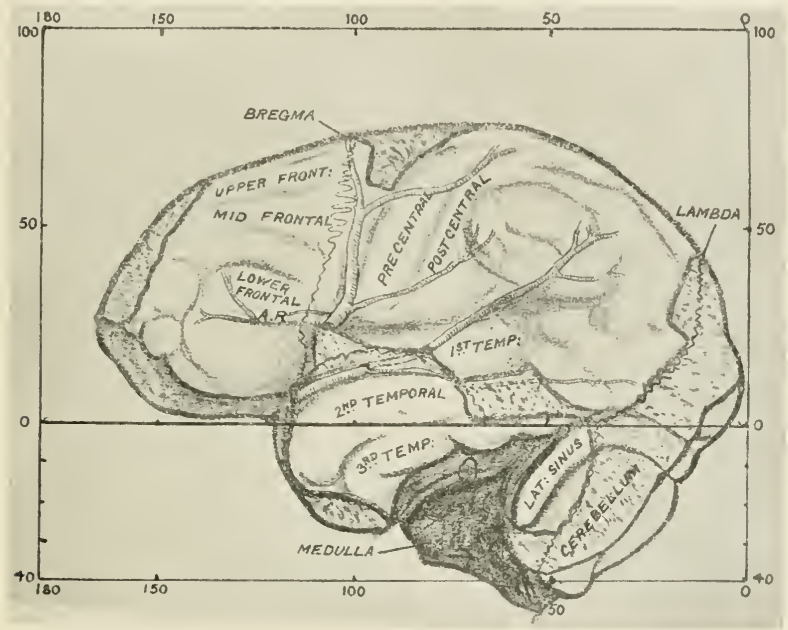

FIG. I48.-Profile drawing of the original cast of the Piltdown brain. The missing parts are stippled and the positions of the suture lines are indicated. To facilitate comparison with other brains, the drawing is set within a standard frame of lines.

crepancies between Dr Smith Woodward's and the writer's reconstruction of the Piltdown skull and brain cast. In the Gibraltar brain cast, perhaps the most primitive representation of the human brain as yet found in fossil man, one clearly recognises the three temporal convolutions - the first, second, and third (fig. I 50). In the gorilla brain cast they are also apparent: the third or lowest is small and but slightly represented on the 
lateral aspect of the skull (fig. I46). In the cast of the Australian brain the three temporal convolutions are apparent (fig. I 49). In these brain casts, the first convolution passes along the whole length of the lobe, on the lower side of the fissure of Sylvius. When the temporal region of the original reconstruction of the Piltdown brain cast is examined (fig. I 48 ), an anomalous

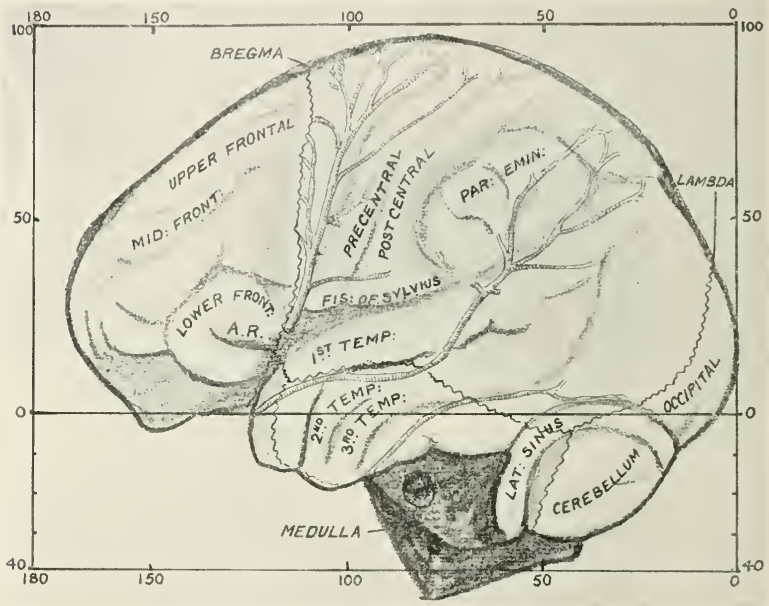

Fig. 149. - Profile drawing of the brain cast from the skull of an Australian native, with a capacity of $145^{\circ}$ c.c. It will be observed that the vessels seen on the surface of the brain cast - the meningeal vessels-are arranged exactly as on the Piltdown brain cast. The positions of the furrows between the brain convolutions and of the sutures between the overlying bones are indicated.

arrangement is seen in the first temporal convolution. The impress of the posterior or upper part of this convolution is well preserved beneath the left parietal bone. On the part preserved there is a well-defined eminence marking the area connected with hearing-the auditory eminence. Towards the lower part of the temporal lobe-in the region of the stem of the fissure of Sylvius - the first temporal convolution is represented 
by a narrow area, less than $8 \mathrm{~mm}$. wide, lying between the second temporal convolution and the orbital part of the third frontal. It would be a very remarkable condition if the second and third temporal convolutions were so well developed as they are in the Piltdown brain, and the first reduced to such a narrow limit at its anterior end. The explanation I offer of this anomaly is that in articulating the temporal bone, which contains the greater part of the temporal lobe of the brain, Dr Smith Woodward tilted it too far forwards. The great wing of the sphenoid was prevented from taking its due share in the formation of the wall of the brain cavity. When the sphenoid is given its fair share, as in fig. I 47, the abnormal contraction of the first temporal convolution disappears. Indeed, if the restoration just suggested is the right one, then the temporal lobe of the Piltdown brain differs very slightly from the corresponding lobe in the brain cast of a modern native Australian or of an average European.

When the temporal bone is articulated as in fig. I 47 another feature disappears from the temporal lobe of the Piltdown brain. Professor Elliot Smith has drawn attention to the manner in which this lobe is bent inwards on the base of the brain. The same feature is present, but to a less extent, in the Gibraltar brain cast and in brain casts of anthropoids. We have a reasonable explanation for the sharp inward bend of the temporal lobe in Neanderthal brain casts. In Neanderthal skulls, as in those of anthropoid apes, the brain chamber is flattened, as if the vault had been compressed towards the base. The shape of the brain explains why the temporal lobe in these cases is bent inwards. In the Piltdown man the sharp inward bend of the temporal lobe results from the manner in which the reconstruction was originally carried out. When the side of the skull is moved outwards so as to bring the parts on the vault into their just relationship with the middle line, and at the same time the temporal bone adjusted so as to give room for the great wing of the sphenoid, the inward bend of the 
temporal lobe becomes reduced almost to an ordinary degree. Thus a survey of the temporal lobe reveals no really primitive feature. The temporal convolutions were apparently simple in form; the auditory centre was plainly indicated, and in general mass the convolutions are such as are met with in human brains of medium or even larger size.

In skull reconstruction nothing is truer than that one

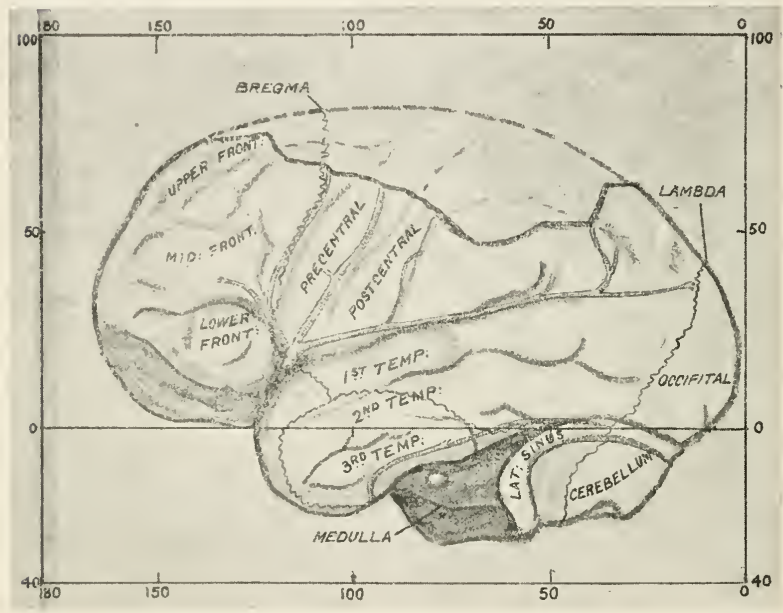

FIf. 150.- Profile drawing of the brain cast of the Gibraltar skull. It represents the smallest known brain of the extinct Neanderthal race.

mistake leads to another, and the effect is cumulative. The malposition of the temporal bone, which led to the partial obliteration of a convolution, also had another consequence, seen in the hinder region of the base of the brain. In a complete brain cast, the stem which prolongs the central nerve system to the spinal cord is represented (fig. I +5). The stem, or medulla oblongata, is seen to lie below and also in front of the cerebellum. A triangular interval filled by the petrous part of the temporal bone is 
seen between the cerebellum and temporal lobe (fig. I 49). The direction of the stem is downwards and backwards. In anthropoids, and also to some degree in Neanderthal skulls, the trend of the brain stem is more backwards than downwards (see fig. 146 ). In the original Piltdown brain cast the trend of the brain stem is the opposite of primitive ; it is directed downwards with a slight forward tendency (fig. 148 ). This anomalous position of the brain stem is the result of two circumstances: (I) the forward twist given to the temporal bone, and, (2), to the anomalous position given to the occipital bone. If the brain cast of a modern skull be examined (fig. I 49) it will be seen that the hinder part of the stem-occupying the posterior margin of the foramen magnum-lies well behind the mastoid part of the temporal bone. In the original reconstruction (fig. I48) the hinder end of the brain stem is situated directly below the mastoid part of the temporal bone, and at an abnormally low level. This arrangement at the hinder part of the base of the brain gives very exceptional and peculiar features to the original Piltdown reconstruction. The forward position of the occipital bone and brain stem necessarily diminished that part of the base of the skull on which the brain stem rests. Indeed, to such a degree was this part of the base of the skull curtailed, that when the face and palate were restored in the original reconstruction it was found that an altogether insufficient space was left for the pharynx. When, however, the temporal bone is adjusted and the occipital bone placed as it is in modern skulls (see fig. 147), all these anomalies disappear, the brain stem assumes its normal trend, the occipital bone its normal relationships, and an ample space is provided for the passage of food and air along the pharynx. So far, then, we have seen no feature of the Piltdown brain to which we can apply with any certainty the term of primitive or simian. All the characters we have encountered are not very unlike those seen in modern skulls and brains.

We have confined our attention to the parts of the brain near the base. When we pass to the region covered 
by the vault and examine such indications as are apparent on the frontal and parietal lobes, our statements become less certain. The two upper frontal convolutions, so far as they are preserved, were apparently simple, but not small. The convolution of the central region-where the centres for movement and common sensation have their seat-are not sharply indicated on the cast; they certainly were not highly developed. On the hinder region of the vault the parietal eminence is well marked. In position and extent, the raised convolutions which form this eminence do not differ from those seen in brain casts taken from modern skulls. I cannot detect any feature in the frontal, parietal, or occipital areas which clearly separates this brain cast from modern ones; nor can I recognise any feature which has a distinct claim to be regarded as simian or primitive. A survey of the convolutionary regions of the brain leads to the conclusion that we are dealing here with a simple and primitive arrangement of parts; but not so simple or so primitive as to make us wish to place the Piltdown brain in a class apart from modern human brains. To my mind it appears, even in its convolutionary arrangement, to fall well within the limits of variation seen in modern human brains.

We have been studying the brain as it presents itself to us in a side view. A cursory survey of the brain casts from behind will prove instructive at this stage of our inquiry. We are thus provided with an opportunity of surveying both hemispheres of the brain-the right and left-and of dealing with the problems relating to their symmetry. The right and left halves of the body are built so as to match each other, but if we use one side more than the other or differently to the other, then we expect a certain degree of asymmetry to appear. The right and left halves will no longer remain exact counterparts, either in function or in form. A difference in form indicates a difference in function. If we are righthanded, then the right side of the body preponderates. There is a crossing of the nerve tracts of the body, and 
it thus comes about that the right half of the body is more directly connected with the left hemisphere of the brain, and vice versâ. I have never seen a human brain in which the convolutionary pattern of both sides was alike. In the human brain there is evidently some degree of specialisation in its two hemispheres. At the

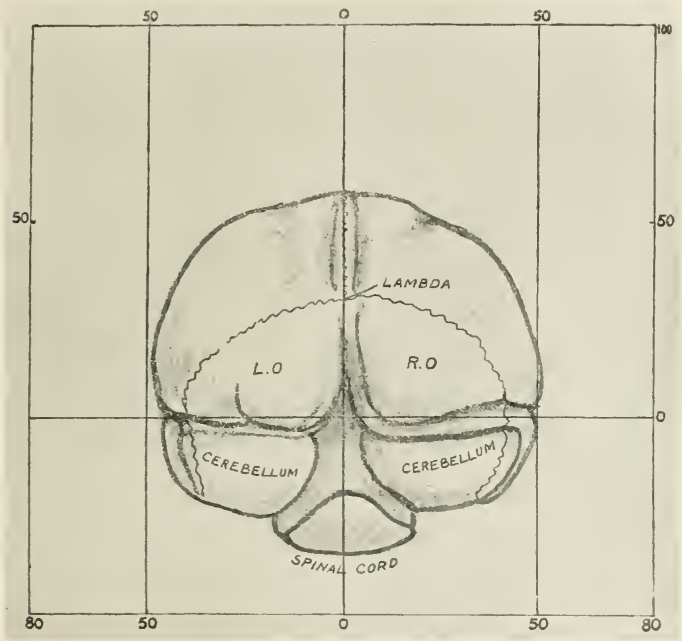

FIG. 151.-The occipital aspect of the brain cast from the skull of a young gorilla, to show the slight degree of asymmetry of the left and right sides. The drawing has been set within the standard lines used for the human brain, so as to give a true comparison as regards size of the anthropoid and human brain.

present time we regard perfect symmetry of the two hemispheres of the brain as indicative of a similarity in function; a high degree of asymmetry, if not due to a disturbance of normal growth, betokens a specialisation of function. An asymmetrical brain, then, is a specialised brain, the opposite to the primitive symmetrical brain.

In fig. I 5 I is represented the occipital or hinder aspect of a gorilla's brain cast. The right and left sides are 
almost alike. The impress of the longitudinal bloodsinus can be detected along the whole length of the vault of the brain between the two hemispheres. As it courses down to the occipital region, it is continued between the right occipital lobe above and the right half of the cerebellum below as the right lateral sinus. The left occipital pole is rather larger than the right pole. The right half of the cerebellum is rather larger than the left half. There is thus some indication of a specialisation of function in the occipital region of even a gorilla's brain - a region connected with the function of sight. The medulla emerges between the lateral lobes of the cerebellum to become continuous with the spinal cord. The outline of the occipital bone is shown; its right and left halves are approximately symmetrical. Further, it will be noticed that in width the gorilla brain just reaches the 50-mm. lateral vertical lines. In height, the right and left halves of the cerebrum fail to reach the $60-\mathrm{mm}$. level.

In fig. 152 the brain cast from an Australian skullthe same specimen as was represented from the side-is drawn from exactly the same point of view as was adopted in the case of the gorilla; there is a marked contrast in shape and size between the two. The vault of the modern human brain cast is not flattened from above downwards, as in the gorilla and as in Neanderthal man, but is lofty and peaked, rising almost to the Ioo-mm. level. In the gorilla the sides of the brain cast bulged outwards, but here, in the Australian brain cast, they are compressed and reach well beyond the 50- $\mathrm{mm}$. verticals, almost to the $70-\mathrm{mm}$. lines. In both, however, there is about the same degree of asymmetry; the left occipital lobe and the right cerebellar are the larger. The longitudinal sinus behaves in the same way in both. Before reaching the hinder ends of the parietal bones, the sinus leaves on the brain cast a long, oval elevation, with a sharply depressed lateral border. Then it passes between the occipital lobes and turns to the right as the right lateral blood-sinus. It will be noted that the lateral sinus and occipital poles descend well below the horizontal 
zero line in the Australian brain cast; in the gorilla's brain cast the poles and sinuses are nearly on a level with the zero line. A low position of the occipital poles is a more highly evolved condition. The brain stem has a downward direction in the Australian, whereas its direction is backwards in the gorilla. The right and left margins of the occipital bone are nearly symmetrical.

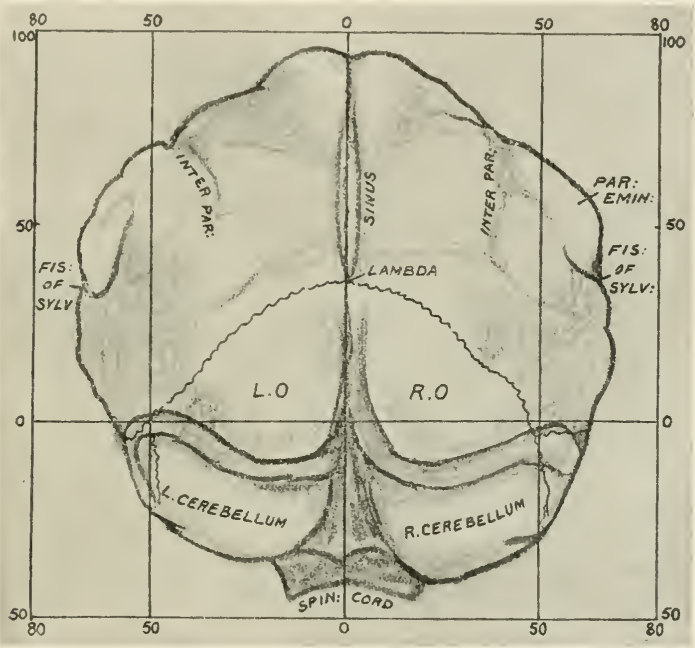

FIG. 152. - Brain cast from the skull of an Australian native (capacity 1450 c.c.), to show the parts of the brain presented in a view from behind.

When we view the original reconstruction of the Piltdown brain cast from behind we are at once impressed by the number of its peculiarities. On the vault of the cast we can note no trace of those signs which indicate the position and course of the longitudinal blood-sinus, such as are to be seen on the brain casts of anthropoids and men. The natural inference is that the parts of the bone which carried the marks of the sinus have been broken away and are missing. The right and left 
occipital poles of the brain are nearly symmetrical; each almost reaches the middle line. As in the casts from the gorilla and Australian native, the longitudinal sinus, seen between the occipital poles, turns to the right. Lower down, however, we note one peculiar feature : the right lobe of the cerebellum passes far to the left of the middle line. Further, we know that the ridge on the occipital bone which marks the middle line of the neck lies nearly ro $\mathrm{mm}$. ( $\frac{2}{5}$ inch) to the left of the middle line given to the brain. While the occipital lobes are thus given a primitive symmetrical arrangement, we note that there is a large degree of discrepancy between the right and left halves of the lambdoidal suture. On the left side this suture crosses the $50-\mathrm{mm}$. line-almost as in the Australian cast. On the right side it falls far short of the $50-\mathrm{mm}$. line; indeed, to obtain approximate symmetry of the two sides the position of the right lambdoidal suture must be moved outwards as is shown in fig. I 53. To make the right hemisphere of the brain match the left, it must be moved outwards to the position of the stippled line shown in fig. I53. A survey of those anomalous features leads us to the conclusion we reached when examining the skull, namely, that they result from faulty reconstruction.

When the fragments of the cranial cast are adjusted as in fig. 154, the size and form of the Piltdown brain undergoes a considerable change. The brain cast is now comparable in all its parts with those taken from modern skulls. Only one trace of the longitudinal sinus on the vault is visible-the sharp, inward depression at the upper angle of the left parietal fragment. There is no escape from the fact that a high degree of occipital asymmetry is present, such a degree as is only seen in modern skulls with a considerable brain capacity. While working in Egypt, amongst the crania of the ancient inhabitants of that country, Professor Elliot Smith and Dr Wood Jones found that individuals which showed in their skulls this high degree of preponderance of the left occipital pole also showed marked evidence of a specialisa- 


\section{THE BRAIN OF FOSSIL MAN}

tion of the right hand and right side of the body. The man who chipped the eoliths which lay beside the skull in the Piltdown gravel evidently had reached a high degree of right-handedness. While investigating the peculiar preponderance of the left occipital pole in modern skulls, I was struck by the fact that it is accompanied by a corresponding asymmetry in the lambdoid suture. On

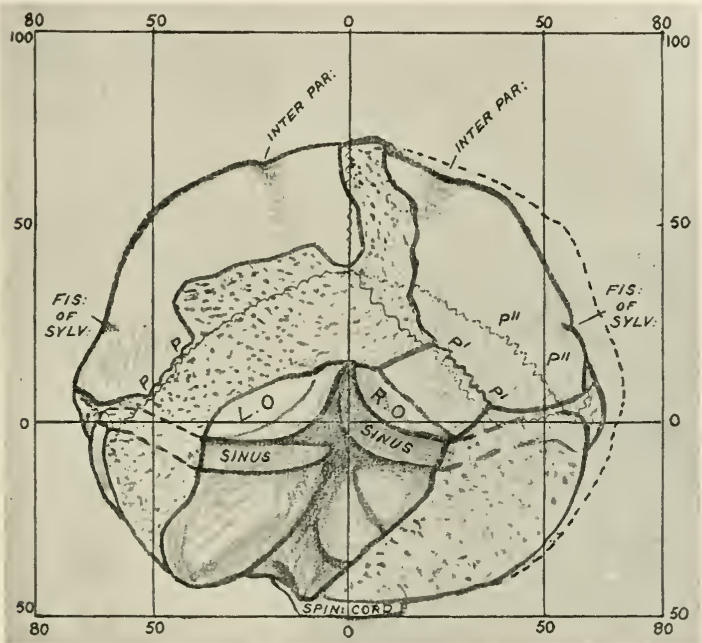

FIG. 153.-An occipital view of the original brain cast of the Piltdown skull. On the right side the stippled line indicates the degree of expansion required to make the right hemisphere of the brain symmetrical with the left.

the left side the lambdoid suture in such skulls crosses the $50-\mathrm{mm}$. line higher up and passes further beyond it than on the right side. I mention this fact because in the reconstructions of the Piltdown fragments shown in figs. I 53 and 154 the condition of the lambdoid suture is reversed. In fig. I 54 the left occipital lobe of the brain is given its just preponderance, and the left half of the occipital bone has been made more extensive than the right. In the development of the occipital poles, then, 
this early Pleistocene man shows, not a primitive feature, but one which must be regarded as evidence of a fairly high degree of specialisation.

Before leaving the occipital aspect of the skull there are several features to which attention should be drawn. It will be observed (fig. I 54) that the lateral sinuses fall almost on the horizontal zero line-a primitive character. A second point worthy of notice is that while the original

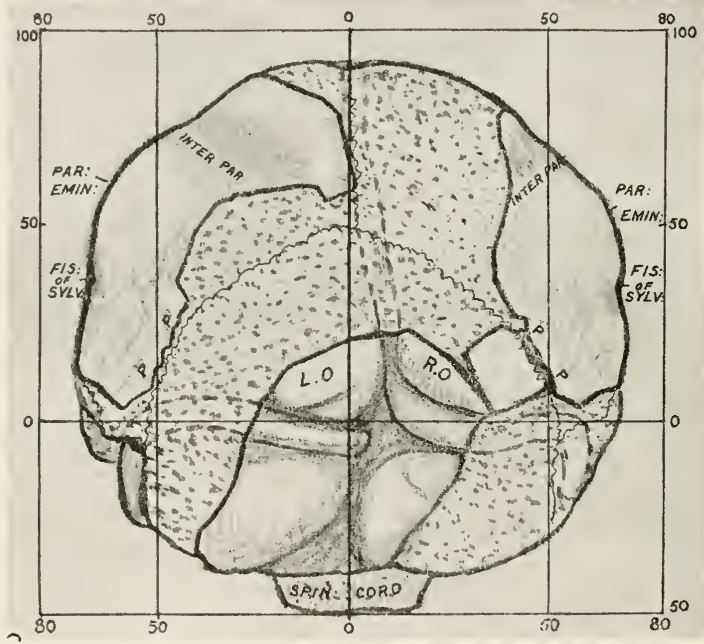

FIG. 154.-Occipital view of the Piltdown brain cast as restored by the Author.

brain cast (fig. I 53) is given the flattened form with which we are familiar in the brain casts of anthropoids and of Neanderthal men, the other reconstruction has assumed a form very similar to that found in brain casts taken from modern skulls (compare figs. I 52 and I 54). The most important feature to be noted, however, is the general enlargement of the brain which results from the opening out of the vault of the skull in order that the various parts may be brought into their proper relationships to 
the middle line. The opening out of the vault completely alters our estimate of the Piltdown brain. In the original cast (fig. 153) the parietal eminences are situated almost on the upper aspect of the vault; the interparietal depression approaches within $20 \mathrm{~mm}$. of the middle line of the vault (fig. 153). When the vault is opened out, the parietal eminences and interparietal depressions assume almost the same relationship as in modern man (compare figs. I 52 and I 54). We have seen that the parietal lobe of the brain-of which the eminence forms a central part--is the seat of higher or association centres. The anomalous closing of the vault in the original brain cast deprived Piltdown man of a very large area of the parietal lobes-deprived him of one of the areas which are characteristic of the human brain.

There is still another aspect of the brain we must examine before we are in a position to give a definite opinion on the cerebral endowment of fossil man. In fig. I 55 a view of the upper or vault aspect of the brain cast from the skull of a native Australian is represented. It is especially important to note the various features seen along the middle line of the vault from front to back, for much of the difference of opinion regarding the Piltdown brain centres round a correct identification of the middle line. In the Australian cast (fig. I 55) the middle line at the very front of the vault is marked by a groove between the right and left frontal lobes. Very soon, however, this groove, in which the longitudinal sinus lies, disappears, and is replaced, before the bregma is reached, by a wide elevation or ridge on which no distinct impress of the median blood-sinus is visible (fig. I 55). This median frontal elevation, with a slight groove running along its summit, is continued backwards under the anterior twothirds of the parietal bones. There, the wider elevation disappears, and is replaced by a narrow, oval ridge-the first clear trace of the great longitudinal blood-sinus to be seen on the vault of the brain cast. A little distance in front of the lambda this narrow, well-defined ridge disappears (fig. 1 55). The wider elevation, running along 
the middle line of the vault in front of, and behind, the bregma, is caused, not by median convolutions of the brain, but by a remarkable vascular arrangement of which the longitudinal sinus forms the main part. The median elevation is a vascular not a convolutionary impression.

The next brain cast we propose to examine on the

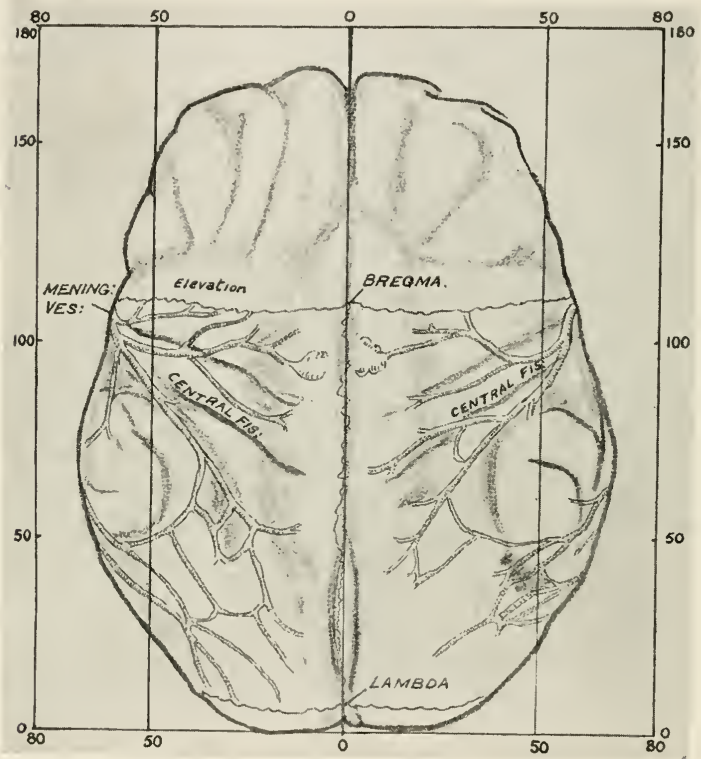

FIG. 155.-View of the upper aspect of a brain cast taken from the skull of a native Australian.

upper aspect is taken from the Neanderthal calvaria (fig. I 56). It has a particular interest for us in solving the problem of man's antiquity. It represents the brain of a remarkable and very ancient type of humanity which we suppose to have died out soon after the middle of the Pleistocene period. A comparison of figs. I 55 and I 56 , representing the modern and ancient forms of brain, at 


\section{THE BRAIN OF FOSSIL MAN}

once brings home to us the fact that a large brain is not the monopoly of modern man. Now, when we examine the track of the longitudinal sinus along the vault of the Neanderthal brain cast (fig. ${ }^{156}$ ), we see many points in which it differs from a modern brain cast. In front, we see at first the same depression or groove between the

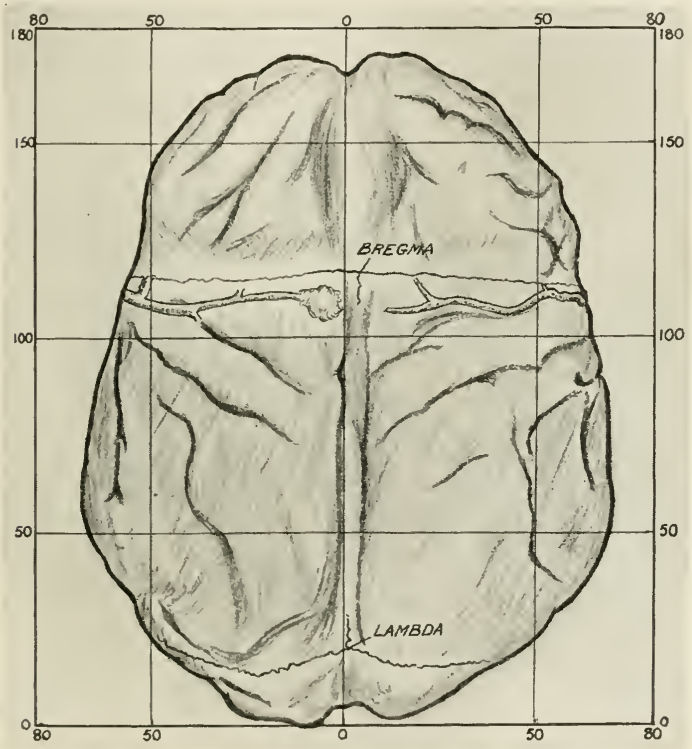

FIG. 156.-Brain cast of the Neanderthal skull viewed from above.

frontal lobe-a depression in which the longitudinal blood-sinus lies. There appears, in front of the bregma, the median vascular elevation seen in brain casts of modern skulls. But behind the bregma the elevation ceases, and the narrow median ridge for the sinus appears, set in a depression or hollow between the raised marginal parts of the cerebral hemispheres. Just in front of the lambda the ridge caused by the longitudinal sinus shows 
sharp, lateral, depressed margins of the same kind as we saw in brain casts of modern man.

To make our study of the median line of the brain cast complete it is necessary to examine the primitive arrangement seen in a brain cast taken from the skull of a young gorilla (fig. I 57). In this instance we can trace

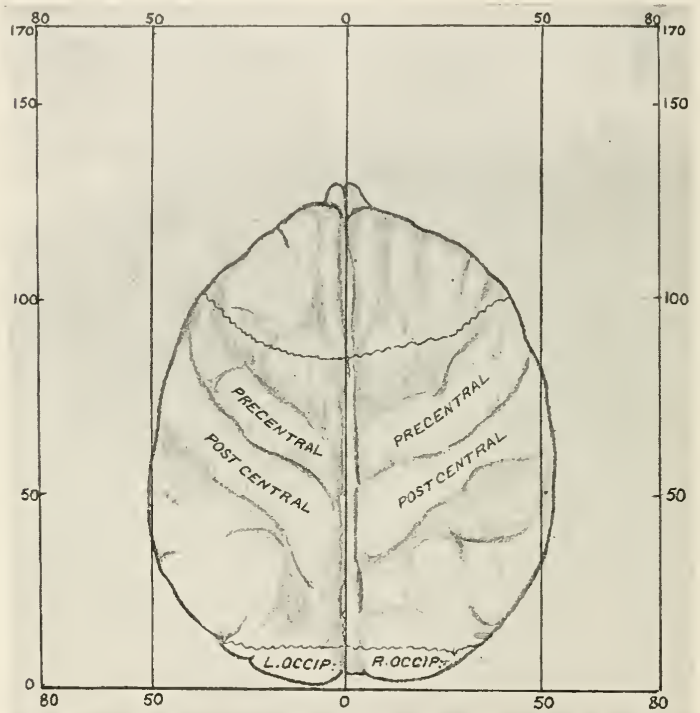

FIG. 157. - Brain cast from the skull of a young gorilla viewed from above, to show the markings for the longitudinal blood-sinus.

the impression for the longitudinal sinus, lying in a groove or depression between the adjacent margins of the cerebral hemispheres. The vascular median elevation, which was so apparent in the brain cast of modern man, and to a less degree in that of Neanderthal man, is absent in the bregmatic region. We must suppose, then, that the primitive condition for the sinus is that represented in the gorilla. 
We now turn to the restoration of the Piltdown brain cast (fig. $15^{8}$ ) to see if we can recognise any of the indications of the middle line enumerated above. The first point to claim our attention is the position of the middle line in front, in the frontal region, for until we

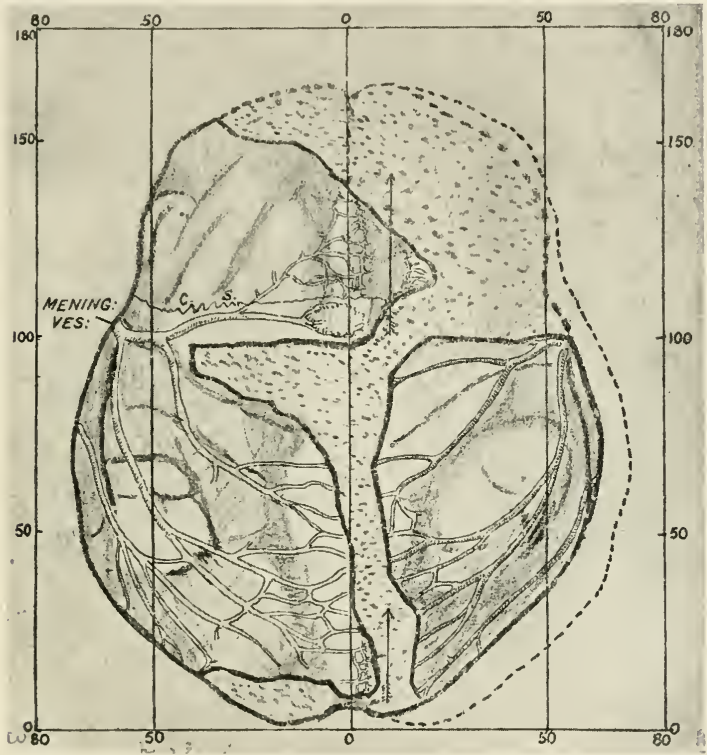

FIG. 158. - Drawings of the Piltdown brain cast as originally restored by Dr Smith Woodward. The stippled line on the right shows the extent to which the right fragments must be moved outwards to make the two sides symmetrical. The arrows indicate the true middle line.

have identified this point to our satisfaction we cannot restore the parts to their natural positions. In the original restoration the middle line in the frontal region runs along a median elevation (fig. I 58 ). Is this elevation the vascular one which we have seen in other human brain casts, or is it the margin of the left hemisphere- 
the upper or first frontal convolution? Undoubtedly it is the latter, for three reasons. (I) If it is not the first frontal convolution, then this convolution was missing in the Piltdown brain-an improbable supposition. (2) It will be noted that the coronal suture (C.S., fig. I $5^{8}$ ) crosses this convolution unchanged in direction, indicating that it has not reached the middle line. (3) If we regard this elevation as lying in the middle line, it is impossible to fit the parts of the skull so as to give the right and left halves an approximate degree of symmetry. To my mind there is no doubt that the shallow groove, marked by an arrow in fig. 158 , represents the position of the middle line. A trace of the marginal elevation of the right frontal lobe is apparent at the point of the frontal fragment. Further, it will be found that at the margins of the lateral sinus of modern skulls, the vessels which supply the skull and outer covering of the brain terminate in a peculiar fringe of fine tributaries. The impress of this vascular fringe is apparent on the left side of the median groove on the original brain cast. We have evidently to deal with a condition similar to that seen in anthropoid brain casts, where the longitudinal sinus is represented by a groove or depression between the adjacent marginal elevations of the frontal lobes. The median elevation is absentnot yet developed.

At the hinder end of the left parietal fragment of the brain cast we meet another clear indication of the longitudinal sinus. The incurved margin at the hinder angle of the parietal fragment represents the lateral boundary of the sinus to which attention has already been drawn. On the incurved margin can be seen a trace of the vascular fringework already described (fig. I $5^{8}$ ). If we suppose that the arrow in fig. I 58 represents the true position of the middle line in front of the lambda, then all the parts fall into conformity with those seen in brain casts of men and anthropoids.

Thus an examination of the brain cast confirms the conclusion reached from an examination of the skull, namely, that a mistake was made in the identification of 
the parts lying in the middle line which greatly diminished the real size of the brain. When the parts are readjusted, the brain cast takes the form and size shown in fig. I 59 . The asymmetry of the two sides has largely disappeared. The arrangement of the meningeal vessels and of the

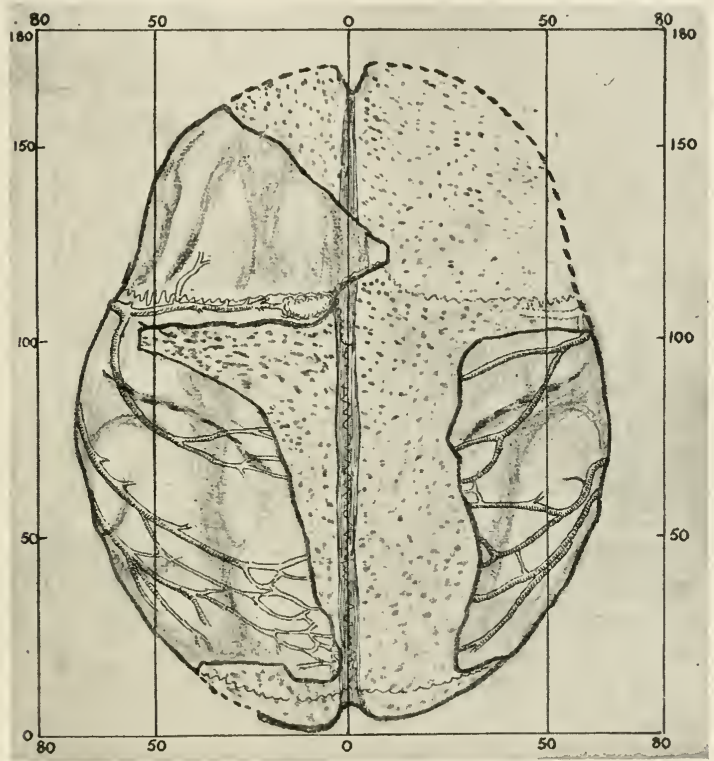

FIG. I 59.-Drawing of the upper aspect of the Piltdown brain cast as restored by the Author. The stippled area represents the missing parts - the parts filled in from inference.

convolutions of the left side are seen to harmonise with those of the right. At the same time the large areas of the brain, representing the higher association centres, are restored, and we obtain a brain primitive in some respects, it is true, but in all its characters directly comparable to that of modern man (compare figs. I 55 and I 59). Indeed the only features in this ancient brain which seem 
to me to really differ from modern brains lie in the frontal region. The absence of the median vascular elevation - a simian condition-in front of the bregma has been described. There is another feature which I have not mentioned so far. If the figures of the gorilla brain casts are examined (figs. I 46, I 57), it will be seen that the two central convolutions-in which centres for movement and ordinary sensation are situated-are distinctly raised above the surrounding areas of the brain. In Neanderthal and modern human brains these central areas appear to be slightly submerged, owing to the areas immediately in front of the motor and immediately behind the sensory areas-true association and therefore higher and later areas-having undergone a special development accompanied by elevation. In the Piltdown brain cast I cannot detect any distinct elevation of the frontal cortex, which lies anterior to the motor cortex. That also must be counted a primitive feature.

To some it may seem that I have entered into the reconstruction of the Piltdown skull and brain too elaborately. When it is remembered, however, that this is the first time we have had an opportunity of learning the degree to which the evolution of the brain had progressed in early man at the beginning of the Pleistocene period, it will be apparent that the task deserves our most painstaking endeavour. We have here-in the discovery at Piltdown-the certain assurance that one race of mankind had reached, so far as the mass of brain is concerned, a modern human standard at the beginning of the Pleistocene period. All the essential features of the brain of modern man are to be seen in the Piltdown brain cast. There are some which must be regarded as primitive. There can be no doubt that it is built on exactly the same lines as our modern brains. A few minor alterations would make it in all respects a modern brain.

Although our knowledge of the human brain is limited -there are large areas to which we can assign no definite function-we may rest assured that a brain which was 
shaped in a mould so similar to our own was one which responded to the outside world as ours does. Piltdown man saw, heard, felt, thought, and dreamt much as we still do. If the eoliths found in the same bed of gravel were his handiwork, then we can also say he had made a great stride towards that state which has culminated in the inventive civilisation of the modern western world. 


\section{CHAPTER XXV -}

THE PILTDOWN MANDIBLE

ALL through the previous chapters we laboured to establish on a sure foundation of fact the size and form of skull and brain of the earliest example of fossil man yet discovered. We have not seen the slightest reason to doubt that all the fragments were parts of the same skull. Further, we did not meet with a single feature in the skull or brain cast which excluded the Piltdown man from our immediate ancestry. In the course of fifty thousand or sixty thousand generations we can well conceive that his brain and skull might have been converted into the forms seen in modern races of mankind. When we come to build up the face our steps are not attended by the same degree of certainty. We have to base our reconstruction on the right half of the mandible. That, the nasal bones, and part of the forehead are all that was found of the face. Are we certain that the mandible does form part of the same individual as the skull fragments? There are many who think it highly improbable that the two do go together. From the very first, Professor Waterston ${ }^{1}$ expressed grave doubts regarding the mandible; he regarded the skull as human, the mandible as simian or anthropoid. There are others besides Professor Waterston who regard the mandible as part of an extinct anthropoid. If only the mandible and the teeth had been found-two molar or cheek teeth and the canine or eye tooth-the great majority of anatomists would have regarded the extinct being of which they

\section{Nature, I9I3, vol. xcii. p. 3 I9.}


formed part as more anthropoid than human in nature. But when we take into account (I) that this mandible lay in the same ancient stratum, and at the same spot as an ancient type of man; (2) that as regards proportionate size, texture of bone, degree of fossilisation, it agrees perfectly with the skull; (3) that the molar teeth are essentially human, I think we must regard it as part of the same individual. If we do not, then we have to accept the much greater improbability that long ago there lived in Sussex (I) a true but early form of man, represented by a skull; (2) an anthropoid with very human molar teeth, represented by a lower jaw; (3) that after death the skull of the one and the mandible of the other came to rest cheek by jowl in the Piltdown gravel. That, of course, is possible, but highly improbable.

On the other hand, that we should find a human form which, in some of its parts, retained or exhibited a marked preponderance of simian characters in such a structure as the lower jaw is not improbable. A close study of the anatomy of man, and of the animals most nearly allied to him, shows many examples of this kind. I can make my meaning more easily understood if I cite a few concrete examples selected from the anthropoid apes which show a very close structural relationship to man. The chimpanzee's teeth are less specialised, more primitive or monkey-like, than those of the gorilla. As regards characters of teeth, man and the chimpanzee have rather more in common than either has with the gorilla. In the anatomy of the lower limbs the case is reversed. The lower limbs of man are by far the most specialised, but the gorilla's also show several human peculiarities which are absent in the chimpanzee. As regards the characters of the lower limb, we would link man with the gorilla. As regards teeth, we would link him with the chimpanzee. I will cite two other examples which occur to me. In all lower forms of apes the liver is divided by deep clefts or fissures into three main lobesright, middle, and left. In all the higher primates-man and anthropoids-the triple division of the liver has dis- 
appeared and the organ has been unified, in all save the gorilla, in which the tripartite state is present. As regards the characters of the liver the gorilla may be described as archaic. The last example $\mathrm{I}$ am to cite has a more direct bearing on the problem of the Piltdown mandible. In the Neanderthal race we find the eyebrow ridges shaped as in anthropoid apes; we suppose that in this ancient human race the primitive or anthropoid type of eyebrow ridge has been retained. These examples are sufficient to show that as new forms of men and apes were evolved the incidence of change or of progress on the evolving body was local or patchy, some systems of the body being affected, others being left untouched. It is therefore quite possible that we may encounter such forms as that found at Piltdown, in which the characters of one part seem to be at variance with those of another-as the mandible with the skull.

We propose, in the first place, to make a cursory examination of the simian characters of the Piltdown jaw, and to see what significance we must attach to them. Before we set out on such a survey, we must obtain a clear mental picture of the essential characters of a human mandible. In fig. I60 a diagram is reproduced to show the chief features which mark the inner or mouth aspect of the human mandible. Passing obliquely downwards and forwards on this aspect of the jaw, from just behind the last molar or wisdom tooth above to below the symphysis or union of the two halves of the jaw in front, is a narrow linear ridge of bone marking the line along which the right mylo-hyoid muscle was attached. The left muscle has a similar origin from the opposite half of the mandible. From such origins the two mylo-hyoid muscles unite along the middle line of the floor of the mouth, forming a muscular floor or diaphragm. The tongue rests on this muscular floor. In all acts, such as swallowing and speaking, the mylo-hyoids come into active use in raising the floor and the tongue. The more these muscles are used, the stronger they become and the more do the mylo-hyoid ridges become emphasised and 
raised on the inner aspect of the mandible. In the more highly evolved races of modern man these ridges reach a very emphatic development. In anthropoids, on the other hand, they are but slightly marked-only the part lying under the molar teeth being easily recognised (fig. I6r). We therefore conclude that a high development of the mylo-hyoid muscle is a human character, and we have also reason for supposing that this high development is more closely connected with speech than with swallowing.

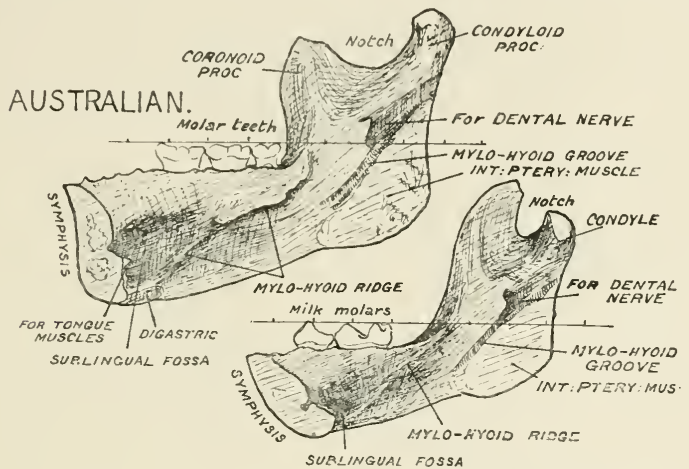

YOUNG GORILLA

FIG. I60.-Right half of the mandible of an Australian native, viewed from the inner or mouth aspect to show certain human characters. Below it there is reptesented the corresponding half of the mandible of an infant gorilla, about two years old.

Now, as may be seen from fig. I6 I, the mylo-hyoid ridge in the Piltdown mandible has the slight development seen in anthropoids. It is possible that the surface of this fossil bone has been rubbed and smoothed somewhat as it lay in the gravel bed of the ancient Sussex stream, but there is no evidence of any marked erosion on the inner aspect of the mandible. We must therefore conclude that the individual of which this mandible formed a part had the mouth and tongue movements of an anthropoid ape. And yet we have seen that the brain which lay within the skull was human in size and form. 
In his address as President of the Anthropological Section of the British Association at Dundee in I9I2 Professor Elliot Smith anticipated that such a combination of parts might occur. He rightly foresaw that before the anthropoid characters would disappear from the body of primal man, the brain, the master organ of the human body, must first have come into its human estate. Under its dominion the parts of the body such as the

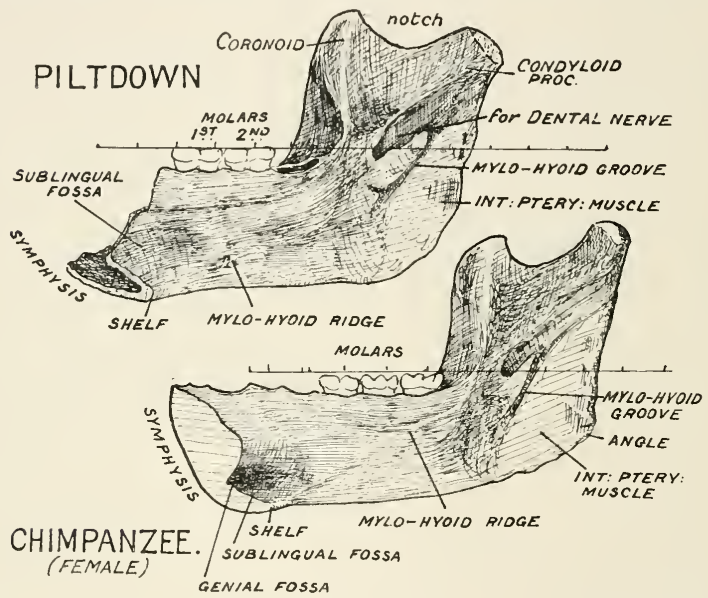

FIG. 16I.- Inner aspect of the right half of the Piltdown mandible contrasted with the corresponding view of the right half of the mandible of a young adult female chimpanzee.

mouth and hands, the particular servants of the brain, became adapted for higher uses. Looking at the problem from this point of view, we cannot reject the Piltdown mandible because as regards the mylo-hyoid ridge it is simian and not human in character.

We pass on to the consideration of another character -one to which Dr Smith Woodward was at first inclined to attach a considerable degree of importance. On the inner aspect of the ascending branch or ramus of the 
mandible-the part to which the muscles of mastication are yoked-the opening for the nerve and vessels, which enter the jaw to nourish the teeth, is seen (fig. I60). Its anterior sharp margin carries a projecting spine. At its hinder lower margin runs off a narrow groove in which lie the vessels and nerve for the supply of the mylohyoid muscle. The groove is known, therefore, as the mylo-hyoid groove. Both vessels and nerve come from the main structures which enter the jaw at the dental foramen. The vascular groove is often separated from the one for the nerve. If the inner aspect of the chimpanzee's jaw is examined (fig. I6I) the dental opening is readily seen; it is large, but there is no short spine on its anterior border and the mylo-hyoid groove takes its departure some distance behind the opening for the dental nerve. Exactly the same characters are seen in the Piltdown jaw; in this respect, also, that mandible is simian. When we seek to appreciate the significance of this character, we note at once that it is not the mylo-hyoid groove which has shifted away from the dental opening. In the human jaw the dental opening lies $20 \mathrm{~mm}$. behind the last molar tooth or more; in the Piltdown jaw and in the chimpanzee's the distance is considerably less-only i $5 \mathrm{~mm}$. It is easy to see how the difference has arisen. During all the years of youth, when the milk teeth are being replaced and space is being provided for the accommodation of the three permanent molars, the ascending ramus of the jaw is undergoing a process of continuous reconstruction. The nature of the change can be realised from the mandible of the infant gorilla shown in fig. I60. The two milk molars are in place. In the course of time, space for three large permanent molars - a space of $45 \mathrm{~mm}$. ( $\mathrm{I} \cdot 8$ inches)- has to be established behind the last milk molar for the three permanent molars. To secure such space, new bone is laid down along the posterior border of the ascending ramus; the anterior border is at the same time removed. Every year the ascending ramus is moved backwards a space; those masons of the animal skeleton-the osteo- 
blasts-carry out the transformation. It will be seen that the opening for the dental nerve has also to be carried backwards. For some reason which we understand only imperfectly at present, the migration of the dental opening is retarded in anthropoid jaws, but the mylo-hyoid groove is not. Hence in adult anthropoids the dental opening and the mylo-hyoid groove usually become separated as in the Piltdown mandible.

Here there is a simian feature, but one on which we must not lay too much stress. It is a remarkable circumstance that in very young anthropoids, especially in the gorilla (see fig. I60), the human form of mylo-hyoid groove is present. In the most primitive forms of anthropoid apes-the gibbons-both the human and anthropoid arrangements of this groove are found. In monkeys the human form is the rule. In this character modern man seems to have relapsed to a more primitive condition. It will also be noted (fig. I60) that the ridge for the mylo-hyoid muscle is more clearly indicated in young than in adult anthropoids.

In a former chapter ( $p .322)$ attention has been drawn to the most outstanding of all the characters of the Piltdown mandible-the shelf or ledge of bone which unites the right and left halves in the region of the symphysis or chin (fig. I6I). That feature has never before been seen in a human lower jaw : it is a characteristic of the anthropoid mandible. The mylo-hyoid ridge ends near the lateral borders of this simian shelf.

We now come to a feature which is rather peculiar to the Piltdown mandible. On the inner side of the jaw, above the "simian" shelf and above the anterior indication of the myloid ridge, is a wide, shallow fossa (see fig. I6I). I do not think there can be any doubt as to the nature of this fossa; it is the impress of the salivary gland-the sublingual-which lies in the front part of the floor of the mouth above the mylo-hyoid muscle. In modern human jaws the impression of the sublingual gland is usually well marked, but variable in size (fig. I60). I have not seen any modern mandible in which the im- 
pression is so extensive as in the Piltdown mandible. The sublingual impression is not so clearly indicated in the mandibles of anthropoids as in the Piltdown specimen, although in them the gland is particularly well developed.

When the architecture of the Piltdown mandible is revealed by the use of $\mathrm{X}$-rays, the arrangement of the trabeculæ and lines of bone then seen within the mandible is reminiscent of the anthropoid rather than of the human form. We know that the structural arrangement of the bony trabeculæ has a very definite significance. These minute bars or crossing lines are laid down in such a manner as to best withstand the strains and stresses to which the mandible is subjected in the course of ordinary use. If, then, the inner structure is more anthropoid than human, we must infer that the uses to which it was subjected in life were of the kind exhibited by living anthropoid rather than by living races of men. Professor Arthur Underwood has conferred a benefit on all students of early man by the publication of X-ray photographs of the Piltdown mandible. ${ }^{1}$ Although the details of architecture revealed in human mandibles by means of $\mathrm{X}$-rays vary from individual to individual, yet one must admit that in its finer structure the Piltdown mandible has more in common with the anthropoid than with the human mandible. I will draw attention to one feature only-the course of the canal which carries the dental nerves and vessels. In the mandible of modern races this canal-as revealed in an X-ray photograph-is distinctly bent during its passage from the ascending ramus to the body of the jaw (fig. I 75, p. 475). The concavity of the bend lies well below the roots of the last molar tooth. In the anthropoid jaw the canal takes an almost straight course from the ascending ramus to the body of the jaw. The roots of the last molar tooth not only reach the bend of the nerve, but may pass beyond it. In these characters the Piltdown jaw resembles an anthropoid jaw.

Thus it will be seen that in many of its features the Piltdown jaw suggests that it should be linked with a 1 Arthur S. Underwood, Brit. Journ. Dent. Sc., 1913, p. 650. 
skull which is distinctly more anthropoid than the one actually found. When we proceed to the next step-that of actually fitting this jaw to the skull-our difficulties become even greater. The very part of the jawthe condyle - which we most need to give us the form of contact with the skull is broken away (fig. I62). Fortunately, that part of the base of the skull which bears the joint for the missing condyle is preserved on the temporal bone. From the size and contour of the surface of this joint we can reckon what the size and shape of the missing condyle must have been. I cannot detect

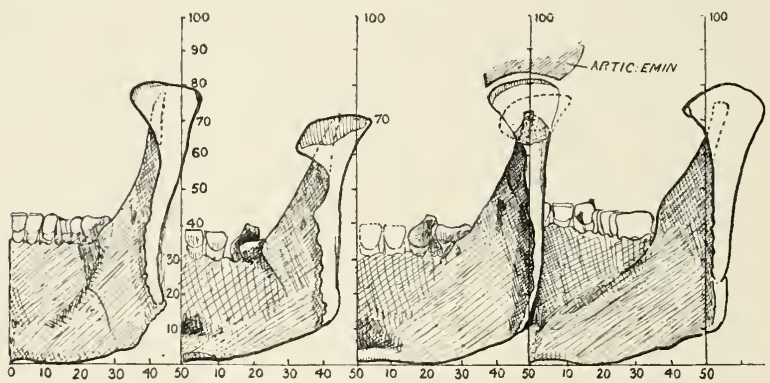

N.CALEDONIAN. CHIMPANZEE. PILTDOWN. HEIDELBERG.

FIG. 162. - The ascending branch of a series of lower jaws, viewed from behind.

any feature in the joint on the Piltdown temporal bone which is not also represented on the temporal bones of primitive modern races of mankind-such as the Patagonians, native Australians, and Melanesians. It is true that the Piltdown articular surface differs from that to be seen in present-day Europeans, but the difference is the result of a change which has set in since the Neolithic period. We infer, then, that the condyle of the jaw which played within the joint of the Piltdown skull was similar in shape and size to that of modern man. A series of mandibles-all placed so that the chewing surface of the molar teeth fall in a horizontal plane-is shown in fig. 162. They are viewed from behind, so 
that the posterior edge or margin of the ascending ramus and of the articular condyle may be seen and compared. Side by side are placed the ascending ramus of a native of New Caledonia and of a female chimpanzee. The posterior border of the human ramus widens gradually as it passes into the condyle; the condyle itself presents a wide, convex surface, very little of the articular surface actually showing on the posterior aspect. In the chimpanzee the posterior margin of the ramus remains narrow until it expands suddenly in the condyle. The condyle shows posteriorly a considerable area of the articular surface. In the same series of drawings the Piltdown and Heidelberg lower jaws are also represented (fig. I 62). The latter shows certain leanings towards the anthropoid form in its straightness, but on the whole its characters are human. In the Piltdown specimen the features are rather anthropoid. Professor Underwood has drawn attention to the manner in which the ramus of the Piltdown jaw is compressed from side to side at the root or neck of the condyle-exactly the form one is familiar with in the mandible of chimpanzees. It is therefore an articular condyle, copied from the jaw of the chimpanzee, which one would fit on the Piltdown specimen if attention is confined to the mandible only. The shape and position of such a condyle is indicated by a stippled outline in fig. I62. A condyle so shaped will not fit the joint on the Piltdown skull-the two are incongruous. Only a condyle shaped as in human races of the modern type can be applied. Such a condyle is represented in fig. I62, with an exact tracing of the articular surface on the base of the Piltdown skull with which such a condyle moved in life. The exact transverse width of the condyle and joint are such as are found in modern primitive races of men-2I mm. In the drawing (fig. I 62 ) it seems perfectly simple to add such a human condyle to the Piltdown jaw; the difficulties which are encountered when such a condyle is actually modelled in clay are much greater. Such difficulties, however, are not of so serious a nature as to make us actually reject the possi- 
bility of the mandible belonging to the skull; but a certain degree of doubt is engendered.

We now come to deal with a very important feature of the Piltdown man. He has developed to the very highest degree a character which most of us who have tried to unravel the geological history of man never expected to find in an early or primitive human type. That feature is the articular eminence-a pulley-like elevation on the anterior part of the joint for the jaw on the base of the skull (fig. I63). The articular eminence is one of the most ingenious of all mechanisms to be found in the human body. It is simple and effective. The manner in which the eminence brings about the opening of the mouth in a modern man is shown in fig. I63. The stippled lines show the position of the condyle, of the coronoid process, to which the temporal muscle is attached, and of the angle of the jaw, when the mouth is closed and the food is being ground between the teeth towards the end of a chewing movement. In that phase, the condyle of the jaw has ascended within a socket-the glenoid cavity-situated on the under-surface of the temporal bone, just in front of the ear. If the reader will place a finger in front of the opening of the ear he will feel the condyle enter its cavity as the lower teeth close against the upper. The position of the various parts of the jaw, when the mouth is opened, is also shown in fig. I $_{3}$. A rotatory movement of the ascending ramus occurs as the mouth is opened. The condyle then mounts the articular eminence (fig. I63). A strong muscle, the external pterygoid, drags the condyle forwards on the eminence, thus depressing the body of the jaw and opening the mouth. It is a general law of the animal body-one established a hundred and fifty years ago by John Hunter-that no muscle can act by itself; its opponents-the muscles which produce an opposite movement-must act at the same time to a moderate and yielding degree. The external pterygoid has three strong opponents-muscles which close the lower jaw and teeth against the upper jaw and teeth, 
thus masticating the food. One of these is the temporal muscle, which rises from the side of the skull and is attached to the coronoid process. The two others are also important for our present purposes and must be mentioned. One is the masseter, which rises from the zygoma (fig. 163) and is attached to the outer surface of the ramus of the jaw, especially in the neighbourhood of the angle. On the deep surface of the ramus there is a counterpart to the masseter muscle-the internal

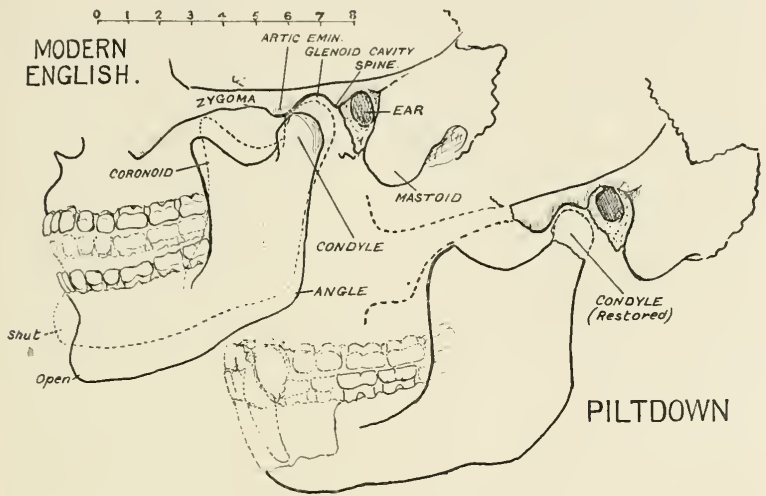

FIG. 163. - Side view of the lower jaw and mandibular joint in a modern skull. The stippled line represents the position of parts when the mouth is shut; the firm line, the open position. The corresponding parts of the Piltdown skull are also shown in the drawing.

pterygoid. Now, it will be seen from fig. I 63 that as the mouth opens under the action of the external pterygoid and the forward movement of the condyle is initiated, the coronoid process is moved forwards and downwards, elongating the temporal, while the angle moves backwards and downwards, stretching the masseter and internal pterygoids, bringing them into an advantageous position for executing a grinding movement. The part played by the articular eminence in the mechanism of opening the mouth will be evident. The resistance it offers to the forward movement of the 
condyle ensures a rapid opening of the mouth. It does more. When the condyle has mounted the eminence, the lower series of teeth is nearly parallel to the upper, not divergent as would be the case if the joint movement were of the hinge type. When the three great muscles press the lower teeth against the upper, crushing the food, the condyle slips home to its socket-the glenoid cavity in front of the ear. It will be seen that, as the teeth meet and the movement comes to an end, there must be a certain degree of rubbing between the teeth, for the condyle passes backwards as it sinks home and the condyles do not come to rest exactly at the same point of time, giving the teeth a lateral movement. We expect, therefore, that the chewing surfaces of the Piltdown teeth should be worn flat, for the highly developed articular eminence and deep glenoid cavity proclaim in unmistakable terms that the chewing movements just described as true of modern man are also true of him. The chewing surface of the Piltdown molars are worn smooth and flat. That is a strong point in favour of the authenticity of the jaw.

An articular eminence of the kind just described has until now only been seen in human races built on the modern type. We naturally regard the form of joint found in anthropoids as the more primitive-the form from which we believe the human one has been evolved. The temporo-maxillary joint of a chimpanzee is shown in fig. I 64 , the mandible being represented in both the opened and closed positions. A passing glance may lead the reader to the conclusion that an articular eminence is absent, but a closer examination will reveal the fact that it is not the eminence but the glenoid cavity which is missing. If figs. $\sigma_{3}$ and ${ }_{1} 6_{4}$ be compared, it will be seen that in the first the floor of the glenoid cavity reaches upwards to the level of the roof of the ear-passage, while the projection of the articular eminence is nearly on the level of the floor of the ear-passage. In the latter (fig. I64) the articular plateau on which the condyle moves is level with the floor of the ear-passage. In the chimpan- 
zee, then, the articular eminence extends backwards to the ear-passage ; it fills up the position which should be occupied by the glenoid cavity. The peculiarity of modern man, then, is not the presence of an articular eminence, but the presence of a hollow or socket behind that eminence, into which the condyle ascends as the teeth meet. ${ }^{1}$ Neither the articular plateau of the anthropoid nor the articular eminence of man are present in

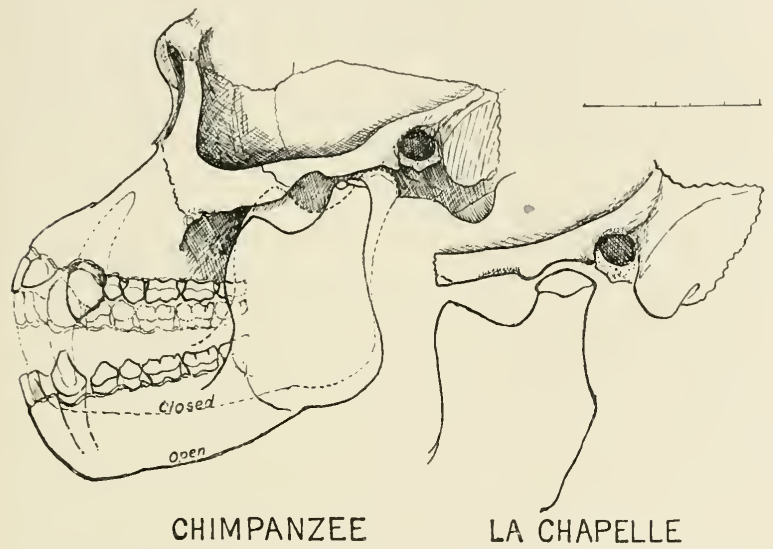

FIG. 164.-Drawing of the left half of a female chimpanzee's mandible-represented in both the opened and closed positions-to show the mechanism of the temporo-mandibular joint of a man of the Neanderthal type ( $\mathrm{La}$ Chapelle -after Professor Boule).

the infantile stage; they become developed as the permanent teeth erupt (see fig. I 70).

The condition of the anthropoid temporo-mandibular joint has a direct bearing on some of the problems we have now on hand. In fig. I 64 is reproduced an outline drawing of the La Chapelle man, described recently by Professor Boule. This mid-Pleistocene representative of Neanderthal man was somewhat aged, but as far as

1 For further details see W. Wallisch, "Das Kiefergelenk des diluvialen Menschen," Archiv fïr Anat. und Physiol., 1913, p. 179. Lubosch, Anat. Anz., 1914, vol. xlvi. p. 449. 
the joint of his jaw is concerned he shows the typical features of his race. There is a raised articular plateau, on which the condyle moves, somewhat similar to the form found in the chimpanzee. The posterior part of the plateau is slightly depressed; there is just a suspicion of a glenoid cavity. The bony floor of the ear-passage is shaped as in the ape; in the Piltdown skull it is fashioned exactly as in modern man.

What are the advantages of the articular plateau in the mechanism of the ape's mandible? Both the advantages and disadvantages are shown in fig. I 64. As the condyle is dragged forwards on the articular plateau, the mouth opens and the muscles of mastication are stretched. The gape thus produced differs from that seen when the human mouth is opened. The front teeth-the canines and incisors-are moved further apart than the hinder teeth or the molar teeth-which are especially used in grinding. With long projecting canine teeth a wide gape in front is a necessity. Our first impulse is to regard an articular plateau as an adaptation for the long and prominent canine teeth, but the impulse is checked when we see a very similar form of articular plateau in Neanderthal man, in whom the canine teeth are ground flush with their neighbours in the dental series. An articular plateau, then, does not necessarily indicate the presence of simian canine teeth. The particular question we have to answer, however, is this: Is a true articular eminence compatible with projecting simian canine teeth? We know that the movements of the Pildown mandible were determined by the contour of the joint surfaces on the temporal bone ; these are exactly similar to those of modern man. The mandibular movements must have been the same in Piltdown man as in us. Are such movements compatible with the presence of projecting canine teeth? The solution of that problem must wait until the canine tooth found at Piltdown has been fixed in the mandible-a task which awaits us in another chapter.

$\mathrm{Up}$ to this point I have passed under review the various characters of the mandible found at Piltdown to see if 
we could obtain any evidence which would definitely debar us from associating it with the skull. We must admit that the majority of the features enumerated are not such as we should have expected to find present in the authentic mandible; on the other hand, there is not one which places the jaw out of court. We now proceed to review the evidence of another kind-proof presumptive in favour of the mandible and skull being parts of one individual.

We have seen that in many features the Piltdown mandible resembles that of the chimpanzee. Let us, therefore, as in fig. I 65, reconstruct it as if it were such, and see the result. In comparing lower jaws, we must select a definite plane on which all are arranged, so that our comparisons may be just. The plane selected here is the upper or chewing surfaces of the three molar teeth. In fig. I 65 two mandibles have been set on that plane and viewed from above. When a chimpanzee's jaw is so examined it is seen that the teeth on each side, from the third molar behind to the canine in front, form a right and left series which are almost parallel ; the outer borders of the canine teeth are nearly as widely separated as the outer margins of the last molars. The two halves of the mandible of Eoanthropus have been given this parallel form in fig. I65, and at first we seem to have obtained a mandible of a reasonable shape with a close resemblance to that of an anthropoid. There is one point, however, in which this reconstruction appears to break the ordinary rules of jaw conformation-the right and left coronoid processes, to which the temporal muscles are attached, are almost as wide apart as the outer ends of the two condyles. In anthropoids, and particularly in human mandibles, the bicondylar width is greater than the bicoronoid-the measurements being made between the outer extremities of these processes. The mandible as reconstructed in fig. I 65 could not be articulated to the Piltdown skull, for the mandible attached to that skull must have had a bicondylar width of at least $120 \mathrm{~mm}$., and the bicoronoid width must have 
been at least $100 \mathrm{~mm}$. In the reconstruction shown in fig. I 65 the dimensions are incompatible with the skull.

It is clear that we cannot reconstruct the Piltdown mandible on such lines and apply it to the skull. That difficulty was appreciated by Dr Smith Woodward in making his original reconstruction. The condyles, to fit

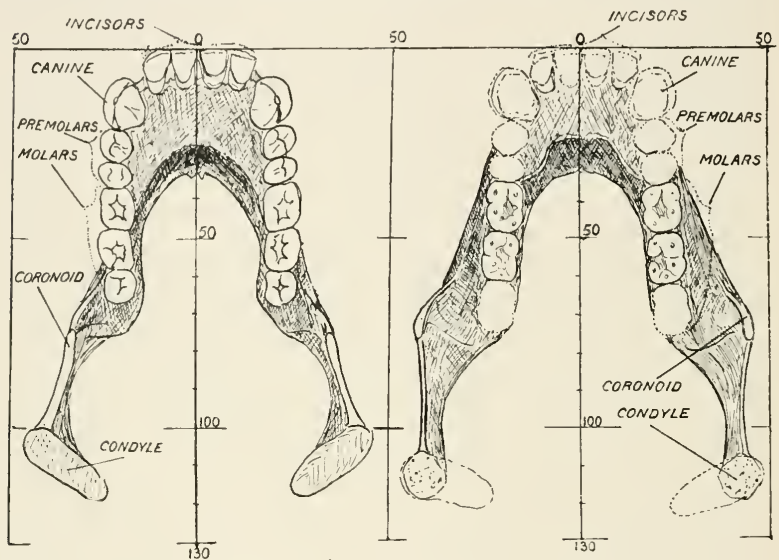

(A) CHIMPANZEE.

(B) EOANTHROPUS.

FIG. I65. -A. Lower jaw of a female chimpanzee, which has been set so that the upper surfaces of the three molar teeth are in a horizontal plane. The'jaw is viewed at right angles to this plane. B. Reconstruction of the mandible of Eoanthropus on chimpanzee lines, and supplied with condyles of the chimpanzee type.

the skull, must be placed at least I $20 \mathrm{~mm}$. apart. If, then, the teeth were to form parallel rows as in anthropoids, a great width must be given to the front part of the jaw. The right half of the mandible is so fractured in the region of the chin as to leave some degree of uncertainty as to whether or not the broken extremity actually reaches the middle line of the chin. Dr Smith Woodward has taken advantage of the doubt in his reconstruction and widened the region of the symphysis 
as in fig. I66. A mandible with distinct anthropoid characters and of very massive proportions is thus obtained. A minute examination leads me to believe that at one point the fragment actually does reach the middle line.

If, on the other hand, we suppose, and I think we are obliged to accept this supposition, that there is present in the right half of the Piltdown mandible a point which actually reaches and slightly crosses the middle line of the chin, then we cannot arrange the teeth in such a way as to make the two rows of teeth parallel as in anthropoids (see fig. I66). As regards the widths between the

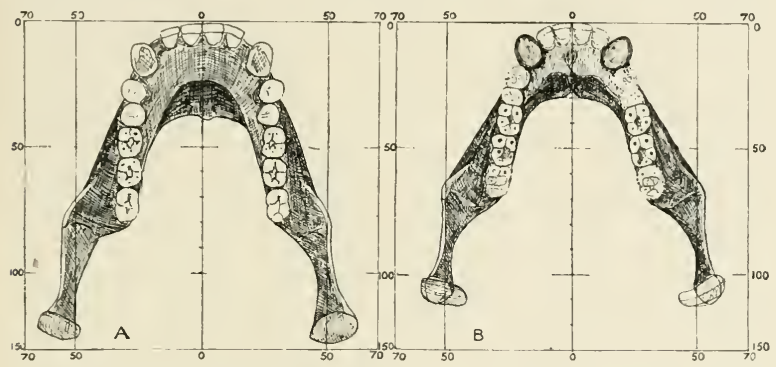

FIG. 166.-A. The original reconstruction of the mandible of Eoanthropus, viewed at right angles to the plane of the molar teeth. B. Similar view of a reconstruction by the Author.

condyles and the coronoid processes, the reconstructions shown in figs. I66, $A$ and $\mathrm{B}$, agree. It may be said that both have been arranged and spaced so as to correspond to the width of the skull. To a certain extent this is true, but if an unwarrantable presumption had been made in giving such a width to the mandible, then we should probably have obtained an abnormal relationship between condylar and coronoid processes. On the other hand, the relations between these processes are such as are met with in primitive types of man. The coronoid process must hold a definite relationship to the zygomatic arch. The bicoronoid width is less by 30 or $36 \mathrm{~mm}$. than the width between the zygomatic arches in all forms of 
human skulls. In Eoanthropus the bizygomatic width is between I 30 and I $40 \mathrm{~mm}$. ; the bicoronoid should be between $\mathrm{IO}_{4}$ and $\mathrm{I}$ IO $\mathrm{mm}$. In both reconstructions the latter is $10_{4} \mathrm{~mm}$. Thus, so far as regards coronoid and condylar widths, the mandible and skull are compatible.

The aspect of the lower jaw presented in the reconstruction (fig. I 66, A, B) gives us an opportunity of looking more closely into another of the peculiar features of Eoanthropus. Within the semi-circle of the lower teeth lies the tongue; the space enclosed by the inner margins of the teeth may be named the lingual area. The larger the intradental area, the larger and more brutal the size of the tongue. If to the lingual space which lies within the teeth we add the area represented by their chewing surfaces, we obtain a means of estimating the degree to which the function of mastication was developed. The area we have to estimatethe counterpart of the palatal area-lies within the outer margins of the teeth, and is bounded behind by a line drawn from the hinder end of the last molar tooth on one side to the extremity of the corresponding molar on the other side. In the original reconstruction (fig. I66, A) of the Piltdown mandible this area measured $78 \mathrm{~mm}$. in length, $66 \mathrm{~mm}$. at its greater width; its total extent $4880 \mathrm{~mm}^{2}$ In the second reconstruction (fig. $\mathrm{i} 66, \mathrm{~B}$ ) the dimensions are : length $70 \mathrm{~mm}$., width $64 \mathrm{~mm}$.; area $3980 \mathrm{~mm}^{2}$ Let us see how those dimensions compare with those of anthropoid apes. The masticatory area finds its highest expression in the gorilla. In the male the dimensions are : length $97 \mathrm{~mm}$., greatest width $64 \mathrm{~mm}$.; area $5600 \mathrm{~mm}^{2}$ In the female chimpanzee we meet with the opposite extreme as regards the size of masticatory area. To take an average example (fig. I $6_{5}, \mathrm{~A}$ ) : length $67 \mathrm{~mm}$., width $54 \mathrm{~mm}$.; area $3180 \mathrm{~mm}^{2}$ Thus in the development of the masticatory system, Eoanthropus rises well above the lower anthropoid limit. The original reconstruction shows an area $720 \mathrm{~mm}$. less than the male gorilla, and I $700 \mathrm{~mm}$. more than the female chimpanzee. With a brain developed to the amount 
already demonstrated for Eoanthropus, such a development of the more animal side of the body was scarcely to be expected.

It will be profitable, at this point, to see how Eoanthropus stands, in this respect, to races of men, both ancient and modern. The specimen we naturally take for our first comparison is the Heidelberg mandible; it is the sole representative of early Pleistocene man on the continent of Europe. The jaw is depicted in fig. 167, A. It has been placed and measured in the manner already described. We see that the molar teeth do not form a

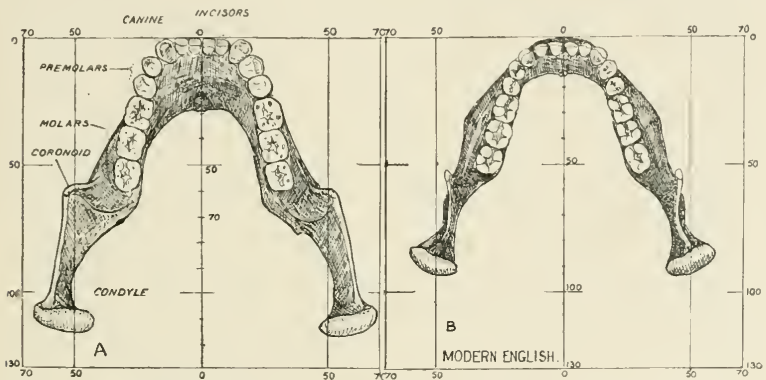

HEIDELBERG

FIG. I67.-A. View from above of the Heidelberg mandible. B. Similar view of a mandible of a modern Englishman. As in other drawings, the specimens have been placed so that the chewing surfaces of the molar teeth occupy a horizontal plane.

parallel, but a converging series. The width of the skull was evidently greater than in the one from Piltdown; the articular cavities for the jaw on the base of the skull must have been at least $10 \mathrm{~mm}$. wider apart. The coronoid processes have the same degree of separation. Indeed, as regards the hinder parts of the jaw, there is a considerable degree of resemblance in the Heidelberg and Piltdown specimens. The masticatory area of the Heidelberg mandible is large: length $60 \mathrm{~mm}$., width $70 \mathrm{~mm}$. ; total area $3540 \mathrm{~mm} .^{2}-440 \mathrm{~mm}^{2}$ less than in the writer's reconstruction of the Piltdown mandible, and $1340 \mathrm{~mm} .{ }^{2}$ less than in that of Dr Smith Woodward. 
If we examine the mandible of a modern Englishman from the same point of view the difference is very striking (fig. I67, B). The bony framework of the modern jaw has undergone a remarkable reduction. The bicondylar and bicoronoid widths have diminished, but not to a very marked extent. The masticatory area is greatly reduced. In the specimen represented in fig. I67, $\mathrm{B}$, the dimensions are the following : length $5 \mathrm{I} \mathrm{mm}$., width (between outer margins of second molars) $60 \mathrm{~mm}$.; total area $2760 \mathrm{~mm}^{2}$ If we presume that the mandible of Eoanthropus as restored by Dr Smith Woodward represents our ancestral condition at the beginning of the Pleistocene period, then during that period the length of the chewing area of the jaw has decreased $37 \mathrm{~mm}$. ( $\mathrm{I} \frac{1}{2}$ inches), the width only $4 \mathrm{~mm}$, and the total area 2 I $20 \mathrm{~mm}^{2}$ It will be observed that it is in length, not in width, that the chewing area of the mandible has decreased. In the Neanderthal race, at least, the width has actually increased.

The modern English mandible represents an advanced stage in the process of reduction. For the purposes of comparison, it is better to select the mandible of a primitive race of the modern type, such as-may be found amongst the extinct Tasmanians. The palate of a Tasmanian native is represented in fig. 52 (p. I 50), one in which the dimensions do not fall far short of those found in the palate of Eoanthropus. The length of the masticatory area in the corresponding Tasmanian mandible is $63 \mathrm{~mm}$., the width $60 \mathrm{~mm}$.; the total area $3210 \mathrm{~mm} .^{2}$, against $3980 \mathrm{~mm}^{2}$ in the writer's reconstruction of the Piltdown mandible, and $3540 \mathrm{~mm}^{2}$ in the Heidelberg mandible. In the mandibles of very ancient man the chewing surface exceeds the highest modern development by a considerable amount. In the course of human evolution, the chewing area has become greatly reduced, a reduction which probably followed the growing mastery of the brain. The condition in Eoanthropus suggests that the brain had reached a volume equal to that of modern man before the reduction of the jaws and teeth set in. 
In the preceding paragraphs, the evidence relating to the masticatory function of the Piltdown mandible has been reviewed with the definite object of seeing whether we can reconcile its simian characters with a brain and skull which are distinctly of a human type. In the midPleistocene man of La Chapelle the brain had a volume of 1620 c.c., the mandible a masticatory area which, from the reconstruction by Professor Boule, I calculate to have been $3450 \mathrm{~mm} .^{2}$ A brain volume of I 400 c.c. and a mandibular chewing area of $3980 \mathrm{~mm} .{ }^{2}$, as in the writer's reconstruction of the Piltdown mandible, seem, when we keep the La Chapelle example in mind, quite a reasonable combination. We cannot reject this mandible because of its anthropoid dimensions and characters.

Before passing on to the next chapter, in which the evidence relating to teeth is to be considered, it will be well to draw attention to some very instructive facts brought out in the drawings shown in figs. 165,166 , and 167. So far we have centred our attention on the upper margin of the mandibular arch-the tooth-bearing margin. We must now examine the changes which have taken place at the lower margin which bounds the floor of the mouth. In the chimpanzee (fig. I65) the lower margin invades and diminishes the floor of the mouth, especially in the anterior or symphyseal region. The lower border of the symphysis lies $35 \mathrm{~mm}$. behind the cutting edge of the incisor teeth, which form the anterior border of the mouth area. In the gorilla the symphysis may extend backwards $55 \mathrm{~mm}$. into the floor; in Dr Smith Woodward's reconstruction it reaches backwards $37 \mathrm{~mm}$. (fig. I 66, A); in the reconstruction by the writer $30 \mathrm{~mm}$. (fig. I66, B); in the Heidelberg jaw $29 \mathrm{~mm}$. (fig. $167, \mathrm{~A}$ ); while in the modern English mandible (fig. 167, B) the distance is only $13 \mathrm{~mm}$. The widening of the aperture of the buccal floor has occurred at the sides as well as in front at the symphysis. Thus we see that in the evolution of the mandible of modern man a double change has been at work: while the teeth and the upper margin of the mandibular arch have undergone a 
great degree of reduction, limiting greatly the tongue space, the lower margin has really increased, giving a greater width to the floor space of the mouth. Such a change will give greater freedom to the tongue in the articulation of words. In both the Piltdown and Heidelberg jaws, especially in the former, the condition of the floor of the mouth, in shape and size, is simian or apelike; the characteristic modern changes have not yet appeared in the mandibles of those ancient types.

Thus in our scrutiny and reconstruction of the Piltdown mandible, although we have come across many details of structure which seem to suggest that it formed part of an anthropoid rather than of a human being, we have met with no feature which clearly debars it from being placed with the skull. It was found in the same stratum and near the skull, and has certain characters which appear to me to prevent us from reconstructing it purely on anthropoid lines. We can with some confidence assume we are dealing with parts of one individual; our difficulties are infinitely greater if we try to allocate the skull to a human being and the mandible to an unknown kind of anthropoid. 


\section{CHAPTER XXVI}

EVIDENCE OF THE TEETH OF FOSSIL MAN

IT will be remembered that Dr Smith Woodward came to the conclusion, on perfectly legitimate grounds, that Eoanthropus had been provided with front teeth, not of the human, but of the anthropoid pattern. When the mandible was reconstructed the space for the front teeth was found to be so great that only teeth of the anthropoid type were sufficient to fill it. The conformation of the mandible, especially in its front part, was essentially the same as in anthropoid apes; it was therefore a natural inference that the teeth, especially the canines, were pointed and prominent and used as in apes. I came to an opposite conclusion-on the grounds enumerated in the last chapter. The joint for the mandible on the skull is similar in all respects to the joint of men of the modern type; I could not see that such a joint was compatible with prominent canines. The molar teeth were worn flat and smooth exactly as in primitive modern races. The temporal muscles of mastication were not larger than in modern man. The front space of the reconstructed mandible could be filled by teeth which were modern in form but of large dimensions. There can also be no doubt that the size of brain influenced me; I did not expect to find a brain which was so eminently human combined with a tooth which was so distinctively simian.

It is instructive to reproduce the reconstructions of the Piltdown teeth and mandible which were made before the canine tooth was actually found (fig. I68). On these early 
reconstructions are superimposed drawings of the teeth and mandible of a modern Englishman. It will be seen that in both reconstructions the Piltdown teeth project in

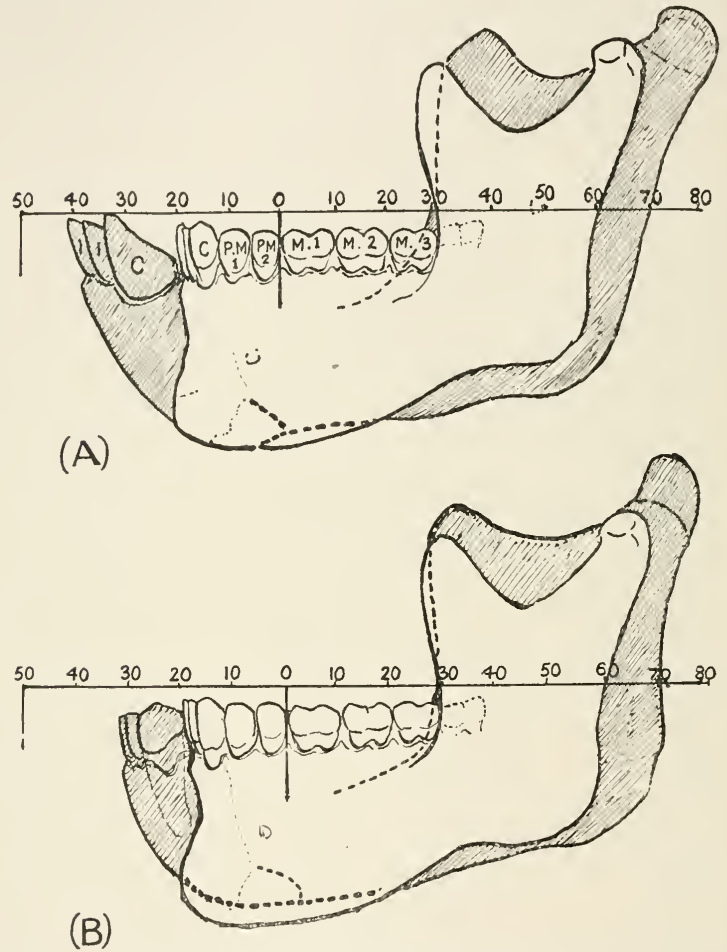

FIc. 168. - A. True profile drawing of the model of the Piltdown mandible and teeth reconstructed under the direction of Dr Smith Woodward. Placed on it is the mandible of a modern Englishman. The first molar tooth of the one is placed over the first molar tooth of the other. B. A reconstruction by the writer. The same modern mandible is used for comparison.

front of and also behind the teeth of the modern man. The total dental length, as seen when the face is turned in true profile, is $50 \mathrm{~mm}$. in the modern Englishman, 
$78 \mathrm{~mm}$. in Dr Smith Woodward's reconstruction, and $70 \mathrm{~mm}$. in the drawing shown in fig. $168, \mathrm{~B}$. The difference in the canine tooth is also apparent. It is conical and pointed, with a back-to-front diameter of I $4.5 \mathrm{~mm}$., in fig. I68, A; it is blunt as in modern man, with a front-to-back diameter of $10 \mathrm{~mm}$., in fig. $\mathrm{I} 68, \mathrm{~B}$. The drawings also bring out another feature to which reference will have to be made. It will be observed, in the scale placed above the teeth (fig. I68), that the zero of the dental scale is placed between the second premolar and the first molar tooth. Behind the zero point lie the three molar teeth, concerned in grinding and pulverising the food; in front of that point are the cutting teeth, five in number-two premolars, one canine, two incisors-concerned in biting off and in the initial breaking up of the food. The zero point is thus situated at the junction of two functional areas-the front and back-and lies in the most stationary or conservative part of the dental series of the group of animals to which man and the higher apes belong. If the molar teeth in the higher primates undergo a change, it is the last or third of the series which is first affected. In the actual reduction or increase of the front teeth, the canine is the centre of the change, but the movement of the series as a whole is towards or away from the zero point. As will be seen from fig. I 68, $\mathrm{A}$ and $\mathrm{B}$, there is no difference of opinion as regards the Piltdown mandible and teeth behind the zero point; the difference concerns the parts which lie in front of the zero point. Whether we regard Eoanthropus as a direct ancestor of modern man, or a collateral stem which became extinct, we must suppose that the mandible represents a primitive human form, and that it is from such a form that our modern mandibles have been evolved. The changes required to convert a Piltdown mandible into one of the modern European type are represented diagrammatically in fig. I68, A and B. In front of the zero line there has been a reduction of over half an inch. Behind the zero point the degree of 
reduction has been much less-only 7 or $8 \mathrm{~mm}$. in the length of the molar teeth, and $10 \mathrm{~mm}$. in the width of the ascending ramus of the jaw. If the reduction depicted in fig. I68 represents changes which have occurred in the human mandible and teeth since the beginning of the Pleistocene period, then we must infer that the structural evolution of man has taken place at a surprisingly rapid pace.

As already said, the reconstructions of the mandible shown in fig. I 68 were made before the actual discovery of the canine tooth. A situation with a certain degree of piquancy thus arose, for we were all well aware that $\mathrm{Mr}$ Charles Dawson was busily extending his researches at Piltdown, and that any day a discovery might be made which would settle finally which reconstruction was right and which was wrong. Early in August I9 I3, Father P. Teilhard de Chardin, who shared in all the toils at Piltdown, discovered first the two nasal bones-the bones which form the bridge of the nose-and secondly a canine tooth, all in the same black Eoanthropic stratum and near the original site of discovery. Like all the fragments of the skull the nasal bones were human in character; like the majority of the features of the mandible the canine tooth was of the anthropoid type. Dr Smith Woodward's reasoning led him in the right direction; mine led me in the wrong. ${ }^{1}$

Accurate drawings of the tooth thus discovered are represented in fig. I69. The middle of the upper series (fig. I69) shows the side of the tooth which is directed towards the tongue, for it is the lower canine of the right side. $^{2}$ It was also the right half of the mandible which was found. For comparison the right lower canine teeth of a young female chimpanzee (I), of a female gorilla (2), of a child in the "milk" stage of dentition (represented

${ }^{1}$ See "Supplementary Note on the Discovery of a Palæolithic Human Skull and Mandible at Piltdown, Sussex," by Charles Dawson, Arthur Smith Woodward, and Grafton Elliot Smith, Quart. Journ. Geol. Soc., 1914, vol. lxx. p. 82 .

2 After a minute study of the Piltdown canine, Mr Leon Williams carne to the conclusion that it is an upper, not a lower tooth. 
twice natural size), and of an Australian native, are placed in series with the Piltdown specimen. All are poised so as to show the inner or lingual aspect. In shape and size the tooth is clearly more closely related to the anthropoid than the human form. The crown is conical pointed

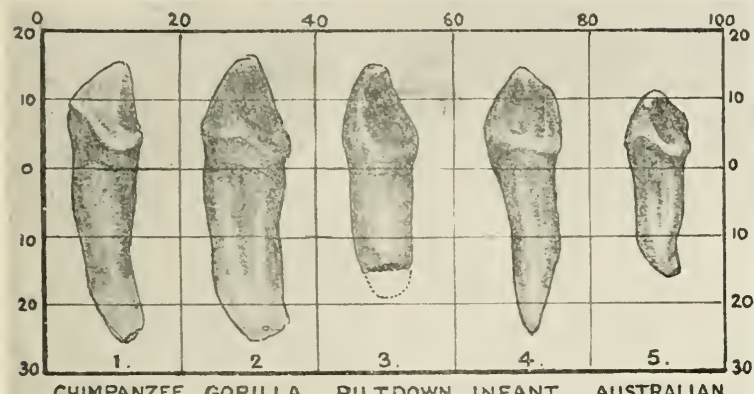

CHIMPANZEE. GORILLA. PILTDOWN. INFANT. AUSTRALIAN.

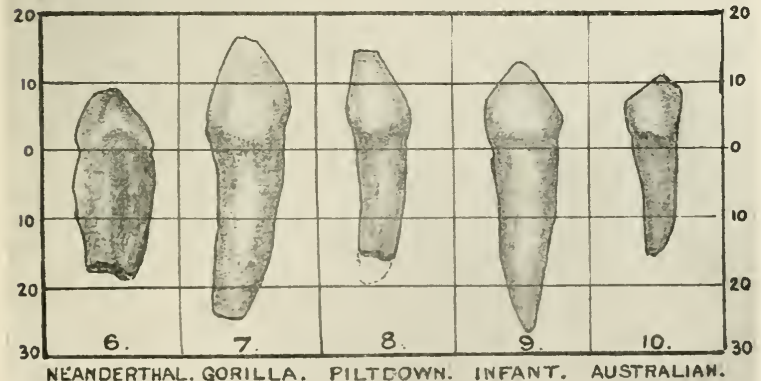

FIG. 169. - The right lower canine tooth found at Piltdown compared with the corresponding tooth of man and of anthropoids.

1. Right lower canine of a young fomale chimpranzce (lingual aspect).

\begin{tabular}{|c|c|c|c|c|}
\hline , & $\because$ & , & Fompthronus & \\
\hline ,. & $"$ & $"$, & Eoanthropus & \\
\hline "s & $\therefore$ & $\because$ & a child (twice nat, size) & \\
\hline Léft & $\ddot{n}$ & $\ddot{~}$ & Neanderthal man & \\
\hline Kight & " & . & fenule gorilla & (anterior \\
\hline , & *. & . & Eoanthropus & \\
\hline 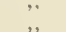 & " & 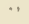 & infant & \\
\hline ", & ," & $\therefore$ & & \\
\hline
\end{tabular}


and rises $\mathrm{I}+\mathrm{mm}$. above the neck-the constriction surrounded by the gum. In female anthropoids, the canines being much smaller than in the males, the crowns rise from $\mathrm{I} 6$ to $20 \mathrm{~mm}$. above the neck. In modern human races the canine crowns are never shaped as in the Piltdown specimen, and rarely rise more than I 2 or $13 \mathrm{~mm}$. above the level of the neck. The greatest diameter of the crown-from the outer or labial margin to the inner or lingual-is somewhat less than Dr Smith Woodward had postulated ( $14.5 \mathrm{~mm}$.). It measures just under I I mm., a dimension never reached in the canines of modern man; in them the greatest diameter rarely exceeds $9 \mathrm{~mm}$. In Neanderthal man this measurement is frequently exceeded (fig. I69), but in shape the Neanderthal canines are merely swollen forms of the modern type. The root of the Piltdown tooth is anthropoid in shape and dimensions. The exact length of the root is doubtful, the tip being broken away, but it was probably not less than $20 \mathrm{~mm}$. in extent. In female anthropoids the roots are about $25 \mathrm{~mm}$. long; in modern human races they seldom exceed i $8 \mathrm{~mm}$.

The original features of the crown or chewing surface cannot be discerned now. It is deeply hollowed by wear. On the excavated area can be seen a black circle marking the site of the exposed pulp cavity. Although the original characters of the crown have been rubbed away by use, we cannot doubt they were those seen on the unworn crowns of the canine teeth of apes and men (see fig. I69). On the lingual aspect of the chimpanzee's canine (fig. I69) a ridge is seen to descend from the tip to the heel of the crown, the heel being raised. The ridge lies between two functional surfaces. The anterior surface plies against the upper lateral incisor, and may therefore be named the "incisor" area. The hinder surface is opposed to the inner or lingual surface of the corresponding upper canine tooth; the two surfaces represent the opposite blades of the canine shears. In the canine of the human infant (fig. I69) the same two surfaces are seen-incisor and canine. They are also 
apparent in the canine teeth of human adults and gorilla (fig. 169). The dividing ridge on the Piltdown crown has been worn away and only a deeply bevelled chewing surface is left. Which surface does it represent-incisor or canine? I think it is incisor ; the bevelling or excavation of the crown has been caused by the upper lateral incisor. There is no mark or impress on it of the corresponding upper canine tooth. The canine of the female gorilla, represented in fig. I69, shows the kind of wear which results from the lateral incisor rubbing or biting against the lower canine, but on the lateral aspect of the crown the upper canine has worn a distinct impression. Thus in the manner in which it has become worn by use, the Piltdown canine differs from all known human and anthropoid teeth.

In the discovery at Piltdown, then, there was revealed, for the first time, a human race in which the canine teeth were pointed, projecting, and shaped as in anthropoid apes. That we should discover such a race, sooner or later, has been an article of faith in the anthropologist's creed ever since Darwin's time. In The Descent of Man a picture is drawn of man's immediate ancestor, one of the stipulated characters being that "the males had great canine teeth, which served them as formidable weapons." Everyone who has made a special study of human teeth - their form, growth, and eruption-has been obliged to have recourse to the theory of descent to explain the numerous facts which come under the notice of the anatomist. In fig. I 70 is represented a dissection of the face of a child, aged three years, to show certain of these dental characters. In each half of the upper and lower jaw is a set of five milk teeth-two incisors, a canine, and two molars. The crown of the first permanent molar, which erupts in the sixth year, is seen buried behind the second milk molar. The canines have constricted necks and sharp, conical crowns; indeed all the milk teeth are constricted at the neck-a character which can also be noted in the Piltdown teeth. When the child bites, the conical crown of the upper milk canine passes into the 
$\mathrm{V}$-shaped gap between the crown of the lower canine and the first milk molar, rubbing against the outer surface of these two lower teeth in exactly the same manner as in an ape. There is this difference, however: while the canine of the ape wears in such a way as to maintain a sharp chisel edge, the points of the human canines become rubbed away. To explain the pointed conical form and the manner in which the human milk canine teeth come into opposition, we must suppose that they were used at one time as in anthropoids. The developmental history of the human permanent canines also

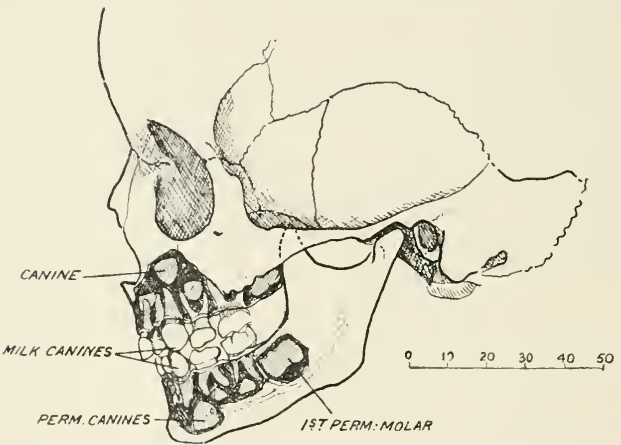

FIG. I70.-Skull of a child, dissected to show the roots of the milk teeth and the crowns of the permanent canines in process of development.

requires explanation. The budding crowns of the permanent teeth are situated at the roots of the milk teeth which they are destined to replace-all except the canine teeth. The crown of the upper canine, as in the anthropoid, begins to form far above the other members of the series-under the roof of the orbit (fig. I 70). The lower canine appears near the lower border of the mandible. A deep origin for the canine is a necessity in an anthropoid. The longer the root of a tooth, the deeper in the jaw must the crown of the tooth be developed; the tip of the root is the last part of a tooth to form, and it is formed at the spot where the crown 
commenced to develop. The canine teeth of modern man have been modified to take their place in the biting series. Their deep seat of development can be explained only by assuming that at one time they had strong and extremely long roots, as in anthropoids. Their time of eruption, too, is peculiar. In anthropoids these great and highly specialised teeth appear late - with the last molar in female anthropoids and after the last molar in the males. In Eoanthropus, the canine, having retained a development which may be called anthropoid in degree, should appear late-about the time at which the third molar cuts. It is strange that the canine tooth of Eoanthropus should be so much worn, and yet the second molar, which comes into use before the canine teeth of anthropoids, should be worn to a relatively less degree. In modern man the date of eruption of the canines has been accelerated. In him it appears about the twelfth year, with or before the second molar. The canine has lost its high degree of specialisation and taken a functional place between the incisor and premolar teeth. The position of the human canine in the dental series justifies us in assuming that it should appear before and not after the premolar teeth. We explain its late appearance by its evolutionary history. The discovery, then, of a race of human beings with pointed simian canine teeth was not unexpected. We did not know at what stage of man's evolution the canine teeth became transformed, nor could we guess the exact manner in which their humanisation had been brought about, until Mr Charles Dawson's discovery at Piltdown.

We now wish to see what light this discovery throws on the evolution of our modern bite- the contact which the lower teeth make with the upper. In the course of quite recent centuries the manner in which the front teeth become opposed in the act of chewing has changed amongst European races and nations of European origin. In over 95 per cent. of modern English people the cutting edges of the lower incisor teeth no longer meet the edges of the upper teeth, but pass behind them. There is an 
"overlapping" bite. In England, during the AngloSaxon period, the incisor teeth met edge to edge in the majority of the inhabitants; the overlapping bite was exceptional. The edge-to-edge incisor bite occurs in all primitive human races; it is also the simian form. In a thousand years or less, then, a very remarkable change has appeared in the bite of English people; the overlapping incisor bite has become the prevalent form. With the change has come a marked tendency to contraction of the palate and to irregularities in the arrangement of the teeth. At first sight it seems as if a marked evolutionary change had been wrought on our teeth and jaws in the course of twenty or thirty generations. The changes in our teeth and jaws are of a functional nature; they are comparable to certain alterations produced in our feet by the use of modern boots and shoes. Were we to abandon boots and walk barefooted, as has been the habit in all primitive human races, our feet, we believe, would resume their natural form. We have every reason to suppose that the changes in our mouths are of a similar nature. If we had to return to the " hard " fare of our early ancestors we should have to use our front teeth in a different manner and restore the edge-to-edge bite.

The manner in which the edge-to-edge incisor bite is produced has a very direct bearing on the problems relating to changes in man's front teeth. It will be found that there is a double mechanism at work during mastication. One of these has to do chiefly with the front teeththe biting mechanism; the other with the back or molar teeth-the grinding mechanism. How different these mechanisms are the reader may prove by personal observation. The great temporal muscle can be felt at work on the side of the head, anywhere between the ear and lateral margin of the forehead. If ordinary chewing movements are made, those which grind the lower molar teeth against the upper and force the condyle of the lower jaw into the depth of its socket in front of the ear-passage, the temporal muscle will be felt to be strongly at work ; it swells and subsides at each phase of 
the movement. When, however, a biting movement is carried out, one in which the edges of the lower incisors are made to meet the opposing edges of the upper incisors, the temporal muscle is felt to remain passive; the muscles which carry out this movement are the two which lie in the cheek-the masseter on the outer side of the ascending ramus of the mandible, and the internal pterygoid on its deep or buried aspect. In the inhabitants of our western cities the biting mechanism has fallen into disuse. The overlapping incisor bite has appeared. The cheeks, which are high and prominent when the biting muscles-the masseter and internal pterygoidare well developed, become reduced and sunken, giving us our narrow, hatchet-shaped faces - our oval cast of countenance.

I have cited those modern tooth changes to introduce another aspect of the Piltdown problem. It is clear, if we are right in differentiating the biting from the chewing mechanism, that this observation will influence us when we come to interpret the Piltdown mandible. We have already seen that the front teeth and the corresponding part of the jaw were developed to a superhuman degree; they were almost anthropoid in size and form. We may further assume that the biting muscles were large in Eoanthropus. We have to determine whether the bite of Eoanthropus was similar in all respects to that of anthropoids, or represented a transitional stage between the primitive human and anthropoid methods of using the front teeth. In fig. I 7 I the problem has been given a concrete representation. On one side is shown the manner in which the lower front teeth come into contact with the upper ones in the skull of that primitive extinct race-the Tasmanians. On the other the front bite of a female chimpanzee is shown. Our present knowledge leads us to regard the arrangement in the chimpanzee as the more primitive - the one which more nearly resembles the common type from which both forms have been evolved. The upper teeth represent the stationary blade of the dental shears, and the lower incisors-two 


\section{6+ THE ANTIQUITY OF MAN}

central, two lateral-represent the moving blade. In both human and anthropoid dentitions (fig. I7I) the lower teeth come into contact with the same parts of the upper teeth. The tooth which most demands our attention is the upper lateral incisor. When an anthropoid bites, the crown of the upper lateral incisor passes into the interval between the lower lateral incisor and lower canine (fig. I7I). It wears each of these teeth. In fig. I7I, A, the crown of the upper lateral incisor comes in contact with the flattened crown of the lower canine; in fig. I 7 I, B, it has descended in front of the pointed

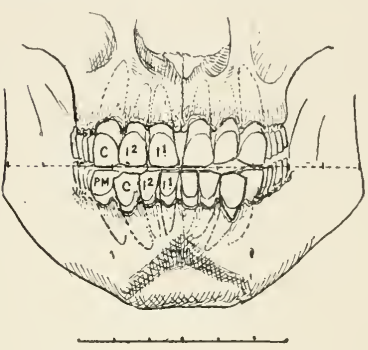

(A) AUSTRALIAN.

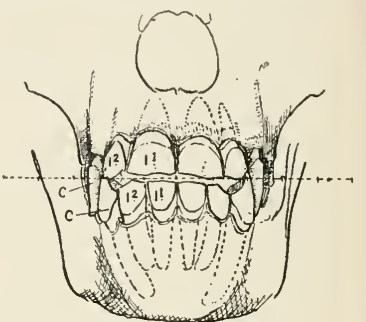

(B) CHIMPANZEE.

FIG. I7 I. - A. The form of contact between the lower and upper teeth of a native Tasmanian. B. The form of contact in a female chimpanzee.

crown of the lower canine. The articulation of the lower lateral incisor is also worthy of note. In both man and anthropoid the crown of this tooth forms a double contact with both upper incisors. So far as concerns the apposition of the incisor teeth, man and ape are alike. The difference relates to the canine teeth. The lower canine of the anthropoid ascends in front of and to the inner side of the upper canine, until the point of the crown reaches the interval between its two upper opponents-the lateral incisor and canine (fig. I 7 I, B). The articulation of the upper canine is even more important. In a front view this tooth is partly hid by the lower canine. Hence its points of contact are best seen from the side (fig. 
I 73, B). In that illustration it will be seen that when the lower jaw is closed the sharp-sided pyramidal crown of the upper canine sinks into the $\mathrm{V}$-shaped interval formed by the adjacent crowns of the lower canine and first premolar teeth. A pointed upper canine necessitates a cutting margin on the first lower premolar tooth. The canines of the anthropoid are shaped so as to serve as particularly stout shears. In man their shape and purpose are different. In him the canines serve almost the same purpose as incisor teeth. From its shape we infer that in the Piltdown race the canines were anthropoid in their action as well as in their form.

A comparison of the human and anthropoid dentitions shown in fig. I $7 \mathrm{I}$ helps us to understand how the anthropoid canines might be converted to a human form. In the human dentition the canines, both upper and lower, form part of the front series; in anthropoids, although the canines are partially seen from the front, they are situated really in the lateral series. The transformation of canine teeth from the anthropoid to the human form apparently resulted from the change in their positionduring their transference from the side to the front series. We have already seen that the evolution of modern human races must have been attended by a great reduction in the size of the incisor teeth and of that part of the jaws in which these teeth are implanted. I think it is probable, from the manner in which the Piltdown canine is worn, that the dental and maxillary reduction had set in, and that the canine was set, not as in apes, completely in the lateral series, but more in the front or incisor series. Hence in reconstructing the lower dentition in the Piltdown mandible I have given the canines an intermediate place between the side and front series (fig. I 66, B).

The discovery at Piltdown again draws attention to the size and growth of canine teeth in the anthropoid apes - the animals which most closely resemble man in structure. Four stages in the development of canine teeth, four degrees in what may be named 
"caninism," are shown in fig. I72-the stages seen in man, the female chimpanzee, the male chimpanzee, and the male gorilla. There are two definite facts we may rely on. (I) That caninism varies in degree according to the kind of anthropoid. It reaches its greatest development amongst gorillas. (2) That the degree of development is influenced by sex. Amongst the great anthropoids males have the canine teeth more developed than females. Amongst the small anthropoids - the gibbons-both sexes have long canines. Now there can be no doubt that secondary sexual characters - to a certain degree caninism is such a

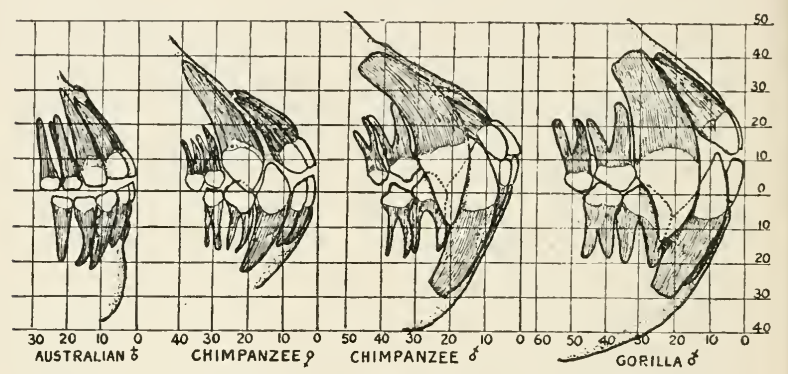

FIG. 172. - The development of the canine teeth in an Australian native, a female chimpanzee, a male chimpanzee, and in a male gorilla.

character-are regulated in development and growth by substances formed in the genital glands. We have evidence that the growth of canine teeth can be regulated by internal secretions or hormones. In that peculiar disease or disturbance of growth, acromegaly, which sometimes attacks men or women, the jaws and the parts of the skull concerned in mastication are particularly liable to become overgrown. The growth of the jaws is also influenced, during normal development, by secretions or substances thrown into the circulating blood by such glands as the pituitary and thyroid. A survey of the dental and maxillary development of the higher primates reveals such various degrees of caninism as are 
shown in fig. $\mathrm{I} 72$, reaching its greatest manifestation in the gorilla and the least in man. We have reason to suppose that these various forms have all been evolved from a common type, and at the present time we have the strong hope that a better knowledge of the laws which regulate the growth and development of the body will reveal to us the exact manner in which these various degrees of caninism have been produced. In the stages shown in fig. I 72 there is only one real break in the series-that between those represented by man and by the female chimpanzee. Does Eoanthropus serve to bridge that gap?

We have only the lower canine to help us in answering this question, and it forms only part of the canine shears. We have seen that the first lower premolar and the lateral incisor are also intrinsic parts of the canine mechanism. To give a complete answer we need not only the canine teeth but their neighbours on each side. The condition of the lower canine can only be explained by supposing that the canines had passed some little way from the anthropoid towards the human condition. We have seen that the crown of the Piltdown canine was worn in a peculiar manner, and that its dimensions were rather small when compared with those of anthropoid teeth. Occasionally we do find anthropoid dentitions in which the lower canines are worn in a manner not altogether unlike the wear seen in the Piltdown specimen. When such cases are examined it is found that the wear is due to the upper lateral incisor, and that the lower canines are less widely separated than is usual. I infer, therefore, that in Eoanthropus the lower canines had undergone an approximation, and that the partial twist which brought them more in line with the incisors than with the molar teeth had taken place. Their chief opponents were not the upper canines but the upper lateral incisors. In brief, there is an indication that the humanisation of the canines had begun in the Piltdown race. In the Heidelberg mandible, which Dr Smith Woodward supposes to have belonged to a form of mankind 
contemporary with the Piltdown race, the humanisation of the canine teeth is complete. That fact has an important bearing on the place we are to assign to the Piltdown race in our ancestral tree (fig. I 87).

In supplying the missing parts of the Piltdown mandible,

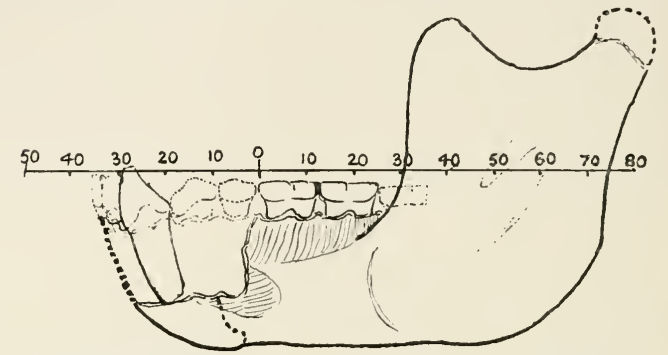

(A) EOANTHROPUS.

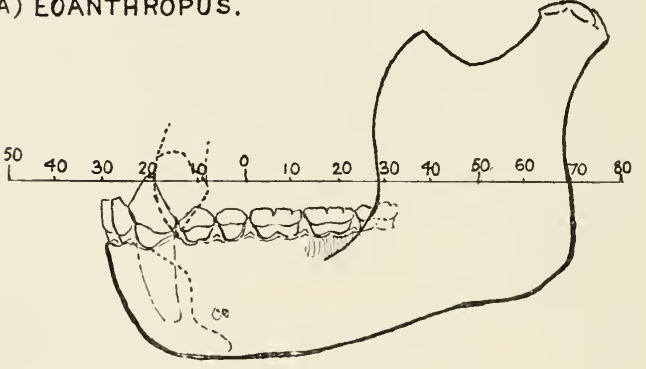

(B) CHIMPANZEE.

FIG. I73.-A. Profile of the mandible and lower teeth of Eoanthropus, as reconstructed by the writer. B. Similar view of the mandible and lower teeth of a female chimpanzee.

and the missing teeth, we must be guided, to a considerable extent, by the corresponding parts of anthropoid apes. In fig. I 73 is reproduced a reconstruction of the Piltdown mandible which differs only in detail from the later reconstruction by Dr Smith Woodward. A drawing of the mandible and teeth of a female chimpanzee is also shown in fig. 173. The reconstruction of the missing 
premolar teeth of Eoanthropus is attended by certain difficulties. We have seen that the first lower premolar tooth is specially modified to serve as an opponent for the upper canine in all anthropoids (fig. 172). Was the first premolar so modified in Eoanthropus? If the upper canine interlocked as in anthropoids, it must have been shaped as represented in fig. $176, \mathrm{p} .480$. If it did, no mark of contact is apparent on the lower canine, which is worn, as we have seen, in a peculiar manner. We have to remember, too, that the articular eminence and glenoid cavity for the articular condyle of the mandible bear witness to the fact that the chewing movements of Eoanthropus were those of modern man. What, then, was the form of the upper canine, and what was its mode of articulation with the lower teeth? The solution of these difficulties must be resolved by future discoveries. In the Piltdown mandible (fig. I 73, A) I have carried the cutting edges of the incisor teeth $36 \mathrm{~mm}$. in front of the zero pointbetween the last premolar and first molar. In his original reconstruction Dr Smith Woodward carried the incisor point $42 \mathrm{~mm}$. forward. In the female chimpanzee shown in fig. $\mathrm{I} 73, \mathrm{~B}$, the incisors are only $30 \mathrm{~mm}$. in front of the zero point. In any reconstruction Eoanthropus must be given a large development of front teeth.

When we come to deal with the molar teeth we feel we are again back on safer ground. The characters of the mandible itself, so far as they have guided us to the place which we must assign to Eoanthropus amongst the higher primates, have taken us in an anthropoid rather than in a human direction. The molar teeth leave us in no doubt; they are human. If the question is asked: What are the characters of these teeth which are so essentially human? it must be confessed that a direct and explicit answer is not easily returned. We recognise at once the face of a friend, but we may be unable to name the number of points which enter into the act of recognition. We become familiar with teeth-we know the appearance of the various anthropoid forms, the various human forms-and yet we find it well-nigh impossible, 
except at excessive length, to state the marks of identification in scientific terms. Regarding the essential humanity of the two molar teeth fixed in the Piltdown mandible there has never been any diversity of opinion. There was the same instant recognition of the human characters in the teeth of the Heidelberg mandible. The mandibular bony frame of that specimen is massive and bestial, but the appearance of the teeth sealed its humanity. However we may waver over the Piltdown mandible, the clear, direct evidence of the molar teeth comes ever to our aid. Their dimensions alone are not particularly remarkable when compared with the largest dentitions of primitive human races. The front-to-back diameter-the "proximodistal" as it is technically called-of the crown of the first molar is $12 \mathrm{~mm} . ;^{1}$ of the second $12.5 \mathrm{~mm}$. ( $\frac{1}{2}$ inch). The third molar is missing, but from the indications given us by the pits for the roots we may safely infer that it was as large as the second. The total length of the molar series was thus about $37 \mathrm{~mm}$. In primitive modern races the total molar length does occasionally reach $40 \mathrm{~mm}$., but the average falls short of the Piltdown measurements. The molar teeth with which we may most profitably compare those of Eoanthropus are those in the Heidelberg mandible. In that specimen the first molar is I I.6 mm. in length of crown, almost the same as in Eoanthropus; the second $12.7 \mathrm{~mm}$., also the same ; the third, I $2.2 \mathrm{~mm}$., corresponds to the estimate made for the third Piltdown molar.

When, however, we place the teeth of modern Englishmen in comparison we see a marked difference. Some time ago I made a series of measurements on twenty-two English students of medicine. In them the first lower molar had a mean length of $10.2 \mathrm{~mm}$, the second IO.I mm., the third $9^{\circ} \mathrm{I} \mathrm{mm}$., the total molar length being $29^{\circ} 4 \mathrm{~mm}$. - 7.6 $\mathrm{mm}$. less than in Eoanthropus. Every one who has made extensive examinations on the

1 These measurements are taken from the casts. Dr Smith Woodward gives the length of the first molar as $1 \mathrm{I} .5 \mathrm{~mm}$., the second as $12 \mathrm{~mm}$., his measurements being made on the original teeth. 
tooth development of ancient races-of people who lived in the Neolithic, Bronze, or early Iron agesis convinced that there has been a reduction in the molar development of the more highly civilised races. We do not know the exact means which has wrought this change in the human body, but we do see the order in which the teeth undergo reduction. It will be noted that in the English students the molar teeth diminish from first to third. In Eoanthropus and in the Heidelberg jaw, the reduction does not come in that order-almost the opposite. The second is larger than the first; the third is also larger than the first, if equal to or perhaps smaller than the second. If we examine the molar teeth of such primates as the gorilla and baboon, in which the teeth reach the zenith of dental development, the order is exactly the reverse of that found in modern highly civilised races. The lower molars increase in size from first to third. It will be remembered that we fixed the zero point in the dental series between the last premolar tooth and first molar. Increase or reduction commences in the teeth furthest removed from the zero point. In the molar series the third or last is the one to show the initial change, whether it be retrogressive or progressive in nature.

The anatomists of a former generation were inclined to rely on the relative development of the molar teeth as a guide to the affinity of animal forms. There can be no doubt as to the close structural relationships between the gorilla and chimpanzee, yet as regards the degree of molar development they represent opposite conditions. In the average gorilla the third molar is the largest of the series; in the average chimpanzee it is the smallest. In one there is a progressive molar development ; in the other there is a retrograde one. If we recognise a state in which the two last molars of the lower jaw are of about the same size, as the normal or "plenal" condition, then we may distinguish those dentitions in which the third molar is the largest of the series, as in the gorilla, as 
"supra-plenal" ; ${ }^{1}$ the condition in the chimpanzee and modern man as "sub-plenal." As regards molar development Eoanthropus must be placed in the plenal groupperhaps in the supra-plenal.

When the chewing surfaces of the molar teeth of Eoanthropus are examined, it is seen that five cusps are clearly marked on each-two outer, two inner, and a fifth which is situated on the hinder border, near the junction of that border with the outer. The molar teeth of Eoanthropus were thus provided with the normal complement of cusps. It is the fifth cusp which is of chief interest. In the dentitions I have described as supraplenal the fifth cusp reaches a higher development in the third molar than in the first; in plenal dentitions the fifth cusp is larger on the crown of the first than of the third molar; in the sub-plenal form the fifth cusp disappears from the last molar and becomes reduced or disappears from the second also. Indeed, it is not uncommon to see modern dentitions in which the fifth cusp has disappeared from all the lower molar teeth. In the Heidelberg teeth the fifth cusp is present on the crowns of all the molars. In Eoanthropus we do not know what the condition was on the third molar, but we can see that the fifth cusp of the second molar, although not quite so large as in the first, is still well developed, and we may infer that it was present in the third of the series. We have thus evidence that the molar teeth reached a plenal development at least-a degree which I have not observed in any modern human dentition.

A plenal development of the molar teeth must be regarded as a primitive feature. So, too, is the relative narrowness of the Piltdown molars. The length or proximo-distal diameter of the crowns is greater than their width-the measurement made between the cheek and tongue margins. The width of the first molar is Io $\mathrm{mm}$. ; in the second $10.5 \mathrm{~mm}$. In the gorilla and chimpanzee the length of the molar crowns is greater than the width;

1 See Keith, "Problems relating to the Teeth of the Earlier Forms of Prehistoric Man," Proc. Roy. Soc. of Med., I9I3, vol. vi. p. Io3. 
in modern human races the width is equal to or greater than the length, although individual exceptions are not rare. In the Heidelberg molars the length slightly exceeds the width. Still, the narrowness of the Piltdown molars reminds us we are dealing with human teeth of a primitive form.

Of late years a study of the pulp cavities of the teeth, of their roots, and of the manner in which the teeth are implanted in the jaws, has thrown quite a new light on some of the problems which relate to the origin of man. The introduction of X-rays as a means of transillumination has made it possible for us to examine the buried parts of the teeth without destroying the mandibles in which they are implanted. It was the study of the pulp cavities and roots of the teeth of Neanderthal man which permitted Dr Adloff ${ }^{1}$ to produce convincing evidence that this mid-Pleistocene race could not stand in an ancestral position to modern man, but represented a terminal offshoot from our ancestral stem.

When the mandible and lower molars are examined by means of X-rays, the central cavities of the molar teeth, containing the sensitive living pulp tissue, are seen as comparatively clear spaces in the opaque bodies of the teeth (see fig. 65, p. I9I). In anthropoids, such as the gorilla and chimpanzee (fig. I 74), the pulp cavities are comparatively shallow spaces between the crown above and upper ends of the roots below. The cavity is situated on a level with the neck of the tooth-the junction of the crown with the body of the tooth-the part formed by the fusion of the upper ends of the roots. In each of the three anthropoid molars the two roots diverge widely, especially in the chimpanzee (fig. 174). The roots of the second and third molar reach, or even pass beyond, the canal containing the dental nerve in the substance of the mandible. Two other points may be noted to complete an imperfect picture of the anthropoid lower molars : (I) on passing from the first to the third

1 For references to Dr Adloff's recent publications, see Anat. Anz., 1913, vol. xlv. p. 191. 
molar the pulp cavity tends to become situated more deeply as regards the upper or alveolar border of the mandible; (2) extensions of the pulp cavity are continued to the tips of the roots; through the canals in the roots vessels and nerves reach the pulp cavity.

When we compare those X-ray pictures of the lower molar teeth of anthropoids with skiagrams obtained from human mandibles certain differences become apparent

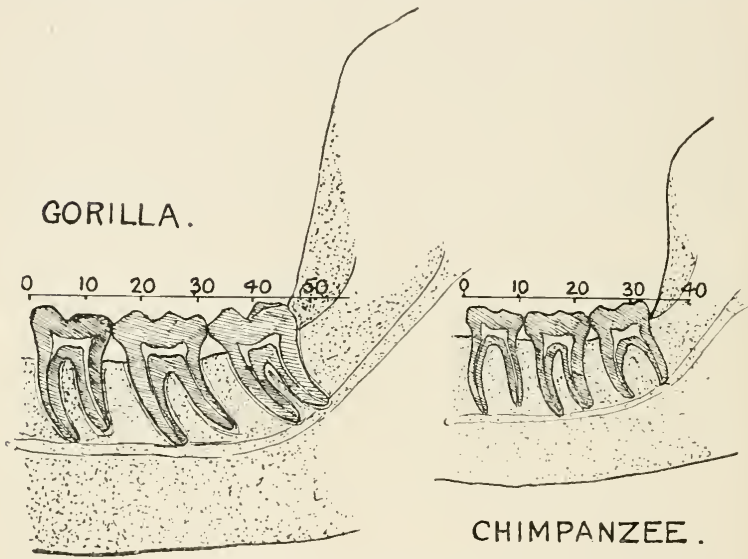

FIG. I74. - Tracings from skiagrams of the lower mulars of a female gorilla and of a female chimpanzee.

(fig. I 75). If, for instance, a tracing of the molar teeth of Eoanthropus, as revealed by the skiagram published by Professor Underwood, is compared first with the tracings shown in fig. I74, and then with the various tracings of human molars shown in fig. I75, we cannot have any doubt as to the group to which the Piltdown molars must be assigned. They belong to the human group; they are remarkably like the modern teeth shown in fig. I 75. The roots of the Piltdown molars are not long, only about $12 \mathrm{~mm}$.; in modern molars a root length of $15 \mathrm{~mm}$. is not unfrequently seen. The 
roots are curved and well separated, assuming a form which may be seen in the mandibles of the more primitive races of modern man. The spread and curvature of the roots is rather less than in the chimpanzee. The third molar is unfortunately missing, but its socket is evident. The appearance of the socket of this tooth, as revealed in the skiagram, at first led me to infer that the mandible

(A)

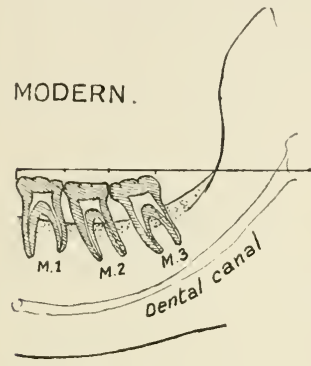

(c)

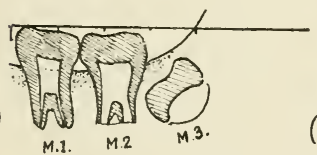

KRAPINA .

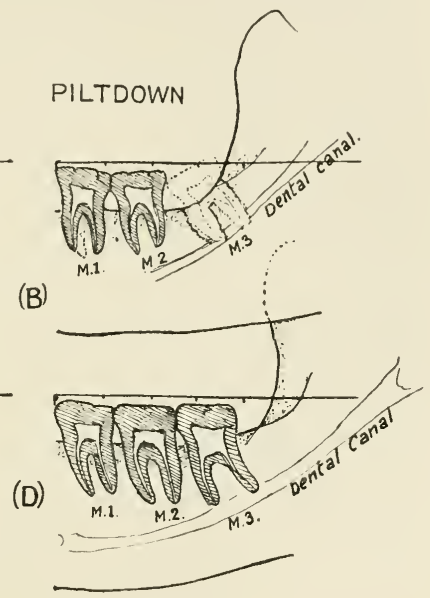

HEIDF.LBERG.

FIf. 175.-Skiagrams of the three lower molars of a modern European, of Eoanthropus, of a Krapina (Neanderthal) individual, and of the Heidelberg man.

must be that of a young adult in which the third molar tooth was not fully erupted-the crown had not quite reached the chewing level. A closer examination of the actual specimen has shown that there are no good grounds for supposing that the third molar had not come into use. As in anthropoids, the roots of the last Piltdown molar reached the dental canal (fig. I 74). That is also the case in the Heidelberg mandible, and occasionally this condition also occurs in the mandibles of modern races. 
Another very remarkable feature of the molar teeth of early human races is also shown in fig. I75. In anthropoid molars we have seen that the pulp cavities, even in young adults, are comparatively small. That is also true of the pulp cavities of the molar teeth of modern human races. In the Neanderthal race there was, as we have already seen, a remarkable development of the pulp cavities, particularly well shown in the specimen found by Professor G. Kramberger at Krapina, in Croatia (fig. I 75, C). The pulp cavities in many of the Krapina molars almost extend to the tips of the roots. This condition is present to a greater or less degree in the teeth of all members of the Neanderthal race. It is a character of that race. It is equally apparent that it is not a primitive feature, for it is the opposite to what obtains in anthropoids and primates generally. Here, then, is a very remarkable fact which throws a sidelight on the antiquity of man: by the middle of the Pleistocene period there was a race of men which showed a very aberrant and highly specialised mode of tooth development.

The enlargement of the pulp cavities is seen to have a remarkable effect on the manner in which the teeth are implanted in the jaws. It is very clear from fig. I $75, \mathrm{C}$, that the pulp cavity enlarges at the expense of the roots; the roots of the teeth become very short, the body long and deeply implanted in the mandible. In the molar teeth of modern man the pulp cavities lie above the level of the upper or alveolar margin of the jaw; this is also the case in anthropoids. We may regard it as the primitive condition. It is true that there is a tendency in the third molar for a downward extension of the pulp cavity to take place. We have, then, two extremes in molar formation: the condition in which the pulp cavity lies above the alveolar border, as in the molar teeth of carnivorous animals, which we may call the "cynodont" form. There is the other extreme seen in Neanderthal man, where the pulp cavity extends deeply within the substance of the jaw, recalling 
the molar teeth of cud-chewing animals - a form which we may call "taurodont." Now when we examine the molar teeth of Heidelberg man there can be no doubt that a considerable degree of "taurodontism" is present. The pulp cavity of the third molar is large and sinks deeply in the substance of the mandible. The other characters of that mandible show us that in the Heidelberg jaw we are dealing with a rather early and massive form of Neanderthal man. The pulp cavities of the Piltdown molars are also large, but there is no indication of a downward extension of the pulp cavity below the alveolar margin. We do not know what the condition may have been in the missing third molar tooth. We do know, however, that with the appearance of taurodontism the body of the tooth enlarges so that the constriction or neck at the junction of body with the crown of the tooth tends to disappear. That constriction is well marked in the Piltdown molar teeth. Although the pulp cavities are large in the molar teeth of both those species of early men-Heidelberg and Piltdown-yet only in the former do we see distinct evidence of taurodontism.

If we sum up the evidence relating to the mandible and teeth of Piltdown man we must, in the first place, emphasise the remarkable mixture of human and ape-like characters which they exhibit. The mandible, as we have seen in a previous chapter, was marked by many simian traits, particularly in the region of the chin or symphysis. The articulation for the mandible, on the temporal bone of the skull, does not differ from that seen in skulls of living races of a primitive type. The molar teeth are essentially human. On the other hand, the canine tooth, in its form and size, is more ape-like than any canine ever before attributed to a human being. In shape and size it is in keeping with the mandible, but even when these admissions are made, certain difficult problems remain to be solved. One of these relates to the upper canine teeth, which must have been equally simian and pointed. The method of articulation between the upper and lower canine teeth cannot have been as in apes, because the 


\section{8

joint for the mandible on the base of the skull shows that the tooth movements were those which take place in modern man. Whatever the exact form of articulation between the upper and lower canines may prove to be, it is certain that the discovery at Piltdown has revealed a human being in which certain anthropoid features were well marked in the teeth and jaws. It is also equally certain that the brain had passed far beyond an anthropoid stage of development. 


\section{CHAPTER XXVII}

\section{THE FACE OF FOSSIL MAN}

THE picture we form of a human being is chiefly based on the appearance of the face. It is therefore natural that we should try to restore the facial outlines of our fossil ancestors. At the most it is only the bare skeletal outline we can rebuild; we cannot hope to restore the living countenance. Imperfect as the picture must be, it is well worth our pains to see how far it is possible to reconstruct the face of so ancient and interesting a human form as that found at Piltdown. Fig. I 76 shows the materials on which our picture has to be framed. There is, in the first place, half of the lower jaw ; that forms a large part of the outline of the face. In the second place, there is the left corner of the forehead and left temple. In the third place, the nasal bones, which form the bridge of the nose. In the fourth, there is the root of the zygomatic process, which guides us to the width of the face and prominence of the cheeks. From such materials we ought to be able to build up an outline of the face, at least in its more general aspects.

In a former chapter an account was given of an experiment in the reconstruction of skulls. As regards the contour of the forehead, when seen in profile, that experiment was a failure. On the other hand, as is shown in fig. 177 , the width and height of the frontal region were correctly reproduced. The skull thus reconstructed, that of an Egyptian woman, had a forehead of average human dimensions. The temporal lines, as they ascend on each side of it, cross within the 50-mm. 
vertical line, a little above the supra-orbital ridges. The minimum width of the forehead was $9^{8} \mathrm{~mm}$. In fig. I 78 the reconstructions of the Piltdown and test skulls are compared. In the fossil skull the temporal lines are wider apart than in the test skull, the minimum frontal width of the former being between 100 and $105 \mathrm{~mm}$. The forehead represents the anterior wall of the brain chamber, and the reader may naturally infer that with

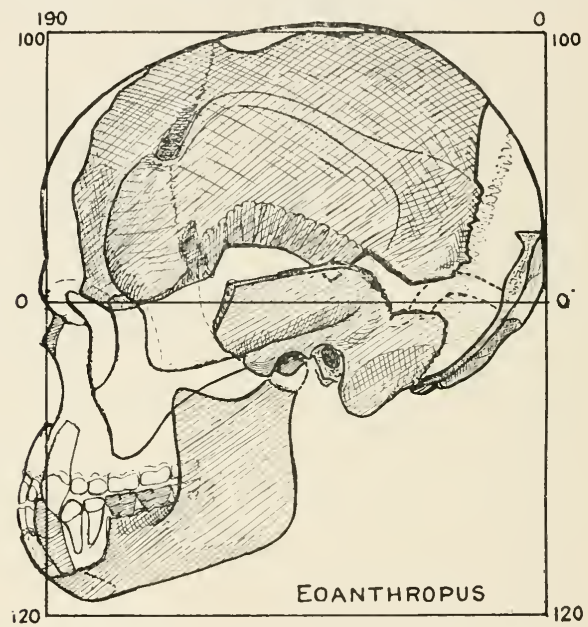

FIG. I76.-Reconstruction of the face of Eoanthropus as seen in profile.

a wide forehead the frontal lobes of the brain of Eoanthropus must also have been above the average width. We must take into account the thickness of the frontal bone; with a thick frontal bone, such as that of the Piltdown skull, the temporal lines are necessarily more widely separated than in a modern thin-walled skull.

If the frontal views of the skull reproduced in fig. I 77 be examined, it will be seen that the temporal lines, as they ascend the forehead, soon pass outside the $50-\mathrm{mm}$. lines, and at the point where they cross the coronal 
suture-that point being known as the "stephanion"they lie $10 \mathrm{~mm}$. outside the $50-\mathrm{mm}$. limit. The "interstephanic" width of the frontal bone of the test skull is thus $120 \mathrm{~mm}$. - a very common measurement in modern skulls. It must also be noted that if the temporal muscles are large, their origins will be placed higher on the vault of the skull, and the temporal lines, which circumscribe their origins, will approach nearer to the middle line of the vault than when the temporal muscles are small. An English skull showing a high position of the temporal lines is represented in fig. I79. In skulls

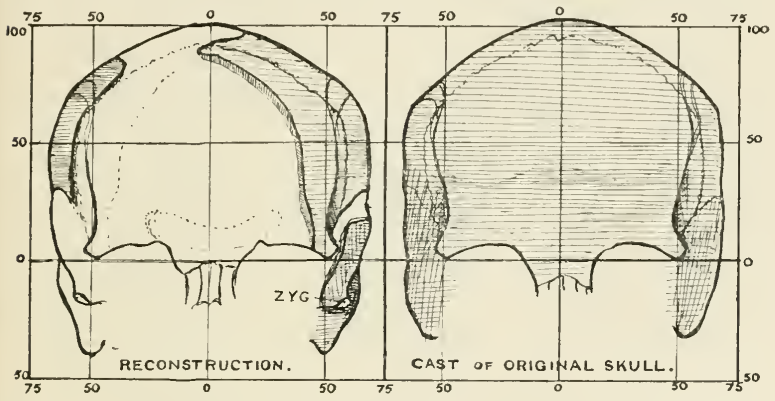

FIf, 177.-Frontal view of a reconstructed skull, compared with a cast of the original-that of an Egyptian woman.

of fossil men we expect to find large temporal muscles, and the temporal lines high up on the vault of the skull so that the interstephanic diameter becomes reduced. In the reconstruction of the Piltdown skull, shown in fig. I 78 , the frontal bone is poised so as to represent the smallest possible frontal width; it has been pushed inwards to a degree which somewhat interferes with the symmetry of other parts of the reconstruction. It will be seen, however, that even when the frontal region is unduly contracted, the temporal lines cross the coronal suture $10 \mathrm{~mm}$. outside the $50-\mathrm{mm}$. line. The interstephanic diameter in the Piltdown skull is not less than I $20 \mathrm{~mm}$., and the temporal lines do not ascend 
further on the vault than in the majority of modern skulls. That is rather an unexpected fact when we remember the size of the lower jaw and the prominence of the canine teeth. In the characters of the forehead Piltdown man does not fulfil our expectation; the forehead, instead of being narrow, low, and receding, is wide, full, and prominent.

In fig. I 79 the right half of the forehead of the Gibraltar skull is set by the side of the opposite half of an English skull to again recall the points of difference between the Neanderthal and modern types. In the

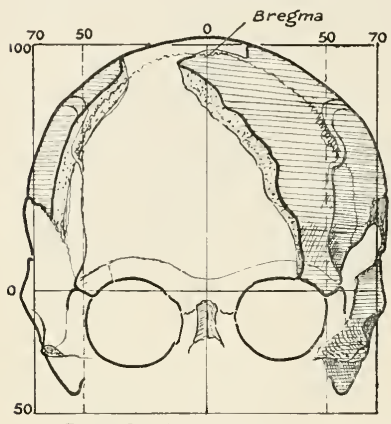

PILTDOWN.

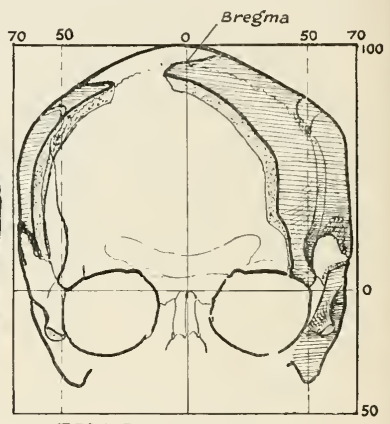

TEST RECONSTRUCTION.

FIG. I78. - Frontal view of a reconstruction of the Piltdown skull by the Author, compared with the reconstruction of the test skull.

Gibraltar skull the forehead is low but wide; the temporal line ascends on the outer side of the $50-\mathrm{mm}$. line. In the English skull, one with uncommonly large temporal muscles, these lines are situated inside the 50-mm. standard; the frontal width is unusually low. In the English skull the frontal boss or eminence is well marked; it can scarcely be detected in the Gibraltar skull. The main point of difference between these two types lies in the conformation of the supra-orbital ridge. In the Neanderthal type this ridge forms a prominent continuous bar of bone, commencing above the root of the nose and ending externally in the angular 
or malar process. In the modern type (fig. I79) the supra-orbital ridge is divided into two parts, inner and outer. As already pointed out, the supra-orbital ridges and angular processes must be included in the bony scaffolding which is thrown out from the skull for the purposes of mastication. Hence in primitive races, with large jaws and strong chewing muscles, these bony ridges, particularly the angular processes, are well developed.

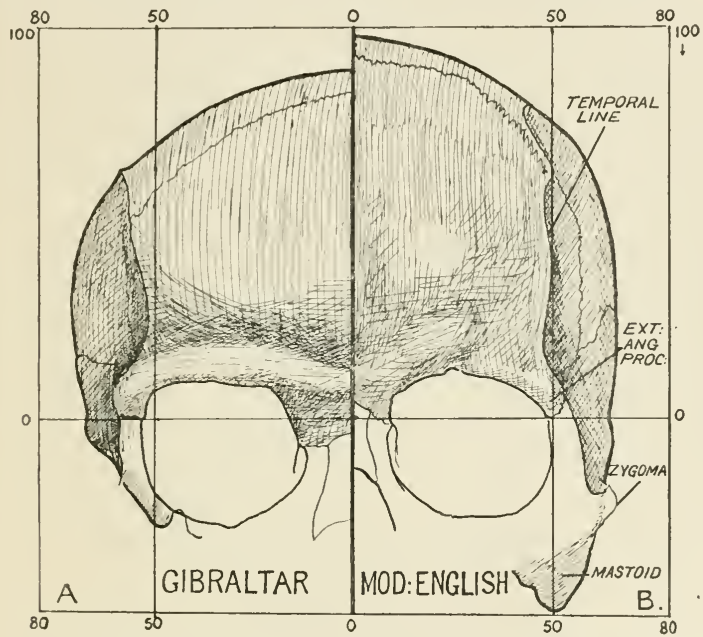

FIG. 179. - Frontal view of the right half of the Gibraltar skull and left half of a modern English skull set side by side to show the difference between the Neanderthal and modern types of forehead.

It is unfortunate that so little of the forehead of Eoanthropus has been preserved. We have the whole of the left angular process and the commencement of the supra-orbital ridge. A study of these parts shows us, in the first place, that the supra-orbital ridges were not modelled as in the gorilla, chimpanzee, Pithecanthropus, and Neanderthal man, and, in the second place, that they were different to those of the modern type of man. The angular processes in the Piltdown forehead were remark- 
ably short and stout; they did not form projecting lateral knobs, such as are seen in Neanderthal skulls and in primitive specimens of modern man. In the young orang and in the skulls of children we find angular processes somewhat resembling the Piltdown type. Piltdown man was evidently marked by peculiar features quite different from any known form of fossil man or ape.

Neanderthal man is characterised by the great width of the supra-orbital bar ; from one angular process to the other it measures from $\mathrm{I} 20$ to I $28 \mathrm{~mm}$. We expect to find a great supra-orbital width in ancient and primitive types of man, and hence it was natural that we should expect such a feature in Eoanthropus. In modelling his first reconstruction, Dr Smith Woodward was influenced by this belief. In fig. I 80 is represented the left half of the original model of Eoanthropus. The angular process projects Io $\mathrm{mm}$. beyond the $50-\mathrm{mm}$. vertical, giving a total supra-orbital width of $120 \mathrm{~mm}$. The temporal lines, as represented in the model, have quite a different direction from that seen on any other human skull. In fig. I 80 is also shown the right half of the forehead of those round-headed men who first landed in England during the Bronze age. They had remarkably prominent supra-orbital ridges and angular processes-offering a striking contrast in this respect to Eoanthropus. The temporal line, after leaving the angular process, draws inwards on the forehead until it touches the $50-\mathrm{mm}$. limit, and then begins to pass outwards as it ascends, in the manner seen in all known types of men. If, however, we were to tilt the vault of the Bronze skull downwards and inwards for a little way, we should produce exactly the same disposition of the temporal lines and of the angular process as are seen in the original model of Eoanthropus. It is highly probable, then, that the peculiar frontal features seen in the original model of Eoanthropus are reconstructional, for when we poise the frontal fragment in Eoanthropus as in all known human skulls, then, as is shown in figs. 178 and $18 \mathrm{I}$, the features normal to all types of men are reproduced. In my first attempts to 
reconstruct the Piltdown skull I also believed that the supra-orbital region of the forehead must be made wide, but this belief had to be abandoned in order that the parts belonging to the middle line of the vault might fall into their proper places.

We have been discussing the characters of the forehead,

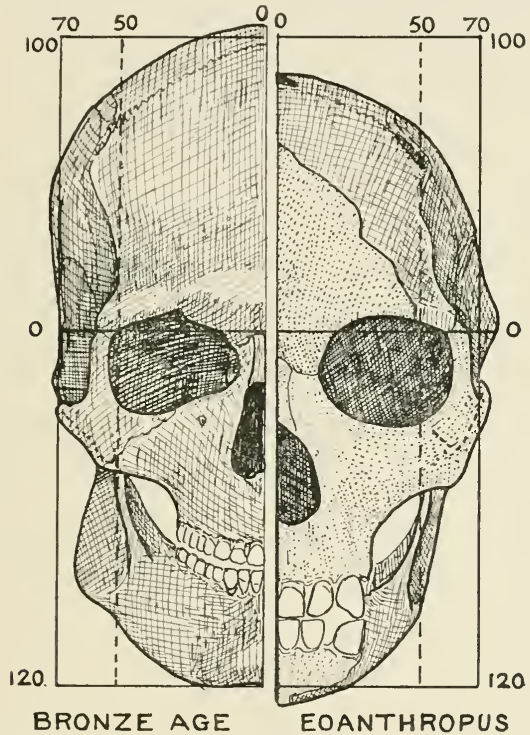

FIG. I So. - Frontal view of the left half of the original model of Eoanthropus contrasted with the opposite half of a Bronze-age English skull.

which, in a strict anatomical sense, does not form part of the face but of the cranium. For the anatomist the face commences at the root of the nose and ends at the chin, thus including those parts which form the eyesockets, the nasal cavity, and the mouth. When the anatomist measures the length of the face his upper limit is the nasion-the point of junction between nasal bones and the frontal; his lower, the under margin of the chin. 
In the reconstructions of Eoanthropus, shown in figs. I 80 and $\mathrm{I} 8 \mathrm{I}$, the length of the face is represented as similar to that of modern man. The width of the face is measured between the zygomatic or cheek arches. Now, on the left temporal bone of Eoanthropus the root of the zygomatic arch is preserved (fig. I 78 ), and we have thus a

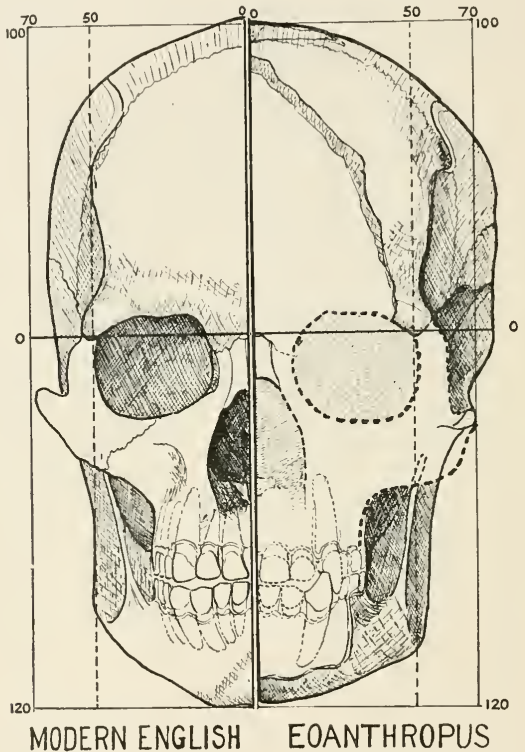

FIG. I8I.-Frontal view of the right half of the forehead and face of a modern Englishman contrasted with the left half of the Piltdown skull, as reconstructed by the Author.

means of judging the total width of the face. As may be seen in figs. 180 and I $8 \mathrm{I}$, we are agreed that in width of face Eoanthropus and modern man are not unlike. In one reconstruction the bizygomatic diameter is represented as I $40 \mathrm{~mm}$. ; in the other-the original model-as $146 \mathrm{~mm}$. In width of face Eoanthropus was very like the modern Chinaman. Another difference between the reconstruc- 
tions shown in figs. I 80 and I 8 I relates to the width of the jowls, measured between the angles of the lower jaw. In both reconstructions the width is represented as $100 \mathrm{~mm}$., quite a common dimension in modern human faces ; but in the original model (fig. I 80) the side contour of the face is that seen in apes, while in the other (fig. I $8 \mathrm{I}$ ) the human form is reproduced. The ape-like contour is due to the fact that in the original model the lower jaw is set at a very oblique angle.

In the nasal bones of Eoanthropus we again come across features which are eminently human. In shape and size they are short and thick. They resemble the nasal bones seen in negroid and in Mongolian races. ${ }^{1}$ If merely the nasal bones had been found at Piltdown, anatomists would have agreed that an ancient representative of a negroid race had been discovered. If merely the canine tooth or mandible had come to light, they would have been equally convinced that they had to deal with parts of an anthropoid. If merely the skull bones had been recovered, Eoanthropus would have been regarded as purely human and given a position in the immediate ancestry of modern man.

From the nasal bones and from the size and shape of the upper canine teeth (see figs. I 80, I 81 ), we are assured that the nose must have been wide and flat as in negroid races. We must infer, too, from the retreating, ape-like chin, from the size of the canine and incisor teeth, that the mouth and jaws formed a projecting muzzle, more so than is the case in any known type of fossil man.

From the cursory survey just given, the reader may have concluded that, so far as the reconstruction of the face of Eoanthropus is concerned, there is no sure foundation of fact on which the anatomist may build. That is not the case. In fig. I 82 a problem in face reconstruction is presented. The skull is from a native Tasmanian with a palate only $\mathrm{I} O \mathrm{~mm}$. shorter than that of Eoanthropus. In this problem of face reconstruction we are given, in the first place, that part of the mandible

1 For details of measurements of nasal bones, see reference on p. 456. 
which is shaded and three teeth. From these we could reconstruct the complete lower jaw with a fair degree of accuracy. In the second place, we are given all those parts of the skull which are shaded-replicas of the Piltdown fragments. The problem is to reproduce the parts of the face and forehead shown by stippled

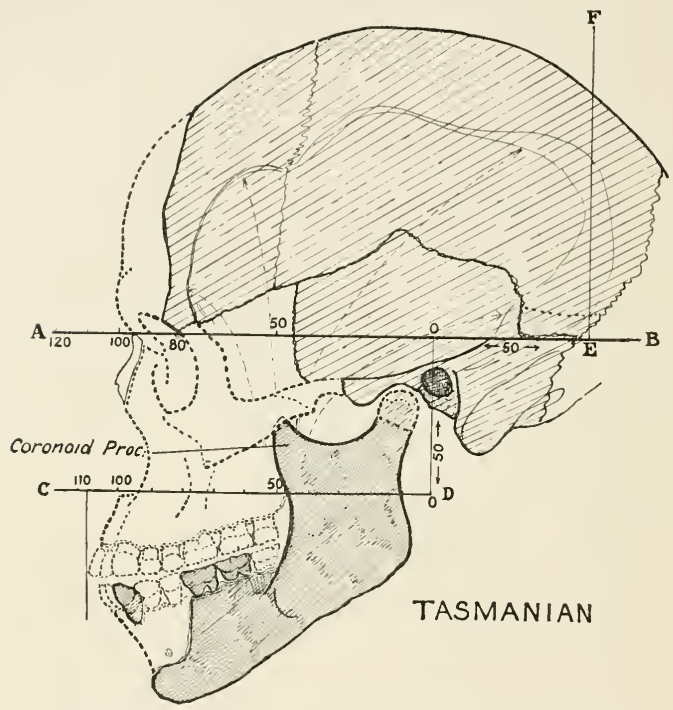

FIG. 182.-Profile of the skull of a native Tasmanian. The parts stippled are those which have to be filled in from inference in reconstructing the Piltdown skull.

lines. Our first step is to complete the mandible and place its condyles in their sockets, in front of the earpassages (fig. I 82). The second step is to complete the zygomatic arch : not a difficult procedure, for its commencement and direction are given us, and so is the angular process of the frontal bone, to which the arch is indirectly joined. Two other points help us: the lower border of the orbit is nearly on a line with the upper border of 
the zygoma, and the root of the nasal bones occupies nearly the level of the plane $\mathrm{A}-\mathrm{B}$, on which the skull is poised.

In the skull shown in fig. I 82 it will be seen that the tip of the coronoid process of the mandible just reaches the zygomatic arch. That is the usual relationship in anthropoid skulls and in human skulls of a primitive type. We therefore, in estimating the length of the face of Eoanthropus, flex the mandible until the coronoid process reaches the zygomatic arch. At that angle the chin reaches its normal position and marks approximately the lower limit of the face. Having thus estimated the length of the face, it is an easy matter to reproduce the palate and upper teeth, for they hold definite relations to the lower. The lower border of the zygomatic process ends above the first molar tooth in both men and anthropoids.

As the Piltdown mandible shows many simian traits, it will be well to see how far the method just employed for the reconstruction of the profile of a human skull can be applied to that of an anthropoid. For this purpose the skull of an orang has been selected, because, as already mentioned, there are some features in the Piltdown forehead reminiscent of the conformation seen in the orang. The problem and its solution are presented in fig. I 83. The plane of orientation, $\mathrm{A}-\mathrm{B}$, has been used for orientation as in fig. 182 . In the human skull the forehead extends forward on that plane to a point which is $100 \mathrm{~mm}$. in front of the ear (fig. I 82); in the orang the forehead is rather less than $80 \mathrm{~mm}$. in front of the same point. When, however, we look at the lower line (C-D), figs. I 82, I 83), which is drawn $50 \mathrm{~mm}$. below and parallel to $\mathrm{A}-\mathrm{B}$, we see the conditions are reversed. The snout or jaws in the anthropoid face project $135 \mathrm{~mm}$. in front of the ear-passage, while in the primitive Tasmanian the projection is less than I IO $\mathrm{mm}$. In man the forehead projects, the jaws recede; in the anthropoid the opposite is the case. There is another striking difference: the zygomatic arch is lower on the base of the skull-lies 
nearer to the $\mathrm{C}$-..D line-in the anthropoid than in the human skull. That is an anthropoid character. It is plain that if we were given those parts of the orang's skull which correspond to the Piltdown fragments and asked to reproduce the original, we could not do otherwise than construct an outline similar to that shown in fig. I 83 .

Let us apply the same method to the reconstruction of the face of a Neanderthal skull, such as that found at Lia Chapelle. The forehead in this case reaches forwards

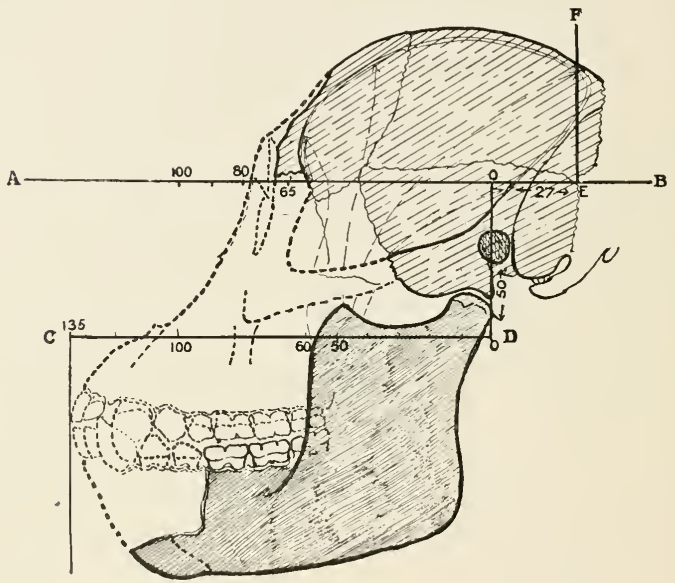

FIG. I83.-Profile of the skull of an orang. The parts which are shown by stippled lines are those missing in the Piltdown skull.

to a point which is $120 \mathrm{~mm}$. in front of the ear, compared with $100 \mathrm{~mm}$. in the Tasmanian and $80 \mathrm{~mm}$. in the orang. When, however, the position of parts on the line C-D is examined, it is seen that the jaws project less than in the Tasmanian. The ancient extinct Neanderthal type is less prognathous-is less simian than the Tasmanian. And yet the jaws and teeth are more massive. It will be seen, too, that the zygoma is situated low down on the base of the Neanderthal skull, as in anthropoids.

By the application of this method to the Piltdown 
fragments we obtain results which give a reliable indication of the size and form of the face of Eoanthropus (fig. 185). The reconstructed cranium is orientated on the plane or line A-B. We have only part of the forehead preserved, the part represented by the angular process. There cannot be any difference of opinion as to

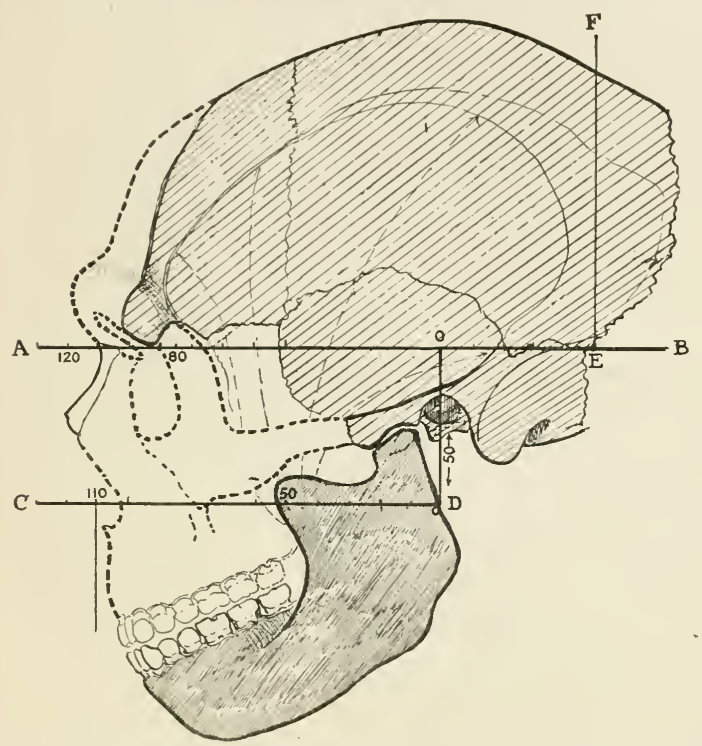

FIG. I 84 . - Profile of the La Chapelle-aux-Saints skull. The parts represented by stippled lines are those which have to be filled by inference in the reconstruction of the Piltdown skull.

the distance of this process in front of the ear. A point $80 \mathrm{~mm}$. in front of the ear marks the centre of the process. The position of the corresponding point in the orang is $65 \mathrm{~mm}$., in the Tasmanian skull $75 \mathrm{~mm}$., in the Neanderthal specimen $85 \mathrm{~mm}$. The angular process of the Piltdown skull thus occupies a normal human position on the plane of orientation. The total projection 
of the Tasmanian forehead was $100 \mathrm{~mm}$. (fig. I 82), that of the La Chapelle forehead $120 \mathrm{~mm}$; w we may safely assign an intermediate amount to the Piltdown forehead - I IO mm. (see fig. I 85 ).

We now turn to the lower line (fig. I $85, \mathrm{C}-\mathrm{D}$ ) to ascertain how the maxillary or facial development of the Piltdown skull compares with that of the other skulls

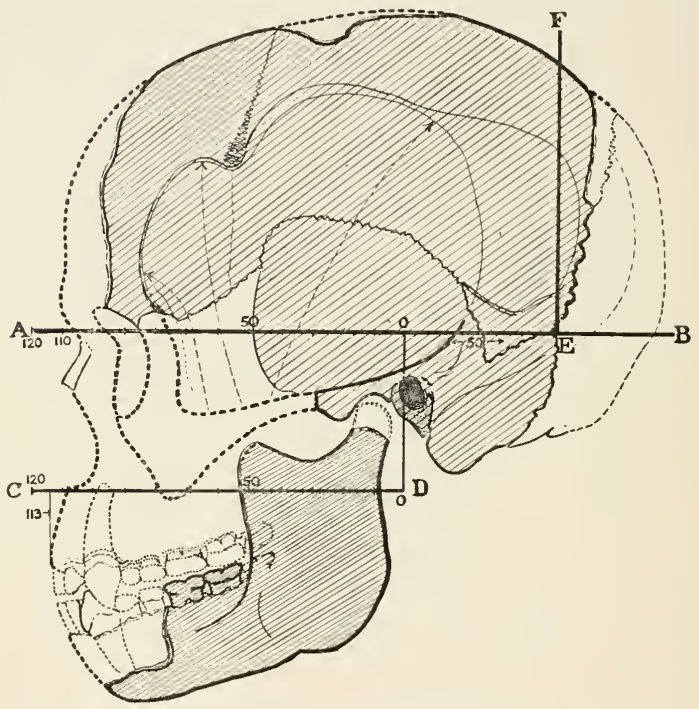

FIG. I 85 - Reconstruction of the facial profile of the Piltdown skull carried out by the method described in the text.

with which we are now dealing. In the Tasmanian and La Chapelle crania the "muzzle" projects almost I IO $\mathrm{mm}$. in front of the ear-holes. In the orang the projection is greater-I $35 \mathrm{~mm}$. In the Piltdown specimen, in spite of the simian characters of the mandible, the facial projection is only a few millimetres more than in the Tasmanian skull. We can estimate the degree of prognathism by comparing the frontal and maxillary lines 
(A-B and $\mathrm{C}-\mathrm{D}$ in the above figures). In the orang (fig. 183 ) the muzzle projects $135 \mathrm{~mm}$. in front of the ear-passage; the forehead $78 \mathrm{~mm}$.; the amount of prognathism-the extent to which the muzzle projects in front of the forehead-is $57 \mathrm{~mm}$. In the Tasmanian the prognathism is $10 \mathrm{~mm}$.; in the Piltdown skull it is not more than $5 \mathrm{~mm}$. at the utmost. In the La Chapelle skull, notwithstanding the great jaws, there is really a degree of "retrognathism"-the muzzle projects about $\mathrm{I} 2 \mathrm{~mm}$. less than the forehead. Prognathism is a simian character, but it is one which was developed to only a slight extent in Eoanthropus. In spite of the pointed canine teeth and massive jaws the face of Eoanthropus was essentially human.

In fig. I 85 several other features of the skull and face of Eoanthropus are indicated. The zygomatic arch is situated at a lower position as regards the plane of orientation-the line $\mathrm{A}-\mathrm{B}$ - than in human skulls of the modern type (fig. I 82). In this respect Eoanthropus resembled Neanderthal man and anthropoid apes. In the reconstruction shown in fig. I 85 , the tip of the coronoid process is placed on a level with the lower border of the zygomatic arch-a position occupied by this process in figs. 182,183 , and $18+$. Further, the length and direction of the fibres of the temporal muscle, which are inserted to the coronoid process, are indicated by long stippled lines. The fibres of that muscle were no longer in the ancient types than in modern types of man. But as regards other muscles of mastication-the masseter and internal pterygoid-the case was different. In ancient man these muscles were very large.

There is another and final test which may apply to the Piltdown skull -one which brings out some of its peculiar characters. In fig. I 86 a series of skulls is shown, each cut open from front to back so as to expose the parts which form the base. The series is so arranged as to bring the external meatus of the ear on the same vertical zero line. Each specimen has been set on a corresponding horizontal plane, represented by the line $\mathrm{A}-\mathrm{B}$. 
The first point which impresses the anatomist, when he examines such a series, is that the basal axis in the orang -or in the skull of any large anthropoid ape-is as long

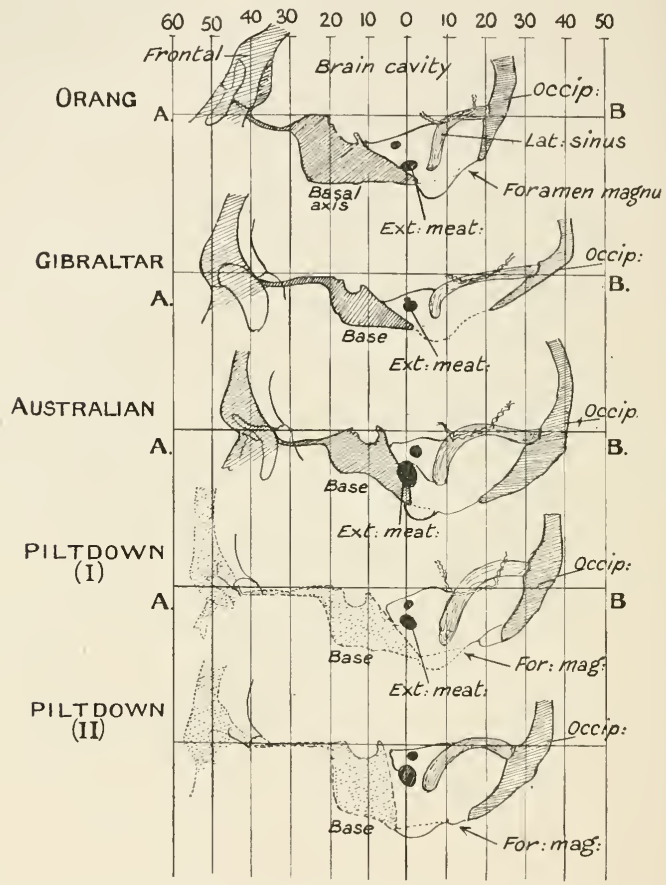

FIG, I 86. - A series of skulls laid open longitudinally to show the parts forming the base or floor of the cranial cavity. Both external and internal auditory meatuses are shown: Piltdown I., from the reconstruction by the writer; Piltdown II., from Dr Smith Woodward's reconstruction-further explanation in the text.

as in the human skull, notwithstanding the fact that the human brain capacity is more than three times that of the ape. In the evolution of the higher primates the length of the basi-cranial axis or floor of the brain chamber remained nearly constant as regards length. In the orang 
(see fig. I 86) the basal axis reaches forwards to the $40-\mathrm{mm}$. vertical line ; this is also the case in the Gibraltar and both reconstructions of the Piltdown skull. In the native Australian - a representative of the modern typethe basal axis falls $5 \mathrm{~mm}$. short of the $40-\mathrm{mm}$. line. In all the types of skulls represented in fig. I 86, the basal axis commences immediately behind the zero line-the line of the external auditory meatus-in all save the lowest drawing, which represents the condition of parts in Dr Smith Woodward's reconstruction of the Piltdown skull. There the basi-cranial axis is contracted to a degree which would seriously incommode Eoanthropus in the acts of breathing and swallowing.

The sections shown in fig. I 86 bring out another change which has occurred during the evolution of the human skull, and also one of the features of Eoanthropus. This relates to the expansion of the human cranial cavity in a backward direction as the brain assumed a greatly increased volume. The occipital wall in the orang's skull (fig. I 86) lies between 20 and $30 \mathrm{~mm}$. behind the auricular vertical line; in the Gibraltar and Australian skulls the occipital bone reaches the $40-\mathrm{mm}$. vertical line, but in the Piltdown reconstructions it falls short of that line. In the modern type of man, as represented by the native Australian, the brain, as it expands, tends to elongate or enlarge the skull in a post-auricular direction. In Eoanthropus the tendency was in an opposite direction, to expand the skull in a pre-auricular or forward direction. Hence the high prominent bulging forehead of Eoanthropus. Attention is drawn to the curtailment or non-expansion of the post-auricular part of the head of Eoanthropus in fig. I 85. A vertical line $(\mathrm{E}-\mathrm{F})$ is raised from the hinder and lower angle of the parietal bone. The posterior border of that bone forms an acute angle with the vertical line, somewhat similar to the condition in the orang's skull (fig. I83). In the Tasmanian and Neanderthal skulls (figs. I 82, 184) the posterior border of the parietal bone slopes upwards and backwards, forming a more open angle with the vertical line. 
In this chapter we finish our survey of the structural features of Eoanthropus. Our inquiry has been prolonged and tedious, for we have had to give an account, not only of the features of this strange and ancient type of man, but to invent and to describe the methods which have to be applied if we are to place the reconstruction of skulls on a sound and scientific basis. So far as the face is concerned we can say with certainty that the forehead of Eoanthropus was well formed. It was high, prominent, and of a width equal to that of a modern human skull of average dimensions. The nasal bones were shaped exactly as in negroid races, and we infer that the nose itself must have been not unlike the broad, flat organ seen in certain primitive living races. The dimensions of the face-its length and width-did not differ from the corresponding facial measurements of other primitive forms of men. Although the front teeth-the incisors and caninesexceeded in size those of any known form of man, and although the palate must have been of very great length, yet the degree of prognathism was not beyond the limits known to occur in living races. The forward extension of the frontal region masked the great size of the jaws. But if this was the effect of the frontal projection, the receding simian formation of the chin must have given the lower part of the face a conformation not unlike that seen in anthropoid apes. 


\section{CHAPTER XXVIII}

A CHAPTER OF CONCLUSIONS

ThOSE of us who set out some thirty years ago to search for evidence which would throw light on the antiquity of man believed we had to deal with a simple problem. We started under the conviction that there was only one kind of man-man of the modern type. We were certain that he was, like all other living things, subject to the laws of evolution, and that as we traced him, by means of fossil remains, into the remote past, we should find him assuming a more and more primitive shape and structure. The discovery of the remains of Neanderthal man in deposits of a mid-Pleistocene date confirmed us in our beliefs. With his great eyebrow ridges and his numerous simian traits, Neanderthal man was just such a being as we had pictured as our ancestor in the Pleistocene period. Then came the discovery of Pithecanthropus-an older and infinitely more primitive type of human being. $\mathrm{He}$ also answered to our expectations, and we adopted him as our late Pliocene or early Pleistocene ancestor. It will be thus seen that we set out prepared to find that man as we know him now was of recent origin, that in the course of a short geological period-one which is estimated at less than half a million of years-a semi-human form of being became endowed with all the attributes of man.

Then came the discoveries of the last ten years. Explorations at Combe Capelle and at Mentone revealed men of the modern type who, if not actually the contemporaries of Neanderthal man, were so closely 
his successors in point of time that it became impossible to believe that Neanderthal man represented a stage in the evolution of modern man. Further, when we came to review critically the facts relating to the earlier discoveries made in England, France, and Italy, we were compelled to admit that men of the modern type had been in existence long before the extinction of the Neanderthal type.

With the recognition of Neanderthal man as a distinct kind or species of human being, our estimate of man's antiquity underwent a profound change. We based our conception of the ancient world of man on the picture which meets our eye when we look abroad at the present time and see a world populated by races which are but variants of one prevailing human type. With such a picture in our minds we peered into the past, expecting to find that the population of every remote geological period was made up of only one type of man. The recognition of the true nature of Neanderthal man compelled us to replace that picture with a different one-one of an ancient population made up of, not mere varieties of one species of mankind as at present, but of totally different species and genera. Amongst this complex of ancient humanity we have to seek for the ancestors of modern man. The problems of man's origin and antiquity are thus less simple than we had anticipated.

We could have avoided our initial mistake if we had kept in mind the condition of things in the anthropoid world. There, amongst the great anthropoids, we find three distinct types, two of them existing side by side in Africa (the gorilla and chimpanzee), while the third (the orang) survives in Sumatra and Borneo. They are so like to man in structure of body that we must, to account for the degree of similarity, regard all of them as collateral descendants of a common stock. We do not hesitate to think that the anthropoids retain, to a much greater degree than man, the structure and manner of living of the ancient stock from which all four have 
been evolved. If, therefore, we try to form a picture of the world of ancient and primitive humanity, we must base it on the conditions now existing among anthropoids, not on those which hold for the modern world of mankind. We should expect, then, when we go far enough back, to find humanity broken up into distinct structural groups or genera, each confined to a limited part of the earth. Inside each group we expect to find, as amongst the great anthropoids, a tendency to produce varieties or species. We have seen that many facts relating to ancient man which were formerly obscure or conflicting become easy of comprehension when this interpretation is applied.

Another line of evidence ought to have raised a suspicion that we were underestimating the antiquity of man in our earlier speculations. The anthropologist, when he seeks for an explanation of the evolution and distribution of modern races of mankind, finds it necessary to make a large demand on the bank of time. We all agree that modern human races, however different they may appear, are so alike in the essentials of structure that we must regard them as well-marked varieties of a common species. Let us look at the problem of their evolution in a concreté form, taking as opposite and contrasted types of modern humanity the fair-haired, white-skinned, round-headed European and the woollyhaired, black-skinned, long-headed negro of West Africa. We shall set those two contrasted types side by side and study them from a purely zoological point of view. We must admit that both are highly specialised types; neither represents the ancestral form. Now, in seeking for the ancestral form of our breeds of dogs, of horses, or of cattle, we select one of a generalised and ancient type, such as we conceive might have become modified into various modern breeds. We must apply the same method to the elucidation of human races. If we search the present world for the type of man who is most likely to serve as a common ancestor for both African and European we find the nearest approach to the object 
of our search in the aboriginal Australian. He is an ancient and generalised type of humanity; he is not the direct ancestor of either African or European, but he has apparently retained the characters of their common ancestor to a greater degree than any other living race. If, then, we accept the Australian native as the nearest approach to the common ancestor of modern mankind, can we form any conception of the length of time which would be required to produce the African on the one hand, and the European on the other, from the Australian type? From what we have seen in Egypt, in Europe, and in North America it is certain that a human type can persist for many thousands of years. A human type changes very slowly. Therefore, we must make a liberal allowance of time for the mere differentiation of the modern type of man into distinct racial forms. Even if we admit that the ancestral type from which all modern races of men have descended was as highly evolved as the Australian native, I do not think that any period less than the whole length of the Pleistocene period, even if we estimate its duration at half a million of years, is more than sufficient to cover the time required for the differentiation and distribution of the modern races of mankind.

The proof that man of a modern build of body was in existence by the close of the Pliocene period is presumptive, not positive. So far, we have no certain trace of the type beyond the middle of the Pleistocene. We presume a greater antiquity in order to obtain a working hypothesis which will explain the facts now at our disposal. The human genealogical tree, given in fig. I 87 , represents, in a concrete form, the anthropologist's working hypothesis. An inspection of that figure will show the reader how little we know of the ancestry of modern races. Of the fossil predecessors of the Australian native race we know nothing. With the possible exception of the discovery made by Dr Hans Reck, we have not found as yet a single trace of the Pleistocene ancestry of the negro. The discovery reported by Dr Hans 


\section{A CHAPTER OF CONCLUSIONS 5OI}

Reck, if substantiated, points to the differentiation and existence of a pure negro type in the Pleistocene period. We know nothing of the fossil remains of the Mongolian

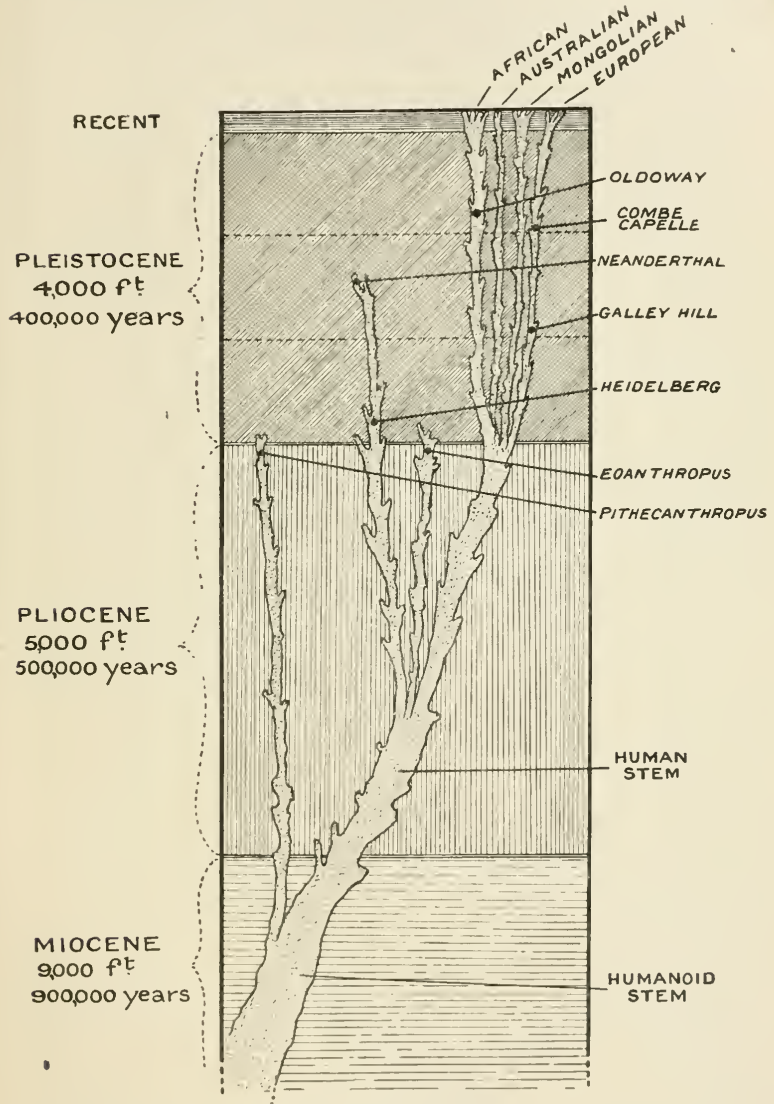

FIG. IS7.-Genealogical tree of man's ancestry. The depth of the deposits and the duration of the geological periods are based on estimates published by Professor Sollas. 
type in Asia because they have never been sought for. The North American Indian, whom we regard as a derivative of the Mongolian type, was certainly evolved before the close of the Pleistocene period. Indeed, our knowledge of ancestral forms is confined to almost a single type-the European. That type, as we have already seen, was in existence by the middle of the Pleistocene period. In some of the ancient Europeans, such as those found at Cromagnon and at Grimaldi, negroid traits can be recognised. At present the Mediterranean forms the boundary line between the European and African types. One can readily believe that in former times the African type may have spread some distance into Europe.

As already said, the genealogical tree depicted in fig. I 87 represents a working hypothesis, nothing more. When we try to represent in such a form the structural relationship between existing and extinct human races we again feel the necessity of postulating a great antiquity for man. That becomes evident when we come to fit the phylum of Neanderthal man into the genealogical tree of the human family (fig. I 87). He was so different from modern man in every point of structure that, in order to account for his structural peculiarities, we have to represent his phylum as separating from that of the modern human type at an early date. In fig. I87 it will be seen that I have shown the separation as having occurred before the middle of the Pliocene period. My reasons for selecting so early a date are : (I) that we must presume that man of the modern type was evolved by the end of the Pliocene period in order to account for the differentiation and distribution of the present races of mankind; (2) that the discovery of the Heidelberg mandible indicates the existence of a Neanderthaloid type of man at the commencement of the Pleistocene period. I am thus presuming that before the middle of the Pliocene period there was in existence a type of man sufficiently high to serve as a common ancestor for the Neanderthal and modern species of man. 
We have seen that, in mid-Pleistocene times, the brain of Neanderthal man, in point of size, was equal to that of contemporary forms of modern man. His culcure, that of the Mousterian age, was not a low one. We might suppose that the common Pliocene ancestor of these two species of man was of a low type, and that afte: their separation from the common stem each became gradually endowed with a large brain and acquired a separate form of culture. The more feasible explanation, however, is to suppose, not that a large brain was an independent acquisition on the part of Neanderthal and the modern species of man, but that it was a common inheritance from their Pliocene ancestor. That is the most reasonable explanation which is available at the present time-the one which presumes that Pliocene man had already reached a brain standard far beyond that of any simian type of animal.

When we come to fix the place which must be assigned to Eoanthropus in the human phylum, we find further evidence in support of man's great antiquity. We have seen that in the opinion of $\mathrm{Mr}$ Charles Dawson the "minimum geological age of the fossil cannot be of later date than the early part of the Pleistocene period." $\mathrm{He}$ is also open to the conviction that it may be much older, and on the evidence given in a former chapter we may reasonably presume that Eoanthropus represents a Pliocene type of man.

The problem we have now to solve is this: Does Eoanthropus represent the stage of evolution reached by modern man about the commencement of the Pleistocene period, or does the Piltdown type, like the Neanderthal, represent a separate human species or genus which became extinct and left no progeny? Dr Smith Woodward's answer to this question is given in his original communication to the Geological Society. ${ }^{1}$ " It seems reasonable," he writes, "to interpret the Piltdown skull as exhibiting a closer resemblance to the skulls of the truly ancestral mid-Tertiary apes than any human

1 Quart. Journ. Geol. Soc., 1913, vol. 1xix. p. 139. 
fossil skull hitherto found. If this view be accepted, the Piltdown type has become modified into the later Mousterian (Neanderthal) type by a series of changes similar to those passed through by the early apes, as they evolved into the typical modern apes, and corresponding with the stages in the developmen: of the skull in the existing ape individual. It tends to support the theory that Mousterian man was a degenerate offshoot of early man, and probably became extinct; while surviving man may have arisen directly from the primitive source of which the Piltdown skull provides the first discovered evidence." Dr Smith Woodward's answer to our question, then, is that Eoanthropus does not necessarily stand in the direct line which leads on to modern man, but represents more closely than any human form yet discovered the common ancestor from which both the Neanderthal and modern types have been derived.

We have seen that Eoanthropus in the size and shape of brain, and in the conformation of the skull, has a very high degree of resemblance to modern man. The characters of the teeth and mandible, on the other hand, were more simian than in any other form of man. The eyebrow ridges, so far as we can judge from the parts preserved, were also peculiar. On the other hand, we find in the skull of Neanderthal man numerous features which are also found in the skulls of anthropoid apes, particularly in the gorilla and chimpanzee. In many ways the Neanderthal skulls and brain casts are more simian, more primitive, than the corresponding Piltdown specimens. In the Neanderthal type of man we find the canine teeth reduced and the chin region of the mandible assuming a non-simian conformation as in the modern type of man. To explain the curious distribution of characters in those three types of man we have to postulate such a generic tree as is shown in fig. I 87 . There the Pliocene human stem, from which we have derived the Neanderthal and modern types, is also seen to give origin to the Piltdown type. 
The common Pliocene ancestor which gave origin to three such types could not be of a very low form. At least in Eoanthropus, as in Neanderthal man, the brain was equal in size to that of modern man. If we suppose that in an early part of the Pliocene period there was a form of man in which the brain had attained a human size, but in which the mandible, the teeth, and the skull still remained anthropoid in conformation, we have such a type as would serve as a common ancestor for Eoanthropus, modern man, and Neanderthal man. In the course of evolution the first named retained the ancestral form of mandible and teeth; the last preserved the ancestral simian features of the skull. It will thus be seen that I look on Eoanthropus, as on Neanderthal man, as a representative of an extinct form of man.

We come, finally, to an important problem: What status are we to assign to Eoanthropus in the zoological scale of classification? Dr Smith Woodward, in giving Eoanthropus a generic rank, seems to me to have altered the scale we have hitherto applied to the classification of human forms. All admit that Eoanthropus must be regarded as a form of man. A complete analysis of the structural characters of the Piltdown type (so far as they are known to us), of the Neanderthal, and of the modern types of man will show that all are of equal rank, and if we elevate one of them to a generic status we must do the same for the other two. Hitherto all modern races of men have been grouped under one species - Homo sapiens. The varieties of men which belong to the Neanderthal type are placed under the specific name of Homo neanderthalensis (primigenius). If we apply the same standard of classification to the Piltdown type, then the name ought to be Homo dawsoni, not Eoanthropus dawsoni. For my part, I would welcome the innovation introduced by Dr Smith Woodward if it could be applied all round. Without doubt distinct varieties of Eoanthropus and of Neanderthal man will be revealed by future discoveries - varieties which are sufficiently characterised to deserve specific names. 
We now come to the position which must be assigned to the humanoid form found in Java by Professor Dubois. The thigh bone was shaped as in man, and we presume Pithecanthropus had a body fashioned much like that of modern man. In size of brain and shape of skull, however, this strange form occupies an intermediate position. The stratum in which the remains were found is assigned to a late Pliocene or early Pleistocene date. Clearly, Pithecanthropus represents an early stage in the evolution of the human phylum. The evidence already adduced indicates that certain forms of early man had already attained a high development in the Pliocene period. Therefore in fig. I 87 the stem represented by Pithecanthropus is shown as separating from the ancestral phylum of man at a late part of the Miocene period. We can only explain the existence of so primitive a form of human being at the end of the Pliocene period by adopting a hypothesis of this kind.

It is only when we come to draft a genealogical tree, such as that shown in fig. I 87 , that we realise the true significance of those extinct human types. When we look at the world of men as it exists now, we see that certain races are becoming dominant; others are disappearing. The competition is world-wide and lies between varieties of the same species of man. In the world of fossil man the competition was different; it was local, not universal; it lay between human beings belonging to different species or genera, not varieties of the same species. Out of that welter of fossil forms only one type has survived-that which gives us the modern races of man. Further, we realise that the three or four human types so far discovered represent but a few fossil twigs of the great evolutionary human tree. We may hope to find many more branches.

There is another route by which we may approach the problem of man's antiquity. All who have made a study of the human body are agreed that we must seek for man's origin in an ape-like ancestor. If, therefore, we review the facts which bear on the evolution of the 
anthropoid apes, we may obtain collateral evidence bearing on the date at which the differentiation of the human body became possible. To save description, I have represented the present state of our knowledge of anthropoid evolution in the form of a genealogical tree (fig. I 88). The stems of the three great anthropoids-the gorilla, chimpanzee, and orang-are seen to join together in the older part of the Pliocene period. We have not many facts to guide us. We know of a late Pliocene anthropoid-Palæopithecus-which shows relationships to both chimpanzee and orang, but was probably not a direct ancestor of either. We know that the great anthropoids were already evolved in the Miocene period. Dryopithecus was alive in that period, and was about the size of the chimpanzee, but more primitive in features of tooth and jaw. We know, too, that the small anthropoids-the gibbons-were already in existence in the Miocene period. So far as our knowledge goes, the Miocene anthropoid apes offer us no form which can serve as a probable human ancestor. The small and large anthropoids were already differentiated, and we may presume that the same was the case with the human form. Hence in fig. 188 the stems of the small anthropoids, of the great anthropoids, and of man are represented as already separated in the Miocene period. The evidence, so far as it goes, justifies us in presuming that the human and anthropoid lines of descent separated in pre-Miocene times. ${ }^{1}$

In fig. 189 the anthropoid and human genealogical trees have been combined. The tree represents a working hypothesis which may require alteration as new facts come to light. It is framed so as to account for the evolution and structural characters of the various forms of ape and man. The discovery of fossil remains of extinct forms gives us some guidance as to the probable date at which various types became evolved. In framing such a genealogical tree it is necessary-at least it seems

1 For a fuller statement of the case, see Reports of British Association, I91 2, p. 753 ("Modern Problems relating to the Antiquity of Man"). 
- so to me-to suppose that the separation of the human from the great anthropoid stem dates back to at least the latter part of the Oligocene period (fig. I 89). If we mean

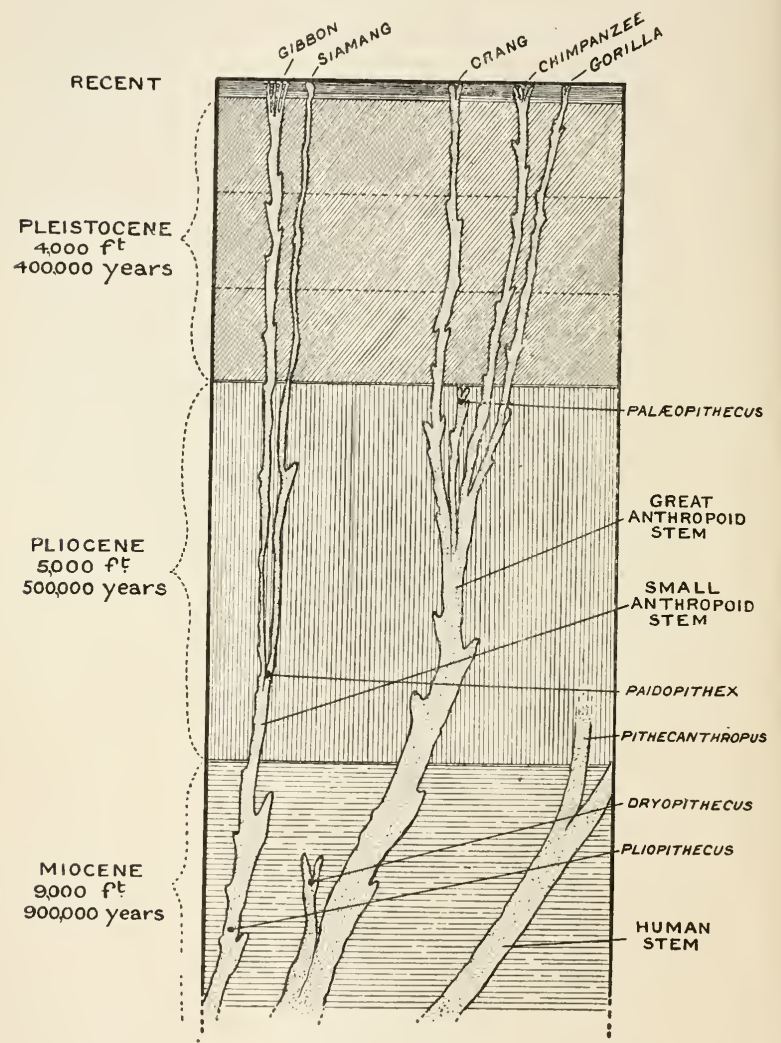

FIG. I88.-Genealogical tree, showing the lines of descent of the anthropoid apes.

by the antiquity of man the period which has elapsed since the human stem became differentiated from that 


\section{A CHAPTER OF CONCLUSIONS 509}

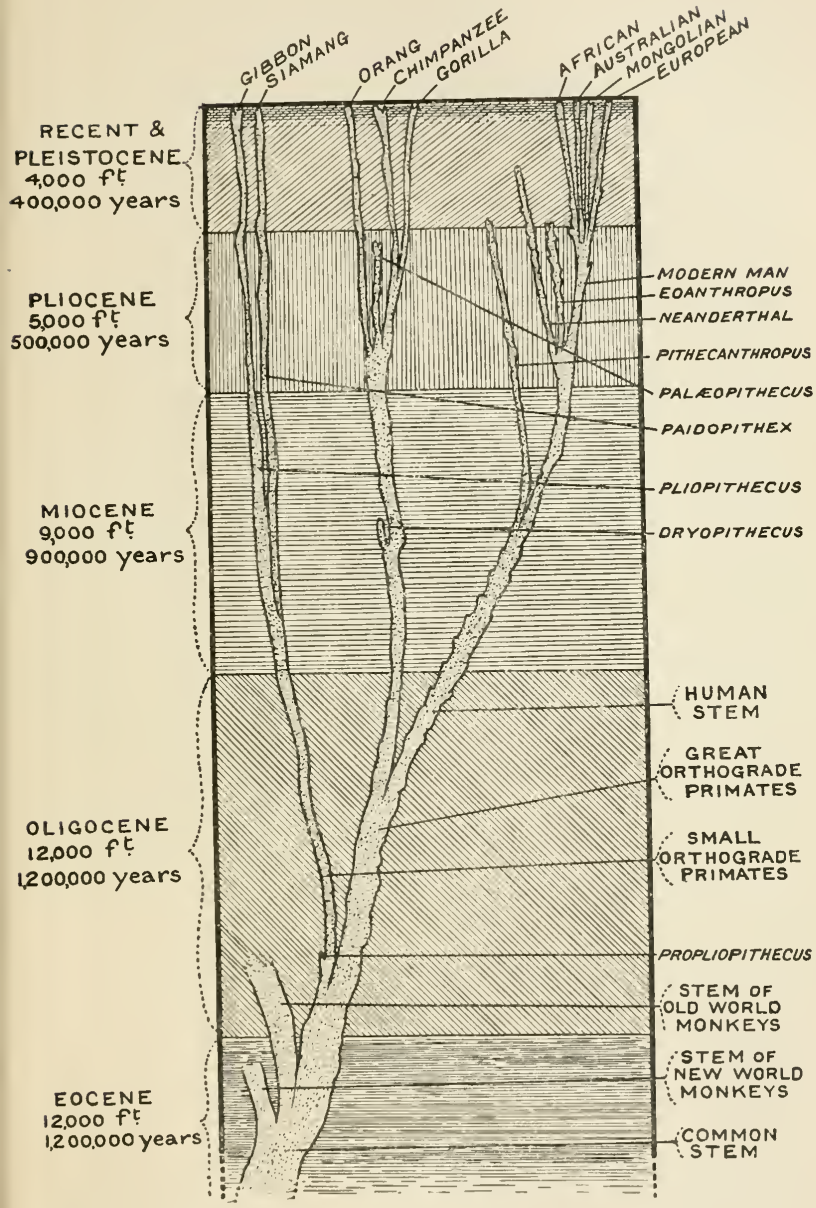

FIG. 189.-Genealogical tree, showing the ancestral stems and probable lines of descent of the higher primates. 
which led on to the great anthropoid apes, then it is apparent from fig. I 89 that the antiquity of man covers an immense period of time. On the scale of time represented in fig. I 89 , which is based on estimates published by Professor Sollas, ${ }^{1}$ a period of about two million years has elapsed since the separation of the human stem, provided, of course, that the hypothesis represented by fig. 189 is approximately right. That tree probably errs in underestimating rather than overestimating the antiquity of the human stem.

When we speak of the antiquity of man, however, most of us have in mind not the date at which the human lineage separated from that of the great anthropoids, but the period at which the brain of man had reached a human level or standard. We may take the lower limits of the brain capacity in modern living races, say I 000 c.c., as a working standard. If it is arbitrary it is also convenient. If, then, we propose to estimate the antiquity of man from the appearance of human types with average brain capacities of I000 c.c. or more, we must still regard man as an ancient form, with a past immeasurably longer than is usually believed. From what we know, and from what we must infer, of the ancestry of Eoanthropus, of Neanderthal man, and of modern man, we have reasonable grounds for presuming that man had reached the human standard in size of brain by the commencement of the Pliocene period. From fig. I 89 it will be seen that the Pleistocene and Pliocene periods are estimated to cover a period of about one million years. That period, on the grounds defined above, represents the antiquity of man.

Perhaps the most important and the most convincing source of evidence relating to man's antiquity is one which has been kept unduly in the background throughout this book. We cannot have more certain evidence of man's existence than the implements which he has shaped and used. We have seen how long it took to convince the modern world that the palæoliths in the gravel deposits of Western Europe were shaped by man's hand. Now

\footnotetext{
${ }^{1}$ See reference on p. 307.
} 
we marvel that anyone should have denied their human origin. Then came the discovery of Eolithic implements in deposits of Pliocene date - at St Prest, on the Kentish plateau, on the uplands of Belgium, under the Crag deposits of East Anglia. The human origin of eoliths is still being called in question, but the more these shaped flints of Pliocene date are investigated and discussed, the greater becomes the number of those who regard them as the work of the hands and brain of Pliocene man. It is also maintained that flints, similar in shape and chipping, have been discovered in deposits of Miocene and even of Oligocene age. If it be proved that such are of human origin, then we must extend still further the period covered by the antiquity of man. There is not a single fact known to me which makes the existence of a human form in the Miocene period an impossibility. 


\section{APPENDIX A}

In the text I have accepted the culture of the Oban caves as being Azilian in character and corresponding in time to the end of the Pleistocene period. In Professor James Geikie's opinion this view of the antiquity of the culture of the Oban caves is untenable. In this matter Professor Geikie's opinion must be accepted as final. He has recognised four phases in Scotland during the Neolithic age, the phases having occurred after the Ice age had ended. During the Neolithic age the climate of Scotland changed four times. In the first phase-the "lower forestian" - the land occupied a high level as regards the sea; the climate suited the growth of trees. In the second phase-the "lower turbarian" - the land occupied a lower level and the climate favoured the formation of peat-deposits. In the third phase-the "upper forestian"-forests again flourished in Scotland. In the fourth and final Neolithic phase-the "upper turbarian"-conditions favourable to the formation of peat again returned. In Professor Geikie's opinion the culture of the Oban caves must be referred to the final phase of the Neolithic age. If we accept that opinion we must adopt the not improbable supposition that cultures of a long past time may have survived in sequestered parts of Europe.

\section{APPENDIX B}

AfTER the preliminary proofs of this work had been revised, Professor Symington of Belfast showed to the members of the Anatomical Society of Great Britain and Ireland a series of very instructive casts of the human brain. Anatomists have always presumed that a cast of the interior of a human skull gives a true picture of the brain which occupied the cranial cavity during life, and that a study of the "cranial" cast gave definite information 
regarding the detailed features of the brain. To test the truth of this supposition Professor Symington compared the cast of the actual brain with the cranial cast in a number of cases. He found that although the cranial cast gave accurate information regarding the major features of the brain, that as regards certain minor features no definite inference could be drawn. He questions the possibility of recognising in a cranial cast the anterior branches of the fissure of Sylvius, the parieto-occipital fissure, and certain other sulci on the surface of the brain. 


\section{INDEX}

Abbeville, I94, I95.

Abbott, Dr C. C., 274.

Abbott, Mr Lewis, 82, 100, 224, 296, 301, $3 \mathrm{II}$.

Aberavon skull, 38, 39.

Acheulean culture, I60, I61, I63, I64, 195. period, duration of, $\pi 6_{5}$.

Acromegaly, 466.

Adloff, Prof., 147, 148, 149, 473.

Africa, sequence of cultures in, 256.

Ameghino, Dr Florentino, 288.

Ancient types of skulls compared, 392.

Anthony, Prof., 118, 121, 407.

Anthropoid ape, neck of, 354 . characters of mandible, 434 .

Anthropoids, fossil forms of, 507 . molar teeth of, 474 .

Antiquity of man, summary of, 5 Io. of modern type of man, 357 .

Arcelin, M., 60.

Argentina, 288.

Articular eminence, significance of, 444 .

Asymmetry of occipital lobes, 4I 5 .

Aurignac, cave at, $51,52,53,56,57$.

Aurignacian culture, I09, 195. flints, $53,6 \mathbf{I}, 64,74,87,92,99$. man, $53,54,65,68,69,75$. period, $53,61,62,64,82,85,127$.

Australian aborigines, 270. position of, 500 .

Azilian period, $57,58,59,6 \mathbf{r}$.

Baker's Hole, ro6, r64.

Barbour, Prof, E. H., 282.

Bardon, Abbé, I I 5.

Base of skull, reconstruction of, 494 . section across, 349 .

Belgium, valley deposits of, 228, 229, 230 .

Bertrand, M. Eugene, $2 \mathrm{O} 2$.

Bone implement found at Piltdown, 302.

Boucher de Perthes, I66, I72, 196, I97, 20I.

Boule, Prof., 63, I17, I24, I3I, I 50, 151 , $\mathrm{I} 57,239,45 \mathrm{I}$.

Bouyssonie, the Abbés A. and J., II 5.

Brain, association areas of, 266.

centres of, 404.

development of, 2.14 .

fissures of, 402 .

frontal impressions of, 384 .

in profile, 402 .

of Australian aborigine, 270 .
Brain of Eoanthropus, 336, 408.

of fossil man, 397.

of man, mininum size of, 397.

of Pithecanthropus, 267, 268.

ratio of, to palate, ${ }_{5} \mathrm{I}, 152,328,450$.

size of, 55 .

topography of, 402.

Brain-capacity, estimation of, 390 .

of apes and men, 398.

of Piltdown skull, 375 .

ratio to size of body, 400 .

significance of, 401 .

Brain-casts, occipital views of, 415 . viewed from above, 422, 425 .

Bregma, 265.

Breuil, Abbé, 56, 74.

Brixham cave, 95 .

Bronze-age skulls, facial parts, 485 .

Brünn skull, 68 .

Buckland, Dean, 47, 48, 54.

Bullbrook, Mr J. A., 75 .

Bury St Edmunds fragment, $\mathbf{I} 7 \mathbf{r}$.

Bushmen of S. Africa, 256.

Busk, G., 37, 200.

Calaveras skull, $28_{3}$.

Canine teeth, 456 . eruption of, 460 . wear of, 467.

tooth of Eoanthropus, $325,455$.

Caninism, 466.

Capitan, Prof., I 12.

Carnon skull, 35, 36 .

Cartailhac, M., 63 .

Castenedolo remains, 246, 247, 251 .

Cave cultures, classification of, 56 . records, 46.

Chamberlin, Prof, , 277, 28r.

Chandler, Mr R. H., I03, I05.

Cheddar caves, 93. skeleton, 93, 94, roo.

Chellean culture, ${ }^{6} 6_{3}$. period, 178.

man of, 185 .

Chimpanzee, craniım viewed from above, $37 \mathrm{r}$.

mandible of, 323,446 .

skull in profile, 379 .

Chin, 145, 188, 241, 243, 310.

Cissbury camp, 98 .

human remains, 99, Ior.

Clarke, Mr W. G., 225. 
Clichy skeleton, 202.

Cocchi, Signor, 206.

Coldrum bones, 7,8 . monument, $1,4,18,19$.

Collyer, Dr, 200.

Conbe Capelle, 108.

skeleton, rog.

skull, $69,137,138,144$. palate of, 97 .

Commont, Prof., 162, 194, 196.

Condyle of mandible, 439 .

Convolutions of brain, 402 .

Cook, Mr W. H., 72, 74.

Coombe rock, ro6.

Corner, Dr Frank, 30, 179.

Couper, Mr J. D. C., 40.

Cranial base, reconstruction of, 494.

Crayford brick earths, I04, 105, 106, 107, 164 .

Cresswell Crags, caves in, 84 .

Cromagnon cave, 54,56 .

man, $54,55,56,65,66$.

Cromer beds, 212, 224, 259, 260.

Cynodont form of teeth, 148,476 .

Dartford skull, 165 . capacity of, 375 .

Davies, Mr H. N., 93, 94.

Dawkins, Prof. Boyd, 5I, 84, 92, 308.

Dawson, Mr Charles, 293, 308, 456.

Denise fragment, 205, 206.

Dental canal, 437.

Derry, Dr Douglas, 255, 359, 366.

Desnoyers, M., 232, 313.

Dewey, Mr Henry, 162, 184, I94.

Dewlish trench, 314 .

Diprothomo, 290.

Drayson, Major-General, 227.

Dubois, Dr Eugene, 257.

Duckworth, Dr W. L. H., 96, 98, 123, 224.

Dupont, M. Edouard, 126.

Ear-passage, 153 .

Edge-to-edge bite, 462 .

Edwards, Dr Spencer, 72.

Egyptian tombs, evolution of, 17, I8.

Egyptians, Ancient, 253.

Elliott, Mr Robert, 179, I82.

Engis, cave at, $49,53,56$.

skull, $49,50,54$.

Eoanthropus, brain of, 336 .

braill-capacity of, $390,399$.

brain-cast from above, 425 .

from behind, 419.

cranial characters of, 333 .

face of, 326 .

mandible of, $43 x$.

viewed from above, 446 .

molar tecth of, +75 .

nasal bones of, $4^{87}$.

position of, in human plyylum, 503 .

profile of brain-cast, 409 .

reconstruction of base of skull, 495 .

of face, 489 .

of skull, 330 .
Eoanthropus, sex of, $3^{88}$.

skull in profile, $48 x$.

teeth of, 455 .

vertex view of skull, 335 .

Eoliths, 2, 225, 230, 257, 295, 300, 314, 315,511 .

Erect posture, 26I.

Evans, Sir John, 185.

Evidence relating to evolution of man, 499.

Evolution of man, previous conception of, $356,497$.

Ewart, Dr Edward, 44.

External angular process, relation of, to brain, $3^{85}$.

Face of fossil man, 478 .

Facial features of Eoanthropus, 496.

Falconer, Dr Hugh, 196, 200.

Favraud, M., I2I.

Fisher, Rev. O., 3I4.

Flint mines, 99.

Flints, Neolithıc, 30, 44 .

found at Piltdown, 301, 302.

Foramen magnum in Eoanthropus, 395.

Forbes Quarry, 123.

Forehead, 481 .

Fossil apes, 506

man, mandibles viewed from above, 446 . teeth of, 453 .

Foxhall jaw, 200, 224.

Fraipont, Julien, 51, 126.

Frankfurt plane, 377 .

Frere, Mr John, 17 r.

Frontal convolutions, $\$ 3$. inmpression of brain, $3^{8} 5$.

Fronto-malar region, 380 .

Fuhlrott, Dr, 128.

Galley Hill, 178, 204.

deposits at, 184 .

skeleton, 178, 309 . description of, 186.

skull, I99-20I, 204. compared, 392.

Geikie, Prof. James, 226.

Genealogical trees, 501, 508, 509 .

Genial pit of mandible, $242,243,324,434$.

Gibraltar brain in profile, 406, 412. skull, 122, I23, 124, 135, I44, I50, I 5 I, $\mathbf{r} 56$.

brain, weight of, 124.

frontal region of, 482 . occipital view of, $35^{2}$.

Glabella-inial line, 377 .

Glacial epochs, 226.

Glenoid cavity of skull, $4+4$.

Gorilla brain, from behind, 415 . in profile, 406.

nandible of, 434 .

occipital view of skull, 354 .

Gourdan, cave of, 121.

Gray, Major Thomas, 38, 39.

Gremelle, human remains found at, 205.

Grimaldi caves, 62,64 .

race, $65,66,67$. position of, 502 . 


\section{I6 THE ANTIQUITY OF MAN}

Grimes Graves, 99.

Grist, Mr C. J., 315.

Grotte des Enfants, remains found in, 64 .

Halling flints, 74 .

skeleton, 71, 72, 82 .

skull, 77,78 .

Hal-Saflieni, Hypogeum at, I4.

Hamy, Prof., 203.

Harlyn Bay, tombs at, 35 .

Harrison, Mr Benjamin, I, 294, 295.

Hauser, Herr O., 69, I 08, I14.

Heidelberg mandible, $232,233,307,448$. molar teeth of, 475 .

teeth of, 237.

Heys, Mr Matthew H., I8I.

Higgins, Mr Brice, 105.

Hinton, Mr A. C., 87, 103, 108, 213.

Holmes, Prof. W. H., 285.

Homo pampaus, 290.

Hoxne, implements found at, I7I.

Hrdlicka, Dr Alěs, 272, 275, 280, 283 , $284,286,292$.

Hunter, John, 198.

Huxley, I4, I30, I 55, 200.

Hythe skulls, II.

Inion, ascent of, 377 .

Ipswich skeleton, 2I4, 22I, 229.

Irving, Dr A., 74, 218.

Isturitz, cave of, I2I.

Jackson, Mr George, 98.

Janensch, Dr, 26o.

Java, remains found in, 257.

Jaw. See Mandible.

Jersey, Neolithic period in, 30, 31, 32.

Jones, Dr Arnalt, $3^{8}$.

Keith's line of orientation, 379.

Kennard, Mr A. S., 87, 103, 105, 213 , 309.

Kent's Cavern, 48, 56, 94, 95, 96.

human remains, 96, 97 .

Kenyon, Colonel, I22.

King, Dr William, r30, I 3 I.

Kits Coty house, 6.

Klaatsch, Prof., I 14, I15, I31, 134, I43, $\mathrm{I} 49, \mathrm{r} 57, \mathrm{I}_{3}$.

Kramberger, Prof, Gorjanovic, 132, I35. I 47,476 .

Krapina, hum in remains found at, I 33. molar teeth, 475 .

La Chapelle skeleton, I I 5, I I7, I I 8, 239. skull, 137, 138, 144, 491. capacity of, 391 .

La Cotte de St Brelade, I 25.

La Ferrassie, II2.

La Motte, island of, 32, 33 .

La Quina, I34. skeleton, I I9, I24, 127.

Lagoa Santa caves, remains discovered in, 286,287 .

Lambda, 267.

Lambdoid suture, direction of, 495 .
Land, elevation and depression of, 44 , 45.

Langwith cave, $85,86,87$.

skull, $87,91,94,1$ II.

Lankester, Sir H. Ray, 225.

Lansing remains, 280,281 . terrace, age of, $28 \mathbf{I}$.

Lartet, Edouard, $5 \mathbf{I}$.

M. Louis, 53 .

Le Moustier, II4.

skeleton, I I4, 127.

Leach, Mr, 105.

Lehmann-Nitsche, Dr, 292.

Leidy, Prof. Joseph, 279.

Les Eyzies, II 2.

Lewis, Mr A. L., 4.

Lohest, Max, I26.

Long's Hill remains, 282,283 .

Lund, Dr, 286.

Lyell, Sir Charles, $48,49,53$, I 29, I30, $204,212,213,224,278$.

Macdonnell, Dr, 9.

MacEnery, Rev. J., 47, 48.

Magdalenian carvings, 84 . flints, $83,87,93,96$. period, $56,58,61,82$.

Makowsky, Prof., 69.

Malarnaud, cave of, I2r.

Malta, Neolithic skulls from, 15, 16, 17.

Man, modern type of, $250,278$. origin of, 143 .

Mandible, $\mathbf{5} 52$.

Australian and Piltdown, 321.

movements of, 440 .

of Eoanthropus, 430 .

relationship to floor of mouth, 45I.

X-ray characters of, 437 .

Mandibular areas, $44^{8}$.

Marett, Dr R. R., 33.

Marr, Prof., 218.

Marriott, Major R. A., 227.

Martin, I)r Henri, II9, I 57.

Mas d'Azil, cavern of, $57,5^{8}, 6 \mathrm{I}$.

Mastoid process, I 53 .

Mauer pit, 232, 234.

sands, 259.

Mediterranean, Neolithic people of, I5, 16.

Medway terraces, $75,76,77$.

valley, subsidence of, 29 .

Megalithic monuments, birthplace of, 17 .

Mello, Rev. J. Magens, 84.

Mesvinien culture, $22 \mathrm{I}$.

Mickleton skull, 4I, 42 .

Mid-line of skull, identification of, 365 .

Modern man, simian features in, 143 . I44, I48.

type of man, antiquity of, 209, 357 . significance of, 497 .

Moir, Mr Reid, 74, 82, 83, 2 II, 2I4, 225 , 302 .

Molar teeth, characters of, 474 .

modifications of, 469 .

Monaco, Prince of, 63,64 .

Mongolian type, 502 . 
Mortillet, M. Gabriel de, 56, 202.

Moulin Quiguon jaw, 197, 198, 199, 200. pit, 197.

Mousterian culture, 6r, 105, 106, 107, I11, 112, 114, I16, I19, 125, 1 26, I34, 195 .

man, I03, 105, I12, i 4, I 6 .

period, 102, 106, 107, 108, 112, 121.

Multins, Rev. F. H., 85.

Mylo-hyoid ridge and groove, 433.

Nasal bones of Eoanthropus, $4^{87}$. grooves, 144,148 .

Natchez, remains found at, 279.

Naulette cave, r26.

mandible, 126, 144 .

Neanderthal and modern skull compared, I 37,157 .

cave, 128.

head poise, I 54,155 .

man, 98, I13, II4, I15, I $16, \mathbf{1} 8$, I 19, I21, 122, 123, I27, 128, I48, 209, $236,250$.

anatonical peculiarities of, 137 .

ancestral position of, $5 \mathrm{O} 2$.

brain-cast from above, 423 .

canine teeth of, 457 .

characters of, $158,159$.

different rices of, 135 .

disappearance of, $135,136$.

face of, $49 \mathrm{I}$.

molar teeth of, 475 .

neck of, 353 .

palate of, I 50, I5I, I 52 .

platycephaly of, $35 \mathrm{I}$.

significance of, 497 .

simian features in, $143, I_{44}, 1_{4} 6$.

teeth of, 125, 147, I 5 I, 237.

temporo - mandibular articulation, 443.

thigh bone of, $\mathbf{1} 58$.

varieties of, 124, 125 .

skeleton, 128.

women, I19, I20.

Neck, attachment of, to skull, 267, 353.

Negro, evolution of, 499.

Nehring, Dr, 132.

Neolithic man in Jersey, 33 .

period, $2,15,16,56,59$.

duration of, $29,30,43,44$.

pit-dwellings, 3 .

race, $43,5^{6}$.

skulls with negroid features, $\mathbf{I} 7$

Newport skull, 39, 40.

Newstead, Mr Robert, 4I.

Newton, Mr E. T., 87, 179, I90, 3 Io.

Mr W. M., I66.

Noetling, Dr Fritz, 257.

North America, antiquity of man in,

Otan caves, $59,5 \mathbf{1} 2$.

Occipital aspect of skulls, 34I.

asymnetry, 344 .

lobes of the brain, 404 .

region, errors in the reconstruction of, 395.
Occipital view of brain-casts, 414 .

of l'iltdown skull, 363 .

Ochos, human remains found at, 132 .

Oldbury rock-shelters, 2.

Oldoway, 50 .

skeleton, 255.

Olmo skull, 206, 207, 249.

Orang, fronto-malar region of, 382 . reconstruction of face, 490 . section across skull of, 350 .

Orientation of skull, 377 .

Overlapping bite, 462 .

Palaeolithic cultures, 230. man, $47,59,60,82$. period, 59 .

Palæoliths, 2.

Palate, 150, I $_{51}, 192$.

Kent's Cavern, 96, 97.

of ape and Eoanthropus, 328.

ratio of, to brain, 328 .

size of, 450 .

Palato-cerebral ratio, 328,450 .

Pampean formation, 289 .

Parietal association areas of brain, 266. bones of Piltdown skull, 346 .

lobes of brain, 404 .

Parsons, Prof. F. G., II, 94. $35^{8}$.

Paviland cave, $47,53,54,56$.

Pearson-Lee formula, 390.

Penck, Prof., 226, 307.

Pengelly, Mr William, 95.

Peringuey, Dr L., 255.

Petrous bone, 349 .

Peyrony, M., I 12.

Piette, M. Edouard, 57, 59, I21.

Piltdown, 296.

deposits at, 299, 300, 3I I.

mandible, 321 .

remains, antiquity of, 307, 308, 309,

$$
3 I_{4} \text {. }
$$

discovery of, 298 .

skull, capacity of, 375 .

cephalic index of, 374 .

compared to others, 392.

diameters of, 390 .

facial parts of, 480 .

fronto-malar region of, 383 .

in profile, $3^{86 .}$

length of, $373,388$.

occipital view, 340 .

parts found of, 316,317 .

section across, 351 .

thickness of, 319, 320 .

vertex view of, 370 .

Pithecanthropus, 257.

fronto-malar region of, $3^{81}$.

phylum of, 506.

skull of, compared, 392.

teeth of, 261, 262.

Pituitary angle, I 56, 265.

Platycephaly, 352.

Pleistocene cultures, $230,232$.

epoch, 62 .

period, duration of, 307 .

Plenal condition of molar teeth, 471 
Pliocene man, 3Io, 3II, 503. period, deposits of, 225 .

Prestwich, Sir Joseph, 295.

Prigg, Mr Henry, 171, 175.

Puydt, Marcel de, I26.

Ragazzoni, Prof., 245.

Reck, Dr Hans, 255, 500.

Reconstruction of face, 479 .

of Piltdown skull, 337.

of skulls, experiment in, 356 .

methods of, $36 \mathrm{r}$.

Red ochre, 65.

Reid, Mr Clement, 23, 28, 44, 172, 309, 315.

River-bed type of skull, 1.4, 15, 16, 28, 34, 4 I, 44, 5 I, 55, 59, 77, 82, 89, 99, I I I.

Rivers, General Pitt, 98.

Riviere, M. Emile, 62.

Rolleston, Prof., 99.

Ruggeri, Prof., 183.

Rutot, Prof., 51, 127, 163, 183, 184, 202, 209, 21. $221,226,228,230,234$, $307,3^{1} 3$.

St Acheul, I6r.

St Prest, 23I, 3I3, 3I4, 5I I .

Sardinia, Neolithic tombs of, 18 .

Sauvage, Dr, 205.

Schaaffhausen, Prof, , 128.

Schipka, human remains found at, 132 .

Schmerling, Dr, 48, 49, 82, 89, 129.

Schoetensack, Dr Otto, 233.

Schwalbe, Prof. Gustav, 122, I31, 149, I $57,291$.

Seine, deposits of, 201, 203, 204.

Selenka, Frau Lenore, 259.

Selignıann, Dr, 254.

Sennen skull, 37,50 .

Sera, Prof. G. L., 1 56, 207.

Sergi, Prof., I 5, 209, 247.

Sex of Eoanthropus, 388.

Simian characters, distribution of, 43 I. shelf, $242,434,43^{6}$.

Sinel, Mr J., 24, 3 I.

Skull, fixation of, 267 .

identification of middle line, 365 .

of Galley Hill man, 187.

section across base of, 349 .

zero-line of, 342 .

Skulls, comparison of ancient types, 392. in profile, 376 .

methods of reconstruction, 360 .

orientation of, 379 .

Smith, Mr Edward, 36.

Mr Reginald, 74, 82, 99, I05, 162, I71, I84, I94.

Prof. Elliot, I7, 244, 253, 336, 365, 396, $407,434$.

Société Jersiaise, 3I, 33.

Sollas, Prof., 47, 54, 122 124, 307, 5 I0.

Solutré, 60.

equine layer at, $6 \mathrm{r}$.

Solutrean culture, I09

flints, 84 , ror, rog.

period, 56, 6r.
Somme, deposits in valley of the, 194. 195.

South America, early man in, 286.

Spain, fossil bones from, 376 .

Speech, 244.

centres of, 404 .

modification of mandible in connection with, $145,146,45^{2}$.

Sphenoid region, reconstruction of, 396.

Spurrell, Mr F. C. J., I64.

Spy mandible, 238,243 .

skeletons, 127, I31.

Strahan, Dr Aubrey, $4 \mathbf{1}$.

Stremme, Dr, 260.

Strepyan deposits, $16_{3}$.

culture, $16_{3}, 184$.

Sturge, Dr Allen, 30, 82, 107, 2 I .

Sub-Crag flints, 225, 226.

Sublingual fossa, 434 .

Submerged forests, 23, 24, 25, 26, 32, 35 . flints, 25, 28 .

Supra-orbital ridges, $140,141,142,143$, 371.

Swanscombe, $161,162$.

Sylvius, fissure of, 402 .

in fossil brains, 407 .

Symington, Prof. J., 512.

Symphyseal region of mandible, 32.3 .

Taubach, deposits at, I3I, I 32 .

teeth found at, 132, 147 .

Taurodont form of teeth, 148,477 .

Teeth, 191, 237, 261 .

modifications of, 464 .

of fossil men, 453 .

of Heidelberg mandible, $237,23^{8}$.

of Neanderthal man, 147,148 .

of Neolithic people, 12, 13.

of Piltdown man, $322,475$.

reduction in size of, 453 .

types of: 476 .

Temporal bone, articulation of, $4 \mathrm{II}$. convolutions, 4 IO.

lines, $375,48 \mathrm{I}$.

of Eoanthropus, 333 .

lobe, 402.

Temporo-mandibular articulation, 44I.

"Tertiary" man, 503 .

Test skull, 362 .

Tetraprothomo, 290.

Thames deposits, sequence of, 162 . terraces, $16_{4}, \mathbf{1} 6_{5}$. valley, subsidence of, 25,28 .

Thigh bone, 158,261 .

Third frontal convolution, $38 \mathrm{r}$.

Thomson, Prof. Arthur, 264.

Tibia of Ipswich man, 221, 222.

Tilbury skeleton, 26, 75 .

Tombs, Neolithic, 16, 17, 18, 19, 20, 33, 35,40 .

Tongue, muscles of, 323 .

Torus supra-orbitalis, 266.

Trent skull, 14, 88, 90.

Trenton gravels, $274,276$. remains found in, 275 .

Trepanned skulls, 20, $2 \mathrm{I}$. 
Trinil strata, 259.

Turner, Sir Willian, 59, 270.

Underwood, Prof. A., 437, 439 .

Upham, Dr Warren, 281.

Vault of skull in profile, 394.

Vendrest, Neolithic tomb at, 20.

Verneau, Dr, 63, 65.

Verner, Colonet IV., 376 .

Vertex view of human skulls, 367 .

Vézère, caves of the, 53.

Villenneuve, Canon de, 63 .

Volk, Mr Ernest, 274.
Warren, Mr Hazzeldine, Ior, I05.

Waterston, Prof. I). 430

Whitaker, Mr William, 2I8.

Whitney, Prof. J. D., 284.

Winchell, Prof. N. H. 281, 283.

Woodward, 1)r Smith, 301, 306.

Wookey Hole, 92.

IVormian bone, 81 .

Wright, Dr G. Freflerick, 273, 276 , 281 .

Zammit, Dr, 15.

Kero-line of skull, $3+2,376$. 



\section{A STANDARD WORK OF SPECIAL INTEREST \\ TO ALL READERS OF PROF. KEITH'S "ANTIQUITY OF MAN"}

\section{PRE-HISTOR I C T I M ES}

AS ILLUSTRATED BY

ANCIENT REMAINS AND THE MANNERS AND CUSTOMS OF MODERN SAVAGES B Y

The Late Rt. Hon. LORD aVEBURY

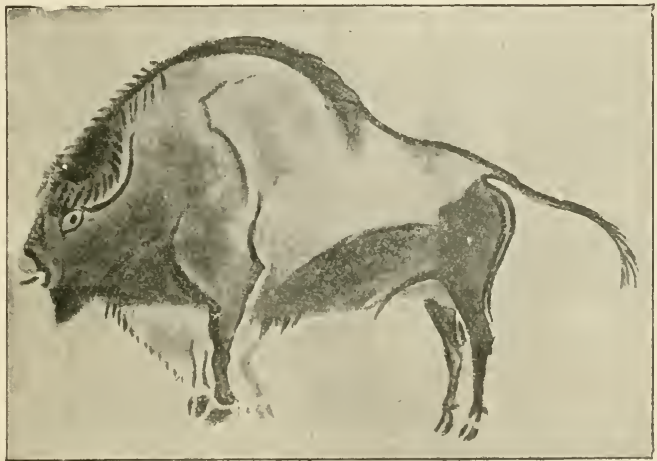

The thorough revision of this volume and the preparation of new material was the last literary work completed by the author just prior to his decease. A large number of new illustrations are included of recent discoveries, bringing the volume entirely up to date.

"A new book of great value even to the initiated in that branch of ethnology and anthropology which concerns itself with the ancient and primitive types of man formerly in existence in countries which are now exhibiting the most advanced type of civilisation."

Sir IIARRY Johnston, K.C. B., in the Westminster Gazelle.

With three illustrations in colour, and nearly 300 other illustrations. In One Volume. Large Demy 8vo. Above 600 pages. 10s. 6d. net; postage inland, $6 d$. extra.

London: WILLIA.MS \& NORGATE, I 4 Henrietta St., Covent Garden. 


\title{
ROCK GARDENS
}

HOW TO MAKE AND MAINTAIN THEM

\author{
By LEWIS B. MEREDITH \\ WITH AN INTRODUCTION BY \\ F. IV. MOORE, M.A., A.L.S.
}

And an Alphabetical List of Plants suitable for the Rock Garden, with notes on the aspect and soil they require.

"It is safe to say it is one of the best of the really practical works which have been written, and we can cordially recommend it to everyone who is embarking, or has already embarked, on this fascinating branch of horticulture."-The Gardener's Chronicle.

Second Edition. With new Illustrations. Demy 8vo. Cloth. 7s. 6d. net; postage inland, 6d. extra.

ILLUSTRATIONS UNCOMMONLY BEAUTIFUL

THE

\section{HERBACEOUS GARDEN}

By Mrs PHILIP MARTINEAU

\section{WITH AN INTRODUCTION BY}

\section{W. ROBINSON}

Part I. of this interesting volume describes and gives full particulars how to make and arrange IIardy Borders; while Part II. consists of an alphabetical list of the most suitable plants.

"The only bad thing about Mrs Martineau's book is its title. 'The Herbaceous Garden' is too ugly a name for a volume which can only be described by that ill-used word, charming. Yet it is not easy to suggest a better title. Weight and wisdom are added in an introduction by Mr William Robinson, and the illustrations are uncommonly beautiful." - The Times.

"Even enthusiasts of long standing are continually confronted with doubts and difficulties, and here these pages, written with knowledge and appreciation by an amateur for amateurs, will appeal as much for their invaluable counsel as for the clear manner in which it is imparted."-Pall Mall Gazetle.

$$
\text { SECOND IMPRESSION. }
$$

Demy 8vo. Cloth. 7s. 6d. net; postage inland, 6d. Illustrated by 32 plates beautifully reproduced by $a$ new process, and with two illustrations in colour. 


\section{WILLIAMS AND NORGATE'S PUBLICATIONS}

\section{ECHOES FROM THE FLEET}

BY

\section{COPE CORNFORD}

NAYAL CORRESPONDENT OF THE "MORNING POST"

\section{WITH A PREFACE BY}

ADMIRAL LORD CHARLES BERESFORD, M.P.

who says: "It is because Mr Cornford's work is a valuable contribution towards a better understanding of the Royal Navy that I hope it will find many readers, and for the accuracy of its presentment I can vouch."

"Mr Cope Cornford's sketches of life in the Navy are full of dash, humour, and go. The volume before us contains the strongest work he has done. Mr Rudyard Kipling would not need to be ashamed of having written 'Lent for the Voyage." "-Evening Standard.

2s. net, Boards. Special Coloured Jacket. 2s. 6d. net, Cloth; postage inland, 3 d. extra.

\section{WAR हٔ THE EMPIRE}

\section{THE PRINCIPLES OF IMPERIAL DEFENCE}

BY

COLONEL HUBERT FOSTER, R.E.

DIRECTOR OF MII.ITARY STUDIES IN THE UNIVERSITY OF SYDNEY LATE QUARTERMASTER-GENERAL IN CANADA, MILITARY ATTACHÉ IN THE UNITED STATES AND MEMBER OF THE INTELLIGENCF DEPARTMENT OF THE WAR OFFICE

AUTHOR OF "ORGANISATIUN: HOW ARMIES ARE FORMLD FOR WAR" AND OF

"STAFF WORK: A GUIDE TO COMMAND AND GENERAL STAFF DUTIFS, ETC."

The author traces with wonderful accuracy and knowledge the principles governing the defence of the King's dominions, thus enabling the layman to understand the policy that has been guiding the developments of the present war.

Crown 8vo. Cloth. With Map. 2s. 6d. net; postage inland, 3d. extra.

LONDON : I4 HENRIETTA STREET, COVENT GARIEN 


\title{
WILLIAMS AND NORGATE'S PUBLICATIONS
}

\section{THE SPIRITUAL MESSAGE OF DANTE}

\section{By the Right Rev. W. BOYD CARPENTER,} K.C.V.O., D.D., D.C.L., D.LitT., LL.D.

CANON OF WESTMINSTER, CLFRK OF THE CL.OSET TO THE KING, I.ATE BISHOP OF RIPON

This book contains the lectures delivered at Harvard University under the William Belden Noble Trust. They are an illustration drawn from history of the principles which the author strove to enforce in the Noble Lecture of 1904 , the struggle of the soul towards the eternal light.

Crozen 8vo. Cloth. Illustrated. 5s. net; postage inland, 4 d. extra.

\section{GENERAL SIR ALEX TAYLOR, G.C.B., R.E. : HIS TIMES, HIS FRIENDS, AND HIS WORK}

\author{
WRITTEN BY HIS DAUGHTER \\ A. CAMERON TAYLOR
}

Sent by John Lawrence to Delhi, the belief is that by his skill and daring "Alex Taylor took Delhi," as John Nicholson said. His statue is now on the Ridge. The biography of this gallant and high-spirited hero makes fascinating reading.

"The biography is of fascinating interest. Written with much literary charm, it depicts a character most lovable and admirable; and the setting of the picture necessarily places before us some of the most stirring scenes of our national history." - Major-General G. K. SCOTt-MoNcriefF in Blackrwood's Magasine.

"The life of a chivalrous soldier, whose forward fiery valour was blended with a calm judgment and a cathulic love, can be read with enthusiastic interest." - The Times.

With Portraits in Photogravure and in Black and White, along with Maps, some of which are printed in colours.

In Treo Volumes. Medium 8vo. Cloth. 25s. net; postage inland, rod. extra. 

THIS BOOK IS DUE ON THE IAST DATE STAMPED BELOW

AN INITIAL FINE OF 25 CENTS WILL BE ASSESSED FOR FAILURE TO RETURN THIS BOOK ON THE DATE DUE. THE PENALTY WILL INCREASE TO SO CENTS ON THE FOURTH DAY AND TO $\$ 1.00$ ON THE SEVENTH DAY OVERDUE.

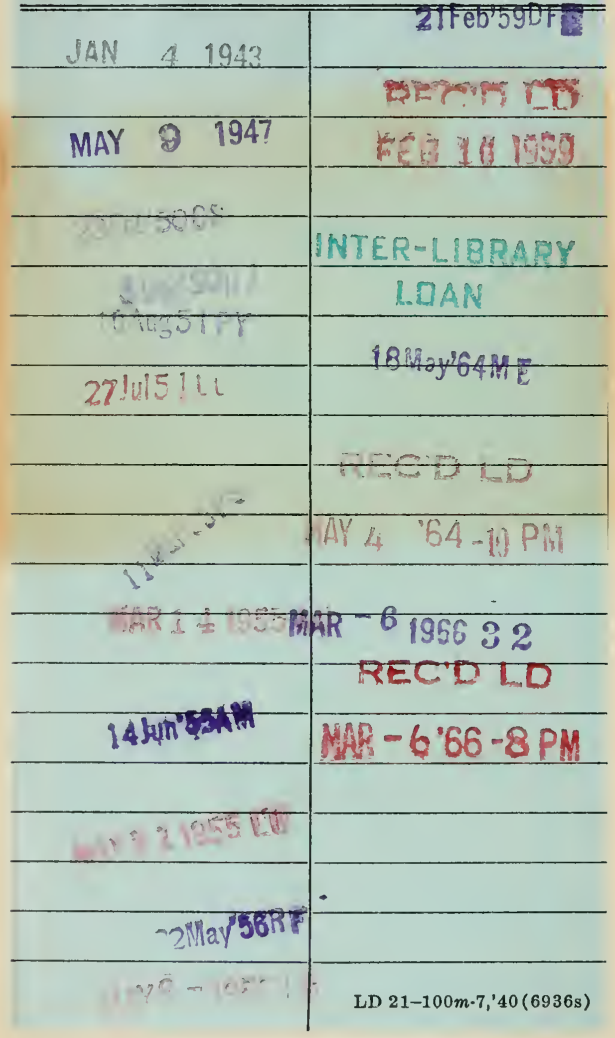




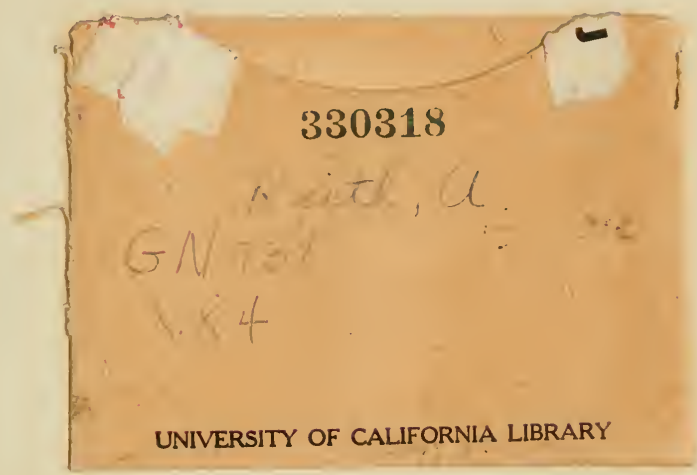

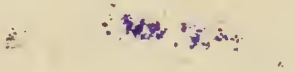


